\title{
Internationale communiste
}

\author{
(1934) [1971]
}

\section{Manifestes, thèses et résolutions des quatre premiers congrès de l'Internationale communiste 1919-1923.}

\section{Textes complets.}

\begin{abstract}
Un document produit en version numérique par Claude Ovtcharenko, bénévole, Journaliste à la retraite près de Bordeaux, à $40 \mathrm{~km}$ de Périgueux

Courriel: c.ovt@wanadoo.fr
\end{abstract}

Dans le cadre de la collection: "Les classiques des sciences sociales" Site web: http://classiques.uqac.ca/

Une collection développée en collaboration avec la Bibliothèque Paul-Émile-Boulet de l'Université du Québec à Chicoutimi Site web: http://bibliotheque.uqac.ca/ 


\section{Politique d'utilisation de la bibliothèque des Classiques}

Toute reproduction et rediffusion de nos fichiers est interdite, même avec la mention de leur provenance, sans l'autorisation formelle, écrite, du fondateur des Classiques des sciences sociales, Jean-Marie Tremblay, sociologue.

Les fichiers des Classiques des sciences sociales ne peuvent sans autorisation formelle:

- être hébergés (en fichier ou page web, en totalité ou en partie) sur un serveur autre que celui des Classiques.

- servir de base de travail à un autre fichier modifié ensuite par tout autre moyen (couleur, police, mise en page, extraits, support, etc...),

Les fichiers (.html, .doc, .pdf., .rtf, .jpg, .gif) disponibles sur le site Les Classiques des sciences sociales sont la propriété des Classiques des sciences sociales, un organisme à but non lucratif composé exclusivement de bénévoles.

Ils sont disponibles pour une utilisation intellectuelle et personnelle et, en aucun cas, commerciale. Toute utilisation à des fins commerciales des fichiers sur ce site est strictement interdite et toute rediffusion est également strictement interdite.

L'accès à notre travail est libre et gratuit à tous les utilisateurs. C'est notre mission.

Jean-Marie Tremblay, sociologue

Fondateur et Président-directeur général, LES CLASSIQUES DES SCIENCES SOCIALES. 
Cette édition électronique a été réalisée par Claude Ovtcharenko, bénévole, journaliste à la retraite près de Bordeaux, à 40 km de Périgueux.

Courriel: c.ovt@wanadoo.fr

à partir de :

Internationale Communiste

Manifestes, thèses et résolutions des quatre premiers congrès de l'Internationale communiste 1919-1923. Textes complets.

Bibliothèque communiste, Librairie du Travail, juin 1934. Réimpression en fac-similé, François Maspero, 1971, 216 pp.

Polices de caractères utilisée : Times New Roman, 12 points.

Édition électronique réalisée avec le traitement de textes Microsoft Word 2008 pour Macintosh.

Mise en page sur papier format : LETTRE (US letter), 8.5'’ x 11'’)

Édition numérique réalisée le 17 avril 2011 à Chicoutimi, Ville de Saguenay, Québec.

\section{Fait avec}

Macintosh 
Internationale Communiste

Manifestes, thèses et résolutions des quatre premiers congrès de l’Internationale communiste 1919-1923.

Textes complets.

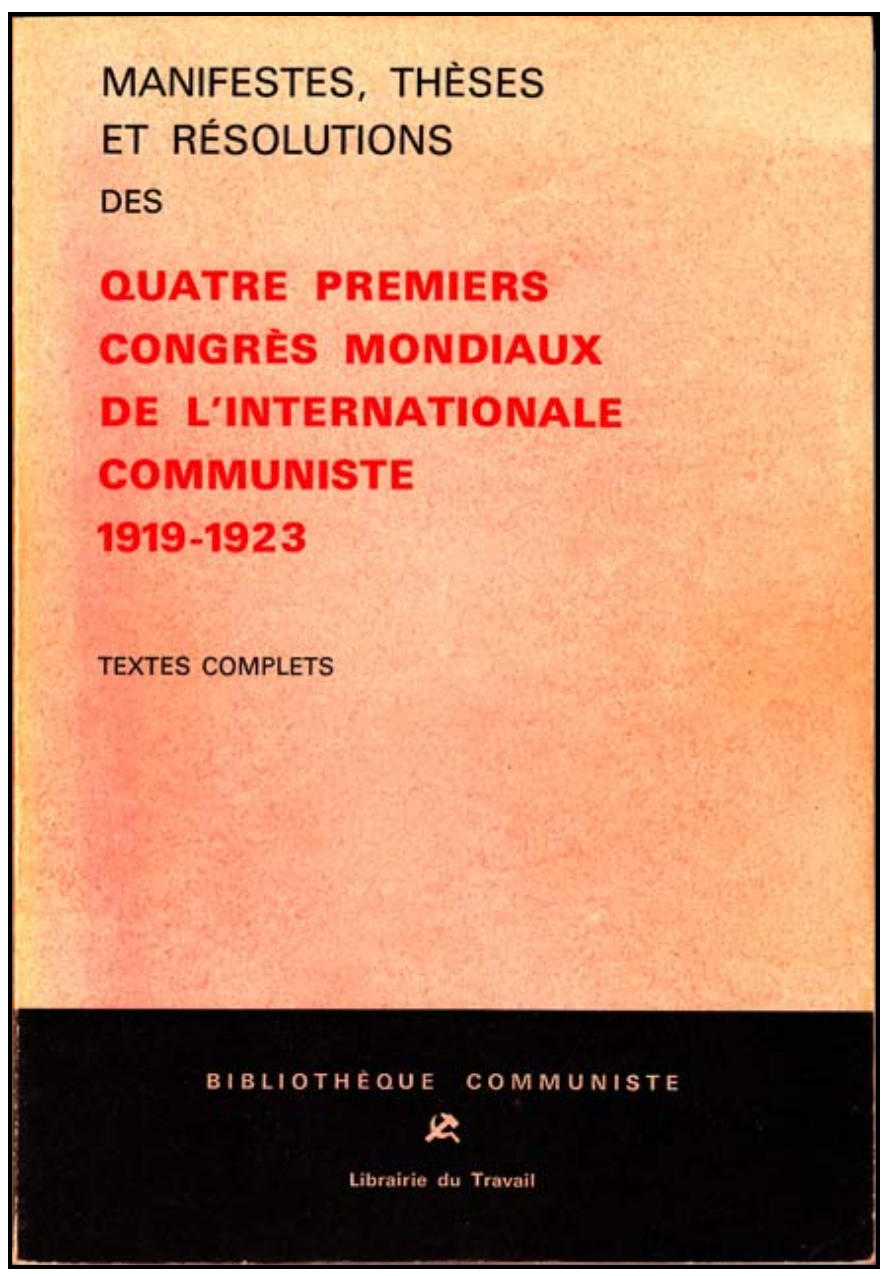

Bibliothèque communiste, Librairie du Travail, juin 1934. Réimpression en fac-similé, François Maspero, 1971, 216 pp. 


\section{Table des matières}

$\underline{\text { Avertissement de l'éditeur }}$

Notice historique

La $3^{\mathrm{e}}$ Internationale communiste

Le premier congrès, mars 1919

Le deuxième congrès, juillet 1920

Le troisième congrès, juin 1921

Le Front unique

La conférence préliminaire des trois Internationales

Le quatrième congrès, novembre 1922.

\section{PREMIER CONGRÈS}

mars 1919.

1.1 Lettre d'invitation au Parti communiste allemand (Spartakusbund) au $1^{\mathrm{er}}$ Congrès de l'I.C », 2-6 mars 1919.

1.2 Discours d'ouverture de Lénine, 2 mars 1919.

1.3 Thèses de Lénine sur la démocratie bourgeoise et la dictature prolétarienne, 4 mars 1919.

$1.4 \quad$ Discours de Lénine sur ses thèses

1.5 Résolution sur la position envers les courants socialistes et la conférence de Berne, mars 1919.

1.6 Déclaration faite par les participants de la Conférence de Zimmerwald, mars 1919.

1.7 Résolution sur la fondation de l'Internationale Communiste, 4 mars 1919.

1.8 Plate-forme de l'Internationale Communiste, mars 1919.

1.9 Thèse sur la situation internationale et la politique de l'entente, mars 1919.

1.10 Résolution sur la terreur blanche, mars 1919.

1.11 Discours du camarade Trotsky, mars 1919.

1.12 Discours de clôture de Lénine, 7 mars 1919.

1.13 Manifeste de l'Internationale Communiste. Aux prolétaires du monde entier !, mars 1919. 


\section{DEUXIÈME CONGRÈS juillet 1920.}

$2.1 \quad$ Statuts de l'Internationale Communiste

2.2 Conditions d'admission des Partis dans l'Internationale Communiste

2.3 Les tâches principales de l'Internationale Communiste

2.4 Résolution sur le rôle du Parti Communiste dans la révolution prolétarien$\underline{\text { ne }}$

2.5 Le mouvement syndical, les comités de fabrique et d'usines

2.6 Thèses et additions sur les questions nationale et coloniale.

2.7 Thèses sur la question agraire.

2.8 Le Parti Communiste et le parlementarisme.

2.9 Manifeste du Congrès. Le monde capitaliste et l'Internationale Communiste.

\section{TROISIÈME CONGRÈS} juin 1921.

3.1 Thèses sur la situation mondiale et la tâche de l'Internationale Communiste.

3.2 Thèses sur la tactique.

3.3 Résolution sur le rapport du Comité Exécutif.

3.4 Thèses sur la structure, les méthodes et l'action des partis communistes.

3.5 Résolution de l'organisation de l'Internationale Communiste.

3.6 Résolution sur l'action de Mars et sur le Parti Communiste Unifié d'Allemagne.

3.7 Thèses et résolution sur la tactique du Parti Communiste de Russie.

3.8 Résolution sur la tactique du Parti Communiste de Russie.

3.9 L'Internationale Communiste et l'Internationale Syndicale Rouge.

3.10 Thèses et résolution sur l'action des communistes dans les coopératives.

3.11 Résolution sur l'Internationale Communiste et le mouvement de la Jeunesse Communiste.

3.12 Adresse pour Max Hoelz.

3.13 Manifeste du Comité Exécutif de l'Internationale Communiste.

3.14 Thèses pour la propagande parmi les femmes.

3.15 Résolution concernant les relations internationales des femmes communistes et le secrétariat féminin de l'Internationale Communiste.

3.16 Résolution concernant les formes et les méthodes du travail communiste parmi les femmes. 
3.17 Appel des 22 aux membres de la conférence de l'Internationale Communiste.

\section{QUATRIÈME CONGRÈS novembre 1922.}

4.1 Résolution sur la tactique de l'I.C.

4.2 Thèses sur l'unité du front prolétarien.

4.3 Résolution sur le rapport du Comité Exécutif.

4.4 Résolution sur le programme de l'Internationale Communiste.

$4.5 \quad$ Résolution sur la Révolution russe.

4.6 Résolution sur le Traité de Versailles.

4.7 Thèses sur l'action communiste dans le mouvement syndical.

4.8 Thèses générales sur la question d'Orient.

4.9 Programme d'action agraire.

4.10 Résolution sur la coopération.

4.11 Thèses sur la question nègre.

4.12 Résolution sur l'Internationale des Jeunesses Communistes.

4.13 Résolution sur l'action féminine.

4.14 Résolution sur la question de l’éducation.

4.15 Résolution sur l'assistance prolétarienne à la Russie soviétique.

4.16 Résolution sur l'aide aux victimes de la répression capitaliste.

4.17 Résolution sur la réorganisation de l'Exécutif et son activité future.

4.18 Résolution sur la question française.

4.19 Programme de travail et d'action du Parti Communiste français.

4.20 Résolution sur la question italienne.

4.21 Résolution sur la question tchécoslovaque.

4.22 Résolution sur la question norvégienne.

4.23 Résolution sur l'Espagne.

4.24 Résolution sur la question yougoslave.

4.25 Résolution sur le Parti danois.

4.26 Résolution sur l'Irlande.

4.27 Résolution sur le Parti Socialiste d’Égypte.

4.28 Lettre de Lénine, Moscou, le 4 novembre 1922.

4.29 Cinq ans de révolution russe et les perspectives de la révolution mondiale. Rapport présenté au 4e congrès de l'Internationale Communiste, le 13 novembre 1922. 
Manifestes, thèses et résolutions des quatre premiers congrès de l’Internationale communiste 1919-1923

(juin 1934)

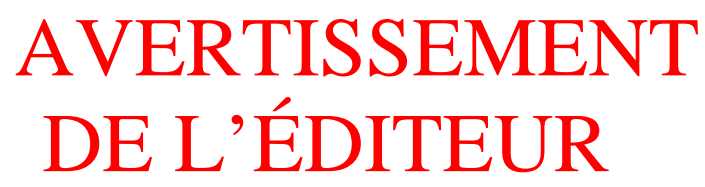

$\underline{\text { Retour à la table des matières }}$

Le recueil que nous présentons ici comprend tous les Manifestes, Thèses et Résolutions adoptées par les quatre premiers Congrès de l'Internationale Communiste, entre 1919 et 1923.

L'énorme quantité de faits et d'événements auxquels se réfèrent ces textes aurait évidemment nécessité des notes abondantes. Car, pour les jeunes générations, la tâche remplie par l'Internationale Communiste du vivant de Lénine et avec la participation active de Trotsky, reste jusqu'à aujourd'hui complètement inconnue.

Que la social-démocratie n’ait au aucun intérêt à faire connaître ces textes, cela se comprend suffisamment : on y apprend comment battre le réformisme, et organiser avec les grandes masses travailleuses l'insurrection prolétarienne.

Quant au silence observé dans les rangs de l'I.C. il s'explique d'une autre façon : c'est que toute l'expérience de l'I.C. entre 1919 et 1923 contredit entièrement le cours politique suivi par elle depuis 1924, et qui est caractérisé par l'échec en Allemagne en 1923, en Bulgarie et en Estonie en 1924, le soutien accordé au réformisme anglais en 1926, l'écrasement de la grande révolution chi- 
noise de 1926-1927, l’impuissance dans la révolution espagnole et la capitulation devant le fascisme allemand en 1932-1933.

Cependant, nous avons dû nous passer de notes, car il nous était impossible d’élargir même ce recueil déjà volumineux. Nous avons même dû renoncer à rédiger une introduction générale, ce qui aurait été cependant bien nécessaire.

Mais nous, qui appartenons à la Ligue Communiste Internationale (ancienne opposition de gauche), nous considérons que l'expérience immense des mouvements révolutionnaires de la guerre et de l'après-guerre, telle qu'elle est résumée, analysée, élaborée et rendue consciente par l’I.C. entre 1919- et 1923, constitue l’acquisition fondamentale du marxisme contemporain.

C’est pourquoi nous avons réédité aujourd'hui ces documents, comme base du marxisme-léninisme contemporain.

Les manifestes (en particulier celui du $2^{\mathrm{e}}$ Congrès) et les résolutions générales, donnent un tableau suffisamment précis de la situation politique et économique.

Un certain nombre de thèses (sur la question nationale, sur la question agraire, sur la démocratie bourgeoise et la démocratie prolétarienne), élaborées par les premiers et deuxième Congrès, demeurent comme la base fondamentale du marxisme dans l’époque actuelle. D’autres donnent d’inappréciables leçons de stratégie et de tactique.

Les textes ont été reproduits d'après les traductions qui ont été faites à l'époque, et qui sont parfois défectueuses. Il ne nous a pas été possible de faire une révision complète, ce qui aurait nécessité un long travail. Or, notre but était de mettre aussi rapidement que possible les documents entre les mains des militants. Certains qui étaient inédits en français, ont dû être traduits.

Ajoutons enfin que les documents des $5^{\mathrm{e}}$ et $6^{\mathrm{e}}$ Congrès de l'I.C. (1925 et 1926) sont facilement accessibles. Ce que le lecteur devra consulter devra consulter sur la période qui suit la mort de Lénine en 1924, c’est avant tout la Critique du projet de programme de l'I.C., de L. Trotsky, dans laquelle toute l'expérience historique et l'activité révolutionnaire des années 1923 à 1928 se trouve examinée à la lumière des principes des quatre premiers Congrès. 
Nous sommes persuadés que ce recueil rencontrera un bon accueil dans les rangs de la jeune génération, qui y trouvera l'orientation marxiste et les riches leçons dont elle a besoin.

\section{L'ÉDITEUR.}


Manifestes, thèses et résolutions des quatre premiers congrès de l’Internationale communiste 1919-1923

(juin 1934)

NOTICE HISTORIQUE

Afin de donner un aperçu général sur les premiers développements de l'Internationale Communiste, nous reproduisons ici la notice rédigée par le camarade Mathias Rakosi, aujourd'hui menacé de mort par le bourreau Horthy,) la veille du IV Congrès, pour l'Annuaire du Travail, publié par l'I.C., en 1923.

\section{LA $3^{e}$ INTERNATIONALE COMMUNISTE}

Retour à la table des matières

La $2^{\mathrm{e}}$ Internationale devait faire ses preuves au moment de la guerre impérialiste, Elle y était intellectuellement préparée. On avait à l'avance très exactement analysé le caractère de la guerre. A différentes reprises, les Congrès internationaux avaient décidé de mener la lutte la plus énergique et même d'employer contre la guerre la grève générale internationale.

Lorsqu'éclata la guerre, ce fut le contraire qui arriva. La $2^{\mathrm{e}}$ Internationale ne fut même pas capable d'une protestation. Au lieu de déclarer la grève générale ou la lutte contre la guerre impérialiste les leaders social-démocrates s'empressèrent de soutenir leur propre bourgeoisie, sous prétexte de défense nationale. Tous étaient dévorés d'opportunisme et de chauvinisme, attachés par mille liens à la bourgeoisie. Naturellement, la $2^{\mathrm{e}}$ Internationale ne pouvait pas être autrement que 
les partis qui la composaient. Les phrases révolutionnaires ne pouvaient arriver à masquer la réalité qu'aussi longtemps que le temps n’était pas venu, où l’on exigerait l'adaptation des actes aux paroles. C’est pourquoi le début de la guerre mondiale marque l'écroulement de la $2^{\mathrm{e}}$ Internationale.

C’est ce qui fit que le mouvement ouvrier international fut privé de sa direction précisément à l'heure de plus grand trouble intellectuel et moral. Les rares hommes qui, même au milieu de la vague d'opportunisme et de chauvinisme qui parut, en août 1914, s’être emparé de tous les cerveaux, ne perdirent par la tête, essayèrent immédiatement de faire comprendre ce fait aux ouvriers. Ce furent tout particulièrement les bolcheviks russes qui, au cours de leur lutte impitoyable contre le tsarisme, particulièrement pendant les années 1905-1906, avaient déjà appris à distinguer entre les paroles et les actes révolutionnaires et qui avaient constitué une aile gauche au sein de la $2^{\mathrm{e}}$ Internationale, dont ils critiquaient l'action. Dans le premier numéro de leur organe central qui parut le $1^{\mathrm{er}}$ novembre 1914, le camarade Lénine écrivait :

« La $2^{\mathrm{e}}$ Internationale est morte, vaincue par l'opportunisme. A bas l'opportunisme et vive la $3^{\mathrm{e}}$ Internationale, débarrassée des renégats et aussi de l’opportunisme! »

« La $2^{\mathrm{e}}$ Internationale a fait un travail utile d'organisation des masses prolétariennes pendant la longue "période pacifique » du pire esclavage capitaliste au cours du dernier tiers du $\mathrm{XIX}^{\mathrm{e}}$ siècle et au début du $\mathrm{XX}^{\mathrm{e}}$ siècle. La tâche de la $3^{\mathrm{e}}$ Internationale sera de préparer le prolétariat à la lutte révolutionnaire contre les gouvernements capitalistes, à la guerre civile contre la bourgeoisie de tous les pays, en vue de la prise des pouvoirs publics et de la victoire du socialisme. "

Quelques semaines plus tard, le camarade Zinoviev écrivait sur «le mot d’ordre de la social-démocratie révolutionnaire » :

« Nous devons lever l'étendard de la guerre civile. L’Internationale adoptera ce mot d'ordre et elle sera digne de son nom, ou elle végétera misérablement. Notre devoir est de nous préparer aux batailles qui viennent et de nous habituer nous-mêmes et le mouvement ouvrier tout entier à cette idée ; ou nous mourrons ou nous vaincrons sous la bannière de la guerre civile. » 
La propagation de pareilles idées se heurtait à d’immenses difficultés. La bourgeoisie de tous les pays, aidée en cela par ses social-patriotes, employait tous les moyens pour empêcher ces idées de pénétrer parmi les masses.

La première tentative de reconstitution d'une Internationale révolutionnaire eut lieu, au début de septembre 1915, à Zimmerwald, en Suisse. Sur l'initiative des socialistes italiens y furent invitées «toutes les organisations ouvrières qui sont restées fidèles au principe de la lutte de classes et de la solidarité internationale ». Etaient présents des délégués de l’Allemagne, de France, d’Italie, des Balkans, de la Suède, de la Norvège, de la Pologne, de la Russie, de la Hollande ou de la Suisse. Toutes les tendances y étaient représentées, depuis les réformistes pacifistes jusqu'aux marxistes révolutionnaires. La Conférence adopta un manifeste, flétrissant la guerre impérialiste et recommandant l'exemple de tous ceux qui furent persécutés pour avoir tenté de réveiller l'esprit révolutionnaire au sein de la classe ouvrière. Quoique confus, ce manifeste marqua un grand pas en avant. Le groupe intitulé la gauche de Zimmerwald répandit une résolution beaucoup plus claire et plus nette. Cette résolution contenait le passage suivant :

« Refus des crédits de guerre, sortie des ministres socialistes des gouvernements bourgeois, nécessité de démasquer le caractère impérialiste de la guerre du haut de la tribune parlementaire, dans les colonnes de la presse légale et, au besoin, illégale, organisations de manifestations contre les gouvernements, propagande des tranchées en faveur de la solidarité internationale, protection des grèves économiques tout en essayant de les transformer en grèves politiques, guerre civile et non paix sociale. »

Le rejet de cette résolution par la Conférence caractérise suffisamment l'état d'esprit de ceux qui y participaient. La Conférence nomma une «Commission socialiste internationale ». Malgré la déclaration formelle de la majorité à la Conférence, disant ne pas vouloir créer une $3^{\mathrm{e}}$ Internationale, la Commission devint par son opposition au « Bureau socialiste international » (organe exécutif de la $2^{\mathrm{e}}$ Internationale), le point de ralliement de l'opposition et l'organisatrice de la nouvelle internationale.

La Conférence de Zimmerwald fut suivie de la Conférence de Kienthal, en avril 1916. Ce qui caractérisa cette deuxième conférence fut le fait que l’idée de la lutte révolutionnaire internationale contre la guerre et, par conséquent, da nécessité d’une nouvelle Internationale apparurent de plus en plus au premier plan. 
L’influence de la « Gauche zimmerwaldienne » augmenta. On travailla avec zèle. On imprima des brochures, des tracts, qu'on envoya dans les différents pays au prix des plus grandes difficultés. De petites entrevues et conférences eurent lieu, qui continuèrent à répandre l’idée de la lutte de classes révolutionnaire.

Lorsque la Révolution éclata en Russie, les éléments les plus actifs de la « Gauche zimmerwaldienne » retournèrent en Russie. C’est ainsi que le centre de la lutte en faveur de la $3^{\mathrm{e}}$ Internationale se transporta en Russie. C'est pourquoi Zinoviev avait raison d'écrire :

« Dès sa naissance, la $3^{\mathrm{e}}$ internationale lia son destin à celui de la Révolution russe. Dans la mesure où celle-ci triompha, le mot d'ordre : «Pour la $3^{\mathrm{e}}$ Internationale » s’imposa. Et dans la même mesure où la Révolution russe se renforça, se renforça aussi la situation de l'Internationale communiste dans le monde entier. »

Au cours des démonstrations du $1^{\mathrm{er}}$ mai 1917, l'un des mots d'ordre principaux des masses prolétariennes fut l'édification de l’Internationale communiste. Ce souhait devint plus ardent encore quand le prolétariat russe eut conquis le pouvoir et que, dans la lutte contre l'impérialisme mondial, la $2^{\mathrm{e}}$ Internationale tout comme dans la guerre mondiale — se mit du côté de la bourgeoisie.

Quelques mois après la chute des puissances centrales, le parti communiste russe prit l'initiative de la fondation de la $3^{\mathrm{e}}$ Internationale. Les révolutions qui suivirent la guerre démontrèrent la banqueroute de la « défense nationale » et de ses partisans, les social-démocrates. Une puissante vague révolutionnaire passa sur la classe ouvrière de tous les pays. En Europe centrale, des insurrections ouvrières apparurent de tous côtés. Non seulement le terrain était suffisamment mûr pour la constitution de l'Internationale communiste, mais celle-ci était devenue une nécessité pour la préparation et l’organisation des luttes révolutionnaires. 


\section{LE PREMIER CONGRÈS - MARS 1919}

Le 24 janvier 1919, la Centrale du Parti communiste russe ainsi que les bureaux étrangers des partis communistes polonais, hongrois, allemand, autrichien, letton et les Comités centraux du parti communiste finlandais, de la Fédération socialiste balkanique et du Parti socialiste ouvrier américain lancèrent l'appel suivant :

« Les partis et organisations soussignés considèrent comme une nécessité impérieuse la réunion du premier congrès de la nouvelle Internationale révolutionnaire. Pendant la guerre et la Révolution, se manifesta non seulement la complète banqueroute des vieux partis socialistes et socialdémocrates et avec eux la $2^{\mathrm{e}}$ Internationale, mais aussi l'incapacité des éléments centristes de la vieille social-démocratie à l'action révolutionnaire. En même temps, se dessinent clairement les contours d'une véritable Internationale révolutionnaire. »

L’appel décrit en douze points le but, la tactique et la conduite des partis « socialistes». Considérant que l'époque actuelle signifie la décomposition et l'écroulement du système capitaliste qui est en même temps l'écroulement de la culture européenne, si l'on ne supprime pas le capitalisme. La tâche du prolétariat est dans la conquête immédiate des pouvoirs publics. Cette conquête du pouvoir public consiste dans l'anéantissement de l'appareil d'Etat bourgeois et dans l'organisation de l'appareil de l'Etat prolétarien. Le nouvel appareil doit incarner la dictature de la classe ouvrière et servir d'instrument à l'oppression systématique et à l'expropriation de la classe exploiteuse. Le type de l'Etat prolétarien n'est pas la démocratie bourgeoise, ce masque sous lequel se cache la domination de l’oligarchie financière, mais la démocratie prolétarienne sous la forme des Conseils. Pour assurer l'expropriation du sol et des moyens de production qui devront passer aux mains du peuple tout entier, il faudra désarmer la bourgeoisie et armer la classe ouvrière. La méthode principale de la lutte est l'action des masses révolutionnaires jusqu’à l’insurrection armée contre l’Etat bourgeois.

En ce qui concerne l'attitude des socialistes, trois groupes sont à considérer. Contre les social-patriotes qui combattent aux côtés de la bourgeoisie, il faudra 
lutter sans merci. Les éléments révolutionnaires du centre devront être scindés ; les chefs, critiqués incessamment et démasqués. A une certaine période du développement, une séparation organique d'avec les centristes s'impose. Un troisième groupe composé des éléments révolutionnaires du mouvement ouvrier devra être constitué. Suivait une énumération de 39 partis et organisations invités au $1^{\mathrm{er}}$ Congrès. La tâche du congrès consiste en la « création d'un organisme de combat chargé de coordonner et de diriger le mouvement de l'Internationale communiste et de réaliser la subordination des intérêts du mouvement des divers pays aux intérêts généraux de la Révolution internationale. »

Le $1^{\mathrm{er}}$ Congrès eut lieu en mars 1919. A cette époque, la Russie des Soviets était complètement bloquée, entourée de tous les côtés de fronts militaires, de sorte qu'un petit nombre seulement de délégués parvint, au prix des plus grandes difficultés, à se rendre au congrès. Au sujet de la constitution de ce congrès, le camarade Zinoviev (dans son rapport au second congrès) écrit ce qui suit :

«Le mouvement communiste, dans les divers pays d'Europe et d'Amérique, à cette époque, n'en était qu'à ses débuts. C’était la tâche du premier Congrès de déployer l'étendard communiste et de proclamer l'idée de l’Internationale communiste. Mais ni la situation générale des partis communistes dans les différents pays, ni le nombre des délégués au premier Congrès ne permirent de discuter à fond les questions pratiques de l'organisation de l'Internationale communiste. »

Le congrès entendit les rapports des délégués sur la situation du mouvement dans leur pays, adopta des résolutions sur les directives de l'Internationale communiste, sur la démocratie bourgeoise et la dictature prolétarienne, sur la position vis-à-vis des courants socialistes, sur la situation internationale : elles étaient toutes rédigées dans l'esprit de l'appel de la fondation. La fondation de l'Internationale communiste fut décidée à l'unanimité moins cinq abstentions. On laissa au $2^{\mathrm{e}}$ Congrès la tâche de la constitution définitive de l'Internationale communiste, dont la direction fut confiée à un Comité exécutif, dans lequel devaient être représentés les partis russe, allemand, hongrois, la Fédération balkanique, les partis suisse et scandinave. Le congrès se termina par un manifeste au prolétariat du monde entier.

Pendant la première année, le Comité exécutif de l'Internationale communiste eut un travail difficile à accomplir. A peu près coupé de l'Europe occidentale, il 
dut rester des mois entiers sans journaux, privé de la plupart de ses membres qui ne pouvaient venir à cause du blocus. Il n'en prit pas moins position sur toutes les questions importantes, précisément dans la première année qui suivit la guerre, où l’on manquait tant de clarté ; les appels et les écrits du Comité exécutif eurent une valeur extrêmement précieuse.

La création de l'Internationale communiste donna un but et une direction aux masses ouvrières opposées à la politique de la $2^{\mathrm{e}}$ Internationale. Il se produisit un véritable afflux des ouvriers révolutionnaires vers l'Internationale communiste. En mars 1919, le parti socialiste italien envoya son adhésion ; en mai, ce fut le tour du parti ouvrier norvégien et du parti socialiste « étroit » bulgare ; en juin, du parti socialiste de gauche suédois, du parti socialiste communiste hongrois, etc... En même temps, la $2^{\mathrm{e}}$ Internationale se vidait rapidement de ses effectifs. L'un après l'autre, ses partis les plus importants la quittèrent. Si, lors de sa fondation, l'Internationale communiste était plus un drapeau qu'une armée, elle avait, au cours de sa première année d'existence non seulement rassemblé une armée autour de son drapeau, mais infligé de graves défaites à son adversaire.

\section{LE DEUXIÈME CONGRÈS - JUILLET 1920}

De nouveaux problèmes apparurent avec les progrès de l'Internationale communiste. Les partis qui venaient d'y adhérer n'étaient pas suffisamment formés. Il n'existait pas encore de clarté suffisante sur le parti, sur le rôle des communistes dans les syndicats et sur leur attitude par rapport à la question du parlementarisme et dans les autres questions. Ce fut la tâche du $2^{\mathrm{e}}$ congrès de fixer les directives.

De tous les pays arrivèrent des délégués. Le congrès s’ouvrit à Pétrograd, le 17 juillet 1920, aux acclamations des ouvriers russes et au milieu de l'attention du monde prolétarien tout entier. On adopta des résolutions de l'Internationale communiste, résolutions où la notion de dictature du prolétariat et de pouvoir des Soviets était éclairée sur la base de l'expérience pratique, ainsi que les conditions d'exécution de ce mot d'ordre dans les différents pays. On envisagea les moyens de renforcer le mouvement communiste. On adopta aussi des résolutions sur le rôle du parti dans la révolution prolétarienne. Le parti communiste doit constituer l'avant-garde, la partie la plus consciente et la plus révolutionnaire de la classe 
ouvrière. Il doit être constitué sur la base du principe de centralisation et constituer, dans toutes les organisations, des noyaux soumis à la discipline du parti.

En ce qui concerne les syndicats, « les communistes doivent y entrer pour en faire des formations de combat contre le capitalisme et des écoles de communistes ». La sortie des communistes hors des syndicats aurait pour résultat de livrer les masses aux chefs opportunistes qui travaillent avec la bourgeoisie. D’autres résolutions furent adoptées sur la question des conseils ouvriers et des conseils de fabrique, sur le parlementarisme, sur la question agraire et coloniale. Enfin, on adopta les statuts de l'Internationale communiste.

De grands débats eurent lieu sur la question du rôle du parti, sur l'activité des communistes dans les syndicats et la participation aux élections. Les opportunistes attaquèrent avec violence les vingt et une conditions d'adhésion à l'Internationale communiste — Le combat héroïque du prolétariat russe, la banqueroute de la bourgeoisie et de son alliée, la $2^{\mathrm{e}}$ Internationale, les mots d'ordre et les appels révolutionnaires de l'Internationale communiste y conduisait une masse de chefs obligée de céder à la pression des masses ouvrières. Ils étaient dévoués corps et âme à la 2e Internationale et n'entraient à l'Internationale communiste que pour ne pas perdre leur influence sur les masses. Même si l'Internationale communiste avait été une organisation déjà puissante et expérimentée, l'entrée de ces éléments opportunistes aurait eu le danger de faire pénétrer au sein de l'Internationale communiste l'esprit de la $2^{\mathrm{e}}$ Internationale. Or, l'Internationale communiste étant composée de partis encore en voie de formation, il était d'une nécessite impérieuse de tenir à l'écart de tels éléments. C’est ce qui explique les vingt et une conditions d'adhésion.

Ces conditions exigent de chaque parti qui veut adhérer à l'Internationale communiste que toute sa propagande et son agitation aient un caractère communiste. La presse doit être complètement soumise au Comité central du parti. Les réformistes devront être écartés de tous les postes responsables. Le Parti doit posséder un appareil illégal et faire une propagande systématique dans l'armée et dans les campagnes. Il doit mener une lutte énergique contre les réformistes et les centristes. Dans les syndicats, il doit lutter contre l'Internationale syndicale d'Amsterdam. Le Parti doit être sévèrement centralisé et prendre le nom de Parti communiste (section de l'Internationale communiste). Tous les Partis qui appartiennent à l'Internationale communiste ou qui veulent y entrer doivent, au plus 
tard 4 mois après le $2^{\mathrm{e}}$ Congrès, examiner ces conditions dans un congrès extraordinaire et exclure du Parti tous ceux de leurs membres qui les repoussent.

Le Congrès se termina le 7 août. Au mois de septembre, le Parti socialdémocrate de Tchécoslovaquie se scinda : une majorité écrasante adopta les 21 conditions et se constitua, plus tard, en Parti communiste. Au mois d'octobre, au Congrès de Halle, la majorité du Parti social-démocrate indépendant d'Allemagne se prononça pour l'adhésion à l'Internationale communiste. En décembre eut lieu la fusion de la gauche du Parti indépendant et K.P.D. (groupe spartakiste) et un grand Parti communiste unifié d'Allemagne sortit de cette fusion. Fin décembre, l'immense majorité du Parti Socialiste français adhéra à l'Internationale communiste. Au mois de janvier 1921, une scission se produisit au sein du Parti socialiste italien, qui appartenait cependant à l'Internationale communiste, mais dont la majorité réformiste repoussait les 21 conditions. Dans tous les pays du monde où existaient des organisations ouvrières, le même processus se produisait : les communistes se séparaient des réformistes et se constituaient en section de l’Internationale communiste.

Parallèlement au progrès et au renforcement de l'Internationale communiste, se produisait la décomposition de la $2^{\mathrm{e}}$ Internationale. Toute une série de partis qui sortirent de la $2^{\mathrm{e}}$ Internationale, mais se refusèrent à entrer dans l'Internationale communiste, constituèrent une «Union Internationale des Partis socialistes », communément appelée l'Internationale $21 / 2$, parce que, dans toutes les questions, elle oscille entre la $2^{\mathrm{e}}$ et $3^{\mathrm{e}}$ Internationale.

\section{LE TROISIÈME CONGRÈS — JUIN 1921}

Le $3^{\mathrm{e}}$ Congrès de l'Internationale communiste, qui se réunit en juin 1921, eut à résoudre de nouvelles tâches. Celles-ci étaient déterminées en partie par le fait que l'Internationale communiste comprenait déjà plus de 50 sections, parmi lesquelles de grands partis de masses des pays européens les plus importants, ce qui faisait surgir des questions de tactique et d'organisation, mais surtout par le fait que le développement de la Révolution et l'écroulement du capitalisme subissaient un certain ralentissement qu'on n'avait pu prévoir à l'époque du $1^{\mathrm{er}}$ et du $2^{\mathrm{e}}$ Congrès. 
Après l'écroulement des Puissances centrales, la vague révolutionnaire était monstrueusement forte et l'on avait l'impression que des Révolutions prolétariennes suivraient immédiatement les Révolutions bourgeoises. En Hongrie et en Bavière, le prolétariat réussit pour quelque temps à s'emparer du pouvoir ; même après la défaite des Républiques soviétiques de Hongrie et de Bavière, l’espoir en une victoire rapide de la classe ouvrière n'avait pas disparu. Qu'on se rappelle l'époque où l'Armée Rouge était devant Varsovie et où le prolétariat tout entier se préparait fiévreusement à de nouvelles luttes.

Mais la bourgeoisie se montra plus capable de résistance qu'on ne l'avait cru. Sa force consistait tout d'abord en ce fait que les social-traîtres qui pendant la guerre se battirent si hérö̈quement contre le prolétariat, se révélèrent, même après la guerre, comme les meilleurs soutiens du capitalisme branlant. Dans tous les pays où la bourgeoisie ne pouvait plus rester maîtresse de la situation, elle remit le pouvoir aux social-démocrates. Ce furent des «gouvernements socialdémocrates », avec Noske et Ebert en Allemagne, Renner et Otto Bauer en Autriche, avec Tusar en Tchécoslovaquie, avec Bôhm et Garami en Hongrie, qui firent les affaires de la bourgeoisie pendant la période révolutionnaire, et étouffèrent dans le sang les tentatives de libération du prolétariat.

La prospérité apparente qui suivit immédiatement la guerre, en permettant aux capitalistes d'occuper les soldats démobilisés, constitua également un obstacle à la Révolution. La bourgeoisie réussit à calmer les ouvriers sans travail, en leur fournissant des subventions. A cela vint s'ajouter encore un phénomène psychologique important, à savoir la fatigue des larges masses de la classe ouvrière qui sortaient à peine des souffrances et des privations subies pendant les quatre années de la guerre impérialiste. Enfin les partis communistes à qui incombait la tâche de diriger et de coordonner la lutte du prolétariat, étaient encore en voie de formation et adoptaient souvent de fausses méthodes de combat.

Toutes ces circonstances permirent à la bourgeoisie de rassembler lentement ses forces, de conquérir son assurance et de reprendre une partie des positions perdues. Lorsque la bourgeoisie n'eut plus besoin d'eux, elle chassa les socialistes du gouvernement dans tous les pays où ils y participaient, et les capitalistes reprirent eux-mêmes la direction de leurs affaires. Ils créèrent des organisations militaires illégales, armèrent la partie consciente de la bourgeoisie et passèrent à l'attaque contre la classe ouvrière. 
Entre temps, la situation économique avait également subi de profondes transformations. Au printemps 1920, une crise apparut au Japon et en Amérique qui s'étendit de proche en proche à toutes les nations industrielles. La consommation diminua rapidement, la production se réduisit, des centaines de milliers, des millions d’ouvriers furent jetés sur le pavé. Les débouchés diminuèrent rapidement, la production fut restreinte. Les luttes défensives des ouvriers prirent de grandes dimensions, mais se terminèrent par des défaites, ce qui renforça la situation de la bourgeoisie.

Telle était la situation, lorsque s'ouvrit le $3^{\mathrm{e}}$ Congrès de l'Internationale communiste. Le Congrès examina tout d'abord la situation de l'économie mondiale et aborda ensuite la question de la tactique nécessitée par la nouvelle situation. La bourgeoisie se renforçait, ainsi que ses serviteurs, les social-démocrates. L’époque des victoires faciles, remportées par l'Internationale communiste, au cours des années qui suivirent immédiatement la guerre, était passée. En attendant de nouveaux combats révolutionnaires, nous devions reconstruire et renforcer nos organisations et conquérir les positions des réformistes par un travail opiniâtre au sein des organisations ouvrières. Les occupations de fabriques en Italie, la grève de décembre en Tchécoslovaquie, l'insurrection de mars en Allemagne, montraient que les Partis communistes, même lorsqu'ils combattaient manifestement pour les intérêts du prolétariat tout entier, ne pouvaient réussir à vaincre les forces unies de la bourgeoisie et de la social-démocratie, quand non seulement ils n’avaient pas la sympathie des larges masses, mais même quand ils n'embrassaient pas ces masses au sein de leurs organisations en les arrachant aux organisations diverses. C'est pourquoi le Congrès lança le mot d’ordre « Allez aux masses ! »

Dans l'Europe occidentale, les Partis communistes doivent faire tout leur possible afin d'obliger les syndicats et les partis s'appuyant sur la classe ouvrière, à une action commune en faveur des intérêts immédiats de la classe ouvrière, tout en préparant celle-ci à la possibilité d’une trahison de la part des partis non communistes.

Une certaine opposition "gauchiste » se manifesta contre cette tactique. Le K.A.P.D. ${ }^{1}$ y vit un abandon de la lutte révolutionnaire et accusa l'Internationale

1 K.A.P.D. : Parti communiste ouvrier d'Allemagne, qu'il ne faut pas confondre avec le K.P.D. ou V.K.P.D. (Parti communiste unifié d'Allemagne). Organisation pour laquelle Lénine inventera le terme de « gauchisme ». 
communiste de faire sur le terrain politique la même retraite que le pouvoir des Soviets s'était vu obligé de faire sur le terrain économique. De bons camarades également ne comprirent pas, au début, la nécessité de cette tactique.

A côté des questions de tactique, ce furent les questions d'organisation qui retinrent le plus d'attention. En vue de la conquête des syndicats, le Bureau syndical organisé par le $2^{\mathrm{e}}$ Congrès, en collaboration avec les syndicats ayant adhéré dans l'intervalle des deux congrès, constitua l'Internationale syndicale rouge. On discuta également la question de l'Internationale des Jeunes et du mouvement des femmes, ainsi que celle concernant le travail dans les coopératives et dans les Unions sportives ouvrières.

Le Congrès entendit ensuite un rapport sur la Russie des Soviets et approuva à l’unanimité la tactique employée.

De grands débats eurent lieu sur le rapport concernant l'activité du Comité exécutif. Certains camarades n’approuvaient pas la politique du Comité exécutif dans la question italienne, dans le cas Lévi et dans la question du K.A.P.D. Mais le Congrès approuva dans toutes ces questions l'activité du Comité exécutif. Les événements n’ont fait que confirmer la justesse de ces décisions.

Le Congrès se termina le 12 août, par la discussion de la question orientale.

Les mois qui suivirent furent relativement calmes et donnèrent aux différents partis communistes la possibilité d'exécuter les décisions du $3^{\mathrm{e}}$ Congrès. Les organisations furent soumises à un examen sévère, la liaison entre les différentes sections et le Comité exécutif tut améliorée. Au cours des trois années de son existence, la $3^{\mathrm{e}}$ Internationale. est devenue une organisation véritablement mondiale. La 2e Internationale, par exemple, n’a aucun parti dans des pays comme la France et l'Italie ; par contre, il n'existe presque aucun pays où la fraction la plus consciente du prolétariat, sans distinction de race ou de couleur, ne soit constituée en section de l'Internationale communiste. Celle-ci comprend près de 60 sections avec un effectif total d'environ 3 millions de membres, et possédant 700 journaux quotidiens. La conquête de nouvelles masses et de nouvelles positions se poursuit avec succès. Le Congrès des travailleurs d'Extrême-Orient, qui se tint à Moscou au mois de janvier 1922, établit la liaison de la classe ouvrière chinoise et japonaise avec l'Internationale communiste. 


\section{LE FRONT UNIQUE}

Le $3^{\mathrm{e}}$ Congrès se réunit à une époque où régnait une grande dépression au sein de la classe ouvrière. Les défaites subies avaient découragé le prolétariat. Cette situation s’aggrava encore après le congrès. En Angleterre, en Amérique, en Italie et dans les pays neutres, les ouvriers souffrent du chômage permanent. La classe ouvrière a perdu ses conquêtes des dernières années. La journée de travail a été prolongée, le niveau d'existence des ouvriers a été ramené à un niveau plus bas qu'avant la guerre. Si, dans les pays à change bas, comme l'Allemagne, l'Autriche, la Pologne, le chômage est moins grand, la misère de la classe ouvrière n'en est que plus dure, vu la diminution constante des salaires réels causée par l'abaissement continuel de la valeur d'achat de l'argent, ce qui met les ouvriers dans l’impossibilité de satisfaire leurs besoins même les plus élémentaires.

Cette situation était intolérable. Sous la pression de la misère croissante, les masses commencèrent à chercher un remède à leur situation. Elles comprirent que les vieilles méthodes étaient impuissantes à obtenir quoi que ce fût. Les grèves échouaient, et, quand elles réussissaient, les avantages obtenus étaient bientôt annulés par la déprécation de l'argent. Les masses virent que la classe ouvrière était scindée en différents partis se combattant mutuellement, alors que la classe capitaliste engageait contre elle une offensive unique. Dans cette situation, la solution qui s’imposait était d'unifier les forces dispersées du prolétariat pour les opposer à l'attaque du capitalisme.

De quelle façon devait se réaliser cette unification des forces du prolétariat ? Là-dessus, les masses ouvrières ne se faisaient aucune idée bien claire. En tout cas, le fait que, partout, un mouvement se produisait dans cette direction, était une preuve de sa profondeur et de sa nécessité. Il prouvait que les masses se détournaient inconsciemment de la politique réformiste de la $2^{\mathrm{e}}$ Internationale et de l'Internationale syndicale d'Amsterdam, et qu'après tant d'erreurs et de défaites, elles étaient enfin décidées à s'engager dans la voie de l'unification des forces du prolétariat.

Cela signifiait en même temps un changement dans l'appréciation du rôle des partis communistes et de l’Internationale communiste. Au cours des années 1918 
et 1919, le prolétariat a été battu, parce que son avant-garde, le Parti communiste, représentait bien plus une tendance qu'une organisation capable de prendre la direction de la lutte de classes. L'expérience de la défaite obligea les communistes à créer, par le moyen de scissions et par la création de partis indépendants, les organisations de combat nécessaires. Cette période des scissions coïncida avec celle où la grande vague révolutionnaire était en voie de décroissance et où commençait la contre-offensive du capitalisme. Même si les social-démocrates n’avaient pas su utiliser adroitement cette circonstance, un mécontentement se serait quand même produit contre les « scissionnistes » au sein des masses qui ne pouvaient comprendre la nécessité de cette tactique. Les masses avaient aussi peu compris les tentatives de soulèvement faites par les communistes, lorsque ces derniers, avant toute la classe ouvrière - précisément parce qu’ils en sont la fraction la plus clairvoyante — réclamaient l'emploi de méthodes de combat plus énergiques. La grève de décembre, en Tchécoslovaquie et l'action de mars, en Allemagne, devaient échouer même si elles avaient été mieux conduites, parce que les larges masses ne comprenaient pas alors la nécessité d'une pareille méthode de combat. Mais la pression de la misère leur fit bientôt comprendre la nécessité de ce qu'elles considéraient autrefois comme des putschs. Le travail que les communistes, à l'époque de la dépression, avaient fait seuls, au prix d’immenses sacrifices, commençait à porter ses fruits.

À cela, vient s'ajouter le fait que, dans la lutte, les ouvriers ne tiennent plus compte des frontières de partis au moyen desquelles les social-démocrates essayent de les éloigner des communistes.

Les partisans d'Amsterdam, ceux de la $2^{\mathrm{e}}$ Internationale et de l'Internationale $21 / 2$, essayèrent d'exploiter le nouveau courant en provoquant un mouvement en faveur de l'unité, contre les communistes. Mais l'époque où de telles manœuvres étaient possibles, parce que les social-démocrates avaient en mains toutes les organisations ouvrières et toute la presse ouvrière, était passée. Le Comité exécutif de l'Internationale communiste démasqua ce plan et engagea une campagne «pour l'unité du prolétariat mondial, contre l'union avec les social-traîtres ». Dans la question du secours aux affamés et du secours aux ouvriers yougoslaves et espagnols, elle s'adressa à l'Internationale d'Amsterdam, au début, sans aucun succès. Mais lorsque les contours de la nouvelle vague devinrent plus clairs et 
plus visibles, le Comité exécutif, après de longues discussions, pris position sur la question.

Dans des « Résolutions sur le front unique des ouvriers et sur les rapports avec les ouvriers qui appartiennent à la $2^{\mathrm{e}}$ Internationale, à l'Internationale 2 1/2, à l'Internationale syndicale d'Amsterdam et aux organisations anarchosyndicalistes », il analysa la situation et fournit un but clair et précis aux efforts élémentaires en vue du front unique. « Le front unique n’est pas autre chose que l'union de tous les ouvriers décidés à lutter contre le capitalisme. » Les communistes doivent soutenir ce mot d'ordre de la plus grande unité possible de toutes les organisations ouvrières dans chaque action contre le capitalisme. Les leaders de la $2^{\mathrm{e}}$ Internationale comme de l'Internationale $2 \frac{1}{2}$ et de l'Internationale syndicale d'Amsterdam, ont trahi les masses ouvrières dans toutes les questions pratiques de la lutte contre le capitalisme. Cette fois aussi, ils préféreront l'unité avec la bourgeoisie à l'unité avec le prolétariat. C'est le devoir de l'Internationale communiste et de ses différentes sections, de persuader, cette fois, les masses ouvrières de l'hypocrisie des social-traîtres, qui se révèlent des destructeurs de l'unité de front de la classe ouvrière. Dans ce but, l'indépendance absolue, la pleine liberté de la critique sont les conditions principales des partis communistes.

Les résolutions insistent également sur les dangers qui peuvent naître, au cours de la mise à exécution de cette tactique, là où les partis communistes n’ont pas encore la clarté idéologique nécessaire et l’homogénéité indispensable.

Les résolutions furent adoptées au milieu du mois de décembre. En vue de la décision définitive, on convoqua, à Moscou, une session élargie du Comité exécutif pour le début du mois de février suivant. Dans un appel daté du $1^{\mathrm{er}}$ janvier 1922, sur le front unique prolétarien, le Comité exécutif montra la nécessité de la lutte commune en rapport avec la conférence de Washington et l'offensive générale du capitalisme contre la classe ouvrière. Les résolutions et l'appel du Comité exécutif furent rapidement répandus dans tous les pays, devinrent l'objet de longues discussions de la part des communistes et de leurs adversaires et contribuèrent à éclairer la question du front unique. Les social-traîtres jetèrent les hauts cris, ils comprirent qu’ils étaient là placés devant une question qui allait les obliger à se démasquer. Mais leur indignation, sur cette « nouvelle manœuvre communiste », ne put faire disparaître, dans les masses, l'impression que les communistes, qu’on appelait jusque-là les « scissionnistes », étaient, en réalité, les vrais 
partisans de l'unité de front du prolétariat. La séance du Comité exécutif élargi, ne se réunit, à cause de la grève des cheminots allemands, qu'à la fin de février. Ce fut, en réalité, un petit congrès composé de plus de 100 délégués représentants trente-six pays. L’ordre du jour était passablement chargé : il comportait les rapports des partis des pays les plus importants, les tâches des communistes dans les syndicats, la question de la lutte contre les dangers de guerre, celle de la nouvelle politique économique de la Russie des Soviets, celle de la lutte contre la misère de la jeunesse ouvrière. Mais la question principale était constituée par la question du front unique et de la participation à la conférence commune proposée par l'Internationale $2 \frac{1}{1} 2$.

Les camarades français et italiens se prononcèrent contre l'unité de front dans la forme où elle était présentée par les résolutions du Comité exécutif. Les camarades français exprimèrent la crainte que les masses ouvrières françaises ne comprissent pas une action commune des communistes avec les dissidents. Ils se déclarèrent partisans du front unique des ouvriers révolutionnaires et déclarèrent que l'activité des communistes, en France, tendait à réaliser, dans les questions de la journée de huit heures et de l’impôt sur les salaires, le bloc des ouvriers révolutionnaires. Le parti français était encore trop jeune et trop peu capable de manœuvre, et il était incapable de mener une action commune avec les socialistes dissidents et les syndicats réformistes dont on venait à peine de se séparer.

Les délégués italiens se déclarèrent partisans de l'unité de front syndical, mais adversaires de l'unité de front politique avec les socialistes. Ils exprimèrent l'avis que les masses ne comprendraient pas une action commune des différents partis ouvriers, et que le véritable terrain où le front unique fût possible était le syndicat, où les communistes et les socialistes sont ensemble.

Tous les autres délégués présents à la conférence exprimèrent un avis différent. Malgré des trahisons innombrables, les leaders réformistes ont, jusqu’à présent, réussi à maintenir leur influence sur la majeure partie des organisations ouvrières. Ce n’est pas en répétant encore une fois que ce sont des traîtres, que nous arriverons à rallier à nous les ouvriers. Il s'agit maintenant, quand une volonté de combat règne dans les masses, de leur montrer que les social-démocrates ne veulent pas combattre non seulement pour le socialisme, mais même pour les revendications les plus immédiates de la classe ouvrière. Jusqu’à présent, nous n’avons pas encore réussi à les démasquer, d’abord parce que nous n’avions pas pour cela 
les moyens nécessaires, ensuite parce que la situation psychologique, l'atmosphère grâce à laquelle les ouvriers comprennent les trahisons dont ils sont l’objet, faisaient défaut. Nous avons, enfin, l’occasion de les démasquer. C'est pourquoi, en nous refusant à lutter avec les réformistes, parce qu’ils ne lutteront jamais sérieusement contre la bourgeoisie dont ils sont les serviteurs, nous aurons l'approbation des camarades qui savent déjà cela, mais nous ne persuaderons pas un seul des ouvriers qui suivent encore les réformistes. Tout au contraire, en se refusant à mener la lutte en commun, à une époque où les masses ouvrières la veulent, les communistes donnent aux social-traîtres la possibilité de les représenter comme des saboteurs de l'unité de front du prolétariat. Mais si nous participons à la lutte, les masses verront bientôt qui veut véritablement la lutte contre la bourgeoisie et qui ne la veut pas. Nos camarades, qui nous voyaient tout d'abord avec mauvaise humeur nous asseyant à une même table avec les réformistes, comprendront, au cours des négociations que, là aussi, nous faisons du travail révolutionnaire.

Après que le Comité exécutif élargi eut adopté à l'unanimité des voix, moins celle des camarades français, italiens et espagnols, les directives contenues dans les résolutions, les trois délégations adversaires du front unique firent une déclaration promettant de s'y soumettre.

Le Comité exécutif élargi décida d’accepter l'invitation de l'Internationale de Vienne de participer à une conférence internationale, en faisant la proposition d'inviter à la conférence, non seulement l'Internationale communiste, mais aussi l'Internationale rouge des syndicats, l'Internationale syndicale d'Amsterdam, les organisations anarcho-syndicalistes et les organisations syndicales indépendantes, et de mettre à l'ordre du jour de la conférence, à côté de la lutte contre l’offensive du capitalisme et contre la réaction, la question de la lutte contre de nouvelles guerres impérialistes, celle de la restauration de la Russie des Soviets, celle des réparations et du traité de Versailles.

Après avoir réglé encore quelques questions (celles de la presse communiste, de l'opposition ouvrière du parti communiste russe, etc...), et après avoir procédé à l'élection du président du Comité exécutif, la conférence se termina le 4 mars. 


\section{LA CONFÉRENCE PRÉLIMINAIRE DES TROIS INTERNATIONALES}

Le 2 avril, eut lieu la première séance des délégations des trois Internationales, composées chacune de 10 membres. Les représentants de la $2^{\mathrm{e}}$ Internationale essayèrent tout de suite de saboter la conférence et d'étouffer dans le germe le front unique. Ils posèrent des conditions à l'Internationale communiste, exigèrent des " garanties » contre la tactique des « noyaux » et se mirent à discuter la question de la Géorgie et celle des social-révolutionnaires. Il en résulta une situation telle qu'on put craindre que la conférence ne dût se séparer. Grâce à l’attitude énergique des délégués de l'Internationale communiste qui exigèrent le front unique sans conditions, les délégués de l’Internationale de Vienne se rangèrent à leur avis, ce qui obligea les délégués de la $2^{\mathrm{e}}$ Internationale à reculer. Après quatre jours de négociations, on décida de convoquer, dans le délai le plus court, une conférence générale. On nomma une Commission composée de trois membres de chaque Comité exécutif, chargée de la préparation de cette conférence. En attendant la réunion de cette conférence générale, on décida d’organiser des manifestations communes de tous les partis adhérents aux trois Internationales, pour le 20 avril suivant et, partout où cela ne serait pas techniquement possible, pour le $1^{\mathrm{er}}$ mai, avec les mots d'ordre suivants :

- $\quad$ Pour la journée de 8 heures ;

- Pour la lutte contre le chômage, provoqué par la politique de réparations des puissances capitalistes ;

- Pour l'action unie du prolétariat contre l’offensive capitaliste ;

- Pour la révolution russe, pour la Russie affamée, pour la reprise des relations politiques et économiques avec la Russie ;

- Pour le rétablissement du front unique prolétarien national et international. 
La Commission d'organisation fut chargée de s’entremettre entre les représentants de l'Internationale syndicale d'Amsterdam et ceux de l'Internationale rouge des syndicats. Les délégués de l’Internationale communiste firent une déclaration aux termes de laquelle le procès des social-révolutionnaires aurait lieu en toute publicité et se terminerait sans condamnation à mort. La résolution constata encore que la conférence générale ne pourrait pas avoir lieu en avril, parce que la $2^{\mathrm{e}}$ Internationale la repoussait sous différents prétextes : celle-ci refusant également d'inscrire à l'ordre du jour de la conférence la question du traité de Versailles et de sa révision.

Les manifestations du 20 avril et du $1^{\mathrm{er}}$ mai suivant, auxquelles participèrent des masses ouvrières immenses, montrèrent que le prolétariat était décidé à lutter en commun pour les mots d'ordre qui avaient été lancés. La $2^{\mathrm{e}}$ Internationale et les partis qui la composent essayent, aujourd'hui comme hier, de saboter le front unique par tous les moyens. Ils se refusent à organiser des manifestations communes, retardent l'exécution des décisions prises et contribuent ainsi à se démasquer devant les masses

C'est la tâche de l'Internationale communiste et de ses sections nationales de démontrer, par leur action, que la lutte contre l'offensive capitaliste et contre le capitalisme en général ne peut réussir que sous la direction de l’Internationale communiste.

Comme il fallait s'y attendre, la $2^{\mathrm{e}}$ Internationale et l'Internationale de Vienne firent sauter la Commission des neuf. Après qu’on fût arrivé à empêcher la réunion de la Commission pendant la conférence de Gênes afin que la bourgeoisie ne fût troublée en rien dans ses délibérations contre la Russie des Soviets, la première séance, qui fut aussi la dernière, eut lieu le 23 mai, à Berlin. Le 21 mai, avait eu lieu une réunion du Labour Party, du Parti ouvrier belge et du Parti socialiste français, au cours de laquelle avait été décidée une conférence générale de tous les partis socialistes à l'exception des communistes. Il était clair que la $2^{\mathrm{e}}$ Internationale et la $2 \frac{1}{2} 2$ étaient revenues à leur projet de front unique contre les communistes. Malgré cela, l’Internationale communiste fit tout son possible pour permettre la réunion d'un congrès international de tous les partis socialistes. Pour arriver aux buts de l'unité de front, à savoir la lutte contre l'offensive du capital, contre la baisse des salaires et contre le chômage, elle se déclara prête à rayer de l’ordre du jour du Congrès la question du secours à la Russie des Soviets, déjà 
adoptée dans la plate-forme commune. Par contre, elle demandait une réponse précise à la question de savoir si la $2^{\mathrm{e}}$ Internationale acceptait, oui ou non, le congrès ouvrier mondial. Placée devant cette question, la $2^{\mathrm{e}}$ Internationale se révéla l'adversaire du front unique, ainsi que son auxiliaire bénévole, l’Internationale de Vienne. La Commission des neuf se sépara.

L'Internationale communiste convoqua alors une nouvelle session du Comité exécutif élargi. Celui-ci se réunit le 7 juin. Y participèrent 60 délégués représentant 27 pays. La conférence discuta la question de la tactique à suivre, après les enseignements de la première étape de la lutte en faveur du front unique, et la tactique des partis dont la politique ne correspondait pas à la politique générale de l'Internationale communiste, enfin la position de l'Internationale communiste visà-vis du procès des social-révolutionnaires, et la convocation du congrès mondial.

En ce qui concerne la tactique du front unique, la conférence constata que, malgré l'échec de la Commission des neuf, les postulats politiques et économiques de la tactique du front unique subsistaient comme auparavant et que, par conséquent, la tactique des diverses sections de l'Internationale communiste devait consister à établir l'unité de front contre l'offensive du capital.

Les partis français, italien et norvégien n’ayant pas exécuté la tactique du front unique ou ne l'ayant exécuté qu'avec hésitation ou en partie, la conférence s'occupa en détail de la situation de ces partis et exprima le vœu que cette tactique fût appliquée également dans ces pays. En ce qui concerne le parti français, étant donné que l'existence d'une droite opportuniste importante faisait obstacle à son activité et à son développement, le Comité exécutif déclara que le meilleur moyen de remédier à la situation était l'union du centre et de la gauche contre la droite. La conférence examina également la situation du parti communiste tchécoslovaque où apparaissaient les symptômes d'une crise prochaine. On en vit la raison dans une certaine passivité de la direction du parti, et l'on fixa les instructions utiles pour la faire disparaître.

En ce qui concerne le procès des S.R., on constata que, du moment que la $2^{\mathrm{e}}$ Internationale et l'Internationale de Vienne avaient entrepris une campagne contre l'Internationale communiste et la Russie des Soviets et qu'en outre il s'agissait là d'une affaire intéressant à la fois la Russie des Soviets, boulevard de la Révolution mondiale, et l'Internationale communiste, cette dernière devait participer 
activement au procès en y envoyant des accusateurs, des défenseurs, des témoins et des experts.

\section{LE QUATRIÈME CONGRÈS - NOVEMBRE 1922}

Le $4^{\mathrm{e}}$ Congrès mondial fut fixé au 7 novembre 1922, cinquième anniversaire de la Révolution prolétarienne avec l’ordre du jour suivant :

$1^{\circ}$ Rapport de l’Exécutif ;

$2^{\circ}$ Tactique de l'Internationale communiste ;

$3^{\circ}$ Programme de l'Internationale communiste et des sections allemande, française, italienne, tchécoslovaque, bulgare, norvégienne, américaine et japonaise ;

$4^{\circ}$ Question agraire ;

$5^{\circ}$ Question syndicale ;

$6^{\circ} \quad$ L’éducation ;

$7^{\circ}$ Question des jeunes;

$8^{\circ}$ La question d’Orient.

Le travail principal du $4^{\mathrm{e}}$ Congrès se portera sur le paragraphe 3 . En vue de la préparation d'un programme de l'Internationale communiste, on nomma immédiatement une Commission qui fut également chargée de collaborer à la rédaction des programmes des différentes sections.

La conférence montra le développement et le renforcement du mouvement communiste dans tous les pays. L'un des meilleurs symptômes en est la nervosité croissante des partisans d'Amsterdam, qui voient avec crainte le progrès de l'influence des communistes dans les syndicats. Beaucoup de signes montrent qu'ils sont, à l'heure actuelle, déterminés à chasser les communistes des syndicats 
dans tous les pays, et que, dans ce but, ils ne reculeront pas devant la scission du mouvement syndical. C'est pourquoi la tâche principale de l'Internationale communiste, dans les syndicats, sera de démasquer cette manœuvre, et de s'opposer à ce que les partisans d'Amsterdam n'affaiblissent pas le prolétariat en détruisant les syndicats. 
Manifestes, thèses et résolutions des quatre premiers congrès de l'Internationale communiste 1919-1923

(juin 1934)

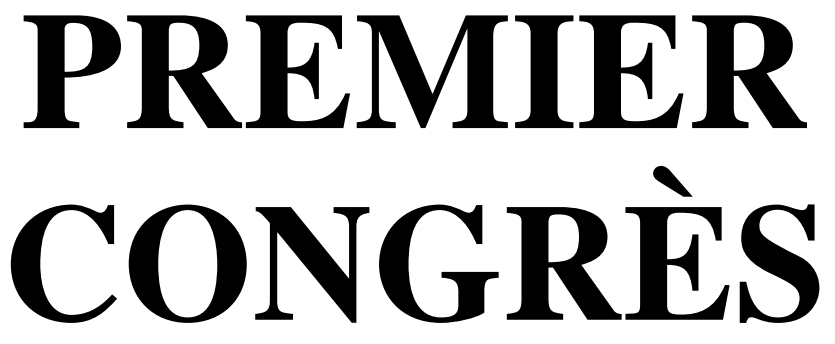

Mars 1919 


\section{Manifestes, thèses et résolutions des quatre premiers congrès de l'Internationale communiste 1919-1923 \\ (juin 1934) \\ Premier Congrès, mars 1919. \\ -1 - \\ Lettre d'invitation \\ au Parti Communiste allemand \\ (Spartakusbund) \\ au $1^{\mathrm{er}}$ Congrès de l'I.C., \\ 2-6 mars 1919}

$\underline{\text { Retour à la table des matières }}$

Chers Camarades ! Les partis et organisations soussignés considèrent que la convocation du premier Congrès de la nouvelle Internationale révolutionnaire est d'une nécessité urgente. Au cours de la guerre et de la révolution s'est manifesté non seulement la faillite complète des anciens partis socialistes et socialdémocrates et en même temps de la Deuxième Internationale, non seulement l'incapacité des éléments intermédiaires de l'ancienne social-démocratie (dite « Centre ») à l'action révolutionnaire effective, mais actuellement on voit déjà se dessiner les contours de la véritable Internationale révolutionnaire. Le mouvement ascendant extrêmement rapide de la révolution mondiale posant constamment de nouveaux problèmes, le danger d'étouffement de cette révolution par l'alliance des Etats capitalistes s’unissant contre la révolution sous le drapeau hypocrite de la «Société des Nations », les tentatives des partis social-traîtres de s'unir et d'aider de nouveau leurs gouvernements et leurs bourgeoisies à trahir la classe ouvrière après s’être accordé une « amnistie » réciproque ; enfin l’expérience révolutionnaire extrêmement riche déjà acquise et l'internationalisation de tout le 
mouvement révolutionnaire - toutes ces circonstances nous obligent à prendre l'initiative de mettre à l'ordre du jour de la discussion la question de la convocation d'un Congrès international des partis prolétariens révolutionnaires.

\section{I. - Les buts et la tactique.}

La reconnaissance des paragraphes suivants, établis ici comme programme et élaborés sur la base des programmes du Spartakusbund en Allemagne et du Parti communiste (bolcheviks) en Russie doit, selon nous, servir de base à la nouvelle Internationale.

1. La période actuelle est celle de la décomposition et de l'effondrement de tout le système capitaliste mondial et sera celle de l'effondrement de la civilisation européenne en général, si on ne détruit pas le capitalisme avec ses contradictions indissolubles.

2. La tâche du prolétariat consiste à présent à prendre le pouvoir d'Etat. La prise du pouvoir d'Etat signifie la destruction de l'appareil d'Etat de la bourgeoisie et l'organisation d'un nouvel appareil du pouvoir prolétarien.

3. Le nouvel appareil du pouvoir doit représenter la dictature de la classe ouvrière et à certains endroits aussi celle des petits paysans et des ouvriers agricoles, c'est-à-dire, qu'il doit être l'instrument du renversement systématique de la classe exploiteuse et celui de son expropriation. Non pas la fausse démocratie bourgeoise - cette forme hypocrite de la domination de l'oligarchie financière - avec son égalité purement formelle, mais la démocratie prolétarienne, avec la possibilité de réaliser la liberté des masses laborieuses; non pas le parlementarisme, mais l'auto-administration de ces masses par leurs organismes élus ; non pas la bureaucratie capitaliste, mais des organes d'administration créés par les masses ellesmêmes, avec la participation réelle de ces masses à l'administration du pays et à l'activité de l'édification socialiste — voilà quel doit être le type de l'Etat prolétarien. Le pouvoir des conseils ouvriers ou des organisations ouvrières est sa forme concrète. 
4. La dictature du prolétariat doit être le levier de l'expropriation immédiate du capital, de l'abolition de la propriété privée sur les moyens de production et de la transformation de cette propriété en propriété populaire.

La socialisation (par socialisation on entend ici l'abolition de la propriété privée qui est remise à l'Etat prolétarien et à l'administration socialiste de la classe ouvrière) de la grande industrie et des banques, ses centres d'organisation; la confiscation des terres des grands propriétaires fonciers et la socialisation de la production agricole capitaliste ; la monopolisation du commerce ; la socialisation des grands immeubles dans les villes et des grandes propriétés à la campagne ; l'introduction de l'administration ouvrière et la centralisation des fonctions économiques entre les mains des organismes émanant de la dictature prolétarienne voilà les problèmes essentiels du jour.

5. Pour la sécurité de la révolution socialiste, pour sa défense contre des ennemis intérieurs et extérieurs, pour l'aide aux autres fractions nationales du prolétariat en lutte, etc..., le désarmement complet de la bourgeoisie et de ses agents, et l’armement général du prolétariat sont nécessaires.

6. La situation mondiale exige maintenant le contact le plus étroit entre les différentes parties du prolétariat révolutionnaire et l'union complète des pays dans lesquels la révolution socialiste a triomphé.

7. La méthode fondamentale de la lutte est l'action de masse du prolétariat, y compris la lutte ouverte à main armée contre le pouvoir d'Etat du capital.

\section{2. - Rapports avec les partis « socialistes ».}

8. La $2^{\mathrm{e}}$ Internationale s'est partagée en trois groupes principaux : les socialpatriotes déclarés qui, pendant toute la guerre impérialiste des années 1914-1918 soutenaient leur propre bourgeoisie et transformaient la classe ouvrière en bourreau de la révolution internationale; le «centre » dont le dirigeant théorique est actuellement Kautsky, et qui représente une organisation d'éléments constamment oscillants, incapables de suivre une ligne directrice déterminée, et agissant parfois en véritables traîtres ; enfin, l’aile gauche révolutionnaire. 
9. À l'égard des social-patriotes, qui partout, aux instants critiques, s'opposent les armes à la main à la révolution prolétarienne, seul la lutte implacable est possible. A l'égard du « centre » - la tactique de l'effritement des éléments révolutionnaires, critique impitoyable, et démasquer les chefs. A une certaine étape du développement, la séparation organisatrice des gens du centre est absolument nécessaire.

10. D’autre part le bloc est nécessaire avec ces éléments du mouvement révolutionnaire qui, tout en n'ayant pas appartenu autrefois au parti socialiste, se placent maintenant dans l'ensemble sur le terrain de la dictature prolétarienne sous la forme du pouvoir soviétique. Ce sont en première ligne les éléments syndicalistes du mouvement ouvrier.

11. Enfin, il est nécessaire d'attirer tous les groupes et organisations prolétariennes qui, tout en ne s'étant pas ralliés ouvertement au courant révolutionnaire de gauche, manifestent néanmoins dans leur développement une tendance dans cette direction.

12. Concrètement, nous proposons que participent au Congrès les représentants des partis, tendances et groupes suivants (les membres à pleins droits de la Troisième Internationale seront des partis tout à fait autres et qui se placeront entièrement sur son terrain): 1. Le Spartakusbund (Allemagne); 2. Le Parti Communiste (Bolchevik) (Russie) ; 3. Le Parti Communiste de l'Autriche allemande ; 4. Celui de la Hongrie ; 5. Celui de la Finlande ; 6. Le Parti Communiste Ouvrier polonais ; 7. Le Parti Communiste d'Estonie ; 8. Celui de la Lettonie ; 9. Celui de la Lituanie ; 10. Celui de la Russie Blanche ; 11. Celui de l'Ukraine ; 12. Les éléments révolutionnaires du parti social-démocrate tchèque ; 13. Le Parti social-démocrate bulgare (étroits) ; 14. Le P. s.-d. roumain ;

15. L’aile gauche du parti s.-d. serbe ; 16. La gauche du parti s.-d. suédois;

17. Parti s.-d. norvégien; 18. Pour le Danemark le groupe Klassenkampen;

19. Le Parti communiste hollandais; 20. Les éléments révolutionnaires du parti ouvrier belge ; 21 et 22. Les groupes et organisations à l'intérieur du mouvement socialiste et syndicaliste français, qui, dans l'ensemble se solidarisent avec Loriot ; 23. La gauche s.-d. de la Suisse ; 24. Le parti socialiste italien ; 25. Les éléments révolutionnaires du P.S. espagnol ; 26. Les éléments de gauche du parti socialiste portugais ; 27. Les partis socialistes britanniques (avant tout le courant représenté par Mac Lean) ; 28. S. L. P. (Angleterre) ; 29. I. W. 
W. (Angleterre) ; 30. I. W. of Great Britain ; 31. Les éléments révolutionnaires des organisations ouvrières de l’Irlande ; 32. Les éléments révolutionnaires des shop stewards (Grande-Bretagne) ; 33. S. L. P. (Amérique) ; 34. Les éléments de gauche du P. S. d'Amérique (la tendance représentée par Debi et la Ligue de Propagande Socialiste) ; 35. I. W. W. Amérique ; 36. I. W. W. (Australie) ; 37. Workers International Industrial Union (Amérique) ; 38. Les groupes socialistes de Tokyo et de Yokohama (représentés par le cam. Katayama) ; 39. L’Internationale socialiste des Jeunes (représentée par le cam. Münzenberg).

\section{3. - La question de l'organisation et le nom du parti}

13. La base de la Troisième Internationale est donnée par le fait que dans différentes parties de l'Europe se sont déjà formés des groupes et des organisations de camarades d'idées, se plaçant sur une plate-forme commune et employant en gros les mêmes méthodes tactiques. Ce sont en premier lieu les spartakistes en Allemagne et les partis communistes dans beaucoup d'autres pays.

14. Le Congrès doit faire paraître, en vue d'une liaison permanente et d'une direction méthodique du mouvement un organe de lutte commun, centre de l'Internationale Communiste, subordonnant les intérêts du mouvement de chaque pays aux intérêts communs de la révolution à l'échelle internationale. Les formes concrètes de l’organisation, de la représentation, etc..., seront élaborées par le Congrès.

15. Le Congrès devra prendre le nom de « Premier Congrès de l'Internationale Communiste », les différents partis devenant sections de celle-ci. Théoriquement Marx et Engels déjà ont trouvé faux le nom de "social-démocrate ». L'effondrement honteux de l'Internationale social-démocrate exige ici aussi une séparation. Enfin le noyau fondamental du grand mouvement est déjà formé par une série de partis qui ont pris ce nom.

Considérant ce qui vient d'être dit, nous proposons à toutes les organisations et partis frères de mettre à l'ordre du jour la question de la convocation du Congrès Communiste International.

Avec notre salut socialiste. 
Le Comité Central du Parti Communiste Russe (Lénine, Trotsky).

Le Bureau étranger du Parti Ouvrier Communiste de Pologne (Karsky).

Le Bureau étranger du Parti Ouvrier Communiste de Hongrie (Rudnianszky).

Le Bureau étranger du Parti Ouvrier Communiste de l'Autriche allemande (Duda).

Le Bureau russe du Comité Central du Parti Communiste de Lettonie (Rosing).

Le Comité Central du Parti Communiste de Finlande (Sirola).

Le Comité Exécutif de la Fédération Social-démocrate Révolutionnaire Balkanique (Rakovsky).

Pour le S. L. P. (Amérique) (Reinstein).

L'invitation ci-dessus convoquait les communistes de tous les pays à une conférence qui devait s'ouvrir à Moscou le 15 février 1919. Les grandes difficultés de circulation en retardèrent l'inauguration. Elle ne put avoir lieu que le 2 mars. La conférence fut ouverte par une courte allocution de Lénine, à six heures du soir. On adopta la langue allemande pour les débats, en outre on parlait le russe, le français et l'anglais.

Comme présidents du congrès furent élus les camarades suivants : Lénine (Russie), Albert (Allemagne), Platten (Suisse) ; le quatrième président fut délégué à tour de rôle par les différents partis. Le Congrès élut comme secrétaire le camarade Klinger.

La Commission des mandats constata la participation des partis suivants et répartit les voix : 


\section{PARTICIPANTS AU CONGRÈS \\ DE L'INTERNATIONALE COMMUNISTE DE MOSCOU}

(2 au 6 mars 1919)

\section{Pays et Parti}

1. Parti Communiste allemand

2. Parti Communiste russe

3. Parti Communiste de l'Autriche allemande

4. Parti Communiste hongrois

5. S.-D. de gauche suédoise

6. P. S.-D. norvégien

7. P. S.-D. suisse

8. $\quad$ S. L.P. américain

9. Fédération Révolutionnaire Balkanique (Tchesniac bulgare et Parti Communiste roumain)

10. Parti Communiste polonais

11. Parti Communiste de Finlande

12. Parti Communiste ukrainien

13. Parti Communiste de Lettonie

14. Parti Communiste blanc-russe et lithuanien

15. Parti Communiste d'Esthonie

16. Parti Communiste arménien

17. Parti Communiste de la Volga allemande

18. Groupe Unifié des Peuples de la Russie Orient.

19. Gauche Zimerwaldienne française

\section{Nombre de voix}

5

5

3

3

3

3

3

5

3

3

3

3

\section{Voix délibératives :}

20. Parti Communiste tchèque.

21. Parti Communiste bulgare.

22. Parti Communiste des pays slaves méridionaux.

23. Parti Communiste anglais.

24. Parti Communiste français.

25. P. S.-D. hollandais.

26. Ligue de la Propagande Socialiste d'Amérique.

\section{Sections du Bureau Central des Pays Orientaux :}

27. Communistes suisses.

28. Communistes tourkestans.

29. Turque. 
30. Géorgienne.

31. Azerbaïdjan.

32. Perse.

33. Parti Ouvrier Socialiste chinois.

34. Union Ouvrière de la Corée.

35. Commission de Zimmerwald. 


\section{Manifestes, thèses et résolutions des quatre premiers congrès de l'Internationale communiste 1919-1923 \\ (juin 1934) \\ Premier Congrès, mars 1919. \\ -2 - \\ Discours d’ouverture de Lénine 2 mars 1919}

Retour à la table des matières

Par mandat du Comité Central du Parti Communiste russe, j’ouvre le premier Congrès international. Avant tout, je vous prie de vous lever pour honorer la mémoire des meilleurs représentants de la $3^{\mathrm{e}}$ Internationale, de Karl Liebknecht et de Rosa Luxembourg.

Camarades, notre Congrès revêt une grande importance dans l'histoire mondiale. Il démontre la banqueroute de toutes les illusions de la démocratie bourgeoise. La guerre civile est devenue un fait, non seulement en Russie, mais dans les pays capitalistes les plus développés, par exemple en Allemagne.

La bourgeoisie est affolée de terreur devant le mouvement révolutionnaire prolétarien qui grandit. Cela se comprend, parce que toute la marche des événements depuis la fin de la guerre impérialiste renforce inévitablement le mouvement révolutionnaire du prolétariat, et que la révolution internationale mondiale commence et grandit dans tous les pays.

Le peuple se rend compte de la grandeur et de l'importance de cette lutte. Il fallait trouver la forme pratique qui permît au prolétariat d'exercer sa domination. Cette forme, c’est le régime des Soviets avec la dictature du prolétariat. La dictature du prolétariat : ces mots étaient « du latin » pour les masses jusqu’à nos jours. Maintenant, grâce au système des Soviets, ce latin est traduit dans toutes les lan- 
gues modernes ; la forme pratique de la dictature est trouvée par les masses populaires. Elle est devenu intelligible à la grande masse des ouvriers grâce au pouvoir des Soviets en Russie, aux spartakistes en Allemagne, à des organisations analogues dans les autres pays, tels les Shop Stewards Committees en Angleterre. Tout cela prouve que la forme révolutionnaire de la dictature prolétarienne est trouvée et que le prolétariat est en train d'exercer sa domination de fait.

Camarades! Je pense qu’après les événements en Russie, après les combats de janvier en Allemagne, il importe surtout de noter que la forme nouvelle du mouvement du prolétariat se manifeste et se fraie une voie dans d'autres pays aussi. Aujourd'hui, j'ai lu dans un journal anglais antisocialiste un télégramme annonçant que le gouvernement anglais avait reçu le soviet de délégués ouvriers de Birmingham et lui avait promis de reconnaître les Soviets comme des organisations économiques. Le système soviétique a remporté la victoire non seulement dans la Russie arriérée, mais dans le pays le plus civilisé de l’Europe: l'Allemagne, et dans le plus vieux pays capitaliste : l'Angleterre.

La bourgeoisie peut sévir ; elle peut assassiner encore des milliers d'ouvriers - mais la victoire est à nous, la victoire de la révolution communiste mondiale est assurée.

Camarades! Je vous souhaite cordialement la bienvenue au nom de notre Comité Central. 


\section{Manifestes, thèses et résolutions des quatre premiers congrès de l'Internationale communiste 1919-1923 \\ (juin 1934) \\ Premier Congrès, mars 1919. \\ - 3 - \\ Thèses de Lénine sur la démocratie bourgeoise et la dictature prolétarienne 4 mars 1919}

\section{$\underline{\text { Retour à la table des matières }}$}

1. La croissance du mouvement révolutionnaire prolétarien dans tous les pays suscite les efforts convulsifs de la bourgeoisie et des agents qu'elle possède dans les organisations ouvrières pour découvrir les arguments philosophico-politiques capables de servir à la défense de la domination des exploiteurs. La condamnation de la dictature et la défense de la démocratie figurent au nombre de ces arguments. Le mensonge et l'hypocrisie d'un tel argument répété à satiété dans la presse capitaliste et à la conférence de l'Internationale jaune de Berne en février 1919 sont évidents pour tous ceux qui ne tentent pas de trahir les principes fondamentaux du socialisme.

2. D’abord, cet argument s'appuie sur les conceptions de « démocratie en général » et de " dictature en général », sans préciser la question de la classe. Poser ainsi le problème, en dehors de la question de classes, en prétendant considérer l'ensemble de la nation, c'est proprement se moquer de la doctrine fondamentale du socialisme, à savoir la doctrine de la lutte de classes, acceptée en paroles, mais oubliée en fait par les socialistes passés dans le camp de la bourgeoisie. Car, dans aucun pays civilisé, dans aucun pays capitaliste, il n’existe de démocratie en géné- 
ral : il n’y a que la démocratie bourgeoise. Il ne s'agit pas davantage de la dictature exercée par la classe opprimée, c’est-à-dire par le prolétariat, sur les oppresseurs et les exploiteurs, sur la classe bourgeoise, dans le but de triompher de la résistance des exploiteurs luttant pour leur domination.

3. L'histoire enseigne qu'aucune classe opprimée n'est jamais parvenue à la domination, et n'a pu y parvenir sans passer par une période de dictature pendant laquelle elle s'empare du pouvoir politique et abat par la force la résistance désespérée, exaspérée, qui ne s'arrête devant aucun crime, qu’ont toujours opposée les exploiteurs. La bourgeoisie dont aujourd'hui la domination est soutenue par les socialistes qui pérorent sur la dictature en général et qui se démènent en faveur de la démocratie en général a conquis le pouvoir dans les pays civilisés au prix d'une série d'insurrections, de guerres civiles, de l'écrasement par la force — des rois, des nobles, des propriétaires d'esclaves - et par la répression des tentative de restauration.

Des milliers de fois, les socialistes de tous les pays ont expliqué au peuple le caractère de classe de ces révolutions bourgeoises, dans leurs livres, dans leurs brochures, dans les résolutions de leurs congrès, dans leurs discours de propagande. C'est pourquoi cette défense actuelle de la démocratie bourgeoise au moyen de discours sur la « dictature en général », tous ces cris et ces pleurs contre la dictature du prolétariat sous prétexte de condamner «la dictature en général », ne sont qu'une trahison véritable du socialisme, qu'une désertion caractérisée au profit de la bourgeoisie, qu'une négation du droit du prolétariat à sa révolution prolétarienne. C'est défendre le réformisme bourgeois, précisément à l'heure où il a fait faillite dans le monde entier, alors que la guerre a créé un état de choses révolutionnaire.

4. Tous les socialistes en démontrant le caractère de classe de la civilisation bourgeoise, de la démocratie bourgeoise, du parlementarisme bourgeois, ont exprimé cette idée déjà formulée, avec le maximum d'exactitude scientifique par Marx et Engels que la plus démocratique des républiques bourgeoises ne saurait être autre chose qu'une machine à opprimer la classe ouvrière à la merci de la bourgeoisie, la masse des travailleurs à la merci d'une poignée de capitalistes. Il n’y a pas un seul révolutionnaire, pas un seul marxiste parmi ceux qui crient aujourd'hui contre la dictature et pour la démocratie qui n'ait juré ses grands dieux devant les ouvriers qu'il acceptait cette vérité fondamentale du socialisme; et 
maintenant que le prolétariat révolutionnaire est en fermentation et en mouvement, qu'il tend à détruire cette machine d’oppression et à conquérir la dictature du prolétariat, ces traîtres au socialisme voudraient faire croire que la bourgeoisie a donné aux travailleurs la "démocratie pure », comme si la bourgeoisie avait renoncé à toute résistance et était prête à obéir à la majorité des travailleurs, comme si, dans une république démocratique, il n’y avait pas une machine gouvernementale faite pour opérer l’écrasement du travail par le capital.

5. La Commune de Paris, que tous ceux qui veulent passer pour socialistes honorent en paroles, parce qu'ils savent que les masses ouvrières sont pleines d'une vive et sincère sympathie pour elle, a montré avec une particulière netteté la relativité historique, la valeur limitée du parlementarisme bourgeois et de la démocratie bourgeoise, institutions marquant un très grand progrès par rapport à celles du moyen-âge, mais exigeant nécessairement une réforme fondamentale à l’époque de la révolution prolétarienne. Marx, qui a apprécié mieux qu'aucun autre l'importance historique de la Commune, a prouvé en l'analysant le caractère d'exploitation de la démocratie et du parlementarisme bourgeois, régime sous lequel les classes opprimées recouvrent le droit de décider en un seul jour pour une période de plusieurs années quel sera le représentant des classes possédantes qui représentera et opprimera le peuple au Parlement. Et c'est à l'heure où le mouvement soviétiste embrassant le monde entier, continue aux yeux de tous l'œuvre de la Commune que les traîtres du socialisme oublient l'expérience concrète de la Commune de Paris, et répètent les vieilles sornettes bourgeoises sur la « démocratie en général ». La Commune n’était pourtant pas une institution parlementaire.

6. La valeur de la Commune consiste, ensuite en ce qu'elle a tenté de bouleverser, de détruire de fond en comble l'appareil gouvernemental bourgeois dans l'administration, dans la justice, dans l'armée, dans la police, en le remplaçant par l’organisation autonome des masses ouvrières, sans reconnaître aucune distinction des pouvoirs législatif et exécutif.

Toutes les démocraties bourgeoises contemporaines, sans excepter la République allemande que les traîtres du socialisme appellent prolétarienne en dépit de la vérité, conservent au contraire le vieil appareil gouvernemental. Ainsi, il se confirme une fois de plus, de façon absolument évidente, que tous ces cris en fa- 
veur de la démocratie ne servent en réalité qu'à défendre la bourgeoisie et ses privilèges de classe exploiteuse.

7. La liberté de réunion peut être prise pour exemple des principes de la démocratie pure. Tout ouvrier conscient qui n’a pas rompu avec sa classe, comprendra du premier coup qu'il serait insensé de permettre la liberté de réunion aux exploiteurs, dans un temps et dans les circonstances où des exploiteurs s'opposent à leur déchéance et défendent leurs privilèges. La bourgeoisie, quand elle était révolutionnaire, soit en Angleterre en 1649, soit en France en 1793, n’a jamais accordé la liberté de réunion aux monarchistes ni aux nobles qui appelaient les troupes étrangères et « se réunissaient » pour organiser des tentatives de restauration. Si la bourgeoisie d'aujourd'hui, qui depuis longtemps est devenue réactionnaire, réclame du prolétariat qu'il garantisse à l'avance, malgré toute la résistance que feront les capitalistes à leur expropriation, la liberté de réunion pour les exploiteurs, les ouvriers ne pourront que rire de l'hypocrisie de cette bourgeoisie.

D’autre part, les ouvriers savent très bien que la liberté de réunion, même dans la république bourgeoise la plus démocratique, est une phrase vide de sens, puisque les riches possèdent les meilleurs édifices publics et privés, ainsi que le loisir nécessaire pour se réunir sous la protection de cet appareil gouvernemental bourgeois. Les prolétaires de la ville et de la campagne et les petits paysans, c'est-àdire l'immense majorité de la population, ne possèdent ni l'un ni l'autre. Tant qu'il en est ainsi, l'égalité, c'est-à-dire la démocratie pure est un leurre. Pour conquérir la véritable légalité, pour réaliser vraiment la démocratie au profit des travailleurs, il faut préalablement enlever aux exploiteurs toutes les riches demeures publiques et privées, il faut préalablement donner des loisirs aux travailleurs, il faut que la liberté de leurs réunions soit protégée par des ouvriers armés et non point par les officiers hobereaux ou capitalistes avec des soldats à leur dévotion.

C'est seulement alors que l'on pourra, sans se moquer des ouvriers, des travailleurs, parler de liberté de réunion et d'égalité. Or, qui peut accomplir cette réforme, sinon l'avant-garde des travailleurs, le prolétariat, par le renversement des exploiteurs et de la bourgeoisie ?

8. La liberté de la presse est également une des grandes devises de la démocratie pure. Encore une fois, les ouvriers savent que les socialistes de tous les pays ont reconnu des millions de fois que cette liberté est un mensonge, tant que les 
meilleures imprimeries et les plus gros stocks de papier sont accaparés par les capitalistes, tant que subsiste le pouvoir du capital dans le monde entier avec d'autant plus de clarté, de netteté et de cynisme que le régime démocratique et républicain est plus développé, comme par exemple en Amérique. Afin de conquérir la véritable égalité et la vraie démocratie dans l'intérêt des travailleurs, des ouvriers et des paysans, il faut commencer par enlever au capital la faculté de louer les écrivains, d'acheter et de corrompre des journaux et des maisons d'édition, et pour cela il faut renverser le joug du capital, renverser les exploiteurs, briser leur résistance. Les capitalistes appellent liberté de la presse la faculté pour les riches de corrompre la presse, la faculté d'utiliser leurs richesses pour fabriquer et pour soutenir la soi-disant opinion publique. Les défenseurs de la « démocratie pure » sont en réalité une fois de plus des défenseurs du système vil et corrompu de la domination des riches sur l'instruction des masses; ils sont ceux qui trompent le peuple et le détournent avec de belles phrases mensongères, de cette nécessité historique d'affranchir la presse de son assujettissement au capital. De véritable liberté ou égalité, il n’y en aura que dans le régime édifié par les communistes, dans lequel il serait matériellement impossible de soumettre la presse directement ou indirectement au pouvoir de l'argent, dans lequel rien n’empêchera chaque travailleur, ou chaque groupe de travailleurs, de posséder ou d'user, en toute égalité, du droit de se servir des imprimeries et du papier de l'Etat.

9. L'histoire du $\mathrm{XIX}^{\mathrm{e}}$ siècle et $\mathrm{du} \mathrm{Xx}^{\mathrm{e}}$ siècle nous a montré, même avant la guerre, ce qu'était la fameuse démocratie pure sous le régime capitaliste. Les marxistes ont toujours répété que plus la démocratie était développée, plus elle était pure, plus aussi devait être vive, acharnée et impitoyable la lutte des classes, et plus apparaissait purement le joug du capital et la dictature de la bourgeoisie. L'affaire Dreyfus de la France républicaine, les violences sanglantes des détachements soudoyés et armés par les capitalistes contre les grévistes dans la république libre et démocratique d'Amérique, ces faits et des milliers d'autres semblables découvrent cette vérité qu'essaye en vain de cacher la bourgeoisie, que c'est précisément dans les républiques les plus démocratiques que règnent en réalité la terreur et la dictature de la bourgeoisie, terreur et dictature qui apparaissent ouvertement chaque fois qu'il semble aux exploiteurs que le pouvoir du capital commence à être ébranlé. 
10. La guerre impérialiste de 1914-1918 a définitivement manifesté, même aux yeux des ouvriers non éclairés, ce vrai caractère de la démocratie bourgeoise, même dans les républiques les plus libres - comme caractère de dictature bourgeoise. C'est pour enrichir un groupe allemand ou anglais de millionnaires ou de milliardaires qu’ont été massacrés des dizaines de millions d’hommes et qu'a été instituée la dictature militaire de la bourgeoisie dans les républiques les plus libres. Cette dictature militaire persiste, même après la défaite de l'Allemagne dans les pays de l'Entente. C'est la guerre qui, mieux que tout, a ouvert les yeux aux travailleurs, a arraché les faux appas à la démocratie bourgeoise, a montré au peuple tout l'abîme de la spéculation et du lucre pendant la guerre et à l'occasion de la guerre. C’est au nom de la liberté et de l'égalité que la bourgeoisie a fait cette guerre ; c’est au nom de la liberté et de l'égalité que les fournisseurs aux armées ont amassé des richesses inouïes. Tous les efforts de l'Internationale jaune de Berne n'arriveront pas à dissimuler aux masses le caractère d'exploitation actuellement manifeste de la liberté bourgeoise, de l'égalité bourgeoise, de la démocratie bourgeoise.

11. Dans le pays capitaliste le plus développé d’Europe, en Allemagne, les premiers mois de cette complète liberté républicaine, apportée par la défaite de l’Allemagne impérialiste, ont révélé aux ouvriers allemands et au monde entier le caractère de classe de la république démocratique bourgeoise. L'assassinat de Karl Liebknecht et de Rosa Luxembourg est un événement d'une importance historique universelle, non seulement par la mort tragique des hommes et des chefs les meilleurs de la vraie Internationale prolétarienne et communiste, mais encore parce qu'il a manifesté dans l'Etat le plus avancé d'Europe et même, on peut le dire, du monde entier, la véritable essence du régime bourgeois. Si des gens en état d'arrestation, c'est-à-dire pris par le pouvoir gouvernemental des socialpatriotes sous sa garde, ont pu être tués impunément par des officiers et des capitalistes, c’est que la république démocratique dans laquelle un pareil événement a été possible n'est que la dictature de la bourgeoisie. Les gens qui expriment leur indignation au sujet de l'assassinat de Karl Liebknecht et de Rosa Luxemburg, mais qui ne comprennent pas cette vérité, ne font que montrer par là leur bêtise ou leur hypocrisie. La liberté, dans une des républiques du monde les plus libres et les plus avancées, dans la république allemande, est la liberté de tuer impunément les chefs du prolétariat en état d'arrestation, et il ne peut en être autrement, tant 
que subsiste le capitalisme, car le développement du principe démocratique, loin d'affaiblir, ne fait que surexciter la lutte de classes qui, par suite des répercussions et des influences de la guerre, a été portée à son point d’ébullition.

Dans tout le monde civilisé, on expulse aujourd'hui les bolcheviks, on les poursuit, on les emprisonne, comme par exemple dans une des plus libres républiques bourgeoises, en Suisse ; on massacre les bolcheviks en Amérique, etc... Du point de vue de la démocratie en général ou de la démocratie pure, il est tout à fait ridicule que les Etats civilisés et avancés, démocratiques, armés jusqu’aux dents, craignent la présence de quelques dizaines d'hommes venus de la Russie retardataire, affamée, ruinée, de cette Russie que, dans leurs dizaines de millions d'exemplaires, les journaux bourgeois appellent sauvage, criminelle, etc... Il est clair que les conditions sociales dans lesquelles une contradiction aussi criante a pu naître réalisent en réalité la dictature de la bourgeoisie.

12. Dans un tel état de choses, la dictature du prolétariat n’est pas seulement absolument légitime, en tant qu'instrument propre au renversement des exploiteurs et à l'écrasement de leur résistance, mais encore absolument indispensable pour toute la masse laborieuse, comme le seul moyen de défense contre la dictature de la bourgeoisie qui a causé la guerre et qui prépare de nouvelles guerres.

Le point le plus important, que ne comprennent pas les socialistes et qui constitue leur myopie théorique, leur emprisonnement dans les préjugés bourgeois et leur trahison politique envers le prolétariat, c’est que dans la société capitaliste, dès que s’aggrave la lutte des classes qui est à sa base, il n’y a pas de milieu entre la dictature de la bourgeoisie et la dictature du prolétariat. Tous les rêves d'une solution intermédiaire ne sont que lamentations réactionnaires de petits bourgeois.

La preuve en est apportée par l'expérience du développement de la démocratie bourgeoise et du mouvement ouvrier depuis plus d'un siècle dans tous les pays civilisés et en particulier par l'expérience des cinq dernières années. C’est aussi la vérité qu'enseigne toute la science de l'économie politique, tout le contenu du marxisme qui explique par quelle nécessité économique naît la dictature de la bourgeoisie, et comment elle ne peut être remplacée que par une classe développée multipliée, fortifiée et devenue très cohérente par le développement même du capitalisme, c’est-à-dire la classe des prolétaires. 
13. Une autre erreur théorique et politique des socialistes, consiste à ne pas comprendre que les formes de la démocratie ont constamment changé pendant le cours des siècles, depuis ses premiers germes dans l'antiquité, à mesure qu'une classe dominante était remplacée par une autre. Dans les anciennes républiques de la Grèce, dans les cités du moyen-âge, dans les pays capitalistes civilisés, la démocratie revêt des formes diverses et un degré d'adaptation différent. Ce serait la plus grande sottise de croire que la révolution la plus profonde dans l'histoire de l'humanité, que le passage du pouvoir, pour la première fois au monde, d'une minorité d'exploiteurs à la majorité d'exploités, puisse se produire dans les vieux cadres de la démocratie bourgeoise et parlementaire, puisse se produire sans brisures nettes, sans que se créent de nouvelles institutions incarnant ces nouvelles conditions de vie, etc...

14. La dictature du prolétariat ressemble à la dictature des autres classes parce qu’elle est provoquée, comme toute espèce de dictature, par la nécessité de réprimer violemment la résistance de la classe qui perd la domination politique. Le point fondamental qui sépare la dictature du prolétariat de celle des autres classes, de la dictature des éléments féodaux au moyen-âge, de la dictature de la bourgeoisie dans tous les pays civilisés capitalistes, consiste en ce que la dictature des éléments féodaux et de la bourgeoisie était l'écrasement violent de la résistance de l'énorme majorité de la population, de la classe laborieuse, tandis que la dictature du prolétariat est l’écrasement, par la force, de la résistance des exploiteurs, c'està-dire d'une infime minorité de la population : les propriétaires fonciers et les capitalistes.

Il s’ensuit encore que la dictature du prolétariat entraîne inévitablement non seulement une modification des formes et des institutions démocratiques en général, mais encore une modification telle qu'elle aboutit à une extension jusqu'alors inconnue du principe démocratique en faveur des classes opprimées par le capitalisme, en faveur des classes laborieuses. En effet, la forme de la dictature du prolétariat, déjà élaborée en fait, c’est-à-dire le pouvoir des Soviets en Russie, le Raete Système en Allemagne, les Shop Stewards Committees et autres institutions analogues dans les autres pays, signifie précisément et réalise pour les classes laborieuses, c'est-à-dire pour l'énorme majorité de la population, une faculté rapide de profiter des droits et libertés démocratiques comme il n’y en a jamais eu, 
même d'approchants, dans les républiques bourgeoises les meilleures et les plus démocratiques.

L'essence du pouvoir des Soviets consiste en ce que la base constante et unique de tout le pouvoir gouvernemental, c'est l'organisation des masses jadis opprimées par les capitalistes, c'est-à-dire les ouvriers et les demi-prolétaires (paysans n'exploitant pas le travail d'autrui et ayant constamment besoin de vendre une partie au moins de leur force de travail). Ce sont ces masses qui, même dans les républiques bourgeoises les plus démocratiques, tout en jouissant de l'égalité selon la loi, étaient écartées en réalité par des milliers de coutumes et de manœuvres de toute participation à la vie politique, de tout usage de droits et de libertés démocratiques et qui maintenant sont appelées à prendre une part considérable et obligatoire, une part décisive à la gestion démocratique de l’Etat.

15. L’égalité de tous les citoyens, indépendamment du sexe, de la religion, de la race, de la nationalité, que la démocratie bourgeoise a toujours et partout promise, mais n’a réalisée nulle part et qu'étant donné la domination du capitalisme, elle ne pouvait pas réaliser, le pouvoir des Soviets ou la dictature du prolétariat la réalise tout d'un coup et complètement, car seul il est en état de réaliser le pouvoir des ouvriers qui ne sont pas intéressés à la propriété privée, aux moyens de production, à la lutte pour leur partage et leur distribution.

16. La vieille démocratie, c’est-à-dire la démocratie bourgeoise et le parlementarisme, était organisée de telle façon que les masses laborieuses étaient de plus en plus éloignées de l'appareil gouvernemental. Le pouvoir des Soviets, c'est-à-dire la dictature du prolétariat, est au contraire construit de façon à rapprocher les masses laborieuses de l'appareil gouvernemental. Au même but tend la réunion du pouvoir législatif et exécutif dans l'organisation soviétiste de l'Etat, ainsi que la substitution aux circonscriptions électorales territoriales d'unités de travail, comme les usines et les fabriques.

17. Ce n'est pas seulement sous la monarchie que l'armée était un instrument d’oppression. Elle l'est restée dans toutes les républiques bourgeoises, même les plus démocratiques. Seul le pouvoir des Soviets, en tant qu'organisation permanente des classes opprimées par le capitalisme est capable de supprimer la soumission de l'armée au commandement bourgeois et de fondre réellement le prolé- 
tariat avec l'armée, en réalisant l'armement du prolétariat et le désarmement de la bourgeoisie, sans lesquels est impossible le triomphe du socialisme.

18. L’organisation soviétiste de l'Etat est adaptée au rôle directeur du prolétariat comme classe concentrée au maximum et éduquée par le capitalisme. L'expérience de toutes les révolutions et de tous les mouvements des classes opprimées, l'expérience du mouvement socialiste dans le monde entier nous enseignent que seul le prolétariat est en état d'unifier et de conduire les masses éparses et retardataires de la population laborieuse et exploitée.

19. Seule l'organisation soviétiste de l'Etat peut réellement briser d'un coup et détruire définitivement le vieil appareil bourgeois, administratif et judiciaire qui s’est conservé et devait inévitablement se conserver sous le capitalisme, même dans les républiques les plus démocratiques, puisqu’il était de fait le plus grand empêchement à la mise en pratique des principes démocratiques en faveur des ouvriers et des travailleurs. La Commune de Paris a fait, dans cette voie, le premier pas d'une importance historique universelle ; le pouvoir des Soviets a fait le second.

20. L’anéantissement du pouvoir gouvernemental est le but que se sont proposés tous les socialistes. Marx le premier. Sans réalisation de ce but, la vraie démocratie, c’est-à-dire l'égalité et la liberté, est irréalisable. Or, le seul moyen pratique d’y arriver est la démocratie soviétiste ou prolétarienne, puisque, appelant à prendre une part réelle et obligatoire au gouvernement les organisations des masses laborieuses, elle commence dès maintenant à préparer le dépérissement complet de tout gouvernement.

21. La complète banqueroute des socialistes réunis à Berne, leur incompréhension absolue de la démocratie prolétarienne nouvelle apparaissent particulièrement dans ce qui suit : le 10 février 1919, Branting clôturait à Berne la conférence internationale de l’Internationale jaune. Le 11 février 1919, à Berlin, était imprimé dans le journal de ses coreligionnaires Die Freiheit une proclamation du parti des Indépendants au prolétariat. Dans cette proclamation est reconnu le caractère bourgeois du gouvernement de Scheidemann, auquel on reproche son désir d’abolir les Soviets appelés les messagers et les défenseurs de la Révolution, auquel on demande de légaliser les Soviets, de leur donner les droits politiques, le 
droit de vote contre les décisions de l'Assemblée Constituante, le référendum demeurant juge en dernier ressort.

Cette proclamation dénote la complète faillite des théoriciens qui défendaient la démocratie sans comprendre son caractère bourgeois. Cette tentative ridicule de combiner le système des Soviets, c'est-à-dire la dictature du prolétariat, avec l’Assemblée Constituante, c'est-à-dire la dictature de la bourgeoisie, dévoile jusqu'au bout, à la fois la pauvreté de pensée des socialistes jaunes et des socialdémocrates, leur caractère réactionnaire de petits bourgeois et leurs lâches concessions devant la force irrésistiblement croissante de la nouvelle démocratie prolétarienne.

22. En condamnant le bolchevisme, la majorité de l'Internationale de Berne, qui n’a pas osé voter formellement un ordre du jour correspondant à sa pensée, par crainte des masses ouvrières, a agi justement de son point de vue de classe. Cette majorité est complètement solidaire des mencheviks et socialistes révolutionnaires russes, ainsi que des Scheidemann allemands.

Les mencheviks et socialistes révolutionnaires russes, en se plaignant d’être poursuivis par les bolcheviks, essayent de cacher le fait que ces poursuites sont causées par la part prise par les mencheviks et les socialistes révolutionnaires à la guerre civile du côté de la bourgeoisie contre le prolétariat. Les Scheidemann et leur parti ont déjà montré de la même façon en Allemagne qu'ils prenaient la même part à la guerre civile du côté de la bourgeoisie contre les ouvriers.

Il est, par suite, tout. à fait naturel que la majorité des participants de l'Internationale jaune de Berne se soit prononcée contre les bolcheviks; par là s’est manifesté, non point le désir de défendre la démocratie pure, mais le besoin de se défendre eux-mêmes, chez des gens qui sentent et qui savent que dans la guerre civile ils sont du côté de la bourgeoisie contre le prolétariat.

Voilà pourquoi, du point de vue de la lutte de classes, il est impossible de ne pas reconnaître la justesse de la décision de la majorité de l’Internationale jaune. Le prolétariat ne doit pas craindre la vérité, mais la regarder en face et tirer les conclusions qui en découlent.

Sur la base de ces thèses, et en considération des rapports des délégués des différents pays, le congrès de l'Internationale Communiste déclare que la tâche 
principale des partis communistes, dans les diverses régions où le pouvoir des Soviets n'est pas encore constitué, consiste en ce qui suit :

$1^{\circ}$ Éclairer le plus largement les masses de la classe ouvrière sur la signification historique de la nécessité politique et pratique d'une nouvelle démocratie prolétarienne, qui doit prendre la place de la démocratie bourgeoise et du parlementarisme ;

$2^{\circ}$ Élargir et organiser des Soviets dans tous les domaines de l'industrie, dans l'armée, dans la flotte, parmi les ouvriers agricoles et les petits paysans ;

$3^{\circ}$ Conquérir, à l'intérieur des Soviets, une majorité communiste, sûre et consciente. 
Manifestes, thèses et résolutions des quatre premiers congrès de l'Internationale communiste 1919-1923

(juin 1934)

Premier Congrès, mars 1919.

\section{-4 - \\ Discours de Lénine sur ses thèses}

$\underline{\text { Retour à la table des matières }}$

Camarades,

Je voudrais ajouter quelques mots aux deux derniers points. Je pense que les camarades qui doivent nous faire le rapport sur la conférence de Berne nous en parleront avec plus de détails.

Pas un mot n’a été dit sur la signification du pouvoir soviétique au cours de toute la conférence de Berne. Il y a deux ans que nous discutions cette question en Russie. Déjà en avril 1917, au congrès du parti, nous avons posé cette question du point de vue théorique et politique : «Qu'est-ce que le pouvoir soviétique, quelle en est la substance, quelle en est la signification historique ? » Voilà bientôt deux ans que nous étudions cette question et au congrès du parti nous avons adopté une résolution sur ce sujet.

La Freiheit, de Berlin, a publié le 11 février un appel au prolétariat allemand signé non seulement par les chefs des social-démocrates indépendants en Allemagne, mais par tous les membres de la fraction des indépendants. En août 1918, le plus grand théoricien des indépendants, Kautsky, écrivait dans sa brochure, La dictature du prolétariat, qu'il était partisan de la démocratie et des organes sovié- 
tiques mais que les Soviets ne devaient avoir qu'un caractère économique et ne sauraient être reconnus comme organisations d’Etat. Kautsky répète cette affirmation dans les numéros de la Freiheit, en date des 11 novembre et 12 janvier. Le 9 février paraît un article de Rudolph Hilferding, qui est également considéré comme un des principaux théoriciens autorisés de la 2e Internationale. Il propose de fusionner juridiquement, c'est-à-dire par la voie législative, les deux systèmes des Soviets et de l'Assemblée Nationale. C'était le 9 février. Cette seconde proposition est adoptée par tout le parti des Indépendants et publiée sous forme d'appel.

Malgré que l’Assemblée Nationale existe déjà en fait, même après que la « démocratie pure » a pris corps et réalité, après que les plus grands théoriciens des social-démocrates indépendants aient expliqué que les organisations soviétiques ne sauraient être des organes d'Etat, après et malgré tout cela, il y a encore des hésitations. Cela prouve que ces messieurs n’ont vraiment rien compris au nouveau mouvement et à ses conditions de lutte. Mais cela prouve en outre, autre chose, à savoir qu'il doit y avoir des circonstances, des motifs déterminant ces hésitations. Lorsque après tous ces événements, après bientôt deux ans de révolution victorieuse en Russie on nous propose de semblables résolutions comme ayant été adoptées à la Conférence de Berne, résolutions dans lesquelles il n’est rien dit des Soviets et de leur signification, et Conférence à laquelle pas un délégué n’a soufflé mot dans un discours quelconque de ces questions, nous avons parfaitement le droit d'affirmer que tous ces messieurs sont morts pour nous en tant que socialistes et théoriciens.

Mais en fait, du point de vue politique, cela prouve, camarades, qu'un grand progrès s’accomplit dans les masses puisque ces indépendants, théoriquement et par principe adversaires de ces organisations d'Etat, nous proposent subitement une sottise telle que la fusion « pacifique » de l'Assemblée Nationale avec le système des Soviets, c’est-à-dire la fusion de la dictature de la bourgeoisie avec la dictature du prolétariat. On voit à quel point ces gens-là ont fait faillite sous les rapports politiques et théoriques et quelle énorme transformation se produit dans les masses. Les masses arriérées du prolétariat allemand viennent à nous, que disje, elles sont venues à nous. Ainsi donc la signification du parti indépendant social-démocrate allemand, la meilleure partie du point de vue théorique et socialiste est égale à zéro ; cependant elle conserve une certaine importance dans ce sens que ces éléments nous servent d’indication de l’état d'esprit de la partie la plus 
arriérée du prolétariat. C'est là à mon avis qu'est l'énorme importance historique de cette conférence. Nous avons vu quelque chose d'analogue au cours de notre révolution : Nos mencheviks ont subi pas à pas, pour ainsi dire, la même évolution que les théoriciens des indépendants en Allemagne. Lorsqu'ils eurent la majorité dans les Soviets ils étaient pour les Soviets. On n’entendait alors que les cris de : «Vivent les Soviets! », «Pour les Soviets ! », « Les Soviets et la démocratie révolutionnaire! ». Mais, lorsque c'est nous qui eûmes la majorité dans les Soviets, nous bolcheviks, ils entonnèrent d'autres chants : " Les Soviets, déclarèrentils, ne doivent pas exister en même temps que l'Assemblée Constituante »; et même certains théoriciens mencheviks proposèrent quelque chose d'analogue à la fusion du système des Soviets avec l'Assemblée Constituante et leur inclusion dans les organisations d'Etat. Une fois de plus il est apparu que le cours général de la révolution prolétarienne est identique dans le monde entier. D’abord constitution spontanée, élémentaire, des Soviets, puis leur extension et développement, ensuite apparition dans la pratique de la question : Soviets ou Assemblée Nationale Constituante ou bien parlementarisme bourgeois, confusion absolue parmi les chefs et enfin révolution prolétarienne. Il me semble cependant qu'après bientôt deux ans de révolution nous ne devons pas poser la question de la sorte mais prendre des résolutions concrètes étant donné que la propagation du système des Soviets est pour nous, et particulièrement pour la majorité des pays de l'Europe Occidentale, la plus essentielle des tâches. L'étranger qui n’a jamais entendu parler du bolchevisme ne peut que bien difficilement se faire une opinion propre sur nos discussions. Tout ce que les bolcheviks affirment, les mencheviks le contredisent et réciproquement. Certes il ne saurait en être autrement au cours de la lutte. C'est pourquoi il est extrêmement important que la dernière conférence du parti menchevik tenue au mois de décembre 1918, ait adopté une longue résolution détaillée entièrement publiée dans le Journal des typographes, organe menchevik. Dans cette résolution, les menchéviks eux-mêmes exposent brièvement l'historique de la lutte des classes et de la guerre civile. Il y est dit que les menchéviks condamnent les groupes du parti alliés aux classes possédantes dans l'Oural et dans le Midi, en Crimée et en Géorgie et ils indiquent avec précision toutes ces régions. Les groupes du parti menchévik qui, alliés aux classes possédantes, ont combattu contre le pouvoir soviétique sont maintenant condamnés dans cette résolution; Mais le dernier point condamne également ceux qui sont passés aux communistes. Il s'ensuit que les mencheviks sont obligés de reconnaî- 
tre qu'il n’y a point d'unité dans leur parti et qu'ils se tiennent ou bien aux côtés de la bourgeoisie ou aux cotés du prolétariat. Une grande partie des mencheviks est passée à la bourgeoisie et a lutté contre nous pendant la guerre civile. Naturellement nous poursuivons les mencheviks, nous les faisons même fusiller lorsque, en guerre contre nous, ils combattent notre armée rouge et font fusiller nos officiers rouges. A la bourgeoisie qui nous a déclaré la guerre, nous avons répondu par la guerre prolétarienne : il ne peut y avoir d'autre issue. Ainsi donc, du point de vue politique, tout cela n'est qu'hypocrisie menchevique. Historiquement, il est incompréhensible que, à la Conférence de Berne, des gens qui ne sont pas officiellement reconnus fous, eussent pu, sur l'ordre des mencheviks et des socialistes révolutionnaires, parler de la lutte des bolcheviks contre eux tout en passant sous silence leur lutte en commun avec la bourgeoisie contre le prolétariat.

Tous ils nous attaquent avec acharnement parce que nous les poursuivons ; c'est exact, mais ils se gardent bien de dire un mot de la part qu'ils ont prise euxmêmes dans la guerre civile. Je pense qu'il convient de remettre, pour transcription au procès-verbal, le texte complet de la résolution et je prie les camarades étrangers de lui accorder toute leur attention car elle représente un document historique dans lequel la question est parfaitement posée et qui fournit la meilleure documentation pour l'appréciation de la discussion entre les diverses tendances « socialistes » en Russie. Entre le prolétariat et la bourgeoisie, il existe une classe de gens inclinant tantôt d'un côté, tantôt de l'autre ; il en fût ainsi toujours et dans toutes les révolutions, et il est absolument impossible que dans la société capitaliste, où le prolétariat et la bourgeoisie constituent deux camps ennemis opposés, il n'existe pas entre eux des couches sociales intermédiaires. Historiquement l'existence de ces éléments flottants est inévitable ; malheureusement ces éléments qui ne savent pas eux-mêmes de quel côté ils combattront demain existeront encore relativement longtemps.

Je désire faire une proposition concrète tendant à faire adopter une résolution dans laquelle trois points doivent particulièrement être soulignés.

1. Une des tâches les plus importantes pour les camarades des pays de l'Europe Occidentale consiste à expliquer aux masses la signification, l'importance et la nécessité du système des Soviets. On constate sous ce rapport une insuffisante compréhension. S’il est vrai que Kautsky et Hilferding ont fait faillite en tant que théoriciens, les derniers articles de la Freiheit prouvent cepen- 
dant qu'ils ont su exprimer exactement l'état d'esprit des parties arriérées du prolétariat allemand. Il est arrivé la même chose chez nous : au cours des huit premiers mois de la révolution russe la question de l'organisation soviétique a été beaucoup discutée, et les ouvriers ne voyaient pas très clairement en quoi consiste le nouveau système, ni si l'on pouvait constituer l'appareil d'Etat avec les Soviets. Dans notre révolution nous avons progressé non par la voie théorique mais par la voie pratique. Ainsi, par exemple, jamais auparavant nous n’avons posé théoriquement la question de l'Assemblée Constituante et nous n'avons jamais dit que nous ne reconnaissons pas celle-ci. Ce n'est que plus tard, lorsque les institutions soviétiques se répandirent à travers tout le pays et conquirent le pouvoir politique que nous décidâmes de disperser l'Assemblée Constituante. Nous voyons à présent que la question se pose avec beaucoup plus d'acuité en Hongrie et en Suisse. D’un côté il est excellent qu'il en soit ainsi ; nous puisons dans ce fait la conviction absolue que la révolution avance plus rapidement dans les Etats de l'Europe Occidentale et qu'elle nous apportera de grandes victoires. Mais, d'autre part, il y a un certain danger et c'est à savoir que la lutte sera tellement acharnée et tendue que la conscience des masses ouvrières ne sera pas en mesure de suivre ce rythme. Encore maintenant la signification du système des Soviets n'est pas claire pour les grandes masses des ouvriers allemands politiquement instruits, parce qu’ils ont été élevés dans l’esprit du parlementarisme et des préjugés bourgeois.

2. Point relatif à la propagation du système des Soviets. Lorsque nous voyons combien rapidement l'idée des Soviets se répand en Allemagne et même en Angleterre, nous pouvons bien nous dire que c'est là une preuve essentielle que la Révolution prolétarienne vaincra. On ne saurait arrêter son cours que pour peu de temps. Mais c'est une tout autre affaire lorsque les camarades Albert et Platten viennent nous déclarer qu'il n’y a guère de Soviets chez eux dans les campagnes, parmi les travailleurs ruraux et la petite paysannerie. J'ai lu, dans la Rote Fahne, un article contre les Soviets paysans, mais (et c'est absolument juste) pour les Soviets de travailleurs ruraux et de paysans pauvres. La bourgeoisie et ses valets, tels que Scheidemann et compagnie, ont déjà donné le mot d'ordre de Soviets paysans. Mais nous ne voulons que les Soviets de travailleurs ruraux et de paysans pauvres. Il ressort malheureusement des rapports des camarades Albert et Platten et autres, qu'à l'exception de la Hongrie, on fait bien peu de choses pour l'expansion du système soviétique dans les campagnes. C'est peut-être là que se 
trouve un danger pratique assez considérable pour l'obtention de la victoire par le prolétariat allemand. En effet, la victoire ne saurait être considérée comme assurée que lorsque seront organisés non seulement les travailleurs de la ville mais aussi les prolétaires ruraux, et organisés non comme auparavant dans les syndicats et coopératives, mais dans les Soviets. Nous avons obtenu la victoire plus facilement parce qu'en octobre 1917, nous avons marché ensemble avec toute la paysannerie. Dans ce sens notre révolution était alors bourgeoise. Le premier pas de notre gouvernement prolétarien consista en ce que les vieilles revendications de toute la paysannerie, exprimées encore sous Kérenski par les Soviets et les assemblées de paysans furent réalisées par la loi édictée par notre gouvernement le 26 octobre (vieux style) 1917, le lendemain de la révolution. C’est en cela que consista notre force et c'est pour cela qu'il nous fût si facile de conquérir les sympathies de la majorité écrasante. Pour la campagne, notre révolution continua à être bourgeoise, mais, plus tard, six mois après, nous fûmes contraints de commencer, dans les cadres de l'organisation d'Etat, la lutte des classes dans les campagnes, d'instituer dans chaque village des comités de pauvreté, de demiprolétaires et de lutter systématiquement contre la bourgeoisie rurale. C'était inévitable chez nous car la Russie est un pays arriéré. Il en sera tout autrement en Europe Occidentale et c'est pourquoi nous devons souligner la nécessité absolue de l'expansion du système des Soviets aussi dans la population rurale en des formes correspondantes et peut-être nouvelles.

3. Nous devons dire que la conquête de la majorité communiste dans les Soviets constitue la principale tâche dans tous les pays où le pouvoir soviétique n'a pas encore triomphé. Notre commission de résolutions a étudié hier cette question. Peut-être d'autres camarades voudront-ils aussi dire leur opinion mais je désirerais proposer qu'on adopte ce troisième point sous forme de résolution spéciale. Il va sans dire que nous ne saurions prescrire sa voie de développement. Il est tout à fait probable que, dans beaucoup d'Etats de l'Europe Occidentale, la révolution éclatera très prochainement ; en tous cas, nous, en qualité de fraction organisée des ouvriers et du Parti, nous tendons et devons tendre à obtenir la majorité dans les Soviets. Alors notre victoire sera assurée et il n’y aura plus de force en mesure d'entreprendre quoi que ce soit contre la révolution communiste. Autrement la victoire ne sera pas si facile à atteindre et ne sera pas de longue durée. 
Manifestes, thèses et résolutions des quatre premiers congrès de l'Internationale communiste 1919-1923

(juin 1934)

Premier Congrès, mars 1919.

-5 -

\section{Résolution sur la position envers les courants socialistes et la conférence de Berne Mars 1919}

$\underline{\text { Retour à la table des matières }}$

Déjà en 1907 au Congrès international socialiste de Stuttgart, lorsque la Deuxième Internationale aborda la question de la politique coloniale et des guerres impérialistes, il s'avéra que plus de la moitié de la Deuxième Internationale et la plupart de ses dirigeants étaient dans ces questions beaucoup plus près des points de vue de la bourgeoisie que du point de vue communiste de Marx et d'Engels.

Malgré cela le Congrès de Stuttgart adopta un amendement proposé par les représentants de l'aile révolutionnaire, N. Lénine et Rosa Luxemburg, et conçu dans ces termes :

« Si néanmoins une guerre éclate, les socialistes ont le devoir d'œuvrer pour sa fin rapide et d'utiliser par tous les moyens la crise économique et politique provoquée par la guerre pour réveiller le peuple et de hâter par là la chute de la domination capitaliste. ».

Au Congrès de Bâle de novembre 1912, convoqué au moment de la guerre des Balkans, la Deuxième Internationale déclara : 
«Que les gouvernements bourgeois n’oublient pas que la guerre franco-allemande donna naissance à l'insurrection révolutionnaire de la Commune, et que la guerre russo-japonaise mit en mouvement les forces révolutionnaires de la Russie. Aux yeux des prolétaires c'est un crime que de s'entre-tuer au profit du gain capitaliste, de la rivalité dynastique et de la floraison des traités diplomatiques ».

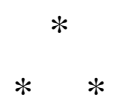

Fin juillet et au début d'août 1914, 24 heures avant le commencement de la guerre mondiale, les organismes et institutions compétents de la Deuxième Internationale continuèrent encore à condamner la guerre qui approchait, comme le plus grand crime de la bourgeoisie. Les déclarations se rapportant à ces jours et émanant des partis dirigeants de la Deuxième Internationale constituent l'acte d'accusation le plus éloquent contre les dirigeants de la Deuxième Internationale.

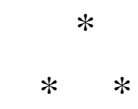

Dès le premier coup de canon tombé sur les champs de la boucherie impérialiste, les principaux partis de la Deuxième Internationale trahirent la classe ouvrière et passèrent, sous le couvert de la " défense nationale » chacun du coté de « sa » bourgeoisie. Scheidemann et Ebert en Allemagne, Thomas et Renaudel en France, Henderson et Hyndman en Angleterre, Vandervelde et De Brouckère en Belgique, Renner et Pernerstorfer en Autriche, Plékhanov et Roubanovitch en Russie, Branting et son parti en Suède, Gompers et ses camarades d’idées en Amérique, Mussolini et Cie en Italie, exhortèrent le prolétariat à une «trêve » avec la bourgeoisie de « leur » pays, à renoncer à la guerre contre la guerre, et à devenir en fait de la chair à canon pour les impérialistes.

Ce fut à ce moment que la Deuxième Internationale fit définitivement faillite et périt.

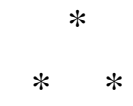

Grâce au développement économique général, la bourgeoisie des pays les plus riches, au moyen de petites aumônes puisées dans ses gains énormes, eut la possibilité de corrompre et de séduire le sommet de la classe ouvrière, l'aristocratie 
ouvrière. Les « compagnons de lutte » petits-bourgeois du socialisme affluèrent dans les rangs des partis social-démocrates officiels et orientèrent peu à peu le cours de ceux-ci dans le sens de la bourgeoisie. Les dirigeants du mouvement ouvrier parlementaire et pacifique, les dirigeants syndicaux, les secrétaires, rédacteurs et employés de la social-démocratie, formèrent toute une caste d'une bureaucratie ouvrière, ayant ses propres intérêts de groupes égoïstes, et qui fut en réalité hostile au socialisme.

Grâce à toutes ces circonstances la social-démocratie officielle dégénéra en un parti anti-socialiste et chauvin.

Dans le sein de la Deuxième Internationale déjà se révélèrent trois tendances fondamentales. Au cours de la guerre et jusqu'au début de la révolution prolétarienne en Europe les contours de ces trois tendances se dessinèrent déjà en toute netteté :

1. La tendance social-chauvine (tendance de la « majorité », dont les représentants les plus typiques sont les social-démocrates allemands, qui partagent maintenant le pouvoir avec la bourgeoisie allemande et qui sont devenus les assassins des chefs de l’Internationale Communiste, Karl Liebknecht et Rosa Luxemburg.

Les social-chauvins se sont révélés à présent complètement comme les ennemis de classe du prolétariat et suivent le programme de « liquidation » de la guerre que la bourgeoisie leur a dicté : faire retomber la plus grande partie des impôts sur les masses laborieuses, inviolabilité de la propriété privée, maintien de l'armée entre les mains de la bourgeoisie, dissolution des conseils ouvriers surgissant partout, maintien du pouvoir politique entre les mains de la bourgeoisie — la « démocratie » bourgeoise contre le socialisme.

Malgré l’âpreté avec laquelle les communistes ont lutté jusqu'ici contre les « social-démocrates de la majorité », les ouvriers n’ont cependant pas encore reconnu tout le danger dont ces traîtres menacent le prolétariat international. Ouvrir les yeux à tous les travailleurs sur l'œuvre de trahison des social-chauvins et mettre par la force des armes ce parti contre-révolutionnaire hors d'état de nuire, voilà une des tâches les plus importantes de la révolution prolétarienne internationale. 
2. La tendance centriste (social-pacifistes, kautskystes, indépendants). Cette tendance a commencé à se former dès avant la guerre, surtout en Allemagne. Au début de la guerre, les principes généraux du «Centre » coïncidaient presque toujours avec ceux des social-chauvins. Kautsky, le chef théorique du «Centre » défendait la politique poursuivie par les social-chauvins allemands et français. L’Internationale n'était qu'un «instrument en temps de paix »; " lutte pour la paix », « lutte de classe - en temps de paix », tels étaient les mots d’ordre de Kautsky.

Depuis le début de la guerre le «Centre » est pour « l'unité » avec les socialchauvins. Après l'assassinat de Liebknecht et de Luxemburg, le « Centre » continue à prêcher cette « unité » ; c’est-à-dire, l'unité des ouvriers communistes avec les assassins des chefs communistes, Liebknecht et Luxemburg.

Dès le début de la guerre, le « Centre » (Kautsky, Victor Adler, Turati, MacDonald) se mit à prêcher «l'amnistie réciproque » à l'égard des chefs des partis social-chauvins d'Allemagne et d'Autriche d'une part, de la France et de l'Angleterre de l'autre. Cette amnistie, le «Centre » la préconise encore aujourd'hui, après la guerre, empêchant ainsi les ouvriers de se faire une idée claire sur les causes de l'effondrement de la Deuxième Internationale.

Le « Centre » a envoyé ses représentants à Berne à la conférence internationale des socialistes de compromis, facilitant ainsi aux Scheidemann et aux Renaudel leur tâche de tromper les ouvriers.

Il est absolument nécessaire de séparer du « Centre » les éléments les plus révolutionnaires, ce à quoi on ne peut aboutir que par la critique impitoyable et en compromettant les chefs du «Centre ». La rupture organisatoire avec le «Centre » est une nécessité historique absolue. La tâche des communistes de chaque pays est de déterminer le moment de cette rupture selon l’étape que le mouvement a atteint chez eux.

3. Les Communistes. Au sein de la Deuxième Internationale où cette tendance a défendu les conceptions communistes-marxistes sur la guerre et les tâches du prolétariat (Stuttgart 1907 ; résolution Lénine-Luxemburg) ce courant était en minorité. Le groupe de la "gauche radicale » (le futur Spartakusbund) en Allemagne, le parti des bolcheviks en Russie, les «tribunistes » en Hollande, le grou- 
pe de Jeunes dans une série de pays, formèrent le premier noyau de la nouvelle Internationale.

Fidèle aux intérêts de la classe ouvrière, cette tendance proclama dès le début de la guerre le mot d'ordre de transformation de guerre impérialiste en guerre civile. Cette tendance s’est constituée maintenant en Troisième Internationale.

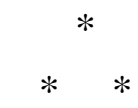

La conférence socialiste de Berne en février 1919 était une tentative de galvaniser le cadavre de la Deuxième Internationale.

La composition de la conférence de Berne montre manifestement que le prolétariat révolutionnaire du monde n’a rien de commun avec cette conférence.

Le prolétariat victorieux de la Russie, le prolétariat héroïque d’Allemagne, le prolétariat italien, le parti communiste du prolétariat autrichien et hongrois, le prolétariat suisse, la classe ouvrière de la Bulgarie, de la Roumanie, de Serbie, les partis ouvriers de gauche suédois, norvégiens, finlandais, le prolétariat ukrainien, letton, polonais, la Jeunesse Internationale, et l'Internationale des Femmes ont ostensiblement refusé de participer à la conférence de Berne des social-patriotes.

Les participants à la conférence de Berne qui ont encore quelque contact avec le véritable mouvement ouvrier de notre époque, ont formé un groupe d’opposition qui, dans la question essentielle du moins « appréciation de la Révolution russe », se sont opposés aux menées des social-patriotes. La déclaration du camarade français Loriot, qui stigmatisa la majorité de la conférence de Berne comme suppôt de la bourgeoisie, reflète la véritable opinion de tous les ouvriers conscients du monde entier.

Dans la prétendue « question des responsabilités », la conférence de Berne se mouvait toujours dans les cadres de l’idéologie bourgeoise. Les social-patriotes allemands et français se firent mutuellement les mêmes reproches que s'étaient lancés réciproquement les bourgeois allemands et français. La conférence de Berne se perdit dans des détails mesquins sur telle ou telle démarche de tel ou tel ministre bourgeois avant la guerre, ne voulant pas reconnaître que le capitalisme, le capital financier des deux groupes de puissances et leurs valets social-patriotes étaient les principaux responsables de la guerre. La majorité des social-patriotes 
de Berne voulait trouver le principal responsable de la guerre. Un coup d'œil dans le miroir aurait suffi pour qu'ils se reconnaissent tous comme responsables.

Les déclarations de la conférence de Berne sur la question territoriale sont pleines d'équivoques. Cette équivoque est justement ce dont la bourgeoisie a besoin. Monsieur Clemenceau, le représentant le plus réactionnaire de la bourgeoisie impérialiste, a reconnu les mérites de la conférence social-patriote de Berne en face de la réaction impérialiste en recevant une délégation de la conférence de Berne et en lui proposant de participer à toutes les commissions de la conférence impérialiste de Paris.

La question coloniale révéla clairement que la conférence de Berne était à la remorque de ces politiciens libéraux-bourgeois de la colonisation, qui justifient l'exploitation et l'asservissement des colonies par la bourgeoisie impérialiste et cherchent seulement à la masquer par des phrases philanthropiques-humanitaires. Les social-patriotes allemands exigèrent que l'appartenance des colonies allemandes au Reich soit maintenue, c'est-à-dire le maintien de l'exploitation de ces colonies par le capital allemand. Les divergences qui se manifestèrent à ce sujet démontrent que les social-patriotes de l'Entente ont le même point de vue de négrier, et considèrent comme tout naturel l'asservissement des colonies françaises et anglaises par le capital métropolitain. Ainsi la conférence de Berne montre qu'elle avait bien oublié le mot d’ordre de « A bas la politique coloniale ».

Dans l’appréciation de la « Société des Nations » la conférence de Berne montra qu'elle suivait les traces de ces éléments bourgeois qui, par l’apparence trompeuse de la soi-disant « Ligue des Peuples » veulent bannir la révolution prolétarienne grandissant dans le monde entier. Au lieu de démasquer les menées de la conférence des alliés à Paris, comme celles d'une bande qui fait de l'usure avec les peuplades et les domaines économiques, la conférence de Berne la seconda en se faisant son instrument.

L'attitude servile de la conférence, qui abandonna à une conférence gouvernementale bourgeoise de Paris le soin de résoudre la question de la législation sur la protection du travail, montre que les social-patriotes se sont consciemment exprimés en faveur de la conservation de l'esclavage du salariat capitaliste et sont prêts à tromper la classe ouvrière par de vaines réformes. 
Les tentatives inspirées par la politique bourgeoise, de faire prendre à la conférence de Berne une résolution, selon laquelle une intervention armée éventuelle en Russie serait couverte par la Deuxième Internationale, n'échouèrent que grâce aux efforts de l'opposition. Ce succès de l'opposition de Berne remporté sur les éléments chauvins déclarés est pour nous la preuve indirecte que le prolétariat de l'Europe occidentale sympathise avec la révolution prolétarienne de Russie et qu'il est prêt à lutter contre la bourgeoisie impérialiste.

À leur crainte de s’occuper le moins du monde de ce phénomène d’importance historique mondiale on reconnaît la peur qu'éprouvent ces valets de la bourgeoisie devant l'extension des conseils ouvriers.

Les conseils ouvriers constituent le phénomène le plus important depuis la Commune de Paris. La conférence de Berne, en ignorant cette question, a manifesté son indigence spirituelle et sa faillite théorique.

Le congrès de l'internationale Communiste considère « l’Internationale » que la conférence de Berne tente de construire comme une Internationale jaune de briseurs de grèves, qui n'est et ne restera qu'un instrument de la bourgeoisie.

Le congrès invite les ouvriers de tous les pays à entamer la lutte la plus énergique contre l'Internationale jaune et à préserver les masses les plus larges du peuple de cette Internationale de mensonge et de trahison. 
Manifestes, thèses et résolutions des quatre premiers congrès de l’Internationale communiste 1919-1923

(juin 1934)

Premier Congrès, mars 1919.

- 6 -

Déclaration faite par les participants de la conférence de Zimmerwald, Mars 1919

\section{$\underline{\text { Retour à la table des matières }}$}

Les conférences de Zimmerwald et de Kienthal eurent leur importance à une époque où il était nécessaire d'unir tous les éléments prolétariens disposés sous une forme ou sous une autre à protester contre la boucherie impérialiste. Mais il pénétra dans le groupement de Zimmerwald, à côté d’éléments nettement communistes, des éléments « centristes », pacifistes et hésitants. Ces éléments centristes, comme l'a montré la conférence de Berne, s’unissent actuellement aux socialpatriotes, pour lutter contre le prolétariat révolutionnaire, utilisant ainsi Zimmerwald au profit de la réaction.

En même temps, le mouvement communiste grandissait dans une série de pays, et la lutte contre les éléments centristes qui font obstacle au développement de la révolution sociale est devenue maintenant la tâche principale du prolétariat révolutionnaire. Le groupement de Zimmerwald a fait son temps. Tout ce qu'il y avait dans le groupement de Zimmerwald de véritablement révolutionnaire passe et adhère à l'Internationale Communiste. 
Les participants soussignés de Zimmerwald déclarent qu'ils considèrent le groupement de Zimmerwald comme dissout et demandent au Bureau de la Conférence de Zimmerwald de remettre tous ses documents au Comité Exécutif de la $3^{\mathrm{e}}$ Internationale.

Rakovsky, Lénine, Zinoviev, Trotsky, Platten.

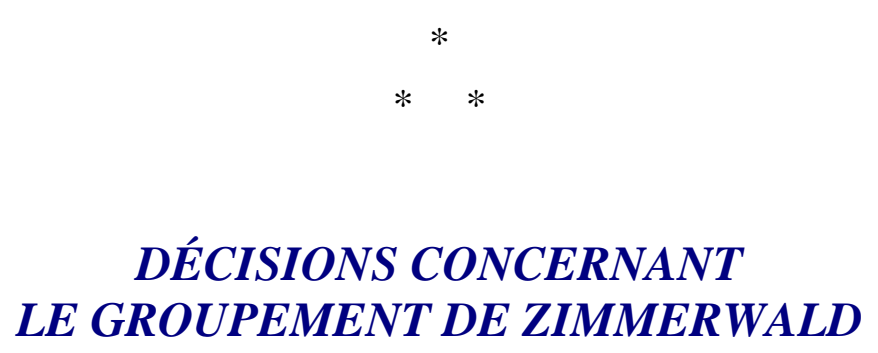

Après avoir entendu le rapport de la camarade Balabanov, secrétaire du Comité Socialiste International, et des camarades Rakovsky, Platten, Lénine, Trotsky et Zinoviev, membres du groupement de Zimmerwald, le premier Congrès de Zimmerwald communiste décide de considérer comme dissout le groupement de Zimmerwald.

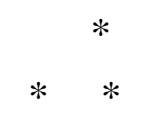

\section{DÉCISION CONCERNANT LA QUESTION D'ORGANISATION}

Afin de pouvoir commencer sans retard son travail actif, le Congrès désigne immédiatement les organes nécessaires, dans l'idée que la constitution définitive de l'Internationale Communiste devra être donnée par le prochain congrès sur la proposition du Bureau.

La direction de l'Internationale Communiste est confiée à un Comité Exécutif. Celui-ci se compose d'un représentant de chacun des partis communistes des pays les plus importants. Les partis de Russie, d'Allemagne, d'Autriche allemande, de Hongrie, de la Fédération des Balkans, de Suisse et de Scandinavie doivent envoyer immédiatement leurs représentants au premier Comité Exécutif. 
Les partis des pays qui déclarent adhérer à l’Internationale Communiste avant le deuxième congrès obtiendront un siège au Comité Exécutif.

Jusqu’à l'arrivée des représentants étrangers, les camarades du pays dans lequel le Comité Exécutif a son siège se chargent d'assurer le travail. Le Comité Exécutif élit un bureau de cinq personnes. 
Manifestes, thèses et résolutions des quatre premiers congrès de l’Internationale communiste 1919-1923

(juin 1934)

Premier Congrès, mars 1919.

- 7 -

\section{Résolution sur la fondation de l'Internationale Communiste, 4 mars 1919.}

\section{$\underline{\text { Retour à la table des matières }}$}

PlatTEN, président. — . ... À présent, je porte à votre connaissance une proposition, présentée par les délégués Rakovsky, Gruber, Grimlund, Rudnianszky. Elle est ainsi conçue :

« Les représentants du Parti Communiste de l’Autriche allemande, du Parti social-démocrate de gauche de Suède, de la Fédération ouvrière révolutionnaire social-démocrate des Balkans, du Parti Communiste de Hongrie, proposent la fondation de l'Internationale Communiste.

«1. La nécessité de la lutte pour la dictature du prolétariat exige l'organisation unifiée, commune et internationale de tous les éléments communistes qui se placent sur ce terrain.

«2. Cette fondation est un devoir d'autant plus impérieux qu'actuellement on tente à Berne et peut-être tentera-t-on aussi plus tard ailleurs de rétablir l'ancienne Internationale opportuniste et de rassembler tous les éléments confus et hésitants du prolétariat. C’est pourquoi il est nécessaire d’établir une séparation nette entre les éléments révolutionnaires prolétariens et les éléments social-traîtres.

« 3. Si la 3e Internationale n’était pas fondée par la Conférence siégeant à Moscou, cela créerait l’impression que les Partis communistes sont 
en désaccord, ce qui affaiblirait notre situation et augmenterait la confusion parmi les éléments indécis du prolétariat de tous les pays.

«4. La constitution de la $3^{\mathrm{e}}$ Internationale est donc un devoir historique absolu, et la Conférence communiste internationale siégeant à Moscou doit en faire une réalité. »

Cette proposition suppose que nous revenions sur une résolution quant à savoir si nous sommes une conférence ou un congrès. La proposition vise à la constitution de la $3^{\mathrm{e}}$ Internationale. La discussion est ouverte.

Après la discussion, le camarade Platten met aux voix la proposition signée par Rakovsky, Gruber, Grimlund, Rudnianszky.

« Cette proposition, dit-il, est faite afin d’amener une décision sur la fondation de la $3^{\mathrm{e}}$ Internationale. »

La résolution fut adoptée à l'unanimité moins 5 abstentions (délégation allemande).

\section{DÉCISION \\ 4 mars 1919.}

La Conférence Communiste Internationale décide de se constituer comme $3^{\mathrm{e}}$ Internationale et d'adopter le nom d'Internationale Communiste. Les proportions des voix accordées ne subissent pas de changement. Tous les partis, toutes les organisations et les groupes conservent le droit, pendant une durée de huit mois, d'adhérer définitivement à la $3^{\mathrm{e}}$ Internationale. 
Manifestes, thèses et résolutions des quatre premiers congrès de l'Internationale communiste 1919-1923

(juin 1934)

Premier Congrès, mars 1919.

- 8 -

Plate-forme

de l'internationale Communiste, Mars 1919.

\section{$\underline{\text { Retour à la table des matières }}$}

Les contradictions du système mondial, auparavant cachées en son sein, se sont révélées avec une force inouïe en une formidable explosion : la grande guerre impérialiste mondiale.

Le capitalisme a tenté de surmonter sa propre anarchie par l'organisation de la production. Au lieu de nombreuses entreprises concurrentes, se sont organisées de vastes associations capitalistes (syndicats, cartels, trusts), le capital bancaire s'est uni au capital industriel, toute la vie économique est tombée sous le pouvoir d'une oligarchie financière capitaliste, qui, par une organisation basée sur ce pouvoir, acquit une maîtrise exclusive. Le monopole supplante la libre concurrence. Le capitaliste isolé se transforme en membre d'une association capitaliste. L’organisation remplace l'anarchie insensée.

Mais dans la mesure même où, dans les Etats pris séparément, les procédés anarchiques de la production capitaliste étaient remplacés par l'organisation capitaliste, les contradictions, la concurrence, l'anarchie, atteignaient dans l'économie mondiale une plus grande acuité. La lutte entre les plus grands Etats conquérants conduisait, avec une inflexible nécessité, à la monstrueuse guerre impérialiste. La soif de bénéfices poussait le capitalisme mondial à la lutte pour la conquête de 
nouveaux marchés, de nouvelles sources de matières brutes, de la main-d’œuvre à bon marché des esclaves coloniaux. Les Etats impérialistes qui se sont partagés le monde entier, qui ont transformé des millions de prolétaires et de paysans d'Afrique, d'Asie, d'Amérique, d'Australie, en bêtes de somme, devaient révéler tôt au tard dans un gigantesque conflit la nature anarchique du capital. Ainsi se produisit le plus grand des crimes — la guerre du banditisme mondial.

Le capitalisme a tenté de surmonter les contradictions de sa structure sociale. La société bourgeoise est une société de classes. Mais le capital des grands Etats « civilisés » s'efforça d’étouffer les contradictions sociales. Aux dépens des peuples coloniaux qu'il détruisait, le capital achetait ses esclaves salariés, créant une communauté d'intérêts entre les exploiteurs et les exploités - communauté d’intérêts dirigée contre les colonies opprimées et les peuples coloniaux jaunes, noirs ou rouges ; il enchaînait l’ouvrier européen ou américain à la « patrie » impérialiste.

Mais cette même méthode de corruption continue, qui créait le patriotisme de la classe ouvrière et sa sujétion morale, produisit, grâce à la guerre, sa propre antithèse. L'extermination, la sujétion totale du prolétariat, un joug monstrueux, l’appauvrissement, la dégénérescence, la faim dans le monde entier — telle fut la dernière rançon de la paix sociale. Et cette paix a fait faillite. La guerre impérialiste est transformée en guerre civile.

Une nouvelle époque est née. Epoque de désagrégation du capitalisme, de son effondrement intérieur. Epoque de la révolution communiste du prolétariat.

Le système impérialiste croule. Troubles aux colonies, fermentation parmi les petites nationalités jusqu’à présent privées d’indépendance, révoltes du prolétariat, révolutions prolétariennes victorieuses dans plusieurs pays, décomposition des armées impérialistes, incapacité absolue des classes dirigeantes à diriger dorénavant les destinées des peuples - tel est le tableau de la situation actuelle dans le monde entier.

L’humanité, dont toute la culture a été dévastée, est menacée de destruction. Il n’est plus qu'une force capable de la sauver, et cette force, c'est le prolétariat. L'ancien « ordre » capitaliste n'est plus. Il ne peut plus exister. Le résultat final des procédés capitalistes de production est le chaos - et ce chaos ne peut être vaincu que par la plus grande classe productrice, la classe ouvrière. C'est elle qui 
doit instituer l'ordre véritable, l'ordre communiste. Elle doit briser la domination du capital, rendre les guerres impossibles, effacer les frontières entre les Etats, transformer le monde en une vaste communauté travaillant pour elle-même, réaliser la solidarité fraternelle et la libération des peuples.

Entre temps, contre le prolétariat, le capital mondial s’arme pour un dernier combat. Sous le couvert de Ligue des Nations et des bavardages pacifiques, il tente ses derniers efforts pour rajuster les parties disjointes d'elles-mêmes du système capitaliste et diriger ses forces contre la révolution prolétarienne irrésistiblement déchaînée.

A ce nouveau, à cet immense complot des classes capitalistes, le prolétariat doit répondre par la conquête du pouvoir politique, tourner ce pouvoir contre ses propres ennemis, s’en servir comme levier pour la transformation économique de la société. La victoire définitive du prolétariat mondial marquera le commencement de l’histoire de l’humanité libérée.

\section{LA CONQUETTE DU POUVOIR POLITIQUE}

La conquête du pouvoir politique par le prolétariat signifie l'anéantissement du pouvoir politique de la bourgeoisie. L'appareil gouvernemental avec son armée capitaliste, placée sous le commandement d'un corps d'officiers bourgeois et de junkers, avec sa police et sa gendarmerie, ses geôliers et ses juges, ses prêtres, ses fonctionnaires, etc..., constitue entre les mains de la bourgeoisie le plus puissant instrument de gouvernement. La conquête du pouvoir gouvernemental ne peut se réduire à un changement de personnes dans la constitution des ministères, mais doit signifier l'anéantissement d'un appareil étatiste étranger, la prise en mains de la force réelle, le désarmement de la bourgeoisie, du corps d’officiers contre-révolutionnaires, des gardes blancs, l’armement du prolétariat, des soldats révolutionnaires et de la garde rouge ouvrière; la destitution de tous les juges bourgeois et l'organisation des tribunaux prolétariens, la destruction du fonctionnarisme réactionnaire et la création de nouveaux organes d'administration prolétariens. La victoire prolétarienne est assurée par la désorganisation du pouvoir ennemi et l'organisation du pouvoir prolétarien; elle doit signifier la ruine de l'appareil étatiste bourgeois et la création de l’appareil étatiste prolétarien. Ce 
n’est qu'après la complète victoire, quand le prolétariat aura définitivement brisé la résistance de la bourgeoisie, qu'il pourra obliger ses anciens adversaires à le servir utilement, les amenant progressivement sous son contrôle, à l'œuvre de construction communiste.

\section{DÉMOCRATIE ET DICTATURE}

Comme tout Etat, l'Etat prolétarien représente un appareil de contrainte et cet appareil est maintenant dirigé contre les ennemis de la classe ouvrière. Sa mission est de briser et de rendre impossible la résistance des exploiteurs, employant dans leur lutte désespérée tous les moyens pour étouffer la révolution dans le sang. D'autre part, la dictature du prolétariat faisant officiellement de cette classe la classe gouvernante, crée une situation transitoire.

Dans la mesure où sera brisée la résistance de la bourgeoisie, elle sera expropriée et se transformera en une masse laborieuse ; la dictature du prolétariat disparaîtra, l’Etat mourra et les classes sociales finiront avec lui.

La soi-disant démocratie, c’est-à-dire la démocratie bourgeoise n’est rien d’autre que la dictature bourgeoise déguisée. « La volonté populaire » tant prônée est une fiction, comme l'unité du peuple. En fait, des classes existent dont les intérêts contraires sont irréductibles. Et comme la bourgeoisie n'est qu'une minorité insignifiante, elle utilise cette fiction, cette prétendue « volonté populaire », afin d'affermir, à la faveur de belles phrases, sa domination sur la classe ouvrière, afin de lui imposer la volonté de sa classe. Au contraire, le prolétariat constituant l'énorme majorité de la population, use ouvertement de la puissance de ses organisations de masses, de ses soviets, pour écourter la transition vers une société communiste sans classes.

L’essence de la démocratie bourgeoise réside dans une reconnaissance purement formelle des droits et des libertés, précisément inaccessibles au prolétariat et aux éléments à demi-prolétariens, à cause du manque de ressources matérielles, tandis que la bourgeoisie a toutes les possibilités de tirer parti de ces ressources matérielles, de sa presse et de son organisation, pour mentir au peuple et le tromper. Au contraire, l'essence du système des Soviets - de ce nouveau type de 
pouvoir gouvernemental - consiste en ce que le prolétariat reçoit la possibilité d'assurer en fait ses droits et sa liberté. Le pouvoir du Soviet remet au peuple les plus beaux palais, les maisons, les typographies, les réserves de papier, etc..., pour sa presse, ses réunions, ses syndicats. Ce n'est qu'alors que devient vraiment possible la démocratie prolétarienne.

Avec son système parlementaire la démocratie bourgeoise ne donne qu'en paroles le pouvoir aux masses, et leurs organisations sont complètement écartées et du pouvoir véritable et de la véritable administration du pays. Dans le système des Soviets, les organisations des masses gouvernent et, par elles, les masses ellesmêmes, les Soviets appelant à l'administration de l'Etat un nombre toujours plus grand d'ouvriers; et ce n'est que de cette façon que tout le peuple ouvrier est à peu près appelé à prendre part effectivement au gouvernement de l'Etat. Le système des Soviets s'appuie de la sorte sur les organisations des masses prolétariennes, représentées par les Soviets mêmes, les unions professionnelles révolutionnaires, les coopératives, etc...

La démocratie bourgeoise et le parlementarisme, par la division des pouvoirs législatif et exécutif et l'absence du droit de rappel des députés, achèvent de séparer les masses de l'Etat. Au contraire, le système des Soviets, par son droit de rappel, par la réunion des pouvoirs législatif et exécutif, et, conséquemment, par l'aptitude des Soviets à constituer des collectivités de travail, lie les masses aux organes des administrations. Ce lien est encore affermi par le fait que, dans le système des Soviets, les élections ne se font pas d'après les subdivisions territoriales artificielles, mais coïncident avec les unités locales de la production.

Le système des Soviets assure de la sorte la possibilité d'une véritable démocratie prolétarienne, démocratie pour le prolétariat et dans le prolétariat, dirigée contre la bourgeoisie. Dans ce système, une situation prédominante est assurée au prolétariat industriel, auquel appartient, par suite de sa meilleure organisation et de son plus grand développement politique, le rôle de classe dirigeante, dont l'hégémonie permettra au demi-prolétariat et aux paysans pauvres de s'élever progressivement. Ces supériorités momentanées du prolétariat industriel doivent être utilisées pour arracher les masses non possédantes de la petite bourgeoisie paysanne à l'influence des gros propriétaires ruraux et de la bourgeoisie pour les organiser et les appeler à collaborer à la construction communiste. 


\section{L'EXPROPRIATION DE LA BOURGEOISIE ET LA SOCIALISATION DES MOYENS DE PRODUCTION}

La décomposition du système capitaliste et de la discipline capitaliste du travail rendent impossible, étant donné les relations entre les classes, la reconstitution de la production sur les anciennes bases. La lutte des ouvriers pour l'augmentation des salaires, même en cas de succès, n'amène pas l'amélioration espérée des conditions d'existence, l'augmentation du prix des produits annulant immanquablement chaque succès. La lutte énergique des ouvriers pour l'augmentation des salaires dans les pays dont la situation est évidemment sans espoir, par son caractère impétueux et passionné, par sa tendance à la généralisation, rend impossibles dorénavant les progrès de la production capitaliste. L'amélioration de la condition des ouvriers ne pourra être atteinte que lorsque le prolétariat lui-même s’emparera de la production. Pour élever les forces productrices de l'économie, pour briser au plus vite la résistance de la bourgeoisie, qui prolonge l'agonie de la vieille société, créant par là même le danger d'une complète ruine de la vie économique, la dictature prolétarienne doit réaliser l'expropriation de la grosse bourgeoisie et de la noblesse et faire des moyens de production et de transport la propriété collective de l’Etat prolétarien.

Le communisme naît maintenant sur les décombres de la société capitaliste ; l'histoire ne laissera pas d'autre issue à l'humanité. Les opportunistes, dans leur désir de retarder la socialisation par leur utopique revendication du rétablissement de l'économie capitaliste, ne font qu’ajourner la solution de la crise et créer la menace d'une ruine totale, tandis que la révolution communiste apparaît pour la vraie force productrice de la société, pour le prolétariat — et avec lui, pour toute la société — comme le meilleur, le plus sûr moyen de salut.

La dictature prolétarienne n’entraîne aucun partage des moyens de production et de transport. Au contraire, sa tâche est de réaliser une plus grande centralisation des moyens et la direction de toute la production selon un plan unique.

Le premier pas vers la socialisation de toute l'économie comporte nécessairement les mesures suivantes : socialisation des grandes banques qui dirigent maintenant la production ; prise en mains par le pouvoir prolétarien de tous les organes 
de l'Etat capitaliste régissant la vie économique ; prise en mains de toutes les entreprises communales; socialisation des branches d'industrie trustées ou syndiquées ; de même, socialisation des branches d'industrie dont le degré de concentration rend la socialisation techniquement possible ; socialisation des propriétés agricoles et leur transformation en entreprises agricoles dirigées par la société.

Quant aux entreprises de moindre importance, le prolétariat doit, en tenant compte de leur grandeur, les socialiser peu à peu.

Il importe de souligner ici que la petite propriété ne doit pas être expropriée et que les petits propriétaires n'exploitant pas le travail d'autrui, ne doivent subir aucune violence. Cette classe sera peu à peu attirée dans la sphère d’organisation sociale, par l'exemple et la pratique démontrant la supériorité de la nouvelle structure sociale qui libère la classe des petits paysans et la petite bourgeoisie du joug des gros capitalistes, de toute la noblesse, des impôts excessifs (principalement par suite de l'annulation des dettes d'Etat, etc...).

La tâche de la dictature prolétarienne dans le domaine économique n’est réalisable que dans la mesure où le prolétariat saura créer des organes de direction de la production centralisée et réaliser la gestion par les ouvriers eux-mêmes. A cette fin, il sera contraint de tirer parti de celles de ses organisations de masses qui sont liées le plus étroitement avec le processus de la production.

Dans le domaine de la répartition, la dictature prolétarienne doit réaliser le remplacement du commerce par une juste répartition des produits. Parmi les mesures à cette fin indispensables, il faut indiquer : la socialisation des grandes entreprises commerciales, la transmission au prolétariat de tous les organes de répartition de l'Etat et des municipalités bourgeoises; le contrôle des grandes unions coopératives dont l'appareil organisateur aura encore, pendant la période de transition, une importance économique considérable, la centralisation progressive de tous ces organes et leur transformation en un tout unique pour la répartition rationnelle des produits.

De même que dans le domaine de la production, dans celui de la répartition, il importe d'utiliser tous les techniciens et les spécialistes qualifiés — sitôt que leur résistance dans le domaine politique aura été brisée, et qu’ils seront en état de servir, au lieu du capital, le nouveau système de production. 
Le prolétariat n'a pas l'intention de les opprimer : au contraire, lui seul leur donnera le premier la possibilité de développer l’activité créatrice la plus énergique. La dictature prolétarienne remplacera la division du travail physique et intellectuel, propre au capitalisme, par l'union, réunissant ainsi le travail et la science.

En même temps qu'il expropriera les fabriques, les mines, les propriétés, etc..., le prolétariat doit mettre fin à l'exploitation de la population par les capitalistes propriétaires d'immeubles, transmettre les grandes habitations aux Soviets ouvriers locaux, installer la population ouvrière dans les appartements bourgeois, etc...

Au cours de cette immense transformation, le pouvoir des Soviets doit, d'une part, échafauder un énorme appareil de gouvernement toujours plus centralisé dans sa forme, et, d'autre part, doit appeler à un travail de direction immédiat des couches toujours plus grandes du peuple travailleur.

\section{LE CHEMIN DE LA VICTOIRE}

La période révolutionnaire exige que le prolétariat use d'une méthode de lutte qui concentre toute son énergie, à savoir l'action directe des masses jusque et y compris sa suite logique, le choc direct, la guerre déclarée avec la machine gouvernementale bourgeoise. A ce but doivent être subordonnés tous les autres moyens, tels que, par exemple, l'utilisation révolutionnaire du parlementarisme bourgeois.

Les conditions préliminaires indispensables à cette lutte victorieuse sont : la rupture, non seulement avec les laquais directs du capital et les bourreaux de la révolution communiste - dont les social-démocrates de droite assument aujourd'hui le rôle — mais encore la rupture avec le « Centre » (groupe Kautsky), qui, au moment critique, abandonne le prolétariat et se lie à ses ennemis déclarés.

D’un autre côté, il est nécessaire de réaliser un bloc avec ces éléments du mouvement ouvrier révolutionnaire qui, bien qu'ils n’aient pas appartenu auparavant au parti socialiste, se placent maintenant en tout et pour tout sur le terrain de la dictature prolétarienne sous sa forme soviétique, c'est-à-dire avec les éléments correspondants du syndicalisme. 
L'accroissement du mouvement révolutionnaire dans tous les pays, le danger, pour cette révolution, d'être étouffée par la ligue des Etats bourgeois, les tentatives d'union des partis traîtres au socialisme (formation de l'Internationale jaune, à Berne), dans le but de servir bassement la ligue de Wilson — et enfin la nécessité absolue pour le prolétariat de coordonner ses efforts - tout cela nous conduit inévitablement à la fondation de l’Internationale communiste, véritablement révolutionnaire et véritablement prolétarienne.

L’Internationale qui se révélera capable de subordonner les intérêts dits nationaux aux intérêts de la révolution mondiale réalisera ainsi l'entraide des prolétaires des différents pays - alors que sans cette aide mutuelle, économique et autre, le prolétariat n'est pas en état d'édifier une société nouvelle. D’autre part, en opposition à l'Internationale socialiste jaune, l'Internationale prolétarienne et communiste soutiendra les peuples exploités des colonies dans leur lutte contre l'impérialisme, afin de hâter l'effondrement final du système impérialiste mondial.

Les malfaiteurs du capitalisme affirmaient au début de la guerre mondiale qu'ils ne font tous que défendre leur patrie. Mais l'impérialisme allemand révéla sa nature bestiale par une série de sanglants forfaits commis en Russie, en Ukraine, en Finlande. Maintenant se révèlent à leur tour, même aux yeux des couches les plus arriérées de la population, les puissances de l'Entente qui pillent le monde entier et assassinent le prolétariat. D'accord avec la bourgeoisie allemande et les social-patriotes, le mot de paix sur les lèvres, elles s'efforcent d'écraser, à l'aide de tanks et de troupes coloniales incultes et barbares la révolution du prolétariat européen. La terreur blanche des bourgeois-cannibales a été indescriptiblement féroce. Les victimes dans les rangs de la classe ouvrière sont innombrables ; elle a perdu ses meilleurs champions : Liebknecht, Rosa Luxemburg.

Le prolétariat doit se défendre en tout état de cause. L’Internationale communiste appelle le prolétariat mondial à cette lutte décisive. Arme contre arme ! Force contre force ! A bas la conspiration impérialiste du capital ! Vive la République internationale des Soviets prolétaires ! 
Manifestes, thèses et résolutions des quatre premiers congrès de l'Internationale communiste 1919-1923

(juin 1934)

Premier Congrès, mars 1919.

- 9 -

Thèses

sur la situation internationale et la politique de l'entente, Mars 1919

\section{$\underline{\text { Retour à la table des matières }}$}

Les expériences de la guerre mondiale ont démasqué la politique impérialiste des «démocraties » bourgeoises comme étant la politique de lutte des grandes puissances, tendant au partage du monde et à l'affermissement de la dictature économique et politique du capital financier sur les masses exploitées et opprimées. Le massacre de millions de vies humaines, la paupérisation du prolétariat tombé en esclavage, l'enrichissement inouï des couches supérieures de la bourgeoisie, grâce aux fournitures de guerre, aux emprunts, etc..., le triomphe de la réaction militaire dans tous les pays, tout cela ne tarda pas à détruire les illusions sur la défense de la patrie, la trêve et la "démocratie ». La " politique de paix » démasque les véritables aspirations des impérialistes de tous les pays et va jusqu'au bout de cette mise à nu. 


\section{LA PAIX DE BREST-LITOVSK ET LA COMPROMISSION DE L'IMPERIALISME ALLEMAND}

La paix de Brest-Litovsk et ensuite celle de Bucarest ont révélé le caractère de rapine et réactionnaire de l'impérialisme des puissances centrales. Les vainqueurs ont arraché à la Russie sans défense, des contributions et des annexions. Ils ont utilisé le droit de libre disposition des peuples comme prétexte d'une politique d'annexions, en créant des Etats vassaux, dont les gouvernements réactionnaires favorisèrent la politique de rapine et réprimèrent le mouvement révolutionnaire des masses laborieuses. L’impérialisme allemand qui, dans le combat international, n’avait pas remporté la victoire entière, n’avait pas à ce moment, la possibilité de montrer tout à fait franchement ses véritables intentions ; il dut se résigner à vivre dans une apparence de paix avec la Russie des Soviets et à couvrir sa politique de rapines et réactionnaire de phrases hypocrites.

Cependant les puissances de l'Entente, sitôt qu'elles avaient remporté la victoire mondiale, laissèrent tomber les masques et révélèrent aux yeux de tout le monde le véritable visage de l’impérialisme mondial.

\section{LA VICTOIRE DE L'ENTENTE ET LE REGROUPEMENT DES ÉTATS}

La victoire de l'Entente a partagé en différents groupes les pays soi-disant civilisés du monde. Le premier des groupes est constitué par les puissances du monde capitaliste, les grandes puissances impérialistes victorieuses (Angleterre, Amérique, France, Japon, Italie). En face d'elles se dressent les pays de l’impérialisme vaincu, ruinés par la guerre et ébranlés dans leur structure par le début de la révolution prolétarienne (Allemagne, Autriche-Hongrie avec leurs vassaux d'autrefois). Le troisième groupe est formé par les Etats vassaux des puissances de l'Entente. Il se compose des petits Etats capitalistes, ayant participé à la guerre aux côtés de l'Entente (Belgique, Serbie, Portugal, etc...) et des petites 
République «nationales » et Etats tampons créés récemment (république TchécoSlovaque, Pologne, républiques Russes contre-révolutionnaires, etc...). Les Etats neutres s'approchent selon leur situation, des Etats vassaux, mais ils subissent une forte pression politique et économique, qui, parfois, rend leur situation semblable à celle des Etats vaincus. La République socialiste russe est un Etat ouvrier et paysan, se plaçant en dehors du monde capitaliste et représentant pour l'impérialisme victorieux un énorme danger social, le danger que tous les résultats de la victoire s'effondrent sous l'assaut de la révolution mondiale.

\section{LA « POLITIQUE DE PAIX » DE L'ENTENTE OÙ L'IMPERIALISME SE DEMASQUE LUI-MEME}

La « politique de paix » des cinq puissances mondiales, lorsque nous la considérons dans son ensemble, était et reste une politique qui se démasque constamment elle-même.

Malgré toutes les phrases sur sa «politique extérieure démocratique » elle constitue le triomphe complet de la diplomatie secrète qui, derrière le dos et aux dépens des millions d'ouvriers de tous les pays, décide du sort du monde par la voie d'arrangements entre les fondés de pouvoir des trusts financiers. Toutes les questions essentielles sont traitées sans exception à huis clos par le comité parisien des cinq grandes puissances, en l'absence des représentants des pays vaincus, neutres et des Etats vassaux eux-mêmes.

Les discours de Lloyd George, de Clemenceau, de Sonnino, etc..., proclament et essaient de motiver ouvertement la nécessité des annexions et des contributions.

Malgré les phrases mensongères sur la «guerre pour le désarmement général » on proclame la nécessité de s'armer encore et avant tout de maintenir la puissance maritime britannique en vue de la soi-disant "protection de la liberté des mers ».

Le droit de libre disposition des peuples par eux mêmes, proclamé par l'Entente, est manifestement foulé aux pieds et remplacé par le partage des domaines contestés entre les Etats puissants et leurs vassaux. 
Sans consulter la population, l’Alsace-Lorraine a été incorporée à la France ; l'Irlande, l'Egypte, les Indes n'ont pas le droit de disposer d'elles-mêmes ; l'Etat slave méridional et la République tchéco-slovaque ont été créés par la force des armes ; on trafique sans vergogne autour du partage de la Turquie d'Europe et d’Asie, le partage des colonies allemandes a déjà commencé, etc..., etc...

La politique des contributions a été poussée à un degré de pillage complet des vaincus. Non seulement on présente aux vaincus des notes se montant à des milliards et des milliards, non seulement on leur enlève tous les moyens de guerre mais les pays de l'Entente leur prennent aussi les locomotives, les chemins de fer, les bateaux, les instruments agricoles, les provisions d'or, etc..., etc... En outre les prisonniers de guerre doivent devenir les esclaves des vainqueurs. On discute des propositions tendant au travail forcé des ouvriers allemands. Les puissances alliées ont l'intention d'en faire des esclaves misérables et affamés du capital de l'Entente.

La politique d'excitation nationale poussée à l'extrême a son expression dans l'excitation constante contre les nations vaincues dans la presse de l'Entente et les administrations de l'occupation, ainsi que dans le blocus de la faim, condamnant les peuples de l'Allemagne et de l'Autriche à l'extermination. Cette politique mène à des pogromes contre les allemands, organisés par les soutiens de l'Entente les éléments chauvins tchèques et polonais, et à des pogromes contre les juifs, qui surpassent tous les hauts-faits du tsarisme russe.

Les États « démocratiques » de l'Entente poursuivent une politique de réaction extrême.

La réaction triomphe aussi bien à l'intérieur des pays de l'Entente elle-même, parmi lesquels la France est revenue aux pires époques de Napoléon 3, que dans le monde capitaliste tout entier, qui se trouve sous l'influence de l'Entente. Les alliés étranglent la révolution dans les pays occupés de l’Allemagne, la Hongrie, de la Bulgarie, etc..., ils excitent les gouvernements opportunistes-bourgeois des pays vaincus contre les ouvriers révolutionnaires en les menaçant de leur supprimer les vivres. Les alliés ont déclaré qu’ils couleraient tous les navires allemands qui oseraient hisser le drapeau rouge de la révolution ; ils ont refusé de reconnaître les conseils allemands ; dans les régions allemandes occupées, ils ont aboli la journée de huit heures. Abstraction faite du soutien de la politique réactionnaire 
dans les pays neutres, et au soutien de celle-ci dans les Etats vassaux (le régime Paderevsky en Pologne), les alliés ont excité les éléments réactionnaires de ces pays (en Finlande, en Pologne, en Suède, etc...) contre la Russie révolutionnaire, et demandent l’intervention des forces armées allemandes.

\section{CONTRADICTIONS ENTRE LES ÉTATS DE L'ENTENTE}

Malgré l’identité des lignes fondamentales de leur politique impérialiste, une série de contradictions profondes se manifestent au sein des grandes puissances qui dominent le monde.

Ces contradictions se concentrent surtout autour du programme de paix du capital financier américain (le programme dit programme Wilson). Les points les plus importants de ce programme sont les suivants : "Liberté des mers », « Société des Nations » et « internationalisation des colonies ». Le mot d’ordre de « liberté des mers »- débarrassé de son masque hypocrite — signifie en réalité l'abolition de la prédominance militaire navale de certaines grandes puissances (en premier lieu de l'Angleterre), et l'ouverture de toutes les voies maritimes au commerce américain. La « Société des Nations » signifie que le droit à l'annexion immédiate des Etats et des peuples faibles sera refusé aux grandes puissances européennes (en premier lieu à la France). «L’internationalisation des colonies » fixe la même règle envers les domaines coloniaux.

Ce programme est conditionné par les faits suivants : le capital américain ne possède pas la plus grande flotte du monde ; il n’a plus la possibilité de procéder à des annexions directes en Europe, et c'est pourquoi il vise à l'exploitation des Etats et des peuples faibles au moyen des relations commerciales et des investissements de capitaux. C'est pourquoi il veut contraindre les autres puissances à former un syndicat des trusts d’Etats, à répartir « loyalement » entre elles les parts de l'exploitation mondiale et à transformer la lutte entre les trusts d'Etats en une lutte purement économique. Dans le domaine de l'exploitation économique le capital financier américain hautement développé obtiendra une hégémonie effective qui lui assurera la prédominance économique et politique dans le monde. 
La «liberté des mers» est en contradiction aiguë avec les intérêts de l'Angleterre, du Japon, en partie aussi de l'Italie (dans l'Adriatique). La « Société des Nations » et «l'internationalisation des colonies » est en contradiction décisive avec les intérêts de la France et du Japon — dans une mesure moindre avec les intérêts de toutes les autres puissances impérialistes. La politique des impérialistes de la France, où le capital financier a une forme particulièrement usurière, où l'industrie est faiblement développée et où la guerre a complètement ruiné les forces productives, vise par des moyens désespérés au maintien du régime capitaliste ; ces moyens sont : le pillage barbare de l'Allemagne, l'assujettissement direct et l'exploitation rapace des Etats vassaux (projets d'une Union Danubienne, d'Etats slaves méridionaux) et extorsion par la violence des dettes contractées par le tsarisme russe auprès du Shylock français. La France, l'Italie (et dans une forme altérée cela est aussi valable pour le Japon) en tant que pays continentaux, sont aussi capables de poursuivre une politique d'annexions directes.

Tout en étant en contradiction avec les intérêts de l'Amérique, les grandes puissances ont des intérêts qui s'opposent réciproquement entre eux. L'Angleterre craint le renforcement de la France sur le continent, elle a en Asie Mineure et en Afrique des intérêts qui s'opposent à ceux de la France. Les intérêts de l'Italie dans les Balkans et au Tyrol sont contraires aux intérêts de la France. Le Japon dispute à l'Australie anglaise les îles situées dans l’Océan Pacifique.

\section{GROUPEMENTS ET TENDANCES À L'INTERIEUR DE L'ENTENTE}

Ces contradictions entre les grandes puissances rendent possibles différents groupements à l'intérieur de l'Entente. Jusqu'ici deux combinaisons principales se sont dessinées : la combinaison franco-anglo-japonaise, qui est dirigée contre l'Amérique et l'Italie et la combinaison anglo-américaine s'opposant aux autres grandes puissances.

La première de ces combinaisons prévalait jusqu'au début de janvier 1919, tant que le Président Wilson n'avait pas encore renoncé à exiger l'abolition de la domination maritime anglaise. Le développement du mouvement révolutionnaire des ouvriers et des soldats en Angleterre, qui a conduit à une entente entre les 
impérialistes de différents pays pour liquider l'aventure russe et pour hâter la conclusion de la paix, a renforcé le penchant de l'Angleterre vers cette combinaison. Elle devient prédominante depuis janvier 1919. Le bloc anglo-américain s’oppose à la priorité de la France dans le pillage de l'Allemagne et à l'intensité exagérée de ce pillage. Il pose certaines limites aux exigences annexionnistes exagérées de la France, de l'Italie et du Japon. Il empêche que les Etats vassaux nouvellement fondés leur soient directement soumis. En ce qui concerne la question russe, la combinaison anglo-américaine a des dispositions pacifiques : elle veut avoir les mains libres afin de pouvoir accomplir le partage du monde, d’étouffer la révolution européenne et ensuite aussi la révolution russe.

À ces deux combinaisons des puissances correspondent deux tendances à l'intérieur des grandes puissances, l'une ultra annexionniste et l'autre modérée, dont la seconde soutient la combinaison Wilson-Lloyd George.

\section{LA «SOCIÉTÉ DES NATIONS »}

Vu les contradictions irréconciliables qui se sont fait jour au sein même de l'Entente, la Société des Nations — même si elle se réalisait sur le papier — ne jouerait cependant que le rôle d'une sainte alliance des capitalistes pour la répression de la révolution ouvrière. La propagation de la « Société des Nations » est le meilleur moyen pour troubler la conscience révolutionnaire de la classe ouvrière. A la place du mot d’ordre d'une Internationale des républiques ouvrières révolutionnaires, on lance celui d'une association internationale de prétendues démocraties, devant être atteinte par une coalition du prolétariat et des classes bourgeoises.

La «Société des Nations » est un mot d’ordre trompeur, au moyen duquel les social-traîtres sur ordre du capital international, divisent les forces prolétariennes et favorisent la contre-révolution impérialiste.

Les prolétaires révolutionnaires de tous les pays du monde doivent mener une lutte implacable contre les idées de la Société des Nations de Wilson et protester contre l'entrée dans cette société de vol, d'exploitation et de contre-révolution impérialiste. 


\section{LA POLITIQUE EXTERIEURE ET INTERIEURE DES PAYS VAINCUS}

L’écrasement militaire et l'effondrement intérieur de l'impérialisme autrichien et allemand ont amené, dans les Etats centraux et pendant la première période de la révolution, la domination du régime bourgeois social-opportuniste. Sous couleur de démocratie et de socialisme les social-traîtres allemands protègent et restaurent la domination économique et la dictature politique de la bourgeoisie. Dans leur politique extérieure ils visent au rétablissement de l'impérialisme allemand en exigeant la restitution des colonies et l'admission de l'Allemagne dans la Société de rapines. A mesure que se renforcent en Allemagne les bandes de gardesblancs et que progresse le processus de décomposition dans le camp de l’Entente, les velléités de la bourgeoisie et des social-traîtres à devenir une grande puissance s'accroissent elles aussi. En même temps le gouvernement bourgeois socialopportuniste mine aussi la solidarité internationale du prolétariat et sépare les ouvriers allemands de ses frères de classe, en accomplissant les ordres contrerévolutionnaires des alliés et surtout en excitant les ouvriers allemands contre la révolution russe prolétarienne pour plaire à l'Entente. La politique de la bourgeoisie et des social-opportunistes en Autriche et en Hongrie est la répétition de la politique du bloc bourgeois opportuniste de l’Allemagne sous une forme atténuée.

\section{LES ÉTATS VASSAUX DE L'ENTENTE}

Dans les Etats vassaux et dans les Républiques que l'Entente vient de créer (Tchécoslovaquie, pays slaves méridionaux ; il faut aussi y compter la Pologne, la Finlande, etc...) la politique de l'Entente, appuyée sur les classes dominantes et les social-nationalistes, vise à créer des centres d'un mouvement national contrerévolutionnaire. Ce mouvement doit être dirigé contre les peuples vaincus, il doit maintenir en équilibre les forces des Etats nouveaux et les assujettir à l'Entente, il doit freiner les mouvements révolutionnaires qui naissent au sein des nouvelles républiques «nationales » et fournir en fin de compte des gardes-blancs pour la lutte contre la révolution internationale et surtout contre la révolution russe. 
En ce qui concerne la Belgique, le Portugal, la Grèce et autres petits pays alliés à l'Entente, leur politique est entièrement déterminée par celle des grands brigands, auxquels ils sont complètement soumis et dont ils sollicitent l'aide pour obtenir des petites annexions et des indemnités de guerre.

\section{LES ÉTATS NEUTRES}

Les Etats neutres sont dans la situation de vassaux non favorisés de l'impérialisme de l'Entente, à l'égard desquels l'Entente emploie, sous une forme atténuée, les mêmes méthodes qu’à l’égard des pays vaincus. Les Etats neutres favorisés formulent différentes revendications aux ennemis de l'Entente (les prétentions du Danemark sur Flensburg, la proposition suisse de l'internationalisation du Rhin, etc...). En même temps, ils exécutent les ordres contre-révolutionnaires de l'Entente (expulsion de l'ambassadeur russe, enrôlement des gardes-blancs dans les pays scandinaves, etc...). D’autres encore sont exposés au danger du démembrement territorial (projet de l'incorporation de la province de Limbourg à la Belgique et de l'internationalisation de l'embouchure de l'Escaut).

\section{L'ENTENTE ET LA RUSSIE SOVIÉTIQUE}

Le caractère rapace anti-humanitaire et réactionnaire de l'impérialisme de l'Entente se manifeste le plus nettement en face de la Russie Soviétique. Dès le début de la Révolution d'octobre les puissances de l'Entente se sont mises du côté des partis et des gouvernements contre-révolutionnaires de la Russie. Avec l'aide des contre-révolutionnaires bourgeois elles ont annexé la Sibérie, l’Oural, les côtes de la Russie d'Europe, le Caucase et une partie du Turkestan. Ils dérobent de ces contrées annexées des matières premières (bois, naphte, manganèse, etc...). Avec l'aide des bandes tchécoslovaques à leurs gages ils ont volé la provision d'or de la Russie. Sous la direction du diplomate anglais Lockhart, des espions anglais et français ont fait sauter des ponts et détruit des chemins de fer et tentèrent de gêner l'approvisionnement en vivres. L'Entente a soutenu, avec des fonds, des armes et par l'aide militaire des généraux réactionnaires Dénikine, Koltchak 
et Krasnov, qui ont fusillé et pendu des milliers d'ouvriers et de paysans à Rostov, Jousovka, Novorossijsk, Omsk, etc... Par les discours de Clemenceau et de Pichon l'Entente proclame ouvertement le principe de «l'encerclement économique », c’est-à-dire qu'on veut vouer à la famine et à la destruction la République des ouvriers et des paysans révolutionnaires ; on y promet un «soutien technique » aux bandes de Dénikine, Koltchak et Krasnov. L'Entente a refusé à différentes reprises les propositions de paix de la puissance soviétique.

Le 23 janvier 1919 les puissances de l'Entente, au sein desquelles les tendances modérées s’étaient momentanément renforcées, a adressé à tous les gouvernements russes la proposition d'envoyer des délégués à l’île des Princes. Cette proposition n'était certainement pas dépourvue d'une intention provocatrice à l'égard du gouvernement soviétique. Bien que le 4 février l'Entente reçut une réponse affirmative du gouvernement soviétique, réponse dans laquelle celui-ci se déclarait même prêt à envisager des annexions, des contributions et des concessions, afin de délivrer les ouvriers et les paysans russes de la guerre qui leur est imposée par l'Entente - celle-ci ne répondit pas plus à cette proposition de paix qu'aux autres.

Cela confirme que les tendances annexionnistes-réactionnaires des impérialistes de l'Entente se fondent sur un terrain solide. Ils menacent la république socialiste de nouvelles annexions et de nouveaux assauts contre-révolutionnaires.

La « politique de paix » de l'Entente dévoile ici définitivement aux yeux du prolétariat international la nature de l'impérialisme de l'Entente et de l’impérialisme en général. Elle prouve en même temps que les gouvernements impérialistes sont incapables de conclure une paix « juste et durable » et que le capital financier est incapable de rétablir l'économie détruite. Le maintien de la domination du capital financier mènerait soit à la destruction complète de la société civilisée ou à l'augmentation de l'exploitation, de l'esclavage, de la réaction politique, des armements et finalement à de nouvelles guerres destructrices. 
Manifestes, thèses et résolutions des quatre premiers congrès de l’Internationale communiste 1919-1923

(juin 1934)

Premier Congrès, mars 1919.

- 10 -

Résolution sur la terreur blanche, Mars 1919.

\section{$\underline{\text { Retour à la table des matières }}$}

Le système capitaliste fut dès son début un système de rapine et d'assassinats massifs. Les horreurs de l'accumulation primitive, la politique coloniale qui, au moyen de la Bible, de la syphilis et de l'alcool, amena l'extermination impitoyable de races et de peuplades entières ; la misère, la famine, l'épuisement et la mort prématurée d’innombrables millions de prolétaires exploités, la répression sanglante de la classe ouvrière lorsqu'elle s’insurgeait contre ses exploiteurs, et enfin la boucherie immense et inouïe qui a transformé la production mondiale en une production de cadavres humains — voilà l'image de l'ordre capitaliste.

Dès le début de la guerre les classes dominantes qui, sur les champs de batailles avaient tué plus de dix millions d’hommes et en avaient estropiés encore bien davantage, ont érigé à l’intérieur de leurs pays aussi le régime de la dictature sanglante. Le gouvernement tsariste russe fusilla et pendit les ouvriers, organisa des pogromes contre les juifs, extermina tout ce qui vivait dans le pays. La monarchie autrichienne étrangla dans le sang l'insurrection des paysans et des ouvriers ukrainiens et tchèques. La bourgeoisie anglaise assassina les meilleurs représentants du peuple irlandais. L’impérialisme allemand fit rage à l'intérieur de son pays et les marins révolutionnaires furent les premières victimes de cette brute. En 
France on abattit les soldats russes qui n’étaient pas prêts à défendre les profits des banquiers français. En Amérique la bourgeoisie lyncha les internationalistes, condamna des centaines parmi les meilleurs prolétaires à vingt ans de travaux forcés, abattit les ouvriers pour faits de grèves.

Lorsque la guerre impérialiste commença à se transformer en guerre civile, et que les classes dominantes, ces malfaiteurs les plus grands que l'histoire du monde ait jamais connus, se trouvèrent menacés du danger immédiat de l'effondrement de leur régime sanglant, leur bestialité devint encore plus cruelle.

Dans sa lutte pour le maintien de l'ordre capitaliste, la bourgeoisie emploie les méthodes les plus inouïes, devant lesquelles palissent toutes les cruautés du moyen-âge, de l'Inquisition et de la colonisation.

La classe bourgeoise, se trouvant au bord de sa tombe, détruit maintenant physiquement la force productive la plus importante de la société humaine - le prolétariat, et s'est démasquée à présent par cette terreur blanche dans toute sa hideuse nudité.

Les généraux russes, cette personnification vivante du régime tsariste. ont tué et tuent encore en masse les ouvriers avec l'appui direct où indirect des socialtraîtres. Durant la domination des socialistes-révolutionnaires et des mencheviks en Russie, des milliers d'ouvriers et de paysans remplissaient les prisons et les généraux exterminaient des régiments entiers pour cause de désobéissance. A présent, les Krasnov et les Dénikine, jouissant de la collaboration bienveillante de l'Entente, ont tué et pendu des dizaines de milliers d’ouvriers, décimé, pour terroriser ceux qui restaient encore, ils laissèrent même pendant trois jours les cadavres pendus à la potence. Dans l'Oural et dans la Volga, les bandes de gardes-blancs tchécoslovaques coupèrent les mains et les jambes des prisonniers, les noyèrent dans la Volga, les firent enterrer vivant. En Sibérie, les généraux abattirent des milliers de communistes, une quantité innombrable d’ouvriers et de paysans.

La bourgeoisie allemande et autrichienne ainsi que les social-traîtres ont bien montré leur nature de cannibales, lorsqu'en Ukraine ils pendirent à des potences transportables en fer, les ouvriers et les paysans qu'ils avaient pillés, ainsi que les communistes, leurs propres compatriotes, nos camarades allemands et autrichiens. En Finlande, pays de la démocratie bourgeoise, ils ont aidé la bourgeoisie finlan- 
daise à fusiller plus de treize à quatorze mille prolétaires et à en torturer à mort plus de quinze mille dans les prisons.

À Helsingfors, ils poussèrent devant eux des femmes et des enfants pour se protéger contre les mitrailleuses. C'est par leur appui que les gardes-blancs finlandais et les aides suédois ont pu se livrer à ces orgies sanglantes contre le prolétariat finlandais vaincu. A Tammerfors on força les femmes condamnées à mort à creuser elles-mêmes leurs tombes, à Viborg on abattit des centaines de femmes, d'hommes et d'enfants finlandais et russes.

À l'intérieur de leur pays, la bourgeoisie et la social-démocratie allemande, par la répression sanglante de l'insurrection ouvrière communiste, par l'assassinat bestial de Liebknecht et de Luxemburg, en tuant et en exterminant les ouvriers spartakistes, ont atteint le degré extrême de la rage réactionnaire. La terreur massive et individuelle des blancs — voilà le drapeau qui guide la bourgeoisie.

Dans d'autres pays c’est le même tableau qui s’offre à nous.

Dans la Suisse démocratique tout est prêt pour l'exécution des ouvriers au cas où ils oseraient violer la loi capitaliste. En Amérique, le bagne, la loi du lynch et la chaise électrique apparaissent comme les symboles choisis de la démocratie et de la liberté.

En Hongrie et en Angleterre, en Bohème et en Pologne — partout la même chose. Les assassins bourgeois ne reculent devant aucune infamie. Pour raffermir leur domination ils déchaînent le chauvinisme et organisent par exemple la démocratie bourgeoise ukrainienne, avec le menchevik Petlyura à sa tête ; celle de Pologne avec le social-patriote Pilsudsky et ainsi de suite ; des pogromes immenses contre les juifs qui dépassent de loin ceux qu’organisaient les policiers du Tsar. Et si la racaille polonaise réactionnaire et «socialiste » a assassiné les représentants de la Croix Rouge russe, ce n'est là qu'une goutte d'eau dans la mer de crimes et d'horreurs du cannibalisme bourgeois décadent.

La «Ligue des Nations » qui, selon les déclarations de ses fondateurs, doit amener la paix, va vers une guerre sanglante contre le prolétariat de tous les pays. Les puissances de l'Entente voulant sauver leur domination, frayant avec des armées de noirs la voie vers une terreur d'une brutalité incroyable. 
En maudissant les assassins capitalistes et leurs aides social-démocrates, le premier Congrès de l'Internationale Communiste appelle les ouvriers de tous les pays à rassembler toutes leurs forces pour mettre définitivement fin au système d'assassinat et de rapine en abattant la puissance du régime capitaliste. 
Manifestes, thèses et résolutions des quatre premiers congrès de l’Internationale communiste 1919-1923

(juin 1934)

Premier Congrès, mars 1919.

- 11 -

Discours du camarade Trotsky Mars 1919.

$\underline{\text { Retour à la table des matières }}$

Le camarade Albert a dit que l'armée rouge est souvent en Allemagne un objet de discussion, et si je l'ai bien compris, elle inquiète aussi MM. Ebert et Scheidemann dans leurs nuits d'insomnie, c'est-à-dire qu'ils craignent l'irruption menaçante de l'Armée rouge en Prusse Orientale. En ce qui concerne l'irruption, le camarade Albert peut bien tranquilliser les maîtres actuels de l'Allemagne : heureusement ou malheureusement - cela dépend du point de vue - nous n’en sommes pas encore là actuellement. En tous cas, en ce qui concerne les invasions qui nous menacent, notre situation est aujourd'hui bien meilleure qu'à l'époque de la paix de Brest-Litovsk. C'est là une chose tout à fait certaine. A cette époque, nous étions encore des enfants quant au développement général du gouvernement soviétique ainsi que de celui de l'Armée rouge. A cette époque, celle-ci s’appelait encore la Garde rouge. Depuis longtemps, cette appellation n'existe plus chez nous. La Garde rouge était composée des premières troupes de partisans, des sections improvisées d’ouvriers révolutionnaires, qui, poussés par leur esprit révolutionnaire, étendirent la Révolution prolétarienne, depuis Pétrograd et Moscou, sur tout le territoire russe. Cette période dura jusqu’à la première rencontre de cette 
Garde rouge avec les régiments allemands réguliers, où l’on vit clairement que ces groupes improvisés n 'étaient pas à même de fournir à la République socialiste révolutionnaire une véritable protection dès qu'il ne s'agissait plus seulement de vaincre la contre-révolution russe, mais de rejeter une armée disciplinée.

Et c'est depuis que commence le revirement dans l'état d'esprit de la classe ouvrière relativement à l'armée, et aussi le changement des méthodes d'organisation de celle-ci. Sous la pression de la situation nous avons procédé à la construction d'une armée bien organisée, ayant une conscience de classe. Car dans notre programme il y a la milice populaire. Mais parler de la milice populaire, de cette revendication politique de la démocratie, dans un pays gouverné par la dictature du prolétariat, est une chose impossible, car l'armée est toujours liée très étroitement au caractère de la puissance qui détient le pouvoir. La guerre, comme disait le vieux Clausewitz, est la continuation de la politique, mais par d'autres moyens. Et l'armée est l'instrument de la guerre et doit correspondre à la politique. Le gouvernement est prolétarien et, dans sa composition sociale, l’armée doit elle aussi correspondre à ce fait.

C'est ainsi que nous avons introduit le cens dans la composition de l'armée. Depuis le mois de mai de l'année dernière, nous sommes passés de l’armée volontaire, de la Garde rouge, à l'armée qui repose sur le service militaire obligatoire, mais nous n’y admettons que les prolétaires, ou les paysans n’exploitant pas de main-d’œuvre extérieure.

Il est impossible de parler sérieusement d'une milice populaire en Russie, lorsqu'on tient compte du fait que nous avions, et que nous avons encore plusieurs armées de classe ennemies sur le territoire de l'ancien empire du tsar. Nous avons même, par exemple, sur le territoire du Don, une armée monarchique, dirigée par des officiers cosaques, composée d'éléments bourgeois et de riches paysans cosaques. Puis nous avions, dans la contrée de la Volga et de l'Oural, l’armée de la Constituante, qui était aussi, selon sa conception, l'armée " populaire », comme on l'appelait. Cette armée s'est dissoute très rapidement. Ces messieurs de la Constituante ont eu le dessous, ils ont quitté le terrain de la démocratie de la Volga et de l'Oural d'une manière tout à fait involontaire et ont cherché chez nous l'hospitalité du gouvernement soviétique. L'amiral Koltchak a simplement mis en état d'arrestation le gouvernement de la Constituante, et l'armée s'est développée en une armée monarchique. Dans un pays qui se trouve en état de guerre civile on 
ne peut donc construire une armée que sur le principe de la classe. C'est bien ce que nous avons fait — et avec succès d'ailleurs.

La question des chefs militaires a soulevé pour nous de grandes difficultés. Evidemment, le premier souci, c’était d'éduquer des officiers rouges, recrutés dans les rangs de la classe ouvrière et parmi les fils de paysans aisés. Dès le début nous avons procédé à ce travail, et même ici, devant la porte de cette salle, vous pouvez voir bien des « sergents » rouges qui, dans peu de temps, entreront comme officiers rouges dans l'armée soviétique. Nous en avons un assez grand nombre. Je ne veux pas donner de chiffre, car un secret de guerre est toujours un secret de guerre. Le nombre - dis-je - en est assez grand, mais nous ne pouvions pas attendre que les jeunes sergents rouges soient devenus généraux rouges, car l'ennemi ne voulait pas nous laisser un aussi long temps de repos. Pour puiser avec succès dans cette réserve et en prendre bien des hommes capables, nous devions nous adresser aussi aux anciens chefs militaires. Nous n’avons évidemment pas cherché nos officiers dans la couche brillante des gens de cour militaires, mais parmi les éléments plus simples nous avons recruté des forces tout à fait capables, qui nous aident maintenant à combattre leurs anciens collègues. D'une part, de bons et loyaux éléments composant l'ancien corps d'officiers, auxquels nous avons adjoint de bons communistes comme commissaires, et d'autre part, les meilleurs éléments parmi les soldats, les ouvriers, les paysans, pour les postes de commandements inférieurs. De cette manière, nous avons composé un corps d'officiers rouge.

Depuis que la République soviétique existe en Russie, elle a toujours été forcée de faire la guerre et elle l'a faite encore aujourd'hui. Nous avons un front de plus de 8000 kilomètres. Au sud et au nord, à l'est et à l'ouest, partout, les armes à la main, on nous combat et nous sommes obligés de nous défendre. Et Kautsky nous a même accusés de cultiver le militarisme. Or, je pense que si nous voulons conserver le pouvoir aux ouvriers, nous devons nous défendre sérieusement. Pour nous défendre, nous devons apprendre aux ouvriers à faire usage des armes qu'ils forgent. Nous avons commencé par désarmer la bourgeoisie et à armer les ouvriers. Si c’est là du militarisme, bien, alors nous avons créé notre militarisme socialiste et nous persévérons fermement en nous appuyant sur lui.

À cet égard, notre situation en août dernier était bien mauvaise ; non seulement nous étions encerclés, mais le cercle contournait d'assez près Moscou. De- 
puis cette époque, nous avons élargi le cercle de plus en plus et, dans les derniers six mois, l’Armée rouge a regagné à l’Union soviétique pas moins de 700000 kilomètres carrés, avec une population d'environ 42 millions d'habitants, 16 gouvernements avec 16 grandes villes dans lesquelles la classe ouvrière avait et a coutume de mener une âpre lutte. Et aujourd'hui encore, si de Moscou vous tirez sur la carte une ligne dans une direction quelconque en la prolongeant, vous trouverez partout un paysan russe, un ouvrier russe au front qui, dans cette nuit froide, se tient avec son fusil à la frontière de la République soviétique pour la défendre.

Et je puis vous assurer que les ouvriers communistes qui forment vraiment le noyau de cette armée se conduisent non seulement comme l'armée de protection de la République socialiste russe, mais aussi comme l’Armée rouge de la 3e Internationale. Et si nous avons aujourd'hui la possibilité de donner l'hospitalité à cette conférence communiste pour remercier pour une fois nos frères de l'Europe occidentale de l'hospitalité qu'ils nous ont donnée pendant des dizaines d'années, nous le devons de notre côté aux efforts et aux sacrifices de l'Armée rouge, dans laquelle les meilleurs camarades de la classe ouvrière communiste agissent comme simples soldats, comme officiers rouges ou comme commissaires, c'est-à-dire comme les représentants directs de notre parti, du gouvernement soviétique, et qui, dans chaque régiment, dans chaque division, donnent le ton politique et moral, c'est-à-dire qui enseignent par leur exemple aux soldats rouges comment on lutte et on meurt pour le socialisme. Chez ces hommes, ce ne sont pas des paroles creuses, car elles sont suivies d'actes, et dans cette lutte nous avons perdu des centaines et des milliers des meilleurs ouvriers socialistes. Je pense qu'ils ne sont pas seulement tombés pour la République soviétique, mais aussi pour la $3^{\mathrm{e}}$ Internationale.

Et si aujourd'hui nous ne pensons même pas à envahir la Prusse Orientale au contraire, nous serions tout à fait heureux si MM. Ebert et Scheidemann nous laissaient en paix - il est cependant exact que, lorsque viendra le moment où les frères d’Occident nous appelleront à leur secours, nous répondrons :

« Nous voici. Pendant ce temps nous avons appris le maniement des armes, nous sommes prêts à lutter et à mourir pour la cause de la Révolution mondiale !» 
Manifestes, thèses et résolutions des quatre premiers congrès de l’Internationale communiste 1919-1923 (juin 1934)

Premier Congrès, mars 1919.

- 12 -

Discours de clôture de Lénine 7 mars 1919.

$\underline{\text { Retour à la table des matières }}$

Ainsi, nous avons terminé notre travail.

Si nous avons pu nous réunir malgré toutes les difficultés et les répressions policières, si nous avons réussi, sans divergences essentielles, à prendre, en un court espace de temps, des décisions importantes sur toutes les questions brûlantes de l'époque révolutionnaire actuelle, c'est parce que les masses prolétariennes du monde entier ont mis toutes ces questions pratiquement à l'ordre du jour par leurs actes et ont commencé à les résoudre en fait.

Nous n’avons eu à résumer ici que ce que les masses ont déjà réussi à conquérir dans leur lutte révolutionnaire.

Le mouvement en faveur des Soviets s'étend toujours plus loin, non seulement dans les pays de l'Europe Orientale mais aussi dans ceux de l'Europe Occidentale, non seulement dans les pays vaincus mais aussi dans les pays victorieux comme l'Angleterre par exemple ; et ce mouvement n'est rien moins qu'un mouvement ayant pour but la création d'une nouvelle démocratie prolétarienne ; il est le 
progrès le plus considérable vers la dictature du prolétariat, vers la victoire complète du communisme.

Que la bourgeoisie du monde entier continue à sévir, qu'elle pourchasse, emprisonne et même assassine spartakistes et bolcheviks, cela ne lui servira de rien. Cela ne pourra qu'éclairer les masses et les déterminer à s'affranchir de leurs vieux préjugés bourgeois démocratiques et à se retremper dans la lutte. La victoire de la révolution prolétarienne est assurée dans le monde entier : la constitution de la République Soviétique Internationale est en marche. 
Manifestes, thèses et résolutions des quatre premiers congrès de l'Internationale communiste 1919-1923

(juin 1934)

Premier Congrès, mars 1919.

- 13 -

\section{Manifeste \\ de l'Internationale Communiste. Aux prolétaires du monde entier ! Mars 1919.}

$\underline{\text { Retour à la table des matières }}$

Il y a soixante-douze ans, le parti communiste présenta au monde son programme sous forme d'un manifeste écrit par les plus grands prophètes de la Révolution prolétarienne, Karl Marx et Friedrich Engels. A cette époque déjà, le communisme, à peine entré dans sa lutte, était accablé sous les poursuites, les mensonges, la haine et les persécutions des classes possédantes qui devinaient justement en lui leur ennemi mortel. Pendant ces trois quarts de siècle, le développement du communisme a suivi des voies complexes, connaissant tour à tour les tempêtes de l'enthousiasme et les périodes de découragement, les succès et les durs échecs. Mais au fond le mouvement suivit la route tracée par le Manifeste du Parti communiste. L'heure de la lutte finale et décisive est arrivée plus tard que ne l'escomptaient et ne l'espéraient les apôtres de la Révolution sociale. Mais elle est arrivée. Nous, communistes, représentants du prolétariat révolutionnaire des différents pays d'Europe, d'Amérique et d'Asie, rassemblés à Moscou, capitale de la Russie soviétique, nous nous sentons les héritiers et les continuateurs de l'œuvre dont le programme a été annoncé il y a soixante-douze ans. 
Notre tâche est de généraliser l'expérience révolutionnaire de la classe ouvrière, de débarrasser le mouvement des mélanges impurs de l'opportunisme et du social-patriotisme, d’unir les forces de tous les partis vraiment révolutionnaires du prolétariat mondial et par là même de faciliter et de hâter la victoire de la Révolution communiste dans le monde entier.

Aujourd'hui que l'Europe est couverte de débris et de ruines fumantes, les plus coupables des incendiaires s'occupent à rechercher les responsables de la guerre. Ils sont suivis de leurs laquais, professeurs, parlementaires, journalistes, social-patriotes et autres soutiens politiques de la bourgeoisie.

Au cours d’une longue série d’années, le socialisme a prédit l’inéluctabilité de la guerre impérialiste ; il en a vu les causes dans le désir insatiable du lucre et de la propriété des classes possédantes des deux concurrents principaux et en général de tous les pays capitalistes. Deux ans avant l'explosion, au congrès de Bâle, les chefs socialistes responsables de tous les pays dénonçaient l’impérialisme comme le fauteur de la guerre future. Ils menaçaient la bourgeoisie de déchaîner sur sa tête la Révolution sociale, vengeance du prolétariat contre les crimes du capitalisme.

Maintenant, après une expérience de cinq ans, alors que l'histoire, ayant mis au jour les appétits rapaces de l'Allemagne, dévoile les agissements non moins criminels des Alliés, les socialistes officiels des pays de l'Entente, à la suite de leurs gouvernements, ne cessent de dénoncer dans le kaiser allemand déchu le grand coupable de la guerre. Bien plus, dans leur abjecte servilité, les socialpatriotes allemands, qui, en août 1914, faisaient du livre blanc diplomatique du Hohenzollern l'évangile sacré des nations, accusent maintenant à leur tour cette monarchie allemande abattue, dont ils furent les fidèles serviteurs, d'être la cause principale de la guerre. Ils espèrent ainsi à la fois oublier le rôle qu'ils ont joué et gagner l'indulgence des vainqueurs. Mais à côté du rôle joué par les dynasties déchues des Romanov, des Hohenzollern, des Habsbourg et des cliques capitalistes de leurs pays, le rôle des classes dirigeantes de France, d'Angleterre, d'Italie et des Etats-Unis apparaît dans toute son ampleur criminelle à la lumière des événements accomplis et des révélations diplomatiques.

Jusqu'à l'explosion même de la guerre, la diplomatie anglaise ne leva point son masque mystérieux. Le gouvernement de la City craignait que s’il déclarait 
catégoriquement son dessein de participer à la guerre aux côtés de l'Entente, le gouvernement de Berlin ne reculât et qu'il n'y eût pas de guerre. C'est pourquoi l'on se conduisit de façon à faire espérer d'une part, à Berlin et à Vienne, la neutralité de l'Angleterre et à permettre, d'autre part, à Paris et à Pétrograd de compter fermement sur l'intervention.

Préparée par la marche de l'histoire pendant plusieurs dizaines d'années, la guerre fut déchaînée par une provocation directe et consciente de la GrandeBretagne. Le gouvernement de ce pays avait fait le calcul de soutenir la Russie et la France exclusivement dans la mesure nécessaire pour les épuiser en épuisant l'Allemagne, son ennemie mortelle. Mais la puissance du système militaire allemand apparut trop dangereuse et imposa une intervention non plus apparente mais réelle de l'Angleterre.

Le rôle de spectateur souriant, auquel la Grande-Bretagne prétendait par tradition, revint aux Etats-Unis. Le gouvernement de Wilson accepta d'autant plus facilement le blocus anglais, qui diminuait les possibilités de spéculation de la Bourse américaine sur le sang européen, que les puissances de l’Entente dédommagèrent, par de gros bénéfices, la bourgeoisie américaine de cette violation du «droit international ». Cependant l'énorme supériorité militaire de l'Allemagne obligea à son tour le gouvernement de Washington à sortir de l'état de neutralité fictive à l'égard de l'Europe. Les Etats-Unis se chargèrent de la mission que l'Angleterre avait remplie dans les guerres passées et qu'elle avait essayé de remplir dans la dernière guerre, par rapport au continent : affaiblir un des camps en se servant de l'autre, et ne se mêler des opérations militaires que dans la mesure indispensable pour s'assurer tous les avantages de la situation. L'enjeu exposé de la loterie américaine n'était pas grand, mais il fut le dernier et par là lui assurait le gain.

Les contradictions du régime capitaliste se révélèrent à l'humanité à la suite de la guerre, sous forme de souffrances physiques : la faim, le froid, les maladies épidémiques et une recrudescence de barbarie. Ainsi est jugée sans appel la vieille querelle académique des socialistes sur la théorie de la paupérisation et du passage progressif du capitalisme au socialisme. Les statisticiens et les pontifes de la théorie de l'arrondissement des angles avaient, pendant des dizaines d'années, recherché dans tous les coins du monde des faits réels ou imaginaires capables de démontrer le progrès du bien-être de certains groupes ou catégories de la classe 
ouvrière. La théorie de la paupérisation des masses était regardée comme enterrée sous les coups de sifflets méprisants des eunuques occupant les tribunes universitaires de la bourgeoisie et des mandarins de l'opportunisme socialiste. Maintenant ce n'est pas seulement la paupérisation sociale, mais un appauvrissement physiologique, biologique, qui se présente à nous dans toute sa réalité hideuse.

La catastrophe de la guerre impérialiste a balayé de fond en comble toutes les conquêtes des batailles syndicalistes et parlementaires. Et pourtant cette guerre est née des tendances internes du capitalisme dans la même mesure que les marchandages économiques ou les compromis parlementaires qu'elle a enterrés dans le sang et dans la boue.

Le capital financier, après avoir précipité l'humanité dans l'abîme de la guerre, a subi lui-même durant cette guerre une modification catastrophique. L'état de dépendance dans lequel était placé le papier-monnaie vis-à-vis du fondement matériel de la production, a été définitivement rompu. Perdant de plus en plus sa valeur de moyen et de régulateur de l'échange des produits dans le régime capitaliste, le papier-monnaie s'est transformé en instrument de réquisition, de conquête et en général d'oppression militaire et économique.

La dépréciation totale des billets de banque marque la crise mortelle générale qui affecte la circulation des produits dans le régime capitaliste. Si la libre concurrence, comme régulateur de la production et de la répartition, fut remplacée dans les champs principaux de l'économie par le système des trusts et des monopoles, plusieurs dizaines d'années avant la guerre, le cours même de la guerre a arraché le rôle régulateur et directeur aux groupements économiques pour le transmettre directement au pouvoir militaire et gouvernemental. La répartition des matières premières, l'exploitation du naphte de Bakou ou de Roumanie, de la houille du Donetz, du froment d'Ukraine, l'utilisation des locomotives, des wagons et des automobiles d'Allemagne, l'approvisionnement en pain et en viande de l'Europe affamée, toutes ces questions fondamentales de la vie économique du monde ne sont plus réglées par la libre concurrence, ni même par des combinaisons de trusts ou de consortiums nationaux et internationaux. Elles sont tombées sous le joug de la tyrannie militaire pour lui servir de sauvegarde désormais. Si l'absolue sujétion du pouvoir politique au capital financier a conduit l'humanité à la boucherie impérialiste, cette boucherie a permis au capital financier non seulement de militari- 
ser jusqu'au bout l'Etat, mais de se militariser lui-même, de sorte qu'il ne peut plus remplir ses fonctions économiques essentielles que par le fer et par le sang.

Les opportunistes qui, avant la guerre, invitaient les ouvriers à modérer leurs revendications sous prétexte de passer lentement au socialisme, qui, pendant la guerre, l'ont obligé à renoncer à la lutte de classes au nom de l'union sacrée et de la défense nationale, exigent du prolétariat un nouveau sacrifice, cette fois afin de triompher des conséquences effroyables de la guerre. Si de tels prêches pouvaient influencer les masses ouvrières, le développement du capital se poursuivrait en sacrifiant de nombreuses générations, avec des formes nouvelles, encore plus concentrées et plus monstrueuses, avec la perspective fatale d'une nouvelle guerre mondiale. Par bonheur pour l’humanité, cela n'est plus possible.

L’étatisation de la vie économique, contre laquelle protestait tant le libéralisme capitaliste, est un fait accompli. Revenir, non point à la libre concurrence, mais seulement à la domination des trusts, syndicats et autres pieuvres capitalistes, est désormais impossible. La question est uniquement de savoir quel sera désormais celui qui prendra la production étatisée : l'Etat impérialiste ou l'Etat du prolétariat victorieux.

En d'autres termes, l'humanité travailleuse tout entière deviendra-t-elle l'esclave tributaire d'une clique mondiale triomphante qui, sous l'enseigne de la Ligue des Nations, au moyen d'une armée « internationale » et d'une flotte « internationale » pillera et étranglera les uns, entretiendra les autres, mais, toujours et partout, enchaînera le prolétariat, dans le but unique de maintenir sa propre domination? Ou bien la classe ouvrière d'Europe et des pays les plus avancés des autres parties du monde s’emparera-t-elle de la vie économique, même désorganisée et détruite, afin d'assurer sa reconstruction sur des bases socialistes?

Abréger l'époque de crise que nous traversons ne se peut que par les méthodes de la dictature du prolétariat, qui ne regarde pas le passé, qui ne compte ni avec les privilèges héréditaires, ni avec le droit de propriété, qui, ne considérant que la nécessité de sauver les masses affamées, mobilise pour cela tous les moyens et toutes les forces, décrète pour tout le monde l'obligation du travail, institue le régime de la discipline ouvrière, afin de ne pas seulement guérir, en quelques années, les plaies béantes faîtes par la guerre, mais encore d'élever l'humanité à une hauteur nouvelle et insoupçonnable. 
L'Etat national, après avoir donné une impulsion vigoureuse au développement capitaliste, est devenu trop étroit pour l'expansion des forces productives. Ce phénomène a rendu plus difficile la situation des petits Etats encastré au milieu des grandes puissances de l'Europe et du Monde. Ces petits Etats, nés à différentes époques comme des fragments des grands, comme la menue monnaie destinée à payer divers tributs, comme des tampons stratégiques, possèdent leurs dynasties, leurs castes dirigeantes, leurs prétentions impérialistes, leurs filouteries diplomatiques. Leur indépendance illusoire a été basée, jusqu’à la guerre, exactement comme était basé l'équilibre européen sur l'antagonisme des deux camps impérialistes. La guerre a détruit cet équilibre. En donnant d'abord un immense avantage à l'Allemagne, la guerre a obligé les petits Etats à chercher leur salut dans la magnanimité du militarisme allemand. L'Allemagne ayant été vaincue, la bourgeoisie des petits Etats, de concert avec leurs « socialistes » patriotes, s'est retournée pour saluer l'impérialisme triomphant des Alliés, et dans les articles hypocrites du programme de Wilson elle s'est employée à rechercher les garanties du maintien de son existence indépendante. En même temps, le nombre des petits Etats s'est accru : de la monarchie austro-hongroise, de l'empire des tsars se sont détachés de nouveaux Etats qui, aussitôt nés, se saisissent déjà les uns les autres à la gorge pour des question de frontière. Les impérialistes Alliés, pendant ce temps, préparent des combinaisons de petites puissances, anciennes et nouvelles, afin de les enchaîner les unes les autres par une haine mutuelle et une faiblesse générale.

Écrasant et violentant les peuples petits et faibles, les condamnant à la famine et à l'abaissement, de même que, peu de temps auparavant, les impérialistes des empires centraux, les impérialistes alliés ne cessent de parler du droit des nationalités, droits qu'ils foulent aux pieds en Europe et dans le monde entier.

Seule, la Révolution prolétarienne peut garantir aux petits peuples une existence libre, car elle libérera les forces productives de tous les pays des tenailles serrées par les Etats nationaux, en unissant les peuples dans une étroite collaboration économique, conformément à un plan économique commun. Seule, elle don- 
nera aux peuples les plus faibles et les moins nombreux la possibilité d'administrer, avec une liberté et une indépendance absolues, leur culture nationale sans porter le moindre dommage à la vie économique unifiée et centralisée de l'Europe et du monde.

La dernière guerre, qui a été dans une large mesure une guerre pour la conquête des colonies, fut en même temps une guerre faite avec l'aide des colonies. Dans des proportions jusqu'alors inconnues les peuples coloniaux ont été entraînés dans la guerre européenne. Les Hindous, les Nègres, les Arabes, les Malgaches se sont battus sur la terre d'Europe, au nom de quoi ? Au nom de leurs droits à demeurer plus longtemps esclaves de l'Angleterre et de la France. Jamais encore le spectacle de la malhonnêteté de l'Etat capitaliste dans les colonies n’avait été aussi édifiant ; jamais le problème de l'esclavage colonial n’avait été posé avec une pareille acuité.

De là une série de révoltes ou de mouvements révolutionnaires dans toutes les colonies. En Europe même, l’Irlande a rappelé par de sanglants combats de rues qu'elle était encore et qu'elle avait conscience d'être un pays asservi. A Madagascar, en Annam, en d'autres lieux, les troupes de la république bourgeoise ont eu plus d'une fois, au cours de la guerre. à mater des insurrections d'esclaves coloniaux. Dans l’Inde, le mouvement révolutionnaire n'a pas cessé un seul jour. Il a abouti en ces derniers temps à des grèves ouvrières grandioses, auxquelles le gouvernement britannique a répondu en faisant intervenir à Bombay les automobiles blindées.

Ainsi la question coloniale est posée dans toute son ampleur non seulement sur le tapis vert du congrès des diplomates à Paris, mais dans les colonies mêmes. Le programme de Wilson a pour but, dans l'interprétation la plus favorable, de changer l'étiquette de l'esclavage colonial. L'affranchissement des colonies n'est concevable que s'il s'accomplit en même temps que celui de la classe ouvrière des métropoles. Les ouvriers et les paysans non seulement de l'Annam, d'Algérie ou du Bengale, mais encore de Perse et d'Arménie, ne pourront jouir d'une existence indépendante que le jour où les ouvriers d'Angleterre et de France, après avoir renversé Lloyd George et Clemenceau, prendront entre leurs mains le pouvoir gouvernemental. Dès à présent, dans les colonies les plus développées, la lutte n’est plus engagée seulement sous le seul étendard de l'affranchissement national, elle prend de suite un caractère social plus ou moins nettement accusé. 
Si l’Europe capitaliste a entraîné malgré elles les parties les plus arriérées du monde dans le tourbillon des relations capitalistes, l'Europe socialiste à son tour viendra secourir les colonies libérées avec sa technique, son organisation, son influence morale, afin de hâter leur passage à la vie économique régulièrement organisée par le socialisme.

Esclaves coloniaux d'Afrique et d'Asie : l'heure de la dictature prolétarienne en Europe sonnera pour vous comme l’heure de votre délivrance.

Le monde bourgeois tout entier accuse les communistes d'anéantir la liberté et la démocratie politique. Cela est faux. En prenant le pouvoir, le prolétariat ne fait que manifester la complète impossibilité d’appliquer les méthodes de la démocratie bourgeoise et créer les conditions et les formes d'une démocratie ouvrière nouvelle, et plus élevée. Tout le cours du développement capitaliste, en particulier dans la dernière époque impérialiste, a sapé les bases de la démocratie politique, non seulement en divisant les nations en deux classes ennemies irréconciliables, mais encore en condamnant au dépérissement économique et à l’impuissance politique de multiples couches de la petite bourgeoisie et du prolétariat au même titre que les éléments les plus déshérités de ce même prolétariat.

La classe ouvrière des pays où le développement historique l'a permis a utilisé le régime de la démocratie politique pour son organisation contre le capital. Il en sera de même à l'avenir dans les pays où ne sont pas encore réalisées les conditions préliminaires d'une révolution ouvrière Mais les masses de la population intermédiaire, non seulement dans les villages, mais encore dans les villes, sont maintenues par le capitalisme loin en arrière, en retard de plusieurs époques sur le développement historique.

Le paysan de Bavière ou de Bade, encore étroitement attaché au clocher de son village, le petit vigneron français ruiné par la falsification des vins des gros capitalistes, le petit fermier américain obéré et trompé par les banquiers et les députés, toutes ces couches sociales, rejetées par le capitalisme loin de la grande route du développement historique, sont conviées sur le papier par le régime de la démocratie politique à participer au gouvernement de l'Etat. En réalité, dans les questions fondamentales dont dépend la destinée des nations, c’est une oligarchie 
financière qui gouverne dans les coulisses de la démocratie parlementaire. Il en fut ainsi naguère dans la question de la guerre. Il en est ainsi maintenant dans la question de la paix.

Dans la mesure où l'oligarchie financière se donne encore la peine de faire sanctionner ses actes de tyrannie par des votes parlementaires, l'Etat bourgeois se sert, pour atteindre les résultats désirés, de toutes les armes du mensonge, de la démagogie, de la persécution, de la calomnie, de la corruption, de la terreur, que les siècles passés d'esclavage ont mises à sa disposition et qu'ont multipliées les prodiges de la technique capitaliste.

Exiger du prolétariat que dans sa dernière lutte à mort contre le capital il observe pieusement les principes de la démocratie politique, cela équivaudrait à exiger d'un homme qui défend son existence et sa vie contre des brigands qu'il observe les règles artificielles et conventionnelles de la boxe française, instituées par son ennemi et que son ennemi ne s'en serve pas.

Dans le domaine de la dévastation, où non seulement les moyens de production et de transport, mais encore les institutions de la démocratie politique ne sont plus qu'un amas de débris ensanglantés, le prolétariat est obligé de créer un appareil à lui, qui serve avant tout à conserver la cohésion interne de la classe ouvrière elle-même et qui lui donne la faculté d'intervenir révolutionnairement dans le développement ultérieur de l’humanité. Cet appareil, ce sont les Soviets.

Les anciens partis, les anciennes organisations syndicales se sont manifestés en la personne de leurs chefs, incapables non seulement de décider, mais même de comprendre les problèmes posés par l'époque nouvelle. Le prolétariat a créé un nouveau type d'organisation large, englobant les masses ouvrières indépendamment de la profession et du degré de développement politique, un appareil souple, capable d'un perpétuel renouvellement, d'un perpétuel élargissement, pouvant toujours entraîner dans son orbe des catégories nouvelles et embrasser les couches des travailleurs voisines du prolétariat de la ville et de la campagne. Cette organisation irremplaçable de la classe ouvrière se gouvernant elle-même, luttant et conquérant finalement le pouvoir politique, a été mise dans différents pays à l'épreuve de l'expérience ; elle constitue la conquête et l'arme la plus puissante du prolétariat de notre époque. 
Dans tous les pays où les masses travailleuses vivent d'une vie consciente se forment aujourd'hui et se formeront des Soviets de députés ouvriers, soldats et paysans. Fortifier les Soviets, élever leur autorité, les opposer à l'appareil gouvernemental de la bourgeoisie, voilà quel est maintenant le but essentiel des ouvriers conscients et loyaux de tous les pays. Par le moyen des Soviets, la classe ouvrière peut échapper aux éléments de dissolution qui portent dans son sein les souffrances infernales de la guerre, de la famine, de la tyrannie des riches avec la trahison de ses anciens chefs. Par le moyen des Soviets, la classe ouvrière, de la manière la plus sûre et la plus facile, peut parvenir au pouvoir dans tous les pays où les Soviets réuniront autour d'eux la majorité des travailleurs. Par le moyen des Soviets, la classe ouvrière, maîtresse du pouvoir, gouvernera tous les domaines de la vie économique et morale du pays, comme cela se passe déjà en Russie.

La débâcle de l'Etat impérialiste, depuis ses formes tsaristes jusqu'aux plus démocratiques, va de pair avec la débâcle du système militaire impérialiste. Les armées de plusieurs millions d’hommes mobilisés par l’impérialisme n’ont pu tenir qu'aussi longtemps que le prolétariat acceptait le joug de la bourgeoisie. La destruction de l'unité nationale signifie la destruction inévitable des armées. C'est ce qui arriva d'abord en Russie, puis en Allemagne et en Autriche. C'est encore ce qu'il faut attendre dans les autres pays impérialistes. La révolte du paysan contre le propriétaire, de l'ouvrier contre le capitaliste, de tous les deux contre la bureaucratie monarchiste ou «démocratique » entraîne inévitablement la révolte des soldats contre les officiers, et ensuite une scission caractérisée entre les éléments prolétaires et bourgeois de l'armée elle-même, La guerre impérialiste opposant les nations aux nations s'est changée et se change de plus en plus en guerre civile opposant les classes aux classes.

Les lamentations du monde bourgeois sur la guerre civile et la terreur rouge constituent la plus monstrueuse hypocrisie qu'ait jamais enregistrée l'histoire des luttes politiques. Il n’y aurait pas de guerre civile si les coteries d'exploiteurs qui ont conduit l'humanité au bord de l'abîme ne s'opposaient pas à toute progression des travailleurs, n'organisaient pas des complots et des meurtres et ne sollicitaient pas le secours armé de l'étranger pour conserver ou restaurer leurs privilèges usurpés.

La guerre civile est imposée à la classe ouvrière par ses ennemis mortels. Si elle ne veut pas se suicider et renoncer à son avenir qui est l'avenir de toute 
l'humanité, la classe ouvrière ne peut pas éviter de répondre par des coups aux coups de ses agresseurs. Les partis communistes ne suscitent jamais artificiellement la guerre civile, s'efforcent d'en diminuer autant que possible la durée toutes les fois qu'elle surgit comme une nécessité inéluctable, de réduire au minimum le nombre des victimes, mais par-dessus tout d'assurer le triomphe du prolétariat. De là découle la nécessité de désarmer à temps la bourgeoisie, d'armer les ouvriers, de créer une armée communiste pour défendre le pouvoir du prolétariat et l'inviolabilité de sa construction socialiste. Telle est l'armée rouge de la Russie soviétique qui a surgi et qui s'élève comme le rempart des conquêtes de la classe ouvrière contre toutes les attaques du dedans et du dehors, Une armée soviétique est inséparable d'un Etat soviétique.

Conscients du caractère universel de leur cause, les ouvriers les plus avancés ont tendu, dès les premiers pas du mouvement socialiste organisé, vers une union internationale de ce mouvement. Les bases en furent posées en 1864 à Londres, par la première Internationale. La guerre franco-allemande, dont est née l'Allemagne des Hohenzollern, faucha la première Internationale et en même temps donna des partis ouvriers nationaux. Dès 1889, ces partis se réunissaient en Congrès à Paris et créaient l'organisation de la 2e Internationale. Mais le centre de gravité du mouvement ouvrier était placé entièrement à cette époque sur le terrain national dans le cadre des Etats nationaux, sur la base de l'industrie nationale, dans le domaine du parlementarisme national. Plusieurs dizaines d'années de travail, d'organisation et de réformes ont créé une génération de chefs dont la majorité acceptaient en paroles le programme de la révolution sociale, mais y ont renoncé en fait, se sont enfoncés dans le réformisme, dans une adaptation servile à la domination bourgeoise. Le caractère opportuniste des partis dirigeants de la $2^{\mathrm{e}}$ Internationale s'est clairement révélé et a conduit au plus immense krach de l'histoire mondiale au moment précis où le cours des événements historiques réclamait des partis de la classe ouvrière des méthodes révolutionnaires de lutte. Si la guerre de 1870 porta un coup à la Première Internationale en découvrant que derrière son programme social et révolutionnaire il n'y avait encore aucune force organisée des masses, la guerre de 1914 a tué la Deuxième Internationale en montrant qu'au-dessus des organisations puissantes des masses ouvrières se tiennent des partis devenus les instruments dociles de la domination bourgeoise. 
Ces remarques ne s'appliquent pas seulement aux social-patriotes qui sont passés nettement et ouvertement dans le camp de la bourgeoisie, qui sont devenus ses délégués préférés et ses agents de confiance, les bourreaux les plu sûrs de la classe ouvrière ; elles s’appliquent encore à la tendance centriste, indéterminée et inconsciente, qui tente de restaurer la $2^{\mathrm{e}}$ Internationale, c'est-à-dire de perpétuer l'étroitesse de vues, l’opportunisme, l'impuissance révolutionnaire de ses cercles dirigeants. Le parti indépendant en Allemagne, la majorité actuelle du parti socialiste en France, le parti ouvrier indépendant d'Angleterre et tous les autres groupes semblables essayent en fait de prendre la place qu'occupaient avant la guerre les anciens partis officiels de la 2e Internationale. Ils se présentent comme autrefois avec des idées de compromis et d'unité, paralysant par tous les moyens l'énergie du prolétariat, prolongeant la crise et multipliant par là les malheurs de l'Europe. La lutte contre le centre socialiste est la conclusion indispensable du succès de la lutte contre l’impérialisme.

Rejetant loin de nous toutes les demi-mesures, les mensonges et la paresse des partis socialistes officiels caducs, nous, communistes, unis dans la 3e Internationale, nous nous reconnaissons les continuateurs directs des efforts et du martyre héroïque acceptés par une longue série de générations révolutionnaires, depuis Babeuf jusqu’à Karl Liebknecht et Rosa Luxemburg.

Si la première Internationale a prévu le développement à venir et a préparé les voies, si la deuxième Internationale a rassemblé et organisé des millions de prolétaires, la troisième Internationale est l'Internationale de l'action des masses, l’internationale de la réalisation révolutionnaire.

La critique socialiste a suffisamment flagellé l'ordre bourgeois. La tâche du parti communiste international est de renverser cet ordre de choses et d'édifier à sa place le régime socialiste. Nous demandons aux ouvriers et ouvrières de tous les pays de s'unir sous l'étendard du communisme qui est déjà le drapeau des premières grandes victoires prolétariennes de tous les pays. Dans la lutte contre la barbarie impérialiste, contre la monarchie et les classes privilégiées, contre l'Etat bourgeois et la propriété bourgeoise, contre tous les aspects et toutes les formes de l’oppression des classes ou des nations, unissez-vous ! 
Sous le drapeau des Soviets ouvriers, de la lutte révolutionnaire pour le pouvoir et la dictature du prolétariat, sous le drapeau de la $3^{\mathrm{e}}$ Internationale, prolétaires de tous les pays, unissez-vous! 
Manifestes, thèses et résolutions

des quatre premiers congrès de

l'Internationale communiste 1919-1923

(juin 1934)

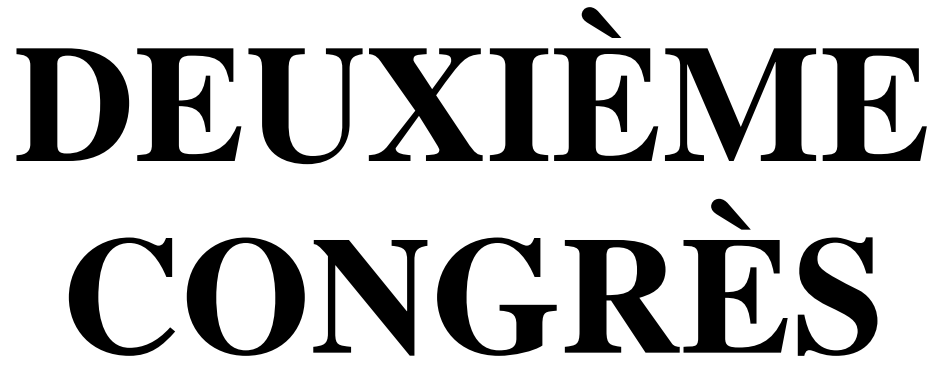

Juillet 1920 


\section{Manifestes, thèses et résolutions \\ des quatre premiers congrès \\ de l’Internationale communiste 1919-1923 \\ (juin 1934) \\ Deuxième Congrès, juillet 1920. \\ - 1 - \\ Statuts de l'Internationale \\ Communiste}

$\underline{\text { Retour à la table des matières }}$

En 1864, fut fondée, à Londres, la première Association Internationale des Travailleurs: la Première Internationale. Les statuts de cette Association portaient :

Considérant :

Que l'émancipation de la classe ouvrière doit être obtenue par la classe ouvrière seule ;

Que la lutte pour cette émancipation ne signifie aucunement une lutte pour la création de nouveaux privilèges de classe et de monopoles, mais pour l'établissement de l'égalité des droits et des devoirs et pour la suppression de toute domination de classe ;

Que la soumission économique de l'homme au travail sous le régime des possesseurs des moyens de production (c'est-à-dire de toutes les sources de la vie) et l'esclavage sous toutes ses formes, sont les causes principales de la misère sociale, de la dégradation morale et de la dépendance politique ; 
Que l'émancipation économique de la classe ouvrière est partout le but essentiel auquel tout mouvement politique doit être subordonné comme moyen ;

Que tous les efforts en vue d'atteindre ce grand but ont échoué par suite de manque de solidarité entre les travailleurs des différentes branches du travail dans chaque pays et d'alliance fraternelle entre les travailleurs des pays différents ;

Que l'émancipation n'est point un problème local ou national, mais un problème social embrassant tous les pays où le régime social moderne existe, et dont la solution dépend de la collaboration théorique et pratique des pays les plus avancés ; que la rénovation actuelle simultanée du mouvement ouvrier dans les pays industriels de l'Europe éveille en nous d'un côté de nouveaux espoirs, mais de l'autre, nous donne un avertissement solennel de ne pas retomber dans les anciennes erreurs, et nous appelle à la coordination immédiate du mouvement qui jusqu’à présent n’avait point de cohérence. »

La $2^{\mathrm{e}}$ Internationale, fondée en 1889, à Paris, s’était engagée à continuer l'œuvre de la Première Internationale. Mais en 1914, au début de la guerre mondiale, elle a subi un krach complet. La $2^{\mathrm{e}}$ Internationale a péri, minée par l’opportunisme et terrassée par la trahison de ses chefs, passés dans le camp de la bourgeoisie.

La $3^{\mathrm{e}}$ Internationale Communiste, fondée en mars 1919, dans la capitale de la République Socialiste Fédérative des Soviets, à Moscou, a déclaré solennellement à la face du monde qu'elle se chargeait de poursuivre et d'achever la grande œuvre entreprise par la Première Internationale des Travailleurs.

La $3^{\mathrm{e}}$ Internationale Communiste s’est constituée à la fin du carnage impérialiste de 1914-1918, au cours duquel la bourgeoisie des différents pays a sacrifié 20 millions de vies.

Souviens-toi de la guerre impérialiste! Voilà la première parole que l'Internationale Communiste adresse à chaque travailleur, quelles que soient son origine et la langue qu'il parle. Souviens-toi que, du fait de l'existence du régime capitaliste, une poignée d’impérialistes a eu, pendant quatre longues années, la possibilité de contraindre les travailleurs de partout à s’entr'égorger ! Souviens-toi que la guerre bourgeoise a plongé l'Europe et le monde entier dans la famine et le dénuement ! Souviens-toi que sans le renversement du capitalisme, la répétition de ces guerres criminelles est non seulement possible, mais inévitable ! 
L'Internationale Communiste se donne pour but la lutte armée pour le renversement de la bourgeoisie internationale, et la création de la république internationale des soviets, première étape dans la voie de la suppression complète de tout régime gouvernemental. L'Internationale Communiste considère la dictature du prolétariat comme l'unique moyen disponible pour arracher l'humanité aux horreurs du capitalisme. Et l'Internationale Communiste considère le pouvoir des Soviets comme la forme de dictature du prolétariat qu'impose l'histoire.

La guerre impérialiste a créé un lien particulièrement étroit entre les destinées des travailleurs d'un pays et celles du prolétariat de tous les autres pays.

La guerre impérialiste a confirmé une fois de plus la véracité de ce qu'on pouvait lire dans les statuts de la Première Internationale : l'émancipation des travailleurs n'est pas une tâche locale, ni nationale, mais bien une tâche sociale et internationale.

L'Internationale Communiste rompt pour tout jamais avec la tradition de la $2^{\mathrm{e}}$ Internationale pour laquelle n'existaient en fait que les peuples de race blanche. L'Internationale Communiste fraternise avec les hommes de race blanche, jaune, noire, les travailleurs de toute la terre.

L'Internationale Communiste soutient, intégralement et sans réserves, les conquêtes de la grande révolution prolétarienne en Russie, de la première révolution socialiste, dans l'histoire, qui ait été victorieuse et invite les prolétaires du monde à marcher dans la même voie. L'Internationale Communiste s'engage à soutenir par tous les moyens qui seront en son pouvoir toute république socialiste qui serait créée en quelque lieu que ce soit.

L'Internationale Communiste n'ignore pas que, pour hâter la victoire, l'Association Internationale des Travailleurs, qui combat pour l'abolition du capitalisme et l'instauration du communisme, doit avoir une organisation fortement centralisée. Le mécanisme organisé de l'Internationale Communiste doit assurer aux travailleurs de chaque pays la possibilité de recevoir, à tout moment, de la part des travailleurs organisés des autres pays, tout le secours possible.

Tout cela considéré, l'Internationale Communiste adopte les statuts que voici : 
Art. 1. - La Nouvelle Association Internationale des Travailleurs est fondée dans le but d'organiser une action d'ensemble du prolétariat des différents pays, tendant à une seule et même fin, à savoir: le renversement du capitalisme, l'établissement de la dictature du prolétariat et d'une république internationale des soviets qui permettront d'abolir totalement les classes et de réaliser le socialisme, premier degré de la société communiste.

Art. 2. - La Nouvelle Association Internationale des Travailleurs adopte le titre d'Internationale Communiste.

Art. 3. - Tout les partis et organisations affiliés à l'Internationale Communiste portent le nom de Parti Communiste de tel ou tel pays (section de l’Internationale Communiste).

Art. 4. - L'instance suprême de l'Internationale Communiste n'est autre que le Congrès mondial de tous les partis et organisations qui y sont affiliés. Le Congrès mondial sanctionne les programmes des différents partis qui adhèrent à l'Internationale Communiste. Il examine et résout les questions essentielles de programme et de tactique ayant trait à l'activité de l'Internationale Communiste. Le nombre de voix délibératives qui, dans le Congrès mondial, appartiendront à chaque parti ou organisation, sera fixé par une décision spéciale du Congrès ; il est, en outre, indispensable de s'efforcer de fixer, le plus tôt possible, les normes de représentation, en se basant sur le nombre effectif des membres de chaque organisation, et en tenant compte de l’influence réelle du Parti.

Art. 5. - Le Congrès international élit un Comité Exécutif de l’Internationale Communiste, qui devient l'instance suprême de l'Internationale Communiste durant les intervalles qui séparent les sessions du Congrès mondial.

Art. 6. - Le siège du Comité Exécutif de l’Internationale Communiste est désigné, à chaque nouvelle session, par le Congrès mondial.

Art. 7. - Un Congrès mondial extraordinaire de l'Internationale Communiste peut être convoqué soit par décision du Comité Exécutif soit sur la demande de la moitié du nombre total des Partis affiliés lors du dernier Congrès mondial. 
Art. 8. - Le travail principal et la grande responsabilité, au sein du Comité Exécutif de l'Internationale Communiste incombent principalement au Parti Communiste du pays où le Congrès mondial a fixé le siège du Comité Exécutif. Le Parti Communiste de ce pays fait entrer dans le Comité Exécutif au moins cinq représentants ayant voix délibérative. Outre cela, chacun des 12 partis communistes les plus importants fait entrer dans le Comité Exécutif un représentant, avec voix délibérative. La liste de ces partis est sanctionnée par le Congrès mondial. Les autres partis ou organisations ont le droit de déléguer auprès du Comité des représentants (à raison d’un par organisation) avec voix consultative.

Art. 9. - Le Comité Exécutif de l'Internationale Communiste dirige dans l'intervalle qui sépare les sessions des Congrès, tous les travaux de l'Internationale Communiste, publie, en quatre langues au moins, un organe central (la revue : l'Internationale Communiste), publie les manifestes qu'il juge indispensables au nom de l'Internationale Communiste et donne à tous les Partis et organisations affiliés des instructions qui ont force de loi. Le Comité Exécutif de l'Internationale Communiste a le droit d'exiger des Partis affiliés que soient exclus tels groupes ou tels individus qui auraient enfreint la discipline prolétarienne; il peut exiger l'exclusion des Partis qui auraient violé les décisions du Congrès mondial. Ces Partis ont le droit d'en appeler au Congrès mondial. En cas de nécessité le Comité Exécutif organise, dans différents pays, des bureaux auxiliaires techniques et autres qui lui sont entièrement subordonnés.

Art. 10. - Le Comité Exécutif de l'Internationale Communiste a le droit de coopter, en leur accordant voix consultative, les représentants des organisations et des Partis non admis dans l'Internationale Communiste, mais sympathisant avec le communisme.

Art. 11. - Les organes de la presse de tous les Partis et organisations affiliés à l'Internationale Communiste, ou sympathisant avec elle, doivent publier tous les documents officiels de l'Internationale Communiste et de son Comité Exécutif.

Art. 12. - La situation générale en Europe et en Amérique impose aux communistes l'obligation de créer, parallèlement à leurs organisations légales, des organisations secrètes. Le Comité Exécutif de l'Internationale Communiste a le devoir de veiller à l'observation de cet article des Statuts. 
Art. 13. - Il est de règle que toutes les relations politiques présentant une certaine importance entre les différents Partis affiliés à l'Internationale Communiste aient pour intermédiaire le Comité Exécutif de l'Internationale Communiste. En cas de nécessité urgente, ces relations peuvent être directes à la condition que le Comité Exécutif de l’Internationale Communiste en soit informé.

Art. 14. - Les Syndicats qui se placent sur le terrain du communisme et qui forment des groupes internationaux sous le contrôle du Comité Exécutif de l'Internationale Communiste, constituent une section syndicale de l'Internationale Communiste. Les Syndicats communistes envoient leurs représentants au Congrès mondial de l'Internationale Communiste, par l'intermédiaire du Parti Communiste de leur pays. La section syndicale de l'Internationale Communiste délègue un de ses membres auprès du Comité Exécutif de l'Internationale Communiste, où il a voix délibérative. Le Comité Exécutif a le droit de déléguer, auprès de la section syndicale de l'Internationale Communiste, un représentant qui a voix délibérative.

Art. 15. - L'Union Internationale de la Jeunesse Communiste est subordonnée à l'Internationale Communiste et à son Comité Exécutif. Elle délègue un représentant de son Comité Exécutif au Comité Exécutif de l'Internationale Communiste, où il a voix délibérative. Le Comité Exécutif de l’Internationale Communiste a la faculté de déléguer auprès du Comité Exécutif de l’Union de la Jeunesse, un représentant, qui a voix délibérative. Les rapports mutuels qui existent entre l'Union de la Jeunesse et le Parti Communiste, en tant qu'organisations, dans chaque pays, sont basés sur le même principe.

Art. 16. - Le Comité Exécutif de l'Internationale Communiste sanctionne la nomination d'un secrétaire du mouvement féminin international et organise une section des Femmes Communistes de l'Internationale.

Art. 17. - Tout membre de l'Internationale Communiste qui se rend d'un pays à un autre, y est fraternellement accueilli par les membres de la $3^{\mathrm{e}}$ Internationale. 
Manifestes, thèses et résolutions des quatre premiers congrès

de l'Internationale communiste 1919-1923

(juin 1934)

Deuxième Congrès, juillet 1920.

- 2 -

Conditions d'admission des partis dans l'Internationale Communiste

\section{$\underline{\text { Retour à la table des matières }}$}

Le premier Congrès constituant de l'Internationale Communiste n'a pas élaboré les conditions précises de l'admission des Partis dans la $3^{\mathrm{e}}$ Internationale. Au moment où eut lieu son premier Congrès, il n’y avait dans la plupart des pays que des tendances et des groupes communistes.

Le deuxième Congrès de l'Internationale Communiste se réunit dans de tout autres conditions. Dans la plupart des pays il y a désormais, au lieu des tendances et des groupes, des Partis et des organisations communistes.

De plus en plus souvent, des Partis et des groupes qui, récemment encore, appartenaient à la $2^{\mathrm{e}}$ Internationale et qui voudraient maintenant adhérer à l'Internationale Communiste s'adressent à elle, sans pour cela être devenus véritablement communistes. La $2^{\mathrm{e}}$ Internationale est irrémédiablement défaite. Les Partis intermédiaires et les groupes du « centre » voyant leur situation désespérée, s'efforcent de s'appuyer sur l'Internationale Communiste, tous les jours plus forte, en espérant conserver cependant une «autonomie » qui leur permettrait de poursuivre leur ancienne politique opportuniste ou « centriste ». L'Internationale Communiste est, d'une certaine façon, à la mode. 
Le désir de certains groupes dirigeants du « centre » d'adhérer à la $3^{\mathrm{e}}$ Internationale nous confirme indirectement que l'Internationale Communiste a conquis les sympathies de la grande majorité des travailleurs conscients du monde entier et constitue une puissance qui croît de jour en jour.

L'Internationale Communiste est menacée de l'envahissement de groupes indécis et hésitants qui n’ont pas encore pu rompre avec l'idéologie de la 2e Internationale.

En outre, certains Partis importants (italien, suédois), dont la majorité se place au point de vue communiste, conservent encore en leur sein de nombreux éléments réformistes et social-pacifistes qui n'attendent que l'occasion pour relever la tête, saboter activement la révolution prolétarienne, en venant ainsi en aide à la bourgeoisie et à la $2^{\mathrm{e}}$ Internationale.

Aucun communiste ne doit oublier les leçons de la République des soviets hongroise. L'union des communistes hongrois avec les réformistes a coûté cher au prolétariat hongrois.

C'est pourquoi le $2^{\mathrm{e}}$ Congrès international croit devoir fixer de façon tout à fait précise les conditions d'admission des nouveaux Partis et indiquer par la même occasion aux Partis déjà affiliés les obligations qui leur incombent.

Le $2^{\mathrm{e}}$ Congrès de l'Internationale Communiste décide que les conditions d'admission dans l'Internationale sont les suivantes :

1. La propagande et l'agitation quotidiennes doivent avoir un caractère effectivement communiste et se conformer au programme et aux décisions de la $3^{\mathrm{e}}$ Internationale. Tous les organes de la presse du Parti doivent être rédigés par des communistes sûrs, ayant prouvé leur dévouement à la cause du prolétariat. Il ne convient pas de parler de dictature prolétarienne comme d'une formule apprise et courante ; la propagande doit être faite de manière à ce que la nécessité en ressorte pour tout travailleur, pour toute ouvrière, pour tout soldat, pour tout paysan, des faits mêmes de la vie quotidienne, systématiquement notés par notre presse. La presse périodique ou autre et tous les services d'éditions doivent être entièrement soumis au Comité Central du Parti, que ce dernier soit légal ou illégal. Il est inadmissible que les organes de publicité mésusent de l'autonomie pour mener 
une politique non conforme à celle du Parti. Dans les colonnes de la presse, dans les réunions publiques, dans les syndicats, dans les coopératives, partout où les partisans de la $3^{\mathrm{e}}$ Internationale auront accès, ils auront à flétrir systématiquement et impitoyablement non seulement la bourgeoisie, mais aussi ses complices, réformistes de toutes nuances.

2. Toute organisation désireuse d'adhérer à l'Internationale Communiste doit régulièrement et systématiquement écarter des postes impliquant tant soit peu de responsabilité dans le mouvement ouvrier (organisations de Parti, rédactions, syndicats, fractions parlementaires, coopératives, municipalités) les réformistes et les « centristes » et les remplacer par des communistes éprouvés, - sans craindre d'avoir à remplacer, surtout au début, des militants expérimentés, par des travailleurs sortis du rang.

3. Dans presque tous les pays de l'Europe et de l'Amérique la lutte de classes entre dans la période de guerre civile. Les communistes ne peuvent, dans ces conditions, se fier à la légalité bourgeoise. Il est de leur devoir de créer partout, parallèlement à l'organisation légale, un organisme clandestin, capable de remplir au moment décisif, son devoir envers la révolution. Dans tous les pays où, par suite de l'état de siège ou de lois d'exception, les communistes n'ont pas la possibilité de développer légalement toute leur action, la concomitance de l'action légale et de l’action illégale est indubitablement nécessaire.

4. Le devoir de propager les idées communistes implique la nécessité absolue de mener une propagande et une agitation systématique et persévérante parmi les troupes. Là, où la propagande ouverte est difficile par suite de lois d'exception, elle doit être menée illégalement ; s’y refuser serait une trahison à l'égard du devoir révolutionnaire et par conséquent incompatible avec l'affiliation à la $3^{\mathrm{e}}$ internationale.

5. Une agitation rationnelle et systématique dans les campagnes est nécessaire. La classe ouvrière ne peut vaincre si elle n'est pas soutenue tout au moins par une partie des travailleurs des campagnes (journaliers agricoles et paysans les plus pauvres) et si elle n'a pas neutralisé par sa politique tout au moins une partie de la campagne arriérée. L'action communiste dans les campagnes acquiert en ce moment une importance capitale. Elle doit être principalement le fait des ouvriers 
communistes en contact avec la campagne. Se refuser à l'accomplir ou la confier à des demi-réformistes douteux c’est renoncer à la révolution prolétarienne.

6. Tout Parti désireux d'appartenir à la $3^{\mathrm{e}}$ Internationale, a pour devoir de dénoncer autant que le social-patriotisme avoué le social-pacifisme hypocrite et faux ; il s'agit de démontrer systématiquement aux travailleurs que, sans le renversement révolutionnaire du capitalisme, nul tribunal arbitral international, nul débat sur la réduction des armements, nulle réorganisation « démocratique » de la Ligue des Nations ne peuvent préserver l’humanité des guerres impérialistes.

7. Les Partis désireux d'appartenir à l'Internationale Communiste ont pour devoir de reconnaître la nécessité d'une rupture complète et définitive avec le réformisme et la politique du centre et de préconiser cette rupture parmi les membres des organisations. L'action communiste conséquente n'est possible qu'à ce prix.

L'Internationale Communiste exige impérativement et sans discussion cette rupture qui doit être consommée dans le plus bref délai. L'Internationale Communiste ne peut admettre que des réformistes avérés, tels que Turati, Kautsky, Hilferding, Longuet, MacDonald et autres, aient le droit de se considérer comme des membres de la 3e Internationale, et qu'ils y soient représentés. Un pareil état de choses ferait ressembler par trop la $3^{\mathrm{e}}$ Internationale à la $2^{\mathrm{e}}$.

8. Dans la question des colonies et des nationalités opprimées, les Partis des pays dont la bourgeoisie possède des colonies ou opprime des nations, doivent avoir une ligne de conduite particulièrement claire et nette. Tout Parti appartenant à la $3^{\mathrm{e}}$ Internationale a pour devoir de dévoiler impitoyablement les prouesses de « ses » impérialistes aux colonies, de soutenir, non en paroles mais en fait, tout mouvement d'émancipation dans les colonies, d'exiger l'expulsion des colonies des impérialistes de la métropole, de nourrir au cœur des travailleurs du pays des sentiments véritablement fraternels vis-à-vis de la population laborieuse des colonies et des nationalités opprimés et d'entretenir parmi les troupes de la métropole une agitation continue contre toute oppression des peuples coloniaux.

9. Tout Parti désireux d'appartenir à l'Internationale Communiste doit poursuivre une propagande persévérante et systématique au sein des syndicats, coopératives et autres organisations des masses ouvrières. Des noyaux communistes doivent être formés, dont le travail opiniâtre et constant conquerra les syndicats au 
communisme. Leur devoir sera de révéler à tout instant la trahison des socialpatriotes et les hésitations du "centre ». Ces noyaux communistes doivent être complètement subordonnés à l'ensemble du Parti.

10. Tout Parti appartenant à l'Internationale Communiste a pour devoir de combattre avec énergie et ténacité l' « Internationale » des syndicats jaunes fondée à Amsterdam. Il doit répandre avec ténacité au sein des syndicats ouvriers l'idée de la nécessité de la rupture avec l'Internationale Jaune d'Amsterdam. Il doit par contre concourir de tout son pouvoir à l'union internationale des syndicats rouges adhérant à l’Internationale Communiste.

11. Les Partis désireux d'appartenir à l'Internationale Communiste ont pour devoir de réviser la composition de leurs fractions parlementaires, d'en écarter les éléments douteux, de les soumettre, non en paroles mais en fait, au Comité Central du Parti, d'exiger de tout député communiste la subordination de toute son activité aux intérêts véritables de la propagande révolutionnaire et de l'agitation.

12. Les Partis appartenant à l'Internationale Communiste doivent être édifiés sur le principe de la centralisation démocratique. A l'époque actuelle de guerre civile acharnée, le Parti Communiste ne pourra remplir son rôle que s'il est organisé de la façon la plus centralisée, si une discipline de fer confinant à la discipline militaire y est admise et si son organisme central est muni de larges pouvoirs, exerce une autorité incontestée, bénéficie de la confiance unanime des militants.

13. Les Partis Communistes des pays où les communistes militent légalement doivent procéder à des épurations périodiques de leurs organisations, afin d'en écarter les éléments intéressés et petit-bourgeois.

14. Les Partis désireux d'appartenir à l'Internationale Communiste doivent soutenir sans réserves toutes les républiques soviétiques dans leurs luttes avec la contre-révolution. Ils doivent préconiser inlassablement le refus des travailleurs de transporter les munitions et les équipements destinés aux ennemis des républiques soviétiques, et poursuivre, soit légalement soit illégalement, la propagande parmi les troupes envoyées contre les républiques soviétiques.

15. Les Partis qui conservent jusqu'à ce jour les anciens programmes socialdémocrates ont pour devoir de les réviser sans retard et d'élaborer un nouveau programme communiste adapté aux conditions spéciales de leur pays et conçu dans l'esprit de l'Internationale Communiste. Il est de règle que les programmes 
des Partis affiliés à l'Internationale Communiste soient confirmés par le Congrès International ou par le Comité Exécutif. Au cas où ce dernier refuserait sa sanction à un Parti, celui-ci aurait le droit d'en appeler au Congrès de l'Internationale Communiste.

16. Toutes les décisions des Congrès de l'Internationale Communiste, de même que celles du Comité Exécutif, sont obligatoires pour tous les Partis affiliés à l'Internationale Communiste. Agissant en période de guerre civile acharnée, l'Internationale Communiste et son Comité Exécutif doivent tenir compte des conditions de lutte si variées dans les différents pays et n'adopter de résolutions générales et obligatoires que dans les questions où elles sont possibles.

17. Conformément à tout ce qui précède, tous les Partis adhérant à l'Internationale Communiste doivent modifier leur appellation. Tout Parti désireux d'adhérer à l'Internationale Communiste doit s'intituler Parti Communiste de... (section de la $3^{\mathrm{e}}$ Internationale Communiste). Cette question d'appellation n'est pas une simple formalité ; elle a aussi une importance politique considérable. L'Internationale Communiste a déclaré une guerre sans merci au vieux monde bourgeois tout entier et à tous les vieux Partis social-démocrates jaunes. Il importe que la différence entre les Partis Communistes et les vieux Partis « socialdémocrates » ou « socialistes » officiels qui ont vendu le drapeau de la classe ouvrière soit plus nette aux yeux de tout travailleur.

18. Tous les organes dirigeants de la presse des Partis de tous les pays sont obligés d'imprimer tous les documents officiels importants du Comité Exécutif de l’Internationale Communiste.

19. Tous les Partis appartenant à l'Internationale Communiste ou sollicitant leur adhésion sont obligés de convoquer (aussi vite que possible), dans un délai de 4 mois après le $2^{\mathrm{e}}$ Congrès de l'Internationale Communiste, au plus tard, un Congrès extraordinaire afin de se prononcer sur ces conditions. Les Comités Centraux doivent veiller à ce que les décisions du $2^{\mathrm{e}}$ Congrès de l'Internationale Communiste soient connues de toutes les organisations locales.

20. Les Partis qui voudraient maintenant adhérer à la $3^{\mathrm{e}}$ Internationale, mais qui n’ont pas encore modifié radicalement leur ancienne tactique, doivent préalablement veiller à ce que les $2 / 3$ des membres de leur Comité Central et des Institutions centrales les plus importantes soient composés de camarades, qui déjà avant 
le $2^{\mathrm{e}}$ Congrès s'étaient ouvertement prononcés pour l'adhésion du Parti à la $3^{\mathrm{e}}$ Internationale. Des exceptions peuvent être faites avec l'approbation du Comité Exécutif de l'Internationale Communiste. Le Comité Exécutif se réserve le droit de faire des exceptions pour les représentants de la tendance centriste mentionnés dans le paragraphe 7.

21. Les adhérents au Parti qui rejettent les conditions et les thèses établies par l'Internationale Communiste doivent être exclus du Parti. Il en est de même des délégués au Congrès extraordinaire. 
Manifestes, thèses et résolutions des quatre premiers congrès de l'Internationale communiste 1919-1923

(juin 1934)

Deuxième Congrès, juillet 1920.

- 3 -

Les tâches principales de l’Internationale Communiste

$\underline{\text { Retour à la table des matières }}$

1. Le moment actuel du développement du mouvement communiste international est caractérisé par le fait que, dans tous les pays capitalistes, les meilleurs représentants du mouvement prolétarien ont parfaitement compris les principes fondamentaux de l'Internationale Communiste, c'est-à-dire : la dictature du prolétariat et le gouvernement des Soviets, et se sont rangés à ses côtés avec un dévouement enthousiaste. Plus important encore est le fait que les plus larges masses du prolétariat des villes et des travailleurs avancés des campagnes manifestent leur sympathie sans réserve pour ces principes essentiels. C'est là un grand pas en avant.

D'autre part, deux fautes ou deux faiblesses du mouvement communiste international, qui croît avec une rapidité extraordinaire, se sont fait remarquer. L'une, très grave et qui présente un grand danger immédiat pour la cause de la libération du prolétariat, consiste en ce que certains anciens leaders, certains vieux partis de la 2e Internationale, en partie inconsciemment sous la pression des masses, en partie consciemment - et alors les trompant pour conserver leur ancienne situation d'agents et d'auxiliaires de la bourgeoisie au sein du mouvement ouvrier - 
annoncent leur adhésion conditionnelle ou sans réserve à la $3^{\mathrm{e}}$ Internationale, tout en restant, en fait, dans tout leur travail pratique quotidien, au niveau de la $2^{\mathrm{e}}$ Internationale. Cet état de choses est absolument inadmissible. Il introduit parmi les masses un élément de corruption, il empêche la formation ou le développement d'un Parti Communiste fort, il met en cause le respect dû à la $3^{\mathrm{e}}$ Internationale en la menaçant du recommencement de trahisons semblables à celle des socialdémocrates hongrois hâtivement travestis en Communistes. Une autre faute, beaucoup moins importante et qui est bien plutôt une maladie de croissance du mouvement, est la tendance "à gauche » qui conduit à une appréciation erronée du rôle et de la mission du Parti par rapport à la classe ouvrière et à la masse, et de l'obligation pour les révolutionnaires communistes de militer dans les parlements bourgeois et dans les syndicats réactionnaires.

Le devoir des Communistes n'est pas de taire les faiblesses de leur mouvement, mais d'en faire ouvertement la critique afin de s'en débarrasser promptement et radicalement. A cette fin, il importe tout d'abord de définir, selon notre expérience pratique, le contenu des notions de dictature du prolétariat et de pouvoir des Soviets; en second lieu, en quoi peut et doit consister dans tous les pays le travail préparatoire, immédiat et systématique, en vue de la réalisation de ces mots d'ordre ; et en troisième lieu, quels voies et moyens nous permettent de guérir notre mouvement de ses faiblesses.

\section{1. - L'essence de la dictature du prolétariat et du pouvoir des Soviets.}

2. La victoire du socialisme (première étape du Communisme) sur le capitalisme exige l'accomplissement par le prolétariat, seule classe réellement révolutionnaire, des trois tâches suivantes :

La première consiste à renverser les exploiteurs et, en premier lieu, la bourgeoisie, leur représentant économique et politique principal ; il s'agit de leur infliger une défaite totale, de briser leur résistance, de rendre impossible de leur part toute tentative de restauration du capital et de l'esclavage salarié. 
La deuxième consiste à entraîner à la suite de l'avant-garde du prolétariat révolutionnaire, de son Parti Communiste, non seulement tout le prolétariat, mais aussi toute la masse des travailleurs exploités par le capital, à les éclairer, à les organiser, à les éduquer, à les discipliner au cours même de la lutte impitoyable et téméraire contre les exploiteurs, - à arracher dans tous les pays capitalistes cette écrasante majorité de la population à la bourgeoisie, à lui inspirer pratiquement confiance dans le rôle de directeur du prolétariat de son avant-garde révolutionnaire.

La troisième, de neutraliser ou de réduire à l'impuissance les inévitables hésitants entre le prolétariat et la bourgeoisie, entre la démocratie bourgeoise et le pouvoir des Soviets, de la classe de petits propriétaires ruraux, industriels et négociants, encore assez nombreux bien que ne formant qu'une minorité de la population et des catégories d'intellectuels, d'employés, etc..., gravitant autour de cette classe.

La première et la deuxième tâches exigent chacune des méthodes d'action particulières à l'égard des exploités et des exploiteurs. La troisième découle des deux premières ; elle n'exige qu'une application habile, souple et opportune des méthodes appliquées aux premières et qu'il s'agit d'adapter aux circonstances concrètes.

3. Dans la conjoncture actuelle, créée dans le monde entier, et surtout dans les pays capitalistes les plus avancés, les plus puissants, les plus éclairés, les plus libres, par le militarisme, l'impérialisme, l'oppression des colonies et des pays faibles, la tuerie impérialiste mondiale et la " paix » de Versailles, la pensée d'une paisible soumission de la majorité des exploités aux capitalistes et d'une évolution pacifique vers le socialisme, n'est pas seulement un signe de médiocrité petitebourgeoise : c'est aussi une duperie, la dissimulation de l'esclavage du salariat, la déformation de la vérité aux yeux des travailleurs. La vérité est que la bourgeoisie la plus éclairée, la plus démocratique, ne recule pas devant le massacre de millions d'ouvriers et de paysans à seule fin de sauver la propriété privée des moyens de production. Le renversement de la bourgeoisie par la violence, la confiscation de ses propriétés, la destruction de son mécanisme d'Etat, parlementaire, judiciaire, militaire, bureaucratique, administratif, municipal, etc... jusqu'à l'exil ou 
l'internement de tous les exploiteurs les plus dangereux et les plus obstinés, sans exception, l'exercice sur leurs milieux d'une stricte surveillance pour la répression des tentatives qu'ils ne manqueront pas de faire dans l'espoir de restaurer l'esclavage capitaliste, telles sont les mesures qui peuvent seules assurer la soumission réelle de la classe entière des exploiteurs.

D’autre part, l'idée coutumière aux vieux partis et aux vieux leaders de la $2^{\mathrm{e}}$ Internationale, que la majorité des travailleurs et des exploités peut, en régime capitaliste, sous le joug esclavagiste de la bourgeoisie — qui revêt des formes infiniment variées, d’autant plus raffinées et à la fois plus cruelles et plus impitoyables que le pays capitaliste est plus cultivé - acquérir une pleine conscience socialiste, la fermeté socialiste, des convictions et du caractère, cette idée, disonsnous, trompe aussi les travailleurs. En fait, ce n'est qu'après que l'avant-garde prolétarienne, soutenue par la seule classe révolutionnaire ou par sa majorité, aura renversé les exploiteurs, les aura brisés, aura libéré les exploités de leurs servitudes et immédiatement amélioré leurs conditions d'existence au détriment des capitalistes expropriés - ce n'est qu'alors, et au prix de la plus âpre guerre civile, que l'éducation, l’instruction, l’organisation des plus grandes masses exploitées pourra se faire autour du prolétariat, sous son influence et sa direction, et qu'il sera possible de vaincre leur égoïsme, leurs vices, leurs faiblesses, leur manque de cohésion, entretenus par le régime de la propriété privée, et de les transformer en une vaste association de libres travailleurs.

4. Le succès de la lutte contre le capitalisme exige un juste rapport des forces entre le Parti Communiste comme guide, le prolétariat, la classe révolutionnaire et la masse, c'est-à-dire l'ensemble des travailleurs et des exploités. Le Parti Communiste, s’il est véritablement l'avant-garde de la classe révolutionnaire, s’il s’assimile tous ses meilleurs représentants, s’il est composé de Communistes conscients et dévoués, éclairés et éprouvés par l'expérience d'une longue lutte révolutionnaire, s'il a su se lier indissolublement à toute l'existence de la classe ouvrière et par son intermédiaire à celle de toute la masse exploitée et leur inspirer une pleine confiance, ce Parti seul est capable de diriger le prolétariat dans la lutte finale, la plus acharnée, contre toutes les forces du capitalisme. Et ce n'est que sous la direction d'un Parti semblable que le prolétariat peut annihiler l'apathie et la résistance de la petite aristocratie ouvrière, composée des leaders du mouve- 
ment syndical et corporatif corrompus par le capitalisme, et développer toutes ses énergies, infiniment plus grandes que sa force numérique parmi la population, par suite de la structure économique du capitalisme lui-même. Enfin, ce n’est que libérée effectivement du joug du capital et de l'appareil gouvernemental de l'Etat, ce n'est qu'après avoir obtenu la possibilité d'agir librement que la masse, c'est-àdire la totalité des travailleurs et des exploités organisés dans les Soviets, pourra développer, pour la première fois dans l'histoire, l'initiative et l'énergie de dizaines de millions d'hommes étouffés par le capitalisme. Ce n’est que lorsque les Soviets seront devenus l'unique mécanisme de l'Etat, que pourra être assurée la participation effective des masses autrefois exploitées à toute l'administration du pays, participation qui, dans les démocraties bourgeoises les plus éclairées et les plus libres, était impossible quatre-vingt quinze fois sur cent. Dans les Soviets, la masse des exploités commence à apprendre, non des livres, mais de son expérience pratique, ce qu'est l'édification socialiste, la création d'une nouvelle discipline sociale et la libre association des travailleurs libres.

\section{2. - EN QUOI DOIT CONSISTER LA PRÉPARATION IMMÉDIATE DE LA DICTATURE PROLÉTARIENNE}

5. Le développement actuel du mouvement communiste international est caractérisé par ce fait que dans nombre de pays capitalistes, le travail de préparation du prolétariat à l'exercice de la dictature n'est pas achevé et très souvent n’a pas encore été commencé de façon systématique. Il ne s’ensuit pas que la révolution prolétarienne soit impossible dans un avenir très prochain ; elle est, au contraire, tout ce qu'il y a de plus possible, la situation politique et économique étant extraordinairement riche en matières inflammables et en causes susceptibles de provoquer leur embrasement inopiné ; un autre facteur de la révolution, en dehors de l'état de préparation du prolétariat, est notamment la crise générale en présence de laquelle se trouvent tous les partis gouvernants et tous les partis bourgeois. Mais il résulte de ce qui a été dit que la tâche actuelle des Partis Communistes consiste à hâter la révolution, sans toutefois la provoquer artificiellement avant une préparation suffisante ; la préparation du prolétariat à la révolution doit être intensifiée par l'action. D’autre part, les cas signalés plus haut dans l’histoire de beaucoup de 
partis socialistes, obligent de bien veiller à ce que la reconnaissance de la dictature du prolétariat ne puisse pas rester purement verbale.

Pour ces raisons, la tâche principale du Parti Communiste, du point de vue du mouvement international prolétarien, est à l’heure présente le groupement de toutes les forces communistes éparses, la formation dans chaque pays d'un Parti Communiste unique (ou le renforcement et le renouvellement des partis déjà existants) afin de décupler le travail de préparation du prolétariat à la conquête du pouvoir sous forme de dictature du prolétariat. L'action socialiste habituelle des groupes et des partis qui reconnaissent la dictature du prolétariat, est loin d'avoir subi cette modification fondamentale, ce renouvellement radical, qui est nécessaire, pour qu'on en reconnaisse l'action comme étant bien communiste et comme correspondant aux tâches de la veille de la dictature prolétarienne.

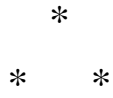

6. La conquête du pouvoir politique par le prolétariat n’interrompt pas la lutte de classe de celui-ci contre la bourgeoisie, mais au contraire, ne fait que la rendre plus large, plus acerbe, plus impitoyable. Tous les groupes, partis, militants du mouvement ouvrier qui adoptent en totalité ou en partie le point de vue du réformisme, du « centre », etc..., se placeront inévitablement, par suite de l'extrême exacerbation de la lutte, soit du côté de la bourgeoisie, soit du côté des hésitants ou (ce qui est plus dangereux) tomberont dans le nombre des amis indésirables du prolétariat victorieux. C'est pourquoi la préparation de la dictature du prolétariat exige non seulement le renforcement de la lutte contre la tendance des réformistes et des « centristes », mais aussi la modification du caractère de cette lutte. Celle-ci ne peut pas se limiter à la démonstration du caractère erroné de ces tendances, mais elle doit aussi démasquer inlassablement et impitoyablement tout militant du mouvement ouvrier qui manifestera ces tendances, le prolétariat ne pouvant pas savoir sans cela avec qui il marche à la lutte finale contre la bourgeoisie. Cette lutte est telle, qu'elle peut changer à tout instant et transformer, comme l'a déjà démontré l'expérience, l'arme de la critique en critique par les armes. Tout manque d'esprit de suite, ou toute faiblesse dans la lutte contre ceux qui se conduisent comme des réformistes ou des « centristes », a pour conséquence un accroisse- 
ment direct du danger de renversement du pouvoir du prolétariat par la bourgeoisie, qui utilisera demain pour la contre-révolution ce qui ne paraît aux bornés qu'un « désaccord théorique » d'aujourd'hui.

7. Il est impossible de se limiter à la négation habituelle de principe de toute collaboration avec la bourgeoisie, de tout « coalitionnisme ». Une simple défense de la « liberté » et de «l'égalité » avec le maintien de la propriété privée des moyens de production, se transforme dans les conditions de la dictature du prolétariat, qui ne sera jamais en état d'abolir d’un coup la propriété privée en entier, en « collaboration » avec la bourgeoisie qui sapera directement le pouvoir de la classe ouvrière. Car la dictature du prolétariat signifie l'affermissement gouvernemental et la défense, par tout le système d’Etat, non pas de « la liberté » pour les exploiteurs de continuer leur œuvre d'oppression et d'exploitation, non pas de « l’égalité » du propriétaire (c’est-à-dire de celui qui conserve pour sa jouissance personnelle certains moyens de production créés par le travail de la collectivité) et du pauvre. Ce qui nous paraît jusqu’à la victoire du prolétariat n’être qu'un désaccord sur la question de la « démocratie » deviendra inévitablement demain, après la victoire, une question qu'il faudra trancher par les armes. Sans transformation radicale de tout le caractère de la lutte contre les « centristes » et les « défenseurs de la démocratie » la préparation même préalable des masses à la réalisation de la dictature du prolétariat est donc impossible.

8. La dictature du prolétariat est la forme la plus décisive et la plus révolutionnaire de la lutte de classes du prolétariat et de la bourgeoisie. Pareille lutte ne peut être victorieuse que lorsque l'avant-garde la plus révolutionnaire du prolétariat entraîne derrière elle l'écrasante majorité ouvrière. La préparation de la dictature du prolétariat exige pour ces raisons, non seulement la divulgation du caractère bourgeois du réformisme et de toute défense de la démocratie impliquant le maintien de la propriété privée sur les moyens de production ; non seulement la divulgation des manifestations de tendances, qui signifient en fait la défense de la bourgeoisie au sein du mouvement ouvrier ; mais elle exige aussi le remplacement 
des anciens leaders par des Communistes dans toutes les formes d'organisation prolétarienne, politiques, syndicales, coopératives, d’éducation, etc...

Plus la domination de la démocratie bourgeoise a été longue et ferme, dans un pays donné, plus la bourgeoisie a réussi a amener aux postes importants du mouvement ouvrier des hommes éduqués par elle, par ses conceptions, par ses préjugés, très souvent directement ou indirectement achetés par elle. Il est indispensable, et il faut le faire avec cent fois plus de hardiesse qu'on ne l'a fait jusqu'ici, de remplacer ces représentants de l'aristocratie ouvrière par des travailleurs même inexpérimentés, proches de la masse exploitée et jouissant de sa confiance dans la lutte contre les exploiteurs. La dictature du prolétariat exigera la désignation de tels travailleurs inexpérimentés aux postes les plus importants du gouvernement, sans quoi le pouvoir de la classe ouvrière restera impuissant et ne sera pas soutenu par la masse.

9. La dictature du prolétariat est la réalisation la plus complète de la domination de tous les travailleurs et de tous les exploités, opprimés, abrutis, terrorisés, éparpillés, trompés par la classe capitaliste, mais conduits par la seule classe sociale préparée à cette mission dirigeante par toute l'histoire du capitalisme. C’est pourquoi la préparation de la dictature prolétarienne doit être partout et immédiatement commencée, entre autres par les moyens que voici :

Dans toutes les organisations sans exception, - syndicats, unions, etc... prolétariennes d'abord et ensuite non-prolétariennes, des masses laborieuses exploitées (qu’elles soient politiques, syndicales, militaires, coopératives, postscolaires, sportives, etc...), des groupes ou des noyaux communistes doivent être formés, de préférence ouvertement, mais, s’il le faut, clandestinement — ce qui devient obligatoire toutes les fois que leur mise hors la loi et l'arrestation de leurs membres sont à craindre ; ces groupes, rattachés les uns aux autres et rattachés au centre du Parti, échangeant le résultat de leur expérience, s’occupant d’agitation, de propagande et d'organisation s'adaptent à tous les domaines de la vie sociale, à tous les aspects et à toutes les catégories de la masse laborieuse, doivent procéder 
par leur travail multiple à leur propre éducation, à celle du Parti, de la classe ouvrière et de la masse.

Il est, cependant, de la plus haute importance d'élaborer pratiquement, — dans leur développement nécessaire - des méthodes d'action, d'une part, à l'égard des leaders ou des représentants autorisés des organisations, complètement corrompus par les préjugés impérialistes et petits-bourgeois (ces leaders, il faut impitoyablement les démasquer et les exclure du mouvement ouvrier) et, d'autre part, à l'égard des masses qui, surtout depuis la tuerie impérialiste, sont disposées à prêter l'oreille à l'enseignement de la nécessité de suivre le prolétariat, seul capable de les tirer de l'esclavage capitaliste. Il convient de savoir aborder les masses avec patience et circonspection, afin de comprendre les particularités psychologiques de chaque profession, de chaque groupe au sein de cette masse.

10. Il est un groupe ou fraction de Communistes qui mérite tout particulièrement l'attention et la surveillance du Parti : c'est la fraction parlementaire, autrement dit, le groupe des membres du parti élus au Parlement (ou aux municipalités, etc...). D'une part, ces tribunes sont, aux yeux des couches profondes de la classe laborieuse retardataire ou farcie de préjugés petits-bourgeois, d'une importance capitale ; c'est d'ailleurs la raison qui fait que les Communistes doivent, du haut de ces tribunes, mener une action de propagande, d'agitation, d'organisation, et expliquer aux masses pourquoi était nécessaire en Russie (comme il le sera, le cas échéant, dans tous les pays) la dissolution du Parlement bourgeois par le congrès panrusse de Soviets. D'autre part, toute l'histoire de la démocratie bourgeoise a fait de la tribune parlementaire, notamment dans les pays avancés, la principale ou l'une des principales arènes des duperies financières et politique, de l'arrivisme, de l'hypocrisie, de l'oppression des travailleurs. C'est pourquoi la haine vivace nourrie à l'égard des parlements par les meilleurs représentants du prolétariat est pleinement justifiée. C'est pourquoi les Partis Communistes et tous les partis adhérents à la $3^{\mathrm{e}}$ Internationale (dans les cas surtout où ces partis n'ont pas été créés par suite d'une scission des anciens partis après une lutte longue et acharnée, mais se sont formés par l'adoption souvent nominale d'une nouvelle position par les anciens partis) doivent observer une attitude très rigoureuse à l'égard de leurs fractions parlementaires, c'est-à-dire exiger : leur subordination complète au Comité Central du Parti; l'introduction de préférence dans leur composition 
d'ouvriers révolutionnaires ; l'analyse la plus attentive dans la presse du Parti et aux réunions de celui-ci, des discours des parlementaires du point de vue de leur attitude communiste ; la désignation des parlementaires pour l'action de propagande parmi les masses, l'exclusion immédiate de tous ceux qui manifesteraient une tendance vers la $2^{\mathrm{e}}$ Internationale, etc...

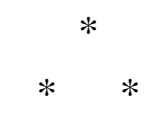

11. Un des obstacles les plus graves au mouvement ouvrier révolutionnaire dans les pays capitalistes développés dérive du fait que grâce aux possessions coloniales et à la plus-value du capital financier, etc..., le capital a réussi à y créer une petite aristocratie ouvrière relativement imposante et stable. Elle bénéficie des meilleures conditions de rétribution ; elle est, par-dessus tout, pénétrée d'un esprit de corporatisme étroit, de petite bourgeoisie et de préjugés capitalistes. Elle constitue le véritable « point d'appui » social de la 2e Internationale des réformistes et des « centristes ", et elle est bien près, à l'heure actuelle, d'être le point d'appui principal de la bourgeoisie. Aucune préparation, même préalable, du prolétariat au renversement de la bourgeoisie n'est possible sans une lutte directe, systématique, large, déclarée, avec cette petite minorité, qui, sans aucun doute (comme l'a pleinement prouvé l'expérience) donnera nombre des siens à la garde blanche de la bourgeoisie après la victoire du prolétariat. Tous les partis adhérant à la $3^{\mathrm{e}}$ Internationale doivent, coûte que coûte, donner corps dans la vie à ce mot d'ordre, «plus profondément dans les masses », en comprenant par masse tout l'ensemble des travailleurs et des exploités par le capital, et surtout les moins organisés et les moins éclairés, les plus opprimés et les moins accessibles à l’organisation.

Le prolétariat ne devient révolutionnaire qu'autant qu'il ne s'enferme pas dans les cadres d'un étroit corporatisme et pour autant qu'il agit dans toutes les manifestations et tous les domaines de la vie sociale, comme le chef de toute la masse laborieuse et exploitée. La réalisation de sa dictature est impossible sans préparation et sans la résolution de consentir aux pertes les plus grandes au nom de la victoire sur la bourgeoisie. Et sous ce rapport, l'expérience de la Russie a une importance pratique de principe. Le prolétariat russe n'aurait pas pu réaliser sa dictature, n’aurait pas pu conquérir la sympathie et la confiance générales de toute 
la masse ouvrière, s'il n'avait pas fait preuve de plus d'esprit de sacrifice et s'il n’avait pas plus profondément souffert de la faim que toutes les autres couches de cette masse, aux heures les plus difficiles des attaques, des guerres, du blocus de la bourgeoisie mondiale.

L’appui le plus complet et le plus dévoué du Parti Communiste et du prolétariat d'avant-garde est tout particulièrement nécessaire à l'égard de tout mouvement gréviste large, violent, considérable, qui est seul en état, sous l’oppression du capital, de réveiller véritablement, d'ébranler et d'organiser les masses, de leur inspirer une confiance pleine et entière en le rôle directeur du prolétariat révolutionnaire. Sans une semblable préparation, aucune dictature du prolétariat n'est possible, et les hommes capables de prendre fait et cause contre les grèves comme le font Kautsky en Allemagne et Turati en Italie, ne doivent pas être tolérés au sein des partis qui se rattachent à la $3^{\mathrm{e}}$ Internationale. Ceci concerne certainement plus encore les leaders parlementaires et trade-unionistes qui, à tout moment, trahissent les ouvriers, en leur enseignant par la grève le réformisme et non la révolution (exemples : Jouhaux en France, Gompers en Amérique, G.-H. Thomas en Angleterre).

12. Pour tous les pays, même pour les plus «libres », les plus « légaux », les plus «pacifiques » au sens de la plus faible exacerbation de la lutte de classe, le moment est venu où il est d'une nécessité absolue pour tout Parti communiste, d'unir l'action légale et illégale, l’organisation légale et l'organisation clandestine. Car dans les pays les plus cultivés et les plus libres, ceux du régime bourgeoisdémocratique le plus «stable », les gouvernements, en dépit de leurs déclarations mensongères et cyniques, établissent déjà de secrètes listes noires de communistes, violent à tout instant leur propre constitution en soutenant plus ou moins secrètement les gardes-blancs et l'assassinat des communistes dans tous les pays, préparent dans l'ombre les arrestations des communistes, introduisent parmi eux des provocateurs, etc...

Il n’est que le plus réactionnaire esprit petit-bourgeois, quelle que soit la beauté des phrases « démocratiques » et pacifiques dont il se pare, qui puisse nier ce 
fait et la conclusion obligatoire qui en découle : la formation immédiate par tous les partis communistes légaux d'organisations clandestines en vue de l'action illégale, organisations qui seront prête pour le jour où la bourgeoisie se mettra à traquer les communistes. Une action illégale dans l'armée, dans la flotte, dans la police est de la plus haute importance ; depuis la grande guerre impérialiste tous les gouvernements du monde ont pris peur de l'armée populaire et ont eu recours à tous les procédés imaginables pour constituer spécialement des unités militaires avec des éléments spécialement triés parmi la bourgeoisie et armés des engins meurtriers les plus perfectionnés.

Il est d'autre part également nécessaire dans tous les cas, sans exception, de ne pas se borner à une action illégale, mais aussi de poursuivre l'action légale en surmontant à cet effet toutes les difficultés, en fondant des journaux légaux et des organisations légales sous les désignations les plus différentes, et le cas échéant en changeant fréquemment leurs dénominations. Ainsi agissent les partis communistes illégaux en Finlande, en Hongrie, en Allemagne et dans une certaine mesure, en Pologne, Lituanie, etc... Ainsi doivent agir les Travailleurs Industriels du Monde (I.W.W.) en Amérique, et devront agir tous les autres partis communistes légaux, au cas où il plairait aux procureurs de leur intenter des poursuites pour la seule acceptation des résolutions des Congrès de l'Internationale Communiste, etc...

L’absolue nécessité d'unir l'action légale et illégale n'est pas déterminée en principe par l'ensemble des conditions de l'époque que nous traversons, période de veille de dictature prolétarienne, mais par le besoin de montrer à la bourgeoisie qu'il n'y a pas et qu'il ne peut pas y avoir de domaines et de champs d'action, que n'aient pas conquis les communistes, et aussi parce qu'il existe encore partout de profondes couches du prolétariat, et dans des proportions plus vastes encore une masse laborieuse et exploitée non prolétarienne, qui font toujours confiance à la légalité bourgeoise démocratique, et qu'il est très important pour nous de dissuader. 
13. L'état de la presse ouvrière dans les pays capitalistes les plus avancés montre de façon éclatante le mensonge de la liberté et de l'égalité en démocratie bourgeoise, de même que la nécessité d'unir systématiquement l'action légale et illégale. Tant dans l'Allemagne vaincue que dans l'Amérique victorieuse, toutes les forces de l'appareil gouvernemental de la bourgeoisie et toute l'astuce des rois de l'or sont mises en mouvement pour dépouiller les ouvriers de leur presse : poursuites judiciaires et arrestations (ou assassinats commis par des spadassins) des rédacteurs, confiscation des envois postaux, confiscation du papier, etc... Et tout ce qui est nécessaire à un journal quotidien en fait d’information se trouve entre les mains des agences télégraphiques bourgeoises, les annonces sans lesquelles un grand journal ne peut pas couvrir ses frais sont à la « libre » disposition des capitalistes. En résumé, la bourgeoisie, par le mensonge, par la pression du capital et de l’Etat bourgeois dépouille le prolétariat révolutionnaire de sa presse.

Pour lutter contre cet état de choses, les Partis Communistes doivent créer un nouveau type de presse périodique destiné à la diffusion en masse parmi les ouvriers, comportant :

$1^{\circ}$ des publications légales qui apprendraient, sans se déclarer communistes et sans parler de leur dépendance du Parti, à tirer parti des moindres possibilités légales, comme les bolcheviks l’ont fait sous le tsarisme après 1905 ;

$2^{\circ}$ des tracts illégaux, ne fût ce que d’un format minime, paraissant irrégulièrement, mais imprimés par les ouvriers dans un grand nombre de typographies (clandestinement, ou si le mouvement s’est renforcé, par la mainmise sur les typographes) donnant au prolétariat une information libre, révolutionnaire, et des mots d’ordre révolutionnaires.

Sans une bataille révolutionnaire, qui entraînera les masses, pour la liberté de la presse communiste, la préparation de la dictature du prolétariat est impossible. 


\section{3. - MODIFICATION DE LA LIGNE DE CONDUITE, ET PARTIELLEMENT, DE LA COMPOSITION SOCIALE DES PARTIS ADHÉRANT OU DÉSIREUX D'ADHÉRER À L'INTERNATIONALE COMMUNISTE}

14. Le degré de préparation du prolétariat des pays les plus importants, au point de vue de l'économie et de la politique mondiales, à la réalisation de la dictature ouvrière se caractérise avec le plus d'objectivité et d'exactitude, par le fait que les partis les plus influents de la $2^{\mathrm{e}}$ Internationale, tels que le Parti Socialiste Français, le Parti Social-Démocrate Indépendant Allemand, le Parti Ouvrier Indépendant Anglais, le Parti Socialiste Américain sont sortis de cette Internationale Jaune et ont décidé, sous condition, d'adhérer à la 3e Internationale. Il est ainsi prouvé que l'avant-garde n’est pas seule, que la majorité du prolétariat révolutionnaire a commencé, persuadée par toute la marche des événements, à passer de notre côté. L'essentiel maintenant est de savoir achever ce passage et solidement affermir par l'organisation ce qui a été obtenu, afin qu'il soit possible d'aller de l’avant sur toute la ligne sans la moindre hésitation.

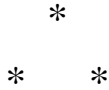

15. Toute l’activité des partis précités (auxquels il faut encore ajouter le Parti Socialiste Suisse si le télégramme nous informant de sa décision d'adhésion à la $3^{\mathrm{e}}$ Internationale est exact) prouve (et n'importe quelle publication de ces partis le confirme indubitablement), qu'elle n'est pas encore communiste et va fréquemment à l'encontre des principes fondamentaux de la $3^{\mathrm{e}}$ Internationale en reconnaissant la démocratie bourgeoise au lieu de la dictature du prolétariat et du pouvoir soviétique.

Pour ces raisons le $2^{\mathrm{e}}$ Congrès de l'Internationale Communiste déclare qu'il ne considère pas comme possible de reconnaître immédiatement ces partis ; qu’il confirme la réponse faite par le Comité Exécutif de l’Internationale Communiste aux indépendants allemands ; qu'il confirme son consentement d'entrer en pourparlers avec tout parti qui sortira de la $2^{\mathrm{e}}$ Internationale et qui exprimera le désir 
de se rapprocher de la $3^{\mathrm{e}}$ Internationale ; qu'il accorde voix consultative aux délégués de ces partis à tous ses Congrès et Conférences ; qu'il pose les conditions suivantes pour l'union complète de ces partis (et partis similaires) avec l’Internationale Communiste.

1. Publication de toutes les décisions de tous les Congrès de l'Internationale Communiste et du Comité Exécutif dans toutes les éditions périodiques du Parti ;

2. Examen de ces dernières à des réunions spéciales de toutes les organisations locales du Parti ;

3. Convocation, après cet examen, d'un Congrès spécial du Parti afin d'en exclure les éléments qui continuent à agir dans l'esprit de la $2^{\mathrm{e}}$ Internationale. Ce Congrès devra être convoqué aussi vite que possible dans un délai maximum de quatre mois après le $2^{\mathrm{e}}$ Congrès de l'Internationale Communiste ;

4. Expulsion du Parti de tous les éléments qui continuent à agir dans l'esprit de la $2^{\mathrm{e}}$ Internationale ;

5. Passage de tous les organes périodiques du Parti aux mains de rédacteurs exclusivement communistes ;

6. Les partis qui voudraient adhérer maintenant à la $3^{\mathrm{e}}$ Internationale mais qui n'ont pas encore modifié radicalement leur ancienne tactique doivent préalablement veiller à ce que les deux tiers des membres de leur comité central et des institutions centrales les plus importantes soient composés de camarades qui, déjà avant le $2^{\mathrm{e}}$ Congrès, s'étaient ouvertement prononcés pour l'adhésion du Parti à la $3^{\mathrm{e}}$ Internationale. Des exceptions peuvent être faites avec l'approbation du Comité Exécutif de l'Internationale Communiste. Le Comité Exécutif se réserve aussi le droit de faire des exceptions en ce qui concerne les représentants de la tendance centriste mentionnés au paragraphe 7 ;

7. Les membres du Parti qui rejettent les conditions et les thèses établies par l'Internationale Communiste doivent être exclus du Parti. Il en est de même des délégués au Congrès extraordinaire. 
16. En ce qui concerne l'attitude des communistes qui forment la minorité actuelle parmi les militants responsables des Partis précités et similaires, le $2^{\mathrm{e}}$ Congrès de l'Internationale Communiste décide que par suite de l'allure rapide du développement actuel de l'esprit révolutionnaire des masses la sortie des communistes de ces Partis n'est pas désirable, aussi longtemps qu'ils auront la possibilité d'y mener une action dans le sens de la reconnaissance de la dictature du prolétariat et du pouvoir soviétique, de critiquer les opportunistes et les centristes qui y demeurent encore.

Toutefois lorsque l'aile gauche d'un parti centriste aura acquis une force suffisante elle pourra, si elle le juge utile au développement du communisme, quitter le Parti en bloc et former un parti communiste.

En même temps le $2^{\mathrm{e}}$ Congrès de la $3^{\mathrm{e}}$ Internationale approuve également l'adhésion des groupes et organisations communistes ou sympathisant au communisme au Labour Party anglais, bien que ce dernier ne soit pas encore sorti de la $2^{\mathrm{e}}$ Internationale. Aussi longtemps que ce Parti laissera à ses organisations leur liberté actuelle de critique, d'action, de propagande, d'agitation et d'organisation pour la dictature du prolétariat et pour le pouvoir soviétique, aussi longtemps qu'il conservera son caractère d'union de toutes les organisations syndicales de la classe ouvrière, les communistes doivent faire toutes les tentatives et aller jusqu'à certains compromis afin d'avoir la possibilité d'exercer une influence sur les grandes masses des travailleurs, de dénoncer leurs chefs opportunistes du haut des tribunes en vue des masses, de hâter le passage du pouvoir politique des mains des représentants directs de la bourgeoisie aux mains des lieutenants ouvriers de la classe ouvrière pour délivrer au plus tôt les masses des dernières illusions a ce sujet.

17. En ce qui concerne le Parti Socialiste Italien, le $2^{\mathrm{e}}$ Congrès de la $3^{\mathrm{e}}$ Internationale, reconnaissant que la révision du programme voté l'année dernière par ce Parti dans son Congrès de Bologne marque une étape très importante dans sa transformation vers le communisme, et que les propositions présentées par la Sec- 
tion de Turin au conseil général du Parti publiées dans le journal l’Ordine Nuovo du 8 mai 1920 correspondent à tous les principes fondamentaux de la $3^{\mathrm{e}}$ Internationale, prie le Parti Socialiste Italien d'examiner, dans le prochain Congrès qui doit être convoqué en vertu des statuts du Parti et des dispositions générales sur l'admission à la 3e Internationale, les susdites propositions et toutes les décisions des deux Congrès de l'Internationale Communiste, particulièrement au sujet de la fraction parlementaire, des Syndicats et des éléments non communistes du Parti.

18. Le $2^{\mathrm{e}}$ Congrès de la $3^{\mathrm{e}}$ Internationale considère comme inadéquates les conceptions sur les rapports du Parti avec la classe ouvrière et avec la masse, sur la participation facultative des Partis Communistes à l'action parlementaire et à l'action des syndicats réactionnaires, qui ont été amplement réfutées dans les résolutions spéciales du présent Congrès, après avoir été surtout défendues par «le Parti Ouvrier Communiste Allemand », et quelque peu par le « Parti Communiste Suisse », par l'organe du bureau viennois de l'Internationale Communiste pour l'Europe Orientale, Kommunismus, par quelques camarades hollandais, par certaines organisations communistes d'Angleterre (dont la «Fédération Ouvrière Socialiste »), etc..., ainsi que par les «I.W.W. » d’Amérique et par les « Shop Stewards Committees » d'Angleterre, etc..., etc...

Néanmoins le $2^{\mathrm{e}}$ Congrès de la 3e Internationale croit possible et désirable la réunion à la $3^{\mathrm{e}}$ Internationale de celles de ces organisations qui n’y ont pas encore officiellement adhéré, car dans le cas présent, et surtout à l'égard des « Shop Stewards Committees » anglais, nous nous trouvons en présence d'un profond mouvement prolétarien, qui se tient en fait sur le terrain des principes fondamentaux de l'Internationale Communiste. Dans de telles organisations, les conceptions erronées sur la participation à l'action des Parlements bourgeois s'expliquent moins par le rôle des éléments issus de la bourgeoisie qui apportent leurs conceptions, d'un esprit au fond petit-bourgeois, telles que le sont souvent celles des anarchistes, que par l’inexpérience politique des prolétaires vraiment révolutionnaires et liés avec la masse. 
Le $2^{\mathrm{e}}$ Congrès de la $3^{\mathrm{e}}$ Internationale prie pour ces raisons toutes les organisations et tous les groupes communistes des pays anglo-saxons de poursuivre même au cas où les «I.W.W. » et les « Shop Stewards Committees » ne se rattacheraient pas immédiatement à la $3^{\mathrm{e}}$ Internationale, une politique de relations plus amicales avec ces organisations, de rapprochement avec elles et avec les masses qui sympathisent avec elles, en leur faisant comprendre amicalement du point de vue de l'expérience de toutes les révolutions russes $\mathrm{du} \mathrm{xx}^{\mathrm{e}}$ siècle, le caractère erroné de leurs conceptions, et en réitérant les tentatives de fusion avec ces organisations dans un Parti Communiste unique.

19. Le Congrès attire l'attention de tous les camarades, surtout des pays romans et anglo-saxons, sur ce fait: depuis la guerre une profonde division d'idées se produit parmi les anarchistes du monde entier au sujet de l'attitude à observer vis-à-vis de la dictature du prolétariat et du pouvoir soviétique. Dans ces conditions, parmi les éléments prolétariens qui on souvent été poussés à l'anarchisme par la haine pleinement justifiée de l'opportunisme et du réformisme de la $2^{\mathrm{e}}$ Internationale, on observe une compréhension particulièrement exacte de ces principes, et qui ne fait que s'étendre davantage au fur et à mesure que l'expérience de la Russie, de la Finlande, de la Hongrie, de la Lituanie, de la Pologne et de l’Allemagne est mieux connue.

Pour ces raisons le Congrès croit du devoir de tous les camarades de soutenir par tous les moyens le passage de tous les éléments prolétariens de masses de l'anarchisme à la $3^{\mathrm{e}}$ Internationale.

Le Congrès considère que le succès de l'action des Partis vraiment communistes doit être apprécié entre autres, dans la mesure où ils auront réussi à attirer à eux tous les éléments vraiment prolétariens de l'anarchisme. 
Manifestes, thèses et résolutions des quatre premiers congrès de l'Internationale communiste 1919-1923

(juin 1934)

Deuxième Congrès, juillet 1920.

-4 -

Résolution sur le rôle du Parti Communiste dans la révolution prolétarienne

$\underline{\text { Retour à la table des matières }}$

Le prolétariat mondial est à la veille d'une lutte décisive. L'époque à laquelle nous vivons est une époque d'action directe contre la bourgeoisie. L'heure décisive approche. Bientôt, dans tous les pays où il y a un mouvement ouvrier conscient, la classe ouvrière aura à livrer une série de combats acharnés, les armes à la main. Plus que jamais, en ce moment, la classe ouvrière a besoin d'une solide organisation. Infatigablement la classe ouvrière doit désormais se préparer à cette lutte, sans perdre une seule heure d'un temps précieux.

Si la classe ouvrière, pendant la Commune de Paris (en 1871) avait eu un Parti Communiste solidement organisé, bien que peu nombreux, la première insurrection de l'héroïque prolétariat français aurait été beaucoup plus forte et elle aurait évité bien des erreurs et bien des fautes. Les batailles que le prolétariat aura maintenant à livrer, dans des conjonctures historiques toutes différentes, auront des résultats beaucoup plus graves qu'en 1871 .

Le $2^{\mathrm{e}}$ Congrès mondial de l'Internationale Communiste signale donc aux ouvriers révolutionnaires du monde entier l'importance de ce qui suit : 
1. Le Parti Communiste est une fraction de la classe ouvrière et bien entendu il en est la fraction la plus avancée, la plus consciente et, partant, la plus révolutionnaire. Il se crée par la sélection spontanée des travailleurs les plus conscients, les plus dévoués, les plus clairvoyants. Le Parti Communiste n'a pas d'intérêts différents de ceux de la classe ouvrière. Le Parti Communiste ne diffère de la grande masse des travailleurs qu'en ce qu'il envisage la mission historique de l'ensemble de la classe ouvrière et s'efforce, à tous les tournants de la route, de défendre non les intérêts de quelques groupes ou de quelques professions, mais ceux de toute la classe ouvrière. Le Parti Communiste constitue la force organisatrice et politique, à l'aide de laquelle la fraction la plus avancée de la classe ouvrière dirige, dans le bon chemin, les masses du prolétariat et du demi-prolétariat.

2. Tant que le pouvoir gouvernemental n'est pas conquis par le prolétariat et tant que ce dernier n'a pas affermi, une fois pour toutes, sa domination et prévenu toute tentative de restauration bourgeoise, le Parti Communiste n'englobera dans ses rangs organisés qu'une minorité ouvrière. Jusqu'à la prise du pouvoir et dans l'époque de transition, le Parti Communiste peut, grâce à des circonstances favorables, exercer une influence idéologique et politique incontestable sur toutes les couches prolétariennes et à demi-prolétariennes de la population, mais il ne peut les réunir organisées, dans ses rangs. Ce n'est que lorsque la dictature prolétarienne aura privé la bourgeoisie de moyens d'action aussi puissants que la presse, l'école, le Parlement, l'Eglise, l'administration, etc..., ce n'est que lorsque la défaite définitive du régime bourgeois sera devenue évidente aux yeux de tous, que tous les ouvriers, ou du moins la plupart, commenceront à entrer dans les rangs du Parti Communiste.

3. Les notions de parti et de classe doivent être distinguées avec le plus grand soin. Les membres des syndicats «chrétiens » et libéraux d'Allemagne, d'Angleterre et d'autres pays, appartiennent indubitablement à la classe ouvrière. Les groupements ouvriers plus ou moins considérables qui se rangent encore à la suite de Scheidemann, de Gompers et consorts lui appartiennent aussi. Dans de telles conditions historiques, il est très possible que de nombreuses tendances ré- 
actionnaires se fassent jour dans la classe ouvrière. La tâche du communisme n’est pas de s'adapter à ces éléments arriérés de la classe ouvrière mais d'élever toute la classe ouvrière au niveau de l'avant-garde communiste. La confusion entre ces deux notions de parti et de classe peut conduire aux fautes et aux malentendus les plus graves. Il est, par exemple, évident que les Partis ouvriers devaient, en dépit des préjugés et de l'état d'esprit d'une portion de la classe ouvrière pendant la guerre impérialiste, s’insurger à tout prix contre ces préjugés et cet état d'esprit, au nom des intérêts historiques du prolétariat qui mettaient son Parti dans l'obligation de déclarer la guerre à la guerre.

C’est ainsi, par exemple, qu'au début de la guerre impérialiste de 1914, les Partis socialistes de tous les pays, soutenant « leurs » bourgeoisies respectives, ne manquaient pas de justifier leur conduite en invoquant la volonté de la classe ouvrière. Ils oubliaient, ce faisant, que si même il en avait été ainsi, c'eut été plutôt la tâche du Parti prolétarien de réagir contre la mentalité ouvrière générale et de défendre envers et contre tous les intérêts historiques du prolétariat. C'est ainsi qu'au commencement du $\mathrm{Xx}^{\mathrm{e}}$ siècle les mencheviks russes (qui se nommaient alors économistes) répudiaient la lutte ouverte contre le tsarisme parce que, disaient-ils, la classe ouvrière dans son ensemble, n'était pas encore en état de comprendre la nécessité de la lutte politique.

C’est ainsi que les indépendants de droite en Allemagne ont justifié toujours leurs demi-mesures en disant qu'il fallait comprendre avant tout les désirs des masses, et ne comprenaient pas eux-mêmes que le Parti est destiné à marcher en avant des masses et à leur montrer le chemin.

4. L'internationale Communiste est absolument convaincue que la faillite des anciens Partis « social-démocrates » de la $2^{\mathrm{e}}$ Internationale ne peut, en aucun cas, être considérée comme la faillite des Partis prolétariens en général. L’époque de la lutte directe en vue de la dictature du prolétariat suscite un nouveau Parti prolétarien mondial — le Parti Communiste.

5. L'internationale Communiste répudie de la façon la plus catégorique l'opinion suivant laquelle le prolétariat peut accomplir sa révolution sans avoir son Parti politique. Toute lutte de classes est une lutte politique. Le but de cette 
lutte, qui tend à se transformer inévitablement en guerre civile, est la conquête du pouvoir politique. C'est pourquoi le pouvoir politique ne peut être pris, organisé et dirigé que par tel ou tel Parti politique. Ce n'est que dans le cas où le prolétariat est guidé par un Parti organisé et éprouvé, poursuivant des buts clairement définis, et possédant un programme d'action susceptible d'être appliqué, tant dans la politique intérieure que dans la politique extérieure, ce n'est que dans ce cas que la conquête du pouvoir politique peut être considérée non comme un épisode, mais comme le point de départ d'un travail durable d'édification communiste de la société par le prolétariat.

La même lutte des classes exige aussi la centralisation et la direction unique des diverses formes du mouvement prolétarien (syndicats, coopératives, comités d'usines, enseignement, élections, etc...). Le centre organisateur et dirigeant ne peut être qu'un Parti politique. Se refuser à le créer et à l'affermir, se refuser à s'y soumettre équivaut à répudier le commandement unique des contingents du prolétariat agissant sur des points différents. La lutte de classe prolétarienne exige une agitation concentrée, éclairant les différentes étapes de la lutte d'un point de vue unique et attirant à chaque moment, toute l'attention du prolétariat sur les tâches qui l'intéressent dans son entier. Cela ne peut être réalisé sans un appareil politique centralisé, c'est-à-dire en dehors d'un Parti politique.

La propagande de certains syndicalistes révolutionnaires et des adhérents du mouvement industrialiste du monde entier (I.W.W.) contre la nécessité d’un Parti politique se suffisant à lui-même n'a aidé et n'aide, à parler objectivement, que la bourgeoisie et les « social-démocrates » contre-révolutionnaires. Dans leur propagande contre un Parti Communiste qu'ils voudraient remplacer par des syndicats ou par des unions ouvrières de formes peu définies et trop vastes, les syndicalistes et les industrialistes ont des points de contact avec des opportunistes avérés.

Après la défaite de la révolution de 1905, les mencheviks russes propagèrent pendant quelques années l'idée d'un Congrès ouvrier (ainsi le nommaient-ils) qui devait remplacer le Parti révolutionnaire de la classe ouvrière ; les «travaillistes jaunes» de toutes sortes en Angleterre et en Amérique veulent remplacer le Parti politique par d'informes unions ouvrières, et ils inventent en même temps une tactique politique absolument bourgeoise. Les syndicalistes révolutionnaires et industrialistes veulent combattre la dictature de la bourgeoisie, mais ils ne savent comment s'y prendre. Ils ne remarquent pas qu'une classe ouvrière sans Parti po- 
litique est un corps sans tête. Le syndicalisme révolutionnaire et l'industrialisme ne marquent un pas fait en avant que par rapport à l'ancienne idéologie inerte et contre-révolutionnaire de la $2^{\mathrm{e}}$ Internationale. Par rapport au marxisme révolutionnaire, c'est-à-dire au communisme, le syndicalisme et l'industrialisme marquent un pas en arrière. La déclaration des communistes « de la gauche allemande K.A.P.D. » (programme élaboré par leur Congrès constituant d'avril dernier) disant qu'ils forment un Parti, mais «non pas un Parti dans le sens courant du mot » (keine Partei im überlieferten Sinne) est une capitulation devant l'opinion syndicaliste et industrialiste, qui est un fait réactionnaire.

Mais ce n'est pas par la grève générale, par la tactique des bras croisés que la classe ouvrière peut remporter la victoire sur la bourgeoisie. Le prolétariat doit en venir à l'insurrection armée. Celui qui a compris cela doit aussi comprendre qu'un Parti politique organisé est nécessaire et que d'informes unions ouvrières ne peuvent pas en tenir lieu.

Les syndicalistes révolutionnaires parlent souvent du grand rôle que doit jouer une minorité révolutionnaire résolue. Or, en fait, cette minorité résolue de la classe ouvrière que l'on demande, cette minorité qui est communiste et qui a un programme, qui veut organiser la lutte des masses, c'est bien le Parti Communiste.

6. La tâche la plus importante d'un Parti réellement communiste est de rester toujours en contact avec les organisations prolétariennes les plus larges. Pour arriver à cela, les communistes peuvent et doivent prendre part à des groupes qui, sans être des groupes du Parti, englobent de grandes masses prolétariennes. Tels sont par exemple ceux que l'on connaît sous le nom d'organisation d'invalides dans divers pays, de sociétés « Ne touchez pas à la Russie » (Hands off Russia) en Angleterre, les unions prolétariennes de locataires, etc... Nous avons ici l'exemple russe des conférences d'ouvriers et de paysans qui se déclarent « étrangers » aux Partis (bezpartinii). Des associations de ce genre seront bientôt organisées dans chaque ville, dans chaque quartier ouvrier et aussi dans les campagnes. A ces associations prennent part les plus larges masses comprenant même des travailleurs arriérés. On mettra à l'ordre du jour les questions les plus intéressantes: approvisionnement, habitation, questions militaires, enseignement, tâche 
politique du moment présent, etc... Les communistes doivent avoir de l'influence dans ces associations et cela aura les résultats les plus importants pour le Parti.

Les communistes considèrent comme leur tâche principale un travail systématique d'éducation et d'organisation au sein de ces organisations. Mais précisément pour que ce travail soit fécond, pour que les ennemis du prolétariat révolutionnaire ne puissent s'emparer de ces organisations, les travailleurs avancés, communistes, doivent avoir leur Parti d'action organisée, sachant défendre le communisme dans toutes les conjonctures et en présence de toutes les éventualités.

7. Les communistes ne s'écartent jamais des organisations ouvrières politiquement neutres, même quand elles revêtent un caractère évidemment réactionnaire (unions jaunes, unions chrétiennes, etc...). Au sein de ces organisations, le Parti Communiste poursuit constamment son œuvre propre, démontrant infatigablement aux ouvriers que la neutralité politique est sciemment cultivée parmi eux par la bourgeoisie et par ses agents afin de détourner le prolétariat de la lutte organisée pour le socialisme.

8. L'ancienne subdivision classique du mouvement ouvrier en trois formes (Partis, syndicats, coopératives) a fait son temps. La révolution prolétarienne en Russie a suscité la forme essentielle de la dictature prolétarienne, les Soviets. La nouvelle division que nous mettons partout en valeur est celle-ci : $1^{\circ}$ le Parti, $2^{\circ}$ le Soviet, $3^{\circ}$ le Syndicat.

Mais le travail dans les Soviets de même que dans les syndicats d'industrie devenus révolutionnaires doit être invariablement et systématiquement dirigé par le Parti du prolétariat, c'est-à-dire par le Parti Communiste. Avant-garde organisée de la classe ouvrière, le Parti Communiste répond également aux besoins économiques, politiques et spirituels de la classe ouvrière toute entière. Il doit être l'âme des syndicats et des Soviets ainsi que de toutes les autres formes d'organisation prolétarienne.

L'apparition des Soviets, forme historique principale de la dictature du prolétariat, ne diminue nullement le rôle dirigeant du Parti Communiste dans la révolution prolétarienne. Quand les communistes allemands de "gauche» (voir leur 
Manifeste au prolétariat allemand du 14 avril 1920 signé par « le Parti ouvrier communiste allemand ») déclarent que « le Parti doit, lui aussi, s’adapter de plus en plus à l’idée soviétique et se prolétariser » (Kommunistische Arbeiterzeitung, $\mathrm{N}^{\circ}$ 54) nous ne voyons là qu'une expression insinuante de cette idée que le Parti Communiste doit se fondre dans les Soviets et que les Soviets peuvent le remplacer.

Cette idée est profondément erronée et réactionnaire.

L’histoire de la révolution russe nous montre à un certain moment, les Soviets allant à l'encontre du Parti prolétarien et soutenant les agents de la bourgeoisie. On a pu observer la même chose en Allemagne. Et cela est aussi possible dans les autres pays.

Pour que les Soviets puissent remplir leur mission historique, l'existence d'un Parti Communiste assez fort pour ne pas «s'adapter» aux Soviets mais pour exercer sur eux une influence décisive, les contraindre à « ne pas s’adapter » à la bourgeoisie et à la social-démocratie officielle, les conduire par le moyen de cette fraction communiste, est au contraire nécessaire.

9. Le Parti Communiste n'est pas seulement nécessaire à la classe ouvrière avant et pendant la conquête, du pouvoir, mais encore après celle-ci. L'histoire du Parti Communiste russe, qui détient depuis trois ans le pouvoir, montre que le rôle du Parti Communiste, loin de diminuer depuis la conquête du pouvoir, s'est considérablement accru.

10. Au jour de la conquête du pouvoir par le prolétariat, le Parti du prolétariat ne constitue pourtant qu'une fraction de la classe des travailleurs. Mais c'est la fraction qui a organisé la victoire. Pendant vingt ans, comme nous l'avons vu en Russie depuis une suite d'années, comme nous l'avons vu en Allemagne, le Parti Communiste lutte non seulement contre la bourgeoisie, mais aussi contre ceux d'entre les socialistes qui ne font en réalité que manifester l'influence des idées bourgeoises sur le prolétariat ; le Parti Communiste s’est assimilé les militants les plus stoïques, les plus clairvoyants, les plus avancés de la classe ouvrière. Et l'existence d'une semblable organisation prolétarienne permet de surmonter tou- 
tes les difficultés auxquelles se heurte le Parti Communiste dès le lendemain de sa victoire. L'organisation d'une nouvelle Armée Rouge prolétarienne, l'abolition effective du mécanisme gouvernemental bourgeois et la création des premiers linéaments de l'appareil gouvernemental prolétarien, la lutte contre les tendances corporatistes de certains groupements ouvriers, la lutte contre le patriotisme régional et l'esprit de clocher, les efforts en vue de susciter une nouvelle discipline du travail, - autant de domaines où le Parti Communiste, dont les membres entraînent par leur vivant exemple les masses ouvrières, doit dire le mot décisif.

11. La nécessité d’un Parti politique du prolétariat ne disparaît qu'avec les classes sociales. Dans la marche du communisme vers la victoire définitive il est possible que le rapport spécifique qui existe entre les trois formes essentielles de l'organisation prolétarienne contemporaine (Partis, Soviets, Syndicats d'industrie) soit modifié et qu'un type unique, synthétique, d'organisation ouvrière se cristallise peu à peu. Mais le Parti Communiste ne se dissoudra complètement au sein de la classe ouvrière que lorsque le communisme cessera d'être l'enjeu de la lutte sociale, lorsque la classe ouvrière sera, toute entière, devenue communiste.

12. Le $2^{\circ}$ Congrès de l'Internationale Communiste doit non seulement confirmer le Parti dans sa mission historique, mais encore indiquer au prolétariat international tout au moins les lignes essentielles du Parti qui nous est nécessaire.

13. L'Internationale Communiste est d'avis que, surtout à l'époque de la dictature du prolétariat, le Parti Communiste doit être basé sur une inébranlable centralisation prolétarienne. Pour diriger efficacement la classe ouvrière dans la guerre civile longue et opiniâtre, devenue imminente, le Parti Communiste doit établir en son sein une discipline de fer, une discipline militaire. L'expérience du Parti Communiste russe qui a pendant trois ans dirigé avec succès la classe ouvrière à travers les péripéties de la guerre civile, a montré que sans la plus forte discipline, sans une centralisation achevée, sans une confiance absolue des adhérents envers le centre directeur du Parti, la victoire des travailleurs est impossible. 
14. Le Parti Communiste doit être basé sur une centralisation démocratique. La constitution par voie d'élection des comités secondaires, la soumission obligatoire de tous les comités au comité qui leur est supérieur et l'existence d'un centre muni de pleins pouvoirs, dont l'autorité ne peut, dans l'intervalle entre les Congrès du Parti, être contestée par personne, tels sont les principes essentiels de la centralisation démocratique.

15. Toute une série de Partis Communistes en Europe et en Amérique sont rejetés par l'état de siège en dehors de la légalité. Il convient de se rappeler que le principe électif peut avoir à souffrir, dans ces conditions, quelques atteintes et qu'il peut être nécessaire d'accorder aux organes directeurs du Parti le droit de coopter des membres nouveaux. Il en fut ainsi naguère en Russie. Durant l'état de siège le Parti Communiste ne peut évidemment pas avoir recours au référendum démocratique, toutes les fois qu'une question grave se pose (comme l'aurait voulu un groupe de communistes américains) ; il doit au contraire donner à son centre dirigeant la possibilité et le droit de décider promptement au moment opportun, pour tous les membres du Parti.

16. La revendication d'une large « autonomie » pour les groupes locaux du Parti ne peut en ce moment qu'affaiblir les rangs du Parti Communiste, diminuer sa capacité d'action et favoriser le développement des tendances anarchistes et petites-bourgeoises contraires à la centralisation.

17. Dans les pays où le pouvoir est encore détenu par la bourgeoisie ou par la social-démocratie contre-révolutionnaire, les Partis communistes doivent apprendre à juxtaposer systématiquement l'action légale et l'action clandestine. Cette dernière doit toujours contrôler effectivement la première. Les groupes parlementaires communistes de même que les fractions communistes opérant au sein des diverses institutions de l'Etat, tant centrales que locales, doivent être entièrement subordonnées au Parti Communiste - quelle que soit la situation, légale ou non, du Parti. Les mandataires qui d'une façon ou d'une autre ne se soumettent pas au Parti doivent en être exclus. La presse légale (journaux, éditions diverses) doit dépendre en tout et pour tout de l’ensemble du Parti et de son comité central. 
18. Dans toute action organisatrice du Parti et des communistes la pierre angulaire doit être posée par l'organisation d'un noyau communiste partout où l'on trouve quelques prolétaires et quelques demi-prolétaires. Dans tout Soviet, dans tout syndicat, dans toute coopérative, dans tout atelier, dans tout comité de locataires, dans toute institution où trois personnes sympathisent avec le communisme, un noyau communiste doit être immédiatement organisé. L’organisation communiste est la seule porte permettant à l'avant-garde de la classe ouvrière d'entraîner derrière elle toute la classe ouvrière. Tous les noyaux communistes agissant parmi les organisations politiquement neutres sont absolument subordonnés au Parti dans son ensemble, que l'action du Parti soit légale ou clandestine. Les noyaux communistes doivent être classés dans une stricte dépendance réciproque, à établir de la façon la plus précise.

19. Le Parti Communiste naît presque toujours dans les grands centres, parmi les travailleurs de l'industrie urbaine. Pour assurer à la classe ouvrière la victoire la plus facile et la plus rapide, il est indispensable que le Parti Communiste ne soit pas exclusivement un Parti urbain. Il doit s’étendre aussi dans les campagnes et, à cette fin, se consacrer à la propagande et à l'organisation des journaliers agricoles, des paysans pauvres et moyens. Le Parti communiste doit poursuivre avec un soin particulier l'organisation de noyaux communistes dans les villages.

L’organisation internationale du prolétariat ne peut être forte que si cette façon d'envisager le rôle du Parti Communiste est admise dans tous les pays où vivent et luttent des communistes. L'Internationale Communiste invite tous les syndicats acceptant les principes de la $3^{\mathrm{e}}$ Internationale à rompre avec l'Internationale Jaune. L'Internationale organisera une section internationale des syndicats rouges qui se placent sur le terrain du communisme. L'Internationale Communiste ne refusera pas le concours de toute organisation ouvrière politiquement neutre désireuse de combattre la bourgeoisie. Mais l'Internationale Communiste ne cessera, ce faisant, de prouver aux prolétaires du monde : $1^{\circ}$ que le Parti communiste est l'arme principale, essentielle, de l'émancipation du prolétariat ; nous devons avoir maintenant dans tous les pays, non plus des groupes et des tendances, mais un Parti Communiste ; $2^{\circ}$ qu'il ne doit y avoir dans chaque pays 
qu'un seul et unique Parti Communiste $; 3^{\circ}$ que le Parti Communiste doit être fondé sur le principe de la plus stricte centralisation et doit instituer en son sein, à l'époque de la guerre civile, une discipline militaire ; $4^{\circ}$ que partout où il n’y a ne fut-ce qu'une dizaine de prolétaires ou de demi-prolétaires, le Parti Communiste doit avoir son noyau organisé $; 5^{\circ}$ que dans toute organisation apolitique il doit y avoir un noyau communiste strictement subordonné au Parti dans son entier ; $6^{\circ}$ que défendant inébranlablement et avec un absolu dévouement le programme et la tactique révolutionnaire du Communisme, le Parti doit rester toujours en relations étroites avec les organisations des grandes masses ouvrières et doit se garder du sectarisme autant que du manque de principes. 
Manifestes, thèses et résolutions des quatre premiers congrès

de l'Internationale communiste 1919-1923

(juin 1934)

Deuxième Congrès, juillet 1920.

-5 -

Le mouvement syndical,

les comités de fabrique et d'usines

\section{I.}

\section{$\underline{\text { Retour à la table des matières }}$}

1. Les syndicats créés par la classe ouvrière pendant la période du développement pacifique du capitalisme représentaient des organisations ouvrières destinées à lutter pour la hausse des salaires ouvriers sur le marché du travail et l'amélioration des conditions du travail salarié. Les marxistes révolutionnaires furent obligés d'entrer en contact avec le Parti politique du prolétariat, le Parti social-démocrate, afin d'engager une lutte commune pour le Socialisme. Les mêmes raisons qui, à de rares exceptions près, avaient fait de la démocratie socialiste non une arme de la lutte révolutionnaire du prolétariat pour le renversement du capitalisme, mais une organisation entrainnant l'effort révolutionnaire du prolétariat dans l'intérêt de la bourgeoisie, firent que, pendant la guerre, les syndicats se présentèrent le plus souvent en qualité d'éléments de l'appareil militaire de la bourgeoisie ; ils aidèrent cette dernière à exploiter la classe ouvrière avec la plus grande intensité et à faire mener la guerre de la manière la plus énergique, au nom des intérêts du capitalisme. N'englobant que les ouvriers spécialisés les mieux rétribués par les patrons, n’agissant que dans des limites corporatives très étroites, 
enchaînés par un appareil bureaucratique, complètement étranger aux masses trompées par leurs leaders opportunistes, les syndicats ont non seulement trahi la cause de la Révolution sociale, mais aussi celle de la lutte pour l'amélioration des conditions de la vie des ouvriers qu'ils avaient organisés. Ils ont abandonné le terrain de la lutte professionnelle contre les patrons et l'ont remplacé, coûte que coûte, par un programme de transactions aimables avec les capitalistes. Cette politique a été non seulement celle des Trade-Unions libérales en Angleterre et en Amérique, des syndicats libres, prétendument socialistes d'Allemagne et d'Autriche, mais aussi des Unions syndicales de France.

2. Les conséquences économiques de la guerre, la désorganisation complète du système économique du monde entier, la cherté affolante de la vie, l'exploitation la plus intense du travail des femmes et des enfants, la question de l'habitation, qui vont progressivement de mal en pis, tout cela pousse les masses prolétariennes dans la voie de la lutte contre le capitalisme. Par son caractère et par son envergure se dessinant plus nettement de jour en jour, ce combat devient une grande bataille révolutionnaire détruisant les bases générales du capitalisme. L’augmentation des salaires d'une catégorie quelconque d'ouvriers, arrachée aux patrons au prix d'une lutte économique acharnée, est réduite le lendemain à zéro par la hausse du coût de la vie. Or, la hausse des prix doit continuer, car la classe capitaliste des pays vainqueurs, tout en ruinant par sa politique d'exploitation l'Europe orientale et centrale, n'est pas en état d'organiser le système économique du monde entier ; elle le désorganise au contraire de plus en plus. Pour s’assurer le succès dans la lutte économique, les larges masses ouvrières qui demeuraient jusqu'à présent en dehors des syndicats y affluent maintenant. On constate dans tous les pays capitalistes une croissance prodigieuse des syndicats qui ne représentent plus maintenant l'organisation des seuls éléments avancés du prolétariat, mais celle de toute sa masse. En entrant dans les syndicats, les masses cherchent à en faire leur arme de combat. L'antagonisme des classes devenant toujours de plus en plus aigu force les syndicats à organiser des grèves dont la répercussion se fait sentir dans le monde capitaliste tout entier, en interrompant le processus de la production et de l'échange capitalistes. En augmentant leurs exigences à mesure qu'augmente le prix de la vie et qu'elles-mêmes s'épuisent de plus en plus, les masses ouvrières détruisent par cela même tout calcul capitaliste qui représente le 
fondement élémentaire d'une économie organisée. Les syndicats, qui étaient devenus pendant la guerre les organes de l'asservissement des masses ouvrières aux intérêts de la bourgeoisie, représentent maintenant les organes de la destruction du capitalisme.

3. Mais la vieille bureaucratie professionnelle et les anciennes formes de l'organisation syndicale entravent de toute manière cette transformation du caractère des syndicats. La vieille bureaucratie professionnelle cherche partout à faire garder aux syndicats leur caractère d'organisations de l'aristocratie ouvrière ; elle cherche à maintenir en vigueur les règles rendant impossible l'entrée des masses ouvrières mal payées dans les syndicats. La vieille bureaucratie syndicale s'efforce encore de remplacer le mouvement gréviste qui revêt chaque jour de plus en plus le caractère d'un conflit révolutionnaire entre la bourgeoisie et le prolétariat par une politique de contrats à long terme qui ont perdu toute signification en présence des variations fantastiques des prix. Elle cherche à imposer aux ouvriers la politique des communes ouvrières, des Conseils réunis de l'industrie (Joint Industrials Councils) et à entraver par la voie légale, grâce à l'aide de l'Etat capitaliste, l'expansion du mouvement gréviste. Aux moments critiques de la lutte, la bourgeoisie sème la discorde parmi les masses ouvrières militantes et empêche les actions isolées de différentes catégories d'ouvriers de fusionner dans une action de classe générale; elle est soutenue dans ces tentatives par l'œuvre des anciennes organisations syndicales, morcelant les travailleurs d'une branche d'industrie en groupes professionnels artificiellement isolés, bien qu'ils soient tous rattachés les uns aux autres par le fait même de l'exploitation capitaliste. Elle s'appuie sur le pouvoir de la tradition idéologique de l'ancienne aristocratie ouvrière, bien que cette dernière soit sans cesse affaiblie par l'abolition des privilèges de divers groupes du prolétariat ; cette abolition s'explique par la décomposition générale du capitalisme, le nivellement de la situation de divers éléments de la classe ouvrière, l'égalisation de leurs besoins et leur manque de sécurité.

C'est de cette manière que la bureaucratie syndicale substitue de faibles ruisseaux au puissant courant du mouvement ouvrier, substitue des revendications partielles réformistes aux buts révolutionnaires généraux du mouvement et entrave d'une manière générale la transformation des efforts isolés du prolétariat en une lutte révolutionnaire unique tendant à la destruction du capitalisme. 
4. Étant donnée la tendance prononcée des larges masses ouvrières à s'incorporer dans les syndicats, et considérant le caractère objectivement révolutionnaire de la lutte que ces masses soutiennent en dépit de la bureaucratie professionnelle, il importe que les communistes de tous les pays fassent partie des syndicats et travaillent à en faire des organes conscients de lutte pour le renversement du régime capitaliste et le triomphe du Communisme. Ils doivent prendre l'initiative de la création des syndicats partout où ces derniers n'existent pas encore.

Toute désertion volontaire du mouvement professionnel, toute tentative de création artificielle de syndicats qui ne serait pas déterminée par les violences excessives de la bureaucratie professionnelle (dissolution des filiales locales révolutionnaires syndicales par les centres opportunistes) ou par leur étroite politique aristocratique fermant aux grandes masses de travailleurs peu qualifiés l'entrée des organes syndicaux, présente un danger énorme pour le mouvement communiste. Elle écarte de la masse les ouvriers les plus avancés, les plus conscients, et les pousse vers les chefs opportunistes travaillant pour les intérêts de la bourgeoisie... Les hésitations des masses ouvrières, leur indécision politique et l'influence que possèdent sur eux les leaders opportunistes ne pourront être vaincus que par une lutte de plus en plus âpre dans la mesure où les couches profondes du prolétariat apprendront par expérience, par les leçons de leurs victoires et de leurs défaites, que jamais le système économique capitaliste ne leur permettra d'obtenir des conditions de vie humaines et supportables, dans la mesure où les travailleurs communistes avancés apprendront, par l'expérience de leur lutte économique, à être non seulement des propagandistes théoriques de l'idée communiste, mais aussi des meneurs résolus de l'action économique et syndicale. Ce n'est que de cette façon qu'il sera possible d'écarter des syndicats leurs leaders opportunistes, de mettre des communistes à la tête et d'en faire un organe de la lutte révolutionnaire pour le Communisme. Ce n'est que de cette manière qu'il sera possible d'arrêter la désagrégation des syndicats, de les remplacer par des Unions industrielles, d'écarter la bureaucratie étrangère aux masses et de lui substituer un organe formé par les représentants des ouvriers industriels (Betriebsvertreter) en n’abandonnant aux institutions centrales que les fonctions strictement nécessaires. 
5. Comme les communistes attachent plus de prix au but et à la substance des syndicats qu'à leur forme, ils ne doivent pas hésiter devant les scissions qui pourraient se produire au sein des organisations syndicales si, pour les éviter, il était nécessaire d'abandonner le travail révolutionnaire, de se refuser à organiser la partie la plus exploitée du prolétariat. S'il arrive pourtant qu'une scission s’impose comme une nécessité absolue, on ne devra y recourir que possédant la certitude que les communistes réussiront par leur participation économique à convaincre les larges masses ouvrières, que la scission se justifie non par des considérations dictées par un but révolutionnaire encore très éloigné et vague, mais par les intérêts concrets immédiats de la classe ouvrière, correspondant aux nécessités de l'action économique. Dans le cas où une scission deviendrait inévitable, les communistes devraient accorder une grande attention à ce que cette scission ne les isole pas de la masse ouvrière.

6. Partout où la scission entre les tendances syndicales opportunistes et révolutionnaires s'est déjà produite, où il existe, comme en Amérique, des syndicats aux tendances révolutionnaires, sinon communistes, à côté des syndicats opportunistes, les communistes sont dans l'obligation de prêter leur concours à ces syndicats révolutionnaires, de les soutenir, de les aider à se libérer des préjugés syndicalistes et à se placer sur le terrain du Communisme, car ce dernier est l'unique boussole fidèle et sûre dans toutes les questions compliquées de la lutte économique. Partout où se constituent des organisations industrielles (soit sur la base des syndicats, soit en dehors d'eux), tels les Shop Stewards, les Betriebsraete (Conseils de Production), organisations se donnant pour but de lutter contre les tendances contre-révolutionnaires de la bureaucratie syndicale, il est bien entendu que les communistes sont tenus de les soutenir avec toute l'énergie possible. Mais le concours prêté aux syndicats révolutionnaires ne doit pas signifier la sortie des communistes des syndicats opportunistes en état d'effervescence politique et en évolution vers la lutte de classe. Bien au contraire, c'est en s'efforçant de hâter cette révolution de la masse des syndicats qui se trouvent déjà sur la voie de la lutte révolutionnaire que les communistes pourront jouer le rôle d'un élément unissant moralement et pratiquement les ouvriers organisés pour une lutte commune tendant à la destruction du régime capitaliste. 
7. À l'époque où le capitalisme tombe en ruines, la lutte économique du prolétariat se transforme en lutte politique beaucoup plus rapidement qu'à l'époque de développement pacifique du régime capitaliste. Tout conflit économique important peut soulever devant les ouvriers la question de la Révolution. Il est donc du devoir des communistes de faire ressortir devant les ouvriers, dans toutes les phases de la lutte économique, que cette lutte ne saurait être couronnée de succès que lorsque la classe ouvrière aura vaincu la classe capitaliste dans une bataille rangée et se chargera, sa dictature une fois établie, de l'organisation socialiste du pays. C'est en partant de là que les communistes doivent tendre à réaliser, dans la mesure du possible, une union parfaite entre les syndicats et le Parti Communiste, en les subordonnant à ce dernier, avant-garde de la Révolution. Dans ce but, les communistes doivent organiser dans tous ces syndicats et Conseils de Production (Betriebsraeie) des fractions communistes, qui les aideront à s emparer du mouvement syndical et à le diriger.

\section{II.}

1. La lutte économique du prolétariat pour la hausse des salaires et pour l'amélioration générale des conditions de la vie des masses accentue tous les jours son caractère de lutte sans issue. La désorganisation économique qui envahit un pays après l'autre, dans une proportion toujours croissante, démontre, même aux ouvriers les plus arriérés, qu'il ne suffit pas de lutter pour la hausse des salaires et la réduction de la journée de travail, que la classe capitaliste perd de plus en plus la capacité de rétablir la vie économique et de garantir aux ouvriers ne fut ce que les conditions d'existence qu'elle leur assurait avant la guerre. La conscience toujours croissante des masses ouvrières fait naître parmi eux une tendance à créer des organisations capables d'entamer la lutte pour la renaissance économique au moyen du contrôle ouvrier exercé sur l'industrie par les Conseils de Production. Cette tendance à créer des Conseils industriels ouvriers, qui gagne les ouvriers de tous les pays, tire son origine de facteurs différents et multiples (lutte contre la bureaucratie réactionnaire, fatigue causée par les défaites essuyées par les syndicats, tendances à la création d'organisations embrassant tous les travailleurs) et s'inspire en définitive de l'effort fait pour réaliser le contrôle de l'industrie, tâche 
historique spéciale des Conseils industriels ouvriers. C’est pourquoi on commettrait une erreur en cherchant à ne former ces Conseils que d'ouvriers partisans de la dictature du prolétariat. La tâche du Parti Communiste consiste, au contraire, à profiter de la désorganisation économique pour organiser les ouvriers et à les mettre dans la nécessité de combattre pour la dictature du prolétariat tout en élargissant l'idée de la lutte pour le contrôle ouvrier, idée que tous comprennent maintenant.

2. Le Parti Communiste ne pourra s'acquitter de cette tâche qu'en consolidant dans la conscience des masses la ferme assurance que la restauration de la vie économique sur la base capitaliste est actuellement impossible ; elle signifierait d'ailleurs un nouvel asservissement à la classe capitaliste. L’organisation économique correspondant aux intérêts des masses ouvrières n'est possible que si l'Etat est gouverné par la classe ouvrière et si la main ferme de la dictature prolétarienne se charge de l'abolition du capitalisme et de la nouvelle organisation socialiste.

3. La lutte des Comités de fabriques et d'usines contre le capitalisme a pour but immédiat l'introduction du contrôle ouvrier dans toutes les branches de l'industrie. Les ouvriers de chaque entreprise, indépendamment de leurs professions, souffrent du sabotage des capitalistes qui estiment assez souvent que la suspension de l'activité de telle ou telle industrie leur sera avantageuse, la faim devant contraindre les ouvriers à accepter les conditions les plus dures pour éviter à quelque capitaliste un accroissement de frais. La lutte contre cette sorte de sabotage unit la plupart des ouvriers indépendamment de leurs idées politiques, et fait des Comités d'usines et de fabriques, élus par tous les travailleurs d'une entreprise, de véritables organisations de masse du prolétariat. Mais la désorganisation de l'économie capitaliste est non seulement la conséquence de la volonté consciente des capitalistes, mais aussi et beaucoup plus celle de la décadence irrésistible de leur régime. Aussi, les Comités ouvriers seront-ils forcés, dans leur action contre les conséquences de cette décadence, à dépasser les bornes du contrôle des fabriques et des usines isolées et se trouveront-ils bientôt en face de la question du contrôle ouvrier à exercer sur des branches entières de l'industrie et sur son ensemble. Les tentatives d'ouvriers d'exercer leur contrôle non seulement sur 
l'approvisionnement des fabriques et des usines en matières premières, mais aussi sur les opérations financières des entreprises industrielles, provoqueront cependant, de la part de la bourgeoisie et du gouvernement capitaliste, des mesures de rigueur contre la classe ouvrière, ce qui transformera la lutte ouvrière pour le contrôle de l'industrie en une lutte pour la conquête du pouvoir par la classe ouvrière.

4. La propagande en faveur des Conseils industriels doit être menée de manière à ancrer dans la conviction des grandes masses ouvrières, même de celles qui n’appartiennent pas directement au prolétariat industriel, que la responsabilité de la désorganisation économique incombe à la bourgeoisie, et que le prolétariat, exigeant le contrôle ouvrier, lutte pour l'organisation de l'industrie, pour la suppression de la spéculation et de la vie chère. La tâche des Partis Communistes est de combattre pour le contrôle de l'industrie, en profitant dans ce but de toutes les circonstances se trouvant à l'ordre du jour, de la pénurie du combustible et de la désorganisation des transports, en fusionnant dans le même but les éléments isolés du prolétariat et en attirant de son côté les milieux les plus larges de la petite bourgeoisie qui se prolétarise davantage de jour en jour et souffre cruellement de la désorganisation économique.

5. Les Conseils industriels ouvriers ne sauraient remplacer les syndicats. Ils ne peuvent que s'organiser au courant de l'action dans diverses branches de l'industrie et créer peu à peu un appareil général capable de diriger toute la lutte. Déjà, à l'heure qu'il est, les syndicats représentent des organes de combat centralisés, bien qu'ils n’englobent pas des masses ouvrières aussi larges que peuvent embrasser les Conseils industriels ouvriers en leur qualité d'organisations accessibles à toutes les entreprises ouvrières. Le partage de toutes les tâches de la classe ouvrière entre les Comités industriels ouvriers et les syndicats est le résultat du développement historique de la Révolution sociale. Les syndicats ont organisé les masses ouvrières dans le but d'une lutte pour la hausse des salaires et pour la réduction des journées ouvrières et l'ont fait sur une large échelle. Les Conseils ouvriers industriels s'organisent pour le contrôle ouvrier de l'industrie et la lutte contre la désorganisation économique ; ils englobent toutes les entreprises ouvriè- 
res, mais la lutte qu'ils soutiennent ne peut revêtir que très lentement un caractère politique général. Ce n’est que dans la mesure où les syndicats arriveront à surmonter les tendances contre-révolutionnaires de leur bureaucratie, ou deviendront des organes conscients de la Révolution, que les communistes auront le devoir de soutenir les Conseils industriels ouvriers dans leurs tendances à devenir des groupes industriels syndicalistes.

6. La tâche des communistes se réduit aux efforts qu'ils doivent faire pour que les syndicats et les Conseils industriels ouvriers se pénètrent du même esprit de résolution combative, de conscience et de compréhension des meilleures méthodes de combat, c'est-à-dire de l'esprit communiste. Pour s'en acquitter, les communistes doivent soumettre, en fait, les syndicats et les Comités ouvriers au Parti Communiste et créer ainsi des organes prolétariens des masses qui serviront de base à un puissant Parti prolétarien centralisé, englobant toutes les organisations prolétariennes et les faisant toutes marcher dans la voie que conduit à la victoire de la classe ouvrière et à la dictature du prolétariat — au Communisme.

7. Pendant que les communistes se font des syndicats et des Conseils industriels une arme puissante pour la Révolution, ces organisations des masses se préparent au grand rôle qui leur incombera avec l'établissement de la dictature du prolétariat. Ce sera en effet leur devoir de devenir la base socialiste de la nouvelle organisation de la vie économique. Les syndicats, organisés en qualité de piliers de l'industrie, s’appuyant sur les Conseils industriels ouvriers qui représenteront les organisations des fabriques et des usines, enseigneront aux masses ouvrières leur devoir industriel, formeront avec les ouvriers les plus avancés des directeurs d'entreprises, organiseront le contrôle technique des spécialistes ; ils étudieront et exécuteront, de concert avec les représentants du pouvoir ouvrier, les plans de la politique économique socialiste. 


\section{III.}

Les syndicats manifestaient en temps de paix des tendances à former une Union internationale. Pendant les grèves, les capitalistes recouraient à la maind'œuvre des pays voisins et aux services des « renards » étrangers. Mais avant la guerre, l'Internationale syndicale n'avait qu'une importance secondaire. Elle s'occupait de l'organisation de secours financiers réciproques et d'un service de statistique concernant la vie ouvrière, mais elle ne cherchait pas à unifier la vie ouvrière parce que les syndicats dirigés par des opportunistes, faisaient leur possible pour se soustraire à toute lutte révolutionnaire internationale. Les leaders opportunistes des syndicats qui, pendant la guerre, furent les serviteurs fidèles de la bourgeoisie dans leurs pays respectifs, cherchent maintenant à restaurer l'Internationale syndicale en se faisant une arme du capitalisme universel international, dirigée contre le prolétariat. Ils créent avec Jouhaux, Gompers, Legien, etc..., un « Bureau de Travail » auprès de la « Ligue des Nations », qui n’est autre chose qu'une organisation de brigandage capitaliste international. Ils tâchent d'étouffer dans tous les pays le mouvement gréviste en faisant décréter l'arbitrage obligatoire des représentants de l'Etat capitaliste. Ils cherchent partout à obtenir, à force de compromis avec les capitalistes, toutes espèces de faveurs pour les ouvriers capitalistes, afin de briser de cette manière l'union chaque jour plus étroite de la classe ouvrière. L'Internationale syndicale d'Amsterdam est donc la remplaçante de la $2^{\mathrm{e}}$ Internationale de Bruxelles en faillite. Les ouvriers communistes qui font partie des syndicats de tous les pays doivent, au contraire, travailler à la création d'un front syndicaliste international. Il ne s'agit plus de secours pécuniaires en cas de grève ; il faut désormais qu'au moment où le danger menacerait la classe ouvrière d'un pays, les syndicats des autres pays, en qualité d'organisations de masses, prennent sa défense et fassent tout pour empêcher la bourgeoisie de leur pays de venir en aide à celle qui est aux prises avec la classe ouvrière. Dans tous les Etats, la lutte économique du prolétariat devient de plus en plus révolutionnaire. Aussi les syndicats doivent-ils employer consciemment toute leur énergie à appuyer toute action révolutionnaire, tant dans leur propre pays que dans les autres. Ils doivent s'orienter dans ce but vers la plus grande centralisation de 
l'action, non seulement dans chaque pays à part, mais aussi dans l'Internationale ; ils le feront en adhérant à l'Internationale Communiste et en y fusionnant en une seule armée les divers éléments engagés dans le combat, afin qu'ils agissent de concert et se prêtent un concours mutuel. 
Manifestes, thèses et résolutions des quatre premiers congrès de l'Internationale communiste 1919-1923

(juin 1934)

Deuxième Congrès, juillet 1920.

- 6 -

Thèses et additions sur les questions nationale et coloniale

\section{A. - Thèses}

\section{$\underline{\text { Retour à la table des matières }}$}

1. La position abstraite et formelle de la question de l'égalité — l'égalité des nationalités y étant incluse - est propre à la démocratie bourgeoise sous la forme de l'égalité des personnes, en général; la démocratie bourgeoise proclame l'égalité formelle ou juridique du prolétaire, de l'exploiteur et de l'exploité, induisant ainsi les classes opprimées dans la plus profonde erreur. L'idée d'égalité, qui n'était que le reflet des rapports créés par la production pour le négoce, devient, entre les mains de la bourgeoisie, une arme contre l'abolition des classes combattue désormais au nom de l'égalité absolue des personnalités humaines. Quant à la signification véritable de la revendication égalitaire, elle ne réside que dans la volonté d'abolir les classe.

2. Conformément à son but essentiel — la lutte contre la démocratie bourgeoise, dont il s'agit de démasquer l'hypocrisie - le Parti communiste, interprète conscient du prolétariat en lutte contre le joug de la bourgeoisie, doit considérer comme formant la clef de voûte de la question nationale, non des principes abstraits et formels, mais : $1^{\circ}$ une notion claire des circonstances historiques et éco- 
nomiques ; $2^{\circ}$ la dissociation précise des intérêts des classes opprimées, des travailleurs, des exploités, par rapport à la conception générale des soi-disant intérêts nationaux, qui signifient en réalité ceux des classes dominantes ; $3^{\circ}$ la division tout aussi nette et précise des nations opprimées, dépendantes, protégées - et oppressives et exploiteuses, jouissant de tous les droits, contrairement à l'hypocrisie bourgeoise et démocratique qui dissimule, avec soin, l'asservissement (propre à l'époque du capital financier de l'impérialisme) par la puissance financière et colonisatrice, de l'immense majorité des populations du globe à une minorité de riches pays capitalistes.

3. La guerre impérialiste de 1914-1918 a mis en évidence devant toutes les nations et toutes les classes opprimées du monde la duperie des phraséologies démocratiques et bourgeoises - le traité de Versailles, dicté par les fameuses démocraties occidentales, ne faisant que sanctionner, à l'égard des nations faibles, des violences plus lâches et plus cyniques encore que celles des junkers et du kaiser à Brest-Litovsk. La Ligue des Nations et la politique de l'Entente dans leur ensemble ne font que confirmer ce fait et développer l'action révolutionnaire du prolétariat des pays avancés et des masses laborieuses des pays colonisés ou assujettis, hâtant ainsi la banqueroute des illusions nationales de la petite-bourgeoise, quant à la possibilité d'un paisible voisinage et d'une égalité véritable des nations, sous le régime capitaliste.

4. Il résulte de ce qui précède que la pierre angulaire de la politique de l'Internationale Communiste, dans les questions coloniale et nationale, doit être le rapprochement des prolétaires et des travailleurs de toutes les nations et de tous les pays pour la lutte commune contre les possédants et la bourgeoisie. Car ce rapprochement est la seule garantie de notre victoire sur le capitalisme, sans laquelle ne peuvent être abolies ni les oppressions nationales, ni l'inégalité.

5. La conjoncture politique mondiale actuelle met à l'ordre du jour la dictature du prolétariat; et tous les événements de la politique mondiale se concentrent inévitablement autour d'un centre de gravité : la lutte de la bourgeoisie internationale contre la République des Soviets, qui doit grouper autour d'elle d'une part les mouvements soviétiques des travailleurs avancés de tous les pays, de l'autre tous les mouvements émancipateurs nationaux des colonies et des nationalités opprimées qu'une expérience amère a convaincues qu'il n’est pas de salut, pour elles, 
en dehors d'une alliance avec le prolétariat révolutionnaire et avec le pouvoir soviétique victorieux de l’impérialisme mondial.

6. On ne peut donc plus se borner à reconnaître ou proclamer le rapprochement des travailleurs de tous les pays. Il est désormais nécessaire de poursuivre la réalisation de l'union la plus étroite de tous les mouvements émancipateurs nationaux et coloniaux avec la Russie des Soviets, en donnant à cette union des formes correspondantes au degré d'évolution du mouvement prolétarien parmi le prolétariat de chaque pays, ou du mouvement émancipateur démocrate bourgeois parmi les ouvriers et les paysans des pays arriérés ou de nationalités arriérées.

7. Le principe fédératif nous apparaît comme une forme transitoire vers l'unité complète des travailleurs de tous les pays. Le principe fédératif a déjà montré pratiquement sa conformité au but poursuivi, tant au cours des relations entre la République Socialiste Fédérative des Soviets russes et les autres républiques des Soviets (hongroise, finlandaise, lettone, par le passé ; azerbaïdjane et ukrainienne, présentement), qu'au sein même de la République russe, à l'égard de nationalités qui n’avaient auparavant ni Etat, ni existence autonome (exemple les républiques autonomes des Bashkirs et des Tartares, créées en Russie soviétique en 1919 et 1920).

8. La tâche de l'Internationale Communiste est d'étudier et de vérifier l'expérience (et le développement ultérieur) de ces nouvelles fédérations basées sur la forme soviétique et sur le mouvement soviétique. Considérant la fédération comme une forme transitoire vers l'unité complète, il nous est nécessaire de tendre à une union fédérative de plus en plus étroite, en tenant compte :

1. de l'impossibilité de défendre, sans la plus étroite union entre elles, les républiques soviétiques entourées d'ennemis impérialistes infiniment supérieurs par leur puissance militaire ;

2. de la nécessité d'une étroite union économique des républiques soviétiques, sans laquelle la réédification des forces productrices détruites par l'impérialisme, la sécurité et le bien-être des travailleurs ne peuvent être assurés ; 
3. de la tendance à la réalisation d'un plan économique universel dont l'application régulière serait contrôlée par le prolétariat de tous les pays, tendance qui s'est manifestée avec évidence sous le régime capitaliste et doit certainement continuer son développement et arriver à la perfection par le régime socialiste.

9. Dans le domaine des rapports sociaux à l'intérieur des Etats constitués, l'Internationale Communiste ne peut se borner à la reconnaissance formelle, purement officielle et sans conséquences pratiques, de l'égalité des nations, dont se contentent les démocrates bourgeois qui s’intitulent socialistes.

Il ne suffit pas de dénoncer inlassablement dans toute la propagande et l'agitation des Partis communistes - et du haut de la tribune parlementaire comme en dehors d'elle - les violations constantes du principe de l'égalité des nationalités et des droits des minorités nationales, dans tous les Etats capitalistes (et en dépit de leurs « constitutions » démocratiques); il faut aussi démontrer sans cesse que le gouvernement des Soviets seul peut réaliser l'égalité des nationalités en unissant les prolétaires d'abord, l'ensemble des travailleurs ensuite, dans la lutte contre la bourgeoisie ; il faut aussi démontrer que le régime des Soviets assure un concours direct, par l'intermédiaire du Parti communiste, à tous les mouvements révolutionnaires des pays dépendants ou lésés dans leurs droits (par exemple, l’Irlande, les noirs d'Amérique, etc...) et des colonies.

Sans cette condition particulièrement importante de la lutte contre l'oppression des pays asservis ou colonisés, la reconnaissance officielle de leur droit à l'autonomie, n'est qu'une enseigne mensongère, comme nous le voyons par la 2e Internationale.

10. C'est la pratique habituelle non seulement des partis du centre de la 2e Internationale, mais aussi de ceux qui ont abandonné cette Internationale pour reconnaître l'internationalisme en paroles et pour lui substituer en réalité, dans la propagande, l'agitation et la pratique, le nationalisme et le pacifisme des petitsbourgeois. Cela se voit aussi parmi les partis qui s'intitulent maintenant communistes. La lutte contre ce mal et contre les préjugés petits-bourgeois les plus profondément ancrés (se manifestant sous des formes variées, telles que la haine des 
races, l'antagonisme national et l'antisémitisme) acquiert une importance d'autant plus grande que le problème de la transformation de la dictature prolétarienne nationale (qui n'existe que dans un pays et qui, par conséquent, est incapable d'exercer une influence sur la politique mondiale) en dictature prolétarienne internationale (celle que réaliseraient au moins plusieurs pays avancés et qui seraient capables d'exercer une influence décisive sur la politique mondiale) devient plus actuel. Le nationalisme petit-bourgeois restreint l'internationalisme à la reconnaissance du principe d'égalité des nations et (sans insister davantage sur son caractère purement verbal) conserve intact l'égoïsme national tandis que l’internationalisme prolétarien exige :

1. La subordination des intérêts de la lutte prolétarienne dans un pays à l'intérêt de cette lutte dans le monde entier ;

2. De la part des nations qui ont vaincu la bourgeoisie, le consentement aux plus grands sacrifices nationaux en vue du renversement du capital international. Dans le pays où le capitalisme atteint déjà son développement complet, où existent les partis ouvriers formant l'avant-garde du prolétariat, la lutte contre les déformations opportunistes et pacifistes de l'internationalisme, par la petite-bourgeoise, est donc un devoir immédiat des plus importants.

11. À l'égard des Etats et des pays les plus arriérés, où prédominent des institutions féodales ou patriarcales rurales, il convient d'avoir en vue :

1. La nécessité du concours de tous les partis communistes aux mouvements révolutionnaires d'émancipation dans ces pays, concours qui doit être véritablement actif et dont la forme doit être déterminée par le Parti communiste du pays, s'il en existe un. L'obligation de soutenir activement ce mouvement incombe naturellement en premier lieu aux travailleurs de la métropole ou du pays, dans la dépendance financière duquel se trouve le peuple en question ; 
2. La nécessité de combattre l'influence réactionnaire et moyenâgeuse du clergé, des missions chrétiennes et autres éléments ;

3. Il est aussi nécessaire de combattre le panislamisme, le panasiatisme et autres mouvements similaires qui tâchent d'utiliser la lutte émancipatrice contre l’impérialisme européen et américain pour rendre plus fort le pouvoir des impérialistes turcs et japonais, de la noblesse, des grands propriétaires fonciers, du clergé, etc... ;

4. Il est d'une importance toute spéciale de soutenir le mouvement paysan des pays arriérés contre les propriétaires fonciers, contre les survivances ou les manifestations de l'esprit féodal ; on doit avant tout s’efforcer de donner au mouvement paysan un caractère révolutionnaire, d'organiser partout où il est possible. les paysans et tous les opprimés en Soviets et ainsi de créer une liaison très étroite du prolétariat communiste européen et du mouvement révolutionnaire paysan de l’Orient, des colonies, et des pays arriérés en général ;

5. Il est nécessaire de combattre énergiquement les tentatives faites par des mouvements émancipateurs qui ne sont en réalité ni communistes, ni révolutionnaires, pour arborer les couleurs communistes; l'Internationale Communiste ne doit soutenir les mouvements révolutionnaires dans les colonies et les pays arriérés, qu’à la condition que les éléments des plus purs partis communistes - et communistes en fait — soient groupés et instruits de leurs tâches particulières, c'est-àdire de leur mission de combattre le mouvement bourgeois et démocratique. L'Internationale Communiste doit entrer en relations temporaires et former aussi des unions avec les mouvements révolutionnaires dans les colonies et les pays arriérés, sans toutefois jamais fusionner avec eux, et en conservant toujours le caractère indépendant de mouvement prolétarien même dans sa forme embryonnaire ;

6. Il est nécessaire de dévoiler inlassablement aux masses laborieuses de tous les pays, et surtout des pays et des nations arriérées. la duperie organisée par les puissances impérialistes, avec l'aide des classes privilégiées dans les pays opprimés, lesquelles font semblant d’appeler à l'existence des Etats politiquement indépendants qui, en réalité, sont 
des vassaux - aux points de vue économique, financier et militaire. Comme exemple frappant des duperies pratiquées à l’égard de la classe des travailleurs dans les pays assujettis par les efforts combinés de l’impérialisme des Alliés et de la bourgeoisie de telle ou telle nation, nous pouvons citer l'affaire des sionistes en Palestine, où, sous prétexte de créer un Etat juif, en ce pays où les juifs sont en nombre insignifiant, le sionisme a livré la population indignée des travailleurs arabes à l'exploitation de l'Angleterre. Dans la conjoncture internationale actuelle, il n’y a pas de salut pour les peuples faibles et asservis hors de la fédération des républiques soviétiques.

12. L’opposition séculaire des petites nations et des colonies par les puissances impérialistes a fait naître, chez les masses laborieuses des pays opprimés, non seulement un sentiment de rancune envers les nations qui oppriment en général, mais encore un sentiment de défiance à l'égard du prolétariat des pays oppresseurs. L’infâme trahison des chefs officiels de la majorité socialiste en 1914-1919, alors que le socialisme chauvin qualifiait du nom de « défense nationale » la défense des « droits » de «sa bourgeoisie » à l'asservissement des colonies et à la mise en coupe réglée des pays financièrement dépendants, n’a pu qu’accroître cette défiance bien légitime. Ces préjugés ne pouvant disparaître qu'après la disparition du capitalisme et de l'impérialisme, dans les pays avancés, et après la transformation radicale de la vie économique des pays arriérés, leur extinction ne peut être que très lente, d'où le devoir, pour le prolétariat conscient de tous les pays, de se montrer particulièrement circonspect envers les survivances du sentiment national des pays opprimés depuis un temps très long, et de voir aussi à consentir à certaines concessions utiles en vue de hâter la disparition de ces préjugés et de cette défiance. La victoire sur le capitalisme est conditionnée par la bonne volonté d'entente du prolétariat d'abord et, ensuite, des masses laborieuses de tous les pays du monde et de toutes les nations. 


\section{B. - Thèses supplémentaires}

1. La fixation exacte des relations de l'Internationale communiste et du mouvement révolutionnaire dans les pays qui sont dominés par l’impérialisme capitaliste, en particulier de la Chine, est une des questions les plus importantes pour le $2^{\mathrm{e}}$ Congrès de l'Internationale Communiste. La révolution mondiale entre dans une période pour laquelle une connaissance exacte de ces relations est nécessaire. La grande guerre européenne et ses résultats ont montré très clairement que les masses des pays assujettis en dehors de l'Europe sont liées d'une façon absolue au mouvement prolétarien d'Europe, et que c’est là une conséquence inévitable du capitalisme mondial centralisé.

2. Les colonies constituent une des principales sources des forces du capitalisme européen.

Sans la possession des grands marchés et des grands territoires d'exploitation dans les colonies, les puissances capitalistes d'Europe ne pourraient pas se maintenir longtemps.

L’Angleterre, forteresse de l'impérialisme, souffre de surproduction depuis plus d'un siècle. Ce n'est qu'en conquérant des territoires coloniaux, marchés supplémentaires pour la vente des produits de surproduction et sources de matières premières pour son industrie croissante, que l'Angleterre a réussi à maintenir, malgré ses charges, son régime capitaliste.

C'est par l'esclavage des centaines de millions d'habitants de l'Asie et de l’Afrique que l’impérialisme anglais est arrivé à maintenir jusqu'à présent le prolétariat britannique sous la domination bourgeoise.

3. La plus-value obtenue par l'exploitation des colonies, est un des appuis du capitalisme moderne. Aussi longtemps que cette source de bénéfices ne sera pas supprimée, il sera difficile à la classe ouvrière de vaincre le capitalisme. 
Grâce à la possibilité d’exploiter intensément la main-d’œuvre et les sources naturelles de matières premières des colonies, les nations capitalistes d'Europe ont cherché, non sans succès, à éviter par ces moyens leur banqueroute imminente.

L’impérialisme européen a réussi dans ses propres pays à faire des concessions toujours plus grandes à l'aristocratie ouvrière. Tout en cherchant d'un côté à maintenir les conditions de vie des ouvriers dans les pays asservis à un niveau très bas, il ne recule devant aucun sacrifice et consent à sacrifier la plus-value dans ses propres pays, celle des colonies lui demeurant.

4. La suppression par la révolution prolétarienne de la puissance coloniale de l’Europe renversera le capitalisme européen. La révolution prolétarienne et la révolution des colonies doivent concourir, dans une certaine mesure, à l'issue victorieuse de la lutte. L'Internationale Communiste doit donc étendre le cercle de son activité. Elle doit nouer des relations avec les forces révolutionnaires qui sont à l'œuvre pour la destruction de l'impérialisme dans les pays économiquement et politiquement dominés.

5. L’Internationale Communiste concentre la volonté du prolétariat révolutionnaire mondial. Sa tâche est d'organiser la classe ouvrière du monde entier pour le renversement de l'ordre capitaliste et l'établissement du communisme.

L'Internationale Communiste est un instrument de lutte qui a pour tâche de grouper toutes les forces révolutionnaires du monde.

La $2^{\mathrm{e}}$ Internationale, dirigée par un groupe de politiciens et pénétrée de conceptions bourgeoises, n’a donné aucune importance à la question coloniale. Le monde n'existait pour elle que dans les limites de l'Europe. Elle n’a pas vu la nécessité de rattacher le mouvement révolutionnaire des autres continents. Au lieu de prêter une aide matérielle et morale au mouvement révolutionnaire des colonies, les membres de la $2^{\mathrm{e}}$ Internationale sont eux-mêmes devenus impérialistes. 
6. L’impérialisme étranger qui pèse sur les peuples orientaux, les a empêchés de se développer socialement et économiquement, simultanément avec les classes de l'Europe et de l'Amérique.

Grâce à la politique impérialiste qui a entravé le développement industriel des colonies, une classe prolétarienne dans le sens propre de ce mot n'a pas pu y surgir, bien que, dans ces derniers temps, les métiers indigènes aient été détruits par la concurrence des produits des industries centralisées des pays impérialistes.

La conséquence en a été que la grosse majorité du peuple s'est trouvée rejetée dans la campagne et obligée de s’y consacrer au travail agricole et à la production de matières premières pour l'exportation.

La conséquence en a été une rapide concentration de la propriété agraire dans les mains soit des gros propriétaires fonciers, soit du capital financier, soit de l'Etat. De cette manière s'est créée une masse puissante de paysans sans terre. Et la grande masse de la population a été maintenue dans l'ignorance.

Le résultat de cette politique est que, dans ceux d'entre ces pays où l'esprit révolutionnaire se manifeste, il ne trouve son expression que dans la classe moyenne cultivée.

La domination étrangère entrave le libre développement des forces économiques. C'est pourquoi sa destruction est le premier pas de la révolution dans les colonies et c'est pourquoi l'aide apportée à la destruction de la domination étrangère dans les colonies n'est pas, en réalité, une aide apportée au mouvement nationaliste de la bourgeoisie indigène, mais l'ouverture du chemin pour le prolétariat opprimé lui-même.

7. Il existe dans les pays opprimés deux mouvements qui, chaque jour, se séparent de plus en plus : le premier est le mouvement bourgeois démocratique nationaliste qui a un programme d'indépendance politique et d'ordre bourgeois ; l'autre est celui des paysans et des ouvriers ignorants et pauvres pour leur émancipation de toute espèce d'exploitation.

Le premier tente de diriger le second et y a souvent réussi dans une certaine mesure. Mais l'Internationale Communiste et les partis adhérents doivent combat- 
tre cette tendance et chercher à développer les sentiments de classe indépendante dans les masses ouvrières des colonies.

L'une des plus grandes tâches à cette fin est la formation de partis communistes qui organisent les ouvriers et les paysans et les conduisent à la révolution et à l'établissement de la République soviétique.

8. Les forces du mouvement d'émancipation dans les colonies ne sont pas limitées au petit cercle du nationalisme bourgeois démocratique. Dans la plupart des colonies il y a déjà un mouvement social-révolutionnaire ou des partis communistes en relation étroite avec les masses ouvrières. Les relations de l'Internationale Communiste avec le mouvement révolutionnaire des colonies doivent servir ces partis ou ces groupes, car ils sont l'avant-garde de la classe ouvrière. S'ils sont faibles aujourd'hui, ils représentent cependant la volonté des masses et les masses les suivront dans la voie révolutionnaire. Les partis communistes des différents pays impérialistes doivent travailler en contact avec ces partis prolétariens dans les colonies et leur prêter une aide matérielle et morale.

9. La révolution dans les colonies, dans son premier stade, ne peut pas être une révolution communiste, mais si dès son début, la direction est aux mains d'une avant-garde communiste, les masses ne seront pas égarées et dans les différentes périodes du mouvement leur expérience révolutionnaire ne fera que grandir.

Ce serait certainement une grosse erreur que de vouloir appliquer immédiatement dans les pays orientaux à la question agraire, les principes communistes. Dans son premier stade, la révolution dans les colonies doit avoir un programme comportant des réformes petites-bourgeoises, telles que la répartition des terres. Mais il n'en découle pas nécessairement que la direction de la révolution doive être abandonnée à la démocratie bourgeoise. Le parti prolétarien doit au contraire développer une propagande puissante et systématique en faveur des Soviets, et organiser des Soviets de paysans et d'ouvriers. Ces Soviets devront travailler en étroite collaboration avec les républiques soviétiques des pays capitalistes avancés pour atteindre à la victoire finale sur le capitalisme dans le monde entier. 
Ainsi les masses des pays arriérés, conduites par le prolétariat conscient des pays capitalistes développés, arriveront au communisme sans passer par les différents stades du développement capitaliste. 
Manifestes, thèses et résolutions

des quatre premiers congrès

de l'Internationale communiste 1919-1923

(juin 1934)

Deuxième Congrès, juillet 1920.

- 7 -

Thèses sur la question agraire

$\underline{\text { Retour à la table des matières }}$

1. Le prolétariat industriel des villes, dirigé par le Parti communiste, peut seul libérer les masses laborieuses des campagnes du joug des capitalistes et des propriétaires fonciers, de la désorganisation économique et des guerres impérialistes, qui recommenceront inévitablement si le régime capitaliste subsiste. Les masses laborieuses des campagnes ne pourront être libérées qu’à condition de prendre fait et cause pour le prolétariat communiste et de l'aider sans réserve dans sa lutte révolutionnaire pour le renversement du régime d'oppression des grands propriétaires fonciers et de la bourgeoisie.

D’un autre côté, le prolétariat industriel ne pourra s acquitter de sa mission historique mondiale, qui est l'émancipation de l'humanité du joug du capitalisme et des guerres, s'il se renferme dans les limites de ses intérêts particuliers et corporatifs et se borne placidement aux démarches et aux efforts tendant à l'amélioration de sa situation bourgeoise parfois très satisfaisante. C'est ainsi que se passent les choses dans nombre des pays avancés où existe une « aristocratie ouvrière ", fondement des partis soi-disant socialistes de la $2^{\mathrm{e}}$ Internationale, mais en réalité ennemis mortels du socialisme, traîtres envers sa doctrine, bourgeois chauvins et agents des capitalistes parmi les travailleurs. Le prolétariat ne pourra 
jamais être une force révolutionnaire active, une classe agissant dans l'intérêt du socialisme, s'il ne se conduit pas comme une avant-garde du peuple laborieux que l'on exploite, s'il ne se comporte pas comme le chef de guerre à qui incombe la mission de le conduire à l'assaut des exploiteurs ; mais jamais cet assaut ne réussira si les campagnes ne participent à la lutte des classes, si la masse des paysans laborieux ne se joint pas au parti communiste prolétarien des villes et si, enfin, ce dernier ne l'instruit pas.

2. La masse des paysans laborieux que l'on exploite et que le prolétariat des villes doit conduire au combat, ou, tout au moins, gagner à sa cause, est représentée, dans tous les pays capitalistes, par :

$1^{\circ}$ ) Le prolétariat agricole composé de journaliers ou valets de ferme, embauchés à l'année, à terme ou à la journée, et qui gagnent leur vie par leur travail salarié dans les diverses entreprises capitalistes d'économie rurale et industrielle. L’organisation de ce prolétariat en une catégorie distincte et indépendante des autres groupes de la population des campagnes (au point de vue politique, militaire, professionnel, coopératif, etc...), une propagande intense dans ce milieu, destinée à l'amener au pouvoir soviétique et à la dictature du prolétariat, telle est la tâche fondamentale des partis communistes dans tous les pays ;

$2^{\circ}$ ) Les demi-prolétaires ou les paysans, travaillant en qualité d'ouvriers embauchés, dans diverses entreprises agricoles, industrielles ou capitalistes, ou cultivant le lopin de terre qu'ils possèdent ou louent et qui ne leur rapporte que le minimum nécessaire pour assurer l'existence de leur famille. Cette catégorie de travailleurs ruraux est très nombreuse dans les pays capitalistes ; les représentants de la bourgeoisie et les « socialistes » jaunes de la $2^{\mathrm{e}}$ Internationale, cherchent à dissimuler ses conditions d'existence véritables, particulièrement la situation économique ; tantôt en trompant sciemment les ouvriers, tantôt par suite de leur propre aveuglement, qui provient des idées routinières de la bourgeoisie ; ils confondent volontiers ce groupe avec la grande masse des " paysans ». Cette manœuvre, foncièrement bourgeoise, en vue de duper les ouvriers, est surtout pratiquée en Allemagne, en France, en Amérique, et dans quelques autres pays. En organisant bien le travail du Parti communiste, ce groupe social pourra devenir un fidèle soutien 
du communisme, car la situation de ces demi-prolétaires est très précaire et l'adhésion leur vaudra des avantages énormes et immédiats.

Dans certains pays, il n'existe pas de distinction claire entre ces deux premiers groupes ; il serait donc loisible, suivant les circonstances, de leur donner une organisation commune ;

$3^{\circ}$ ) Les petits propriétaires, les petits fermiers qui possèdent ou louent de petits lopins de terre et peuvent satisfaire aux besoins de leur ménage et de leur famille sans embaucher des travailleurs salariés. Cette catégorie de ruraux a beaucoup à gagner à la victoire du prolétariat ; le triomphe de la classe ouvrière donne aussitôt à chaque représentant de ce groupe les biens et les avantages qui suivent :

a) Non-paiement du prix du bail et abolition du métayage (il en serait ainsi en France, en Italie, etc...) payés jusqu’à présent aux grands propriétaires fonciers ;

b) Abolition des dettes hypothécaires ;

c) Émancipation de l'oppression économique exercée par les grands propriétaires fonciers, laquelle se présente sous les aspects les plus divers (droit d'usage des bois et forets, de friches, etc...);

d) Secours agricole spécial et financier immédiat du pouvoir prolétarien, notamment secours en outillage agricole; octroi de constructions se trouvant sur le territoire de vastes domaines capitalistes expropriés par le prolétariat, transformation immédiate par le gouvernement prolétarien de toutes les coopératives rurales et des compagnies agricoles, qui n'étaient avantageuses sous le régime capitaliste qu'aux paysans riches et aisés, en organisations économiques ayant pour but de secourir, en premier lieu, la population pauvre, c'est-à-dire les prolétaires, les demi-prolétaires et les paysans pauvres.

Le Parti communiste doit aussi comprendre que pendant la période de transition du capitalisme au communisme, c'est-à-dire pendant la dictature du prolétariat, cette catégorie de la population rurale manifestera des hésitations plus ou moins sensibles et un certain penchant à la liberté du commerce et à la propriété 
privée ; car, nombre de ceux qui la composent faisant, au moins dans une petite mesure, le commerce des articles de première nécessité, sont déjà démoralisés par la spéculation et par leurs habitudes de propriété. Si, cependant, le gouvernement prolétarien réalise, dans cette question, une politique ferme et inexorable, et si le prolétariat vainqueur écrase sans merci les gros propriétaires fonciers et les paysans aisés, ces hésitations ne sauront être de longue durée et ne pourront modifier ce fait indubitable qu'en fin de compte le groupe dont il s'agit sympathise avec la révolution prolétarienne.

3. Ces trois catégories de la population rurale, prises ensemble, forment, dans tous les pays capitalistes, la majorité de la population. Le succès d'un coup d'Etat prolétarien, tant dans les villes que dans les villages, peut donc être considéré comme indiscutable et certain. L'opinion opposée est cependant très en faveur dans la société actuelle. En voici les raisons : elle ne se maintient qu'à force d'agissements trompeurs de la science : de la statistique bourgeoise qui cherche à voiler par tous les moyens en son pouvoir l'insondable abîme qui sépare ces classes rurales de leurs exploiteurs, les propriétaires fonciers et les capitalistes, ainsi que les demi-prolétaires et les paysans pauvres des paysans aisés; cette opinion persiste grâce à la maladresse des héros de la $2^{\mathrm{e}}$ Internationale Jaune et de « l'aristocratie ouvrière » dépravée par les privilèges impérialistes, et à la mauvaise volonté qu'ils mettent à faire, parmi les paysans pauvres, une propagande prolétarienne et révolutionnaire vigoureuse et un bon travail d'organisation ; les opportunistes employaient et emploient toujours leurs efforts à imaginer diverses variétés d'accord pratiques et théoriques avec la bourgeoisie, y compris les paysans riches et aisés, et ne pensent nullement au renversement révolutionnaire du gouvernement bourgeois et de la bourgeoisie elle-même ; enfin, l'opinion dont il s'agit se maintient jusqu'ici grâce à un préjuge opiniâtre et, pour ainsi dire, inébranlable, parce qu'il se trouve étroitement uni à tous les autres préjugés du parlementarisme et de la bourgeoisie démocratique ; ce préjugé consiste dans la noncompréhension d'une vérité parfaitement démontrée par le marxisme théorique et suffisamment prouvée par l'expérience de la révolution prolétarienne russe ; cette vérité est que les trois catégories de la population rurale dont nous avons parlé, abruties, désunies, opprimées et vouées, dans les pays même les plus civilisés, à une existence demi-barbare, ont, par conséquent, un intérêt économique, social et 
intellectuel à la victoire du socialisme, mais ne peuvent néanmoins appuyer vigoureusement le prolétariat révolutionnaire qu'après la conquête du pouvoir politique, lorsqu'il aura fait justice des gros propriétaires fonciers et capitalistes mettant ainsi les masses rurales dans l'obligation de constater qu'elles ont, en lui, un chef et un défenseur organisé, assez puissant pour les diriger et leur montrer la bonne voie.

4. Les « paysans moyens » sont au point de vue économique de petits propriétaires ruraux qui possèdent ou prennent à terme, eux aussi, des lopins de terre peu considérables sans doute, mais leur permettant quand même, sous le régime capitaliste, non seulement de nourrir leur famille et d'entretenir en bon état leur petite propriété rurale, mais de réaliser encore un excédent de bénéfices, pouvant, tout au moins dans les années de bonne récolte, être transformé en économies relativement importantes; ces paysans embauchent assez souvent des ouvriers (par exemple, deux ou trois ouvriers par entreprises) dont ils ont besoin pour toutes sortes de travaux. On pourrait citer ici l'exemple concret de «paysans moyens » d'un pays capitaliste avancé : ceux de l’Allemagne. Il y avait, en Allemagne, d'après le recensement de 1907, une catégorie de propriétaires ruraux possédant chacun de cinq à dix hectares, dans les propriétés desquels le nombre des ouvriers embauchés s'élevait presque au tiers du chiffre total des travailleurs des champs (1). En France, où les cultures spéciales, comme la viticulture, sont plus développées, et où la terre demande beaucoup plus d'effort et de soins, les propriétés rurales de cette catégorie emploient probablement un nombre plus important de travailleurs salariés.

Pour son avenir le plus rapproché et pour toute la première période de sa dictature, le prolétariat révolutionnaire ne peut pas se donner comme tâche la conquête politique de cette catégorie rurale et doit se borner à sa neutralisation, dans la lutte qui se livre entre le prolétariat et la bourgeoisie. Le penchant de cette couche de la population tantôt vers un parti politique, tantôt vers un autre, est iné-

1. Voici quelques chiffres exacts : Allemagne : propriétés rurales de 5 à 10 hectares, employant des ouvriers embauchés : 652798 (sur 5736 082), ouvriers salariés : 487 764, ouvriers mariés : 2003 633. Autriche (recensement de 1910) : 383351 propriétés rurales, dont 126.136 employant des travailleurs embauchés, ouvriers salariés : 146 044, ouvriers mariés : 1265969. Le nombre total des fermes en Autriche s’élève à 2856349. 
vitable et, probablement, sera-t-il au commencement de la nouvelle époque et dans les pays foncièrement capitalistes, favorable à la bourgeoisie. Tendance d'ailleurs fort naturelle, l'esprit de propriété privée jouant chez elle un rôle prépondérant. Le prolétariat vainqueur améliorera immédiatement la situation économique de cette couche de la population en supprimant le système du bail, les dettes hypothécaires et en introduisant dans l'agriculture l'usage des machines et l'emploi de l'électricité. Cependant, dans la plupart des pays capitalistes, le pouvoir prolétarien ne devra pas abolir sur le champ et complètement le droit de propriété privée, mais il devra affranchir cette classe de toutes les obligations et impositions auxquelles elle est sujette de la part des propriétaires fonciers ; le pouvoir soviétique assurera aux paysans pauvres et d'aisance moyenne la possession de leurs terres, dont il cherchera même à augmenter la superficie, en mettant les paysans en possession de terres qu'ils affermaient autrefois (abolition du fermage).

Toutes ces mesures, suivies d'une lutte sans merci contre la bourgeoisie, assureront le succès complet de la politique de neutralisation. C'est avec la plus grande circonspection que le pouvoir prolétarien doit passer à l'agriculture collectiviste, progressivement, à force d'exemples, et sans la moindre mesure de coercition à l'égard des paysans « moyens ».

5. Les paysans riches et aisés sont les entrepreneurs capitalistes de l'agriculture ; ils cultivent habituellement leurs terres avec le concours des travailleurs salariés et ne sont rattachés à la classe paysanne que par leur développement intellectuel très restreint, par leur vie rustique et par le travail personnel qu'ils font en commun avec les ouvriers qu'ils embauchent. Cette couche de la population rurale est très nombreuse et représente en même temps l'adversaire le plus invétéré du prolétariat révolutionnaire. Aussi, tout le travail politique des partis communistes dans les campagnes doit-il se concentrer dans la lutte contre cet élément, pour émanciper la majorité de la population rurale laborieuse et exploitée, de l'influence morale et politique, si pernicieuse, de ces exploiteurs ruraux.

Il est bien possible que, dès la victoire du prolétariat dans les villes, ces éléments aient recours à des actes de sabotage et même à des prises d'armes, manifestement contre-révolutionnaires. Aussi, le prolétariat révolutionnaire devra-t-il 
commencer sur-le-champ la préparation intellectuelle et organisatrice de toutes les forces dont il aura besoin pour les désarmer et pour leur porter, tandis qu'il renversera le régime capitaliste et industriel, le coup de grâce. A cet effet, le prolétariat révolutionnaire des villes devra armer ses alliés ruraux et organiser, dans tous les villages des soviets où nul exploiteur ne sera admis et où les prolétaires et les demi-prolétaires seront appelés à jouer le rôle prépondérant. Même dans ce cas cependant, la tâche immédiate du prolétariat vainqueur ne devra pas comporter l'expropriation des grandes propriétés paysannes, parce que à ce moment même les conditions matérielles et, en partie, techniques et sociales, nécessaires à la socialisation des grandes propriétés, ne seront pas encore réalisées. Tout porte à croire que, dans certains cas isolés, des terres affermées ou strictement nécessaires aux paysans pauvres du voisinage seront confisquées ; on accordera également à ces derniers, l'usage gratuit, à certaines conditions toutefois, d'une partie de l’outillage agricole des propriétaires ruraux riches ou aisés. Mais, en règle générale, le pouvoir prolétarien devra laisser leurs terres aux paysans riches et aisés et ne s'en emparer que dans le cas d'une opposition manifeste à la politique et aux prescriptions du pouvoir des travailleurs. Cette ligne de conduite est nécessaire, l'expérience de la révolution prolétarienne russe, où la lutte contre les paysans riches et aisés traîne en longueur dans des conditions très complexes, ayant démontré que ces éléments de la population rurale, douloureusement frappés pour toutes leurs tentatives de résistance, même les moindres, sont pourtant capables de s'acquitter loyalement des travaux que leur confie l'Etat prolétarien et commencent même, quoique très lentement, à se pénétrer de respect envers le pouvoir qui défend tout travailleur et écrase impitoyablement le riche oisif.

Les conditions spéciales qui ont compliqué et retardé la lutte du prolétariat russe, vainqueur de la bourgeoisie, contre les paysans riches, dérivaient uniquement du fait qu’après l'événement du 25 octobre 1917, la révolution russe avait traversé une phase « démocratique » — c'est-à-dire, au fond, bourgeoise démocratique - de lutte des paysans contre les propriétaires fonciers ; on doit encore ces conditions spéciales à la faiblesse numérique et à l'état arriéré du prolétariat des villes et, enfin, à l'immensité du pays et au délabrement de ses voies de communication. Mais les pays avancés de l'Europe et de l'Amérique ignorent toutes ces causes de retard, et c'est pourquoi leur prolétariat révolutionnaire doit briser plus énergiquement, plus rapidement, avec plus de décision et beaucoup plus de 
succès, la résistance des paysans riches et aisés et leur ôter, à l'avenir, toute possibilité d'opposition. Cette victoire de la masse des prolétaires, des demiprolétaires et des paysans, est absolument indispensable, et tant qu'elle n'aura pas été remportée, le pouvoir prolétarien ne pourra se considérer comme une autorité stable et ferme.

6. Le prolétariat révolutionnaire doit confisquer immédiatement et sans réserve toutes les terres appartenant aux grands propriétaires fonciers, c'est-à-dire à toutes les personnes exploitant systématiquement, dans les pays capitalistes, que ce soit de façon directe ou par l'entremise de leurs fermiers, les travailleurs salariés, les paysans pauvres et même, assez souvent, les paysans moyens de la région, à tous les propriétaires qui ne participent aucunement au travail physique dans la plupart des cas, descendants des barons féodaux (nobles de Russie, d'Allemagne et de Hongrie, seigneurs restaurés de France, lords anglais, anciens possesseurs d'esclaves en Amérique), magnats de la haute finance ou, enfin, ceux qui sont issus de ces deux catégories d'exploiteurs et de fainéants.

Les partis communistes doivent s’opposer énergiquement à l'idée d'accorder une indemnité aux grands propriétaires fonciers expropriés et lutter contre toute propagande en ce sens ; les partis communistes ne doivent pas oublier que le versement d'une semblable indemnité serait une trahison envers le socialisme et une contribution nouvelle imposée aux masses exploitées, accablées par le fardeau de la guerre qui a multiplié le nombre des millionnaires et a accru leurs fortunes.

Dans les pays capitalistes avancés, l’Internationale Communiste estime qu'il serait bon et pratique de maintenir intactes les grandes propriétés agricoles et de les exploiter de la même façon que les « propriétés soviétiques » russes ${ }^{2}$.

Quant à la culture des terres enlevées par le prolétariat vainqueur aux grands propriétaires fonciers, en Russie, elles étaient jusqu’à présent partagées entre les paysans ; c’est que le pays est très arriéré au point de vue économique. Dans des cas très rares le gouvernement prolétarien russe a maintenu en son pouvoir des propriétés rurales dites « soviétiques » et que l’Etat prolétarien exploite lui-même,

2 Il serait bon de favoriser la création de domaines administrés par des collectivités (Communes). 
en transformant les anciens ouvriers salariés en "délégués de travail » ou en membres de soviets.

La conservation des grands domaines sert mieux les intérêts des éléments révolutionnaires de la population, surtout des agriculteurs qui ne possèdent point de terres, des demi-prolétaires et des petits propriétaires qui vivent souvent de leur travail dans les grandes entreprises. En outre, la nationalisation des grands domaines rend la population urbaine moins dépendante à l'égard des campagnes au point de vue du ravitaillement.

Là où subsistent encore des vestiges du système féodal, où les privilèges des propriétaires fonciers engendrent des formes spéciales d'exploitation, où l’on voit encore le "servage » et le « métayage », il est nécessaire de remettre aux paysans une partie du sol des grands domaines.

Dans les pays où les grands domaines sont en nombre insignifiant, où un grand nombre de petits tenanciers demandent des terres, la distribution des grands domaines en lots peut être un moyen sûr pour gagner les paysans à la révolution, alors que la conservation de ces quelques grands domaines ne serait d'aucun intérêt pour les villes, au point de vue du ravitaillement.

La première et la plus importante tâche du prolétariat est de s’assurer une victoire durable. Le prolétariat ne doit pas redouter une baisse de la production, si cela est nécessaire, pour le succès de la révolution. Ce n’est qu'en maintenant la classe moyenne des paysans dans la neutralité et en s’assurant l'appui de la majorité, si ce n'est de la totalité, des prolétaires des campagnes, que l’on pourra assurer au pouvoir prolétarien une existence durable.

Toutes les fois que les terres des grands propriétaires fonciers seront distribuées, les intérêts du prolétariat agricole devront passer avant tout.

Tout l'outillage agricole et technique des grandes propriétés foncières et rurales doit être confisqué et remis à l'Etat, à condition toutefois, qu'après la distribution de cet outillage, en quantité suffisante, aux grandes propriétés rurales de l'Etat, les petits paysans puissent en profiter gratuitement, en se conformant aux règlements élaborés à ce sujet par le pouvoir prolétarien.

Si, tout au commencement de la révolution prolétarienne, la confiscation immédiate des grandes propriétés foncières, ainsi que l’expulsion ou l’internement 
de leurs propriétaires, leaders de la contre-révolution et oppresseurs impitoyables de toute la population rurale, sont absolument nécessaires, le pouvoir prolétarien doit tendre systématiquement, au fur et à mesure de la consolidation de sa position dans les villes et les campagnes, à l'utilisation des forces de cette classe, qui possède une expérience précieuse des connaissances et des capacités organisatrices, pour créer avec son concours, et sous le contrôle de communistes éprouvés, une vaste agriculture soviétique.

7. Le socialisme ne vaincra définitivement le capitalisme et ne sera à jamais affermi qu'au moment où le pouvoir gouvernemental prolétarien, ayant réprimé toute résistance des exploiteurs et assuré son autorité, aura réorganisé toute l'industrie sur la base d'une nouvelle production collectiviste et sur un nouveau fondement technique (application générale de l'énergie électrique dans toutes les branches de l'agriculture et de l'économie rurale). Cette réorganisation seule peut donner aux villes la possibilité d'offrir aux campagnes arriérées une aide technique et sociale susceptible de déterminer un accroissement extraordinaire de la productivité du travail agricole et rural et d'engager, par l'exemple, les petits laboureurs à passer, dans leur propre intérêt, progressivement, à une culture collectiviste mécanique.

C’est précisément dans les campagnes que la possibilité d'une lutte victorieuse pour la cause socialiste exige de la part de tous les partis communistes un effort pour susciter, parmi le prolétariat industriel, le sentiment de la nécessité des sacrifices à consentir pour le renversement de la bourgeoisie et pour la consolidation du pouvoir prolétarien ; chose absolument nécessaire parce que la dictature du prolétariat signifie qu'il sait organiser et conduire les travailleurs exploités et que son avant-garde est toujours prête, pour atteindre ce but, au maximum d'efforts héroïques et de sacrifices ; en outre, pour remporter la victoire définitive, le socialisme exige que les masses laborieuses les plus exploitées des campagnes puissent voir, dès la victoire des ouvriers, leur situation presque immédiatement améliorée aux dépens des exploiteurs; s'il n'en était pas ainsi, le prolétariat industriel ne pourrait pas compter sur l'appui des campagnes et ne pourrait pas, de ce fait, assurer le ravitaillement des villes. 
8. Les difficultés énormes que présentent l'organisation et la préparation à la lutte révolutionnaire de la masse des travailleurs ruraux que le régime capitaliste avait abrutis, éparpillés et asservis, à peu près autant qu'au moyen-âge, exige de la part des partis communistes, la plus grande attention envers le mouvement gréviste rural, l'appui vigoureux et le développement intense des grèves de masses de prolétaires et des demi-prolétaires ruraux. L'expérience des révolutions russes de 1905 et 1917, confirmée et complétée actuellement par celle de la révolution allemande et d'autres pays avancés, prouve que seul le mouvement gréviste, progressant sans cesse (avec la participation, dans certaines conditions, des " petits paysans ») peut tirer les villages de leur léthargie, réveiller chez les paysans la conscience de classe et le sentiment de la nécessité d'une organisation de classe des masses rurales exploitées et montrer clairement aux habitants de la campagne l'importance pratique de leur union avec les travailleurs des villes. A ce point de vue, la création de syndicats ouvriers agricoles et la collaboration des communistes dans les organisations d'ouvriers agricoles et forestiers sont de la plus haute importance. Les communistes doivent particulièrement soutenir les organisations formées par la population agricole étroitement liée au mouvement ouvrier révolutionnaire. Une propagande énergique doit être faite parmi les paysans prolétaires.

Le Congrès de l'Internationale Communiste flétrit et condamne sévèrement les socialistes félons et traîtres que l'on trouve malheureusement, non seulement au sein de la l'Internationale Jaune, mais aussi parmi les trois partis européens les plus importants, sortis de cette Internationale ; le congrès voue à la honte les socialistes capables non seulement de considérer d'un œil indifférent le mouvement gréviste rural, mais encore de lui résister (comme K. Kautsky), de peur qu'il n'en résulte une réduction du ravitaillement. Tous les programmes et toutes les déclarations les plus solennels n'ont aucune valeur, s'il n'est pas possible de prouver pratiquement que les communistes et les leaders ouvriers savent mettre au-dessus de toutes choses le développement de la révolution prolétarienne et sa victoire, qu'ils savent consentir pour elle aux sacrifices les plus pénibles, parce qu'il n'est pas d'autres issues, pas d'autres moyens pour vaincre la famine et la désorganisation économique et pour conjurer de nouvelles guerres impérialistes.

9. Les partis communistes doivent faire tout ce qui dépend d'eux pour commencer au plus tôt l'organisation des soviets dans les campagnes et en premier 
lieu, des soviets qui représenteraient des travailleurs salariés et les demiprolétaires. Ce n'est qu'en coopération étroite avec le mouvement gréviste des masses et avec la classe la plus opprimée que les soviets seront à même de s'acquitter de leur mission et deviendront assez forts pour soumettre à leur influence (et les incorporer par la suite) les « petits paysans ». Si cependant le mouvement gréviste n’est pas encore assez développé et la capacité d'organisation du prolétariat rural est encore trop faible, tant à cause de l'oppression des propriétaires fonciers et des paysans riches, que de l'insuffisance de l'appui fourni par les ouvriers industriels et par leurs syndicats, la création des soviets dans les campagnes demande une longue préparation; elle doit être faite par la création des foyers communistes, par une propagande active, en termes clairs et nets, des aspirations communistes que l'on expliquera à force d'exemples illustrant les diverses méthodes d'exploitation et d'oppression, et enfin au moyen de tournées de propagande systématiques des les travailleurs industriels dans les campagnes. 
Manifestes, thèses et résolutions

des quatre premiers congrès

de l’Internationale communiste 1919-1923

(juin 1934)

Deuxième Congrès, juillet 1920.

- 8 -

Le Parti Communiste et le parlementarisme

\section{I. - LA NOUVELLE ÉPOQUE ET LE NOUVEAU PARLEMENTARISME}

$\underline{\text { Retour à la table des matières }}$

L'attitude des partis socialistes à l'égard du parlementarisme consistait à l'origine, à l'époque de la Première Internationale, à utiliser les Parlements bourgeois pour l'agitation. On envisageait la participation à l'action parlementaire du point de vue du développement de la conscience de classe, c'est-à-dire de l'éveil de l'hostilité des classes prolétariennes contre les classes dirigeantes. Cette attitude se modifia, non sous l'influence d'une théorie, mais sous celle du progrès politique. Par suite de l'augmentation incessante des forces productrices et de l'élargissement du domaine de l'exploitation capitaliste, le capitalisme et, avec lui, les Etats parlementaires acquirent une stabilité durable.

De là, l'adaptation de la tactique parlementaire des partis socialistes à l'action législative « organique » des Parlements bourgeois et l'importance toujours croissante de la lutte pour l'introduction des réformes dans les cadres du capitalisme, la prédominance du programme minimum des partis socialistes, la transformation du programme maximum en une plate-forme destinée aux discussions sur un «but 
final » éloigné. Sur cette base se développèrent l'arrivisme parlementaire, la corruption, la trahison ouverte ou camouflée des intérêts primordiaux de la classe ouvrière.

L'attitude de la $3^{\mathrm{e}}$ Internationale envers le parlementarisme n'est pas déterminée par une nouvelle doctrine, mais par la modification du rôle du parlementarisme même. A l'époque précédente, le Parlement, instrument du capitalisme en voie de développement, a, dans un certain sens, travaillé pour le progrès historique. Dans les conditions actuelles, caractérisées par le déchaînement de l'impérialisme, le Parlement est devenu un instrument de mensonge, de fraude, de violences, de destruction, d'actes de brigandage, œuvres de l'impérialisme; les réformes parlementaires, dépourvues d'esprit de suite et de stabilité et conçues sans plan d'ensemble, ont perdu toute importance pratique pour les masses laborieuses.

Le parlementarisme a perdu sa stabilité de même que toute la société bourgeoise. La transition de la période organique à la période critique crée une nouvelle base à la tactique du prolétariat dans le domaine parlementaire. C'est ainsi que le parti ouvrier russe (le parti bolchevik) détermina déjà les bases du parlementarisme révolutionnaire à l'époque antérieure, la Russie ayant perdu depuis 1905 son équilibre politique et social et étant entrée dès lors dans une période de tourmentes et de bouleversements.

Quand des socialistes, aspirant au communisme, soulignent que l'heure de la révolution n'est pas encore venue dans leurs pays et se refusent à se séparer des opportunistes parlementaires, ils procèdent, au fond, d'une représentation, consciente ou inconsciente, de la période qui s’ouvre, considérée comme une période de stabilité relative de la société impérialiste et pensent pour cette raison qu'une collaboration avec les Turati et les Longuet peut donner sur cette base des résultats pratiques dans la lutte pour les réformes.

Le communisme doit prendre pour point de départ l'étude théorique de notre époque (apogée du capitalisme, tendances de l’impérialisme à sa propre négation et à sa propre destruction, aggravation continue de la guerre civile, etc...). Les formes des relations politiques et des groupements peuvent différer dans les divers pays, mais le fond des choses reste le même partout : il s'agit pour nous de la 
préparation immédiate, politique et technique, du soulèvement prolétarien qui doit détruire le pouvoir bourgeois et établir le nouveau pouvoir prolétarien.

Pour les communistes, le Parlement ne peut être en aucun cas, à l'heure actuelle, le théâtre d'une lutte pour des réformes et pour l'amélioration de la situation de la classe ouvrière, comme il arriva à certains moments, à l'époque antérieure. Le centre de gravité de la vie politique actuelle est complètement définitivement sorti du Parlement. D’autre part, la bourgeoisie est obligée, par ses rapports avec les masses laborieuses et aussi par suite des rapports complexes existant au sein des classes bourgeoises, de faire approuver de diverses façons certaines de ses actions par le Parlement, où les coteries se disputent le pouvoir, manifestent leurs forces et leurs faiblesses, se compromettent, etc...

Aussi le devoir historique immédiat de la classe ouvrière est-il d'arracher ces appareils aux classes dirigeantes, de les briser, de les détruire et de leur substituer les nouveaux organes du pouvoir prolétarien. L'état-major révolutionnaire de la classe ouvrière est d'ailleurs profondément intéressé à avoir dans les institutions parlementaires de la bourgeoisie des éclaireurs qui faciliteront son œuvre de destruction. On voit clairement dès lors la différence essentielle entre la tactique des communistes allant au Parlement à des fins révolutionnaires, et celle du parlementarisme socialiste qui commence par reconnaître la stabilité relative, la durée indéfinie du régime. Le parlementarisme socialiste se donne pour tâche d'obtenir à tout prix des réformes ; il est intéressé à ce que chaque conquête soit mise par les masses au compte du parlementarisme socialiste (Turati, Longuet et $\mathrm{C}^{\mathrm{ie}}$ ).

Le vieux parlementarisme d'adaptation est remplacé par un parlementarisme nouveau, qui est l'un des moyens de détruire le parlementarisme en général. Mais les traditions écœurantes de l'ancienne tactique parlementaire rapprochent certains éléments révolutionnaires des antiparlementaires par principe (les I.W.W., les syndicalistes révolutionnaires, le Parti ouvrier communiste d'Allemagne).

Considérant cette situation, le $2^{\mathrm{e}}$ Congrès de l'Internationale Communiste arrive aux conclusions suivantes : 


\section{II. - LE COMMUNISME, LA LUTTE POUR LA DICTATURE DU PROLÉTARIAT ET « POUR L'UTILISATION » DU PARLEMENT BOURGEOIS}

1. Le parlementarisme de gouvernement est devenu la forme « démocratique » de la domination de la bourgeoisie, à laquelle il faut, à un moment donné de son développement, une fiction de représentation populaire exprimant en apparence la « volonté du peuple » et non celle des classes, mais constituant en réalité, aux mains du Capital régnant, un instrument de coercition et d’oppression.

2. Le parlementarisme est une forme déterminée de l’Etat. Aussi ne convientil en aucune façon à la société communiste, qui ne connaît ni classes, ni lutte de classes, ni pouvoir gouvernemental d'aucune sorte.

3. Le parlementarisme ne peut pas être non plus la forme du gouvernement " prolétarien » dans la période de transition de la dictature de la bourgeoisie à la dictature du prolétariat. Au moment le plus grave de la lutte de classes, lorsque celle-ci se transforme en guerre civile, le prolétariat doit bâtir inévitablement sa propre organisation gouvernementale, considérée comme une organisation de combat dans laquelle les représentants des anciennes classes dominantes ne seront pas admis ; toute fiction de volonté populaire est, au cours de cette phase, nuisible au prolétariat ; celui-ci n’a nul besoin de la séparation parlementaire des pouvoirs, qui ne pourrait que lui être néfaste ; la République des Soviets est la forme de la dictature du prolétariat.

4. Les Parlements bourgeois, constituant un des principaux appareils de la machine gouvernementale de la bourgeoisie, ne peuvent pas plus être conquis par le prolétariat que l'Etat bourgeois, en général. La tâche du prolétariat consiste à faire sauter la machine gouvernementale de la bourgeoisie, à la détruire, y compris les institutions parlementaires, que ce soit celles des Républiques ou celles des monarchies constitutionnelles.

5. Il en est de même des institutions municipales ou communales de la bourgeoisie, qu'il est théoriquement faux d'opposer aux organes gouvernementaux. A la vérité, elles font aussi partie du mécanisme gouvernemental de la bourgeoisie : 
elles doivent être détruites par le prolétariat révolutionnaire et remplacées par les Soviets de députés ouvriers.

6. Le communisme se refuse donc à voir dans le parlementarisme une des formes de la société future; il se refuse à y voir la forme de la dictature de classe du prolétariat ; il nie la possibilité de la conquête durable des Parlements; il se donne pour but l'abolition du parlementarisme. Il ne peut dès lors être question de l'utilisation des institutions gouvernementales bourgeoises qu'en vue de leur destruction. C'est dans ce sens et uniquement dans ce sens que la question peut être posée.

7. Toute lutte de classes est une lutte politique, car elle est, en fin de compte, une lutte pour le pouvoir. Toute grève, étendue à un pays entier, devient une menace pour l'Etat bourgeois et acquiert par là même un caractère politique. S'efforcer de renverser la bourgeoisie et de détruire l'Etat bourgeois, c'est soutenir une lutte politique. Nous devons créer un appareil de gouvernement et de coercition prolétarien, de classe, contre la bourgeoisie réfractaire ; c'est, quel que soit cet appareil, conquérir le pouvoir politique.

8. La lutte politique ne se réduit donc nullement à une question d'attitude envers le parlementarisme. Elle embrasse toute la lutte de la classe du prolétariat, pour autant que cette lutte cesse d'être locale et partielle et tend au renversement du régime capitaliste en général.

9. La méthode fondamentale de la lutte du prolétariat contre la bourgeoisie, c'est-à-dire contre son pouvoir gouvernemental, est avant tout celle des actions en masse. Ces dernières sont organisées et dirigées par les organisations de masse du prolétariat (syndicats, partis, soviets), sous la conduite générale du Parti communiste, solidement uni, discipliné et centralisé. La guerre civile est une guerre. Dans cette guerre, le prolétariat doit avoir de bons cadres politiques et un bon étatmajor politique dirigeant toutes les opérations dans tous les domaines de l'action.

10. La lutte des masses constitue tout un système d'actions en voie de développement, qui s'avivent par leur forme même et mènent logiquement à l'insurrection contre l'Etat capitaliste. Dans cette lutte de masse, appelée à se transformer en guerre civile, le parti dirigeant du prolétariat doit, en règle générale, fortifier toutes ses positions légales, en faire des points d'appui secondaires de 
son action révolutionnaire et les subordonner au plan de la campagne principale, c'est-à-dire à la lutte des masses.

11. La tribune du Parlement bourgeois est un de ces points d'appui secondaires. On ne peut pas invoquer contre l'action parlementaire, la qualité bourgeoise de l'institution même. Le Parti communiste y entre non pour s'y livrer à une action organique, mais pour saper de l'intérieur la machine gouvernementale et le Parlement (exemples : l'action de Liebknecht en Allemagne, celle des bolcheviks à la Douma du tsar, à la "Conférence démocratique » et au «Pré-parlement » de Kérensky, à l'Assemblée constituante, dans les municipalités ; enfin, l'action des communistes bulgares).

12. Cette action parlementaire, qui consiste surtout à user de la tribune parlementaire à des fins d'agitation révolutionnaire, à dénoncer les manœuvres de l'adversaire, à grouper autour de certaines idées les masses qui, surtout dans les pays arriérés, considèrent la tribune parlementaire, avec de grandes illusions démocratiques, doit être totalement subordonnée aux buts et aux tâches de la lutte extra-parlementaire des masses.

La participation aux campagnes électorales et la propagande révolutionnaire du haut de la tribune parlementaire ont une signification particulière pour la conquête politique des milieux de la classe ouvrière qui, comme les masses laborieuses rurales, sont demeurés jusqu'à présent à l'écart du mouvement révolutionnaire et de la politique.

13. Les communistes, s'ils obtiennent la majorité dans les municipalités, doivent : a) former une opposition révolutionnaire à l'égard du pouvoir central de la bourgeoisie ; b) s'efforcer par tous les moyens de rendre service à la partie la plus pauvre de la population (mesures économiques, création ou tentative de création d’une milice ouvrière armée, etc...) ; c) révéler en toute occasion les obstacles suscités par l'Etat bourgeois contre toute réforme radicale ; $d$ ) développer sur cette base une propagande révolutionnaire énergique, sans craindre le conflit avec le pouvoir bourgeois ; e) remplacer, dans certaines circonstances, les municipalités par des Soviets de députés ouvriers. Toute l'action des communistes dans les municipalités doit donc s’intégrer dans l'œuvre générale de désagrégation du système capitaliste ; 
14. La campagne électorale elle-même doit être menée, non dans le sens de l'obtention du maximum de mandats parlementaires, mais dans celui de la mobilisation des masses sous les mots d'ordre de la révolution prolétarienne. La lutte électorale ne doit pas être le fait des seuls dirigeants du Parti, l'ensemble des membres du Parti doit y prendre part ; tout mouvement des masses doit être utilisé (grèves, manifestations, effervescence dans l'armée et la flotte, etc...) ; on établira avec ce mouvement un contact étroit ; l'activité des organisations prolétariennes de masse sera sans cesse stimulée.

15. Ces conditions et celles qui sont indiquées dans une instruction spéciale étant observées, l'action parlementaire se trouve en complète opposition avec l'écœurante petite politique des partis socialistes de tous les pays, dont les députés vont au Parlement pour soutenir cette institution « démocratique », et, dans le meilleur des cas, pour la « conquérir ». Le Parti communiste ne peut admettre que l'utilisation exclusivement révolutionnaire du parlementarisme, à la manière de Karl Liebknecht, de Hoeglund et de bolcheviks.

\section{AU PARLEMENT}

16. «L’antiparlementarisme » de principe, conçu comme le refus absolu et catégorique de participer aux élections et à l'action parlementaire révolutionnaire, n’est donc qu'une doctrine enfantine et naïve ne résistant pas à la critique, résultat parfois d'une saine aversion pour les politiciens parlementaires, mais qui n’aperçoit pas, par ailleurs, la possibilité du parlementarisme révolutionnaire. Il arrive, de plus, que cette opinion se base sur une notion tout à fait erronée du rôle du Parti, considéré non comme l'avant-garde ouvrière centralisée et organisée pour le combat, mais comme un système décentralisé de groupes mal reliés entre eux.

17. D’un autre côté, la nécessité d'une participation effective à des élections et à des assemblées parlementaires données ne découle nullement de la reconnaissance en principe de l'action révolutionnaire au Parlement. Tout dépend ici d'une série de conditions spécifiques. La sortie des communistes du Parlement peut devenir nécessaire à un moment donné. C’était le cas, lorsque les bolchéviks se retirèrent du Pré-parlement de Kérensky, afin de le torpiller, de le rendre du coup 
impuissant et de lui opposer plus nettement le Soviet de Pétrograd à la veille de se mettre à la tête de l'insurrection ; c'était le cas, lorsque les bolchéviks reportèrent le centre de gravité des événements politiques au $3^{\mathrm{e}}$ Congrès des Soviets. En d'autres circonstances, le boycottage les élections peut s'imposer, ou l'anéantissement immédiat, par la force, de l'Etat bourgeois et de la coterie bourgeoise ; ou encore la participation aux élections coïncidant avec le boycottage du Parlement même, etc...

18. Reconnaissant ainsi, en règle générale, la nécessité de participer aux élections parlementaires et municipales et de travailler dans les Parlements et les municipalités, le Parti communiste doit trancher la question selon le cas concret, en s'inspirant des particularités spécifiques de la situation. Le boycottage des élections ou du Parlement, de même que la sortie du Parlement, sont surtout admissibles en présence de conditions permettant le passage immédiat à la lutte armée pour la conquête du pouvoir.

19. Il est indispensable d'avoir constamment en vue le caractère relativement secondaire de cette question. Le centre de gravité étant dans la lutte extraparlementaire pour le pouvoir politique, il va de soi que la question générale de la dictature du prolétariat et de la lutte des masses pour cette dictature ne peut se comparer à la question particulière de l'utilisation du parlementarisme.

20. C'est pourquoi l'Internationale communiste affirme de la façon la plus catégorique qu'elle considère comme une faute grave envers le mouvement ouvrier toute scission ou tentative de scission provoquée au sein du Parti communiste par cette question et uniquement par cette question. Le Congrès invite tous les partisans de la lutte de masse pour la dictature du prolétariat, sous la direction d'un parti centralisé sur toutes les organisations de la classe ouvrière, à réaliser l'unité complète des éléments communistes, en dépit des divergences de vues possibles quant à l'utilisation des Parlements bourgeois. 


\section{IV. - LA TACTIQUE RÉVOLUTIONNAIRE}

Les mesures suivantes s'imposent afin de garantir l'application effective d'une tactique révolutionnaire au Parlement :

1. Le Parti communiste dans son ensemble et son Comité central s'assurent, dès la période préparatoire qui précède les élections, de la sincérité et de la valeur communiste des membres du groupe parlementaire communiste ; il a le droit indiscutable de récuser tout candidat désigné par une organisation, s'il n’a pas la conviction que ce candidat fera une politique véritablement communiste.

Les partis communistes doivent renoncer à la vieille habitude socialdémocrate de faire exclusivement élire des parlementaires "expérimentés », et surtout des avocats. De règle, les candidats seront pris parmi les ouvriers : on ne craindra pas de désigner de simples membres du Parti sans grande expérience parlementaire.

Les partis communistes doivent repousser avec un mépris impitoyable les arrivistes qui viennent à eux, à seule fin d'entrer au Parlement. Les Comités centraux ne doivent approuver que les candidatures d'hommes qui, de longues années durant, ont donné des preuves indiscutables de leur dévouement à la classe ouvrière.

2. Les élections achevées, il appartient exclusivement au Comité central du Parti communiste d'organiser le groupe parlementaire, que le Parti soit à ce moment légal ou illégal. Le choix du président et des membres du bureau du groupe parlementaire doit être approuvé par le Comité central. Le Comité central du Parti aura au groupe parlementaire un représentant permanent jouissant du droit de veto. Sur toutes les questions politiques importantes, le groupe parlementaire est tenu de demander les directives préalables du Comité central.

Le Comité central a le droit et le devoir de désigner ou de récuser les orateurs du groupe appelés à intervenir sur des questions importantes et d'exiger que les thèses ou le texte complet de leurs discours, etc..., soient soumis à son approbation. Tout candidat porté sur la liste communiste signe l'engagement officiel de 
résigner son mandat à la première injonction du Comité central, afin que le Parti ait toujours la possibilité de le remplacer.

3. Dans les pays où des réformistes, des demi-réformistes, voire simplement des arrivistes ont déjà réussi à s'introduire dans le groupe parlementaire communiste (c'est déjà le cas pour plusieurs pays), les Comités centraux des partis communistes sont tenus de procéder à une épuration radicale de ces groupes, en s'inspirant du principe qu'un groupe parlementaire peu nombreux, mais vraiment communiste sert beaucoup mieux les intérêts de la classe ouvrière qu'un groupe nombreux sans ferme politique communiste.

4. Tout député communiste est tenu, sur décision du Comité central, d'unir le travail illégal au travail légal. Dans les pays où les députés communistes bénéficient encore, en vertu des lois bourgeoises, d'une certaine immunité parlementaire, cette immunité doit servir à l'organisation et à la propagande illégale du Parti.

5. Les députés communistes sont tenus de subordonner toute leur activité parlementaire à l'action extra-parlementaire du Parti. Le dépôt régulier de projets de loi purement démonstratifs conçus, non en vue de leur adoption par la majorité bourgeoise, mais pour la propagande, l'agitation et l'organisation, doit avoir lieu sur les indications du Parti et de son Comité central.

6. Le député communiste est tenu de se mettre en tête des masses prolétariennes, au premier rang, bien en vue, dans les manifestations et les actions révolutionnaires.

7. Les députés communistes sont tenus de nouer par tous les moyens (sous le contrôle du Parti) des relations épistolaires et autres avec les ouvriers, les paysans et les travailleurs révolutionnaires de toutes catégories, sans imiter en aucun cas les députés socialistes qui s'efforcent d'entretenir avec leurs électeur des relations d'affaires. Ils sont à tout moment à la disposition des organisations communistes pour le travail de propagande dans le pays.

8. Tout député communiste au Parlement est tenu de se rappeler qu'il n'est pas un « législateur » cherchant un langage commun avec d'autres législateurs, mais un agitateur du Parti envoyé chez l'ennemi pour appliquer les décisions du Parti. Le député communiste est responsable non devant la masse anonyme des électeurs, mais devant le Parti communiste légal et illégal. 
9. Les députés communistes doivent tenir au Parlement un langage intelligible à l'ouvrier, au paysan, à la blanchisseuse, au pâtre, de façon que le Parti puisse éditer leurs discours en tracts et les répandre dans les coins les plus reculés du pays.

10. Les ouvriers communistes du rang doivent, même s'ils n'en sont qu'à leurs débuts parlementaires, aborder sans crainte la tribune des Parlements bourgeois et ne point céder la place à des orateurs plus «expérimentés ». En cas de nécessité, les députés ouvriers liront simplement leurs discours, destinés à être reproduits par la presse et en tracts.

11. Les députés communistes sont tenus d'utiliser la tribune parlementaire pour démasquer non seulement la bourgeoisie et sa valetaille officielle, mais aussi les social-patriotes, les réformistes, les politiciens équivoques du centre et, de façon générale, les adversaires du communisme, et, aussi, en vue de propager largement les idées de la $3^{\mathrm{e}}$ Internationale.

12. Les députés communistes, n’y en aurait-il qu'un ou deux, sont tenus de jeter, par toute leur attitude, le défi au capitalisme et de ne jamais oublier que celuilà seul est digne du nom de communiste qui se révèle, non verbalement, mais par des actes, l'ennemi de la société bourgeoise et de ses serviteurs social-patriotes. 
Manifestes, thèses et résolutions

des quatre premiers congrès

de l'Internationale communiste 1919-1923

(juin 1934)

Deuxième Congrès, juillet 1920.

- 9 -

Manifeste du Congrès

Le monde capitaliste

et l'Internationale Communiste

\section{I. - LES RAPPORTS INTERNATIONAUX APRÈS VERSAILLES}

$\underline{\text { Retour à la table des matières }}$

C'est avec mélancolie et regret que la bourgeoisie du monde entier se rappelle les jours d'antan. Tous les fondements de la politique internationale ou intérieure sont bouleversés ou ébranlés. Pour le monde des exploiteurs demain est gros d'orages. La guerre impérialiste a achevé de détruire le vieux système des alliances et des assurances mutuelles sur lequel étaient basés l'équilibre international et la paix armée. Aucun équilibre nouveau ne résulte de la paix de Versailles.

La Russie d'abord, ensuite l'Autriche-Hongrie et l'Allemagne ont été jetées hors de la lice. Ces puissances de premier ordre, qui avaient occupé la première place parmi les pirates de l'impérialisme mondial, sont devenues elles-mêmes les victimes du pillage et ont été livrées au démembrement. Devant l'impérialisme vainqueur de l'Entente s'est ouvert un champ illimité d'exploitation coloniale, commençant au Rhin, embrassant toute l'Europe centrale et orientale, pour finir à l’Océan Pacifique. Est-ce que le Congo, la Syrie, l'Egypte et le Mexique peuvent 
entrer en comparaison avec les steppes, les forêts et les montagnes de la Russie, avec les forces ouvrières, avec les ouvriers qualifiés de l'Allemagne ? Le nouveau programme colonial des vainqueurs était bien simple : renverser la république prolétarienne en Russie, faire main basse sur nos matières premières, accaparer la main-d'œuvre allemande, le charbon allemand, imposer à l'entrepreneur allemand le rôle de garde-chiourme et avoir à leur disposition les marchandises ainsi obtenues ainsi que les revenus des entreprises. Le projet « d'organiser l'Europe » qui avait été conçu par l'impérialisme allemand à l'époque de ses succès militaires, a été repris par l’Entente victorieuse. En traduisant à la barre des accusés les chenapans de l'empire allemand les gouvernements de l'Entente les considèrent bien comme leurs pairs.

Mais même dans le camp des vainqueurs il y a des vaincus.

Enivrée par son chauvinisme et par ses victoires, la bourgeoisie française se voit déjà maîtresse de l'Europe. En réalité jamais la France n’a été à tous les points de vue dans une dépendance plus servile vis-à-vis de ses rivales plus puissantes, l'Angleterre et l'Amérique. La France prescrit à la Belgique un programme économique et militaire, et transforme sa faible alliée en province vassale, mais, vis-à-vis de l’Angleterre, elle joue, en plus grand, le rôle de la Belgique. Pour le moment les impérialistes anglais laissent aux usuriers français le soin de se faire justice dans les limites continentales qui leur sont assignées, faisant ainsi retomber sur la France l'indignation des travailleurs de l'Europe et de l’Angleterre même. La puissance de la France, saignée à blanc et ruinée, n’est qu'apparente et factice ; un jour plus tôt ou plus tard les social-patriotes français seront bien obligés de s'en apercevoir. L'Italie a encore plus perdu de son poids dans les relations internationales. Manquant de charbon, manquant de pain, manquant de matières premières, absolument déséquilibrée par la guerre, la bourgeoisie italienne, en dépit de toute sa mauvaise volonté, n’est pas capable de réaliser dans la mesure où elle le voudrait, les droits qu'elle croit avoir au pillage et à la violence, même dans les coins de colonies que l’Angleterre a bien voulu lui abandonner.

Le Japon, en proie aux contradictions inhérentes au régime capitaliste dans une société demeurée féodale, est à la veille d'une crise révolutionnaire des plus profondes ; déjà, malgré des circonstances plutôt favorables dans la politique internationale, cette crise a paralysé son élan impérialiste. 
Restent seulement deux véritables grandes puissances mondiales, la GrandeBretagne et les Etats-Unis.

L’impérialisme anglais s’est débarrassé de son rival asiatique, le tsarisme, et de la menaçante concurrence allemande. La puissance de la Grande-Bretagne sur les mers atteint son apogée. Elle entoure les continents d'une chaîne de peuples qui lui sont soumis. Elle a mis la main sur la Finlande, l'Estonie et la Lettonie ; elle enlève à la Suède et à la Norvège les derniers vestiges de leur indépendance ; elle transforme la mer Baltique en un golfe qui appartient aux eaux britanniques. Personne ne lui résiste dans la mer du Nord. Possédant le Cap, l’Egypte, l’Inde, la Perse, l'Afghanistan, elle fait de l'Océan Indien une mer intérieure entièrement soumise a son pouvoir. Etant maîtresse des océans, l'Angleterre contrôle les continents. Souveraine du monde, elle ne trouve des limites à sa puissance que dans la république américaine du dollar et dans la république russe des Soviets.

La guerre mondiale a définitivement obligé les Etats-Unis à renoncer à leur conservatisme continental. Elargissant son essor, le programme de son capitalisme national, — «l'Amérique aux Américains » (doctrine de Monroe) — a été remplacé par le programme de l’impérialisme : «Le monde entier aux Américains ». Ne se contentant plus d'exploiter la guerre par le commerce, par l'industrie et par les opérations de Bourse, cherchant d'autres sources de richesse que celles qu'elle tirait du sang européen, lorsqu'elle était neutre, l’Amérique est entrée dans la guerre, a joué un rôle décisif dans la défaite de l'Allemagne et s'est mêlée de résoudre toutes les questions de politique européenne et mondiale.

Sous le drapeau de la Société des Nations, les Etats-Unis ont tenté de faire passer de l'autre côté de l'océan l'expérience qu'ils avaient déjà faite chez eux d'une association fédérative de grands peuples appartenant à des races diverses ; ils ont voulu enchaîner à leur char triomphal les peuples de l'Europe et des autres parties du monde, en les assujettissant au gouvernement de Washington. La Ligue des Nations ne devait plus être en somme qu'une société jouissant d'un monopole mondial, sous la firme : « Yankee \& Co ».

Le Président des Etats-Unis, le grand prophète des lieux communs, est descendu de son Sinaï pour conquérir l'Europe, apportant avec lui ses quatorze articles. Les boursiers, les ministres, les gens d'affaires de la bourgeoisie ne se sont pas trompés une seule minute sur le véritable sens de la nouvelle révélation. En 
revanche, les «socialistes » européens, travaillés par le ferment de Kautsky, ont été saisis d'une extase religieuse et se sont mis à danser, comme le roi David, en accompagnant l'arche sainte de Wilson.

Lorsqu'il a fallu résoudre des questions pratiques, l'apôtre américain a fort bien vu qu’en dépit de la hausse extraordinaire du dollar, la primauté appartenait encore et toujours à la Grande-Bretagne sur toutes les routes maritimes qui réunissent et qui séparent les nations ; car l'Angleterre dispose de la flotte la plus forte, du câble le plus long, et elle a une antique expérience de la piraterie mondiale. En outre, Wilson s’est heurté à la république soviétique et au communisme. Profondément blessé, le Messie américain a désavoué la Ligue des Nations dont l'Angleterre avait fait une de ses chancelleries diplomatiques, et il a tourné le dos à l'Europe.

Ce serait toutefois un enfantillage de penser qu'après avoir subi un premier échec de la part de l'Angleterre l’impérialisme américain rentrera dans sa coquille, nous voulons dire : se conformera de nouveau à la doctrine de Monroe. Non, continuant à asservir par des moyens de plus en plus violents le continent américain, transformant en colonies les pays de l’Amérique centrale et méridionale, les Etats-Unis, représentés par leurs deux partis dirigeants, les démocrates et les républicains, se préparent, pour faire pièce à la Ligue des Nations créée par l'Angleterre, à constituer leur propre Ligue, dans laquelle l'Amérique du Nord jouerait le rôle d'un centre mondial. Pour prendre les choses par le bon bout, ils ont l'intention de faire de leur flotte, dans le courant des trois ou cinq prochaines années, un instrument de lutte plus puissant que n'est la flotte britannique. C'est ce qui oblige l'Angleterre impérialiste à se poser la question : être ou ne pas être ?

À la rivalité furieuse de ces deux géants dans le domaine des constructions navales s’ajoute une lutte non moins furieuse pour la possession du pétrole.

La France qui comptait jouer un rôle d'arbitre entre l'Angleterre et les EtatsUnis s’est trouvée entraînée dans l’orbite de la Grande-Bretagne, comme un satellite de deuxième grandeur ; la Ligue des Nations est pour elle un fardeau intolérable et elle cherche à s'en défaire en fomentant un antagonisme entre l'Angleterre et l'Amérique du Nord.

Ainsi les forces les plus puissantes travaillent à préparer un nouveau duel mondial. 
Le programme de l’émancipation des petits nations, qui avait été mis en avant pendant la guerre, a amené la débâcle complète et l'asservissement absolu des peuples des Balkans, vainqueurs et vaincus, et la balkanisation d'une partie considérable de l'Europe. Les intérêts impérialistes des vainqueurs les ont engagés à détacher des grandes puissances qu'ils avaient battues certains petits Etats représentants des nationalités distinctes. Ici il ne saurait être question de ce que l'on appelle le principe des nationalités : l'impérialisme consiste à briser les cadres nationaux, même ceux des grandes puissances. Les petits Etats bourgeois récemment créés ne sont que les sous-produits de l’impérialisme. En créant, pour y trouver un appui provisoire, toute une série de petites nations, ouvertement opprimées ou officiellement protégées, mais en réalité vassales — l’Autriche, la Hongrie, la Pologne, la Yougoslavie, la Bohème, la Finlande, l'Estonie, la Lettonie, la Lituanie, l’Arménie, la Géorgie, etc... - en les dominant au moyen des banques, des chemins de fer, du monopole des charbons l'impérialisme les condamne à souffrir de difficultés économiques et nationales intolérables, de conflits interminables, de querelles sanglantes.

Quelle monstrueuse raillerie est dans l'histoire ce fait que la restauration de la Pologne, après avoir fait partie du programme de la démocratie révolutionnaire et des premières manifestations du prolétariat international, a été réalisée par l’impérialisme afin de faire obstacle à la Révolution ! La Pologne « démocratique », dont les précurseurs moururent sur les barricades de l'Europe entière, est en ce moment un instrument malpropre et sanglant entre les mains des brigands anglo-français qui attaquent la première république prolétarienne que le monde ait jamais vu.

À côté de la Pologne, la Tchécoslovaquie, « démocratique », vendue au capital français, fournit une garde blanche contre la Russie soviétique, contre la Hongrie soviétique.

La tentative héroïque faite par le prolétariat hongrois pour s’arracher au chaos politique et économique de l'Europe centrale et entrer dans la voie de la fédération soviétique, — qui est vraiment l'unique voie de salut — a été étouffée par la réaction capitaliste coalisée, au moment où, trompé par les partis qui le dirigent, le prolétariat des grandes puissances européennes s’est trouvé incapable de remplir son devoir envers la Hongrie socialiste et envers lui-même. 
Le gouvernement soviétique de Budapest a été renversé avec l'aide de socialtraîtres qui, après s'être maintenus au pouvoir pendant trois ans et demi, ont été jetés à terre par la canaille contre-révolutionnaire déchaînée, dont les crimes sanglants ont surpassé ceux de Koltchak, de Dénikine, de Wrangel et des autres agents de l'Entente... Mais, même abattue pour un temps, la Hongrie soviétique continue à éclairer, comme un phare splendide, les travailleurs de l'Europe centrale.

Le peuple turc ne veut pas se soumettre à la honteuse paix que lui imposent les tyrans de Londres. Pour faire exécuter les clauses du traité, l'Angleterre a armé et lancé la Grèce contre la Turquie. De cette manière la péninsule balkanique et l'Asie-Mineure, Turcs et Grecs, sont condamnés à une dévastation complète, à des massacres mutuels.

Dans la lutte de l'Entente contre la Turquie, l’Arménie a été inscrite au programme, de même que la Belgique dans la lutte contre l'Allemagne, de même que la Serbie dans la lutte contre l'Autriche-Hongrie. Après que l'Arménie a été constituée - sans frontières définies, sans possibilité d'existence — Wilson a refusé d'accepter le mandat arménien que lui proposait « la Ligue des Nations » : car le sol de l’Arménie ne renferme ni naphte, ni platine. L’Arménie « émancipée » est plus que jamais sans défense.

Presque chacun des Etats «nationaux » nouvellement créés a son irrédentisme, c'est-à-dire son abcès national latent.

En même temps la lutte nationale, dans les domaines possédés par les vainqueurs, a atteint sa plus haute tension. La bourgeoisie anglaise qui voudrait prendre sous sa tutelle les peuples des quatre parties du monde, est incapable de résoudre d'une manière satisfaisante la question irlandaise qui se pose dans son voisinage immédiat.

La question nationale dans les colonies est encore plus grosse de menaces. L'Egypte, l'Inde, la Perse sont secoués par les insurrections. Les prolétaires avancés de l'Europe et de l'Amérique transmettent aux travailleurs des colonies la devise de la fédération soviétique.

L'Europe officielle, gouvernementale, nationale, civilisée, bourgeoise, — telle qu'elle est sortie de la guerre et de la paix ce Versailles - suggère l'idée d'une maison de fous. Les petits Etats créés par des moyens artificiels, morcelés, étouf- 
fant au point de vue économique dans les bornes qui leur ont été prescrites, se prennent à la gorge et combattent pour s’arracher des ports, des provinces, des petites villes de rien du tout. Ils cherchent la protection des Etats plus forts, dont l'antagonisme s'accroît de jour en jour. L'Italie garde une attitude hostile à la France et serait disposée à soutenir contre elle l'Allemagne, si celle-ci se trouvait capable de relever la tête. La France est empoisonnée par l'envie qu'elle porte à l'Angleterre et, pour obtenir qu'on lui paie ses rentes, elle est prête à mettre de nouveau le feu aux quatre coins de l'Europe. L'Angleterre maintient avec l'aide de la France l'Europe dans un état de chaos et d'impuissance qui lui laisse les mains libres pour effectuer ses opérations mondiales, dirigées contre l’Amérique. Les Etats-Unis laissent le Japon s'enliser dans la Sibérie orientale, pour assurer pendant ce temps à leur flotte la supériorité sur celle de la Grande-Bretagne avant 1925, à moins que l’Angleterre ne se décide à se mesurer avec eux avant cette date.

Pour compléter comme il convient ce tableau, l'oracle militaire de la bourgeoisie française, le maréchal Foch nous prévient que la guerre future aura pour point de départ le point où la guerre précédente s’est arrêtée : on verra d’abord apparaître les avions et les tanks, le fusil automatique et les mitrailleuses au lieu du fusil portatif, la grenade au lieu de la baïonnette.

Ouvriers et paysans de l'Europe, de l'Amérique, de l'Asie, de l'Afrique et de l'Australie ! Vous avez sacrifié dix millions de vies, vingt millions de blessés et d'invalides. Maintenant vous savez du moins ce que vous avez obtenu à ce prix !

\section{LA SITUATION ÉCONOMIQUE}

En même temps l’humanité continue à se ruiner.

La guerre a détruit mécaniquement les liens économiques dont le développement constituait une des plus importantes conquêtes du capitalisme mondial. Depuis 1914, l’Angleterre, la France et l’Italie ont été complètement séparées de l'Europe centrale et du proche Orient, depuis 1917 — de la Russie.

Durant plusieurs années d'une guerre qui a détruit ce qui avait été l'œuvre de plusieurs générations, le travail humain, réduit au minimum, a été appliqué prin- 
cipalement à transformer en marchandises les réserves des matières premières dont on disposait depuis longtemps et dont on a fait surtout des armes et des instruments de destruction.

Dans les domaines économiques où l’homme entre en lutte immédiate avec la nature avare et inerte, en tirant de ses entrailles le combustible et les matières premières, le travail a été progressivement réduit à néant. La victoire de l'Entente et la paix de Versailles n’ont point arrêté la destruction économique et la décadence générale, elles en ont seulement modifié les voies et les formes. Le blocus de la Russie soviétique et la guerre civile suscitée artificiellement le long de ses fertiles frontières ont causé et causent encore des dommages inappréciables au bien-être de l'humanité toute entière. Si la Russie était soutenue, au point de vue technique, dans une mesure même très modeste, — l'Internationale l'affirme devant le monde entier - elle pourrait, grâce aux formes soviétiques d'économie, donner deux et trois fois plus de produits alimentaires et de matières premières à l'Europe que n'en donnait autrefois la Russie du Tsar. Au lieu de cela, l'impérialisme anglo-français force la République des travailleurs à employer toute son énergie et toutes ses ressources à sa défense. Pour priver les ouvriers russes de combustible, l'Angleterre a retenu entre ses griffes Bakou dont le pétrole est resté de cette façon à peu près inutilisé, car elle n’a réussi a en importer qu'une infime partie. Le richissime bassin houiller du Don a été dévasté par les bandits blancs aux gages de l'Entente, chaque fois qu'ils ont réussi à prendre l’offensive dans ce secteur. Les ingénieurs et les sapeurs français se sont plus d'une fois appliqués à détruire nos ponts et nos voies ferrés ; et le Japon n’a pas cessé jusqu’ici de piller et de ruiner la Sibérie orientale.

La science industrielle allemande et le taux de production très élevé de la main-d'œuvre allemande, ces deux facteurs d'une extrême importance pour la renaissance de la vie économique européenne, sont paralysés par les clauses de la paix de Versailles encore plus qu'ils ne l'avaient été par la guerre. L’Entente se trouve devant un dilemme : pour pouvoir exiger le payement il faut donner le moyen de travailler, pour laisser travailler il faut laisser vivre. Et donner à l’Allemagne ruinée, dépecée, exsangue, le moyen de se refaire une vie, c’est lui rendre possible un sursaut de protestation. Foch a peur d'une revanche allemande, et cette crainte transpire dans tout ce qu'il entreprend, par exemple dans la façon 
de resserrer chaque jour davantage l'étau militaire qui doit empêcher l'Allemagne de se redresser.

Tous manquent de quelque chose, tous sont dans le besoin. Non pas seulement le bilan de l'Allemagne, mais également celui de la France et de l'Angleterre, se signalent exclusivement par leur passif. La dette française s'élève à 300 milliards de francs, dont les deux tiers au moins, selon l'assertion du sénateur réactionnaire Gaudin de Villaine, sont les résultats de toute sorte de déprédations, d'abus et de désordres.

La France a besoin d'or, la France a besoin de charbon. Les bourgeois français en appellent aux tombes innombrables des soldats tombés pendant la guerre pour réclamer les intérêts de ses capitaux. L’Allemagne doit payer : est-ce que le général Foch n’a pas assez de Sénégalais pour occuper les villes allemandes ? La Russie doit payer! Pour nous en persuader, le gouvernement français dépense à dévaster la Russie, les milliards arrachés aux contribuables pour la reconstitution des départements français.

L'entente financière internationale qui devait alléger le fardeau des impôts français en annulant les dettes de guerre, cette entente n'a pas eu lieu : les EtatsUnis se sont montrés très peu disposés à faire à l'Europe un cadeau de 10 milliards de livres sterling.

L'émission du papier-monnaie continue, atteignant chaque jour un chiffre plus imposant. En Russie, où il existe une organisation économique unifiée, une répartition systématique des denrées et où le salaire en montée tend de plus en plus à être remplacé par le payement en nature, l'émission continuelle des papiermonnaie et la chute rapide de leur taux ne font que confirmer le délabrement du vieux système financier et commercial. Mais dans les pays de capitalisme la quantité croissante des bons du trésor en cours sont l'indice d'un profond désarroi économique et d'une faillite imminente.

Les conférences convoquées par l'Entente voyagent de place en place, cherchant à s'inspirer de telle ou telle plage à la mode. Chacun réclame les intérêts du sang versé pendant la guerre, une indemnité proportionnelle au nombre de ses tués. Cette manière de bourse ambulante rabâche tous les quinze jours la même question : à savoir, si c'est 50 ou $55 \%$ que la France doit recevoir, d'une contribution que l'Allemagne n'est pas en état de payer. Ces conférences fantasmagori- 
ques sont bien faites pour couronner la fameuse « organisation » de l'Europe, qu’on s'était tant plu à vanter.

La guerre a fait subir au capitalisme une évolution. Le pressurage systématique de la plus-value qui fut jadis pour l'entrepreneur la seule source de revenu, semble à présent une occupation trop fade aux messieurs les bourgeois qui ont pris l'habitude de doubler, de décupler leurs dividendes dans l'espace de quelques jours, au moyen de spéculations savantes basées sur le brigandage international.

Le bourgeois a rejeté quelques préjugés qui le gênaient et acquis par contre un certain coup de main qui lui manquait jusqu'ici. La guerre l’a accoutumé, comme aux actes les plus ordinaires, à réduire par le blocus des pays entiers à la famine, à bombarder et incendier des villes et villages pacifiques, à infecter les sources et les rivières en y jetant des cultures du choléra, à transporter des la dynamite dans des valises diplomatiques, à émettre des billets de banque faux imitant ceux de l'ennemi, à employer la corruption, l'espionnage et la contrebande dans des proportions jusque-là inouïes. Les moyens d'action appliqués à la guerre restèrent en vigueur dans le monde commercial après la conclusion de la paix. Les opérations commerciales de quelque importance s'effectuent sous l'égide de l'Etat. Ce dernier est devenu semblable à une association de malfaiteurs armés jusqu’aux dents. Le terrain de la production mondiale se rétrécit chaque jour davantage et la mainmise sur la production devient d'autant plus frénétique et revient d'autant plus chère.

Empêcher : voilà le dernier mot de la politique du capitalisme, la devise qui remplace le protectionnisme et le libre-échangisme ! L’agression dont a été victime la Hongrie de la part des chenapans roumains qui y pillèrent tout ce qui leur tomba sous la main, locomotives et bijoux indifféremment, caractérise la philosophie économique de Lloyd George et de Millerand.

Dans sa politique économique intérieur, la bourgeoisie ne sait à quoi s’en tenir entre un système de nationalisation, de réglementation et de contrôle de l'Etat qui pourrait être des plus efficaces, et, d'autre part, les protestations qui se font entendre contre la mainmise effectuée par l'Etat sur les affaires économiques. Le parlement français cherche à trouver un compromis qui lui permettrait de concentrer la direction de toutes les voies ferrées de la république dans des mains uniques sans pour cela léser les intérêts des capitalistes actionnaires dans les compagnies 
de chemin de fer privées. En même temps, la presse capitaliste mène une campagne enragée contre «l'étatisme » qui est le premier pas de l'intervention de l'Etat et qui met un frein à l'initiative privée. Les chemins de fer américains, qui, dirigés pendant la guerre par l'Etat, avaient été désorganisés, sont tombés dans une situation encore plus difficile lorsque le contrôle du gouvernement a été supprimé. Néanmoins, le parti républicain promet dans son programme d'affranchir la vie économique de l'arbitrage gouvernemental. Le chef des trade-unions américains, Samul Gompers, ce vieux cerbère du Capital, lutte contre la nationalisation des chemins de fer que, de leur coté, les naïfs adeptes les charlatans du réformisme proposent à la France en guise de pensée universelle. En réalité, l'intervention désordonnée de l'Etat ne serait faite que pour seconder l'activité pernicieuse des spéculateurs, pour achever d'introduire le désarroi le plus complet dans l'économie du capitalisme, à l'heure où celui-ci se trouve dans sa période de décadence. Enlever aux trusts les moyens de production et de transport pour les transmettre à «la nation », c'est-à-dire à l'Etat bourgeois, c'est-à-dire au plus puissant et au plus avide des trusts capitalistes, c'est non pas enrayer le mal, mais en faire une loi commune.

La baisse de prix et la hausse du taux de la monnaie ne sont que des indices trompeurs qui ne peuvent cacher la ruine imminente. Les prix ont beau baisser, cela ne veut pas dire qu'il y ait une augmentation de matières premières ni que le travail soit devenu plus productif.

Après l'épreuve sanglante de la guerre, la masse ouvrière n'est plus capable de travailler avec la même vigueur dans les mêmes conditions. La destruction au cours de quelques heures de valeurs dont la création avait demandé des années, l'impudent agiotage d'une clique financière avec des enjeux de plusieurs milliards et, à coté de cela, des monceaux d'ossements et de ruines - ces leçons données par l'histoire, étaient peu faites pour soutenir dans la classe ouvrière la discipline automatique inhérente au travail salarié. Les économistes bourgeois et les faiseurs de feuilletons nous parlent d'une «vague de paresse » qui déferlerait, selon eux, sur l'Europe, menaçant son avenir économique. Les administrateurs cherchent à gagner du temps en accordant certains privilèges aux ouvriers qualifiés. Mais ils perdent leur peine. Pour la reconstitution et le développement de la production au travail, il est nécessaire que la classe ouvrière sache pertinemment que chaque coup de marteau aura pour résultat d'améliorer son sort, de lui rendre plus facile 
l'instruction et de la rapprocher d'une paix universelle. Or, cette assurance ne peut lui être donnée que par une révolution sociale.

La hausse de prix sur les denrées alimentaires sème le mécontentement et la révolte dans tous les pays. La bourgeoisie de France, d'Italie, d'Allemagne et des autres pays ne trouve que des palliatifs à opposer au fléau de la vie chère et à la vague menaçante des grèves. Pour être en mesure de payer aux agriculteurs ne fut ce qu'une partie de leurs frais de production, l'Etat, couvert de dettes, s'engage dans des spéculations louches, se dévalise lui-même pour retarder le quart d’heure de Rabelais. S’il est vrai que certaines catégories d'ouvriers vivent actuellement dans des conditions même meilleures qu'avant la guerre, cela ne signifie rien en réalité quant à ce qui concerne l'état économique des pays capitalistes. On obtient des résultats éphémères en s'adressant à demain pour ouvrir des emprunts de charlatans ; demain amènera la misère et toutes sortes de calamités.

Que dire des Etats-Unis ? «L’Amérique est l'espoir de l’humanité » : par la bouche de Millerand, le bourgeois français répète cette sentence de Turgot, il espère qu'on lui remettra ses dettes, lui qui ne les remet à personne. Mais les EtatsUnis ne sont pas capables de tirer l'Europe de l'impasse économique où elle est engagée. Durant les six dernières années ils ont épuisé leur stock de matières premières. L'adaptation du capitalisme, américain aux exigences de la guerre mondiale, a rétréci sa base industrielle. Les Européens ont cessé d'émigrer en Amérique. Une vague de retour a arraché à l’industrie américaine des centaines de milliers d'Allemands, d'Italiens, Polonais, de Serbes, de Tchèques qu'appelaient en Europe soit la mobilisation, soit le mirage d'une patrie recouvrée. Le manque de matières premières et de forces ouvrières pèse lourdement sur la République transatlantique et engendre une profonde crise économique, par suite de laquelle le prolétariat américain entre dans une nouvelle phase de lutte révolutionnaire. L’Amérique s'européanise rapidement.

Les neutres n’ont pas échappé aux conséquences de la guerre et du blocus. Semblable à un liquide enfermé dans des vases communiquants, l'économie des Etats capitalistes étroitement reliés entre eux, grand ou petits, belligérants ou neutres, vainqueurs ou vaincus, tend à prendre un seul et même niveau — celui de la misère de la famine et du dépérissement. 
La Suisse vit au jour le jour, chaque éventualité menace de la jeter hors de tout équilibre. En Scandinavie, une riche importation d'or ne saurait résoudre le problème de l'approvisionnement. On est obligé de demander du charbon à l'Angleterre par petites portions, et cela avec force courbettes. En dépit de la famine en Europe, la pêche en Norvège subit une crise inouïe.

L'Espagne, d'où la France a fait venir des hommes, des chevaux et des vivres, ne peut se tirer de nombre de difficultés, au point de vue du ravitaillement, lesquelles entraînent à leur tour des grèves violentes et des manifestations de la part des masses que la faim oblige à descendre dans la rue.

La bourgeoisie compte fermement sur les campagnes. Ses économistes affirment que le bien-être des paysans a extraordinairement augmenté. C'est une illusion. Il est vrai que les paysans qui apportent leurs produits au marché ont plus ou moins fait fortune, partout, pendant la guerre. Ils ont vendu leurs produits à très haut prix et ont payé d'une monnaie qui leur revient à bon marché les dettes qu'ils avaient faites lorsque l'argent coûtait cher. C'est là pour eux un avantage évident. Mais, durant la guerre, leurs exploitations sont tombées dans le désordre et leur rendement a faibli. Ils ont besoin d'objets fabriqués. Et le prix de ces objets a augmenté dans la mesure où l'argent est devenu meilleur marché. Les exigences du fisc sont devenues monstrueuses et menacent d'engloutir le paysan avec ses produits et ses terres. Ainsi après une période de relèvement momentané du bienêtre, les paysans de la petite classe tombent de plus en plus dans des difficultés irréductibles. Leur mécontentement au sujet des résultats de la guerre ne fera que croître et, représenté par une armée permanente, le paysan prépare à la bourgeoisie pas mal de surprises désagréables.

La restauration économique de l'Europe, dont parlent les ministres qui la gouvernent, est un mensonge. L’Europe se ruine et le monde entier se ruine avec elle.

Sur les bases du capitalisme il n'est point de salut. La politique de l'impérialisme ne saurait éliminer le besoin, elle ne peut que le rendre plus douloureux en favorisant la dilapidation des réserves dont on dispose encore.

La question du combustible et des matières premières est une question internationale que l'on ne peut résoudre que sur la base d'une production réglée sur un plan, mise en commun, socialisée. 
Il faut annuler les dettes d'Etat. Il faut émanciper le travail et ses fruits du tribut monstrueux qu'il paie à la ploutocratie mondiale. Il faut renverser la ploutocratie. Il faut jeter à bas les barrières gouvernementales qui fractionnent l'économie mondiale. Au Conseil Suprême Economique des impérialistes de l'Entente, il faut substituer un Conseil Suprême Economique du prolétariat mondial pour l'exploitation centralisée de toutes les ressources de l'humanité.

Il faut tuer l'impérialisme pour que le genre humain puisse continuer à subsister.

\section{III. - LE RÉGIME BOURGEOIS APRÈS LA GUERRE}

Toute l'énergie des classes opulentes est concentrée sur ces deux questions : se maintenir au pouvoir dans la lutte internationale et ne pas permettre au prolétariat de devenir maître du pays. Conformément à ce programme, les anciens groupes politiques parmi la bourgeoisie en Russie où l'étendard du parti constitutionnel-démocrate (K. D.) est devenu durant la période décisive de la lutte, l'étendard de tous les riches dressés contre la révolution des ouvriers et des paysans, mais aussi dans les pays dont la culture politique est plus ancienne et a des racines plus profondes, les programmes d'autrefois qui séparaient les diverses fractions de la bourgeoisie ont disparu, presque sans laisser de traces, bien avant l'attaque ouverte qui a été menée par le prolétariat révolutionnaire.

Lloyd George se fait le héraut de l'union des conservateurs, des unionistes et des libéraux pour la lutte en commun contre la domination menaçante de la classe ouvrière. Ce vieux démagogue établit à la base de son système la sainte église, qu'il compare à une station centrale d'électricité fournissant un courant égal à tous les partis des classes opulentes. En France, l'époque si peu lointaine encore et si bruyante de l'anticléricalisme semble n'être plus qu'une vision de l'autre monde : les radicaux, les royalistes et les catholiques constituent actuellement un bloc de l'ordre national contre le prolétariat qui lève la tête. Tendant la main à toutes les forces de la réaction, le gouvernement français soutient le cent-noir Wrangel et renoue ses rapports diplomatiques avec le Vatican. 
Le neutre convaincu, le germanophile Giolitti se saisit du gouvernail de l'Etat italien en qualité de chef commun des interventionnistes, des neutralistes, des cléricaux, des mazzinistes : il est prêt à louvoyer dans les questions secondaires de la politique intérieure et extérieure pour repousser avec d'autant plus d'énergie l'offensive des prolétaires révolutionnaires dans les villes et les villages. Le Gouvernement de Giolitti se considère à bon droit comme le dernier atout de la bourgeoisie italienne.

La politique de tous les gouvernements allemands et des partis gouvernementaux, après la défaite des Hohenzollern, a tendu à établir de concert avec les classes dirigeantes de l'Entente, un terrain commun de haine contre le bolchevisme, c’est-à-dire contre la révolution prolétarienne.

Au moment où le Shylock anglo-français étouffe avec une férocité croissante le peuple allemand, la bourgeoisie allemande, sans distinction de partis, demande à l'ennemi de relâcher le nœud qui l'étrangle juste assez pour pouvoir, de ses propres mains, égorger l'avant-garde du prolétariat allemand. C'est en somme à cela que reviennent toujours les conférences périodiques qui ont lieu et les conventions que l'on signe au sujet du désarmement et de la livraison des engins de guerre.

En Amérique, on ne fait plus aucune différence entre Républicains et Démocrates. Ces puissantes organisations politiques d'exploiteurs, adaptées au cercle restreint des intérêts américains, ont montré en toute évidence à quel point elles étaient dénuées de consistance lorsque la bourgeoisie américaine est entrée dans la lice du brigandage mondial.

Jamais encore les intrigues des chefs et de leurs bandes - dans l'opposition comme dans les ministères - n'avaient fait preuve d'un semblable cynisme, n'avaient agi aussi ouvertement. Mais en même temps tous les chefs, et leurs cliques, les partis bourgeois de tous les pays, constituent un front commun contre le prolétariat révolutionnaire.

Au moment où les imbéciles de la social-démocratie continuent à opposer le chemin de la démocratie aux violences de la voie dictatoriale, les derniers vestiges de la démocratie sont foulés aux pieds et anéantis dans tous les Etats du monde.

Après une guerre durant laquelle les chambres de représentants, quoique ne disposant pas du pouvoir, servaient à couvrir par leurs cris patriotiques l'action des bandes dirigeantes impérialistes, les parlements sont tombés dans une complè- 
te prostration. Toutes les questions sérieuses se résolvent en dehors des parlements. L'élargissement illusoire des prérogatives parlementaires, solennellement proclamé par les saltimbanques de l'impérialisme en Italie et dans les autres pays, ne change rien à l'état des choses. Véritables maîtres de la situation, disposant du sort de l'Etat, lord Rothschild, lord Weir, Morgan et Rockfeller, Schneider et Loucheur, Hugo Stinnes et Felix Deutsch, Rizzello et Agnelli — ces rois de l'or, du charbon, du pétrole et du métal - agissent derrière les coulisses en envoyant aux parlements leurs petits commis pour exécuter leurs travaux.

Le parlement français, qu'amuse encore la procédure des lectures à trois reprises de projets de lois insignifiants, le parlement français plus que tout autre discrédité par l'abus de la rhétorique, par le mensonge, par le cynisme avec lequel il se laisse acheter, apprend tout à coup que les quatre milliards qu'il avait destinés aux réparations dans les régions dévastées de la France ont été dépensées par Clemenceau pour des fins tout autres, et principalement pour poursuivre l'œuvre de dévastation entreprise dans les provinces russes.

L'écrasante majorité des députés du parlement anglais, soi-disant toutpuissant, n'est pas plus renseignée au sujet des véritables intentions de Lloyd George et de Kerson, en ce qui concerne la Russie Soviétique et même la France, que les vieilles femmes dans les villages du Bengale.

Aux Etats-Unis le parlement est un chœur obéissant ou qui ronchonne quelquefois sous la baguette du président ; celui-ci n'est que le suppôt de la machine électorale qui sert d'appareil politique aux trusts - maintenant, après la guerre, dans une beaucoup plus large mesure qu'auparavant.

Le parlementarisme tardif des Allemands, avorton de la révolution bourgeoise, qui n'est elle-même qu'un avorton de l'histoire, est sujet dès l'enfance à toutes les maladies qui affectent les vieux chiens. Le Reichstag de la République d'Ebert, « le plus démocratique du monde », reste impuissant non seulement devant le bâton de maréchal que brandit Foch, mais aussi devant les machinations de ses boursiers, de ses Stinnes ainsi que devant les complots militaires d'une clique d'officiers. La démocratie parlementaire allemande n'est qu'un vide entre deux dictatures.

Il s'est produit durant la guerre de profondes modifications dans la composition même de la bourgeoisie. En face de l'appauvrissement général du monde 
entier, la concentration des capitaux a fait tout à coup un grand saut en avant. On a vu se mettre en vedette des maisons de commerce qui restaient autrefois dans l’ombre. La solidité, l’équilibre, la propension aux compromis « raisonnables », l'observation d'un certain décorum dans l'exploitation comme dans l'utilisation des produits, — tout cela a disparu sous le torrent de l’impérialisme.

Ce sont de nouveaux riches qui ont occupé l'avant-scène : fournisseurs d'armée, spéculateurs de bas étage, parvenus, rastaquouères, maraudeurs, repris de justice couverts de diamants, canaille sans foi ni loi, avide de luxe, prête aux dernières atrocités pour entraver la révolution prolétarienne qui ne peut leur promettre qu'un nœud coulant.

Le régime actuel en tant que domination des riches, se dresse devant les masses dans toute sont impudence. En Amérique, en France, en Angleterre le luxe d’après-guerre a pris un caractère frénétique. Paris, bondé de parasites du patriotisme international, ressemble, d'après l'aveu du Temps, à une Babylone à la veille d'une catastrophe.

C’est au gré de cette bourgeoisie que se rangent la politique, la justice, la presse, l'art, l’Eglise. Tous les freins, tous les principes sont laissés de côté. Wilson, Clemenceau, Millerand, Lloyd George, Churchill ne s’arrêtent pas devant les plus impudentes tromperies, devant les mensonges les plus grossiers et, lorsque on les surprend à accomplir des actes malhonnêtes, ils poursuivent tranquillement des exploits qui devraient les mener devant la cour d'assises. Les règles classiques de la perversité politique, telles que les a rédigées le vieux Machiavel, ne sont plus que les innocents aphorismes d'un nigaud de province en comparaison avec les principes sur lesquels se règlent les gouvernants bourgeois d'aujourd'hui. Les tribunaux, qui couvraient autrefois d'un clinquant démocratique leur essence bourgeoise, se sont mis à bafouer ouvertement les prolétaires et accomplissent un travail de provocation contre-révolutionnaire. Les juges de la $3^{\mathrm{e}}$ République acquittent sans broncher l'assassin de Jaurès. Les tribunaux de l'Allemagne, qui avait été proclamée république socialiste, encouragent les assassins de Liebknecht, de Rosa Luxemburg et de bien d'autres martyrs du prolétariat. Les tribunaux des démocraties bourgeoises servent à légaliser solennellement tous les crimes de la terreur blanche. 
La presse bourgeoise se laisse ouvertement acheter, elle porte l'estampille des vendus sur le front, comme une marque de fabrique. Les journaux dirigeants de la bourgeoisie mondiale sont des fabriques monstrueuses de mensonges, de calomnies et de prisons spirituelles.

Les dispositions et les sentiments de la bourgeoisie sont sujets à des hausses et à des baisses nerveuses, comme le prix de ses marchés. Durant les premiers mois qui ont suivi la fin de la guerre, la bourgeoisie internationale, surtout la bourgeoisie française, claquait des dents devant le communisme menaçant. Elle se faisait de l'imminence du danger une idée en rapport avec les crimes sanglants qu'elle avait commis. Mais elle a su repousser la première attaque. Reliés à elle par les chaînes d'une responsabilité commune, les partis socialistes et les syndicats de la $2^{\mathrm{e}}$ Internationale lui ont rendu un dernier service, en prêtant le dos aux premiers coups portés par la colère des travailleurs. Au prix du naufrage complet de la $2^{\mathrm{e}}$ Internationale, la bourgeoisie a reçu quelque répit. Il a suffi d’un certain nombre de votes contre-révolutionnaires obtenus par Clemenceau aux élections parlementaires, de quelques mois d'équilibre instable, de l'insuccès de la grève de mai pour que la bourgeoisie française envisage avec assurance la solidité inébranlable de son régime. L’orgueil de cette classe a atteint le niveau auquel s’étaient autrefois élevées ses craintes.

La menace est devenue l'argument unique de la bourgeoisie. Elle ne croit pas aux phrases et exige des actes : qu'on arrête, qu'on disperse les manifestations, qu'on confisque, qu'on fusille ! Les ministres bourgeois et les parlementaires tâchent d'en imposer à la bourgeoisie en faisant figure d'hommes bien trempés, d'hommes d'acier. Lloyd George conseille sèchement aux ministres allemands de fusilier leurs communards, comme on l'a fait en France en 1871. Un fonctionnaire de troisième ordre peut compter sur les applaudissements tumultueux de la Chambre s'il sait mettre à la fin d'un pauvre compte rendu quelques menaces à l’adresse des ouvriers.

Tandis que l'administration se transforme en une organisation de plus en plus éhontée, destinée à exercer des répressions sanglantes, à l’égard des classes laborieuses, d'autres organisations contre-révolutionnaires privées, formées sous son égide et mises à sa disposition, travaillent à empêcher par la force les grèves, à commettre des provocations, à donner de faux témoignages, à détruire les organisations révolutionnaires, à s'emparer des institutions communistes, à massacrer et 
incendier, à assassiner les tribus révolutionnaires, et prennent d'autres mesures à l’avenant pour défendre la propriété privée et la démocratie.

Les fils des gros propriétaires, des gros bourgeois, les petits bourgeois qui ne savent à quoi s’en prendre et en général les éléments déclassés, en premier lieu les ci-devant de diverses catégories émigrés de Russie, forment d’inépuisables cadres de réserve pour les armées irrégulières de la contre-révolution. Des officiers élevés à l’école de la guerre impérialiste sont à leur tète.

Les vingt mille officiers de l'armée de Hohenzollern constituent, surtout après la révolte de Kapp-Lüttwitz, un noyau contre-révolutionnaire solide dont la démocratie allemande ne sera pas à même de venir à bout si le marteau de la dictature du prolétariat ne vient le briser. Cette organisation centralisée des terroristes de l'ancien régime se complète par les détachements de partisans formés par les hauts bourreaux prussiens.

Aux Etats-Unis, des unions comme la National Security League ou le Knigths of Liberty sont les régiments d'avant-garde du capital et sur leurs flancs agissent ces bandes de brigands que sont les Detective agencies d'espionnage privé.

En France la Ligue Civique n'est autre chose qu'une organisation perfectionnée de « renards » et la Confédération du Travail, d’ailleurs réformiste, est mise hors la loi.

La maffia des officiers blancs de Hongrie qui persiste à avoir une existence clandestine bien que leur gouvernement de bourreaux contre-révolutionnaires subsiste par le bon plaisir de l'Angleterre, a montré au prolétariat du monde entier comment se pratiquent cette civilisation et cette humanité que préconisent Wilson et Lloyd George après avoir maudit le pouvoir des Soviets et les violences révolutionnaires.

Les gouvernements «démocratiques » de la Finlande, de la Géorgie, de la Lettonie et de l'Estonie suent sang et eau pour atteindre le niveau de perfection de leur prototype hongrois. A Barcelone, la police a sous ses ordres une bande d'assassins. Et il en est de même partout.

Même dans un pays vaincu et ruiné comme la Bulgarie, les officiers sans emploi se réunissent en sociétés secrètes qui sont prêtes au premier signe à faire preuve de leur patriotisme au détriment des ouvriers bulgares. 
Tel qu'il est mis en pratique dans le régime bourgeois d'après guerre, le programme d'une conciliation des intérêts contradictoires, d'une collaboration des classes, d'un réformisme parlementaire, d'une socialisation graduelle et d'un accord mutuel au sein de chaque nation, tout cela ne présente qu'une sinistre bouffonnerie.

La bourgeoisie s'est refusée une fois pour toutes à concilier ses propres intérêts et ceux du prolétariat au moyen de simples réformes. Elle corrompt ceux qui ont pris les aumônes de la classe ouvrière et soumet le prolétariat par le fer et le sang à une règle inflexible.

Pas une seule question importante ne se décide à la majorité des voix. Du principe démocratique il n'est resté qu’un souvenir dans les cervelles fumeuses des réformistes. L'Etat se borne chaque jour davantage à recruter ce qui constitue le nerf essentiel des gouvernements, c'est-à-dire des régiments de soldats. La bourgeoisie ne perd plus son temps à « compter les poires sur l'arbre », elle compte les fusils, les mitrailleuses et les canons qui seront à sa disposition lorsque l'heure sera venue où la question du pouvoir et de la propriété ne souffrira plus aucun délai.

Qui vient nous parler de collaboration ou de médiation ? Ce qu'il faut pour notre salut, c’est la ruine de la bourgeoisie et seule la révolution prolétarienne peut causer cette ruine.

\section{IV. - LA RUSSIE SOVIÉTISTE}

Le chauvinisme, la cupidité, la discorde s’entrechoquent dans une sarabande effrénée et seul à la face du monde le principe du communisme reste vivace et créateur. Bien que le pouvoir des Soviets se soit établi pour commencer dans un pays arriéré, dévasté par la guerre, entouré d'ennemis puissants, il s'est montré doué non seulement d'une ténacité peu commune, mais aussi d'une activité inouïe. Il a prouvé par le fait la force potentielle du communisme. Le développement et le raffermissement du pouvoir soviétique constituent le point culminant de l'histoire du monde depuis la création de l’Internationale Communiste. 
La capacité de former une armée a toujours été considérée jusqu'ici comme le critérium de toute activité économique ou politique. La force ou la faiblesse de l'armée sont l'indice qui sert à évaluer la force ou la faiblesse de l'Etat au point de vue économique. Le pouvoir des Soviets a créé au bruit du canon une force militaire de premier ordre, et grâce à elle il a battu avec une supériorité indiscutable non seulement les champions de la vieille Russie monarchiste et bourgeoise, les armées de Koltchak, Dénikine, Youdénitch, Wrangel et autres, mais aussi les armées nationales des républiques «démocratiques » qui entrent en ligne pour le bon plaisir de l'impérialisme mondial (Finlande, Estonie, Lettonie, Pologne).

Au point de vue économique c'est déjà un grand miracle que la Russie soviétique ait tenu bon ces trois premières années. Elle a fait mieux, elle s'est développée, parce que, ayant eu l'énergie d'arracher d'entre les mains de la bourgeoisie les instruments d'exploitation, elle en a fait des instruments de production industrielle et les a mis méthodiquement en action. Le fracas des pièces d'artillerie le long du front immense qui encercle la Russie des toutes parts ne l'a pas empêchée de prendre des mesures pour rétablir la vie économique et intellectuelle bouleversée.

La monopolisation par l'Etat socialiste des principales denrées alimentaires et la lutte sans merci contre les spéculateurs ont seules sauvegardé les villes russes d'une famine mortelle et donné la possibilité de ravitailler l'Armée Rouge. La réunion de toutes les usines, des fabriques, des chemins de fer et de la navigation sous l'égide de l'Etat a seule permis de régulariser la production et d'organiser le transport. La concentration de l'industrie et du transport entre les mains du gouvernement amène à la simplification des méthodes techniques en créant des modèles uniques pour les diverses pièces, modèles qui servent de prototype à toute production ultérieure. Seul le socialisme rend possible d'évaluer avec précision la quantité de boulons pour locomotives, pour wagons et pour steamers qui sont à produire et à réparer.

De même on peut prévoir périodiquement la production en gros nécessaire des pièces des machines adaptées au prototype, ce qui présente des avantages incalculables pour l'intensification de la production.

Le progrès économique, l'organisation scientifique de l'industrie, la mise en pratique du système Taylor épuré de toutes tendances au «sweating », ne ren- 
contrent plus en Russie soviétique d'autres obstacles que ceux que tâchent de susciter les impérialistes étrangers.

Tandis que les intérêts des nationalités, se heurtant aux prétentions impérialistes, sont une source continuelle de conflits universels, de révoltes et de guerres, la Russie socialiste a montré qu'un gouvernement ouvrier est capable de concilier les besoins nationaux avec les besoins économique, épurant les premiers de tout chauvinisme et les seconds de tout impérialisme. Le socialisme a pour but de relier toutes les régions, toutes les provinces, toutes les nationalités par l'unité d'un même système économique. Le centralisme économique n’admettant plus l'exploitation d'un classe par une autre, d'une nation par une autre, et étant par cela même également avantageux pour toutes, ne paralyse en aucune façon le libre développement de l’économie nationale.

L’exemple de la Russie des Soviets permet aux peuples de l'Europe Centrale, du sud-est des Balkans, des possessions coloniales de la Grande-Bretagne, à toutes les nations, à toutes les peuplades opprimées, aux Egyptiens et aux Turcs, aux Hindous et aux Persans, aux Irlandais et aux Bulgares, de se rendre compte que la solidarité de toutes les nationalités du monde n’est réalisable que par une fédération de républiques soviétiques.

La révolution a fait de la Russie la première puissance prolétarienne. Depuis trois ans qu'elle existe, ses frontières n’ont pas cessé de se transformer. Devenues plus étroites sous les coups de boutoir de l'impérialisme mondial, elles reprenaient leur extension lorsque la poussée diminuait d’intensité. La lutte pour les Soviets est devenue la lutte contre le capitalisme mondial. La question de la Russie des Soviets est devenue une pierre de touche pour toutes les organisations ouvrières. La deuxième et infâme trahison de la social-démocratie allemande après celle du 4 août 1914, c'est que, faisant partie du gouvernement elle a demandé secours à l'impérialisme occidental, au lieu de s’allier à la révolution d'Orient. L’Allemagne soviétique alliée à la Russie soviétique, elles auraient été plus fortes à elles deux que tous les Etats capitalistes pris ensemble.

L’Internationale Communiste a fait sienne la cause de la Russie soviétique. Le prolétariat international ne remettra son glaive au fourreau que lorsque la Russie soviétique sera devenue l'un des chaînons d’une Fédération de républiques soviétiques embrassant le monde. 


\section{V. - LA RÉVOLUTION PROLÉTARIENNE ET L'INTERNATIONALE COMMUNISTE}

La guerre civile est mise à l'ordre du jour dans le monde entier. La devise en est : « Le pouvoir aux Soviets ».

Le capitalisme a transformé en prolétariat l’immense majorité de l’humanité. L’impérialisme a tiré les masses de leur inertie et les a incitées au mouvement révolutionnaire. Ce que nous entendons actuellement par le mot «masse » n’est pas ce que nous entendions par là il y a quelques années. Ce qui était la masse à l'époque du parlementarisme et du trade-unionisme est devenu de nos jours l'élite. Des millions et des dizaines de millions d'hommes qui avaient vécu jusqu'ici en dehors de toute politique sont en train de se transformer en une masse révolutionnaire. La guerre a mis tout le monde sur pied, a éveillé le sens politique des milieux les plus arriérés, leur a donné des illusions et des espérances, et les a toutes déçues. Etroite discipline corporative et, en somme, inertie des prolétaires les plus conscients d'un côté, apathie incurable des masses, de l'autre - ces traits caractéristiques des anciennes formes du mouvement ouvrier, sont tombés dans l'oubli pour toujours. Des millions de nouvelles recrues viennent d'entrer en ligne. Les femmes qui ont perdu leurs maris et leurs pères et qui ont dû se mettre au travail à leur place, prennent une large part au mouvement révolutionnaire. Les ouvriers de la nouvelle génération, habitués dès l'enfance aux grondements et aux éclairs de la guerre mondiale, ont accueilli la révolution comme leur élément naturel. La lutte passe par des phases différentes suivant le pays, mais cette lutte est la dernière. Il arrive que les vagues révolutionnaires, déferlant contre l'édifice d'une organisation surannée, lui prêtent une nouvelle vie. Des vieilles enseignes, des devises à demi effacées surnagent ça et là à la surface des flots. Il y a dans les cervelles du trouble, des ténèbres, des préjugés, des illusions. Mais le mouvement dans son ensemble a un caractère profondément révolutionnaire. On ne peut ni l'éteindre ni l'arrêter. Il s'étend, se raffermit, se purifie, rejette tout ce qui a fait son temps. Il ne s’arrêtera pas que le prolétariat mondial ne soit arrivé au pouvoir.

La grève est le moyen d'action le plus habituel au mouvement révolutionnaire. Ce qui la cause le plus souvent, irrésistiblement, c'est la hausse des prix sur les 
denrées de première nécessité. La grève surgit souvent de conflits régionaux. Elle est le cri de protestation des masses impatientées par le tripotage parlementaire des socialistes. Elle exprime la solidarité entre les exploités d'un même pays ou de pays différents. Ses devises sont de nature à la fois économique et politique. Souvent des bribes de réformisme s'y entremêlent à des mots d'ordre de révolution sociale. Elle se calme, semble vouloir finir, puis reprend de plus belle, ébranlant la production, menaçant l'appareil gouvernemental. Elle met en fureur la bourgeoisie parce qu'elle profite de toute occasion pour exprimer sa sympathie à la Russie soviétique. Les pressentiments des exploiteurs ne les trompent pas. Cette grève désordonnée n'est autre chose en effet qu'une revue des forces révolutionnaires, un appel aux armes du prolétariat révolutionnaire.

L'étroite dépendance dans laquelle se trouvent tous les pays vis-à-vis les uns des autres et qui s'est révélée d'une façon si catastrophique pendant la guerre, donne une importance particulière aux branches du travail qui relient les pays et place au premier rang les cheminots et les ouvriers du transport en général. Le prolétariat du transport a eu l'occasion de montrer une partie de sa force dans le boycottage de la Hongrie et de la Pologne blanches. La grève et le boycottage, méthodes que la classe ouvrière mettait en œuvre au début de sa lutte tradeunioniste, c'est-à-dire quand elle n'avait pas encore commencé à utiliser le parlementarisme, ont revêtu de nos jours la même importance et la même signification redoutables que la préparation de l'artillerie avant la dernière attaque.

L'impuissance à laquelle l'individu se trouve de plus en plus réduit devant la poussée aveugle des événements historiques oblige non seulement de nouveaux groupes d'ouvriers et d'ouvrières, mais encore les employés, les fonctionnaires, les intellectuels petits-bourgeois à entrer dans les rangs des organisations syndicales. Avant que la marche de la révolution prolétarienne oblige à créer des Soviets qui planeront au dessus de toutes les vieilles organisations ouvrières, les travailleurs se groupent en syndicats, tolèrent en attendant l'ancienne constitution de ces syndicats, leur programme officiel, leur élite dirigeante, mais en apportant dans ces organisations l'énergie révolutionnaire croissante des masses qui ne s'étaient point révélées jusque-là.

Les couches les plus basses, les prolétaires des campagnes, les manœuvres relèvent la tête. En Italie, en Allemagne et dans d'autres pays on observe une crois- 
sance magnifique du mouvement révolutionnaire des ouvriers agricoles et leur rapprochement avec le prolétariat des villes.

Les paysans pauvres regardent d'un meilleur œil le socialisme. Si les intrigues des réformistes parlementaires qui cherchent à exploiter les préjugés de propriété du moujik sont restées infructueuses, le mouvement vraiment révolutionnaire du prolétariat, sa lutte indomptable contre les oppresseurs, font naître une lueur d'espérance dans le cœur du travailleur le plus humble, le plus courbé vers la glèbe, le plus miséreux.

L’abîme de la misère humaine et de l'ignorance est insondable. Toute couche qui vient de se redresser en laisse derrière elle une autre qui tente à peine de se soulever. Mais l'avant-garde ne doit pas attendre la masse compacte de l'arrière pour engager le combat. Le soin de réveiller, de stimuler et d'éduquer ses couches les plus arriérées, la classe ouvrière le prendra lorsqu'elle sera parvenue au pouvoir.

Les travailleurs des colonies et des pays à demi coloniaux se sont réveillés. Dans les espaces infinis de l'Inde, de l'Egypte, de la Perse, sur lesquels se dresse l'hydre monstrueuse de l'impérialisme anglais, sur cette mer humaine sans fond, s'accomplit un travail latent ininterrompu, soulevant des vagues qui font trembler dans la City les actions de la Bourse et les cœurs.

Dans le mouvement des peuples coloniaux, l’élément social sous toutes ses formes se mêle à l'élément national, mais tous les deux sont dirigés contre l’impérialisme. Depuis les premières tentatives jusqu’aux formes perfectionnées, le chemin de la lutte se poursuit dans les colonies et dans les pays arriérés en général à marches forcées, sous la pression de l'impérialisme moderne et sous la direction du prolétariat révolutionnaire.

Le rapprochement fécond qui s’opère entre les peuples musulmans et nonmusulmans, unis par les chaînes communes de la domination anglaise et de la domination étrangère en général, l'épuration intérieure du mouvement, la diminution constante de l'influence du clergé et de la réaction chauvine, la lutte simultanée menée par les indigènes à la fois contre les envahisseurs et contre leurs propriétaires suzerains, prêtres et usuriers, font de l'armée de l'insurrection coloniale grandissante une force historique de premier ordre, une réserve inépuisable pour le prolétariat mondial. 
Les parias se lèvent. Leur pensée qui s’éveille se reporte vers la Russie des Soviets, vers les barricades dressées dans les rues des villes d'Allemagne, vers la lutte désespérée des ouvriers grévistes de l’Angleterre, vers l'Internationale Communiste.

Le socialisme qui, directement ou indirectement, défend la situation privilégiée de certaines nations au détriment des autres, qui s’accommode de l'esclavage colonial, qui admet des différences de droits entre les hommes de race et de couleur différentes ; qui aide la bourgeoisie de la métropole à maintenir sa domination sur les colonies au lieu de favoriser l'insurrection armée de Ces colonies ; le socialisme anglais qui ne soutient pas de tout son pouvoir l'insurrection de l'Irlande, de l'Egypte et de l'Inde contre la ploutocratie londonienne - ce « socialisme » loin de pouvoir prétendre au mandat et à la confiance du prolétariat, mérite sinon des balles, du moins la marque de l’opprobre.

Or, dans ses efforts pour amener la révolution mondiale, le prolétariat se heurte non seulement aux lignes de fil de fer barbelé à moitié détruites qui se dressent encore entre les pays depuis la guerre, mais surtout à l'égoïsme, au conservatisme, à l'aveuglement et à la trahison des vieilles organisations de partis et des syndicats qui ont vécu de lui à l’époque précédente.

La trahison dont s'est rendue coutumière la social-démocratie internationale n’a rien d'égal dans l'histoire de la lutte contre l'asservissement. C'est en Allemagne que les conséquences en sont les plus terribles. La défaite de l'impérialisme allemand a été en même temps celle du système d'économie capitaliste. En dehors du prolétariat il n’y avait aucune classe qui pût prétendre au pouvoir d'Etat. Le perfectionnement de la technique, le nombre et le niveau intellectuel de la classe ouvrière allemande étaient un sur garant du succès de la révolution sociale. Malheureusement la social-démocratie allemande s'est mise en travers de la voie. Grâce à des manœuvres compliquées dans lesquelles la ruse se mêle à la bêtise, elle a paralysé l'énergie du prolétariat pour le détourner de la conquête du pouvoir qui était son but naturel et nécessaire.

La social-démocratie s'était évertuée pendant des dizaines d’années à conquérir la confiance des ouvriers, pour, ensuite, au moment décisif, quand le sort de la société bourgeoise était en jeu, mettre toute son autorité au service des exploiteurs. 
La trahison du libéralisme et la faillite de la démocratie bourgeoise sont des épisodes insignifiants en comparaison de la trahison monstrueuse des partis socialistes. Le rôle de l'Eglise elle-même, cette station électrique centrale du conservatisme, comme l'a définie Lloyd George, pâlit devant le rôle anti-socialiste de la $2^{\mathrm{e}}$ Internationale.

La social-démocratie a voulu justifier sa trahison envers la révolution pendant la guerre par la formule de défense nationale. Elle couvre sa politique contrerévolutionnaire, après la conclusion de la paix, avec la formule de démocratie. Défense nationale et démocratie, voilà les formules solennelles de capitulation du prolétariat devant la volonté de la bourgeoisie.

Mais la chute ne s'arrête pas là. Continuant sa politique de défense du régime capitaliste, la social-démocratie est obligée, à la remorque de la bourgeoise, de fouler aux pieds la «défense nationale » et la «démocratie ». Scheidemann et Ebert baisent les mains de l'impérialisme français dont ils réclament l'appui contre la révolution soviétique. Noske incarne la terreur blanche et la contrerévolution bourgeoise.

Albert Thomas se transforme en commis de la Ligue des Nations, cette honteuse agence de l'impérialisme. Vandervelde, éloquente image de la fragilité de la $2^{\mathrm{e}}$ Internationale dont il était le chef, devient ministre du roi, collègue du calotin Delacrois, défenseur des prêtres catholiques belges et avocat des atrocités capitalistes commises sur les nègres du Congo.

Henderson, qui singe les grands hommes de la bourgeoisie, qui figure à tour de rôle comme ministre du roi et représentant de l'opposition ouvrière de Sa Majesté ; Tom Shaw qui réclame du gouvernement soviétique des preuves irréfutables comme quoi le gouvernement de Londres est composé d'escrocs, de bandits et de parjures, que sont donc tous ces messieurs, sinon les ennemis jurés de la classe ouvrière?

Renner et Seitz, Niemets et Tousar, Troelstra et Branting, Daszinsky et Tchkéidzé, chacun d'eux traduit, dans la langue de sa petite bourgeoisie malhonnête, la faillite de la 2e Internationale.

Karl Kautsky enfin, ex-théoricien de la $2^{\mathrm{e}}$ Internationale et ex-marxiste, devient le conseiller ânonnant attitré de la presse jaune de tous les pays. 
Sous l’impulsion des masses, les éléments plus élastiques du vieux socialisme, sans pour cela changer de nature, changent de tournure et de couleur, rompent ou s’apprêtent à rompre avec la $2^{\mathrm{e}}$ Internationale, battant en retraite comme toujours devant toute action de masse et révolutionnaire et même devant tout prélude sérieux de l'action.

Pour caractériser et, en même temps, pour confondre les acteurs de cette mascarade, il suffit de dire que le parti socialiste polonais qui a pour chef Daszinsky et pour patron Pilsudsky, le parti du cynisme bourgeois et du fanatisme chauvin, déclare se retirer de la $2^{\mathrm{e}}$ Internationale.

L’élite parlementaire dirigeante du parti socialiste français qui vote actuellement contre le budget et contre le traité de Versailles, reste au fond un des piliers de la république bourgeoise. Ses gestes d'opposition vont, de temps en temps juste assez loin pour ne pas ébranler la demi-confiance des milieux les plus conservateurs parmi le prolétariat.

Dans les questions capitales de la lutte de classe, le socialisme parlementaire français continue de tromper la volonté de la classe ouvrière, en lui suggérant que le moment actuel n'est pas propice à la conquête du pouvoir, parce que la France est trop appauvrie de même qu'hier il était défavorable à cause de la guerre, comme à la veille de la guerre c’était la prospérité industrielle qui y faisait obstacle et, auparavant, la crise industrielle. A côté du socialisme parlementaire et sur le même plan siège le syndicalisme bavard et trompeur des Jouhaux et $C^{\text {ie }}$.

La création d'un parti communiste fort et trempé par l'esprit d'unité et de discipline en France est une question de vie ou de mort pour le prolétariat français.

La nouvelle génération des ouvriers allemands fait son éducation et puise sa force dans les grèves et les insurrections. Son expérience lui coûte d'autant plus de victimes que le Parti Socialiste Indépendant continuera de subir l'influence des conservateurs social-démocrates et des routiniers qui se remémorent la socialdémocratie des temps de Bebel, qui ne comprennent rien au caractère de l'époque révolutionnaire actuelle, tremblent devant la guerre civile et la terreur révolutionnaire, se laissent aller au courant des événements, dans l’attente du miracle qui doit venir en aide à leur incapacité. C'est dans le feu de la lutte que le parti de Rosa Luxemburg et de Karl Liebknecht enseigne aux ouvriers allemands où se trouve le bon chemin. 
Parmi le mouvement ouvrier anglais la routine est telle qu'on n'a pas encore senti en Angleterre le besoin de changer son fusil d'épaule : les chefs du parti ouvrier britannique s'entêtent à vouloir rester dans les cadres de la $2^{\mathrm{e}}$ Internationale.

Tandis que le cours des événements des dernières années, en rompant la stabilité de la vie économique dans l'Angleterre conservatrice, a rendu les masses travailleuses on ne peut plus aptes à assimiler le programme révolutionnaire, la mécanique officielle de la nation bourgeoise avec son pouvoir royal, sa Chambre des lords, sa Chambre des Communes, son Eglise, ses trade-unions, son parti ouvrier, George V, l'évêque de Canterbury et Henderson, reste intacte comme un frein automatique puissant contre le développement. Il n’y a que le parti communiste affranchi de la routine et de l'esprit de secte, intimement lié aux grandes organisations ouvrières qui peut opposer l'élément prolétarien à cette élite officielle.

En Italie, où la bourgeoisie reconnaît franchement que le sort du pays se trouve désormais, en fin de compte, entre les mains du parti socialiste, la politique de l'aile droite représentée par Turati s’efforce de faire rentrer le torrent de la révolution prolétarienne dans l’ornière des réformes parlementaires. C’est dans ce sabotage intérieur que réside actuellement le plus grand danger.

Prolétaires d'Italie, songez à la Hongrie dont l'exemple est entré dans l'histoire pour rappeler malheureusement que dans la lutte pour le pouvoir, comme pendant l'exercice du pouvoir, le prolétariat doit rester intrépide, rejeter tous les éléments équivoques et faire impitoyablement justice de toutes les tentatives de trahison!

Les catastrophes militaires, suivies d'une crise économique redoutable, inaugurent un nouveau chapitre dans le mouvement ouvrier des Etats-Unis et dans les autres pays du continent américain. La liquidation du charlatanisme et de l'impudence du wilsonisme, c'est la liquidation par le fait même de ce socialisme américain, mélange d'illusions pacifistes et d'activité mercantile, dont le tradeunionisme gauche des Gompers et Cie, est le couronnement. L’union étroite des partis ouvriers révolutionnaires et des organisations prolétariennes du continent américain, de la presqu'île de l'Alaska au cap Horn, en une section américaine compacte de l'Internationale, en face de l’impérialisme tout puissant et menaçant 
des Etats-Unis, voilà le problème qui doit être réalisé dans la lutte contre toutes les forces mobilisées par le dollar pour sa défense.

Les socialistes de gouvernement et leurs consorts de tous les pays ont eu beaucoup de raisons pour accuser les communistes de provoquer, par leur tactique intransigeante, l'activité de la contre-révolution dont ils contribuent à resserrer les rangs. Cette inculpation politique n'est pas autre chose qu'une réédition tardive des plaintes du libéralisme. Ce dernier précisément affirmait que la lutte spontanée du prolétariat pousse les privilégiés dans le camp de la réaction. C’est une vérité incontestable. Si la classe ouvrière ne s’attaquait pas aux fondements de la domination de la bourgeoisie, celle-ci n’aurait pas besoin de répressions. L’idée même de contre-révolution n’existerait pas si l'histoire ne connaissait pas de révolution. Si les insurrections du prolétariat entraînent fatalement l'union de la bourgeoisie pour la défense et la contre-attaque, cela ne prouve qu'une chose, c'est que la révolution est la lutte de deux classes irréconciliables qui ne peut aboutir qu'au triomphe définitif de l'une sur l'autre.

Le communisme récuse avec mépris la politique qui consiste à maintenir les masses dans la stagnation, en leur faisant redouter la massue de la contrerévolution.

À l'incohérence et au chaos du monde capitaliste dont les derniers efforts menacent d'engloutir toute la civilisation humaine, l'Internationale Communiste oppose la lutte combinée du prolétariat mondial, pour la destruction de la propriété particulière comme instrument de production, et pour la reconstruction d'une économie nationale et mondiale fondée sur un plan économique unique, établi et réalisé par la société solidaire des producteurs. En groupant sous le drapeau de la dictature du prolétariat et du système soviétique de l'Etat les millions de travailleurs de toutes les parties du monde, l'Internationale Communiste lutte obstinément pour organiser et pour purifier ses propres éléments.

L’Internationale Communiste, c'est le parti de l'insurrection du prolétariat mondial révolutionné. Elle rejette toutes les organisations et les partis qui, sous une forme ouverte ou voilée, endorment, démoralisent et énervent le prolétariat, en l'exhortant à s'incliner devant les fétiches dont se pare la dictature de la bourgeoisie : la légalité, la démocratie, la défense nationale, etc... 
L'Internationale Communiste ne peut pas non plus tolérer dans ses rangs les organisations qui, tout en inscrivant dans leur programme la dictature du prolétariat, persistent à mener une politique qui s'entête à chercher une solution pacifique à la crise historique. Ce n'est pas résoudre la question que de reconnaître le système soviétique. L'organisation soviétique ne renferme pas une vertu miraculeuse. Cette vertu révolutionnaire réside dans le prolétariat lui-même. Il faut que celui-ci n’hésite pas à se soulever et à conquérir le pouvoir et alors seulement l'organisation soviétique manifestera ses qualités et restera pour lui l'arme la plus efficace.

L'Internationale Communiste prétend expulser des rangs du mouvement ouvrier tous les chefs qui sont liés directement ou indirectement par une collaboration politique avec la bourgeoisie. Ce qu'il nous faut, ce sont des chefs qui n'aient pour la société bourgeoise qu'une haine mortelle, qui organisent le prolétariat en vue d'une lutte impitoyable, qui soient prêts à mener au combat l'armée des insurgés, qui ne s'arrêtent pas à mi-chemin quoiqu'il arrive et qui ne craignent pas de recourir à des mesures de répression impitoyables contre tous ceux qui tenteront par la force de les contrecarrer.

L'Internationale Communiste, c'est le parti international de l'insurrection et de la dictature prolétariennes. Pour elle, il n'existe pas d'autres buts ni d'autres problèmes que ceux de la classe ouvrière. Les prétentions des petites sectes dont chacune veut sauver la classe ouvrière à sa manière, sont étrangères et contraires à l'esprit de l'Internationale Communiste. Elle ne possède pas la panacée universelle, le remède infaillible à tous les maux ; elle tire leçon de l'expérience de la classe ouvrière dans le passé et dans le présent, cette expérience lui sert à réparer ses fautes et ses omissions; elle en tire un plan général et elle ne reconnaît et n'adopte que les formules révolutionnaires qui sont celles de l'action de masse.

Organisation professionnelle, grève économique et politique, boycottage, élections parlementaires et municipales, tribune parlementaire, propagande légale et illégale, organisations secrètes au sein de l'armée, travail coopératif, barricades, l'Internationale Communiste ne repousse aucune des formes d'organisation ou de lutte créées au cours du développement du mouvement ouvrier, mais aussi elle n’en consacre aucune en qualité de panacée universelle. 
Le système des Soviets n'est pas uniquement un principe abstrait que les communistes veulent opposer au système parlementaire. Les Soviets sont un appareil du pouvoir prolétarien qui, après la lutte et seulement par le moyen de cette lutte, doit remplacer le parlementarisme. Tout en combattant de la façon la plus décidée contre le réformisme des syndicats, contre le carriérisme et le crétinisme des parlements, l'Internationale Communiste ne laisse pas de condamner le fanatisme de ceux qui invitent les prolétaires à quitter les rangs d'organisations syndicales comptant des millions de membres et à tourner le dos aux institutions parlementaires et municipales. Les communistes en aucune façon ne se détournent des masses dupées et vendues par les réformistes et les patriotes, mais ils acceptent la lutte avec eux, au sein même des organisations de masses et des institutions créées par la société bourgeoise, de façon à pouvoir renverser celle-ci rapidement et à coup sûr.

Pendant que, sous l'égide de la $2^{\mathrm{e}}$ internationale, les systèmes d'organisation de classe et les moyens de lutte presque exclusivement légaux se sont trouvés, en fin de compte, assujettis au contrôle et à la direction de la bourgeoisie et que la classe révolutionnaire a été musclée par les agents réformistes, l'Internationale Communiste tout au contraire arrache d'entre les mains de la bourgeoisie les guides qu'elle avait accaparées, prend sur soi l'organisation du mouvement ouvrier, le rassemble sous un commandement révolutionnaire et, aidée par lui, propose au prolétariat un but unique, à savoir : la prise du pouvoir pour la destruction de l'Etat bourgeois et la constitution d'une société communiste.

Au cours de toute son activité, qu'il soit instigateur d'une grève de protestation, chef d'une organisation clandestine, secrétaire d'un syndicat, propagandiste dans les meetings ou député au parlement, pionnier de la coopération ou soldat à la barricade, le communiste se doit de rester fidèle, c'est-à-dire qu'il doit être soumis à la discipline du parti, lutteur infatigable, ennemi. mortel de la société capitaliste, de ses bases économiques, de ses formes administratives, de son mensonge démocratique, de sa religion et de sa morale ; il doit être le défenseur plein d'abnégation de la révolution prolétarienne et l'infatigable champion de la société nouvelle.

Ouvriers et ouvrières ! 
Il n'y a sur la terre qu'un seul drapeau qui mérite que l'on combatte et qu'on meure sous ses plis, c'est le drapeau de l'Internationale Communiste !

SIGNÉ :

RUSSIE :

ALLEMAGNE :

FRANCE :

ANGLETERRE :

AMÉRIQUE (E.-U.) :

ITALIE :

NORVÈGE :

SUÈDE :

DANEMARK :

HOLLANDE :

BELGIQUE :

ESPAGNE :

SUISSE :

HONGRIE :

GALICIE :

POLOGNE :

LATVIE :

LITHUANIE :

TCHÉCOSLOVAQUIE :

ESTONIE :

FINLANDE :

BULGARIE :

YOUGOSLAVIE :

GÉORGIE :

ARMÉNIE :

TURQUIE :

PERSE :

INDE :

INDES-

NÉERLANDAISES :

CHINE :

CORÉE :
N. Lénine, G. Zinoviev, N. Boukharine, L. Trotsky. P. Lévi, E. Meyer, Y. Walcher, R. Wolfstein.

Rosmer, Jacques Sadoul, Henri Guilbeaux. ${ }^{3}$

Tom Quelch, Gallacher, Silvya Pankhurst, Mas

Fleen, A. Frayna, A. Bilan, J. Reed.

D.M. Serrati, N. Bombacci, Graziadei, A. Bordiga.

Frys, Shaefflo, A. Madsen.

K. Dalstroem, Samuelson, Winberg.

O. Jorgenson, M. Nilsen.

Wijncup, Jansen, Van Leuve.

Van Overstraeten.

Pestaña.

Herzog, J. Humbert-Droz.

Racoczy, A. Roudnyansky, Varga.

Levitsky.

J. Marchlevsky.

Stoutclika, Krastjyn.

Mitzkévich-Kapsukas.

Vanek, Gula, Zapototsky.

R. Wakman, G. Poegelman.

I. Rakhia, Letonmiaky, K. Manner.

Kabaktchiev, Maximov, Chabline.

Milkitch.

M. Tsakiah.

Nazaritian.

Nichad.

Sultan-Zadé.

Atcharia, Sheffik.

Maring.

Laou-Siou-Tchéou.

Pak Djinchoun, Him Houlin.

3 Selon Marcel Ollivier, délégué au congrès par la gauche des jeunesses de la SFIO, seul Rosmer était en fait délégué avec voix délibérative. Sadoul et Guilbeaux n'étaient qu’observateurs au congrès. 
Manifestes, thèses et résolutions

des quatre premiers congrès de

l'Internationale communiste 1919-1923

(juin 1934)

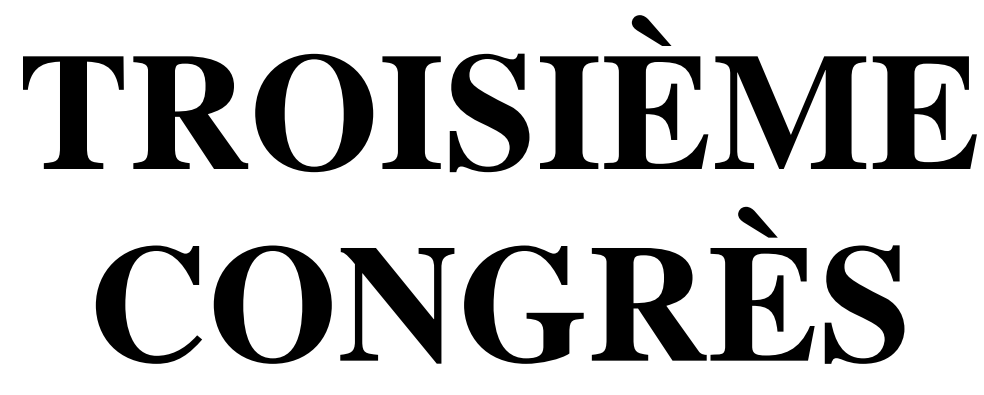

Juin 1921 
Manifestes, thèses et résolutions

des quatre premiers congrès

de l'Internationale communiste 1919-1923

(juin 1934)

Troisième Congrès, juin 1921.

- 1 -

\section{Thèses sur la situation mondiale et la tâche de l’Internationale \\ Communiste}

\section{I. - LE FOND DE LA QUESTION}

$\underline{\text { Retour à la table des matières }}$

1. Le mouvement révolutionnaire, à l'issue de la guerre impérialiste et depuis cette guerre, se distingue par son ampleur sans précédent dans l'histoire. En mars 1917, le tsarisme est renversé. En mai 1917, orageuse lutte gréviste en Angleterre. En novembre 1917, le prolétariat russe s'empare du pouvoir de l'Etat. En novembre 1918, chute des monarchies allemande et austro-hongroise. Le mouvement gréviste s'empare de toute une série de pays européens et se développe particulièrement au cours de l'année suivante. En mars 1919, la République Soviétique est installée en Hongrie. Vers la fin de la même année, les Etats-Unis sont ébranlés par les formidables grèves des métallurgistes, des mineurs et des cheminots. En Allemagne, après les combats de janvier et de mars 1919, le mouvement atteint son point culminant, au lendemain de l'émeute de Kapp, en mars 1920. En France, le moment de la plus haute tension de la vie intérieure arrive au mois de mai 1920. En Italie, le mouvement du prolétariat industriel et rural s'accroît sans cesse et mène en septembre 1920 à la mainmise par les ouvriers sur les usines, les fabri- 
ques et les propriétés foncières. Le prolétariat tchèque, en décembre 1920, saisit l’arme de la grève générale politique. En mars 1921, soulèvement des ouvriers de l’Allemagne centrale et grève des ouvriers mineurs en Angleterre.

Le mouvement atteint des proportions particulièrement grandes et une intensité plus violente dans les pays hier belligérants et surtout dans les pays vaincus mais il s'étend aussi aux pays neutres. En Asie et en Afrique, il suscite ou renforce l’indignation révolutionnaire des nombreuses masses coloniales.

Cette puissante vague ne réussit pourtant pas à renverser le capitalisme mondial, ni même le capitalisme européen.

2. Pendant l'année qui s'est écoulée entre le $2^{\mathrm{e}}$ et le $3^{\mathrm{e}}$ Congrès de l'Internationale Communiste, une série de soulèvements et de luttes de la classe ouvrière se terminent en partie par la défaite (avance de l'armée rouge sur Varsovie en août 1920, mouvement du prolétariat italien en septembre 1920, soulèvement des ouvriers allemands en mars 1921).

La première période du mouvement révolutionnaire, après la guerre, est caractérisée par sa violence élémentaire, par l’imprécision très significative des buts et des méthodes et par l'extrême panique qui s'empare des classes dirigeantes ; elle paraît être terminée dans une large mesure. Le sentiment de sa puissance de classe qu'a la bourgeoisie, et la solidité extérieure de ses organes d'Etat se sont indubitablement renforcés. La peur du communisme s’est affaiblie si elle n’a pas complètement disparu. Les dirigeants de la bourgeoisie vantent la puissance de leur mécanisme d'Etat et passent même dans tous les pays à l'offensive contre les masses ouvrières, tant sur le front économique que sur le front politique.

3. En raison de cette situation, l'Internationale Communiste se pose à ellemême et pose à la classe ouvrière les questions suivantes : Dans quelle mesure les nouveaux rapports réciproques de la bourgeoisie et du prolétariat correspondentils réellement aux rapports plus profonds de leurs forces respectives ? La bourgeoisie est-elle vraiment à présent plus en mesure de rétablir l'équilibre social détruit par la guerre ? Y a-t-il des raisons de supposer qu'après une époque d'ébranlements politiques et de luttes de classes vient une nouvelle époque, pro- 
longée du rétablissement et de l'agrandissement du capitalisme ? Ne s'ensuit-il pas la nécessité de réviser le programme ou la tactique de l’Internationale Communiste?

\section{II. - LA GUERRE, LA PROSPÉRITE SPÉCULATIVE ET LA CRISE. LES PAYS EUROPÉENS}

4. Les deux dizaines d'années qui avaient précédé la guerre furent une époque d'ascension capitaliste particulièrement puissante. Les périodes de prospérité se distinguent par leur durée et par leur intensité, les périodes de dépression ou de crise, au contraire, par leur brièveté. D’une façon générale, la source s’était brusquement élevée ; les nations capitalistes s’étaient enrichies.

Enserrant le marché mondial par leurs trusts, leurs cartels et leurs consortiums, les maîtres des destinées du monde se rendaient compte que le développement enragé de la production devait se heurter aux limites de la capacité d'achat du marché capitaliste mondial ; ils essayèrent de sortir de cette situation par les moyens de violence; la crise sanglante de la guerre mondiale devait remplacer une longue période menaçante de dépression économique avec le même résultat d'ailleurs, c'est-à-dire la destruction d'énormes forces de production.

La guerre a cependant réuni l'extrême puissance destructrice de ses méthodes à la durée imprévisiblement longue de leur emploi. Le résultat fut qu'elle ne détruisit pas seulement, au sens économique, la production "superflue », mais qu'elle affaiblit, ébranla, mina le mécanisme fondamental de la production en Europe. Elle contribua en même temps au grand développement capitaliste des Etats-Unis et à l'ascension fiévreuse du Japon. Le centre de gravité de l'économie mondiale passa d'Europe en Amérique.

5. La période de cessation du massacre prolongé pendant quatre années, période de démobilisation et de transition de l'état de guerre à l'état de paix, inévitablement accompagnée d'une crise économique, conséquence de l'épuisement et du chaos de la guerre, apparaissait aux yeux de la bourgeoisie - et avec raison comme grosse des plus grands périls. A la vérité, pendant les deux années qui 
suivirent la guerre, les pays qu'elle avait ravagés devinrent l'arène de puissants mouvements prolétariens.

Le fait que ce ne fut pas la crise inévitable, semblait-il, qui se produisit, quelques mois après la guerre, mais un relèvement économique, fut une des causes principales de ce que la bourgeoisie conserva néanmoins sa position dominante. Cette période dura environ un an et demi. L’industrie occupait la presque totalité des ouvriers démobilisés. Quoique, en règle générale, les salaires ne pussent atteindre les prix des articles de consommation, ils s’élevaient cependant suffisamment pour créer le mirage de conquêtes économiques.

C’est précisément cet essor économique de 1919-1920 qui, adoucissant la phase la plus aiguë de liquidation de la guerre, eut pour résultat une extraordinaire recrudescence de l'assurance bourgeoise et souleva la question de l'avènement d’une nouvelle époque organique de développement capitaliste.

Cependant, le relèvement de 1919-1920 ne marquait pas, au fond, le début de la restauration de l'économie capitaliste après la guerre, mais la continuation de la situation artificielle de l'industrie et du commerce, créée par la guerre, et qui put ébranler l'économie capitaliste.

6. La guerre impérialiste éclata à l'époque où la crise industrielle et commerciale, qui prit alors naissance en Amérique (1913), commençait à envahir l'Europe.

Le développement normal du cycle industriel fut interrompu par la guerre qui devint elle-même le plus puissant facteur économique. La guerre créa pour les branches fondamentales de l'industrie un marché à peu près illimité, complètement à l'abri de toute concurrence. Le grand acheteur n'avait jamais assez de tout ce qu'on lui fournissait. La fabrication des moyens de production se transforma en fabrication des moyens de destruction. Les articles de consommation personnelle étaient acquis à des prix de plus en plus élevés par des millions d’individus qui, ne produisant rien, ne faisaient que détruire. C’était là le processus même de la destruction ; mais, en vertu des contradictions monstrueuses de la société capitaliste, cette ruine prit la forme de l'enrichissement. L'Etat lançait emprunt sur emprunt, émission sur émission, et — des budgets se chiffrant par millions - passa aux milliards. Machines et constructions s’usaient et n’étaient pas remplacées. La terre 
était mal cultivée. Des constructions essentielles dans les villes et sur les chemins de fer étaient arrêtées. En même temps le nombre des valeurs d'Etat, des bons de crédit et du Trésor et des fonds s'accrut sans cesse. Le capital fictif s'enfla dans la mesure même dans laquelle le capital productif était détruit. Le système du crédit, moyen de circulation des marchandises, se transforma en un moyen d'immobiliser les biens nationaux, y compris ceux qui devront être créés par les générations futures.

Par crainte d'une crise qui eut été une catastrophe, l'Etat capitaliste agit après la guerre de la même façon que pendant celle-ci : nouvelles émissions, nouveaux emprunts, réglementation des prix de vente et d'achat des articles les plus importants, garantie de profits, denrées à des prix réduits, multiples allocations en addition aux appointements et aux salaires - et avec tout cela, censure militaire et dictature de galonnés.

7. En même temps, la cessation des hostilités et le rétablissement des relations internationales révélèrent la demande considérable des marchandises les plus diverses, sur toute la surface du globe. La guerre avait laissé d'immenses stocks de produits, d'énormes sommes d'argent, concentrés entre les mains des fournisseurs et des spéculateurs, qui les employèrent là où le profit momentanément était le plus grand. Il s'ensuivit une activité commerciale fiévreuse, alors que, avec l'élévation inouïe des prix et des dividendes fantastiques, dans aucune de ses branches fondamentales, l'industrie ne se rapprochait en Europe de son niveau d'avant-guerre.

8. Au prix de la destruction économique du système économique, accroissement de capital fictif, baisse du cours, spéculation, au lieu de panser les plaies économiques, le gouvernement bourgeois, agissant de concert avec les consortiums des banques et avec les trusts de l'industrie, réussit à éloigner le début de la crise économique, au moment où s'achevait la crise politique de la démobilisation et le premier examen des conséquences de la guerre.

Ayant ainsi obtenu un répit important, la bourgeoisie crut que le danger de la crise était écarté pour un temps indéterminé. Un optimisme extrême s’empara des esprits ; il sembla que les besoins de la reconstruction dussent ouvrir une époque 
de prospérité industrielle, commerciale et surtout de spéculations heureuses. L’année 1920 fut l'année des espoirs déçus.

Sous une forme financière, tout d'abord, sous une forme commerciale ensuite, et enfin sous une forme industrielle, la crise se produisit en mars 1920 au japon, en avril aux Etats-Unis (une légère baisse des prix avait commencé en janvier) ; elle passa en Angleterre, en France, en Italie, toujours en avril, dans les pays neutres de l'Europe, se manifesta sous une forme assez légère en Allemagne et se répandit dans la seconde moitié de 1920 dans tout le monde capitaliste.

9. De la sorte, la crise de l'année 1920, et c'est là l'essentiel pour la compréhension de la situation mondiale, n'est pas une étape du cycle «normal », industriel, mais une réaction plus profonde contre la prospérité fictive du temps de guerre et des deux années suivantes, prospérité basée sur la destruction et sur l'épuisement.

L'alternative normale des crises et des périodes de prospérité se poursuivait auparavant suivant la courbe du développement industriel. Pendant les sept dernières années, pas contre, les forces productrices de l'Europe, loin de s'élever, tombèrent brutalement.

La destruction des bases mêmes de l'économie doit d'abord se manifester dans toute la superstructure. Pour arriver à une certaine coordination intérieure, l'économie de l'Europe devra pendant les quelques années à venir se restreindre et diminuer. La courbe des forces productrices tombera de sa hauteur fictive actuelle. Des périodes de prospérité ne peuvent avoir dans ce cas qu'une courte durée et surtout un caractère de spéculation. Les crises seront longues et pénibles. La crise actuelle en Europe est une crise de sous-production. C'est la réaction de la misère contre les efforts pour produire, trafiquer et vivre sur un pied analogue à celui de l'époque capitaliste précédente.

10. En Europe, l'Angleterre est le pays économiquement le plus fort et qui a le moins souffert de la guerre ; on ne saurait cependant, même par rapport à elle, parler d'un rétablissement de l'équilibre capitaliste après la guerre. Certes, grâce à son organisation mondiale et à sa situation de triomphatrice, l'Angleterre a obtenu 
après la guerre certains succès commerciaux et financiers, elle a amélioré son bilan commercial, elle a relevé le cours de la livre sterling et elle a obtenu un excédent des revenus sur les dépenses aux budgets ; mais sur le terrain industriel, l'Angleterre a rétrogradé depuis la guerre. Le rendement du travail et les revenus nationaux sont incomparablement plus bas qu'avant la guerre. La situation industrielle la plus importante, celle du charbon, s’aggrave de plus en plus, aggravant la situation des autres branches. Les mouvements grévistes incessants sont non la cause, mais la conséquence de la ruine de l’économie anglaise.

11. La France, la Belgique, l’Italie sont irréparablement ruinées par la guerre. La tentative de restaurer l'économie de la France aux dépens de l’Allemagne est un véritable brigandage accompagné d’oppression diplomatique qui, sans sauver la France, ne tend qu'à épuiser définitivement l'Allemagne (en charbon, machines, bétail, or). Cette mesure porte un coup sérieux à toute l'économie de l'Europe continentale dans son ensemble. La France gagne bien moins que ne perd l'Allemagne, et elle court à la ruine économique, bien que ses paysans aient de nouveau, grâce à des efforts extraordinaires, rétabli une grande partie des cultures agricoles et que certaines branches d'industrie (par exemple l'industrie des produits chimiques) se soient considérablement développées pendant la guerre. Les dettes et les dépenses d'Etat (par suite du militarisme) ont atteint des dimensions incroyables ; à la fin de la dernière période de prospérité, le cours du change français était tombé de $60 \%$. Le rétablissement de l'économie française est entravé par les lourdes pertes en vies humaines causées par la guerre, pertes impossibles à compenser par suite du faible accroissement de la population française. Il en est de même, à peu de chose près, pour l’économie de la Belgique et de l’Italie.

12. Le caractère illusoire de la période de prospérité est surtout évident en Allemagne ; dans un laps de temps pendant lequel les prix se sont élevés en une année et demie au sextuple, la production du pays a continué de baisser très rapidement. La participation, triomphante en apparence, de l'Allemagne au trafic commercial international d'avant-guerre est payée d'un double prix : gaspillage du capital fondamental de la nation (par la destruction de l'appareil de production, de transport et de crédit) et abaissement successif du niveau d'existence de la classe 
ouvrière. Les profits des exportateurs allemands s'expriment par une perte sèche du point de vue de l'économie publique. Sous forme d'exportation, c'est la vente à bas prix de l'Allemagne même qui a lieu. Les maîtres capitalistes s'assurent une part toujours croissante de la fortune nationale qui, elle, diminue sans cesse. Les ouvriers allemands deviennent les coolies de l'Europe.

13. De même que l'indépendance politique fictive des petits pays neutres repose sur l'antagonisme des grandes puissances entre elles, de même leur prospérité économique dépend du marché mondial, dont le caractère fondamental était déterminé avant la guerre par l'Angleterre, l'Allemagne, les Etats-Unis et la France. Au cours de la guerre, la bourgeoisie des petits Etats neutres d'Europe réalisa des bénéfices monstrueux. Mais la destruction et la ruine des pays belligérants d'Europe entraînèrent la ruine économique des petits pays neutres. Leurs dettes s'accrurent, leurs changes baissèrent, la crise leur porta coup sur coup.

\section{III. - ÉTATS-UNIS, JAPON, PAYS COLONIAUX ET RUSSIE DES SOVIETS}

14. Le développement des Etats-Unis pendant la guerre présente en un certain sens le contraire du développement de l'Europe. La participation des Etats-Unis à la guerre fut surtout une participation de fournisseurs. Les Etats-Unis ne ressentirent nullement les effets destructeurs de la guerre. L'influence indirectement destructrice de la guerre sur les transports, sur l'économie rurale, etc..., fut bien plus faible dans ce pays qu'en Angleterre - sans parler même de la France ou de l'Allemagne. D'autre part, les Etats-Unis exploitèrent de la manière la plus complète la suppression ou du moins l'extrême affaiblissement de la concurrence européenne et poussèrent leurs industries les plus importantes à un degré de développement inespéré (naphte, constructions navales, automobiles, charbon); ce ne sont pas seulement le naphte et les céréales américains, mais aussi le charbon, qui tiennent maintenant dans leur dépendance la plupart des pays d’Europe.

$\mathrm{Si}$, jusqu'à la guerre, l'Amérique exportait surtout des produits agricoles et des matières premières (constituant les deux tiers de l'exportation totale), à pré- 
sent, au contraire, elle exporte surtout des produits industriels (60 \% de son exportation). Si, jusqu'à la guerre, l’Amérique était débitrice, à présent elle est devenue la créancière du monde entier. La moitié environ de la réserve mondiale de l’or continue toujours à y affluer. Le rôle déterminant sur le marché mondial est passé de la livre sterling au dollar.

15. Cependant, le capital américain, lui aussi, est sorti de l'équilibre. L’essor extraordinaire de l'industrie américaine a été exclusivement déterminé par l'ensemble des conditions mondiales : suppression de la concurrence européenne et surtout demande du marché militaire de l’Europe. Si l’Europe, ruinée, n’a pas pu, même après la guerre, revenir en qualité de concurrente de l'Amérique, à sa situation d'avant-guerre sur le marché mondial, elle ne peut, d'autre part, en qualité de marché pour l’Amérique, n’avoir désormais qu’une part insignifiante de son importance antérieure. Les Etats-Unis sont devenus dans une mesure infiniment plus grande qu'avant-guerre un pays d'exportation. L'appareil productif surdéveloppé pendant la guerre ne peut être complètement utilisé à cause du manque de débouchés. Quelques industries sont ainsi devenues des industries de saison qui ne peuvent donner du travail aux ouvriers que pendant une partie de l'année. La crise est aux Etats-Unis le commencement d'une profonde et durable ruine économique résultant de la chute de l’Europe. C’est là le résultat de la destruction de la division du travail mondial.

16. Le Japon aussi a profité de la guerre pour élargir sa place sur le marché mondial. Son développement est incomparablement plus limité que celui des Etats-Unis et, dans une série de branches, il revêt un caractère purement artificiel. Si ses forces productrices furent suffisantes pour la conquête d’un marché déserté par les concurrents, elles apparaissent cependant insuffisantes pour lui garder ce marché dans la lutte avec les pays capitalistes plus puissants. Il en résulta une crise aiguë qui fut précisément le commencement de toutes les autres crises.

17. Les pays maritimes exportant des matières premières, et dans ce nombre les pays coloniaux (Amérique du Sud, Canada, Australie, Indes, Egypte, etc...), profitèrent à leur tour de l'interruption des communications internationales pour 
développer leur industrie indigène. La crise mondiale s'est étendue à présent chez eux aussi. Le développement de l'industrie nationale dans ces pays devient à son tour une source de nouvelles difficultés commerciales pour l'Angleterre et pour toute l'Europe.

18. Dans le domaine de la production du commerce et du crédit, et cela non seulement en Europe, mais sur une échelle mondiale, il n’y a donc pas de raison d'affirmer un rétablissement quelconque d'équilibre stable après la guerre.

La chute économique de l'Europe continue, mais la destruction des bases de l'économie européenne se manifestera à peine pendant les années qui viennent.

Le marché mondial est désorganisé. L’Europe a besoin des produits américains, mais elle ne peut donner à l'Amérique aucun équivalent. L'Europe est anémiée, l'Amérique est hypertrophiée. Le change or est supprimé. La dépréciation du change des pays européens (qui atteint jusqu'à 99 \%) est un obstacle presque insurmontable pour le commerce international. Les fluctuations continuelles et imprévues du change transforment la production capitaliste en une spéculation effrénée. Le marché mondial n’a plus d'équivalent général. Le rétablissement du cours or en Europe ne pourrait être obtenu que par l'élévation de l'exportation et la diminution des importations. L'Europe ruinée est incapable de cette transformation. L’Amérique se défend à son tour des importations européennes artificielles (dumping) en élevant les tarifs douaniers.

L'Europe reste une maison d'aliénés. La plupart des Etats promulguent des interdictions d'exportation et d'importation; ils multiplient leurs tarifs protecteurs. L'Angleterre établit des droits prohibitifs contre l'exportation allemande et toute la vie économique de l'Allemagne est à la merci d'une bande de spéculateurs de l'Entente et surtout français. Le territoire de l'Autriche-Hongrie est divisé par une dizaine de lignes douanières. L'écheveau des traités de paix est chaque jour plus embrouillé.

19. La disparition de la Russie soviétique en tant que débouché pour les produits industriels et en tant que fournisseur de matières brutes a contribué dans une grande mesure à rompre l'équilibre de l'économie mondiale. Le retour de la Rus- 
sie sur le marché mondial ne peut pas, pendant la prochaine période, y porter de bien grands changements. L'organisme capitaliste de la Russie se trouvait, sous le rapport des moyens de production, dans la plus étroite dépendance de l’industrie mondiale, et cette dépendance s'est encore accentuée par rapport aux pays de l'Entente, pendant la guerre, alors que l'industrie intérieure de la Russie était entièrement mobilisée. Le blocus rompit d'un coup tous ces liens vitaux. Il ne saurait même être question que ce pays épuisé et ruiné par trois années de guerre civile puisse organiser chez lui les nouvelles branches d'industrie sans lesquelles les anciennes ont été inévitablement ruinées par l’épuisement de leur matériel fondamental. A tout cela s'ajoute le fait de l'absorption dans l'armée rouge de centaines de milliers des meilleurs ouvriers et, dans une mesure considérable, des plus qualifiés. Dans ces conditions historiques, aucun autre régime n’aurait pu, cerné par le blocus, réduit à des guerres incessantes, recueillant un terrible héritage de ruines, maintenir la vie économique et créer une administration centralisée. Mais on ne peut douter que la lutte contre l'impérialisme mondial ait été payée de l'épuisement prolongé des forces productrices de la Russie dans plusieurs branches fondamentales de l'économie. Ce n'est qu'à présent, à la suite du relâchement du blocus et du rétablissement de certaines formes plus normales des rapports entre la ville et la campagne, que le pouvoir soviétique reçoit la possibilité d'une direction centralisée constante et inflexible en vue du relèvement du pays.

\section{IV. - TENSION DES ANTAGONISMES SOCIAUX}

20. La guerre, qui entraîna une destruction sans précédent dans l'histoire des forces productrices, n’a pas arrêté le processus de la différenciation sociale ; au contraire, la prolétarisation des larges couches intermédiaires, y compris la nouvelle classe moyenne (employés, fonctionnaires, etc...) et la concentration de la propriété entre les mains d'une petite minorité (trusts, cartels, consortiums, etc...),

firent, pendant les sept dernières années, des progrès monstrueux dans les pays qui ont le plus souffert de la guerre. La question Stinnes est devenue une question essentielle de la vie économique allemande.

La hausse des prix sur toutes les marchandises, concomitante à la baisse catastrophique du change dans tous les pays européens belligérants, attestait au fond 
une nouvelle répartition du revenu national au détriment de la classe ouvrière, des fonctionnaires, des employés, des petits rentiers et, d’une façon générale, de toutes les catégories d’individus ayant un revenu plus ou moins déterminé.

De la sorte, sous le rapport de ses ressources matérielles, l'Europe fut ramenée a une dizaine d'années en arrière et la tension des antagonismes sociaux, qui ne peut désormais être comparée à ce qu'elle était autrefois, loin d’être arrêtée dans son cours, s’accentua avec une rapidité extraordinaire. Ce fait capital est déjà suffisant pour détruire tout espoir fondé sur un développement prolongé et pacifique des forces de la démocratie ; la différenciation progressive — d'un côté la « stinnesation » et, de l'autre, la prolétarisation et la paupérisation — basée sur la ruine économique, détermine le caractère tendu, conclusif et cruel de la lutte des classes.

Le caractère actuel de la crise ne fait que prolonger sous ce rapport le travail de la guerre et de l'essor spéculatif qui la suivit.

21. La hausse des prix des produits agricoles, tout en créant l'illusion de l'enrichissement général de la campagne, provoqua un accroissement réel des revenus et de la fortune des paysans riches. Les paysans purent, en effet, avec du papier déprécié, qu’ils avaient amassé en grande quantité, payer leurs dettes contractées au cours normal. Malgré la hausse énorme du prix de la terre, malgré l'abus éhonté du monopole des moyens de subsistance; malgré enfin l'enrichissement des grands propriétaires fonciers et des paysans aisés, la régression dans l'économie rurale de l'Europe est indiscutable : c'est une régression multiforme qui se traduit par l'extension des formes d'économie rurale, la transformation de terres arables en prairies, la destruction du bétail, l'application du système de la jachère. Cette régression a eu encore pour causes l'insuffisance, la cherté et la hausse des prix des articles manufacturés, enfin - en Europe centrale et orientale - la réduction systématique de la production, qui est une réaction contre les tentatives du pouvoir étatique d'accaparer le contrôle des produits agricoles. Les paysans aisés, et en partie les paysans moyens, créent des organisations politiques et économiques pour se protéger contre les charges de la bourgeoisie et pour dicter à l'Etat — comme prix du secours accordé contre le prolétariat — une politique de tarifs et d'impôts unilatérale et exclusivement profitable aux paysans, 
une politique qui entrave la reconstruction capitaliste. Ainsi se crée entre la bourgeoisie urbaine et la bourgeoisie villageoise une opposition qui affaiblit la puissance de toute la classe bourgeoise. En même temps une grande partie des paysans pauvres sont prolétarisés, le village se convertit en une armée de mécontents et la conscience de classe du prolétariat rural s'accroît.

D’autre part, l'appauvrissement général de l'Europe, qui la rend incapable d'acheter la quantité nécessaire de céréales américaines, entraîna une lourde crise de l'économie rurale transatlantique. On observe une aggravation de la situation du paysan et du petit fermier non seulement en Europe, mais aussi aux Etats-Unis, au Canada, en Argentine, en Australie, en Afrique du Sud.

22. La situation des fonctionnaires et des employés, par suite de la diminution de la capacité d'achat de l'argent, s’est aggravée d'une façon générale plus durement que la situation du prolétariat. Les conditions d'existence des fonctionnaires subalternes et moyens étant complètement ébranlées, ces éléments sont devenus un ferment de mécontentement politique, qui sape la solidité du mécanisme d'Etat, qu'ils servent. "La nouvelle caste moyenne », qui selon les réformistes, représentait le centre des forces conservatrices, devient plutôt, pendant l'époque de transition, un facteur révolutionnaire.

23. L’Europe capitaliste a finalement perdu sa situation économique prédominante dans le monde. D'autre part, son équilibre de classes relatif reposait sur cette vaste domination. Tous les efforts des pays européens (l'Angleterre et, en partie, la France), pour rétablir la situation intérieure, ne purent qu'aggraver le chaos de l'incertitude.

24. Tandis qu'en Europe la concentration de la propriété s'accomplit sur les bases de la ruine, aux Etats-Unis cette concentration et les antagonismes de classe atteignirent un degré extrême sur le fond d'un enrichissement capitaliste fiévreux. Les brusques changements de la situation, par suite de l'incertitude générale du marché mondial, donnent à la lutte des classes sur le sol américain un caractère 
extrêmement tendu et révolutionnaire. A une apogée capitaliste sans précédent dans l’histoire, doit succéder une apogée de lutte révolutionnaire.

25. L'émigration des ouvriers et des paysans au delà de l'océan servait toujours de soupape de sûreté au régime capitaliste d'Europe. Elle augmentait dans les époques de dépression prolongée et après l'échec des mouvements révolutionnaires. Mais maintenant l'Amérique et l'Australie entravent toujours davantage l'immigration. La soupape de sûreté de l'émigration ne fonctionne plus.

26. Le développement énergique du capitalisme en Orient, particulièrement aux Indes et en Chine, a créé de nouvelles bases sociales pour la lutte révolutionnaire. La bourgeoisie de ces pays a resserré encore plus étroitement ses liens avec le capital étranger et est devenue de la sorte son principal instrument de domination. Sa lutte contre l'impérialisme étranger, lutte du plus faible concurrent, a essentiellement un caractère à demi fictif. Le développement du prolétariat indigène paralyse les tendances révolutionnaires nationales de la bourgeoisie capitaliste. Mais, en même temps, les rangs nombreux des paysans reçoivent en la personne de l'avant-garde communiste consciente de véritables chefs révolutionnaires.

La réunion de l'oppression militaire nationaliste de l'impérialisme étranger, de l'exploitation capitaliste par la bourgeoisie indigène et par la bourgeoisie étrangère, ainsi que la survivance de la servitude féodale, créent des conditions dans lesquelles le prolétariat naissant se développera rapidement et se mettra à la tête du large mouvement des paysans.

Le mouvement populaire révolutionnaire aux Indes, dans les autres colonies, est devenu maintenant partie intégrante de la révolution mondiale des travailleurs, dans la même mesure que le soulèvement du prolétariat dans les pays capitalistes de l'ancien ou du nouveau monde. 


\section{V. - RAPPORTS INTERNATIONAUX}

27. La situation générale de l'économie mondiale et, avant tout, la ruine de l'Europe déterminent une longue période de lourdes difficultés économiques, de secousses, de crises partielles et générales, etc... Les rapports internationaux, tels

qu’ils s’établirent comme résultat de la guerre et du traité de Versailles, rendent la situation sans issue.

L’impérialisme a été engendré par les besoins des forces productrices tendant à supprimer les frontières des Etats nationaux et à créer un territoire européen et mondial économique unique ; le résultat du conflit des impérialismes ennemis a été l'établissement dans l'Europe Centrale et Orientale de nouvelles frontières, de nouvelles douanes et de nouvelles armées. Au sens économique et pratique, l’Europe a été ramenée au Moyen-Age.

Sur une terre épuisée et ruinée, on entretient actuellement une armée une fois et demie plus grande qu’en 1914, c’est-à-dire à l’apogée de la « paix armée ».

28. La politique dirigeante de la France sur le continent européen peut être divisée en deux parties : l'une, attestant la rage aveugle de l'usurier prêt à étouffer son débiteur insolvable, et l'autre, représentée par la cupidité de la grande industrie pillarde en vue de créer, à l'aide des bassins de la Sarre, de la Ruhr et de la Haute-Silésie, les conditions favorables à un impérialisme industriel, susceptible de remplacer l’impérialisme financier en faillite.

Mais ces efforts vont à l'encontre des intérêts de l'Angleterre. La tâche de celle-ci consiste à séparer le charbon allemand du minerai français, dont la réunion est pourtant une condition indispensable à la régénération de l’Europe.

29. L’Empire Britannique paraît actuellement au sommet de sa puissance. Il a maintenu ses anciennes possessions et il en a conquis de nouvelles. Mais précisément le moment actuel montre que la situation prédominante de l'Angleterre est en contradiction avec sa déchéance économique effective. L’Allemagne, avec son 
capitalisme incomparablement plus progressif sous le rapport de la technique et de l'organisation, est écrasée par la force armée. Mais, en la personne des EtatsUnis économiquement maîtres des deux Amériques, se dresse en face de l'Angleterre un adversaire triomphant et plus menaçant que l'Allemagne. Grâce à une meilleure organisation et à une meilleure technique, le rendement du travail dans les industries des Etats-Unis est incomparablement supérieur à ce qu'il est en Angleterre. Les Etats-Unis produisent 65 à $70 \%$ du naphte consommé dans le monde entier et dont dépend l'usage des automobiles, celui des tracteurs, la flotte et l'aviation. La situation séculaire et presque monopolisée de l'Angleterre sur le marché du charbon est définitivement ruinée, l’Amérique a pris la première place. Son exportation en Europe augmente de façon menaçante. Sa flotte commerciale est presque égale à celle de l'Angleterre. Les Etats-Unis ne veulent plus se résigner au monopole mondial des câbles, détenu par l'Angleterre. Dans le domaine industriel, la Grande-Bretagne passe à la défensive et, sous prétexte de lutter contre la concurrence «malsaine » de l'Allemagne, s'arme de mesures protectionnistes contre les Etats-Unis. Enfin, tandis que la flotte militaire de l'Angleterre, comptant un grand nombre d'unités vieillies, s'est arrêtée dans son développement, le gouvernement Harding a repris le programme au gouvernement Wilson relativement aux constructions navales, lesquelles, au cours des deux ou trois prochaines années, donneront l'hégémonie des mers au pavillon américain.

La situation est telle que, ou l'Angleterre sera automatiquement repoussée à l'arrière-plan et, malgré sa victoire sur l'Allemagne, deviendra une puissance de second ordre, ou bien - et elle s'y croit déjà obligée - elle engagera à fond, dans un très prochain avenir, toutes les forces par elle acquises dans le passé dans une lutte à mort avec les Etats-Unis.

C'est dans cette perspective que l'Angleterre maintient son alliance avec le Japon et s'efforce, au prix de concessions de plus en plus grandes, d'acquérir l'appui ou, tout au moins, la neutralité de la France.

La croissance du rôle international — dans les limites du continent — de cette dernière au cours de l'année écoulée a pour cause non un affaiblissement de la France, mais un affaiblissement international de l'Angleterre. 
La capitulation de l'Allemagne en mai dernier, dans la question des contributions de guerre, signale partout une victoire temporaire de l'Angleterre et assure la chute économique ultérieure de l'Europe centrale, sans exclure, dans un avenir rapproché, l'occupation par la France du bassin de la Ruhr et de la Haute-Silésie.

30. L'antagonisme du Japon et des Etats-Unis, provisoirement dissimulé à la suite de leur participation à la guerre contre l'Allemagne, développe en ce moment ouvertement ses tendances. Le Japon s'est, par suite de la guerre, rapproché des côtes américaines, ayant reçu dans l'Océan Pacifique des îles d'une grande importance stratégique.

La crise de l'industrie rapidement développée du Japon a de nouveau réveillé la question de l'émigration ; le Japon, pays à population dense, et pauvre en ressources naturelles, est obligé d'exporter des marchandises ou des hommes. Dans un cas comme dans l'autre, il se heurte aux Etats-Unis, en Californie, en Chine et sur l'île de Jap.

Le japon dépense plus de la moitié de son budget pour l'armée et pour la flotte. Dans la lutte de l'Angleterre avec l'Amérique, le Japon aura sur mer le rôle joué sur terre par la France dans la guerre avec l'Allemagne. Le Japon profite actuellement de l'antagonisme entre la Grande-Bretagne et l'Amérique, mais la lutte décisive de ces deux géants pour la domination du monde se décidera finalement à son détriment.

31. Le grand massacre récent fut européen par ses causes et par ses principaux participants. L'axe de la lutte, c'était l'antagonisme entre l'Angleterre et l'Allemagne. L'intervention des Etats-Unis élargit les cadres de la lutte, mais ne l'écarte pas de sa tendance fondamentale ; le conflit européen fut résolu au moyen du monde entier. La guerre, qui résolut à sa manière le différend entre l'Angleterre et l'Allemagne, non seulement n'a pas résolu la question des rapports entre les Etats-Unis et l'Angleterre, mais, au contraire, l'a reposée au premier plan dans toutes ses proportions, en tant que question fondamentale de la politique mondiale, de même qu'elle a posé une question de second ordre, celle des rapports entre les Etats-Unis et le Japon. La dernière guerre a de la sorte été la préfa- 
ce européenne à la guerre véritablement mondiale qui décidera de la domination impérialiste exclusive.

32. Mais ce n'est là qu'un des axes de la politique mondiale. Il y a un autre axe encore : la Fédération des Soviets russes et la 3e Internationale sont nées des conséquences de la dernière guerre. Le groupement des forces révolutionnaires internationales est entièrement dirigé contre tous les groupements impérialistes.

La conservation de l'alliance entre l'Angleterre et la France ou, au contraire, sa destruction a le même prix au point de vue des intérêts du prolétariat et au point de vue de la paix que le renouvellement ou le non-renouvellement de l'alliance anglo-japonaise, que l'entrée (ou le refus d'entrer) des Etats-Unis dans la Société des Nations. Le prolétariat ne saurait voir une grande garantie de paix dans le groupement passager, cupide et sans foi des Etats capitalistes dont la politique, évoluant de plus en plus autour de l'antagonisme anglo-américain, l'entretient en préparant une sanglante explosion.

La conclusion, par quelques pays capitalistes, de traités de paix et de conventions commerciales avec la Russie soviétique ne signifie pas, loin de là, la renonciation de la bourgeoisie mondiale à la destruction de la République des Soviets. On ne peut y voir qu'un changement peut-être passager de formes et de méthodes de lutte. Le coup d'état japonais en Extrême-Orient signifie peut-être le commencement d'une nouvelle période d'intervention armée.

Il est absolument évident que, plus le mouvement révolutionnaire prolétarien mondial se ralentit, et plus les contradictions de la situation internationale économique et politique stimulent inévitablement la bourgeoisie à tenter de nouveau de provoquer un dénouement par les armes à l'échelle mondiale. Cela voudrait dire que le « rétablissement de l'équilibre capitaliste » après la nouvelle guerre se baserait sur un épuisement économique et sur un recul de la civilisation, tels qu'en comparaison de la situation actuelle de l'Europe, il semblerait le comble du bienêtre.

33. Quoique l'expérience de la dernière guerre ait confirmé avec une certitude terrifiante que «la guerre est un calcul trompeur» - vérité qui contient tout le 
pacifisme, tant socialiste que bourgeois - la préparation de la nouvelle guerre, préparation économique, politique, idéologique et technique, se poursuit à vive allure dans tout le monde capitaliste. Le pacifisme humanitaire antirévolutionnaire est devenu une force auxiliaire du militarisme.

Les social-démocrates de toutes nuances et les syndicalistes d'Amsterdam insufflent au prolétariat international la conviction de la nécessité de s’adapter aux règles économiques et au droit international des Etats, tels qu'ils ont été établis par suite de la guerre, et apparaissent ainsi comme des auxiliaires insignes de la bourgeoisie impérialiste dans la préparation du nouveau massacre qui menace de détruire définitivement la civilisation humaine.

\section{VI. - LA CLASSE OUVRIÈrE APRÈS LA GUERRE}

34. Au fond, la question du rétablissement du capitalisme sur les bases tracées plus haut se résume ainsi : la classe ouvrière est-elle disposée à faire, dans des conditions nouvelles incomparablement plus difficiles, les sacrifices indispensables pour affermir les conditions de son propre esclavage, plus étroit et plus dur qu'avant la guerre?

Pour restaurer l'économie européenne, en remplacement de l’appareil de production détruit pendant la guerre, une forte création nouvelle de capital serait nécessaire. Cela ne serait possible que si le prolétariat était prêt a travailler davantage dans des conditions d'existence très inférieures. C'est ce que les capitalistes demandent ; c'est ce que lui conseillent les chefs traîtres des Internationale jaunes: d'abord aider à la restauration du capitalisme, ensuite lutter pour l'amélioration de la situation des ouvriers. Mais le prolétariat d'Europe n'est pas prêt à se sacrifice, il réclame une amélioration de ses conditions d'existence, ce qui actuellement est en contradiction absolue avec les possibilités objectives du capitalisme. D’où les grèves et les insurrections sans fin et l'impossibilité de restaurer l'économie européenne. Rétablir le cours du change, c'est pour divers Etats européens (Allemagne, France, Italie, Autriche, Hongrie, Pologne, Balkans) avant tout se débarrasser de charges dépassant la mesure de leurs forces, c'est-à-dire se déclarer en faillite ; c'est aussi donner une puissante impulsion à la lutte de toutes les classes pour une nouvelle répartition du revenu national. Rétablir le cours du 
change, c'est à l'avenir diminuer les dépenses de l'Etat au détriment des masses (renoncer à fixer le salaire minimum, le prix des articles de consommation générale), c'est empêcher l'arrivée des articles de première nécessité à meilleur marché provenant de l'étranger et relever l'exportation en diminuant les frais de la production, c'est-à-dire encore une fois, au premier chef, renforcer l'exploitation de la masse ouvrière. Toute mesure sérieuse, tendant à rétablir l'équilibre capitaliste, ébranle plus encore l'équilibre déjà rompu des classes et donne un nouvel élan à la lutte révolutionnaire. La question de savoir si le capitalisme peut se régénérer devient par conséquent une question de lutte entre forces vivantes : celles des classes et des partis. Si, des deux classes fondamentales, la bourgeoisie et le prolétariat, l'une, la dernière, renonçait à la lutte révolutionnaire, l'autre, la bourgeoisie, retrouverait en fin de compte, indubitablement, un nouvel équilibre capitaliste - équilibre de décomposition matérielle et morale — au moyen de nouvelles crises, de nouvelles guerres, de l'appauvrissement poursuivi de pays entiers et de la mort de dizaines de millions de travailleurs.

Mais la situation actuelle du prolétariat international ne donne guère de raisons de pronostiquer cet équilibre.

35. Les éléments sociaux de stabilité, de conservatisme, de tradition, ont perdu la plus grande partie de leur autorité sur l'esprit des masses laborieuses. Si la social-démocratie et les trade-unions conservent encore quelque influence sur une partie considérable du prolétariat, grâce à l'héritage de l'appareil d'organisation, du passé, cette influence est tout à fait inconsistante. La guerre a modifié non seulement l'état d'esprit, mais la composition même du prolétariat et ces modifications sont tout à fait incompatibles avec l'organisation graduelle d'avant la guerre.

Au sommet du prolétariat, dans la plupart des pays domine encore la bureaucratie ouvrière extrêmement développée, étroitement unie, qui élabore ses propres méthodes et ses procédés de domination, et se rattache par des milliers de liens aux institutions et aux organes de l'Etat capitaliste.

Vient ensuite un groupe d'ouvriers, le mieux placé dans la production, occupant ou comptant occuper des postes d'administration, et qui sont l'appui le plus sûr de la bureaucratie ouvrière. 
Puis la vieille génération des social-démocrates et des syndicalistes ouvriers qualifiés pour la plupart, rattachés à leur organisation par des dizaines d'années de lutte et qui ne peuvent se décider à rompre avec elle, malgré ses trahisons et ses faillites. Toutefois, dans bien des branches de production, les ouvriers qualifiés sont mélangés à des ouvriers non qualifiés, des femmes surtout.

Viennent encore des millions d'ouvriers qui ont fait l'apprentissage de la guerre, qui sont familiarisés avec le maniement des armes et prêts, pour la plupart, à s'en servir contre l'ennemi de classe, à la condition toutefois d'une préparation sérieuse, préalable, d’une ferme direction, choses indispensables au succès.

Puis des millions de nouveaux ouvriers, d’ouvrières en particulier, attirés dans l'industrie pendant la guerre et communiquant au prolétariat non seulement leurs préjugés petits-bourgeois, mais encore leurs aspirations impatientes vers de meilleures conditions d'existence.

Enfin, des millions de jeunes ouvriers et ouvrières élevés pendant la tempête révolutionnaire, plus accessibles à la parole communiste, brûlant du désir d’agir.

En dernier lieu, une gigantesque armée de chômeurs, pour la plupart déclassés et mi-déclassés, reflétant le plus vivement dans ses fluctuations le cours de la décadence de l'économie capitaliste et tenant l'ordre bourgeois sous sa constante menace.

Ces éléments du prolétariat, si divers par leur origine et leur caractère, ne sont entraînés dans le mouvement après la guerre, ni simultanément, ni de la même manière. De là, les hésitations, les fluctuations, les progrès et les reculs de la lutte révolutionnaire. Mais, dans son écrasante majorité, la masse prolétarienne serre promptement les rangs parmi la ruine de toutes ses anciennes illusions, l'effrayante incertitude de la vie quotidienne, devant la toute-puissance du capital concentré, devant les méthodes de brigandage de l'Etat militarisé. Cette masse, qui compte de nombreux millions d'hommes, cherche une direction ferme et claire, un programme net d'action, et crée par là même une base au rôle décisif que le parti communiste cohérent et centralisé est appelé à jouer.

36. La situation de la classe ouvrière s’est évidemment aggravée pendant la guerre. Certains groupes d’ouvriers ont prospéré. Les familles dans lesquelles 
quelques membres ont pu travailler dans les usines pendant la guerre ont même réussi à maintenir et à élever leur niveau d'existence. Mais, d'une façon générale, le salaire n’a pas augmenté proportionnellement à la cherté de la vie.

Dans l'Europe Centrale, le prolétariat a, pendant la guerre, été voué à des privations toujours croissantes. Dans les pays continentaux de l'Entente, la chute du niveau d'existence fut moins brutale jusqu'à ces temps derniers. En Angleterre, le

prolétariat arrêta, pendant la dernière période de la guerre, au moyen d'une lutte énergique, le processus d’aggravation des conditions de son existence.

Aux Etats-Unis, la situation de quelques couches de la classe ouvrière s'est améliorée, quelques couches ont conservé leur ancienne situation ou ont subi un abaissement de leur niveau d'existence.

La crise s’abattit sur le prolétariat du monde entier avec une force terrifiante. La réduction des salaires dépassa la baisse des prix. Le nombre des chômeurs et des demi-chômeurs devient énorme, sans précédent dans l'histoire du capitalisme. Les fréquents changements dans les conditions de l'existence personnelle influent très défavorablement sur le rendement du travail, mais ils excluent la possibilité d'établir l'équilibre des classes sur le terrain fondamental, c'est-à-dire sur celui de la production. L'incertitude des conditions d'existence, reflétant l'inconsistance générale des conditions économiques nationales et mondiales, constitue à présent le facteur le plus révolutionnaire.

\section{PERSPECTIVES ET TÂCHES}

37. La guerre n’a pas déterminé immédiatement la révolution prolétarienne. La bourgeoisie note ce fait, avec une certaine apparence de raison, comme sa plus grande victoire.

Il n’y a qu'un esprit borné petit-bourgeois qui puisse voir la faillite du programme de l’Internationale Communiste dans le fait que le prolétariat européen n’a pas renversé la bourgeoisie pendant la guerre ou immédiatement après. Le développement de l'Internationale Communiste dans la révolution prolétarienne n’implique pas la fixation dogmatique d’une date déterminée au calendrier de la révolution, ni l’obligation d’amener mécaniquement la révolution à la date fixée. 
La révolution était et reste une lutte de forces vivantes sur les bases historiques données. La destruction de l'équilibre capitaliste par la guerre à l’échelle mondiale a créé des conditions favorables pour les forces fondamentales de la révolution, pour le prolétariat. Tous les efforts de l'Internationale Communiste étaient et restent dirigés vers l'utilisation complète de cette situation.

Les divergences entre l’Internationale Communiste et les social-démocrates des deux groupes ne consistent pas en ce que nous aurions déterminé une date fixe pour la révolution, alors que les social-démocrates nient la valeur de l'utopie et du « putschisme » (tentatives insurrectionnelles); ces divergences résident en ce que les social-démocrates réagissent contre le développement révolutionnaire effectif, en aidant de toutes leurs forces, au gouvernement aussi bien que dans l'opposition, au rétablissement de l'équilibre de l'Etat bourgeois, tandis que les communistes profitent de toutes les occasions, de tous les moyens et de toutes les méthodes pour renverser et écraser l’Etat bourgeois par la dictature du prolétariat.

Au cours des deux années et demie écoulées depuis la guerre, le prolétariat des différents pays a manifesté tant d'énergie, tant de disposition à la lutte, tant d'esprit de sacrifice, qu'il aurait pu suffire largement à sa tâche et accomplir une révolution triomphante s’i1 s'était trouvé à la tête de la classe ouvrière un parti communiste réellement international, bien préparé et fortement centralisé. Mais diverses causes historiques et les influences du passé ont placé à la tête du prolétariat européen, pendant la guerre et depuis, l’organisation de la $2^{\mathrm{e}}$ Internationale, qui est devenue et qui reste un instrument politique inappréciable aux mains de la bourgeoisie.

38. En Allemagne, vers la fin de l'année 1918 et au commencement de 1919, le pouvoir appartenait en fait à la classe ouvrière. La social-démocratie - majoritaires et indépendants - les syndicats, firent agir toute leur influence traditionnelle et tout leur appareil pour remettre ce pouvoir entre les mains de la bourgeoisie.

En Italie, le mouvement révolutionnaire impétueux du prolétariat a crû de plus en plus pendant les derniers dix-huit mois et seul le manque de caractère d'un parti socialiste petit-bourgeois, la politique de trahison de la fraction parlementaire, l'opportunisme lâche des organisations syndicales ont pu permettre à la bourgeoisie de rétablir son appareil, de mobiliser sa garde blanche, de passer à 
l'attaque contre le prolétariat momentanément découragé par la faillite de ses vieux organes dirigeants.

Le puissant mouvement gréviste des dernières années en Angleterre s'est constamment brisé contre la force armée de l'Etat, qui intimidait les chefs des trade-unions. Si ces chefs étaient restés fidèles à la cause de la classe ouvrière, on aurait quand même pu, malgré tous ses défauts, faire servir aux combats révolutionnaires le mécanisme des trade-unions. Lors de la dernière crise de la « Triple Alliance » apparut la possibilité d'une collusion révolutionnaire avec la bourgeoisie, mais cette collision fut entravée par l'esprit conservateur, la poltronnerie et la traîtrise des chefs syndicaux; si l'organisme des trade-unions anglais fournissait en ce moment, dans l'intérêt du socialisme, seulement la moitié du travail qu'il effectue dans l'intérêt du capital, le prolétariat anglais s'emparerait du pouvoir avec le minimum de sacrifices et pourrait s'atteler à la tâche de réorganisation systématique du pays.

Ce que nous venons de dire s'applique dans une mesure plus ou moins grande à. tous les pays capitalistes.

39. Il est absolument incontestable que la lutte révolutionnaire du prolétariat pour le pouvoir manifeste à l'heure actuelle à l'échelle mondiale un certain fléchissement, un certain ralentissement. Mais, au fond des choses, il n'était pas permis de s'attendre à ce que l'offensive révolutionnaire d'après-guerre, dans la mesure où elle ne donna pas d'emblée la victoire, se développât suivant une ligue ininterrompue. Le développement politique a aussi ses cycles, ses hauts et ses bas. L'ennemi ne reste pas passif : il combat lui aussi. Si l'attaque du prolétariat n'est pas couronnée de succès, la bourgeoisie passe à la première occasion à la contreattaque. La perte par le prolétariat de quelques positions conquises sans difficulté entraîne une certaine dépression dans ses rangs. Mais s’il reste incontestable qu’à l'époque où nous vivons, la courbe du développement capitaliste est, d'une façon générale, descendante avec des mouvements passagers de relèvement, la courbe de la révolution est montante avec quelques fléchissements.

La restauration du capitalisme a pour condition sine qua non l'intensification de l'exploitation, la perte de millions de vies humaines, l'abaissement pour des millions d'êtres humains des conditions moyennes d'existence au-dessous du ni- 
veau minimum (Existenzminimum), l'insécurité perpétuelle du prolétariat, ce qui est un facteur constant de grève et de révolte. C'est sous la pression de ces causes et dans les combats qu'elles engendrent que croît la volonté des masses de renverser la société capitaliste.

40. La tâche capitale du Parti Communiste dans la crise que nous traversons est de diriger les combats défensifs du prolétariat, de les élargir, de les approfondir, de les grouper et de les transformer - selon le processus du développement - en combats politiques pour le but final. Mais Si les événements se développent plus lentement et qu'une période de relèvement succède, dans un nombre plus ou moins grand de pays, à la crise économique actuelle, cela ne saurait en aucune manière être interprété comme l'avènement d'une époque d'«organisation ». Aussi longtemps que le capitalisme existera, les fluctuations du développement seront inévitables. Ces fluctuations accompagneront le capitalisme dans son agonie comme elles l'ont accompagné dans sa jeunesse et dans sa maturité.

Au cas où le prolétariat serait repoussé par l'attaque du Capital dans la crise actuelle, il passera à l'offensive dès qu'il se manifestera quelque amélioration dans la situation. Son offensive économique qui, dans ce dernier cas, serait inévitablement menée sous les mots d'ordre de revanche contre toutes les mystifications du temps de guerre, contre tout le pillage et tous les outrages infligés pendant la crise, aura, pour cette même raison, la même tendance à se transformer en guerre civile ouverte que la lutte défensive actuelle.

41. Que le mouvement révolutionnaire au cours de la prochaine période suive un cours plus animé ou plus ralenti, le parti communiste doit, dans les deux cas, devenir un parti d'action. Il est à la tête des masses combattantes, il formule fermement et clairement des mots d'ordre de combat, il dénonce les mots d'ordre équivoques de la social-démocratie, basés toujours sur le compromis. Le parti communiste doit s'efforcer, au cours de toutes les alternatives du combat, de renforcer par des moyens d'organisation ses nouveaux points d'appui ; il doit former les masses aux manœuvres actives, les armer de nouvelles méthodes et de nouveaux procédés, basés sur le choc direct et ouvert avec les forces de l'ennemi. En profitant de chaque répit pour s'assimiler l'expérience de la phase précédente de 
la lutte, le parti communiste doit s'efforcer d'approfondir et d'élargir les conflits de classe et de les relier sur une échelle nationale et internationale dans l'idée du but et de l'action pratique, de façon qu'au sommet du prolétariat soient brisées toutes les résistances dans la voie de la dictature et de la Révolution sociale. 
Manifestes, thèses et résolutions

des quatre premiers congrès

de l'Internationale communiste 1919-1923

(juin 1934)

Troisième Congrès, juin 1921.

- 2 -

Thèses sur la tactique

\section{I. - DÉLIMITATION DES QUESTIONS}

«La Nouvelle Association Internationale des Travailleurs est fondée dans le but d'organiser une action d'ensemble du prolétariat des différents pays, tendant à une seule et même fin, à savoir : le renversement du capitalisme, l'établissement de la dictature du prolétariat et d'une République Internationale des Soviets qui permettront d'abolir totalement les classes et de réaliser le socialisme, premier degré de la société communiste. »

\section{Retour à la table des matières}

Cette définition des buts de l'Internationale Communiste, posée dans ses statuts, délimite clairement toutes les questions de tactique qui sont à résoudre.

Il s'agit de la tactique à employer dans notre lutte pour la dictature du prolétariat. Il s'agit des moyens à employer pour conquérir aux principes du communisme la plus grande partie de la classe ouvrière, des moyens à employer pour organiser les éléments socialement déterminants du prolétariat dans la lutte pour la réalisation du communisme. Il s'agit des relations avec les couches petitesbourgeoises prolétarisées, des moyens et procédés à prendre pour démolir le plus rapidement possible les organes du pouvoir bourgeois, les réduire en ruines et engager la lutte finale internationale pour la dictature. 
La question de la dictature elle-même, comme unique voie menant à la victoire est hors de discussion. Le développement de la révolution mondiale a montré nettement qu'il n'y a qu'une alternative offerte dans la situation historique actuelle : dictature capitaliste ou dictature prolétarienne.

Le $3^{\mathrm{e}}$ Congrès de l'Internationale Communiste reprend l'examen des questions de tactique dans des conditions nouvelles, puisque dans bien des pays la situation objective a pris une acuité révolutionnaire et que plusieurs grands partis communistes se sont formés, qui cependant ne possèdent encore nulle part la direction effective du gros de la classe ouvrière dans la lutte révolutionnaire réelle.

\section{II. - À LA VEILLE DE NOUVEAUX COMBATS}

La révolution mondiale, c’est-à-dire la destruction du capitalisme, le rassemblement des énergies révolutionnaires du prolétariat et l'organisation du prolétariat en une puissance agressive et victorieuse, exigera une période assez longue de combats révolutionnaires.

L’acuité diverse des antagonismes, la différence de la structure sociale et des obstacles à surmonter selon les pays, le haut degré d'organisation de la bourgeoisie dans les pays de haut développement capitaliste de l'Europe Occidentale et de l'Amérique du Nord, étaient des raisons suffisantes pour que la guerre mondiale n’aboutisse pas immédiatement à la victoire de la révolution mondiale. Les communistes ont donc eu raison de déclarer, déjà pendant la guerre, que la période de l'impérialisme conduirait à l'époque de la révolution sociale, c'est-à-dire à une longue suite de guerres civiles à l'intérieur des divers Etats capitalistes et de guerres entre les Etats capitalistes d'une part, les Etats prolétariens et les peuples coloniaux exploités d'autre part.

La révolution mondiale n'est pas un processus qui progresse en ligne droite ; c’est la dissolution lente du capitalisme, c’est la sape révolutionnaire quotidienne, qui s’intensifient de temps à autre et se concentrent en crises aiguës.

Le cours de la révolution mondiale a été rendu encore plus traînant du fait que de puissantes organisations et partis ouvriers, à savoir les partis ainsi que les syndicats social-démocrates, fondés par le prolétariat pour guider sa lutte contre la 
bourgeoisie, se sont transformés pendant la guerre en instruments d'influence contre-révolutionnaire et d'immobilisation du prolétariat et sont restés tels quels après la fin de la guerre. C'est ce qui a permis à la bourgeoisie mondiale de surmonter facilement la crise de la démobilisation ; c'est ce qui lui a permis pendant la période de prospérité apparente de 1919-1920 d'éveiller dans la classe ouvrière un nouvel espoir d'améliorer sa situation dans le cadre du capitalisme, cause essentielle de la défaite des soulèvements de 1919 et du ralentissement des mouvements révolutionnaires en 1919-1920.

La crise économique mondiale, qui apparut au milieu de 1920 et qui s'est étendue aujourd'hui sur tout l'univers, augmentant partout le chômage, prouve au prolétariat international que la bourgeoisie n'est pas en mesure de reconstruire le monde. L'exaspération de tous les antagonismes politiques mondiaux, la campagne rapace de la France contre l'Allemagne, les rivalités anglo-américaine et américano-japonaise avec la course aux armements qui s'ensuit, montrent que le monde capitaliste à l'agonie titube de nouveau vers la guerre mondiale. La Société des nations, trust international des Etats vainqueurs pour l'exploitation des concurrents vaincus et des peuples coloniaux, est minée pour le moment par la concurrence américaine. L’illusion avec laquelle la social-démocratie internationale et la bureaucratie syndicale ont détourné les masses ouvrières de la lutte révolutionnaire, l'illusion qu'elles pourraient, en renonçant à la conquête du pouvoir politique par la lutte révolutionnaire, obtenir graduellement et pacifiquement le pouvoir économique et le droit de s'administrer elles-mêmes, cette illusion est en train de mourir.

En Allemagne les comédies de socialisation avec lesquelles le gouvernement Scheidemann-Noske, en mars 1919, chercha à retenir le prolétariat de l'assaut décisif, touchent à leur fin. Les phrases sur la socialisation ont fait place au système bien réel de Stinnes, c'est-à-dire à la soumission de l'industrie allemande à un dictateur capitaliste et à sa clique. L'attaque du gouvernement prussien sous la direction du social-démocrate Severing contre les mineurs de l'Allemagne centrale forme l'introduction à l'offensive générale de la bourgeoisie allemande en vue de la réduction des salaires du prolétariat allemand.

En Angleterre tous les plans de nationalisation sont tombés à l'eau. Au lieu de réaliser les projets de nationalisation de la commission Sankey, le gouvernement appuie d'une levée de troupes le lock-out contre les mineurs anglais. 
Le gouvernement français n'arrive à ajourner sa banqueroute économique que par une expédition de rapine en Allemagne. Il ne pense à aucune reconstruction systématique de son économie nationale. Même la reconstruction des contrées dévastées du Nord de la France, dans la mesure où elle est entreprise, ne sert qu'à l'enrichissement des capitalistes privés.

En Italie la bourgeoisie est montée à l'attaque de la classe ouvrière avec l'aide des bandes blanches des fascistes.

Partout la démocratie bourgeoise a du se démasquer, plus complètement dans les vieux Etats démocratiques bourgeois que dans les nouveaux, issus de l'écroulement impérialiste. Gardes-blancs, arbitraire dictatorial du gouvernement contre les mineurs grévistes en Angleterre, fascistes et Guarda Regia en Italie, Pinkertons, exclusion des députés socialistes des parlements, loi de lynch aux Etats-Unis, terreur blanche en Pologne, en Yougoslavie, en Roumanie, Lettonie, Estonie, légalisation de la terreur blanche en Finlande, en Hongrie, et dans les pays Balkaniques, « lois communistes » en Suisse, France etc..., partout la bourgeoisie cherche à faire retomber sur la classe ouvrière les conséquences de l'anarchie économique croissante, à allonger la journée de travail et à faire tomber les salaires. Partout la bourgeoisie trouve des auxiliaires dans les chefs de la social-démocratie et de l'Internationale Syndicale d'Amsterdam. Cependant ces derniers peuvent retarder l'éveil des masses ouvrières pour un nouveau combat et l'approche de nouvelles vagues révolutionnaires, ils ne peuvent pas les empêcher.

Déjà on voit le prolétariat allemand se préparer à la contre-attaque ; on voit les mineurs anglais, malgré la trahison des chefs trade-unionistes, tenir bon, héroïquement, pendant de longues semaines dans la lutte contre le capital minier. Nous voyons comment la volonté de combat s'accroît dans les rangs avancés du prolétariat italien après l'expérience qu'il a faite de la politique d'hésitation du groupe Serrati, volonté de combat qui s'exprime par la formation du Parti Communiste d'Italie. Nous voyons comment en France, après la scission, après la séparation des social-patriotes et de centristes, le parti socialiste commence à passer de l'agitation et de la propagande du communisme à des manifestations de masses contre les appétits rapaces de l'impérialisme français. En Tchécoslovaquie, nous assistons à la grève politique de décembre, entraînant malgré son manque complet d'une direction unique, un million d'ouvriers, avec, comme conséquence, la formation d'un Parti Communiste tchèque, parti des masses. En février nous avons 
eu en Pologne une grève des cheminots, dirigée par le Parti Communiste, et une grève générale en est résultée, et nous avons assisté à la décomposition progressive du Parti Socialiste Polonais social-patriote.

Ce qu'il nous faut attendre, ce n’est pas le fléchissement de la révolution mondiale ni le reflux de ses vagues, mais tout le contraire : dans les circonstance données une exaspération immédiate des antagonismes sociaux et des combats sociaux est ce qu'il y a de plus vraisemblable.

\section{III. - LA TÂCHE LA PLUS IMPORTANTE DU MOMENT}

La conquête de l'influence prépondérante sur la plus grande partie de la classe ouvrière, l'introduction dans le combat des fractions déterminantes de cette classe, voilà à l'heure actuelle le problème le plus important de l'Internationale Communiste.

Car nous avons beau être en présence d'une situation économique et politique objectivement révolutionnaire dans laquelle la crise révolutionnaire la plus aiguë peut éclater absolument à l'improviste (à la suite d'une grande grève, d'une révolte coloniale, d'une nouvelle guerre ou même d'une grande crise parlementaire, etc...), le plus grand nombre des ouvriers n'est pas encore sous l'influence du communisme, surtout dans les pays où la puissance particulièrement forte du capital financier a donné naissance à de vastes couches d'ouvriers corrompus par l’impérialisme (par exemple en Angleterre et aux Etats-Unis), et où la véritable propagande révolutionnaire parmi les masses vient seulement de commencer.

Dès le premier jour de sa fondation, l’Internationale Communiste s'est donnée pour but, clairement et sans équivoque, non pas de former de petites sectes communistes cherchant à exercer leur influence sur les masses ouvrières uniquement par l'agitation et la propagande, mais de prendre part à la lutte des masses ouvrières, de guider cette lutte dans le sens communiste et de constituer dans le processus du combat de grands partis communistes révolutionnaires.

Déjà au cours de sa première année d'existence, l’Internationale Communiste a répudié les tendances sectaires en prescrivant aux partis affiliés, si petits fus- 
sent-ils, de collaborer aux syndicats, de participer à vaincre leur bureaucratie réactionnaire de l'intérieur même des syndicats et de les transformer en organisations révolutionnaires des masses prolétariennes, en instruments de combat. Dès sa première année d'existence, l'Internationale Communiste a prescrit aux Partis Communistes de ne pas se renfermer dans des cercles de propagande, mais de se servir pour l'éducation et l'organisation du prolétariat, de toutes les possibilités que la constitution de l'Etat bourgeois est obligée de leur laisser ouvertes : liberté de la presse, liberté de réunion et d'association et toutes les institutions parlementaires bourgeoises, si lamentables soient-elles, pour en faire des armes, des tribunes, des places d'armes du communisme. A son $2^{\mathrm{e}}$ Congrès, l'Internationale Communiste, dans ses résolutions sur la question syndicale et sur l'utilisation du parlementarisme, a répudié ouvertement toutes les tendances au sectarisme.

Les expériences de ces deux ans de lutte des Partis Communistes ont confirmé en tous points la justesse du point de vue de l'Internationale Communiste. Celleci, par sa politique, a amené les ouvriers révolutionnaires dans bien des Etats à se séparer, non seulement des réformistes déclarés, mais aussi des centristes. Dès lors que les centristes ont formé une Internationale 2 1/2 qui s’allie publiquement aux Scheidemann, aux Jouhaux et aux Henderson sur le terrain de l'Internationale Syndicale d'Amsterdam, le champ de bataille est devenu beaucoup plus clair pour les masses prolétariennes, ce qui facilitera les combats à venir.

Le communisme allemand, grâce à la tactique de l'Internationale Communiste (action révolutionnaire dans les syndicats, lettre ouverte, etc...), d'une simple tendance politique qu'il était dans les combats de janvier et mars 1919, s'est changé en un grand parti des masses révolutionnaires. Il a acquis dans les syndicats une influence telle que la bureaucratie syndicale a été forcé d'exclure de nombreux communistes des syndicats par crainte de l'influence révolutionnaire de leur action syndicale, et de prendre sur elle l’odieux de la scission.

En Tchécoslovaquie, les communistes ont réussi à gagner à leur cause la majorité des ouvriers organisés.

En Pologne, le Parti Communiste, grâce surtout à son travail de sape dans les syndicats, a su non seulement entrer en contact avec les masses, mais devenir leur guide dans la lutte, malgré les persécutions monstrueuses qui contraignent les organisations communistes à une existence absolument clandestine. 
En France, les communistes ont conquis la majorité au sein du Parti socialiste.

En Angleterre, le processus de consolidation des groupes communistes sur le terrain des directives tactiques de l'Internationale Communiste se termine et l'influence croissante des communistes oblige les socialistes-traîtres à essayer de rendre impossible aux communistes l'entrée dans le Labour Party.

Les groupes communistes sectaires par contre (comme le K.A.P.D. etc...), n’ont pas rencontré sur leur voie un seul succès. La théorie du renforcement du communisme par la propagande et l'agitation seules, par la fondation de syndicats communistes distincts, a fait complètement faillite. Nulle part aucun Parti communiste de quelque influence n’a pu être fondé de cette façon.

\section{4. - LA SITUATION AU SEIN DE L'INTERNATIONALE COMMUNISTE}

Dans cette voie menant à la formation de partis communistes de masses, l'Internationale Communiste n'est pas allée suffisamment loin partout. Et même dans deux des pays les plus importants du capitalisme victorieux elle a encore tout à faire dans ce domaine.

Aux Etats-Unis, dans l’Amérique du Nord, dans lesquels déjà avant la guerre pour des raisons historiques, il n'existait aucun mouvement révolutionnaire de quelque ampleur, les communistes ont toujours devant eux les tâches primordiales les plus simples: la formation d'un noyau communiste et son rattachement aux masses ouvrières. La crise économique, qui a fait 5 millions d'ouvriers sans travail, fournit pour cela un terrain très favorable. Conscient du danger qui le menace d'une radicalisation du mouvement ouvrier et de l'influence de ce mouvement par les communistes, le capital américain essaie de briser le jeune mouvement communiste par des persécutions barbares, de l'anéantir et de le contraindre à l'illégalité, dans laquelle, pense-t-il, ce mouvement, sans contact avec les masses, dégénérerait en une secte de propagande et se dessécherait.

L'Internationale Communiste attire l'attention du Parti Communiste Unifié d’Amérique sur le fait que l'organisation illégale ne doit constituer qu'un terrain de rassemblement, de clarification, pour les forces communistes les plus actives, 
mais que le Parti unifié a le devoir de tenter tous les moyens et toutes les voies pour sortir de ses organisations illégales et atteindre les grandes masses ouvrières en fermentation; qu'il a le devoir de trouver les formes et les voies propres à concentrer politiquement ces masses dans leur vie publique en vue de la lutte contre le capital américain.

Le mouvement communiste anglais, lui non plus, n’a pas encore réussi, malgré la concentration de ses forces en un Parti Communiste uni, à devenir un parti de masses.

La désorganisation durable de l'économie anglaise, l'aggravation inouïe du mouvement gréviste, le mécontentement croissant des grandes masses populaires à l'égard du régime de Lloyd George, la possibilité d'une victoire du Labour Party et du Parti libéral aux prochaines élections parlementaires, tout cela ouvre dans le développement de l'Angleterre de nouvelles perspectives révolutionnaires et pose devant les communistes anglais des questions d'une importance extrême.

La première et principale tâche du Parti Communiste d'Angleterre est de devenir un Parti de masses. Les communistes anglais doivent se placer de plus en plus fermement sur le terrain du mouvement de masses existant en fait et se développant sans cesse ; ils doivent pénétrer dans toutes les particularités concrètes de ce mouvement et faire des revendications isolées ou partielles des ouvriers le point de départ de leur propre agitation et de leur propagande inlassable et énergique.

Le puissant mouvement gréviste met à l'épreuve, aux yeux de centaines de milliers et de millions d'ouvriers le degré de capacité, de fidélité, de constance et de conscience des trade-unions et de leurs chefs. Dans ces conditions, l'action des communistes au sein des syndicats acquiert une importance décisive. Aucune critique du Parti, venant du dehors, ne saurait, même dans une mesure éloignée, exercer sur les masses une influence semblable à celle qui peut être exercée par le travail quotidien et constant des noyaux communistes dans les syndicats, par le travail tendant à démasquer et à discréditer les traîtres et les bourgeois du tradeunionisme, qui en Angleterre plus encore que dans tout autre pays, sont le jouet politique du capital.

Si, dans d'autres pays, la tâche des partis communistes devenus partis de masses consiste dans une importante mesure à prendre l'initiative d'actions de mas- 
ses, en Angleterre la tâche du Parti Communiste consiste avant tout, sur la base des actions de masses qui se développent en fait, à montrer par son propre exemple et à prouver que les communistes sont capables d'exprimer justement et courageusement les intérêts, les besoins et les sentiments de ces masses.

Les Partis communistes de masses de l'Europe Centrale et Occidentale se trouvent en pleine formation de leurs méthodes d'agitation et de propagande révolutionnaire, en pleine formation de méthodes d'organisation répondant à leur caractère de combat, enfin en pleine transition de la propagande et de l'agitation communistes à l'action. Ce processus est entravé par le fait que dans bien des pays l'entrée des ouvriers devenus révolutionnaires dans le camp du communisme s'est accomplie sous la direction de chefs qui n’ont pas encore surmonté leurs tendances centristes et qui ne sont pas en état de mener une efficace agitation et propagande communistes dans le peuple, qui craignent même cette propagande parce qu'ils savent qu'elle conduirait les Partis aux combats révolutionnaires.

Ces tendances centristes ont mené en Italie à la scission du Parti. Les chefs du Parti et des syndicats groupés autour de Serrati, au lieu de transformer les mouvements spontanés de la masse ouvrière et son activité croissante en une lutte consciente pour le pouvoir - lutte pour laquelle la situation était mûre en Italie - laissèrent ces mouvements s’enliser. Le communisme n’était pas pour eux un moyen de secouer et de concentrer les masses ouvrières en vue du combat. Et parce qu'ils craignaient le combat, ils durent délayer la propagande et l'agitation communistes et la conduire dans les eaux centristes. Ils renforcèrent de la sorte l'influence des réformistes comme Turati et Trèves dans le Parti et comme d'Aragona dans les syndicats. Comme ils ne se distinguaient des réformistes, ni par la parole ni par les actes, ils ne voulurent pas non plus se séparer d'eux. Ils préférèrent se séparer des communistes. La politique de la tendance Serrati, en renforçant d'une part l'influence des réformistes, créa d'autre part le double danger de renforcer les anarchistes et les syndicalistes et d'engendrer des tendances antiparlementaires radicales uniquement en paroles dans le Parti même.

La scission de Livourne, la formation du Parti Communiste d'Italie, la concentration de tous les éléments réellement communistes sur le terrain des décisions du $2^{\mathrm{e}}$ Congrès de l'Internationale Communiste en un Parti communiste, feront du communisme dans ce pays une force de masses, pourvu que le Parti Communiste d'Italie combatte sans relâche et sans faiblesse la politique opportu- 
niste du Seratisme et se donne ainsi la possibilité de rester lié aux masses du prolétariat dans les syndicats, dans les grèves, dans les luttes avec les organisations contre-révolutionnaires des fascistes, de fondre ensemble les mouvements de ces masses et de transformer en combats soigneusement préparés leurs actions spontanées.

En France, où le poison chauvin de la « défense nationale » et ensuite l'ivresse de la victoire ont été plus forts que partout ailleurs, la réaction contre la guerre s'est développée plus lentement que dans les autres pays. Grâce à l'influence de la Révolution russe, aux luttes révolutionnaires dans les pays capitalistes et à l'expérience des premières luttes du prolétariat français trahi par ses chefs, le Parti Socialiste a évolué dans sa majorité vers le communisme, avant même d'avoir été placé par le cours des événements devant les questions décisives de l'action révolutionnaire. Cette situation sera d'autant mieux et d'autant plus largement utilisée par le Parti Communiste Français qu'il liquidera plus catégoriquement dans son propre sein, surtout dans les milieux dirigeants, les survivances de l'idéologie du pacifisme nationaliste et du réformisme parlementaire. Le Parti doit, dans une mesure bien plus grande, non seulement par rapport au passé, se rapprocher des masses et de leurs couches opprimées et donner une expression claire, complète et inflexible de leurs souffrances et de leurs besoins. Dans sa lutte parlementaire, le Parti doit rompre catégoriquement avec les formes repoussantes et pénétrées de mensonge du parlementarisme français, consciemment forgées par la bourgeoisie pour hypnotiser et intimider les représentants de la classe ouvrière. Les parlementaires français doivent s'efforcer, dans toutes leurs interventions, d'arracher le voile national-démocrate, républicain et traditionnellement révolutionnaire, et de présenter nettement toute question comme une question d'intérêt et d'impitoyable lutte de classes.

L'agitation pratique doit prendre un caractère beaucoup plus concentré, plus tendu et plus énergique. Elle ne doit pas se disperser à travers les situations et les combinaisons changeantes et variables de la politique quotidienne. De tous les événements petits ou grands, elle doit toujours tirer les mêmes conclusions fondamentales révolutionnaires et les inculquer aux masses ouvrières même les plus arriérées. Ce n'est qu'à la condition d'observer cette attitude véritablement révolutionnaire que le Parti Communiste cessera de paraître — et d'être en réalité une simple aile gauche de ce bloc radical longuettiste qui offre avec une insistan- 
ce et un succès de plus en plus grands ses services à la société bourgeoise pour la protéger des ébranlements qui s'annoncent en France, avec une logique inflexible. Abstraction faite de la question de savoir si ces événement révolutionnaires décisifs arriveront plus ou moins tôt, un Parti Communiste moralement éduqué, entièrement pénétré de volonté révolutionnaire, trouvera la possibilité, même dans l'époque actuelle de préparation, de mobiliser les masses ouvrières sur le terrain politique et économique et de donner à leur lutte un caractère plus clair et plus vaste.

Les tentatives faites par des éléments révolutionnaires impatients et politiquement inexpérimentés, voulant employer dans des questions et pour des buts isolés les méthodes extrêmes qui par leur essence constituent les méthodes du soulèvement révolutionnaire décisif du prolétariat (ainsi la proposition d'inviter la classe 19 à ne pas répondre à la mobilisation), ces tentatives peuvent en cas d'application réduire à néant pour longtemps la préparation réellement révolutionnaire du prolétariat à la conquête du pouvoir. C'est un devoir pour le Parti Communiste français, ainsi que pour tous les partis analogues, de repousser ces méthodes extrêmement dangereuses. Mais ce devoir ne doit en aucun cas donner lieu à l'inactivité du Parti. Bien au contraire.

Renforcer la liaison du Parti avec les masses, c'est avant tout le rattacher plus étroitement aux syndicats. Le but ne consiste point du tout à ce que les syndicats soient soumis mécaniquement et extérieurement au Parti et renoncent à l'autonomie découlant nécessairement du caractère de leur action : il consiste à ce que les éléments véritablement révolutionnaires réunis dans le Parti Communiste donnent, dans le cadre même des syndicats, une tendance correspondant au intérêts communs du prolétariat, luttant pour la conquête du pouvoir.

En considération de ce fait, le Parti Communiste Français doit faire la critique, sous une forme amicale mais décisive et claire, de toutes les tendances anarchistes-syndicalistes qui repoussent la dictature du prolétariat et la nécessité d'une union de son avant-garde en une organisation dirigeante, centralisée, c'est-à-dire en un Parti Communiste, ainsi que de toutes les tendances syndicalistes transitoires qui, sous le manteau de la charte d'Amiens, élaborée huit ans avant la guerre, ne sauraient plus donner aujourd'hui une réponse claire et nette aux questions essentielles de l'époque nouvelle d'après-guerre. 
La haine qui se manifeste dans le syndicalisme français contre l'esprit de caste politique est avant tout une haine bien justifiée contre les parlementaires « socialistes-traditionnels ». Mais le caractère purement révolutionnaire du Parti Communiste lui donne la possibilité de faire comprendre à tous les éléments révolutionnaires la nécessité du groupement politique dans le but de la conquête du pouvoir par la classe ouvrière.

La fusion du groupement syndicaliste révolutionnaire avec l'organisation communiste dans son ensemble est une condition nécessaire et indispensable à toute lutte sérieuse du prolétariat français.

L'on ne parviendra à surmonter et à écarter les tendances vers l'action prématurée et à vaincre l'imprécision de principes et le séparatisme d'organisation des syndicalistes-révolutionnaires que lorsque le Parti lui-même, comme nous l'avons dit plus haut, sera devenu, en traitant de façon vraiment révolutionnaire toute question de la vie et de la lutte quotidienne des masses ouvrières françaises, un centre d'attraction pour elles.

En Tchécoslovaquie, les masses laborieuses, au cours de ces deux ans et demi, se sont en grande partie affranchies des illusions réformistes et nationalistes. En septembre dernier, la majorité des ouvriers social-démocrates s'est séparée de ses chefs réformistes. En décembre, un million d'ouvriers environ sur les 3 millions et demi de travailleurs industriels que compte la Tchécoslovaquie, s’opposa en une action révolutionnaire de masses au gouvernement capitaliste tchécoslovaque. Au mois de mai de cette année, le Parti Communiste tchécoslovaque s'est constitué avec environ 350000 membres à côté du Parti Communiste de la Bohème allemande précédemment formé et comptant environ 600000 membres. Les communistes constituent ainsi une grande partie non seulement du prolétariat de la Tchécoslovaquie, mais aussi de toute sa population. Le Parti Tchécoslovaque se trouve placé maintenant devant ce problème d'attirer, au moyen d'une agitation véritablement communiste, des masses ouvrières encore plus étendues, d'instruire des membres, - anciens ou nouvellement acquis - par une propagande communiste claire et sans timidité, d'unir les ouvriers de toutes les nationalités de Tchécoslovaquie pour former un front ininterrompu des prolétaires contre le nationalisme, cette citadelle de la bourgeoisie en Tchécoslovaquie, et de transformer la force ainsi créée du prolétariat au cours des combats à venir contre les tendances oppressives du capitalisme et contre le gouvernement en une puissance invincible. 
Le Parti communiste de Tchécoslovaquie sera d'autant plus promptement à la hauteur de cette mission qu'il saura avec clarté et décision vaincre toutes les traditions et préjugés centristes, qu'il mènera une politique éduquant révolutionnairement et concentrant les plus grandes masses du prolétariat et qu'il sera ainsi en mesure de préparer ces actions des masses et de les exécuter victorieusement. Le Congrès décide que les Partis Communistes Tchécoslovaque et Allemandbohémien doivent fusionner leurs organisations et former un Parti unique, dans un délai qui sera déterminé par le Comité Exécutif.

Le Parti Communiste Unifié d'Allemagne, né de l'union du groupe Spartacus avec les masses ouvrières des Indépendants de gauche, quoique étant déjà un grand Parti de masses, a la mission immense d'augmenter son influence sur les grandes masses, de renforcer les organisations de masses prolétariennes, de conquérir les syndicats, de briser l'influence du Parti social-démocrate et de la bureaucratie syndicale, et de deviner, dans les luttes futures du prolétariat, les chefs des mouvements de masses. Cette tâche principale du Parti exige qu'il y applique tous ses efforts d'adaptation, de propagande et d'organisation, qu'il tâche de conquérir les sympathies de la majorité du prolétariat, sans laquelle, étant donné la puissance du capital allemand, aucune victoire du communisme n'est possible en Allemagne.

Le Parti Unifié d'Allemagne ne s'est pas encore montré à la hauteur de cette tâche, en ce qui concerne l'ampleur et le contenu de l'agitation. Il n'a pas encore su suivre avec logique la voie qu'il a prise par sa «lettre ouverte », la voie sur laquelle s'opposent les intérêts pratiques du prolétariat à la politique traîtresse des partis social-démocrates et de la bureaucratie syndicale. La presse et l'organisation du Parti portent encore trop le cachet de sociétés et non d'instruments et d'organisations de lutte. Les tendances centristes qui s'expriment encore dans ce Parti et qui n’y ont pas encore été surmontées ont mené d'une part à cette situation que le Parti, placé devant la nécessité du combat, dut y entrer sans préparation suffisante et ne sut pas garder suffisamment la liaison morale avec les masses non communistes. Les exigences d'action qui seront bientôt imposées au Parti Communiste Unifié l'Allemagne par le processus de destruction de l'économie allemande, par l'offensive du capital contre l'existence des masses ouvrières, ne sauraient être satisfaites que si le Parti, loin d'opposer à son but d'action ses buts d'agitation et d'organisation, tient toujours éveillé l'esprit de 
combativité dans son organisation, donne à son agitation un caractère réellement populaire, revêt son organisation d'une forme qui la mette en mesure, en développant sa liaison avec les masses, de poser de la façon la plus soigneuse, la situation de la lutte et de préparer non moins soigneusement cette lutte.

Les Partis de l'Internationale Communiste deviendront des Partis de masses révolutionnaires, s'ils savent vaincre l'opportunisme, ses survivances et ses traditions, dans leurs propres rangs, en cherchant à se lier étroitement aux masses ouvrières combattantes, en puisant leurs buts dans les luttes pratiques du prolétariat, en repoussant au cours de ces luttes aussi bien la politique opportuniste de l'aplanissement et de l'effacement des antagonismes insurmontables que les phrases révolutionnaires qui empêchent de voir le rapport réel des forces et les véritables difficultés du combat. Les partis communistes sont nés de la scission des anciens partis social-démocrates. Cette scission résulte du fait que ces partis ont trahi pendant la guerre par une alliance avec la bourgeoisie ou par une politique hésitante cherchant à éviter toute lutte. Les principes des partis communistes forment le seul terrain sur lequel les masses ouvrières pourraient à nouveau se réunir, car ces principes expriment les besoins de la lutte du prolétariat. Et puisqu'il en est donc ainsi, ce sont actuellement les partis et les tendances social-démocrates et centristes qui représentent la division et le morcellement du prolétariat, tandis que les partis communistes constituent un élément d'union.

En Allemagne ce sont les centristes qui se sont séparés de la majorité de leur parti, lorsque celle-ci suivit le drapeau du communisme. Par crainte de l'influence unificatrice du communisme, les social-démocrates et les Indépendants d'Allemagne, ainsi que la bureaucratie syndicale social-démocrate refusèrent de collaborer en des actions communes avec les communistes à la défense des intérêts les plus simples du prolétariat. En Tchécoslovaquie, ce furent les socialdémocrates qui firent sauter l'ancien parti lorsqu'ils se rendirent compte du triomphe du communisme. En France ce furent, les longuettistes qui se séparèrent de la majorité des ouvriers socialistes, tandis que le Parti Communiste s'efforça d'unir les ouvriers socialistes et syndicalistes. En Angleterre, ce furent les réformistes et les centristes qui, par crainte de leur influence, chassèrent les communistes du Labour Party et sabotèrent la concentration des ouvriers dans leur lutte contre les capitalistes. Les partis communistes deviennent ainsi des facteurs 
d'union du prolétariat dans sa lutte pour ses intérêts, et dans la conscience de leur rôle ils amasseront de nouvelles forces.

\section{V. - COMBATS ET REVENDICATIONS PARTIELLES}

Les Partis communistes ne peuvent se développer que dans la lutte. Même les plus petits des partis communistes ne doivent pas se borner à la simple propagande et à l'agitation. Ils doivent constituer, dans toutes les organisations de masses du prolétariat, l'avant-garde qui montre aux masses retardataires, hésitantes - en formulant pour elles des buts concrets de combat, en les incitant à lutter pour réclamer leur besoins vitaux - comment il faut mener la bataille et qui par là leur révèle la traîtrise de tous les partis non communistes. C'est seulement à condition de savoir se mettre à la tête du prolétariat dans tous ses combats, et de provoquer ces combats, que les partis communistes peuvent gagner effectivement les grandes masses prolétariennes à la lutte pour la dictature.

Toute l'agitation et la propagande, toute l'action du Parti Communiste doivent être pénétrées de ce sentiment que, sur le terrain du capitalisme, aucune amélioration durable de la situation de la masse du prolétariat n'est possible; que seul le renversement de la bourgeoisie et la destruction de l'Etat capitaliste permettront de travailler à améliorer la situation de la classe ouvrière et à restaurer l'économie nationale ruinée par le capitalisme.

Mais ce sentiment ne doit pas nous faire renoncer à combattre pour les revendications vitales actuelles et immédiates du prolétariat, en attendant qu'il soit en état de les défendre par sa dictature. La social-démocratie qui, maintenant, au moment où le capitalisme n'est plus en état d'assurer aux ouvriers même une existence d'esclaves rassasiés, présente le vieux programme social-démocrate des réformes pacifiques, réformes qui doivent être réalisées par la voie pacifique sur le terrain et dans le cadre du capitalisme en faillite, cette social-démocratie trompe sciemment les masses ouvrières. Non seulement le capitalisme, pendant la période de sa dislocation, n'est pas capable d'assurer aux ouvriers des conditions d'existence quelque peu humaines, mais encore les social-démocrates, les réformistes de tous les pays prouvent chaque jour qu'ils n'ont pas la moindre intention 
de mener le moindre combat pour la plus modeste des revendications contenues dans leur propre programme.

Revendiquer la socialisation ou la nationalisation des plus importantes branches d'industrie, comme le font les partis centristes, c'est encore tromper les masses populaires. Les centristes n'ont pas seulement induit les masses en erreur en cherchant à les persuader que la socialisation peut arracher des mains du capital les principales branches d'industrie sans que la bourgeoisie soit vaincue, ils cherchent encore à détourner les ouvriers de la lutte vitale réelle pour leurs besoins les plus immédiats, en leur faisant espérer une mainmise progressive sur les diverses industries les unes après les autres, après quoi commencera la construction « systématique » de l'édifice économique. Ils reviennent ainsi au programme minimum de la social-démocratie, c'est-à-dire à la réforme du capitalisme, qui est aujourd'hui une véritable duperie contre-révolutionnaire.

Si dans ce programme de nationalisation, par exemple de l'industrie du charbon, l'idée lassalienne joue encore un rôle pour fixer toutes les énergies du prolétariat sur une revendication unique, pour en faire un levier d'action révolutionnaire conduisant par son développement à la lutte pour le pouvoir, dans ce cas nous avons affaire à une rêverie de songe-creux : la classe ouvrière souffre aujourd'hui dans tous les Etats capitalistes de fléaux si nombreux et si effroyables qu'il est impossible de combattre toutes ces charges écrasantes et ces coups en poursuivant un objet trop subtil tout à fait imaginaire. Il faut au contraire prendre chaque besoin des masses comme point de départ de luttes révolutionnaires qui, dans leur ensemble, pourront constituer le courant puissant de la révolution sociale. Les Partis communistes ne mettent en avant pour ce combat aucun programme minimum tendant à fortifier et à améliorer l'édifice vacillant du capitalisme. La ruine de cet édifice reste leur but directeur, leur tâche actuelle. Mais pour remplir cette tâche, les Partis Communistes doivent émettre des revendications dont la réalisation constitue une nécessité immédiate et urgente pour la classe ouvrière et ils doivent défendre ces revendications dans la lutte des masses, sans s'inquiéter de savoir si elles sont compatibles ou non avec l'exploitation usuraire de la classe capitaliste.

Les Partis Communistes doivent prendre en considération non pas les capacités d'existence et de concurrence de l'industrie capitaliste, non pas la force de résistance des finances capitalistes, mais l'étendue de la misère que le prolétariat 
ne peut pas et ne doit pas supporter. Si ces revendications répondent aux besoins vitaux des larges masses prolétariennes, si ces masses sont pénétrées du sentiment que sans la réalisation de ces revendications leur existence est impossible, alors la lutte pour ces revendications deviendra le point de départ de la lutte pour le pouvoir. A la place du programme minimum des réformistes et des centristes, l'Internationale Communiste met la lutte pour les besoins concrets du prolétariat, pour un système de revendications qui dans leur ensemble démolissent la puissance de la bourgeoisie, organisent le prolétariat et constituent les étapes de la lutte pour la dictature prolétarienne et dont chacune en particulier donne son expression à un besoin des larges masses, même si ces masses ne se placent pas encore consciemment sur le terrain de la dictature du prolétariat.

Dans la mesure où la lutte pour ces revendications embrasse et mobilise des masses de plus en plus grandes, dans la mesure où cette lutte oppose les besoins vitaux des masses aux besoins vitaux de la société capitaliste, la classe ouvrière prendra conscience de cette vérité que si elle veut vivre, le capitalisme doit mourir. Cette constatation fera naître en elle la volonté de combattre pour la dictature. C'est la tâche des Partis Communistes d'élargir les luttes qui se développent au nom de ces revendications concrètes, de les approfondir et de les relier entre elles. Toute action partielle entreprise par les masses ouvrières pour des revendications partielles, toute grève économique sérieuse, provoque immédiatement la mobilisation de toute la bourgeoisie pour protéger ceux des entrepreneurs qui sont menacés, et pour rendre impossible toute victoire, ne fût-ce que partielle du prolétariat (Secours technique des briseurs de grèves bourgeois pendant la grève des cheminots anglais, fascistes). La bourgeoisie mobilise également tout le mécanisme de l'Etat pour combattre les ouvriers (militarisation des ouvriers en Pologne, lois d'exception pendant la grève des mineurs en Angleterre). Les ouvriers qui luttent pour leurs revendications partielles sont entraînés automatiquement à combattre toute la bourgeoisie et son appareil d'Etat. Dans la mesure où les luttes pour des revendications partielles, où les luttes partielles des divers groupes d'ouvriers grandissent en une lutte générale de la classe ouvrière contre le capitalisme, le Parti Communiste a le devoir de proposer des mots d'ordre plus élevés et plus généraux, jusque et y compris celui du renversement direct de l’adversaire.

En établissant leurs revendications partielles, les partis communistes doivent veiller à ce que ces revendications, ayant leur attache dans les besoins des larges 
masses, ne se bornent pas à entraîner ces masses dans la lutte, mais par ellesmêmes soient de nature à les organiser.

Tous les mots d'ordre concrets ayant leur source dans les besoins économiques des masses ouvrières doivent être introduits dans le plan de la lutte pour le contrôle ouvrier, qui ne sera pas un système d'organisation bureaucratique de l'économie nationale sous le régime du capitalisme, mais la lutte contre le capitalisme menée par les soviets industriels et les syndicats révolutionnaires. Ce n’est que par la construction d'organisations industrielles de cette sorte, ce n'est que par leur liaison en branches d'industrie et en centres industriels, que la lutte des masses ouvrières pourra acquérir une unité organique, qu'une opposition pourra être faite à la division des masses par la social-démocratie et par les chefs syndicaux. Les soviets industriels accompliront cette tâche seulement s’ils prennent naissance dans la lutte pour des buts économiques communs aux plus larges masses des ouvriers, seulement s’il créent la liaison entre toutes les parties révolutionnaires du prolétariat : le Parti Communiste, les ouvriers révolutionnaires et les syndicats en voie de développement révolutionnaire.

Toute objection contre l'élévation de revendications partielles de ce genre, toute accusation de réformisme sous prétexte de ces luttes partielles, découlent de cette même incapacité à comprendre les conditions vivantes de l'action révolutionnaire qui s'est manifestée déjà dans l'opposition de certains groupes communistes à la participation aux syndicats et à l'utilisation du parlementarisme. Il ne s’agit point de se borner à prêcher toujours au prolétariat les buts finaux, mais de faire progresser une lutte concrète, qui seule peut le conduire à lutter pour ces buts finaux. A quel point les objections contre les revendications partielles sont dénuées de base et étrangères aux exigences de la vie révolutionnaire, cela ressort surtout du fait que même les petites organisations fondées par les communistes dits de gauche, comme asiles de la pure doctrine, ont été obligées de mettre en avant des revendications partielles, quand elles ont voulu essayer d'entraîner dans la lutte des masses ouvrières plus nombreuses que celles qui se groupent autour d'elles ou quand elles veulent prendre part aux luttes des grandes masses populaires pour pouvoir y exercer leur influence.

La nature révolutionnaire de l'époque actuelle consiste précisément en ceci que les conditions d'existence les plus modestes des masses ouvrières sont incompatibles avec l’existence de la société capitaliste, et que pour cette raison la 
lutte même pour les revendications les plus modestes prend les proportions d'une lutte pour le communisme.

Tandis que les capitalistes profitent de l'armée toujours croissante des sanstravail pour exercer une pression sur le travail organisé en vue d'une réduction des salaires, les social-démocrates, les Indépendants et les chefs officiels des syndicats se détournent lâchement des sans-travail, les considèrent simplement comme sujets de la bienfaisance gouvernementale et syndicale et les caractérisent politiquement comme un lumpenprolétariat. Les communistes doivent se rendre clairement compte que dans les conditions actuelles l'armée des sans-travail constitue un facteur révolutionnaire d'une valeur colossale. La direction de cette armée doit être prise par les communistes. Par la pression exercée par les sans-travail sur les syndicats, les communistes doivent hâter le renouvellement des syndicats, en premier lieu leur libération de l'influence des chefs traîtres. Le parti communiste, en unissant les sans-travail à l'avant-garde du prolétariat dans la lutte pour la révolution socialiste, retiendra les éléments les plus révolutionnaires et les plus impatients des sans-travail d'actes désespérés isolés et rendra capable toute la masse d'appuyer dans des conditions favorables l'attaque commencée par un groupe de prolétaires, de développer ce conflit au-delà des cadres donnés, d'en faire le point de départ d'une offensive décidée ; en un mot il transformera toute cette masse et, d'une armée de réserve de l'industrie, il en fera une armée active de la révolution.

En prenant avec la plus grande énergie la défense de cette catégorie d'ouvriers, en descendant dans les profondeurs de la classe ouvrière, les partis communistes ne représentent pas les intérêts d'une couche ouvrière contre une autre, ils représentent ainsi l'intérêt commun de la classe ouvrière, trahi par les chefs contre-révolutionnaires, au profit des intérêts momentanés de l'aristocratie ouvrière : plus large est la couche de sans-travail et de travailleurs à temps réduit, et plus son intérêt se transforme en l'intérêt commun de la classe ouvrière, plus les intérêts passagers de l'aristocratie ouvrière doivent être subordonnés à ces intérêts communs. Le point de vue qui s'appuie sur les intérêts de l'aristocratie ouvrière pour les retourner comme une arme contre les sans-travail ou pour abandonner ces derniers à leur sort déchire la classe ouvrière et est en fait contrerévolutionnaire. Le Parti Communiste, comme représentant de l'intérêt général de la classe ouvrière, ne saurait se borner à reconnaître et à faire valoir par la propagande cet intérêt commun. Il ne peut représenter efficacement cet intérêt général 
qu'en menant dans certaines circonstances le gros même de la masse ouvrière la plus opprimée et la plus appauvrie au combat contre la résistance de l'aristocratie ouvrière.

\section{VI. - LA PRÉPARATION DE LA LUTTE}

Le caractère de la période de transition fait un devoir à tous les partis communistes d'élever au plus haut point leur esprit de combativité. Chaque combat isolé peut aboutir à un combat pour le pouvoir. Le Parti ne peut acquérir ce mordant nécessaire que s'il donne à l'ensemble de sa propagande le caractère d'une attaque passionnée contre la société capitaliste, s’il sait dans cette agitation se lier aux plus larges masses du peuple, s’il sait leur parler de façon qu'elles puissent acquérir la conviction d'être sous la direction d'une avant-garde luttant effectivement pour le pouvoir. Les organes et les manifestes du Parti communiste ne doivent pas être des publications académiques qui cherchent à prouver théoriquement la justesse du communisme ; ils doivent être des cris d'appel à la révolution prolétarienne. L'action des communistes dans les parlements ne doit pas tendre à discuter avec l'ennemi ou à le persuader, mais à le démasquer sans réserve et sans merci, à démasquer les agents de la bourgeoisie, à secouer la volonté de combat des masses ouvrières et à amener les couches petites-bourgeoises, semi-prolétariennes du peuple à se joindre au prolétariat. Notre travail d'organisation dans les syndicats comme dans les Partis ne doit pas viser à une construction mécanique, à une augmentation numérique de nos rangs ; il doit être pénétré du sentiment des luttes prochaines. Ce n'est que lorsque le Parti, dans toutes ses manifestations de vie et dans toutes ses formes d'organisation, sera la volonté de combat faite corps, qu’il sera en mesure d'accomplir sa mission dans les moments où les conditions nécessaires à de plus grandes actions combatives seront réunies.

Là où le Parti communiste représente une force massive, où son influence s'étend au delà des cadres de ses organisations propres de Parti, sur les larges masses ouvrières, il a le devoir d'inciter par l'action les masses ouvrières au combat. De grands Partis de masses ne sauraient se contenter de critiquer la carence d'autres Partis et d'opposer les revendications communistes aux leurs. C'est sur eux, en tant que partis des masses, que repose la responsabilité du développement 
de la révolution. Là où la situation des masses ouvrières devient de plus en plus intolérable, les Partis communistes doivent tout essayer pour porter les masses ouvrières à défendre leurs intérêts par la lutte. En présence de ce fait qu'en Europe Occidentale et en Amérique, où les masses ouvrières sont organisées en syndicats et en partis politiques, où par conséquent on ne saurait compter jusqu'à nouvel ordre sur des mouvements spontanés que dans des cas très rares, les Partis communistes ont le devoir, en usant de toute leur influence dans les syndicats, en augmentant leur pression sur les autres Partis qui s'appuient sur les masses ouvrières, de chercher à obtenir un déclenchement général du combat pour les intérêts immédiats du prolétariat, et si les Partis non communistes sont contraints de participer à ce combat, la tâche des communistes consiste à préparer d'avance les masses ouvrières à une trahison possible de la part de Partis non communistes pendant l'une des phases ultérieures du combat, à tendre le plus possible la situation et à l'aggraver afin d'être capable de continuer le combat, le cas échéant, sans les autres Partis (voir la lettre ouverte du V.K.P.D., qui peut servir de point de départ exemplaire pour d'autres actions). Si la pression du Parti Communiste dans les syndicats et dans la presse ne suffit pas pour entrainer le prolétariat au combat sur un front unique, c'est alors le devoir du Parti communiste d'essayer d'entraîner tout seul de grandes fractions des masses ouvrières. Cette politique indépendante consistant à faire défendre les intérêts vitaux du prolétariat par sa fraction la plus consciente et la plus active ne sera couronnée de succès, ne réussira à secouer les masses retardataires que si les buts du combat découlant de la situation concrète, sont compréhensibles aux larges masses, et si ces masses voient dans ces buts leurs buts propres, tout en n'étant pas encore capables de combattre pour eux.

Le Parti communiste ne doit cependant pas se borner à défendre le prolétariat contre les dangers qui le menacent, à parer les coups destinés aux masses ouvrières. Le Parti communiste est, dans la période de la révolution mondiale, de par son essence même, un Parti d'attaque, un Parti d'assaut contre la société capitaliste ; il a pour devoir, dès qu'une lutte défensive prend contre la société capitaliste, de la profondeur et de l'ampleur, de l'agrandir en une offensive. Le Parti a de plus le devoir de tout faire pour conduire d'emblée les masses ouvrières à cette offensive, là où les conditions favorables sont données. 
Celui qui s’oppose en principe à la politique de l'offensive contre la société capitaliste viole les directives du communisme.

Ces conditions consistent premièrement dans l'exaspération des combats dans le camp de la bourgeoisie elle-même, dans le cadre national et international. Si les luttes intestines au sein de la bourgeoisie ont pris une proportion telle qu'on peut prévoir que la classe ouvrière aura affaire à des forces adverses fractionnées et coupées, le Parti doit prendre l'initiative, après une minutieuse préparation dans le domaine politique et si possible dans celui de l'organisation intérieure, de conduire les masses au combat.

La deuxième condition pour des sorties, des attaques offensives sur un large front, c'est la grande fermentation existant dans les catégories déterminantes de la classe ouvrière, fermentation qui permet de prévoir que la classe ouvrière sera prête a lutter sur tout le front contre le gouvernement capitaliste. S’il est indispensable, lorsque le mouvement s'accroît en étendue, d'accentuer les mots d'ordre du combat, c'est également un devoir pour les dirigeants communistes du combat, au cas où le mouvement prendrait une allure rétrograde, de retirer de la bataille les masses combattantes avec le maximum d'ordre et de cohésion.

La question de savoir si le Parti Communiste doit employer l'offensive ou la défensive dépend des circonstances concrètes. L'essentiel est qu'il soit pénétré d'un esprit combatif, qu'il triomphe de cette passivité centriste, qui fait nécessairement échouer même la propagande du parti dans la routine semi-réformiste. Cette disposition constante au combat, doit constituer la caractéristique des grands partis communistes, non seulement parce que sur eux, en tant que partis de masses, repose la charge du combat, mais encore en raison de l'ensemble de la situation actuelle : désagrégation du capitalisme et paupérisation croissante des masses. Il faut réduire cette période de désagrégation, si l’on ne veut pas que toutes les bases matérielles du communisme soient anéanties et que toute l'énergie des masses ouvrières soit détruite, pendant cette période. 


\section{VII. - LES ENSEIGNEMENTS DE L'ACTION DE MARS}

L'action de mars fut une lutte imposée au Parti Communiste Unifié l'Allemagne par l'attaque du gouvernement contre le prolétariat de l'Allemagne centrale.

Au cours de ce premier grand combat que le Parti Communiste Unifié eut à soutenir après sa formation, il commit une série de fautes dont la principale consista en ce que, au lieu de faire clairement ressortir le caractère défensif de cette lutte, par son cri d’offensive, il fournit aux ennemis sans scrupules du prolétariat, à la bourgeoisie, au parti social-démocrate et au parti indépendant un prétexte pour dénoncer le parti unifié au prolétariat comme un fauteur de putsch. Cette faute fut encore exagérée par un certain nombre de camarades du parti, représentant l'offensive comme la méthode essentielle de lutte du Parti Communiste Unifié d’Allemagne dans la situation actuelle. Les organes officiels du parti, comme son président, le camarade Brandler, se sont déjà élevés contre ces fautes.

Le $3^{\mathrm{e}}$ Congrès de l'Internationale Communiste considère l'action de mars du Parti Communiste Unifié d'Allemagne comme un pas en avant. Le Congrès est d'avis que le Parti Communiste Unifié sera d'autant plus en mesure d'exécuter avec succès ses actions de masses qu'il saura mieux adapter à l'avenir ses mots d'ordre de combat à la situation réelle, qu'il étudiera plus soigneusement cette situation, et qu'il agira avec plus d’unité.

Le Parti Communiste Unifié d'Allemagne, dans l'intérêt d'une appréciation minutieuse des possibilités de lutte devra prendre attentivement en considération les faits et les réflexions et peser soigneusement le bien-fondé des opinions qui indiquent les difficultés de l'action. Mais dès l'instant où une action a été décidée par les autorités du parti, tous les camarades doivent se soumettre aux décisions du parti et exécuter ces actions. La critique de ces actions ne peut commencer qu'après qu'elles soient terminées et elle ne doit être exercée qu’à l'intérieur du parti et de ses organes et en prenant en considération la situation dans laquelle se trouve le parti par rapport à l'ennemi de classe. 
Du fait que Lévi a méconnu ces exigences évidentes de la discipline et les conditions posées à la critique du parti, le Congrès approuve son exclusion du parti et considère comme inadmissible toute collaboration politique des membres de l’Internationale Communiste avec lui.

\section{VIII. - FORME ET MÉTHODES DU COMBAT DIRECT}

Les formes et méthodes du combat, ses proportions, de même que la question de l'offensive ou de la défensive, dépendent de certaines conditions que l'on ne saurait arbitrairement créer. Les expériences précédentes de la révolution ont montré différentes formes d'actions partielles :

1) Actions partielles de couches isolées du prolétariat (action des mineurs, des cheminots, etc... en Allemagne, en Angleterre, des ouvriers agricoles, etc...).

2) Actions partielles de l'ensemble des ouvriers pour des buts limités (l'action pendant les journées de Kapp, l'action des mineurs anglais contre l'intervention militaire du gouvernement anglais pendant la guerre russopolonaise).

Au point de vue territorial, ces luttes partielles peuvent embrasser des régions isolées, des pays entiers ou plusieurs pays à la fois.

L’action de mars fut une lutte héroïque menée par des centaines de milliers de prolétaires contre la bourgeoisie. Et en se mettant vigoureusement à la tête de la défense des ouvriers de l'Allemagne Centrale, le Parti Communiste Unifié d'Allemagne prouve qu'il est réellement le parti du prolétariat révolutionnaire allemand.

Toutes ces formes de combat sont destinées au cours de la révolution dans chaque pays à se succéder les unes aux autres à plusieurs reprises. Le parti communiste ne peut évidemment pas se refuser à des actions partielles territorialement limitées, mais ses efforts doivent tendre à transformer tout combat local plus important en une lutte générale du prolétariat. De même qu'il a le devoir, pour défendre les ouvriers combattants d'une branche d'industrie, d'appeler à la rescous- 
se, si possible, la classe ouvrière tout entière, de même il est obligé, pour défendre les ouvriers combattant sur un point donné, de mettre sur pied, autant que possible, les ouvriers des autres centres industriels. L'expérience de la révolution montre que plus le champ de bataille est grand, et plus grandes sont les perspectives de victoire. La bourgeoisie, dans sa lutte contre la révolution mondiale qui se développe, s'appuie d'une part sur les organisations de gardes-blancs, d'autre part sur l'émiettement effectif de la classe ouvrière, sur la lenteur réelle du front prolétarien à se former. Plus grandes sont les masses du prolétariat qui entrent en lice, plus grand est le champ de bataille - et plus l'ennemi devra diviser et disséminer ses forces. Même si les autres parties de la classe ouvrière accourant au secours d'une partie du prolétariat en mauvaise posture ne sont pas capables pour le moment d'engager tout l'ensemble de leurs forces pour la soutenir, leur seule intervention oblige les capitalistes à diviser leurs forces militaires, car ils ne peuvent pas savoir quelle étendue et quel mordant prendra la participation au combat du reste du prolétariat.

Au cours de l'année passée, pendant laquelle nous remarquons une offensive de plus en plus arrogante du capital contre le travail, nous voyons en même temps dans tous les pays la bourgeoisie, non contente du travail de ses organes politiques, créer des organisations de gardes-blancs, légales ou semi-légales, mais toujours sous la protection de l'Etat et qui jouent un rôle déterminant dans tout grand choc économique et politique.

En Allemagne, c'est l'Orgesch, soutenue par le gouvernement et comprenant les partis de toutes nuances depuis Stinnes jusqu’à Scheidemann.

En Italie, se sont les fascistes, dont les prouesses héroïques de bandits ont modifié l’état d'esprit de la bourgeoisie et crée l’illusion d'une transformation complète du rapport entre les forces politiques.

En Angleterre, le gouvernement de Lloyd George, pour s’opposer au danger gréviste, s’adressa aux volontaires, dont la tâche consiste à « protéger la propriété et la liberté du travail », tantôt par le remplacement des grévistes et tantôt par la destruction de leurs organisations.

En France, le journal semi-officiel Le Temps, inspiré par la clique Millerand, mène une propagande énergique en faveur du développement des « ligues civi- 
ques » déjà existantes et de l'implantation des méthodes fascistes sur le sol français.

Les organisations de briseurs de grèves et d'assassins qui ont de tout temps complété le régime de liberté américaine ont eu un organe dirigeant sous la forme de la Légion Américaine qui subsiste après la guerre.

La bourgeoisie qui compte sur sa force et qui se vante de sa solidité sait parfaitement, dans la personne de ses gouvernants, qu'elle n'obtient ainsi qu'un moment de répit et que dans les conditions actuelles toute grande grève a tendance à se transformer en guerre civile et en lutte immédiate pour le pouvoir.

Dans la lutte du prolétariat contre l'offensive du capital, c'est le devoir des communistes non seulement de prendre les premières places et d'instruire les combattants à comprendre les buts essentiels à réaliser par la révolution, mais encore de s’appuyer sur les éléments les meilleurs et les plus actifs dans les entreprises et les syndicats pour créer leur propre troupe ouvrière et leurs propres organisations de combat pour opposer résistance aux fascistes et faire perdre à la jeunesse dorée de la bourgeoisie l’habitude d’insulter les grévistes.

En raison de l'importance exceptionnelle des troupes d'attaque contrerévolutionnaires, le parti communiste, les noyaux communistes dans les syndicats, doivent attacher la plus grande attention à la question du service de liaison et d'instruction, de la surveillance constante à exercer sur les organes de lutte, sur les forces des gardes-blancs, ses Etats-majors, ses dépôts d'armes, la liaison de ses cadres avec la police, avec la presse et les partis politiques, et de la préparation préalable de toutes les particularités nécessaires pour la défense et pour la contre-attaque.

Le parti communiste doit de cette façon inculquer aux plus larges couches du prolétariat, par le fait et par la parole, l’idée que tout conflit économique ou politique peut, en cas d'un concours favorable de circonstances, se transformer en guerre civile, au cours de laquelle ce sera la tâche du prolétariat de s’emparer du pouvoir politique.

Le Parti Communiste, en présence des actes de terreur blanche et de la rage de l'ignoble caricature de justice des bancs, doit maintenir constamment dans le prolétariat cette idée qu'il ne doit pas, au moment du soulèvement, se laisser tromper par les appels de l'adversaire à la douceur, mais, au contraire, par des actes de 
juridiction populaire organisée, fournir une expression à la justice prolétarienne et régler ses comptes avec les bourreaux de sa classe. Mais dans les moments où le prolétariat n'est encore qu'au début de la tâche, quand il s'agit encore de le mobiliser par l'agitation, par les campagnes politiques, par les grèves, l'usage des armes et les actes de sabotage ne sont utiles que lorsqu'ils servent à empêcher des transports de troupes contre les masses prolétariennes combattantes ou à arracher à l'adversaire une position importante dans la lutte directe. Des actes de terrorisme individuel, quoiqu'ils doivent être grandement appréciés comme preuve, comme symptôme de l'effervescence révolutionnaire et si défendables qu'ils soient en regard de la loi de lynch de la bourgeoisie et de ses laquais socialdémocrates, ne sont cependant susceptibles en aucune façon d'élever le degré d'organisation et les dispositions combatives du prolétariat, car ils éveillent dans les masses l'illusion que des actes héroïques isolés peuvent suppléer à la lutte révolutionnaire du prolétariat.

\section{IX. - L'ATTITUDE À L'ÉGARD DES COUCHES MOYENNES ET DU PROLÉTARIAT}

En Europe Occidentale, il n'y a aucune autre grande classe qui, en dehors du prolétariat, puisse être un facteur déterminant de la révolution mondiale, comme ce fut le cas en Russie, où la classe paysanne était destinée d'avance, grâce à la guerre et au manque de terre, à être un facteur décisif dans le combat révolutionnaire, à côté de la classe ouvrière.

Mais en Europe Occidentale il y a des parties des paysans, de grandes fractions de la petite bourgeoisie urbaine, une large couche de ce nouveau Tiers-Etat, comprenant les employés, etc... qui sont placées dans des conditions d'existence de plus en plus intolérables. Sous la pression du renchérissement de la vie, de la crise du logement, de l'incertitude de leur situation, ces masses entrent dans une fermentation qui les fait sortir de leur inactivité politique et les entraîne dans le combat entre la révolution et la contre-révolution. La banqueroute de d'impérialisme dans les Etats vaincus, la banqueroute du pacifisme et des tendances social-réformistes dans le camp de la contre-révolution déclarée dans les pays 
victorieux, poussent une partie de ces couches moyennes dans celui de la révolution. Le Parti Communiste doit accorder à ces couches son attention de tous les instants.

Conquérir le petit paysan aux idées du communisme, conquérir et organiser l'ouvrier agricole, voilà une des conditions préalables les plus essentielles pour la victoire de la dictature prolétarienne, car elle permet de transporter la révolution des centres industriels dans les campagnes et crée pour elle les points d'appui les plus importants pour résoudre la question du ravitaillement, qui est la question vitale de la révolution.

La conquête de cercles assez vastes d'employés du commerce et de l'industrie, de fonctionnaires inférieurs et moyens et d'intellectuels faciliterait à la dictature du prolétariat, pendant l'époque de transition entre le capitalisme et le communisme, la solution des questions de technique, et d'organisation de l'industrie, d'administration économique et politique. Elle porterait le désarroi dans les rangs de l'ennemi et ferait cesser l'isolement du prolétariat dans l'opinion publique.

Les Partis communistes doivent surveiller de la manière la plus attentive la fermentation des couches petites-bourgeoises; ils doivent utiliser ces couches de la manière la plus appropriée, même si elles ne sont pas encore affranchies des illusions petites-bourgeoises. Ils doivent incorporer les fractions des intellectuels et des employés, affranchis de ces illusions, au front prolétarien et les faire servir à l'entraînement de masses petites-bourgeoises en fermentation.

La ruine économique et l'ébranlement des finances publiques qui en est résulté contraignent la bourgeoisie elle-même à livrer la base de son propre appareil gouvernemental, les fonctionnaires inférieurs et moyens, à une paupérisation croissante. Les mouvements économiques qui se produisent dans ces couches, atteignent directement la charpente de l'Etat bourgeois et même si celui-ci est raffermi chaque fois pour un temps, il lui sera non moins impossible d'assurer l'existence matérielle du prolétariat tout en maintenant son système d'exploitation. En prenant la défense des besoins économiques des fonctionnaires moyens et inférieurs avec toute leur force d'action et sans égards pour l'état des finances publiques, les partis communistes accomplissent le travail préliminaire 
efficace pour la destruction des institutions gouvernementales bourgeoises et préparent les éléments de l'édifice gouvernemental prolétarien.

\section{X. - LA COORDINATION INTERNATIONALE DE L'ACTION}

Pour que toutes les forces de l'Internationale Communiste puissent être mises en œuvre afin de rompre le front de la contre-révolution internationale, pour hâter la victoire de la révolution, il faut s'efforcer avec la dernière énergie de donner à la lutte révolutionnaire une direction internationale unique.

L'Internationale Communiste impose à tous les Partis Communistes le devoir de se prêter réciproquement au combat l'appui le plus énergique. Les luttes économiques qui se développent exigent partout où cela est possible, l'intervention du prolétariat des autres pays. Les communistes doivent agir dans les syndicats pour que ces derniers empêchent par tous les moyens non seulement l'introduction de briseurs de grèves, mais aussi boycottent l'exportation pour les pays dans lesquels une partie importante du prolétariat est en lutte. Dans les cas où les gouvernants capitalistes d'un pays prennent des mesures de violence contre un autre pays pour le piller ou le subjuguer, c'est le devoir des Partis Communistes de ne point se contenter de protestations, mais de faire tout pour empêcher l'expédition de brigandage de leur gouvernement.

Le $3^{\mathrm{e}}$ Congrès de l'Internationale Communiste félicite les Communistes français de leurs manifestations, comme d'un commencement d'accentuation de leur action contre le rôle contre-révolutionnaire rapace du capital français. Il leur rappelle leur devoir de travailler de toutes leurs forces pour que les soldats français des pays occupés apprennent à comprendre leur rôle de bourreaux au service du capital français et à se soulever contre la mission honteuse qui leur est attribuée. C'est la tâche du Parti Communiste français de faire entrer dans la conscience du peuple français qu'en tolérant la formation d'une armée d'occupation française imbue d'esprit nationaliste, il nourrit son propre ennemi. Dans les régions occupées, des troupes sont exercées, qui ensuite seront prêtes à noyer dans le sang le mouvement révolutionnaire de la classe ouvrière française. La présence des troupes noires sur le sol de la France et des régions occupées impose au parti commu- 
niste français des tâches particulières. Cette présence donne au Parti français la possibilité d'atteindre ces esclaves coloniaux, de leur expliquer qu'ils servent leurs exploiteurs et leurs bourreaux et de les inciter à la lutte contre le régime des colonisateurs, et de se mettre par leur intermédiaire en rapports avec les populations des colonies françaises.

Le Parti Communiste allemand doit par son action faire comprendre au prolétariat allemand qu'aucune lutte n'est possible contre son exploitation par le capital de l'Entente sans renverser le gouvernement capitaliste allemand, qui, malgré ses criailleries contre l'Entente se constitue l'huissier et l'exécuteur du capital de l'Entente. Ce n'est qu'en prouvant par une lutte violente et sans réserves contre le gouvernement allemand, qu'il ne cherche pas une issue pour l'impérialisme allemand en banqueroute, mais qu'il s'applique à déblayer le terrain des ruines de l'impérialisme allemand, que le V.K.P.D. sera en état d'augmenter dans les masses prolétariennes de France la volonté de lutte contre l’impérialisme français.

L'Internationale Communiste, qui a dénoncé au prolétariat international les prétentions du capital de l'Entente aux réparations de guerre comme une campagne de pillage contre les masses laborieuses des pays vaincus, qui flétrit les tentatives des longuettistes et des Indépendants allemands pour donner une certaine forme à ce pillage qui est pour le moins très douloureux pour les masses ouvrières, qui les flétrit comme une lâche capitulation devant les requins de la Bourse de l'Entente, l'Internationale Communiste montre en même temps au prolétariat français et allemand la seule voie menant à la reconstruction des régions détruites, à l'indemnisation des veuves et des orphelins, en invitant les prolétaires des deux pays à la lutte commune contre leurs exploiteurs.

La classe ouvrière allemande ne peut aider le prolétariat russe dans sa lutte difficile que si par sa lutte victorieuse elle hâte l'union de la Russie agricole avec l'Allemagne industrielle.

C'est le devoir des Partis Communistes de tous les pays dont les troupes participent à l'asservissement et au dépècement de la Turquie de mettre en œuvre tous les moyens pour révolutionner ces troupes.

Les Partis Communistes des pays balkaniques ont le devoir de tendre toutes les forces des masses qu'ils encadrent pour maîtriser le nationalisme par la création d'une confédération balkanique communiste, de ne rien omettre pour rappro- 
cher le moment de leur victoire. Le triomphe des Partis Communistes en Bulgarie et en Serbie, qui amènera la chute de l'ignoble régime de Horty et la liquidation de la féodalité des boyars roumains étendra dans la plupart des pays voisins développés la base agricole nécessaire à la révolution italienne.

Soutenir sans réserves la Russie des Soviets demeure comme précédemment le devoir dominant des communistes de tous les pays. Ils ne doivent pas seulement s'élever de la manière la plus énergique contre toute attaque contre la Russie Soviétique ; ils doivent encore s'employer avec toute leur énergie à supprimer les obstacles que les Etats capitalistes mettent au rapports de la Russie Soviétique avec le marché mondial et avec tous les peuples. Il faut que la Russie Soviétique réussisse à rétablir sa situation économique, et atténuer l'immense misère causée par trois ans de guerre impérialiste et trois ans de guerre civile, il faut qu'elle réussisse à relever la capacité de travail de ses masses populaires, pour qu'elle soit en état d'aider à l'avenir les Etats prolétariens victorieux de l'Occident en leur fournissant des vivres et des matières premières et de les protéger contre l'étranglement par le capital américain.

Ce n'est pas seulement en des manifestations à l'occasion d'événements particuliers, mais en un perfectionnement de la liaison Internationale entre les communistes dans leur lutte commune constante sur un front ininterrompu que consiste le rôle en politique universelle de l'Internationale Communiste. Sur quel secteur de ce front aura lieu la percée victorieuse du prolétariat ? Sera-ce dans l'Allemagne capitaliste avec son prolétariat soumis à une oppression extrême de la bourgeoisie allemande et ententiste et placé devant l'alternative de mourir ou de vaincre, serace dans les pays agricoles du sud-est, ou bien en Italie, où la démolition de la bourgeoisie est si avancée ? Cela ne peut être dit à l'avance. C’est le devoir de l'Internationale Communiste d'intensifier à l'extrême l'effort sur tous les secteurs du front mondial du prolétariat et c'est le devoir des Partis Communistes de tout faire pour appuyer les luttes décisives de chaque section de l'internationale Communiste de tous les moyens à leur disposition. Cette liaison doit se marquer avant tout en ceci que lorsqu'une grande crise commence dans un pays, dans les autres, les Parti Communistes s'efforcent d'aiguiser et de faire déborder tous les conflits intérieurs. 


\section{XI. - L'ÉCROULEMENT DES INTERNATIONALES 2 ET 2 1/2}

La troisième année d'existence de l'Internationale Communiste a été témoin d'une chute plus complète des Partis Social-démocrates et des leaders syndicaux réformistes, qui ont été démasqués et mis à nu.

Mais cette année a vu aussi leur tentative pour se grouper en une organisation et pour prendre l'offensive contre l'Internationale Communiste.

En Angleterre des chefs du Labour Party et des trade-unions ont montré pendant la grève des mineurs que leur but ne consiste en rien d'autre qu'à bouleverser consciemment le front prolétarien en formation et à défendre consciemment les capitalistes contre les ouvriers. L’écroulement de la Triple-Alliance fournit la preuve que les leaders syndicaux réformistes ne sont même pas disposés à lutter pour l'amélioration du sort du prolétariat dans le cadre du capitalisme.

En Allemagne le Parti social-démocrate, sorti du gouvernement, a prouvé qu'il est incapable de mener même une opposition de propagande, telle que l'avait faite l'ancienne social-démocratie d'avant la guerre. A chaque geste d'opposition, ce Parti était préoccupé uniquement de ne déchaîner aucun combat de la classe ouvrière. Bien que se trouvant soi-disant dans d'opposition dans le Reich, le Parti social-démocrate a organisé en Prusse l'expédition des gardes-blancs contre les mineurs de l'Allemagne centrale, afin de les provoquer à la lutte armée, ainsi qu'il l'a avoué lui-même, avant que les rangs communistes fussent en ordre pour le combat. Devant la capitulation de la bourgeoisie allemande devant l'Entente, devant ce fait évident que cette bourgeoisie ne saurait exécuter les conditions dictées par l'Entente qu'en rendant l'existence du prolétariat allemand complètement intolérable, la social-démocratie allemande est rentrée dans le gouvernement pour aider la bourgeoisie à transformer le prolétariat allemand en troupeau d’ilotes.

En Tchécoslovaquie, la social-démocratie mobilise l'armée et la police pour arracher aux ouvriers communistes la possession de leurs maisons et de leurs institutions. 
Le Parti Socialiste Polonais aide, par sa tactique mensongère, Pilsudski à organiser son expédition de brigandage contre la Russie Soviétique. Il aide son gouvernement à jeter dans les prisons des milliers de communistes en cherchant à les chasser des syndicats, où malgré toutes les persécutions ils réunissent autour d'eux des masses de plus en plus grandes.

Les social-démocrates belges restent dans un gouvernement qui prend part à la réduction complète en esclavage du peuple allemand.

Les partis et les groupes centristes de l'Internationale 2 1/2 ne se montrent pas moins hideux que les partis de la contre-révolution.

Les Indépendants d'Allemagne repoussent brutalement l'invitation du Parti Communiste à mener en commun la lutte contre l'aggravation du sort de la classe ouvrière, malgré les divergences de principe. Au cours des journées de mars, ils ont pris délibérément le parti du gouvernement des gardes-blancs contre les ouvriers de l’Allemagne centrale pour ensuite, après avoir aidé à la victoire de la terreur blanche, après avoir dénoncé à l’opinion publique bourgeoise les rangs avancés du prolétariat comme un prolétariat de voleurs et de brigands, se lamenter hypocritement sur cette même terreur blanche. Quoique ayant pris l'engagement au Congrès de Halle de soutenir la Russie Soviétique, les Indépendants mènent dans leur presse une campagne de calomnies contre la République des Soviets de Russie. Ils entrent dans les rangs de toute la contre-révolution russe avec Wrangel, Milioukov et Bourtsev, en soutenant le soulèvement de Cronstadt contre la République des Soviets, soulèvement qui manifeste les débuts d'une nouvelle tactique de la contre-révolution internationale à l'égard de la Russie Soviétique : renverser le parti communiste de Russie, l'âme, le cœur, la colonne vertébrale et le système nerveux de la République Soviétique, pour tuer cette dernière et n’avoir plus ensuite qu’à balayer son cadavre.

Aux côtés des Indépendants allemands, les Longuettistes français s’associent à cette campagne et se rallient ainsi publiquement à la contre-révolution française, qui, comme on le sait, a inauguré cette nouvelle tactique à l'égard de la Russie.

En Italie, la politique des groupes du centre, de Serrati et d'Aragona, la politique de recul devant toute lutte a rempli la bourgeoisie d'un nouveau courage et lui a donné la possibilité, au moyen des bandes blanches des fascistes, de dominer toute la vie de l'Italie. 
Quoique les partis du centre et de la social-démocratie ne diffèrent entre eux que par des phrases, l'union des deux groupes en une Internationale unique n'est pas encore réalisée pour le moment.

Les partis centristes se sont unis en février en une association internationale séparée avec une plate-forme politique et des statuts spéciaux. Cette Internationale $2 \frac{1}{2} 2$ essaie d'osciller sur le papier entre les deux mots d'ordre de la démocratie et de la dictature du prolétariat. En pratique, elle n'aide pas seulement la classe capitaliste dans chaque pays en cultivant l'esprit d'indécision dans la classe ouvrière, mais encore et même en présence des ruines accumulées par la bourgeoisie internationale, en présence de la soumission d'une partie du monde à la volonté des Etats capitalistes victorieux de l'Entente, elle offre ses conseils à la bourgeoisie pour réaliser son plan de pillage sans déchaîner les forces révolutionnaires des masses populaires. L'Internationale $2 \frac{1}{2} 2$ se distingue de la $2^{\mathrm{e}}$ Internationale uniquement en ce qu'elle joint, à la peur commune de la puissance du capital qui unit les réformistes avec les centristes, la peur de perdre, en formulant clairement son point de vue, ce qui lui reste d'influence sur les masses encore indécises, mais de sentiment révolutionnaire. L’identité politique essentielle des réformistes et des centristes trouve son expression dans la défense qu'ils font en commun de l'Internationale Syndicale d'Amsterdam, ce dernier bastion de la bourgeoisie mondiale. En s'unissant, partout où ils possèdent de l'influence sur les syndicats, aux réformistes et à la bureaucratie syndicale pour combattre les communistes, en répondant aux tentatives pour révolutionner les syndicats, par l'exclusion des communistes et par la scission des syndicats, les centristes prouvent que, tout comme les social-démocrates, ils sont les adversaires décidés de la lutte du prolétariat et les aides de la contre-révolution.

L'Internationale Communiste doit, comme elle l'a fait jusqu'à présent, mener la lutte la plus décidée, non seulement contre la $2^{\mathrm{e}}$ Internationale et contre l'Internationale Syndicale d'Amsterdam, mais aussi contre l'Internationale 2 1/2. Ce n'est que par cette lutte sans merci que l'Internationale Communiste peut enlever à la social-démocraties et aux centristes leur influence sur la classe ouvrière ; ces agents de la bourgeoisie, loin d'avoir la moindre intention de lutter pour vaincre le capitalisme, n’ont pas même celle de lutter pour les plus besoins les plus simples et les plus immédiats de la classe ouvrière. 
Pour mener cette lutte jusqu'à la victoire, elle doit étouffer dans le germe toute tendance et tout accès centriste dans ses propres rangs et prouver par son action quotidienne qu'elle est l'Internationale de l'action communiste et non de la phrase et de la théorie communistes. L'Internationale Communiste est la seule organisation du prolétariat international susceptible, de par ses principes, de diriger la lutte contre le capitalisme. Elle doit si bien fortifier sa cohésion intérieure, sa direction internationale, son action, qu'elle puisse atteindre les buts qu'elle s'est proposée dans ses statuts : "Organisation d'actions communes des prolétaires des différents pays qui poursuivent le but commun : renversement du capitalisme, établissement de la dictature du prolétariat et d'une République Soviétique Internationale ». 
Manifestes, thèses et résolutions

des quatre premiers congrès

de l'Internationale communiste 1919-1923

(juin 1934)

Troisième Congrès, juin 1921.

- 3 -

\section{Résolution sur le rapport du Comité Exécutif}

$\underline{\text { Retour à la table des matières }}$

Le Congrès prend avec satisfaction connaissance du rapport du Comité Exécutif et constate que la politique et l'activité du Comité Exécutif pendant l'année écoulée avaient pour objet la réalisation des décisions du $2^{\mathrm{e}}$ Congrès. Le Congrès approuve en particulier l'application par le Comité Exécutif aux différents pays des 21 conditions formulées par le $2^{\mathrm{e}}$ Congrès. Il approuve également l'activité du Comité Exécutif dans le but de favoriser la formation de grands partis communistes des masses et la lutte décidée contre les tendances opportunistes qui s'étaient manifestées dans ces partis.

1. En Italie, l'attitude prise par le groupe de chefs autour de Serrati immédiatement après le $2^{\mathrm{e}}$ Congrès mondial montra qu'il n'avait pas sérieusement la volonté de réaliser les décisions du Congrès mondial et de l’Internationale Communiste. Mais c'est surtout le rôle joué par ce groupe de chefs lors des luttes de septembre, son attitude à Livourne et plus encore la politique qu'il a suivie depuis, qui ont démontré clairement qu'ils voulaient se servir du communisme comme d'une enseigne cachant leur politique opportuniste. Dans ces conditions, la scission est inévitable. Le Congrès approuve l'intervention décidée et ferme de 
l'Exécutif dans ce cas, qui a pour l'Internationale Communiste une portée de principe. Il approuve la décision du Comité Exécutif qui alors a immédiatement reconnu le parti communiste d'Italie comme seule section communiste de ce pays.

Confirmant les décisions en vertu desquelles le Parti socialiste italien a adhéré à la $3^{\mathrm{e}}$ Internationale, dont il a accepté sans réserve les principes fondamentaux, le $18^{\mathrm{e}}$ Congrès proteste contre l'exclusion de ce parti de l'Internationale Communiste - exclusion qui lui a été notifiée par le représentant de l'Exécutif, à la suite de divergences de vues dans l'appréciation de questions locales et de détails qu'on pouvait et qu'on devait aplanir au moyen d'explications amicales et d'une entente fraternelle.

Confirmant on adhésion pleine et entière à la 3e Internationale, il déclare s’en remettre au prochain Congrès de celle-ci pour solutionner le conflit et s'engage d’ores et déjà à se soumettre à sa décision et à l'appliquer.

Après la sortie des communistes du Congrès de Livourne, le Congrès a adopté la résolution suivante, présentée par Bentivoglio :

Le $3^{\mathrm{e}}$ Congrès mondial de l'Internationale Communiste est persuadé que cette résolution est imposée aux groupes des chefs Serrati par les ouvriers révolutionnaires. Le Congrès attend que les éléments révolutionnaires et prolétariens fassent tout leur possible après les décisions du $3^{\mathrm{e}}$ Congrès mondial pour mettre en exécution ces décisions.

Le Congrès mondial en réponse à l’appel du Congrès de Livourne déclare catégoriquement :

Aussi longtemps que le P.S.I. n’aura pas exclu ceux qui ont participé à la conférence de Reggio Emilia et ceux qui les soutiennent, le Parti socialiste italien ne peut appartenir à l’Internationale Communiste.

Si cette condition préalable - condition qui est un ultimatum - est remplie, le Congrès mondial charge le Comité Exécutif d'entreprendre les démarches utiles pour unir le P.S.I. purifié des éléments réformistes et le P.C.I. en une section unifiée de l’Internationale Communiste.

2. En Allemagne, le Congrès du Parti socialiste indépendant tenu à Halle a été la suite des décisions du $2^{\mathrm{e}}$ Congrès mondial qui ont dressé le bilan de l'évolution du mouvement ouvrier. L’intervention de l'Exécutif tendait à la formation forte 
d'un parti communiste en Allemagne et l'expérience a montré que cette politique était juste.

Le Congrès approuve entièrement l'attitude de l'Exécutif dans les événements ultérieurs qui s'étaient déroulés au sein du Parti communiste unifié d'Allemagne. Le Congrès attend du Comité Exécutif qu'il applique aussi à l'avenir les principes de la discipline révolutionnaire internationale.

3. L'admission du Parti communiste ouvrier d'Allemagne, en qualité de parti sympathisant de l'Internationale Communiste, avait pour but d'assurer par cette épreuve si ce parti se développerait dans le sens de l'Internationale Communiste. La période écoulée est suffisamment concluante à cet égard. Il est temps de demander au P.C.O. d'Allemagne l'affiliation, dans un délai déterminé, au parti communiste, ou bien, dans le cas contraire, de décider son exclusion de l'Internationale Communiste en tant que parti sympathisant.

4. Le Congrès approuve la façon dont le Comité Exécutif a appliqué les 21 conditions au Parti français, ce qui a permis de soustraire de grandes masses ouvrières se trouvant en marche vers le communisme, à l'influence des opportunistes longuettistes et des centristes et d'accélérer cette évolution. Le Congrès attend de l'Exécutif qu'il contribue aussi à l'avenir au développement du Parti afin de fortifier la clarté de ses principes et sa force combative.

5. En Tchécoslovaquie, le Comité Exécutif a suivi avec patience, et en tenant compte de toute la situation, le développement révolutionnaire d'un prolétariat qui a déjà fourni des preuves de sa volonté et de sa faculté de combattre. Le Congrès approuve la résolution du Comité Exécutif. Qu'il veille à l'application intégrale, également au Parti tchécoslovaque, des 21 conditions et qu'il s'emploie à la formation dans un bref délai d'un parti communiste ferme. Il est nécessaire de réaliser le plus rapidement possible la lutte systématique pour la conquête des syndicats et pour leur unification internationale.

Le Congrès approuve l'activité de l'Exécutif dans le Proche et l'ExtrêmeOrient et salue le début de la propagande énergique de l’Exécutif dans ces pays. Le Congrès estime qu'il est nécessaire d'y intensifier également le travail d'organisation.

Enfin, le Congrès repousse les arguments opposés par des adversaires ouverts ou masqués du communisme contre une forte centralisation internationale du 
mouvement communiste. Il est au contraire d'avis que les partis communistes, indissolublement liés, ont besoin d'une direction politique centrale douée de plus d'initiative et d'énergie encore, ce qui peut être assuré par l'envoi au Comité Exécutif de leurs meilleures forces. Ainsi, par exemple, l'intervention de l'Exécutif dans la question des chômeurs et des réparations n’a été ni assez rapide, ni assez efficace. Le Congrès attend que l'Exécutif, soutenu par une collaboration renforcée des partis affiliés, améliore le système de liaison avec les partis. La participation renforcée des délégués des partis à l’Exécutif lui permettra mieux de remplir encore que jusqu'ici les tâches croissantes qui lui incombent. 
Manifestes, thèses et résolutions

des quatre premiers congrès

de l'Internationale communiste 1919-1923

(juin 1934)

Troisième Congrès, juin 1921.

-4 -

\section{Thèses sur la structure, les méthodes et l'action des partis communistes}

\section{I. - - GÉNÉRALITÉS}

\section{$\underline{\text { Retour à la table des matières }}$}

1. L'organisation du Parti doit être adaptée aux conditions et aux buts de son activité. Le Parti communiste doit être l'avant-garde, l'armée dirigeante du prolétariat pendant toutes les phases de sa lutte de classes révolutionnaire, et pendant la période de transition ultérieure vers la réalisation du socialisme, ce premier degré de la société communiste.

2. Il ne peut pas y avoir une forme d'organisation immuable et absolument convenable pour les partis communistes. Les conditions de la lutte prolétarienne se transforment sans cesse et, conformément à ces transformations, les organisations d'avant-garde du prolétariat doivent aussi chercher constamment les nouvelles formes convenables. Les particularités historiques de chaque pays déterminent aussi des formes spéciales d'organisation pour les différents partis.

Mais ces différenciations ont une certaine limite. La similitude des conditions de la lutte prolétarienne dans les différents pays et dans les différentes phases de 
la révolution prolétarienne constitue, malgré toutes les particularités existantes, un fait d'une importance essentielle pour le mouvement communiste. C'est cette similitude qui donne la base commune de l'organisation des partis communistes de tous les pays.

C’est sur cette base qu'il faut développer l'organisation des partis communistes et non tendre à la fondation de quelque nouveau parti modèle à la place de celui qui existe déjà ou chercher une forme d'organisation absolument correcte ou des statuts idéaux.

3. La plupart des partis communistes ainsi que l'Internationale Communiste, comme ensemble du prolétariat révolutionnaire du monde entier, ont ceci de commun dans les conditions de leur lutte qu'ils doivent lutter contre la bourgeoisie encore régnante. La victoire sur celle-ci, la conquête du pouvoir arraché à la bourgeoisie, constitue pour ces partis et pour cette Internationale le but principal déterminant.

L'essentiel donc, pour tout le travail d'organisation des Partis Communistes dans les pays capitalistes, est donc d'édifier une organisation qui rende possible la victoire de la révolution prolétarienne sur les classes possédantes et qui l'affermisse.

4. Dans les actions communes il est indispensable pour le succès d'avoir une direction ; celle-ci est nécessaire surtout en vue des grands combats de l'histoire mondiale. L'organisation de partis communistes, c'est l'organisation de la direction communiste dans la révolution prolétarienne.

Pour bien guider les masses, le Parti a besoin lui-même d'une bonne direction. La tâche essentielle d'organisation qui s'impose à nous est donc la suivante : formation, organisation et éducation d'un Parti communiste pur et réellement dirigeant pour guider véritablement le mouvement révolutionnaire prolétarien.

5. La direction de la lutte sociale révolutionnaire suppose chez les Partis communistes et dans leurs organes dirigeants la combinaison organique de la plus 
grande puissance d'attaque et de la plus parfaite adaptation aux conditions changeantes de la lutte.

Une bonne direction suppose en outre de la manière la plus absolue la liaison la plus étroite avec les masses prolétariennes. Sans cette liaison, le Comité directeur ne guidera jamais les masses, il ne pourra dans le meilleur cas que les suivre.

Ces relations organiques doivent être obtenues dans les organisations du Parti communiste au moyen de la centralisation démocratique.

\section{II. - LA CENTRALISATION DÉMOCRATIQUE}

6. La centralisation démocratique dans l'organisation du Parti communiste doit être une véritable synthèse, une fusion de la centralisation et de la démocratie prolétarienne. Cette fusion ne peut être obtenue que par une activité permanente commune, par une lutte également commune et permanente de l'ensemble du Parti.

La centralisation dans le Parti communiste ne doit pas être formelle et mécanique ; ce doit être une centralisation de l'activité communiste, c'est-à-dire la formation d'une direction puissante, prête à l'attaque et en même temps capable d'adaptation.

Une centralisation formelle ou mécanique ne serait que la centralisation du « pouvoir » entre les mains d'une bureaucratie en vue de dominer les autres membres du parti ou les masses du prolétariat révolutionnaire extérieures au parti. Mais seuls les ennemis du communisme peuvent prétendre que, par ces fonctions de direction de la lutte prolétarienne et par la centralisation de cette direction communiste, le Parti communiste veut dominer le prolétariat révolutionnaire. C'est là un mensonge et, de plus, à l'intérieur du Parti, la lutte pour la domination ou un antagonisme d'autorités est incompatible avec les principes adaptés par l’Internationale Communiste relativement à la centralisation démocratique.

Dans les organisations du vieux mouvement ouvrier non révolutionnaire se développa un dualisme de même nature que dans l'organisation de l'Etat bourgeois. Nous voulons parler du dualisme entre la bureaucratie et le «peuple». Sous l'influence desséchante de l'atmosphère bourgeoise, les fonctions s'isolèrent 
en quelque sorte et la communauté du travail fut remplacée per une démocratie purement formelle, et l'organisation elle-même se divisa en fonctionnaires actifs et en une masse passive. Le mouvement ouvrier révolutionnaire hérite jusqu'à un certain point inévitablement du milieu bourgeois cette tendance du formalisme et du dualisme.

Le Parti Communiste doit surmonter radicalement ces antagonismes par un travail systématique, politique et d'organisation et par des améliorations et des révisions répétées.

7. Un grand Parti socialiste en se transformant en Parti communiste ne doit pas se borner à concentrer dans sa direction centrale la fonction d'autorité en laissant subsister pour le reste l'ancien ordre des choses. Si la centralisation ne doit pas rester lettre morte, mais devenir un fait réel, il faut que sa réalisation s'accomplisse de sorte qu'elle soit pour les membres du Parti un renforcement et un développement, réellement justifiés, de leur activité et de leur combativité commune. Autrement, elle apparaîtrait aux masses comme une simple bureaucratisation du Parti et provoquerait ainsi une opposition contre toute centralisation, toute direction et toute discipline stricte. L'anarchisme est antipode du bureaucratisme.

Une démocratie purement formelle dans le parti ne peut écarter ni les tendances bureaucratiques, ni les tendances anarchiques, car c'est précisément sur la base de cette démocratie que l'anarchie et le bureaucratisme, dans le mouvement ouvrier, ont pu se développer. Pour cette raison, la centralisation, c'est-à-dire l'effort pour obtenir une direction forte ne peut avoir de succès si on essaie de l'obtenir sur le terrain de la démocratie formelle. Il est donc indispensable avant tout de développer et de maintenir le contact vivant et des rapports mutuels aussi bien au sein du Parti, entre les organes dirigeants et les membres, qu'entre le Parti et les masses du prolétariat qui ne lui appartiennent pas. 


\section{III. - LE DEVOIR DE TRAVAIL DES COMMUNISTES}

8. Le Parti Communiste doit être une école de travail du marxisme révolutionnaire. C'est par le travail quotidien commun dans les organisations du Parti que se resserrent les liens entre les différents groupements et entre les différents membres.

Dans les Partis communistes légaux il manque encore aujourd'hui la participation régulière de la plupart de membres au travail politique quotidien. C'est leur plus grand défaut et la cause d’une incertitude perpétuelle de leur développement.

9. Le danger qui menace toujours un Parti ouvrier qui fait ses premiers pas vers la transformation communiste est de se contenter de l'acceptation d'un programme communiste, de remplacer dans sa propagande sa doctrine précédente par celle du communisme et de substituer seulement aux fonctionnaires hostiles à cette doctrine, des communistes. Mais l'adoption d'un programme communiste n’est qu'une manifestation de la volonté de devenir communiste. S’il ne s’y ajoute point d'actions communistes et si, dans l'organisation du travail politique, la passivité de la masse des membres est maintenue, le Parti n’accomplit pas la moindre partie de ce qu'il a promis au prolétariat par l'acceptation du programme communiste. Car la première condition d'une sérieuse réalisation de ce programme, c'est l'entraînement de tous les membres au travail quotidien permanent.

L'art de l'organisation communiste consiste à utiliser tout et tous pour la lutte prolétarienne des classes, à répartir rationnellement parmi tous les membres du Parti le travail politique et à entraîner par leur intermédiaire de plus grandes masses du prolétariat dans le mouvement révolutionnaire, à maintenir fermement dans ses mains la direction de l'ensemble du mouvement, non pas par la force du pouvoir, mais par la force de l'autorité, c’est-à-dire celle de l'énergie, de l'expérience, de la capacité et de la tolérance. 
10. Tout Parti communiste doit donc, dans ses efforts pour n'avoir que des membres véritablement actifs, exiger de chacun de ceux qui figurent dans ses rangs qu'il mette à la disposition de son parti sa force et son temps dans la mesure où il peut en disposer dans les circonstances données et de consacrer toujours au parti le meilleur de soi. Pour être membre du Parti Communiste, il faut d'une façon générale, avec la conviction communiste, cela va sans dire, accomplir aussi les formalités de l'inscription tout d'abord éventuellement comme candidat, ensuite comme membre. Il faut payer régulièrement les cotisations établies, l'abonnement au journal du Parti, etc... Mais le plus important, c'est la participation de chaque membre au travail politique quotidien.

11. Tout membre du Parti doit d’une façon générale, en vue du travail politique quotidien, être incorporé dans un petit groupe de travail : dans un comité, une commission, un bureau, un collège, une fraction ou un noyau. Ce n'est que de cette manière que le travail politique peut être réparti, dirigé et accompli régulièrement.

Il va sans dire qu’il faut aussi prendre part aux réunions générales des membres des organisations locales. Il est mauvais, dans des conditions légales, de chercher à remplacer ces réunions périodiques par des représentations locales ; il faut au contraire que tous les membres soient obligés d'assister régulièrement à ces réunions. Mais cela n’est point du tout suffisant. La seule préparation régulière de ces réunions suppose un travail fait dans de petits groupes ou par les camarades spécialement désignés, de même que la préparation de l'utilisation efficace des réunions générales des ouvriers, manifestations et actions de masses du prolétariat. Les tâches multiples de cette activité ne peuvent être tentées et réalisées avec intensité que par de petits groupes. Sans ce travail, constant, quoique trivial, de l'ensemble des membres, réparti dans le grand nombre de petits groupes ouvriers, les efforts les plus zélés dans la lutte de classe du prolétariat ne peuvent que rendre vaines toutes tentatives pour influencer ces luttes; elles ne peuvent pas entraîner la concentration nécessaire de toutes les forces vivantes révolutionnaires en un Parti communiste uni et capable d'agir. 
12. Il faut fonder des noyaux communistes pour le travail quotidien dans différents domaines de l'activité politique du Parti pour l'agitation à domicile, pour les études du Parti, pour le service de la presse, pour la distribution de la littérature, pour le service des nouvelles, pour celui des liaisons, etc...

Les noyaux communistes sont des groupes pour le travail communiste quotidien dans les entreprises et dans les ateliers, dans les syndicats, dans les associations prolétariennes, dans les unités militaires, etc..., partout où il $\mathrm{y}$ a au moins quelques membres ou quelques candidats du Parti communiste. S'il y en a plusieurs dans la même entreprise ou dans le même syndicat, etc..., le noyau devient une fraction dont le travail est dirigé par le groupe du noyau.

S'il faut former tout d'abord une fraction plus vaste et d'opposition générale, ou s'il faut simplement prendre part à une telle organisation existant déjà, les communistes doivent s'efforcer d'en obtenir la direction par leur noyau.

La fondation d'un noyau communiste, sa transformation ou son action publique en qualité de communiste sont subordonnées à l'observation scrupuleuse et à l'analyse des dangers et des avantages que présente la situation particulière envisagée.

13. C'est une tâche particulièrement difficile pour un Parti de masses communiste que d'établir le devoir général de travail dans le Parti et l'organisation de ces petits groupes de travail. Et certes, on ne saurait accomplir cette tâche en une nuit, car elle exige une persévérance infatigable, une réflexion mûre et beaucoup d'énergie.

Ce qui est particulièrement important, c'est que cette réorganisation soit accomplie dès le début avec le plus grand soin et après mûre réflexion. Il serait trop facile de répartir dans chaque organisation tous les membres suivant un schéma formel en petits noyaux et d'inviter ces noyaux à agir dans la vie quotidienne du Parti. Un tel début serait pire que l'inaction. Il provoquerait aussitôt la méfiance et l'éloignement des membres du Parti contre cette importante transformation.

Il faut recommander que les dirigeants du parti élaborent d'abord après consultation approfondie avec des organisateurs assidus, les premières lignes directrices de cette transformation. Les organisateurs doivent être en même temps 
des communistes absolument convaincus et zélés et être exactement renseignés sur l'état du mouvement dans les différents centres principaux du pays. Après quoi les organisateurs ou les comités d'organisation, qui ont reçu les instructions nécessaires, doivent se mettre à préparer régulièrement le travail sur le lieu même, ils doivent choisir et désigner les chefs de groupes et prendre les premières mesures immédiates en vue de cette transformation. L'on doit ensuite poser des tâches tout à fait définies et concrètes devant les organisations, les groupes d'ouvriers, les noyaux et les différents membres, et l'on doit le faire de telle façon que ces tâches leur apparaissent utiles, désirables et pratiques. S'il est nécessaire on peut encore leur montrer par des exemples pratiques comment il faut s'y prendre pour exécuter les tâches. Et ce faisant, on doit surtout leur faire comprendre contre quelles erreurs ils doivent se garder tout spécialement.

14. Ce nouveau mode d'organisation il faut le réaliser pas à pas dans la vie. C'est pourquoi il ne faut pas fonder trop de nouveaux noyaux ou de groupes d'ouvriers dans les organisations locales. Il faut d'abord s'assurer, en se basant sur les résultats d'une courte pratique, que les noyaux formés dans différentes usines et ateliers importants fonctionnent régulièrement et que les groupes ouvriers indispensables soient créés dans les autres domaines de l'activité de parti et qu'ils se consolident à un certain degré (par exemple dans le service d'information, de liaison, dans l'agitation à domicile, le mouvement des femmes, la distribution d'écrits, le service de la presse, le mouvement des chômeurs, etc...). En tout cas on ne doit pas aveuglément détruire le châssis de l'ancienne organisation avant que la nouvelle ne se soit, pour ainsi dire, stabilisée.

Mais durant tout ce travail la tâche fondamentale du travail d'organisation communiste doit être partout poursuivie le plus énergiquement possible. Cela exige de grands efforts - non seulement de la part des organisations illégales. Jusqu'à ce qu'il y ait en réalité un large réseau de noyaux, de fractions et de groupes ouvriers à tous les points vitaux de la lutte de classe prolétarienne, jusqu’à ce que chaque membre du parti puissant et conscient de ses buts prenne part au travail quotidien révolutionnaire et que cet acte de participation devienne pour les membres une question d'habitude naturelle, jusqu'à ce moment-là, le parti ne doit se permettre aucun repos dans ses efforts en vue de l'exécution de cette tâche. 
15. Cette tâche fondamentale d'organisation oblige les organes dirigeants du parti à guider continuellement et à influencer systématiquement le travail du parti et à le faire d'une façon complète et sans intermédiaires. Il en résulte pour les camarades qui sont à la tête des organisations de parti l'obligation d'entreprendre les labeurs les plus divers. L'organe central dirigeant du parti communiste doit non seulement veiller à ce que tous les camarades en général soient occupés, mais il doit encore leur venir en aide, diriger leur travail selon un plan ordonné et en connaissance pratique de cause, en les orientant dans la bonne voie à travers toutes les conditions et circonstances spéciales. Dans sa propre activité le centre doit également tâcher de trouver les erreurs commises et, en se basant sur l'expérience acquise, toujours chercher à améliorer ses méthodes de travail, en ne perdant en même temps jamais de vue le but de la lutte.

16. Notre travail politique général c’est la lutte pratique ou théorique ou la préparation de cette lutte. La spécialisation de ce travail a été très défectueuse jusqu’à présent. Il y a des domaines très importants sur lesquels le Parti n’a guère fait jusqu’à présent que des efforts tout à fait accidentels, ainsi par exemple presque rien n’a été fait par les partis légaux dans la lutte spéciale contre la police politique. L’instruction des camarades du Parti ne s’accomplit en général que d'une manière tout à fait accidentelle et secondaire et cela d'une manière tellement superficielle que la plus grande partie des décisions les plus importantes du Parti, que même le programme et les résolutions de l'Internationale Communiste sont encore tout à fait inconnus des grandes couches des membres du Parti. Le travail d'instruction doit être ordonné et approfondi sans cesse par tout le système des organisations du Parti, tous les groupements de travail, afin d'obtenir par ces efforts systématiques, un degré toujours plus élevé de spécialisation.

17. La reddition des comptes est un devoir des plus indispensables pour les organisations communistes. Il s’impose aussi bien à toutes les organisations et à tous les organes du Parti, qu'à chaque membre individuellement. La reddition de comptes doit être accomplie régulièrement à de cours intervalles. Il faut à cette occasion, faire des rapports sur l'accomplissement des missions spéciales confiées 
par le Parti. Il importe d'accomplir ces redditions de comptes d'une façon tellement systématique qu'elle s'enracine dans le mouvement communiste comme une de ses meilleures traditions.

18. Le Parti doit faire régulièrement un rapport à la direction de l'Internationale Communiste. Les différentes organisations du parti doivent faire leur rapport au Comité immédiatement supérieur (par exemple, le rapport mensuel de l'organisation locale au Comité du Parti respectif).

Chaque noyau, fraction et groupe ouvrier doit faire un rapport à l'organe du Parti sous la direction effective duquel il se trouve. Les membres individuellement en font un, mettons hebdomadaire, au noyau ou au groupe de travail (et même à son chef hiérarchique) auquel il appartient relativement à l'accomplissement des missions spéciales dont il a été chargé par l'organe du Parti auquel il adresse le rapport.

Cette sorte de reddition de comptes doit avoir lieu, à la première occasion, oralement si le Parti ou le mandant n'exige pas un rapport écrit. Les rapports doivent être concis et contenir des faits. L'organe qui le reçoit porte la responsabilité de la conservation de ces communications qui ne sauraient être publiées sans danger. Il est également responsable de la communication des rapports importants à l’organe dirigeant du Parti et cela, sans aucune remise.

19. Il va sans dire que ces rapports du Parti ne doivent pas se borner à faire connaître ce que le rapporteur a fait, mais aussi contenir des communications au sujet des circonstances remarquées pendant son activité et qui peuvent être importantes pour notre lutte. Ils doivent mentionner particulièrement, les observations qui peuvent occasionner un changement ou une amélioration de notre tactique future. Il faut aussi y proposer les améliorations dont le besoin s'est fait sentir au cours de l’activité.

Dans tous les noyaux, fractions et groupes de travail communistes, les rapports reçus par ces organisations ou à faire par ceux-ci doivent devenir une habitude. 
Dans les noyaux et groupes de travail, on doit veiller à ce que les membres individuellement ou en groupes reçoivent régulièrement la mission spéciale d'observer et de rapporter ce qui se passe dans les organisations de l'adversaire et particulièrement dans les organisations ouvrières petites bourgeoises et des Partis « socialistes ».

\section{IV. - PROPAGANDE ET AGITATION}

20. Notre tâche la plus importante avant le soulèvement révolutionnaire déclaré, est la propagande pour l'agitation révolutionnaire. Cette activité et son organisation est menée souvent encore, pour la plus grande partie, à l'ancienne manière formaliste. Par des manifestations occasionnelles, par des réunions de masses et sans souci particulier du contenu révolutionnaire concret des discours et des écrits.

La propagande et l'agitation communiste doit avant tout prendre racine dans les milieux les plus profonds du prolétariat. Elle doit être engendrée par la vie concrète des ouvriers, par leurs intérêts communs particulièrement par leurs luttes et efforts.

Ce qui donne le plus de force à la propagande communiste est son contenu révolutionnairisant. A ce point de vue, il faut toujours considérer le plus attentivement possible les mots d'ordre et l'attitude à prendre à l'endroit des questions concrètes dans des situations diverses. Afin que le parti puisse toujours prendre une juste position, il faut donner un cours d'instruction prolongé et complet non seulement aux propagandistes et agitateurs de profession, mais encore à tous ses autres membres.

21. Les formes principales de propagande et d'agitation communistes sont: entretiens personnels verbaux, participation aux combats des mouvements ouvriers syndicaux et politiques, action par la presse et la littérature du parti. Chaque membre d'un Parti légal ou illégal doit d'une façon ou d'une autre prendre part régulièrement à cette activité. 
La propagande personnelle verbale doit être menée en premier lieu en guise d'agitation à domicile organisée systématiquement et confiée à des groupes institués spécialement dans ce but. Pas une seule maison, située dans la sphère d'influence de l'organisation locale du parti ne doit rester en dehors de cette agitation. Dans les villes plus importantes, une agitation de rue spécialement organisée au moyen de placards et de feuilles peut souvent avoir de bons résultats. En outre, dans les usines et les ateliers on doit organiser une agitation personnelle régulière, menée par les noyaux ou fractions de parti et accompagnée de distribution de littérature.

Dans les pays dont la population contient des minorités nationales, le devoir du Parti est d'accorder toute l'attention nécessaire à la propagande et à l'agitation dans les couches prolétariennes de ces minorités. L'agitation et la propagande devront naturellement être menées dans la langue des minorités nationales respectives ; il faudra dans ce but que le parti crée des organes appropriés.

22. Quand la propagande communiste se fait dans les pays capitalistes où la majorité du prolétariat n'a encore aucun penchant révolutionnaire conscient, il faut chercher des méthodes d'action toujours plus parfaites pour aller au-devant de la compréhension de l'ouvrier pas encore révolutionnaire mais commençant à le devenir, et pour lui ouvrir l'entrée dans le mouvement révolutionnaire. La propagande communiste doit se servir de ses principes dans les différentes situations pour soutenir l'esprit de l'ouvrier, pendant sa lutte intérieure contre les traditions et les tendances bourgeoises, mais qui sont pour lui un élément de progrès révolutionnaire.

En même temps la propagande communiste ne doit pas se borner aux demandes ou espérances des masses prolétaires telles qu'elles sont aujourd'hui, c'est-àdire restreintes et indécises. Les germes révolutionnaires de ces demandes et espérances ne forment que le point de départ qui nous est nécessaire pour les influencer. Car c'est seulement dans cette combinaison qu'on peut expliquer au prolétariat d'une façon plus compréhensible le communisme.

23. Il faut mener l'agitation communiste parmi les masses prolétariennes de telle manière que les prolétaires militants reconnaissent notre organisation com- 
muniste comme celle qui doit diriger loyalement et courageusement, avec prévoyance et énergie, leur propre mouvement vers un but commun.

À cette fin, les communistes doivent prendre part à tous les combats spontanés et tous les mouvements de la classe ouvrière et prendre sur soi de sauvegarder les intérêts des ouvriers dans tous leurs conflits avec les capitalistes au sujet de la journée de travail, etc... Les communistes doivent, ce faisant, s'occuper énergiquement des questions concrètes de la vie des ouvriers, les aider à se débrouiller dans ces questions, attirer leur attention sur les cas d'abus les plus importants, les aider à formuler exactement et sous une forme pratique leurs revendications aux capitalistes et en même temps développer chez eux l'esprit de solidarité et la conscience de la communauté de leurs intérêts et de ceux des ouvriers de tous les pays comme d'une classe unie et qui constitue une partie de l'armée mondiale du prolétariat.

Ce n'est qu'en prenant constamment part à ce menu travail quotidien absolument nécessaire, en apportant tout son esprit de sacrifice dans tous les combats du prolétariat, que le « Parti Communiste » peut se développer en vrai parti communiste. Ce n'est que par ce travail que les communistes se distingueront de ces partis socialistes de pure propagande et d'enrôlement qui ont fait leur temps et dont l'activité ne consiste qu'en réunions de membres, en discours sur les réformes et en exploitation des impossibilités parlementaires. La participation consciente et dévouée de toute la masse des membres d'un parti à l'école des combats et des différends quotidiens entre les exploités et les exploiteurs sont les prémisses indispensables non seulement de la conquête, mais dans une mesure encore plus large de la réalisation de la dictature du prolétariat. Ce n'est qu'en se plaçant à la tête des masses ouvrières dans leurs guérillas constantes contre les attaques du capital que le parti communiste peut devenir capable de devenir cette avant-garde de la classe ouvrière, d'apprendre systématiquement à diriger de fait le prolétariat et d'acquérir les moyens de préparer consciemment l'expulsion de la bourgeoisie.

24. Les communistes doivent être mobilisés en grand nombre pour prendre part au mouvement des ouvriers surtout pendant les grèves et les lock-out et les autres licenciements en masse. 
Les communistes commettent une faute très grave s'ils s'en rapportent au programme communiste et à la bataille révolutionnaire finale pour prendre une attitude passive et négligente ou même hostile à l'égard des combats quotidiens que les ouvriers livrent aujourd'hui pour des améliorations, même peu importantes, de leurs conditions de travail. Si menues et modestes que soient les revendications pour la satisfaction desquelles l'ouvrier est déjà prêt aujourd'hui à entrer en lutte contre les capitalistes, les communistes ne doivent jamais en prendre prétexte pour se tenir à l'écart du combat. Notre activité d'agitation ne doit pas donner lieu à croire que les communistes sont des instigateurs aveugles de grèves stupides et autres actions insensées, mais nous devons mériter partout parmi les ouvriers militants la renommée des meilleurs camarades de combat.

25. La pratique du mouvement syndical a montré que les noyaux et fractions communistes sont assez souvent confus et ne savent que faire lorsqu'ils sont mis en présence des plus simples questions du jour. il est facile, quoique bien stérile de ne faire toujours que prêcher les principes généraux du communisme pour tomber dans la voie tout à fait négative d'un syndicalisme vulgaire dans les premières questions concrètes venues. Par de pareilles actions, on ne fait que faciliter le jeu des dirigeants de l'Internationale Jaune d'Amsterdam.

Les communistes doivent, au contraire, déterminer leur attitude selon les données matérielles de chaque question qui se pose. Par exemple, au lieu de s’opposer par principe à tout contrat de tarif ouvrier, ils devraient avant tout mener directement la lutte pour des modifications matérielles du texte de ces contrats, recommandés par les chefs d’Amsterdam. Il est vrai qu'il faut condamner et combattre résolument toutes les entraves qui empêchent les ouvriers d'être prêts aux combats. Il ne faut pas oublier que c'est justement le but des capitalistes et de leurs complices d'Amsterdam de lier les mains aux ouvriers au moyen de chaque contrat de tarif. C'est pourquoi il est évident que le devoir du communiste est d'exposer ce but aux ouvriers. Mais en règle générale le meilleur moyen pour les communistes d'arriver à contrecarrer ce but est de proposer un tarif qui ne lie pas les ouvriers.

Cette même attitude est, par exemple, très utile par rapport aux caisses d'assistance et aux institutions de secours des syndicats ouvriers. La collection de 
moyens de combat et la distribution de subventions en temps de grève par les caisses mutuelles ne sont pas des actions mauvaises en elles-mêmes et s'opposer en principe à ce genre d'activité serait mal placé. Seulement il faut dire que ces collectes d'argent et ce moyen de le dépenser, qui sont d'accord avec les recommandations des chefs d'Amsterdam, sont en contradiction avec les intérêts des classes révolutionnaires. Par rapport aux caisses syndicales d'hôpital, etc..., il conviendrait que les communistes réclament la suppression des cotisations spéciales et également la suppression de toutes les conditions de contraintes dans les caisses volontaires. Mais si nous défendons aux membres d'apporter leur argent pour venir en aide aux organisations de secours aux malades, la partie de ces membres qui veut toujours continuer à assurer par leurs dons l'aide accordée à ces institutions ne nous comprendra pas si nous leur défendons sans autre explication. Il faut d'abord délivrer ces membres, par le moyen d'une propagande personnelle intensive, de leur tendance petite-bourgeoise.

26. Il n’y a rien à espérer d'aucune espèce d'entretiens avec les chefs des syndicats, de même qu’avec ceux des différents partis ouvriers social-démocrates et petits-bourgeois. Contre ceux-là on doit organiser la lutte avec toute son énergie. Mais le seul moyen sûr et victorieux de les combattre consiste à détacher d'eux leurs adeptes et à montrer aux ouvriers l'aveugle service d'esclaves que leurs chefs social-traîtres rendent au capitalisme. On doit donc, autant que possible, mettre d'abord ces chefs dans une situation où ils seront obligés de se démasquer, et les attaquer, après ces préparatifs, de la façon la plus énergique.

Il ne suffit nullement de jeter simplement à la face des chefs d'Amsterdam l’injure de « jaune ». Leur caractère de « jaunes » doit être montré en détail et par des exemples pratiques. Leur activité dans les unions d’ouvriers, au Bureau International du Travail de la Ligue des Nations, dans les ministères et les administrations bourgeoises, leurs paroles trompeuses dans les discours prononcés aux conférences et aux parlements, les passages essentiels de leurs nombreux articles pacificateurs dans des centaines de journaux et de revues, mais surtout, leur manière hésitante et oscillante de se conduire quand il s’agit de préparer et de mener à bien même les moindres mouvements de salaire et les combats d'ouvriers, tout cela offre chaque jour l'occasion d'exposer la conduite déloyale et de traîtrise des chefs d'Amsterdam et de les marquer du nom de «jaunes ». On peut le faire en 
soumettant des propositions, des motions et par des discours formulés tout à fait simplement.

Il faut que les noyaux et fractions du parti réalisent systématiquement les tâches pratiques. Les communistes ne doivent pas se laisser arrêter par les explications de la couche inférieure de la bureaucratie syndicale, qui cherche à se défendre de sa faiblesse - qui apparaît parfois, malgré toute sa bonne volonté — en en rejetant le blâme sur les statuts, les décisions des conférences et les ordres reçus de leurs comités centraux. Les communistes doivent constamment réclamer de cette couche de la bureaucratie des réponses claires et lui demander ce qu'elle a fait pour écarter les obstacles qu'elle allègue et si elle est prête à combattre avec les ouvriers pour leur destruction.

27. Les fractions et les groupes d'ouvriers doivent soigneusement se préparer d'avance à la participation des communistes aux assemblées et aux conférences des organisations syndicales. On doit, par exemple, élaborer ses propres propositions, choisir ses rapporteurs et les orateurs pour les défendre, proposer comme candidats des camarades capables, expérimentés et énergiques, etc...

Les organisations communistes doivent également, au moyen de leurs groupes ouvriers, se préparer avec soin à toutes les assemblées générales, aux assemblées électorales, aux démonstrations, aux fêtes politiques ouvrières, etc..., montées par les partis ennemis. Lorsqu'il s’agit d'assemblées ouvrières générales arrangées par les communistes mêmes, les groupes ouvriers communistes doivent, en aussi grand nombre que possible, tant avant qu'au cours des assemblées, agir d'après un plan unique, afin d'être sûrs de profiter amplement de ces assemblées au point de vue organisation.

28. Les communistes doivent aussi toujours de mieux en mieux apprendre à attirer pour toujours dans la sphère d'influence du parti les ouvriers non-organisés et non-conscients. Nos noyaux et fractions doivent tout faire pour faire naître le mouvement parmi ces ouvriers, pour les faire entrer dans les syndicats et pour leur faire lire notre journal. On peut se servir également d'autres unions ouvrières en qualité d’intermédiaires pour propager notre influence (comme, par exemple, les 
sociétés d'instruction et les cercles d'études, les sociétés sportives, théâtrales, les unions de consommateurs, les organisations des victimes de la guerre, etc...).

Là où le Parti Communiste est obligé de travailler illégalement, de telles unions ouvrières peuvent, avec l'approbation et sous le contrôle de l'organe du parti dirigeant, être formées en dehors du parti par l'initiative de ses membres (Unions de Sympathisants). Les organisations communistes de la Jeunesse et des Femmes peuvent, elles aussi, grâce à leurs cours, aux soirées de conférences, aux excursions, aux fêtes, aux pique-niques des dimanches, etc..., éveiller d'abord dans beaucoup de prolétaires restés encore indifférents aux questions politiques, l'intérêt pour une vie d'organisation commune et ensuite les attirer pour toujours et leur faire prendre part de cette façon à un travail utile à notre parti (par exemple, la distribution des feuilles, proclamations et autres, la répartition des journaux du parti, des brochures, etc...). C’est par une participation active aux mouvements communs que ces ouvriers seront le plus facilement délivrés de leurs tendances petites-bourgeoises.

29. Pour conquérir les couches semi-prolétariennes de la masse ouvrière et en faire des sympathisants au prolétariat révolutionnaire, les communistes doivent surtout utiliser la contradiction de leurs intérêts, socialement opposés aux grands propriétaires de biens fonciers, aux capitalistes et à l'Etat capitaliste. Ils doivent, au moyen d'entretiens continuels, débarrasser ces couches intermédiaires de leur défiance envers la révolution prolétarienne. Pour arriver à ce résultat, il faudra parfois mener sa propagande pendant un temps assez long. Il faut témoigner un intérêt sensible pour leurs exigences de vie, i1 faut arranger des bureaux de renseignements gratuits pour eux et leur venir en aide pour surmonter de petites difficultés dont ils ne peuvent se tirer eux-mêmes. Il faut les attirer dans des institutions spéciales qui serviront à les instruire gratuitement, etc... Toutes ces mesures pourront augmenter la confiance dans le mouvement communiste. Il faut en même temps être très prudent et agir infatigablement contre les organisations et les personnes hostiles qui ont de l'autorité en un endroit donné ou qui possèdent une influence sur les petits paysans travailleurs, sur les artisans à domicile et les autres éléments demi-prolétaires. Il faut caractériser les ennemis les plus proches, ceux que les exploités connaissent, comme leurs oppresseurs, par leur propre expérience ; il faut les caractériser comme les représentants personnifiant le crime du capi- 
talisme tout entier. Les propagandistes et agitateurs communistes doivent utiliser à l'extrême et d'une façon compréhensible pour tous, tous les éléments et faits quotidiens qui mettent la bureaucratie d'Etat en conflit direct avec l'idéal de la démocratie petite-bourgeoise et de «l'Etat du droit».

Toutes les organisations locales à la campagne doivent partager exactement entre leurs membres les tâches de l'agitation à domicile qu'elles doivent développer dans la sphère de leur activité dans tous les villages, dans toutes les cours de châteaux et dans les fermes et maisons séparées.

30. Pour la propagande dans l'armée et dans la flotte de l'Etat capitaliste, il faudra rechercher dans chaque pays les méthodes les mieux appropriées. L'agitation antimilitariste dans le sens pacifiste est tout à fait mauvaise, car elle ne peut qu'encourager la bourgeoisie dans son désir de désarmer le prolétariat. Le prolétariat repousse en principe et combat de la manière la plus énergique toutes les institutions militaristes de l'Etat bourgeois et de la classe bourgeoise en général. D’autre part le prolétariat profite de ces institutions (armée, sociétés de préparation militaire, milice pour la défense des habitants, etc...) pour exercer militairement les ouvriers en vue des luttes révolutionnaires. L'agitation intensive ne doit donc pas être dirigée contre la formation militaire de la jeunesse et des ouvriers, mais contre l'ordre militariste et contre l'arbitraire des officiers. Le prolétariat doit utiliser de la façon la plus énergique toute possibilité de se procurer des armes.

L'antithèse de classes qui se manifeste dans les privilèges matériels des officiers et dans les mauvais traitements infligés aux soldats doit être rendue consciente pour ces derniers. En outre, dans l'agitation parmi les soldats, il faut nettement faire ressortir comment tout leur avenir est lié étroitement au sort de la classe exploitée. Dans la période avancée de la fermentation révolutionnaire, l'agitation en faveur de l'élection démocratique du commandement par les soldats et par les matelots, et en faveur de la formation de soviets de soldats peut être très efficace pour saper les bases de la domination de la classe capitaliste.

Le maximum d'attention et d'énergie est constamment nécessaire dans l'agitation contre les troupes spéciales que la bourgeoisie arme pour la guerre de classes, et en particulier contre ses bandes de volontaires armés. La décomposi- 
tion sociale doit être portée systématiquement et en temps voulu dans leurs rangs, là où la composition sociale et son milieu corrompu le permettent. Quand ces bandes où ces troupes portent un caractère de classe uniformément bourgeois, comme par exemple dans les troupes composées exclusivement d'officiers, il faut les démasquer devant l'ensemble de la population, les rendre méprisables et odieuses de façon à provoquer leur dissolution intérieure par suite de l'isolement qui en découlera.

\section{V. - ORGANISATION DES LUTTES POLITIQUES}

31. Pour un Parti communiste, il n'y a pas de moment où l'organisation du Parti puisse rester politiquement inactive. L'utilisation organique de toute situation politique et économique et de toute modification de cette situation doit être élevée au degré d’une stratégie et d'une tactique organisées.

Si le Parti est encore faible, il est cependant en mesure de profiter d'événements politiques ou de grandes grèves qui ébranlent toute la vie économique, pour mener une action de propagande radicale systématiquement et méthodiquement organisée. Une fois qu’un Parti a pris sa décision dans une situation de ce genre, il doit mettre en mouvement pour cette campagne, avec la dernière énergie, tous ses membres et toutes les branches de son mouvement.

En premier lieu, il faudra utiliser toutes les liaisons que le Parti s’est créées par le travail de ses noyaux et de ses groupes de propagande pour organiser des réunions dans les principaux centres politiques ou grévistes, réunions dans lesquelles les orateurs du Parti devront montrer aux assistants que les principes communistes sont le moyen de sortir des difficultés de la lutte. Des groupes de travail spéciaux devront préparer jusque dans leurs moindres détails toutes ces réunions. S’il ne leur est pas possible d'organiser eux-mêmes des réunions, des camarades expérimentés devront se présenter comme principaux orateurs dans les réunions générales des grévistes, ou de prolétaires en général, menant un combat sous quelque forme que ce soit. 
S'il y a espoir de gagner la majorité — ou tout au moins une grande partie des participants à la réunion - à nos principes, ceux-ci devront être formulés dans des propositions et résolutions bien rédigées et adroitement motivées. Une fois de semblables propositions ou résolutions composées, il faudra s'appliquer à ce que, sous une forme identique ou analogue, ces propositions soient admises par tout au moins de fortes minorités dans toutes les réunions tenues sur le même sujet dans la localité en question ou dans d'autres. Ainsi nous obtiendrons la concentration des couches prolétariennes en mouvement qui pour le moment subissent seulement notre influence morale, et nous leur ferons admettre la nouvelle direction.

Après toutes ces réunions, les groupes de travail ayant participé à leur préparation et à leur utilisation devront se rencontrer non seulement pour faire un rapport au Comité Directeur du Parti, mais aussi pour tirer des expériences faites ou des fautes éventuellement commises les enseignements nécessaires à l'activité ultérieure.

Selon les situations, les mots d'ordre pratiques devront être portés à la connaissance des masses ouvrières intéressées, au moyen d'affiches et de petites feuilles volantes, ou encore au moyen de tracts détaillés remis directement aux combattants et sous lesquels le communisme est éclairé par des devises d'actualité adaptées à la situation. Pour répandre adroitement les tracts, des groupes spécialement organisés sont nécessaires ; ces groupes auront à trouver les endroits où les affiches devront être collées et à choisir le moment opportun pour cette opération. La distribution des feuilles volantes dans et devant les lieux de travail, dans les établissements publics, dans les maisons communes des ouvriers participant au mouvement, aux carrefours, dans les bureaux de placement et dans les gares, devra être accompagnée autant que possible d'une discussion en termes frappants, susceptible d'être transportée dans les masses ouvrières en mouvement. Les tracts détaillés devront être répandus autant que possible seulement dans les lieux couverts, dans les ateliers, dans les habitations et d'une façon générale partout où on peut attendre une attention soutenue.

Cette propagande intense doit être appuyée par une action parallèle dans toutes les assemblées de syndicats ou d'entreprises entraînés dans le mouvement, soit qu'ils aient organisé eux-mêmes ces assemblées, qu'ils devront alors munir de rapporteurs ou d'orateurs appropriés. Les journaux du Parti doivent constamment mettre à la disposition de ce mouvement la majeure portion de leurs colonnes et 
leurs meilleurs arguments ; l'ensemble de l'appareil du parti devra d'ailleurs pendant tout le temps que durera le mouvement être entièrement et sans relâche au service de l’idée générale qui l’anime.

32. Les manifestations et les actions démonstratives exigent une direction très dévouée et très mobile, qui aie constamment en vue le but de ces actions et soit à tout moment en mesure de se rendre compte si la manifestation a obtenu son plus grand effet ou si, dans la situation donnée, il est possible de l'intensifier encore en l'élargissant pour en faire une action de masses sous la forme tout d'abord de grèves démonstratives et ensuite de grèves de masses. Les manifestations pacifistes pendant la guerre nous ont enseigné que, même après l'écrasement de ces sortes de manifestations, un vrai Parti prolétarien de lutte, même illégal, ne doit ni hésiter, ni s'arrêter quand il s'agit d'un grand but actuel important, éveillant nécessairement dans les masses un intérêt toujours croissant.

Les manifestations dans la rue trouvent leur meilleur appui dans les grandes entreprises. Lorsqu'on en est arrivé à créer un certain état d'esprit commun, au moyen du travail préparatoire méthodique de nos noyaux et de nos fractions, à la suite $d$ une propagande orale ou par tracts, les hommes de confiance de notre parti dans les entreprises, les chefs des noyaux et des fractions, devront être convoqués par le Comité Directeur à une conférence où seront discutés pour le jour suivant l'opération convenable, le moment exact de la rencontre, le caractère des mots d'ordre, les perspectives de l'action, son intensification et le moment de sa cessation et de sa dissolution. Un groupe de fonctionnaires munis de bonnes instructions et experts dans les questions d'organisation devra constituer l'axe de la manifestation depuis le départ du lieu du travail jusqu'à la dislocation du mouvement de masses. Afin que ces fonctionnaires maintiennent le contact vivant entre eux et puissent recevoir constamment les directions politiques nécessaires à chaque moment, des travailleurs responsables du Parti doivent participer méthodiquement, parmi les masses, à la manifestation. Cette direction mouvante politique et organisée de la manifestation constitue la condition la plus favorable au renouvellement et éventuellement à l'intensification de l'action et à sa transformation en grandes actions de masses. 
33. Les partis communistes qui jouissent déjà d’une certaine solidité intérieure, qui disposent d'un groupe de fonctionnaires éprouvés et d'un nombre de partisans considérable dans les masses, doivent tout faire pour détruire au moyen de grandes campagnes l'influence des chefs socialistes-traîtres et pour amener la majorité des ouvriers sous la direction communiste. Les campagnes doivent être organisées différemment selon que les luttes actuelles permettent au Parti communiste d'agir comme guide du prolétariat et de se mettre à la tête du mouvement ou que règne une stagnation momentanée. La composition du Parti sera aussi un élément déterminant pour les méthodes d’organisation des actions.

C’est ainsi que pour gagner, plus que cela n’était possible dans les différentes circonscriptions, les couches socialement décisives du prolétariat, le Parti Communiste Unifié d'Allemagne comme jeune Parti de masses recourut au moyen dit de la «lettre ouverte ». Afin de démasquer les chefs socialistes-traîtres, le Parti Communiste s'adressa, à un moment où la misère et les antagonismes de classe s’aggravaient, aux autres organisations du prolétariat pour exiger d'elles une réponse nette devant le prolétariat à la question de savoir si elles étaient disposées, avec leurs organisations apparemment si puissantes, à entreprendre la lutte commune, d'accord avec le Parti Communiste, pour les revendications minima, pour un misérable morceau de pain et contre la misère évidente du prolétariat.

Lorsque le Parti Communiste commence une campagne semblable il doit prendre toutes mesures pour provoquer un écho à son action dans les plus larges masses ouvrières. Toutes les fractions professionnelles et tous les fonctionnaires syndicaux du Parti doivent dans toutes les réunions des ouvriers par entreprises ou par syndicats, et dans toutes les réunions publiques en général, mettre en discussion les revendications vitales du prolétariat.

Partout où nos fractions et nos noyaux veulent préparer à nos revendications l'approbation des masses des feuilles volantes, des tracts et des affiches devront être répandus avec adresse afin d'émouvoir l’opinion. La presse de notre Parti, pendant les semaines que dure cette campagne, doit éclairer le mouvement tantôt brièvement, tantôt avec plus de détails, mais sous des aspects toujours nouveaux. Les organisations devront pourvoir la presse d'informations courantes relatives au mouvement et veiller énergiquement à ce que les rédacteurs ne se relâchent jamais dans cette campagne du parti. Les fractions du parti au Parlement et dans les institutions municipales devront aussi se mettre systématiquement au service de ces 
luttes. Elles devront provoquer la discussion par des propositions correspondantes dans les assemblées délibérantes, suivant les directives du Parti. Les députés devront agir et se sentir comme des membres conscients des masses combattantes, comme leurs porte-parole dans le camp de leurs ennemis de classe, comme des fonctionnaires responsables et comme des travailleurs du parti.

Lorsque l'action concentrée, organisée et cohérente de tous les membres du parti aura provoqué un nombre d'ordres du jour d'approbation toujours plus grands et augmentant sans cesse dans le cours de quelques semaines, le Parti se trouvera placé devant cette grave question : organiser et concentrer organiquement les masses adhérant à nos mots d'ordre.

Si le mouvement a pris surtout un caractère syndical, il faut avant tout s'appliquer à augmenter notre influence dans les syndicats, en prescrivant à nos fractions communistes de s'attaquer, après bonne préparation, directement à la direction syndicale locale pour ou bien la renverser ou bien la contraindre à mener la lutte organisée sur la base des mots d'ordre de notre Parti.

Là où il y a des comités d'usines, des conseils d'industrie ou autres institutions analogues, il faut que nos fractions agissent en sorte que ces institutions participent à cette lutte. Une fois qu'un certain nombre d'organisations locales ont été acquises à cette lutte, sous la direction communiste pour les intérêts vitaux les plus élémentaires du prolétariat, les réunions générales d'entreprises qui se sont décidées dans le même sens y enverront leurs délégués. La nouvelle direction ainsi consolidée sous l'influence communiste gagne, par cette concentration des groupes actifs du prolétariat organisé, une nouvelle force d'attaque qui doit être utilisée, à son tour, pour pousser en avant la direction des Partis socialistes et des syndicats, ou tout au moins pour les anéantir désormais aussi organiquement.

Dans les régions économiques où notre Parti dispose de ses meilleures organisations et où il a trouvé les plus nombreuses approbations pour ses mots d'ordre, il faut, par une pression organisée sur les syndicats et les soviets d'entreprises locaux, concentrer toutes les luttes économiques isolées éclatant dans cette région et aussi les mouvement développés par d'autres groupes et les transformer en une vaste lutte unique dépassant désormais le cadre des intérêts professionnels particuliers, et poursuivant quelques revendications élémentaires communes, afin de 
réaliser ces revendications à l'aide des forces réunies de toutes les organisations de la région.

Dans un pareil mouvement, le Parti Communiste sera le vrai guide du prolétariat prêt à la lutte, tandis que la bureaucratie syndicale et les Partis socialistes qui s’opposeraient à un mouvement organisé avec un tel accord seraient brisés non seulement par la perte de toute autorité politique et morale, mais aussi par la destruction effective de leur organisation.

34. Si le Parti Communiste est obligé d'essayer de prendre en main la direction des masses à un moment où les antagonismes politiques et économiques sont surexcités et provoquent de nouveaux mouvements et de nouvelles luttes, on peut renoncer à établir des revendications particulières et adresser des appels simples et concis directement aux membres des partis socialistes et des syndicats, les invitant à ne point éviter les luttes nécessaires contre les entrepreneurs, même en dépit des conseils de leurs chefs bureaucrates, étant donné la grande misère et l’oppression croissante, afin de n’être pas poussés à la perte et à la ruine complète. Les organes du Parti et surtout les quotidiens doivent chaque jour démontrer et souligner pendant ce mouvement que les communistes sont prêts à participer en chefs aux luttes actuelles ou proches des prolétaires réduits à la misère, et qu’ils accourront au secours de tous les opprimés dès que cela sera possible dans la situation tendue actuelle. Il faudra prouver quotidiennement que le prolétariat ne saurait plus continuer à subsister sans ces luttes et que néanmoins les anciennes organisations cherchent à les éviter et à les empêcher.

Les fractions syndicales et professionnelles doivent sans cesse faire appel dans les réunions à l'esprit de combat de leurs camarades communistes en leur faisant comprendre clairement qu'on ne saurait plus hésiter. Mais l'essentiel pendant une campagne de ce genre est la concentration et l'unification organique des luttes et des mouvements provoqués par la situation. Non seulement les noyaux et les fractions communistes des entreprises et des syndicats entraînés dans la lutte doivent constamment garder entre eux le contact le plus étroit, mais encore les directions doivent mettre immédiatement à la disposition des mouvements qui se produisent des fonctionnaires et des militants actifs du Parti chargés, d’accord avec les combattants, de généraliser, d’élargir et d’intensifier, en même temps que les diriger, 
tous ces mouvements. La tâche principale de l'organisation consiste à faire ressortir partout ce qu'il y a de commun entre tout et ces différentes luttes pour pouvoir ainsi arriver en cas de besoin à une lutte générale par des moyens politiques.

Pendant la généralisation et l'intensification des luttes, il sera nécessaire de créer des organes uniques de direction. Au cas où dans certains syndicats, le comité de grève bureaucratique viendrait à manquer à sa tâche, il faudra que les communistes obtiennent à temps, en exerçant la pression nécessaire, le remplacement de ces bureaucrates par des communistes qui assureront la direction ferme et décidée de cette lutte. Dès qu'on aura réussi à combiner plusieurs combats, il faudra instituer une direction commune pour l'ensemble de l'action, et là les communistes devront autant que possible dominer. Cette unité de direction peut facilement être obtenue Si une préparation appropriée est faite par la fraction communiste dans les syndicats ou dans les entreprises, par les soviets d'usines, par les assemblées plénières de ces soviets, mais plus particulièrement par les assemblées générales des grévistes.

Si le mouvement, par suite de sa généralisation et de l'entrée en action des organisations patronales et des autorités publiques, prend un caractère politique, il faut aussitôt commencer la propagande et la préparation administrative en vue de l'élection vraisemblablement possible et nécessaire de soviets ouvriers ; au cours de ce travail, tous les organes du Parti doivent faire ressortir avec la plus grande intensité l'idée que ce n'est que par des organes semblables de la classe ouvrière, sortis directement des luttes ouvrières, que le véritable affranchissement du prolétariat peut être obtenu, avec le mépris qui convient pour la bureaucratie syndicale et ses aides du Parti socialiste.

35. Les partis communistes déjà suffisamment forts, et en particulier les grands partis de masses, doivent par des mesures prises à l'avance être toujours prêts à de grandes actions politiques. Au cours des actions démonstratives et des mouvements économiques aussi bien qu'au cours des actions partielles, il faut toujours penser à utiliser de la manière la plus énergique les expériences d'organisation fournies par ces mouvements en vue d'un contact de plus en plus ferme avec les grandes masses. Les leçons de tous les nouveaux grands mouvements doivent être discutées et étudiées avec soin dans des conférences élargies 
de fonctionnaires dirigeants et de militants responsables du parti avec les délégués d'usines grandes et moyennes, afin d'établir des relations de plus en plus étroites et de plus en plus sûres par l’intermédiaire des délégués d'usines. Le meilleur gage que des actions politiques de masses ne seront pas entreprises prématurément et ne le seront que dans la mesure permise par les circonstances et par l'influence actuelle du Parti, consiste dans des rapports de confiance entre fonctionnaires et militants responsables du parti et les délégués d'usines.

Sans ce contact le plus étroit possible entre le Parti et les masses prolétariennes travaillant dans les grandes et moyennes entreprises, le Parti Communiste ne saurait réaliser de grandes actions de masses et des mouvements véritablement révolutionnaires. Si en Italie le soulèvement incontestablement révolutionnaire de l'année passée, qui trouva sa plus forte expression dans l'occupation des usines, échoua avant terme c'est certainement pour une part, à cause de la trahison de la bureaucratie syndicale et de l'insuffisance de la direction politique du Parti, mais c'est aussi parce qu'il n'y avait pas entre le Parti et les usines une liaison intimement organisée au moyen de délégués d'usines politiquement informés, et s’intéressant à la vie du Parti. Le mouvement des mineurs anglais cette année a lui aussi sans nul doute extraordinairement souffert de ce défaut qui lui a enlevé sa valeur politique.

\section{VI. - LA PRESSE DU PARTI}

36. La presse communiste doit être développée et améliorée par le Parti avec une infatigable énergie.

Aucun journal ne doit être reconnu comme organe communiste s’il ne se soumet pas aux directives du Parti. Ce principe doit être appliqué aussi pour les productions littéraires telles que livres, brochures, écrits périodiques, etc..., en prenant en considération leur caractère scientifique, de propagande ou autre.

Le Parti doit s'efforcer bien plus d'avoir de bons journaux que d'en avoir beaucoup. Tout parti communiste doit avant tout avoir un organe central autant que possible quotidien. 
37. Un journal communiste ne doit jamais devenir une entreprise capitaliste comme le sont les journaux bourgeois et souvent aussi les journaux soi-disant « socialistes ». Notre journal doit être indépendant des institutions de crédit capitalistes. L'organisation adroite de la publicité par annonces, qui peut améliorer considérablement les moyens d'existence de notre journal, ne doit cependant jamais le faire tomber dans la dépendance de quelques grandes entreprises de publicité. Bien plutôt une attitude inflexible dans toutes les questions sociales prolétariennes procurera aux journaux de nos Partis de masses une force et une considération absolues. Notre journal ne doit pas servir à satisfaire le goût du sensationnel ni l'amusement d'un public varié. Il ne doit pas concéder à la critique des littérateurs petits-bourgeois ou des virtuoses du journalisme pour se créer une clientèle de salon.

38. Un journal communiste doit avant tout défendre les intérêts des ouvriers opprimés combattants. Il doit être notre meilleur propagandiste et agitateur, le propagandiste dirigeant de la révolution prolétarienne.

Notre journal a pour tâche de réunir les expériences acquises au cours de l'activité de tous les membres du Parti et d'en faire comme un guide politique pour la révision et l'amélioration des méthodes d'action communiste. Ces expériences doivent être échangées dans des réunions de rédacteurs de tout le pays, réunions cherchant à créer la plus grande unité de ton et de tendance dans l'ensemble de la presse du Parti. Ainsi cette presse, de même que chaque journal en particulier sera le meilleur organisateur de notre travail révolutionnaire.

Sans ce travail conscient d'organisation et de coordination des journaux communistes et en particulier de l'organe central la mise en pratique de la centralisation démocratique, et d'une sage division du travail à l'intérieur du Parti Communiste, et par conséquent aussi l'accomplissement de la mission historique est impossible.

39. Le journal communiste doit tendre à devenir une entreprise communiste, c'est-à-dire une organisation prolétarienne de combat, une association d'ouvriers révolutionnaires, de tous ceux qui écrivent régulièrement pour le journal, qui le composent, l'impriment, l'administrent, le distribuent qui réunissent le matériel 
d'information, qui le discutent et l'élaborent dans les noyaux, enfin qui agissent quotidiennement pour le répandre, etc...

Pour faire véritablement du journal une organisation de combat, une puissante et vivante association de travailleurs communistes, une série de mesures pratiques s'imposent.

Tout communiste se lie étroitement à son journal en travaillant et en se sacrifiant pour lui. Il est son arme quotidienne qui, pour servir, doit être rendue chaque jour plus forte et plus tranchante. Ce n'est que grâce aux plus grands sacrifices financiers et matériels que le journal communiste pourra se maintenir. Les membres du parti doivent constamment fournir les moyens nécessaires pour son organisation et pour son amélioration jusqu'à ce qu'il soit assez répandu dans les grands partis légaux et assez solide sous le rapport de l'organisation pour le mouvement communiste.

Il ne suffit pas d'être un agitateur et un recruteur zélé pour le journal, il faut encore en devenir un collaborateur utile. Il faut l'informer au plus vite de tout ce qui mérite d'être remarqué, du point de vue social et économique, dans la fraction syndicale et dans le noyau, depuis l'accident du travail jusqu'à la réunion professionnelle, depuis les mauvais traitements des jeunes apprentis jusqu'au rapport commercial de l'entreprise. Les fractions syndicales doivent le renseigner sur toutes les réunions, et sur les décisions et les mesures les plus importantes prises par ces réunions, pur les secrétariats des Unions, ainsi que sur l'activité de nos adversaires. La vie publique des réunions et de la rue offre très souvent aux militants attentifs du parti l'occasion d'observer avec un sens critique des détails dont l'utilisation dans les journaux rendra claire aux plus indifférents notre attitude par rapport aux exigences de la vie.

La commission de rédaction doit traiter avec le plus grand amour et le plus grand zèle ces informations sur la vie des ouvriers et des organisations ouvrières et les utiliser ou bien comme brèves communications donnant à notre journal le caractère d'une véritable communauté de travail vivante et puissante ou bien pour, à la lumière de ces exemples pratiques de la vie quotidienne des ouvriers, rendre compréhensibles les enseignements du communisme, ce qui constitue la voie la plus rapide pour arriver à rendre vivante et intime l'idée du communisme aux grandes masses ouvrières. Dans la mesure du possible, la commission de rédac- 
tion doit être aux heures de réception, c’est-à-dire aux heures les plus favorables de la journée, à la disposition des ouvriers visitant notre journal pour accueillir leurs désirs et leurs plaintes relativement aux misères de leur existence, pour les noter avec soin et s'en servir pour donner de la vie au journal. Certes, dans la société capitaliste, aucun de nos journaux ne peut devenir une véritable association de travail communiste. On peut cependant, même dans les conditions les plus difficiles, organiser un journal révolutionnaire ouvrier en partant de ce point de vue. Ceci est prouvé par l'exemple de la « Pravda » de nos camarades russes pendant les années 1912-1913. Ce journal constitua vraiment une organisation permanente active des ouvriers révolutionnaires conscients dans les centres les plus importants de l'Empire russe. Ces camarades rédigeaient, éditaient et répandaient à la fois et ensemble le journal ; la plupart d'entre eux économisant l'argent nécessaire pour les frais par leur travail et par le salaire de leur travail. Le journal de son côté put leur donner ce qu'ils désiraient, ce dont ils avaient besoin à ce moment là dans le mouvement et ce qui leur sert aujourd'hui encore dans le travail et dans la lutte, Un tel journal put en effet devenir pour les membres du Parti, ainsi que pour tous les ouvriers révolutionnaires, ce qu’ils appelaient « notre journal ».

40. L’élément essentiel de l'activité de la presse de combat communiste c'est la participation directe aux campagnes menées par le Parti. Si à un certain moment l’activité du Parti est concentrée dans une campagne déterminée, le journal du Parti doit mettre au service de cette campagne toutes ses colonnes, toutes ses rubriques et non seulement les articles de fond politiques. La rédaction doit trouver dans tous les domaines du matériel pour entretenir cette campagne et pour en alimenter, sous la forme la plus convenable, tout le journal.

41. Le recrutement pour notre journal doit être poursuivi suivant un système établi. Tout d'abord il faut utiliser toutes les situations dans lesquelles les ouvriers sont plus vivement entraînés dans le mouvement et dans lesquelles la vie politique et sociale est plus agitée par suite de quelque événement politique et économique. Ainsi après chaque grève ou lock-out, pendant lesquels le journal a défendu franchement et énergiquement les intérêts des ouvriers combattants, on doit organiser immédiatement après la fin de la grève, un travail de recrutement d'homme à 
homme auprès de ceux qui avaient fait la grève. Non seulement les fractions communistes des syndicats et des professions entraînés dans le mouvement gréviste doivent mener la propagande du journal dans leur milieu au moyen de listes et de feuilles d'abonnement, mais encore, dans la mesure du possible, on doit se procurer les listes des ouvriers ayant fait la grève ainsi que leurs adresses afin que les groupes spéciaux chargés des intérêts du journal puissent mener une agitation énergique à domicile.

De même après toute campagne politique électorale par laquelle l'intérêt des masses ouvrières a été éveillé, une agitation systématique à domicile doit être menée de maison en maison par les groupes de travailleurs chargés spécialement de cette besogne dans les différents quartiers ouvriers.

Pendant les époques de crises politiques ou économiques latentes dont les effets se font sentir aux masses ouvrières sous la forme du renchérissement de la vie, du chômage et d'autres misères, on doit tout essayer pour, après une propagande habile contre ces misères, obtenir, si possible, par l'intermédiaire des fractions syndicales, de grandes liste d'ouvriers organisés dans les syndicats afin que le groupe spécial chargé des intérêts du journal puisse continuer systématiquement l'agitation à domicile. La dernière semaine du mois est la plus convenable pour ce travail permanent de recrutement. Toute organisation locale qui laisse passer cette dernière semaine du mois, ne serait-ce qu'une fois par an, sans poursuivre sa propagande en faveur de la presse commet un retard coupable dans l'extension du mouvement communiste. Le groupe spécial chargé des intérêts du journal ne doit laisser passer aucune réunion publique d'ouvriers, aucune grande manifestation sans, dès Je début, et aussi pendant les intervalles et à la fin, agir de la manière la plus active pour obtenir des abonnements à notre journal. Les fractions syndicales doivent accomplir cette même tâche dans toutes les réunions de leurs syndicats, de même que les noyaux et les fractions syndicales, dans les réunions professionnelles.

42. Notre journal doit être constamment défendu par les membres du Parti contre tous ses ennemis. 
Tous les membres doivent mener une lutte impitoyable contre la presse capitaliste, révéler à tous et flétrir énergiquement sa vénalité, ses mensonges, ses viles réticences et toutes ses intrigues.

La presse social-démocrate et socialiste indépendante doit être vaincue en démasquant son attitude traître par des exemples de la vie quotidienne, au moyen d'attaques continuelles mais sans se perdre dans de petites polémiques de fraction. Les fractions syndicales et autres doivent s'appliquer par des mesures d'organisation à soustraire à l'influence troublante et paralysante des journaux social-démocrates les membres des syndicats et des autres associations ouvrières. Le travail de recrutement d'abonnés pour notre journal, de même que l'agitation à domicile ou dans les entreprises, doit également être dirigé avec habileté contre la presse des socialistes traîtres.

\section{VII. - LA STRUCTURE D'ENSEMBLE DU PARTI}

43. Pour l'extension et la consolidation du Parti, on ne devra pas établir des divisons d'après un schéma formel, géographique. Il faudra surtout tenir compte de la structure réelle, économique et politique, des régions en question et des moyens techniques de communication. La base de ce travail doit être surtout dans les capitales et dans les centres prolétariens de la grande industrie.

Au moment de l'organisation d'un nouveau Parti, on constate souvent dès le début des efforts tendant à étendre le réseau des organisations du Parti sur tout le pays. Malgré les forces très limitées à la disposition des organisateurs, on s'applique souvent à les disperser néanmoins aux quatre vents. La force d'attraction et la croissance du Parti sont ainsi affaiblies. Au bout de quelques années, on arrive, il est vrai, à avoir tout un système de bureaux très vastes, mais les plus souvent le Parti n'a réussi a se fixer fermement dans aucune des villes industrielles les plus importantes du pays.

44. Pour donner au parti une centralisation aussi grande que possible, il ne faut point décomposer sa direction en toute une hiérarchie comportant de nom- 
breux degrés complètement subordonnés les uns aux autres. Il faut s'appliquer à construire dans tout centre économique, politique ou de communications un réseau s'étendant sur la large banlieue de cette ville et sur la région économique ou politique en dépendant. Le Comité du Parti qui de cette ville, comme de la tête de ce corps, dirige le travail du parti dans la région et qui exerce sa direction politique doit se tenir dans le plus étroit contact avec les masses communistes du cheflieu.

Les organisateurs nommés par les conférences des régions ou par le congrès régional du Parti et confirmés par la direction centrale doivent participer régulièrement à la vie du Parti au chef-lieu de la région. Le Comité régional du Parti doit constamment être renforcé par des travailleurs choisis parmi les membres du cheflieu, de sorte que s'établisse un contact vivant et étroit entre le comité politique du Parti dirigeant la région et les masses communistes de son chef-lieu. Lorsqu'on est arrivé à un certain stade d'organisation, il faut que le Comité de la région soit en même temps la direction politique du chef-lieu de cette région. De la sorte, les comités dirigeants du Parti dans les organisations régionales, de concert avec le Comité Central, auront le rôle d'organes vraiment dirigeants dans les organisations du Parti. L'étendue d'une circonscription politique du Parti ne doit naturellement pas être déterminée par l'étendue matérielle de la région. Ce qu'il faut considérer avant tout, c'est la possibilité pour les Comités régionaux du Parti de diriger concentriquement toutes les organisations locales de la région. Quand cela n’est pas possible, il faut partager la région et fonder un nouveau Comité régional du Parti.

Naturellement, dans les grands pays, le Parti a besoin de certains organes de liaison aussi bien entre la direction centrale et les différentes directions régionales (direction provinciale, direction départementale, etc...) qu'entre la direction régionale et les différentes organisations locales (direction d'arrondissement et de canton). Dans certaines circonstances, il peut même être utile de donner à l'un ou à l'autre de ces organes intermédiaires un rôle dirigeant, par exemple dans une grande ville comptant un nombre assez considérable de membres. D’une façon générale cette sorte de décentralisation doit être évitée. 
45. Les grandes unités du Parti (circonscriptions) sont constituées par les organisations locales du Parti : par les « groupes locaux » de campagnes et des petites villes et par les « districts » ou « rayons » des différents quartiers des grandes villes.

Une organisation locale du Parti qui, dans des conditions légales, n’est plus en mesure de tenir des réunions générales de ses membres, doit être dissoute ou divisée.

Dans les organisations locales du Parti, les membres doivent être répartis en vue du travail quotidien du Parti dans les différents groupes de travail. Dans les organisations plus grandes, il peut être utile de réunir ces groupes de travail en différents groupes collectifs. Dans un même groupe collectif, il faut, en règle générale, inclure tous les membres qui, à leur poste de travail ou d’une façon générale dans leur existence quotidienne, se rencontrent et viennent le plus souvent en contact entre eux. Le groupe collectif a pour tâche de distribuer le travail général du Parti parmi les différents groupes de travail, de recevoir les rapports des préposés, de former des candidats pour le Parti dans leur milieu, etc...

46. Le Parti dans son ensemble, est sous la direction de l'Internationale Communiste. Les directives et résolutions de la direction internationale dans les questions intéressant les partis adhérents sont adressées : 1. : ou bien à la direction centrale générale du Parti, ou 2. : par l’intermédiaire de la direction centrale, ou comité dirigeant telle ou telle action spéciale ou, enfin 3. : à toutes les organisations du Parti.

Les directives et les décisions de l'Internationale sont obligatoires pour le Parti et aussi, cela va sans dire pour chacun des ses membres.

47. Le Comité Central du Parti (conseil central ou commission) est responsable devant le congrès du Parti et devant la direction de l'Internationale Communiste. Le Petit Comité central, ainsi que le Comité complet ou élargi, le conseil ou la commission sont élus, en règle générale, par le congrès du Parti. Si le congrès du Parti le juge nécessaire, il peut charger la direction centrale d'élire dans son sein une direction étroite composée du Bureau politique et du Bureau 
d'organisation. La politique et les affaires courantes du Parti sont dirigées, sous la responsabilité de la direction étroite, par ces deux Bureaux. La direction étroite convoque régulièrement des réunions générales du Comité directeur pour prendre des décisions de grande importance et de haute portée. Afin de prendre connaissance de la situation politique générale avec tout le sérieux nécessaire et de connaître exactement la capacité d'action du Parti, d'en avoir une image exacte et claire, il est indispensable, aux élections à la direction centrale du Parti, de prendre en considération les propositions apportées par les différentes régions du pays. Pour la même raison, les opinions tactiques divergentes de caractère sérieux ne doivent pas être opprimées aux élections à la direction centrale. Au contraire, il faut faire en sorte que ces opinions divergentes soient représentées au Comité Directeur par leurs meilleurs défenseurs. La direction étroite doit cependant être cohérente dans ces conceptions et pour être ferme et assurée, elle ne doit pas se baser seulement sur son autorité propre, mais aussi sur une majorité solide évidente et nombreuse dans l'ensemble du Comité directeur.

Grâce à une constitution aussi large de sa direction centrale, le grand Parti légal aura bientôt assis son Comité Central sur la meilleure des bases : une discipline ferme et la confiance absolue des membres ; en outre, il pourra ainsi combattre et guérir les maladies et les faiblesses qui peuvent apparaître parmi les fonctionnaires ; il pourra éviter également l'accumulation de ces sortes d'infections dans le Parti et la nécessité d'une opération, peut-être catastrophique, qui s’imposerait ensuite au congrès.

48. Chaque Comité du Parti doit établir dans son sein une division du travail efficace afin de pouvoir mener effectivement le travail politique dans les différents domaines. Sous ce rapport, il peut apparaître nécessaire d'instituer, pour certains domaines, des directions spéciales (par exemple, pour la propagande, pour le service du journal, pour la lutte syndicale, pour l'agitation dans les campagnes, pour l'agitation parmi les femmes, pour la liaison, pour l'assistance révolutionnaire etc...). Les différentes directions spéciales sont soumises, ou bien à la direction centrale, ou au Comité régional du Parti. Le contrôle de l'activité, ainsi que le contrôle de la bonne composition de tous les comités subordonnés, appartient au comité régional du Parti et en dernier lieu à la direction centrale. Les membres employés au travail politique du Parti ainsi que les parlementaires sont 
directement soumis au Comité Directeur. Il peut apparaître utile de changer de temps à autre les occupations et le travail des camarades fonctionnaires du Parti (par exemple des rédacteurs, des propagandistes, des organisateurs, etc...) sans trop gêner le fonctionnement. Les rédacteurs et les propagandistes doivent participer pendant une période prolongée à l'action politique régulière du Parti dans un des groupes spéciaux de travail.

49. La direction centrale du Parti ainsi que celle de l'Internationale Communiste sont en droit d'exiger à tout moment des informations complètes de toutes les organisations communistes, de leurs comités et de leurs différents membres. Les représentants et les délégués de la direction centrale doivent être admis à toutes les réunions et à toutes les séances avec voix consultative et avec droit de veto. La direction centrale du Parti doit constamment avoir à sa disposition des délégués (commissaires), afin de pouvoir instruire et informer les différentes directions régionales ou départementales non seulement par circulaires sur la politique et sur l'organisation, ou par correspondances, mais aussi oralement, directement. Une commission de révision, composée de camarades éprouvés et instruits, doit fonctionner auprès de la direction centrale et aussi auprès de chaque direction régionale : cette commission doit exercer le contrôle sur les caisses et la comptabilité, et faire des rapports réguliers au grand comité (conseils ou commissions.)

Toute organisation ou tout organe du Parti, ainsi que tout membre, a le droit de communiquer à tout moment et directement à la direction centrale du Parti ou à l’Internationale ses désirs, initiatives, observations ou plaintes.

50. Les directives et les décisions des organes dirigeants du Parti sont obligatoires pour les organisations subordonnées et pour les différents membres.

La responsabilité des organes dirigeants et leur devoir de se protéger contre les retards et les abus de la part des organisations dirigeantes ne peuvent être déterminés que formellement et en partie. Plus leur responsabilité formelle est petite, par exemple, dans les partis illégaux, et plus ils doivent chercher à connaître l'opinion du reste des membres du Parti, à se procurer des informations solides et régulières et à ne prendre de décisions propres qu’après mûre et sérieuse réflexion. 
51. Les membres du Parti doivent dans leur action publique agir toujours en membres disciplinés d'une organisation combattante. Lorsque des divergences d’opinion se produisent sur la manière la plus correcte d'agir, on doit décider sur ces divergences autant que possible avant l'action, au sein des organisations du Parti et n’agir qu'après avoir pris cette décision. Afin que toute décision du Parti soit appliquée avec énergie par toutes les organisations et par tous les membres, il faut appeler autant que possible les masses du Parti à la discussion et à la décision des différentes questions. Les organisations et les instances du Parti ont le devoir de décider si, sous quelle forme et dans quelle mesure, telle ou telle question peut être discutée par les différents camarades devant l'opinion publique du parti (dans la presse, dans des brochures). Mais, même si cette décision de l’organisation ou de la direction du Parti est erronée selon l'avis de certains membres, ceux-ci ne doivent jamais oublier dans leur action publique que la pire infraction disciplinaire et la faute la plus grave qu'on puisse commettre pendant la lutte, c'est de rompre l'unité de front commun ou même de l'affaiblir.

C'est le devoir suprême de tout membre du Parti de défendre contre tous l'Internationale Communiste. Celui qui oublie cela et qui, au contraire, attaque publiquement le Parti ou l'Internationale Communiste doit être traité comme un adversaire du Parti.

Les décisions de l’Internationale Communiste doivent être appliquées sans délai par les Partis adhérents, même au cas où des modifications correspondantes devront être faites aux statuts et aux décisions du Parti, conformément aux statuts.

\section{VIII. - LA LIAISON DU TRAVAIL LÉGAL AVEC LE TRAVAIL ILLÉGAL}

53. Des variations fonctionnelles peuvent se produire selon les différentes phases de la révolution dans la vie courante d'un Parti communiste. Mais, au fond il n’y a pas de différence essentielle dans la structure que doivent s'efforcer d’obtenir un parti légal et un parti illégal. 
Le Parti doit être organisé de telle sorte qu'il puisse s'adapter promptement aux modifications des conditions de la lutte.

Le Parti Communiste doit devenir une organisation de combat capable, d'une part, d'éviter, en champ ouvert, un ennemi en forces supérieures concentrées sur un point et, d'autre part, d'utiliser les difficultés de cet ennemi pour l'attaquer là où il s'y attend le moins. Ce serait la plus grande faute de se préparer exclusivement pour les soulèvements et les combats de rues ou pour les périodes de plus grande oppression. Les communistes doivent accomplir leur travail révolutionnaire préparatoire dans toutes les situations et être toujours prêts à la lutte, car il est souvent presque impossible de prévoir l'alternance des périodes d'éveil et d'accalmie ; on ne pourrait profiter de cette prévision pour réorganiser le Parti parce que le changement est d'habitude trop rapide et arrive même souvent tout à fait par surprise.

54. Les Partis communistes légaux des pays capitalistes n'ont d'ordinaire pas encore suffisamment compris comme étant leur tâche cette préparation en vue de soulèvements révolutionnaires en vue de combats en armes et en général en vue de la lutte illégale. On construit trop souvent l'organisation du Parti en vue d'une action légale prolongée, et selon les exigences des tâches légales quotidiennes.

Dans les partis illégaux, par contre, souvent on ne comprend pas assez qu'il faut utiliser les possibilités d'action légale et construire le Parti de telle sorte qu'il soit en liaison vivante avec les masses révolutionnaires. Les efforts du Parti ont tendance à devenir comme un travail de Sisyphe ou une conspiration impuissante.

Ce deux fautes, aussi bien celle du Parti illégal que celle du Parti légal, sont graves. Tout Parti Communiste légal doit savoir se préparer, de la manière la plus énergique, à la nécessité d'une existence clandestine et être particulièrement armé en vue de soulèvements révolutionnaires. Et d'autre part, chaque Parti communiste illégal doit pouvoir utiliser toutes les possibilités du mouvement ouvrier légal pour devenir, par un travail politique intensif, l'organisateur et le véritable guide des grandes masses révolutionnaires. La direction du travail légal et du travail illégal doit être constamment unie entre les mains de la même direction centrale du Parti. 
55. Dans les Partis légaux, comme dans les Partis illégaux, le travail illégal est souvent conçu comme la fondation et l'entretien d'une organisation fermée, exclusivement militaire et isolée du reste de la politique et de l’organisation du Parti. Cette conception est parfaitement erronée. Dans la période pré-révolutionnaire, la formation de notre organisation de combat doit au contraire être principalement le résultat de l'ensemble de l'action communiste du Parti. Le Parti dans son ensemble doit devenir une organisation de combat pour la révolution.

Les organisations révolutionnaires isolées, de caractère militaire, nées prématurément avant la révolution, montrent trop facilement une tendance à la dissolution et à la démoralisation, parce qu'elles manquent dans le parti, de travail immédiatement utile.

56. Pour un Parti illégal, c’est une chose évidemment de la plus grande importance de toujours éviter à ses membres et ses organes d'être découverts ; il faut donc éviter qu'ils soient livrés par des listes d'enregistrement, par des imprudences dans la distribution des matériaux et le versement des cotisations. Un Parti illégal ne doit donc pas se servir dans la même mesure qu'un Parti légal des formes ouvertes d'organisation pour des buts conspiratifs; il doit cependant s’appliquer à pouvoir le faire de plus en plus.

Toutes les mesures devront être prises pour empêcher des éléments douteux et peu sûrs de pénétrer dans le Parti. Les moyens à employer dans ce but dépendent fortement du caractère du Parti, légal ou illégal, persécuté ou toléré, en voie de croissance ou dans la stagnation. Un moyen qui dans certaines circonstances a pu servir avec efficacité, c'est le système de candidature. Les personnes cherchant à être admises au Parti le sont d'abord comme candidats, sur présentation de deux membres du Parti et selon la façon dont elles s’acquittent des tâches qui leur sont confiées elles sont admises ou non comme membres du Parti.

La bourgeoisie enverra inévitablement des provocateurs et des agents dans les organisations illégales. Il faut mener contre eux une lutte constante et minutieuse : l'une des meilleures méthodes consiste à combiner adroitement l'action légale avec l’illégale. Un travail révolutionnaire légal d’une certaine durée est le meilleur moyen de se rendre compte du degré de confiance que mérite chacun, de sa 
conscience, de son courage, de son énergie, de sa ponctualité ; on saura ainsi qui l’on peut charger d'un travail illégal correspondant le plus à ses capacités.

Un Parti illégal doit se préparer de mieux en mieux contre toute surprise (par exemple, en mettant en sûreté les adresses d’intermédiaires, en détruisant en règle générale les lettres, en conservant soigneusement à l’abri les documents nécessaires, en instruisant clandestinement les agents de liaison, etc...).

57. Notre travail politique général doit être réparti de façon à ce que déjà avant le soulèvement révolutionnaire ouvert se développent et s’affermissent les racines d'une organisation de combat correspondant aux exigences de cette phase. Il est particulièrement important que dans son action la direction du Parti communiste ait constamment en vue ces exigences, qu'elle essaie dans la mesure du possible de se les représenter à l'avance. Elle ne peut certes pas s'en faire une idée exacte et claire, mas ce n'est pas une raison pour négliger le point de vue essentiel de la direction de l'organisation communiste.

Car si un changement fonctionnel survient dans le Parti Communiste au moment du soulèvement révolutionnaire déclaré, le Parti le mieux organisé peut se trouver placé en face de problèmes extrêmement difficiles et compliqués. Il peut arriver qu’on soit obligé dans un intervalle de quelques jours de mobiliser le Parti pour une lutte armée ; de mobiliser non seulement le Parti, mais aussi ses réserves, d'organiser les sympathisants et tout l'arrière-ban, c'est-à-dire les masses révolutionnaires non organisées. Il ne saurait être question à un tel moment de former une armée rouge régulière. Nous devons vaincre sans armée construite à l'avance, seulement avec les masses placées sous la direction du Parti. Si donc notre Parti n'est pas préparé à l'avance par son organisation en vue de ce cas, la lutte la plus héroïque ne servira à rien.

58. Dans des situations révolutionnaires, on a remarqué à plusieurs reprises que les directions centrales révolutionnaires ne se sont pas montrées à la hauteur de leur tâche. Dans l’organisation au degré inférieur, le prolétariat a pu montrer des qualités magnifiques pendant la révolution ; mais dans son Etat-Major le désordre, le chaos et l'impuissance règnent le plus souvent. Il y manque parfois même la plus élémentaire division du travail, le service d’information est le plus 
souvent si mauvais qu'il présente plus d'inconvénients que d'utilité ; le service de liaison ne mérite aucune confiance. Lorsqu'on a besoin de poste secrète, de transport, d'abris, d'imprimerie clandestine, on ne les obtient ordinairement que par suite d'un hasard heureux. Toute provocation de la part de l'ennemi organisé a une chance de réussir.

Et il n'en saurait être autrement, si le Parti révolutionnaire qui a la direction ne s'est pas organisé à l'avance. Ainsi par exemple, la surveillance et la découverte de la police politique exigent une expérience spéciale ; un appareil pour la liaison secrète ne peut fonctionner avec promptitude et sûreté que s'il a un long entraînement. Dans tous ces domaines de l'activité révolutionnaire spéciale, tout Parti communiste légal doit faire des préparations secrètes, si minimes soient-elles.

En grande partie, dans ce domaine aussi, l'appareil nécessaire peut être développé par une action tout à fait légale, Si l'on veille pendant le fonctionnement de cet appareil à ce qu'on puisse immédiatement le transformer en appareil illégal. Ainsi par exemple, l'organisation chargée de la distribution, exactement réglée, des tracts légaux, des publications et des lettres peut être transformée en appareil secret de liaison (service de courriers, postes secrètes, logements secrets, transports conspiratifs, etc...).

59. L'organisateur communiste doit voir à l'avance tout membre du Parti et tout militant révolutionnaire dans son rôle historique futur de soldat de notre organisation de combat, pendant l'époque de la révolution. Ainsi il peut l'appliquer à l'avance, dans le noyau dont il fait partie, au travail correspondant le mieux à son poste et à son service futurs. Son action actuelle doit toutefois constituer un service utile en soi et nécessaire à la lutte présente, et non pas seulement un exercice, que l'ouvrier pratique ne comprendrait pas immédiatement ; mais cette activité est en partie aussi un exercice en vue des exigences les plus essentielles de la lutte finale de demain. 
Manifestes, thèses et résolutions

des quatre premiers congrès

de l’Internationale communiste 1919-1923

(juin 1934)

Troisième Congrès, juin 1921.

-5 -

\section{Résolution sur l'organisation de l’Internationale Communiste}

$\underline{\text { Retour à la table des matières }}$

Le Comité Exécutif de l'Internationale Communiste doit être organisé de telle sorte qu'il puisse prendre position sur toutes les questions d'action du prolétariat. Dépassant les cadres des appels généraux tels qu’ils étaient lancés jusqu’à présent sur telle ou telle question en discussion, le Comité Exécutif doit de plus en plus chercher à trouver les moyens et les voies pour développer son initiative pratique quant à l'action commune des différentes sections dans les questions internationales d'organisation et de propagande en discussion. L'Internationale Communiste doit devenir une Internationale de fait, une Internationale dirigeant les luttes communes et quotidiennes du prolétariat révolutionnaire de tous les pays. Les conditions indispensables pour cela sont les suivantes :

1. Les Partis adhérents à l'internationale Communiste doivent faire tout ce qui est en leur pouvoir pour maintenir le contact le plus étroit et le plus actif avec le Comité Exécutif ; ils ne doivent pas seulement envoyer au sein de l'Exécutif les meilleurs représentants de leur pays, mais encore lui faire parvenir de façon permanente les informations les plus prudentes et les plus circonspectes, afin qu'il 
puisse prendre position en s'appuyant de documents et informations approfondis sur les problèmes politiques qui surgissent. Pour l'élaboration fructueuse de ces matériaux, l'Exécutif doit organiser des sections spéciales pour les différentes branches. En outre, un Institut international d'Economie et de Statistique du mouvement ouvrier et du communisme doit être créé auprès de l’Exécutif.

2. Les partis adhérents doivent entretenir les rapports les plus étroits pour leur information mutuelle et leur liaison organique, en particulier lorsque ces partis sont voisins et par suite également intéressés aux conflits politiques engendrés par les antagonismes capitalistes. Le meilleur moyen d'établir actuellement ces relations est l'envoi réciproque des résolutions des plus importantes conférences et l'échange général de militants bien choisis. Cet échange doit devenir un usage permanent et immédiat de toute section capable d'agir.

3. L'Exécutif doit provoquer la fusion nécessaire de toutes les sections nationales en un Parti international cohérent de propagande et d'action prolétariennes communes et pour cela publier en Europe Occidentale, dans les langues les plus importantes, une correspondance politique, à l'aide de laquelle l'idée communiste sera mise en valeur d'une manière de plus en plus claire et uniforme et qui, par une information fidèle et régulière, fournira aux différentes sections la base d'une action énergique et simultanée.

4. L'envoi de représentants autorisés dans les sections permettra au Comité Exécutif d'appuyer par le fait la tendance à une véritable Internationale de la lutte quotidienne et commune du prolétariat de tous les pays. Ces représentants auront pour tâche d'informer l'Exécutif des conditions particulières dans lesquelles les Partis Communistes ont à lutter dans les pays capitalistes ou coloniaux. Ils devront veiller ensuite à ce que ces partis conservent le contact le plus intime aussi bien avec l'exécutif qu'entre eux, afin d'augmenter la puissance d'attaque de l'un et des autres. L'Exécutif, de même que les Partis, devront veiller à ce que les rapports mutuels entre adhérents, tant personnels par camarades de confiance, que par correspondances écrites, deviennent plus fréquents et plus prompts de façon à pouvoir dans toutes les grandes questions politiques prendre une position unanime.

5. Pour être en mesure de déployer une activité aussi considérablement accrue, l'Exécutif doit être fortement élargi. Les sections auxquelles ce congrès a accordé 
40 voix, ainsi que le Comité Exécutif de l’Internationale de la Jeunesse Communiste, auront chacun deux voix à l'Exécutif ; les sections qui ont eu 30 et 20 voix au Congrès en auront une. Le Parti Communiste de Russie dispose comme par le passé de 5 voix. Les représentants des autres sections ont voix consultative. Le président de l’Exécutif est élu par le Congrès. L’Exécutif est chargé de désigner trois secrétaires, qui seront choisis autant que possible dans des sections différentes. En outre, les membres délégués au Comité Exécutif par les différentes sections sont obligés de prendre part comme rapporteurs à l'expédition du travail courant, soit en dirigeant la section nationale correspondante, soit en se chargeant de l'étude de tel ou tel domaine. Les membres du Petit Bureau d'affaires sont élus par un vote spécial du Comité Exécutif.

6. Le siège de l'Exécutif est en Russie, premier Etat prolétarien. L'Exécutif, à l'effet de centraliser plus solidement la direction politique et organique de toute l'Internationale, devra toutefois chercher à étendre le cercle de son influence au moyen de conférences qu'il organisera hors de Russie. 
Manifestes, thèses et résolutions

des quatre premiers congrès

de l’Internationale communiste 1919-1923

(juin 1934)

Troisième Congrès, juin 1921.

- 6 -

\section{Résolution sur l'action de Mars et sur le Parti Communiste Unifié d'Allemagne}

$\underline{\text { Retour à la table des matières }}$

Le $3^{\mathrm{e}}$ Congrès mondial constate avec satisfaction que les résolutions les plus importantes, et particulièrement la partie de la résolution sur la tactique, concernant l'action ardemment discutée de mars, ont été adoptées à l'unanimité et que même les représentants de l'opposition allemande dans leur résolution sur l'action de mars se sont placés en fait sur un terrain identique à celui du Congrès.

Le Congrès y voit une preuve qu'un travail cohérent et une collaboration intime sur la base des décisions du $3^{\mathrm{e}}$ Congrès sont non seulement désirés, mais encore possibles au sein du Parti Communiste Unifié d'Allemagne. Le Congrès estime que tout morcellement des forces au sein du Parti Communiste Unifié d'Allemagne, toute formation de fractions, sans parler même de scission, constitue le plus grand danger pour l'ensemble du mouvement.

Le Congrès attend de la Direction Centrale et de la majorité du Parti Communiste Unifié d'Allemagne une attitude tolérante à l'égard de l'ancienne opposition, pourvu qu'elle applique loyalement les décisions prises par le $3^{\mathrm{e}}$ Congrès ; celui- 
ci est de plus persuadé que la Direction Centrale fera tout son possible pour réunir toutes les forces du Parti.

Le Congrès demande à l'ancienne opposition de dissoudre immédiatement toute organisation de fraction, de subordonner absolument et complètement sa fraction parlementaire à la Direction Centrale, de subordonner entièrement la Presse aux organisations respectives du Parti, de cesser immédiatement toute collaboration (dans des revues, etc...) avec Paul Levi, exclu du Parti et de l'Internationale Communiste.

Le Congrès charge l'Exécutif de suivre attentivement le développement ultérieur du mouvement allemand et de prendre immédiatement les mesures les plus énergiques dans le cas de la moindre infraction à la discipline. 
Manifestes, thèses et résolutions

des quatre premiers congrès

de l'Internationale communiste 1919-1923

(juin 1934)

Troisième Congrès, juin 1921.

- 7 -

\title{
Thèses et résolution sur la tactique du Parti Communiste de Russie
}

\author{
I. - LA SITUATION INTERNATIONALE \\ DE LA RÉPUBLIQUE FÉDÉRATIVE \\ DES SOVIETS DE RUSSIE
}

\section{$\underline{\text { Retour à la table des matières }}$}

La situation internationale de la R.S.F.S.R. est caractérisée actuellement par un certain équilibre, lequel, tout en étant extrêmement instable, a cependant créé une conjoncture originale dans la politique universelle.

Cette originalité consiste en ce qui suit : d'une part, la bourgeoisie internationale est pleine d'une haine et d'une hostilité furieuse envers la Russie Soviétique et est prête à chaque instant à se précipiter pour l'étouffer. D'autre part, toutes les tentatives d'intervention armée, qui ont coûté à cette bourgeoisie des centaines de millions de francs, se sont terminées par une complète faillite, bien que le Pouvoir des Soviets fût alors plus faible qu'aujourd'hui, et que les grands propriétaires et les capitalistes russes eussent des armées entières sur le territoire de la R.S.F.S.R. L'opposition contre la guerre avec la Russie Soviétique s'est extrêmement fortifiée dans tous les pays capitalistes, nourrissant le mouvement révolutionnaire du prolétariat et embrassant des masses très vastes de la démocratie petite- 
bourgeoise. La diversité d'intérêts existant entre les différents Etats impérialistes s'est exaspérée et s'exaspère de jour en jour de façon plus profonde. Le mouvement révolutionnaire parmi les centaines de millions d'individus des populations opprimées de l'Orient s'accroît avec une force remarquable. En conséquence de toutes ces conditions, l'impérialisme international s'est trouvé hors d'état d'étouffer la Russie Soviétique, bien qu'il fût beaucoup plus fort qu'elle, et a été contraint pour le moment de la reconnaître ou de la presque reconnaître et d'entrer en tractations commerciales avec elle.

Le résultat a été un équilibre peut-être extrêmement branlant, extrêmement instable, mais un équilibre pourtant, permettant à la République Socialiste d'exister, pour un temps peu prolongé évidemment, dans son environnement capitaliste.

\section{LE RAPPORT DES FORCES SOCIALES DANS LE MONDE ENTIER}

Sur la base de cet état de choses, le rapport des forces sociales dans le monde entier s'est établi de la façon suivante :

La bourgeoisie internationale, privée du moyen de mener une guerre déclarée contre la Russie Soviétique, reste dans l'expectative, guettant le moment où les circonstances lui permettront de reprendre cette guerre.

Le prolétariat des pays capitalistes avancés a déjà partout détaché en avant de lui une avant-garde en la personne des partis communistes, qui grandissent, marchant sans relâche à la conquête de la majorité du prolétariat dans chaque pays, ruinant l'influence des anciens bureaucrates trade-unionistes et les sommets de la classe ouvrière américaine et occidentale corrompus par les privilèges impérialistes.

La démocratie petite-bourgeoise des Etats capitalistes, représentée dans sa partie avancée par les Internationales 2 et 2 112,2, est actuellement le soutien princi-

pal du capitalisme, dans la mesure où son influence s'étend encore sur la majorité ou sur une partie considérable des ouvriers et des employés de l'industrie et du commerce, qui craignent, en cas de révolution, de perdre leur bien-être petit- 
bourgeois relatif, résultant des privilèges de l'impérialisme. Mais la crise économique grandissante empire partout la situation des masses, et cette circonstance, ajoutée à la fatalité de plus en plus évidente de nouvelles guerres impérialistes si le capitalisme subsiste, rend ce soutien de plus en plus branlant.

Les masses laborieuses des pays coloniaux et semi-coloniaux, masses composant l'énorme majorité de la population du globe, ont été éveillées à la vie politique dès le début du $\mathrm{Xx}^{\mathrm{e}}$ siècle, grâce en particulier aux révolutions de Russie, de Turquie, de Perse et de Chine. La guerre impérialiste de 1914-1918 et le Pouvoir des Soviets en Russie transforment définitivement ces masses en un facteur actif de la politique universelle, et de destruction révolutionnaire de l'impérialisme, quoique les petits-bourgeois éclairés d'Europe et d'Amérique s'obstinent toujours à ne pas le voir, et dans ce nombre, les leaders des Internationales 2 et $\frac{1}{2} 2$. L'Inde britannique est à la tête de ces pays, et là la révolution grandit d'autant plus rapidement que d'une part le prolétariat industriel et ferroviaire y devient plus considérable et que d'autre part devient plus sauvage la terreur exercée par les Anglais, lesquels recourent de plus en plus souvent même à des meurtres en masse (Amritsar), à des flagellations publiques, etc...

\section{LE RAPPORT DES FORCES SOCIALES EN RUSSIE}

La situation politique intérieure de la Russie Soviétique est déterminée par le fait que dans ce pays nous voyons, pour la première fois au cours de l'histoire universelle, l'existence, pendant plusieurs années, de deux classes seulement : le prolétariat éduqué pendant plusieurs dizaines d'années par une industrie mécanique très jeune, mais néanmoins moderne et grande, et la classe des petits paysans, composant l'énorme majorité de la population.

Les grands propriétaires fonciers et les grands capitalistes n'ont pas disparu en Russie. Mais ils ont été soumis à une complète expropriation, parfaitement défaits politiquement, en tant que classe, et leurs débris seulement se cachent parmi les employés gouvernementaux du pouvoir des Soviets. Leur organisation de classe ne s'est conservée qu'à l'étranger, sous la forme d'une émigration, qui compte vraisemblablement de un million et demi à deux millions d'hommes, et qui pos- 
sède plus d'une demi-centaine de journaux quotidiens de tous partis bourgeois et « socialistes » (c'est-à-dire petits-bourgeois) ainsi que les débris d'une armée et de multiples liaisons avec la bourgeoisie internationale. Cette émigration travaille de toutes ses forces et par tous les moyens à ruiner le pouvoir des Soviets et à restaurer le capitalisme en Russie.

\section{LE PROLÉTARIAT ET LA CLASSE PAYSANNE EN RUSSIE}

Etant donné cette situation intérieure, le prolétariat russe, en tant que classe dominante, doit se proposer principalement pour le moment de déterminer judicieusement et de réaliser les mesures indispensables pour diriger la classe paysanne, pour maintenir une alliance ferme avec elle, pour parcourir les nombreuses étapes successives conduisant à la collectivisation en grand de l'agriculture. Cette tâche en Russie est particulièrement difficile, tant en vertu du caractère retardataire de notre pays que par suite de sa désolation extrême après sept ans de guerre impérialiste et civile. Mais, outre cette particularité, cette tâche appartient au nombre des problèmes les plus difficiles de l'organisation socialiste, problèmes qui se poseront dans tous les Etats capitalistes, à la seule exception, peut-être, de l'Angleterre. Cependant, même en ce qui concerne l'Angleterre, il est impossible d'oublier que si la classe des petits cultivateurs-fermiers y est spécialement peu nombreuse, par contre, on y trouve une proportion exceptionnellement élevée d'ouvriers et d'employés ayant une existence petite-bourgeoise, grâce à l'esclavage de fait de centaines de millions d'habitants des colonies «appartenant » à l’Angleterre.

C’est pourquoi, du point de vue de l'évolution de la révolution prolétarienne universelle en tant que processus d'ensemble, l'importance de l'époque traversée par la Russie consiste en ce qu'elle permet d'éprouver et de vérifier par la pratique la politique d'un prolétariat tenant en main le pouvoir gouvernemental, par rapport à une masse petite-bourgeoise. 


\section{L'ALLIANCE MILITAIRE DU PROLÉTARIAT ET DE LA CLASSE PAYSANNE DANS LA R.S.F.S.R.}

Les fondements de relations réciproques rationnelles entre le prolétariat et la classe paysanne ont été posés dans la Russie Soviétique par l'époque de 19171921, alors que l'invasion des capitalistes et des grands propriétaires - soutenus à la fois par toute la bourgeoise mondiale et par tous les partis de la démocratie petite-bourgeoise (socialistes-révolutionnaires et mencheviks) — a engendré, fixé et précisé l'alliance militaire du prolétariat et de la classe paysanne pour la défense du pouvoir des Soviets. La guerre civile est la forme la plus aiguë de la lutte de classes, et plus cette lutte prend d'activité, plus rapidement et plus clairement la pratique elle-même montre aux couches même les plus retardataires de la classe paysanne que cette classe ne peut être sauvée que par la dictature du prolétariat, tandis que les socialistes-révolutionnaires et les mencheviks jouent effectivement le rôle de valets des grands propriétaires et des capitalistes.

Mais si l'alliance militaire du prolétariat et de la classe paysanne a été - et elle ne pouvait pas ne pas l'être - la première forme de leur alliance solide, cela n'empêche qu'elle ne pourrait se maintenir, même quelques semaines, sans une certaine alliance économique de ces deux mêmes classes. Le paysan a reçu de l'Etat ouvrier toute la terre et la protection contre le grand propriétaire et l'exploiteur villageois ; les ouvriers ont reçu des paysans des produits alimentaires à crédit en attendant le rétablissement de la grande industrie. 


\section{COMMENT RÉTABLIR LES RELATIONS ÉCONOMIQUES RATIONNELLES ENTRE LE PROLÉTARIAT ET LA CLASSE PAYSANNE?}

Une alliance entièrement rationnelle et stable du point de vue socialiste entre les petits paysans et le prolétariat ne peut s'établir que le jour où les transports et la grosse industrie, étant complètement rétablis, permettront au prolétariat de donner aux paysans, en échange des produits alimentaires, tous les objets dont ils ont besoin pour leur usage et pour l'amélioration de leur exploitation. Vu la désolation immense du pays, il a été absolument impossible d'atteindre ce résultat du premier coup. Les réquisitions ont constitué la mesure gouvernementale la plus accessible à un Etat insuffisamment organisé pour lui permettre de se maintenir dans une guerre invraisemblablement difficile contre les grands propriétaires. La mauvaise récolte de 1920 a particulièrement empiré la misère déjà lourde des paysans, rendant absolument nécessaire un changement immédiat d'orientation dans le sens de l'impôt alimentaire.

Cet impôt modéré donne du coup un grand soulagement à la situation de la classe paysanne, et l'intéresse en même temps à étendre la surface ensemencée et à améliorer ses procédés de culture.

L'impôt alimentaire constitue une étape intermédiaire entre la réquisition de tous les excédents de céréales du paysan et l'échange rationnel des produits que prévoit le socialisme entre l'industrie et l'agriculture. 


\section{LA NATURE ET LES CONDITIONS D'ADMISSION PAR LE POUVOIR DES SOVIETS, DU CAPITALISME ET DES CONCESSIONS}

L’impôt alimentaire, de par son essence même, équivaut pour le paysan à la liberté de disposer des excédents qui lui restent après versement de l’impôt. Dans la mesure où l'Etat ne sera pas capable d'offrir aux paysans des produits de l'industrie socialiste en échange du total de ces excédents, dans la même mesure la liberté de commerce qui en résulte équivaut inévitablement à une liberté de développement pour le capitalisme.

Néanmoins, dans les limites indiquées, la chose n’est aucunement redoutable pour le socialisme, tant que les transports et la grande industrie demeurent entre les mains du prolétariat. Au contraire, le développement du capitalisme sous le contrôle et la réglementation de l'Etat prolétarien (c'est-à-dire le développement du capitalisme « d'Etat », dans ce sens-là du mot) est avantageux et indispensable dans un pays de petits paysans, extrêmement ruiné et retardataire (naturellement jusqu’à un certain point seulement), pour autant qu’il en résulte une accélération immédiate du progrès de la culture paysanne.

Cela se rapporte davantage encore aux concessions. Sans opérer aucune dénationalisation, l'Etat ouvrier remet à bail certaines mines, certains secteurs forestiers, certaines exploitations pétrolifères, etc..., à des capitalistes étrangers, afin de recevoir d'eux un supplément d'outillage et de machines lui permettant de hâter le rétablissement de la grande industrie soviétique.

Le dédommagement accordé aux concessionnaires sous la forme d'un pourcentage prélevé sur des produits d'une haute valeur est sans aucun doute un tribut payé par l'Etat ouvrier à la bourgeoisie internationale. Sans dissimuler aucunement ce fait, nous devons nettement comprendre qu'il nous est avantageux de verser ce tribut, si par là nous obtenons plus rapidement le rétablissement de notre grande industrie et l'amélioration sérieuse du sort des ouvriers et des paysans. 


\section{LES SUCCÈS DE NOTRE POLITIQUE ALIMENTAIRE}

La politique alimentaire de la Russie Soviétique dans la période de 1917 à 1921 a été sans doute très grossière, très imparfaite, et a donné lieu à beaucoup d'abus. De nombreuses erreurs ont été commises dans sa mise en pratique, mais elle était la seule possible dans les conditions données, si nous la considérons dans son ensemble. Et elle a rempli sa mission historique : elle a sauvé la dictature prolétarienne dans un pays ruiné et retardataire. C’est un fait indéniable qu'elle s'est progressivement perfectionnée. Dans la première année où notre pouvoir a été complet ( $1^{\mathrm{er}}$ août $1918-1^{\mathrm{er}}$ août 1919), l'Etat a rassemblé 110 millions de pouds de céréales. Dans la deuxième année : 220 millions, dans la troisième : plus de 285.

Munis aujourd'hui d'une expérience pratique, nous nous proposons de rassembler, et nous comptons y réussir, 400 millions de pouds (l'impôt alimentaire a été fixé à 240 millions). C'est seulement à la condition d'être effectivement détenteur d'un fonds alimentaire suffisant que l'Etat ouvrier sera en mesure, de tenir solidement au point de vue économique, de garantir un rétablissement, lent mais régulier, de la grande industrie, et de constituer un système financier rationnel.

\section{LA BASE MATÉRIELLE DU SOCIALISME ET LE PLAN D'ÉLECTRIFICATION DE LA RUSSIE}

L'unique base matérielle que puisse avoir le socialisme est la grande industrie mécanique, capable de réorganiser l'agriculture elle-même Mais on ne saurait se borner à cette proposition générale. Il faut la concrétiser. La grande industrie répondant au niveau de la technique moderne et capable de réorganiser l'agriculture, c'est l'électrification de tout le pays. Nous avons dû exécuter les travaux scientifiques préparatoires de ce plan d'électrification pour la R.S.F.S.R., et nous les avons exécutés. Avec la collaboration de plus de 200 des meilleurs savants, ingénieurs et agronomes de Russie, ce travail a été terminé, imprimé sous 
la forme d'un gros volume et approuvé dans son ensemble par le $8^{\mathrm{e}}$ Congrès Panrusse des Soviets en décembre 1920. Aujourd'hui nous sommes déjà prêts à la convocation d'un Congrès Panrusse d'électrotechniciens, qui se rassemblera au mois d'août 1920 et qui examinera en détail ce travail, lequel recevra alors la sanction définitive de l'Etat. Les travaux d'électrification déclarés de première urgence s'étendent sur une durée de dix ans et exigeront 370 millions environ de journées d'ouvriers.

En 1918, nous avions seulement 8 stations électriques nouvellement construites avec 4557 kilowatts. En 1919 ce chiffre s'est élevé a 36 avec 1648 kilowatts, et en 1920 à 100 avec 8699 kilowatts.

Si modestes que soient ces débuts pour notre immense pays, néanmoins le fondement est posé, le travail est commencé et avance de mieux en mieux. Le paysan russe, après la guerre impérialiste, après un million de prisonniers qui se sont familiarisés en Allemagne avec la technique moderne perfectionnée, après la dure mais profitable expérience de trois années de guerre civile, n’est plus ce qu'il était autrefois. De mois en mois il voit avec plus de clarté et plus d'évidence que seule la direction du prolétariat est capable d'arracher la masse des petits cultivateurs à l'esclavage du capital pour la conduire au socialisme.

\section{LE RÔLE DE LA “ DÉMOCRATIE PURE " DES INTERNATIONALES 2 ET 2 1/2, DES SOCIALISTES- RÉVOLUTIONNAIRES ET DES MENCHEVIKS EN TANT QU'ALLIÉS DU CAPITAL}

La dictature du prolétariat ne signifie pas la cessation de la lutte de classes, mais bien sa continuation sous une forme nouvelle, avec des armes nouvelles. Aussi longtemps que subsistent les classes, aussi longtemps que la bourgeoisie, renversée dans un pays, décuple ses attaques contre le socialisme dans le monde entier, cette dictature est indispensable. La classe des petits propriétaires fonciers ne peut pas ne pas passer par une série d'oscillations, pendant l'époque de transition. Les difficultés de la situation transitoire, l'influence de la bourgeoisie, suscitent inévitablement de temps à autre des fluctuations dans la mentalité de cette masse. C’est au prolétariat, affaibli et, jusqu’à un certain point, déclassé par la 
désorganisation de sa base vitale, la grande industrie mécanique, qu'incombe la tâche, très difficile et la plus grande de toutes historiquement, de tenir bon en dépit de ces fluctuations et de mener à bon terme son œuvre consistant à affranchir le travail du joug du capital.

Les fluctuations de la petite bourgeoisie trouvent leur expression politique dans la politique des partis de la démocratie petite-bourgeoise, c'est-à-dire des partis des internationales 2 et $2 \frac{1}{1} 2$, représentés en Russie par les «socialistesrévolutionnaires » et les mencheviks. Ces partis, qui ont aujourd'hui leurs EtatsMajors et leurs journaux à l'étranger, font bloc avec toute la contre-révolution bourgeoise et sont ses fidèles serviteurs.

Les chefs intelligents de la grande bourgeoisie russe, Milioukov en tête, le leader du parti cadet («Constitutionnel-Démocrate »), ont apprécié avec une clarté, une exactitude et une franchise complètes le rôle ainsi joué par la démocratie petite-bourgeoise, c'est-à-dire les socialistes-révolutionnaires et les mencheviks. A propos de la mutinerie de Cronstadt, qui a manifesté l'union des forces des mencheviks, des socialistes-révolutionnaires et des gardes-blancs, Milioukov s'est prononcé en faveur de la devise : «Les Soviets sans les Bolchéviks ». Développant cette pensée, il a écrit: "Honneur et place libre » aux socialistesrévolutionnaires et aux mencheviks (« Pravda » 1921, numéro de Paris) car à eux incombe la tâche de faire le premier déplacement du pouvoir en s’écartant des bolchéviks. Milioukov, chef de la grande bourgeoisie, tient judicieusement compte des leçons fournies par toutes les révolutions, qui ont montré que la démocratie petite-bourgeoise est incapable de garder le pouvoir, puisqu'elle n'a jamais été qu'un masque pour la dictature de la grosse bourgeoisie et qu'un degré conduisant à l'autocratie de la grosse bourgeoisie.

La révolution prolétarienne de Russie confirme une fois de plus cette leçon des révolutions de 1789-1794 et de 1848-1849, et confirme aussi les paroles de Frédéric Engels, écrivant le 11 décembre 1885, dans une lettre à Bebel : «...La démocratie pure... au moment de la révolution acquiert pour un temps limité une importance temporaire... en tant que dernière planche de salut pour tout le système économique bourgeois et même féodal... En 1848, de mars à septembre, toute la masse féodale et bureaucratique n'a jamais cessé de soutenir les libéraux pour maintenir dans l'obéissance les masses révolutionnaires. Dans tous les cas, pendant la crise et au lendemain de la crise, notre unique adversaire sera toute la mas- 
se réactionnaire, groupée autour de la démocratie pure, et cette vérité, à mon avis, ne doit en aucun cas être perdue de vue. » (publié en russe dans le journal «Le Travail Communiste » n 360 du 9 juin 1921, dans l'article d’Adoratski, intitulé « Marx et Engels sur la démocratie » et en allemand dans le livre « Frédéric Engels : Testament politique » Berlin 1920. Bibliothèque Internationale de la Jeunesse $\mathrm{n}^{\circ} 12$, pages $\left.18-19\right)$. 
Manifestes, thèses et résolutions

des quatre premiers congrès

de l'Internationale communiste 1919-1923

(juin 1934)

Troisième Congrès, juin 1921.

- 8 -

\section{Résolution sur la tactique du Parti communiste de Russie}

$\underline{\text { Retour à la table des matières }}$

Le troisième Congrès mondial de l'Internationale Communiste, après avoir entendu le discours du camarade Lénine sur la tactique du Parti Communiste de Russie et après avoir pris connaissance des thèses qui y sont annexées, déclare :

Le troisième Congrès mondial de l'Internationale Communiste admire le prolétariat russe, qui a lutté pendant 4 ans pour la prise du pouvoir politique. Le Congrès approuve à l'unanimité la politique du Parti Communiste de Russie qui depuis le début a reconnu en toute situation les dangers qui le menaçaient, qui est resté fidèle aux principes du marxisme révolutionnaire, qui a su toujours trouver moyen de les appliquer, qui aujourd'hui encore, après la fin de la guerre civile, concentre toujours par sa politique envers la classe paysanne dans la question des concessions et la reconstruction de l'industrie toutes les forces du prolétariat, dirigé par le parti Communiste de Russie en vue de garder la dictature du prolétariat en Russie jusqu'au moment où le prolétariat de l'Europe occidentale lui viendra en aide. 
Le Congrès exprime sa conviction, que ce n'est que grâce à cette politique consciente et logique du Parti Communiste de Russie que la Russie Soviétique est encore la première et la plus importante citadelle de la révolution mondiale.

Le Congrès blâme la politique de trahison des partis mencheviks, qui ont renforcé, grâce à leur opposition contre la Russie soviétique et contre la politique du Parti Communiste de Russie, la lutte de la réaction capitaliste contre la Russie, et qui tâchent de retarder la révolution sociale dans le monde entier.

Le Congrès mondial invite le prolétariat de tous les pays à se ranger du côté des ouvriers et des paysans russes pour réaliser la révolution d'octobre dans le monde entier.

Vive la lutte pour la dictature du prolétariat !

Vive la Révolution Socialiste mondiale ! 
Manifestes, thèses et résolutions

des quatre premiers congrès

de l’Internationale communiste 1919-1923

(juin 1934)

Troisième Congrès, juin 1921.

- 9 -

\title{
L'Internationale Communiste et l'Internationale Syndicale Rouge
}

\author{
(La lutte contre l'Internationale jaune d'Amsterdam)
}

$\underline{\text { Retour à la table des matières }}$

La bourgeoisie tient dans l'esclavage la classe ouvrière, non seulement par la force brutale, mais aussi par des tromperies raffinées. L'école, l'église, le parlement, les arts, la littérature, la presse quotidienne, sont autant de puissants instruments dont se sert la bourgeoisie pour abrutir les masses ouvrières et faire pénétrer les idées bourgeoises parmi le prolétariat.

Au nombre de ces idées bourgeoises que la classe dominante a réussi a insinuer aux masses laborieuses, se trouve l'idée de la neutralité des Syndicats, de leur caractère apolitique, étranger à tout parti.

Depuis les dernières décades de l'histoire contemporaine et en particulier depuis la fin de la guerre impérialiste, dans toute l'Europe et en Amérique, les Syndicats sont les organisations les plus nombreuses du prolétariat: dans certains Etats ils embrassent même toute la classe ouvrière sans exception. La bourgeoisie comprend parfaitement que le sort du régime capitaliste dépend aujourd'hui de 
l'attitude de ces syndicats à l'égard de l'influence bourgeoise universelle et de ses valets social-démocrates pour maintenir coûte que coûte les syndicats captifs des idées bourgeoises.

La bourgeoise ne peut pas inviter ouvertement les syndicats ouvriers à soutenir les partis bourgeois. C'est pourquoi elle les invite à ne soutenir aucun parti, sans excepter le parti du communisme révolutionnaire.

La devise de la « neutralité » ou de « l'apolitisme » des syndicats a déjà derrière elle un long passé. Au cours d’une dizaine d’années, cette idée bourgeoise a été inoculée aux syndicats d'Angleterre, d’Allemagne d'Amérique et des autres pays, tant aux chefs des syndicats bourgeois à la Hirsch-Dunker qu'aux dirigeants des syndicats cléricaux et chrétiens, tant aux représentants des soi-disant syndicats libres d'Allemagne qu'aux leaders des vieilles et pacifiques trade-unions anglaises, et à beaucoup d'autres partisans du syndicalisme. Legien, Gompers, Jouhaux, Sidney Webb, pendant des années et des dizaines d’années, ont prêché aux syndicats la neutralité.

En réalité, les syndicats n’ont jamais été neutres et n’auraient jamais pu l’être, même s’ils l'avaient voulu. La neutralité des syndicats ne pourrait être que nuisible à la classe ouvrière, mais elle est même irréalisable. Dans le duel entre le travail et le capital, aucune grande organisation ouvrière ne peut demeurer neutre. Par conséquent les syndicats ne peuvent pas être neutres entre les partis bourgeois et le parti du prolétariat. Les partis bourgeois s’en rendent parfaitement compte. Mais de même que la bourgeoisie a besoin que les masses croient à la vie éternelle, elle a besoin qu'on croie également que les syndicats peuvent être apolitiques et peuvent conserver la neutralité à l'égard du parti communiste ouvrier. Pour que la bourgeoisie puisse continuer à dominer et à pressurer les ouvriers pour en tirer sa plus-value, elle n’a pas besoin seulement du prêtre, du policier, du général, il lui faut encore le bureaucrate syndical, le « leader ouvrier » qui prêche aux syndicats ouvriers la neutralité et l’indifférence dans la lutte politique.

Même avant la guerre impérialiste, la fausseté de cette idée de neutralité devenait de plus en plus évidente pour les prolétaires conscients d'Europe et d'Amérique. A mesure que les antagonismes sociaux s'exaspèrent, le mensonge devient encore plus frappant. Lorsque commença la boucherie impérialiste, les 
anciens chefs syndicaux se trouvèrent contraints de jeter le masque de la neutralité et de marcher franchement chacun avec « sa » bourgeoisie.

Pendant la guerre impérialiste, tous les social-démocrates et les syndicalistes, qui avaient passé des années à prêcher aux syndicats l'indifférence politique, lancèrent en réalité ces mêmes syndicats au service de la plus sanglante et de la plus vile politique des partis bourgeois. Eux, champions hier de la neutralité, on les voit agir maintenant comme les agents déclarés de tel parti politique, sauf un seul, le parti de la classe ouvrière.

Après la fin de la guerre impérialiste, ces mêmes chefs social-démocrates et syndicalistes essayent de nouveau d'imposer aux syndicats le masque de la neutralité et de l'apolitisme. Le danger militaire étant passé, ces agents de la bourgeoisie s'adaptent aux circonstances nouvelles et, de plus, essayent de faire dévier les ouvriers de la voie révolutionnaire dans celle qui est avantageuse à la bourgeoisie.

L'économique et la politique ont toujours été indissolublement liées l'une et l'autre. Ce lien est particulièrement indissoluble à des époques comme celle que nous traversons. Il n'est pas une seule question importante de la vie politique qui ne doive intéresser à la fois le parti ouvrier et le syndicat ouvrier. Inversement, il n’est pas une question économique importante qui puisse intéresser le syndicat sans intéresser à la fois le parti ouvrier.

Lorsqu'en France le gouvernement impérialiste décrète la mobilisation de certaines classes pour occuper le bassin de la Ruhr ou pour opprimer l'Allemagne en général, un syndicat français réellement prolétarien peut-il dire que c’est là une question strictement politique qui ne doit pas intéresser les syndicats ? Un syndicat français véritablement révolutionnaire peut-il se déclarer « neutre » ou « apolitique » dans cette question?

Ou bien, si inversement, en Angleterre, il se produit un mouvement purement économique comme la dernière grève des mineurs, le parti communiste a-t-il le droit de dire que cette question ne le concerne pas et intéresse uniquement les syndicats ? Lorsque la lutte est engagée contre la misère et la pauvreté endurées par des millions de sans-travail, lorsqu'on est obligé de poser pratiquement la question de la réquisition des logements bourgeois pour soulager les besoins du prolétariat, lorsque des masses de plus en plus nombreuses d'ouvriers sont 
contraintes par la vie même de mettre à l'ordre du jour l'armement du prolétariat, lorsque dans un pays ou un autre, les ouvriers organisent l'occupation des fabriques et des usines, dire que les syndicats ne doivent pas se mêler de la lutte politique ou doivent être «neutres » entre tous les partis, c'est en réalité se mettre au service de la bourgeoisie.

Malgré toute la diversité de leurs dénominations, les partis politiques d'Europe et d'Amérique peuvent être divisés en trois grands groupes: 1. les partis de la bourgeoisie, 2. les partis de la petite-bourgeoisie (surtout les socialdémocrates), 3. le parti du prolétariat (les communistes).

Les syndicats qui se proclament « apolitiques » et «neutres » à l'égard de ces trois groupes ne font en réalité qu'aider les partis de la petite-bourgeoisie et de la bourgeoisie.

L'association syndicale d'Amsterdam est une organisation où se rencontrent et se donnent la main les Internationales 2 et $2 \frac{1}{2} 2$. Cette organisation est considérée avec espoir et sollicitude par toute la bourgeoisie mondiale. La grande idée de l'Internationale Syndicale d'Amsterdam pour le moment, c'est la neutralité des syndicats. Ce n'est pas par hasard que cette devise sert à la bourgeoisie et à ses valets social-démocrates ou syndicalistes de droite de moyen pour essayer de rassembler de nouveau les masses ouvrières d'Occident et d'Amérique. Tandis que la Seconde Internationale politique, en passant ouvertement du côté de la bourgeoisie, a fait lamentablement faillite, l'Internationale d'Amsterdam, en essayant à nouveau de se couvrir de l'idée de la neutralité, a encore quelque succès.

Sous le pavillon de la « neutralité », l'Internationale Syndicale d'Amsterdam prend sur elle les commissions les plus difficiles et les plus sales de la bourgeoisie : étrangler la grève des mineurs en Angleterre (comme a accepté de le faire le fameux J. H. Thomas qui est en même temps le président de 2e Internationale et un des leaders les plus en vue de l'Internationale Syndicale Jaune d'Amsterdam), abaisser les salaires, organiser le pillage systématique des ouvriers allemands pour les péchés de Guillaume et de la bourgeoisie impérialiste allemande. Leipart et Grassmann, Wissel et Bauer, Robert Schmidt et J. H. Thomas, Albert Thomas et Jouhaux, Daszynski et Zulavski - tous, ils se sont partagé les rôles : les uns, anciens chefs syndicaux, participent aujourd'hui aux gouvernements bourgeois en qualité de ministres, de commissaires gouvernementaux ou de fonctionnaires 
quelconques, tandis que les autres, entièrement solidaires des premiers, restent à la tête de l'Internationale Syndicale d'Amsterdam pour prêcher aux ouvriers syndiqués la neutralité politique.

L'Internationale Syndicale d'Amsterdam est actuellement le principal appui du capital mondial. Il est impossible de combattre victorieusement cette forteresse du capitalisme, si on n’a pas compris auparavant la nécessité de combattre l'idée mensongère de l'apolitisme et de la neutralité des syndicats. Afin d'avoir une arme convenable pour combattre l'Internationale Jaune d'Amsterdam, il faut avant tout établir des relations mutuelles claires et précises entre le parti et les syndicats dans chaque pays.

Le Parti communiste est l'avant-garde du prolétariat, l'avant-garde qui a reconnu parfaitement les voies et moyens pour libérer le prolétariat du joug capitaliste et qui pour cette raison a accepté consciemment le programme communiste.

Les syndicats sont une organisation plus massive du prolétariat, tendant de plus en plus à embrasser sans exception tous les ouvriers de chaque branche d'industrie et à faire entrer dans leurs rangs non seulement des communistes conscients, niais aussi des catégories intermédiaires et même tout à fait retardataires de travailleurs, qui apprennent seulement peu à peu, et par l'expérience de la vie, le communisme.

Le rôle des syndicats, dans la période qui précède le combat du prolétariat pour la mainmise sur le pouvoir, dans la période de ce combat et, ensuite, après la conquête, diffère sous bien des rapports, mais toujours avant, pendant, et après, les syndicats demeurent une organisation plus vaste, plus massive, plus générale que le parti, et par rapport à ce dernier ils jouent jusqu'à un certain point le rôle de la circonférence par rapport au centre.

Avant la conquête du pouvoir, les syndicats véritablement prolétariens organisent les ouvriers principalement sur le terrain économique, pour la conquête des améliorations qui sont possibles, pour le renversement du capitalisme, mais mettent au premier plan de toute leur activité l'organisation de la lutte des masses prolétariennes contre le capitalisme en vue de la révolution prolétarienne.

Pendant la révolution prolétarienne, les syndicats véritablement révolutionnaires, la main dans la main avec le parti, organisent les masses pour faire l'assaut 
des forteresses du capital et se chargent du premier travail d'organisation de la production socialiste.

Après la conquête et l'affermissement du pouvoir prolétarien, l'action des syndicats se transporte surtout dans le domaine de l'organisation économique et ils consacrent presque toutes leurs forces à la construction de l'édifice économique sur les bases socialistes, devenant ainsi une véritable école pratique du communisme.

Pendant ces trois stades de la lutte du prolétariat, les syndicats doivent soutenir leur avant-garde, le parti communiste, qui dirige la lutte prolétarienne dans toutes ses étapes. A cet effet les communistes et les éléments sympathisants doivent constituer à l'intérieur des syndicats des groupements communistes entièrement subordonnés au parti communiste dans son ensemble.

La tactique consistant à former des groupements communistes dans chaque syndicat, formulée par le $2^{\mathrm{e}}$ Congrès Mondial de l'Internationale Communiste, s'est vérifiée entièrement pendant l'année écoulée et a donné des résultats considérables en Allemagne, en Angleterre, en France, en Italie et dans beaucoup d'autres pays. Si par exemple des groupes importants d'ouvriers, peu endurcis et insuffisamment expérimentés en politique, sortent des syndicats socialdémocrates libres d'Allemagne, parce que ils ont perdu tout espoir d'obtenir un avantage immédiat de leur participation à ces syndicats libres, cela ne doit en aucun cas changer l'attitude de principe de l'Internationale Communiste à l'égard de la participation communiste au mouvement professionnel. Le devoir des communistes est d'expliquer à tous les prolétaires que le salut ne consiste pas à sortir des anciens syndicats pour en créer de nouveaux ou pour se disperser en une poussière d'hommes inorganisés, mais à révolutionner les syndicats, à en chasser l'esprit réformiste et la trahison des leaders opportunistes, pour en faire une arme active du prolétariat révolutionnaire.

Pendant la prochaine période, la tâche capitale de tous les communistes est de travailler avec énergie, avec persévérance, avec acharnement à conquérir la majorité des syndiqués ; les communistes ne doivent en aucun cas se laisser décourager par les tendances réactionnaires qui se manifestent en ce moment dans le mouvement syndical, mais s'appliquer par la participation la plus active à tous les com- 
bats journaliers, à conquérir les syndicats au communisme malgré tous les obstacles et toutes les oppositions.

La meilleure mesure de la force d'un parti communiste, c'est l'influence réelle qu'il exerce sur les masses des ouvriers syndiqués. Le parti doit savoir exercer l'influence la plus décisive sur les syndicats sans les soumettre à la moindre tutelle. Le parti a des noyaux communistes dans tel et tel syndicats, mais le syndicat lui-même ne lui est pas soumis. Ce n'est que par un travail continuel, soutenu et dévoué, des noyaux communistes au sein des syndicats que le Parti peut arriver à créer un état de choses où tous les syndicats suivront volontiers avec joie les conseils du parti.

Un excellent processus de fermentation se remarque en ce moment dans les syndicats français. Les ouvriers se remettent enfin de la crise du mouvement ouvrier et apprennent aujourd'hui à condamner la trahison des socialistes et des syndicalistes réformistes.

Les syndicalistes révolutionnaires sont encore imbus dans une certaine mesure de préjugés contre l’action politique et contre l’idée du parti politique prolétarien. Ils professent la neutralité politique telle qu'elle a été exprimée en 1906 dans la Charte d’Amiens. La position confuse et fausse de ces éléments syndicalistesrévolutionnaires implique le plus grand danger pour le mouvement. Si elle obtenait la majorité, cette tendance ne saurait qu'en faire et resterait impuissante en face des agents du capital, des Jouhaux et des Dumoulin.

Les syndicalistes-révolutionnaires français n’auront pas de ligne de conduite ferme tant que le parti communiste n'en aura pas non plus. Le Parti communiste français doit s'appliquer à amener une collaboration amicale avec les meilleurs éléments du syndicalisme-révolutionnaire. Il ne doit cependant compter en premier lieu que sur ses propres militants, il doit former des noyaux partout où il $\mathrm{y}$ a trois communistes. Le parti doit entreprendre une campagne contre la neutralité. De la façon la plus amicale, mais aussi la plus résolue, le parti doit souligner les défauts de l'attitude du syndicalisme-révolutionnaire. Ce n'est que de cette façon qu’on peut révolutionnariser le mouvement syndical en France et établir sa collaboration étroite avec le parti.

En Italie, nous avons une situation semblable : la masse des ouvriers syndiqués y est animée d'un esprit révolutionnaire, mais la direction de la Confédéra- 
tion du Travail est entre les mains de réformistes et de centristes déclarés, qui sont de tout cœur avec Amsterdam. La première tâche des communistes italiens est d'organiser une action quotidienne acharnée et persévérante au sein des syndicats et de s'appliquer systématiquement et patiemment à dévoiler le caractère équivoque et irrésolu des dirigeants, afin de leur arracher les syndicats.

Les tâches qui incombent aux communistes italiens à l'endroit des éléments révolutionnaires syndicalistes d'Italie sont, en général, les mêmes que celles des communistes français.

En Espagne, nous avons un mouvement syndical puissant, révolutionnaire, mais pas encore tout à fait conscient de ses buts et nous y avons en même temps un parti communiste encore jeune et relativement faible. Etant donné cette situation, le Parti doit tendre à s'affermir dans les syndicats, le Parti doit leur venir en aide par ses conseils et par son action, il doit éclairer le mouvement syndical et s'attacher à lui par des liens amicaux, en vue de l'organisation commune de tous les combats.

Des événements de la plus grande importance se développent dans le mouvement syndical anglais qui se révolutionnarise très rapidement. Le mouvement de masses s'y développe. Les anciens chefs des syndicats perdent très rapidement leurs positions. Le parti doit faire les plus grands efforts pour s'affermir dans les grands syndicats, tels que la Fédération des Mineurs, etc... Tout membre du parti doit militer dans quelque syndicat et doit, par un travail organique, persévérant et actif, l'orienter vers le communisme. Rien ne doit être négligé en vue d'établir la liaison la plus étroite avec les masses.

En Amérique, nous remarquons les mêmes développements, mais un peu plus lent. En aucun cas les communistes ne doivent se borner à quitter la Fédération du Travail, organisme réactionnaire : ils doivent au contraire mettre tout en œuvre pour pénétrer dans les anciennes unions et les révolutionnariser. Il importe nécessairement de collaborer avec les meilleurs éléments des I.W.W., mais cette collaboration n’exclut pas la lutte contre leurs préjugés.

Un puissant mouvement syndical se développe spontanément au Japon, mais il manque encore de direction claire. La tâche principale des éléments communistes du Japon est de soutenir ce mouvement et d'exercer sur lui une influence marxiste. 
En Tchécoslovaquie, notre parti a pour lui la majorité de la classe ouvrière, tandis que le mouvement syndical demeure encore en grande partie entre les mains des social-patriotes et des centristes et, en outre, est scindé par nationalités. C’est là le résultat du manque d’organisation et de clarté de la part des syndiqués, même animés de l'esprit révolutionnaire. Le parti doit tout faire pour mettre fin à cet état de choses et conquérir le mouvement syndical au communisme. Pour atteindre ce but, il est absolument indispensable de créer des noyaux communistes, de même qu'un organe syndical communiste central et commun pour tous les pays. Il faut pour cela travailler énergiquement à fusionner en un tout unique les différentes unions scindées par nations.

En Autriche et en Belgique, les social-patriotes ont su prendre avec habileté et fermeté la direction du mouvement syndical, qui dans ce pays est le principal enjeu de combat. C'est dans cette direction que les communistes doivent donc porter leur attention.

En Norvège, le parti, qui a pour lui la majorité des ouvriers, doit prendre plus sûrement entre ses mains le mouvement syndical et écarter les éléments dirigeants centristes.

En Suède, le parti a à combattre non seulement le réformisme, mais encore le courant petit-bourgeois qui existe dans le socialisme, et doit appliquer à cette action toute son énergie.

En Allemagne, le parti est en excellente voie pour conquérir graduellement les syndicats. Aucune concession ne peut être faite à ceux qui préconisent la sortie des syndicats. Elle ferait le jeu des social-patriotes. Aux tentatives pour exclure les communistes il importe d'opposer une résistance vigoureuse et opiniâtre ; les plus grands efforts doivent être faits pour conquérir la majorité dans les syndicats.

Toutes ces considérations déterminent les rapports qui doivent exister entre l'Internationale Communiste d'une part et l'Internationale Syndicale Rouge d'autre part.

L'Internationale Communiste ne doit pas diriger seulement la lutte politique du prolétariat au sens étroit du mot, mais encore toute sa campagne libératrice, quelque forme qu'elle prenne. L’Internationale Communiste ne peut pas être seulement la somme arithmétique des Comités Centraux des partis communistes des différents pays. L’Internationale Communiste doit inspirer et coordonner l'action 
et les combats de toutes les organisations prolétariennes, aussi bien professionnelles, coopératives, soviétiques, éducatives, etc..., que strictement politiques.

L'Internationale Syndicale Rouge, différant en cela de l'Internationale Jaune d'Amsterdam, ne peut en aucun cas accepter le point de vue de la neutralité. Une organisation qui voudrait être neutre, en face des Internationales 2, $2 \frac{1}{2} 2$, et 3 , serait inévitablement un jouet entre les mains de la bourgeoisie. Le programme d'action de l'Internationale Syndicale Rouge, qui est exposé ci-dessous et que le troisième Congrès Mondial de l'internationale Communiste propose à l'attention du premier Congrès Mondial des Syndicats Rouges, sera défendu en réalité uniquement par les partis communistes, uniquement par l'Internationale Communiste. Pour cette seule raison pour insuffler l'esprit révolutionnaire dans le mouvement professionnel de chaque pays, pour exécuter loyalement leur nouvelle tâche révolutionnaire, les syndicats rouges de chaque pays seront obligés de travailler la main dans la main, en contact étroit, avec le parti communiste de ce même pays, et l'Internationale Syndicale Rouge devra dans chaque pays, cordonner son action avec celle de l'Internationale Communiste.

Les préjugés de neutralité, d'indépendance, d'apolitisme, d'indifférence aux partis, qui sont le péché de bien des syndicalistes révolutionnaires loyaux de France, d'Espagne, d'Italie et de quelques autres pays, ne sont objectivement rien d'autre qu'un tribut payé aux idées bourgeoises. Les syndicats rouges ne peuvent pas triompher d'Amsterdam, ne peuvent pas par conséquent triompher du capitalisme, sans rompre une fois pour toutes avec cette idée bourgeoise d'indépendance et de neutralité.

Du point de vue de l'économie des forces et de la concentration plus parfaite des coups, la situation idéale serait la constitution d'une Internationale prolétarienne unique, groupant à la fois les partis politiques et toutes les autres formes d'organisation ouvrière. Il ne fait pas de doute que l'avenir appartient à ce type d'organisation. Mais au moment actuel de transition, avec la variété et la diversité des syndicats dans les différents pays, il faut constituer une union autonome des syndicats rouges acceptant dans l'ensemble le programme de l'Internationale Communiste, mais d'une façon plus libre que les partis politiques appartenant à cette Internationale. 
L'Internationale Syndicale Rouge qui sera organisée sur ces bases aura droit à tout le soutien du $3^{\mathrm{e}}$ Congrès Mondial de l'Internationale Communiste. Pour établir une liaison plus étroite entre l'Internationale Communiste et l'Internationale Rouge des Syndicats, le troisième Congrès Mondial de l'internationale Communiste propose une représentation mutuelle permanente de 3 membres de l'internationale Communiste dans le Comité Exécutif de l'Internationale Syndicale Rouge et inversement.

Le programme d'action des Syndicats Rouges, d'après l'avis de l'internationale Communiste, est approximativement le suivant :

\section{PROGRAMME D'ACTION}

1. La crise aiguë qui sévit dans l'économie du monde entier, la chute catastrophique des prix de gros et la surproduction coïncident de fait avec la disette des marchandises, la politique agressive de la bourgeoisie à l'égard de la classe ouvrière, une tendance obstinée à abaisser les salaires et à ramener la classe ouvrière à plusieurs dizaines d'années en arrière. L'irritation des masses qui se développe sur ce terrain, d'une part, et l'impuissance des vieux syndicats ouvriers et de leurs méthodes, d'autre part - tous ces faits imposent aux syndicats révolutionnaires de tous les pays des tâches nouvelles. De nouvelles méthodes de lutte économique en rapport avec la période de désagrégation capitaliste sont nécessaires : il faut que les syndicats adoptent une politique économique agressive, pour rejeter l'offensive du capital, fortifier les anciennes positions et passer à l'offensive.

2. L'action directe des masses révolutionnaires et leurs organisations contre le capital constitue la base de la tactique syndicale. Toutes les conquêtes des ouvriers sont en rapport direct avec l'action directe et la pression révolutionnaire des masses. Par l'expression "d'action directe », il faut comprendre toutes sortes de pressions directes exercées par les ouvriers sur les patrons et sur l'Etat ; à savoir : boycottage, action dans les rues, démonstrations, occupation des usines, opposition violente à la sortie des produits de ces entreprises, soulèvement armé et autres actions révolutionnaires propres à unir la classe ouvrière dans la lutte pour le socialisme. La tâche des syndicats révolutionnaires consiste donc à faire de l'action 
directe un moyen d'éduquer et de préparer les masses ouvrières pour la lutte pour la révolution sociale et pour la dictature du prolétariat.

3. Ces dernières années de lutte ont montré avec une particulière évidence toute la faiblesse des unions étroitement professionnelles. L'adhésion simultanée des ouvriers d'une entreprise à plusieurs syndicats les affaiblit pendant la lutte. Il faut passer, et ce doit être là le point initial d'une lutte incessante, de l'organisation purement professionnelle à l'organisation par industries : «Une entreprise - un syndicat », tel est le mot d'ordre dans le domaine de la structure syndicale. Il faut tendre à la fusion des syndicats similaires par la voie révolutionnaire en posant la question directement devant les syndiqués des fabriques et des entreprises, en élevant plus tard le débat jusqu'aux conférences locales et régionales et aux congrès nationaux.

4. Chaque fabrique, chaque usine doit devenir un bastion, une forteresse de la révolution. L'ancienne forme de liaison entre les syndiqués et leur syndicat (délégués d'ateliers recevant les cotisations, représentants, personnes de confiance etc...) doit être remplacée par la création de comités de fabriques et d'usines. Ceux-ci doivent être élus par tous les ouvriers de l'entreprise, à quelque syndicat qu'ils appartiennent, quelles que soient les convictions politiques qu'ils professent. La tâche des partisans de l'Internationale Syndicale Rouge est d'entraîner tous les ouvriers de l'entreprise à prendre part à l'élection de leur organe représentatif. Les tentatives pour faire élire les comités de fabriques et d'usines par les seuls communistes ont pour résultat d'éloigner les masses «sans parti »; c'est pourquoi ces tentatives doivent être catégoriquement condamnées. Ce serait là un noyau et non un comité de fabrique. La partie révolutionnaire doit réagir et influer, par l'intermédiaire des noyaux, des comités d'action et de ses simples membres, sur l'assemblée générale et sur le comité de fabrique élu.

5. La première tâche qu'il faut proposer aux ouvriers et aux comités de fabriques et d'usines, est d'exiger l'entretien aux frais de l'établissement des ouvriers congédiés par suite du manque de travail. On ne doit tolérer dans aucun cas que les ouvriers soient jetés à la rue sans que l'établissement s'occupe d'eux. Le patron doit verser à ses chômeurs leur salaire complet Voilà l'exigence autour de laquelle il faut organiser non seulement les chômeurs mais surtout les ouvriers travaillant dans l'entreprise, en leur expliquant en même temps que la question du 
chômage ne peut être résolue dans le cadre capitaliste et que le meilleur remède contre le chômage, c’est la révolution sociale et la dictature du prolétariat.

6. La fermeture des entreprises est actuellement, dans la plupart des cas, un moyen de les épurer de leurs éléments suspects, aussi la lutte doit-elle se faire contre la fermeture des entreprises et les ouvriers doivent se livrer à une enquête sur les causes de cette fermeture. Il faut créer à cet effet des Commissions spéciales de contrôle sur les matières premières, le combustible, les commandes, obtenir une vérification effective de la quantité disponible de matières premières, de matériaux nécessaires à la production et de ressources financières déposées dans les banques. Les Commissions de contrôle spécialement élues doivent étudier de la façon la plus attentive les rapports financiers entre l'entreprise en question et les autres entreprises, et la suppression du secret commercial doit être proposée aux ouvriers comme une tâche pratique.

7. L'un des moyens d'empêcher la fermeture en masse des entreprises dans un but de diminution des salaires et d'aggravation des conditions du travail peut être l'occupation de la fabrique ou de l'usine et la continuation de la production en dépit du patron.

En présence de la disette de marchandises actuelle, il est particulièrement important d'empêcher tout arrêt dans la production, aussi les ouvriers ne doivent-ils pas tolérer une fermeture préméditée des fabriques et usines. Suivant les conditions locales, les conditions de la production, la situation politique, et l'intensité de la lutte sociale, la mainmise sur les entreprises peut et doit être accompagnée encore d'autres méthodes d'action sur le capital. La gestion de l'entreprise saisie doit être remise entre les mains du comité de fabrique ou d'usine et du représentant spécialement désigné par le syndicat.

8. La lutte économique doit être livrée sous le mot d'ordre de l'augmentation des salaires et de l'amélioration des conditions du travail, qui doivent être portés à un niveau sensiblement supérieur à celui d'avant-guerre. Les tentatives pour ramener les ouvriers aux conditions de travail d'avant-guerre doivent être repoussées de la façon la plus décisive et la plus révolutionnaire. La guerre a eu pour résultat l'épuisement de la classe ouvrière : aussi l'amélioration des conditions de travail est-elle une condition indispensable pour réparer cette perte de forces. Les allégations des capitalistes qui mettent en cause la concurrence étrangère ne doi- 
vent aucunement être prises en considération : les syndicats révolutionnaires ne doivent pas aborder les questions de salaires et de conditions de travail du point de vue de la concurrence entre les profiteurs des différentes nations, ils doivent se placer au point de vue de la conservation et de la protection de la force de travail.

9. Si la tactique réductrice des capitalistes coïncide avec une crise économique dans le pays, le devoir des syndicats révolutionnaires est de ne pas se laisser battre par détachements séparés. Dès le début il faut entraîner dans la lutte les ouvriers des établissements d'utilité publique (mineurs, cheminots, électriciens, ouvriers du gaz, etc...) pour que la lutte contre l'offensive du capital touche dès le début les nœuds vitaux de l’organisme économique. Ici, toutes les formes de résistance sont nécessaires et conformes au but, depuis la grève partielle, intermittente, jusqu’à la grève générale s’étendant à quelque grosse industrie sur un plan national.

10. Les syndicats doivent se proposer comme une tâche pratique du jour la préparation et l'organisation d'actions internationales par industries. L'arrêt des transports ou de l'extraction de la houille, réalisé sur un plan international, est un puissant moyen de lutte contre les tentatives réactionnaires de la bourgeoisie de tous les pays.

Les syndicats doivent suivre avec attention la conjoncture mondiale pour choisir le moment le plus propice à leur offensive économique ; ils ne doivent pas oublier un seul instant ce fait, qu'une action internationale ne sera possible que si des syndicats révolutionnaires sont créés, syndicats qui ne doivent rien avoir de commun avec l'Internationale Jaune d'Amsterdam.

11. La foi dans la valeur absolue des contrats collectifs, propagée par les opportunistes de tous les pays, doit rencontrer la résistance âpre et décidée du mouvement syndical révolutionnaire. Le contrat collectif n’est qu'un armistice. Les patrons brisent les contrats collectifs toutes les fois qu'ils en ont la moindre possibilité. Un respect religieux à l'égard des contrats collectifs témoigne de la profonde pénétration de l'idéologie bourgeoise dans les têtes des chefs de la classe ouvrière. Les syndicats révolutionnaires ne doivent pas renoncer aux contrats collectifs, mais ils doivent se rendre compte de leur valeur relative, ils doivent toujours envisager nettement la méthode à suivre pour rompre ces contrats toutes les fois que c'est avantageux à la classe ouvrière. 
12. La lutte des organisations ouvrières contre le patron individuel et collectif doit être adaptée aux conditions nationales et locales, elle doit utiliser toute l'expérience de la lutte libératrice de la classe ouvrière. Aussi toute grève importante ne doit pas seulement être bien organisée. Les ouvriers doivent, dès son début, créer des cadres spéciaux pour combattre les briseurs de grève et pour s'opposer à l'offensive provocatrice des organisations blanches de toutes nuances appuyées par les Etats bourgeois. Les fascistes en Italie, l'aide technique en Allemagne, les gardes civiques formées d'anciens officiers et sous-officiers en France et en Angleterre, toutes ces organisations ont pour but la démoralisation, la défaite de toute action ouvrière, une défaite qui se réduirait non pas à un simple remplacement des grévistes, mais à la débâcle matérielle de leur organisation et au massacre des chefs du mouvement. Dans ces conditions l'organisation de bataillons de grèves spéciaux, de détachements spéciaux de défense ouvrière, est une question de vie ou de mort pour la classe ouvrière.

13. Les organisations de combat ainsi créées ne doivent pas se borner à combattre les organisations des patrons et des briseurs de grèves, elles doivent se charger d'arrêter tous les colis et marchandises expédiés à destination de l'usine en grève par d'autres entreprises et s'opposer au transfert des commandes à d'autres usines et d'autres entreprises. Les syndicats des ouvriers des transports sont appelés à jouer sous ce rapport un rôle particulièrement important : à eux incombe la tâche d'entraver le transport des marchandises, ce qui ne saurait être réalisé sans l’aide unanime de tous les ouvriers de la région.

14. Toute la lutte économique de la classe ouvrière au cours de la période qui vient, doit se concentrer autour du mot d'ordre du contrôle ouvrier sur la production, ce contrôle devant être réalisé sans attendre que le gouvernement ou les classes dominantes aient inventé quelque succédané de contrôle. Il faut combattre violemment toutes les tentatives des classes dominantes et des réformistes pour créer des associations paritaires, des commissions paritaires et un strict contrôle sur la production doit être réalisé : alors seulement il donnera des résultats déterminés. Les syndicats révolutionnaires doivent combattre résolument le chantage et l'escroquerie exercés au nom de la socialisation par les chefs des vieux syndicats avec le concours des classes dominantes. Tout le verbiage de ces messieurs à propos de la socialisation pacifique poursuit ce but unique de détourner les ouvriers des actes révolutionnaires et de la révolution sociale. 
15. Pour distraire l'attention des ouvriers de leurs tâches immédiates et éveiller en eux des velléités petites-bourgeoises, on met en avant l'idée de la participation des ouvriers aux bénéfices, c'est-à-dire de la restitution aux ouvriers d'une faible partie de la plus-value créée par eux ; ce mot d’ordre de perversion ouvrière doit recevoir sa critique sévère et implacable : «Pas de participation aux bénéfices. La destruction des bénéfices capitalistes. », tel est le mot d’ordre des syndicats révolutionnaires.

16. Pour entraver ou briser la force combative de la classe ouvrière, les Etats bourgeois ont profité de la possibilité de militariser provisoirement certaines usines ou des branches entières d'industrie sous prétexte de protéger les industries d’importance vitale. Alléguant la nécessité de se préserver autant que possible contre des perturbations économiques, les Etats bourgeois introduisirent pour protéger le Capital des cours d'arbitrage et des commissions de conciliation obligatoires. C'est aussi dans l'intérêt du Capital et pour faire retomber entièrement sur les ouvriers le poids des charges de la guerre qu'on introduisit un nouveau système de perception des impôts ; ceux-ci sont retenus sur le salaire de l'ouvrier par le patron, qui joue ainsi le rôle de percepteur. Les syndicats doivent mener une lutte des plus opiniâtres contre ces mesures gouvernementales ne servant qu'aux intérêts de la classe capitaliste.

17. Les syndicats révolutionnaires qui luttent pour améliorer les conditions du travail, élever le niveau de subsistance des masses, établir le contrôle ouvrier, doivent constamment se rendre compte que dans le cadre du capitalisme tous ces problèmes ne sauraient être résolus ; aussi doivent-ils, tout en arrachant pas à pas des concessions aux classes dominantes, tout en les obligeant à appliquer la législation sociale, mettre clairement les masses ouvrières en face de ce fait que seul le renversement du capitalisme et l'instauration de la dictature du prolétariat sont capables de résoudre la question sociale. Aussi, pas une action partielle, pas une grève partielle ni le moindre conflit ne doivent passer sans laisser de traces à ce point de vue. Les syndicats révolutionnaires doivent généraliser ces conflits en élevant constamment la mentalité des masses ouvrières jusqu’à la nécessité et à l’inéluctabilité de la révolution sociale et de la dictature du prolétariat.

18. Toute lutte économique est une lutte politique, c'est-à-dire une lutte menée par toute une classe. Dans ces conditions, Si considérables que soient les couches ouvrières embrassées par la lutte, celle-ci ne peut être réellement révolution- 
naire, elle ne peut être réalisée avec le maximum d'utilité pour la classe ouvrière dans son ensemble que si les syndicats révolutionnaires marchent la main dans la main, en union et en collaboration étroite, avec le Parti Communiste du pays. La théorie et la pratique de la division de l'action de la classe ouvrière en deux moitiés autonomes est très pernicieuse, surtout dans le moment révolutionnaire actuel. Chaque action demande un maximum de concentration des forces, qui n'est possible qu'à la condition de la plus haute tension de toute l'énergie révolutionnaire de la classe ouvrière, c'est-à-dire de tous ses éléments communistes et révolutionnaires. Des actions isolées du Parti Communiste et des syndicats révolutionnaires de classe sont d'avance vouées à l'insuccès et à la débâcle. C'est pourquoi l'unité d'action, une liaison organique entre les Partis Communistes et les syndicats ouvriers, constituent la condition préalable du succès dans la lutte contre le capitalisme. 
Manifestes, thèses et résolutions

des quatre premiers congrès

de l’Internationale communiste 1919-1923

(juin 1934)

Troisième Congrès, juin 1921.

- 10 -

Thèses et résolution

sur l'action des communistes

dans les coopératives

$\underline{\text { Retour à la table des matières }}$

1. À l'époque de la révolution prolétarienne les coopératives révolutionnaires doivent se proposer deux buts : a) aider les travailleurs dans leur lutte pour la conquête du pouvoir politique. b) Là où ce pouvoir est déjà conquis, aider les travailleurs à organiser la société socialiste.

2. Les anciennes coopératives marchaient dans la voie du réformisme et évitaient de toute façon la lutte révolutionnaire sous toutes ses formes. Elles prêchaient l'idée d'une entrée graduelle dans le « socialisme » sans passer par la dictature du prolétariat.

Les anciennes coopératives prêchent la neutralité politique, alors qu'en réalité elles cachent sous cette enseigne leur subordination à la politique de la bourgeoisie impérialiste. 
Leur internationalisme n’existe qu'en paroles. En réalité, elles substituent à la solidarité internationale des travailleurs, la collaboration de la classe ouvrière avec la bourgeoisie de chaque pays.

Par toute cette politique, les anciennes coopératives, loin de concourir au développement de la révolution, l'entravent et, loin d'aider le prolétariat dans sa lutte, le gênent.

3. Les diverses formes de coopératives ne peuvent à aucun degré servir les buts révolutionnaires du prolétariat. Les plus convenables pour cela sont les coopératives de consommation. Mais même parmi ces dernières, il en est beaucoup qui groupent des éléments bourgeois. Ces coopératives ne seront jamais du coté du prolétariat dans sa lutte révolutionnaire. Seule la coopération ouvrière dans les villes et dans les campagnes peut avoir ce caractère.

4. La tâche des communistes dans le mouvement coopératif consiste en ce qui suit :

1) Propager les idées communistes.

2) Faire de la coopération un instrument de lutte de classe pour la révolution, sans détacher les diverses coopératives de leur groupement central.

Dans toutes les coopératives, les communistes doivent être organisés en fractions constituées, se proposant de former dans chaque pays un centre de la coopération communiste.

Ces groupements et leur centre doivent avoir une liaison étroite avec le parti communiste et ses représentants dans la coopération. Le centre doit également élaborer les principes de la tactique communiste dans le mouvement coopératif national, diriger et organiser ce mouvement.

5. Les buts pratiques que doit actuellement se proposer la coopération révolutionnaire d'Occident apparaîtront entièrement au cours du travail. Mais dès maintenant on peut indiquer certains d'entre eux : 
$1^{\circ}$ Propager, par l'écrit et par la parole, les idées communistes, mener campagne pour affranchir les coopératives de la direction et de l'influence de la bourgeoisie et des opportunistes.

$2^{\circ}$ Rapprocher les coopératives des partis communistes, des syndicats révolutionnaires. Faire participer les coopératives, directement et indirectement, à la lutte politique, en prenant part aux démonstrations et aux campagnes politiques du prolétariat. Soutenir matériellement les partis communistes et leur presse. Soutenir matériellement les ouvriers en grève ou victimes de lock-out.

$3^{\circ}$ Combattre la politique impérialiste de la bourgeoisie, et en particulier l'intervention dans les affaires de la Russie soviétique et des autres pays.

$4^{\circ}$ Créer des relations non seulement de pensée, d’organisation, mais encore d’affaires, entre les coopératives ouvrières des différents pays.

$5^{\circ}$ Réclamer la conclusion immédiate de traités de commerce et l'engagement de relations commerciales avec la Russie et les autres républiques soviétiques.

$6^{\circ}$ Participer le plus largement possible aux échanges commerciaux avec ces républiques.

$7^{\circ}$ Participer à l'exploitation des richesses naturelles des républiques soviétiques en se chargeant de concessions sur leur territoire.

6. Après le triomphe de la révolution prolétarienne, les coopératives doivent prendre leur plein développement.

Déjà l'exemple de la Russie soviétique permet d'esquisser certains traits caractéristiques :

1) Les coopératives de consommation devront se charger de la répartition des produits d'après les plans du gouvernement prolétarien. Cette fonction donnera aux coopératives un essor inouï jusqu’à ce jour.

2) Les coopératives doivent servir de lien organique entre les exploitations isolées des petits producteurs (paysans et artisans) et les services écono- 
miques de l'État prolétarien. Ces derniers, par l'intermédiaire des coopératives, dirigeront le travail de ces petites exploitations conformément à un plan d'ensemble. En particulier, les coopératives de consommation recueilleront les denrées alimentaires et les matières premières des petits producteurs pour les remettre aux consommateurs et à l'Etat.

3) Les coopératives de production peuvent grouper les petits producteurs dans des ateliers ou grandes exploitations communes permettant l'application des machines et des procédés techniques perfectionnés. Elles donneront ainsi à la petite production la base technique qui permettra d'édifier sur ce fondement la production socialiste et qui permettra aux petits producteurs de se débarrasser de leur mentalité individualiste pour développer en eux l'esprit collectiviste.

7. Prenant en considération le rôle immense que les coopératives révolutionnaires doivent jouer pendant la révolution prolétarienne, le troisième Congrès de l'Internationale Communiste rappelle aux partis, groupes et organisations communistes qu'ils doivent continuer de travailler énergiquement à propager l'idée de la coopération, des groupements de coopératives en un instrument de la lutte de classe, et à former un front unique des coopératives avec les syndicats révolutionnaires.

Le Congrès charge le Comité Exécutif de l'Internationale de former une section coopérative chargée de mettre en pratique le programme ci-dessus indiqué. En outre cette section devra dans la mesure des besoins convoquer des conférences et des congrès pour réaliser dans l'Internationale la mission révolutionnaire des coopératives.

\section{Résolution du $3^{e}$ Congrès de l'Internationale communiste sur l'action dans les coopératives}

Le $3^{\mathrm{e}}$ Congrès de l'Internationale charge le Comité Exécutif de créer une section coopérative qui devra préparer selon les besoins la convocation de consultations, conférences et congrès coopératifs internationaux, pour réaliser dans l’Internationale les buts déterminés dans les thèses. 
La section devra, en outre, se proposer les buts pratiques suivants :

1. Renforcer l'activité coopérative des travailleurs des campagnes et de l'industrie en constituant des coopératives d'artisans demi-prolétaires, en amenant les travailleurs à rechercher la direction et l'amélioration en commun de leur exploitation.

2. Mener la lutte pour la remise aux coopératives de la répartition des vivres et des objets de consommation dans tout l'Etat.

3. Mener la propagande pour les principes et les méthodes de la coopération révolutionnaire et diriger l'activité de la coopération prolétarienne vers l'appui matériel de la classe ouvrière combattante.

4. Favoriser l'établissement de rapports commerciaux et financiers internationaux entre coopératives ouvrières et organiser leur production commune. 
Manifestes, thèses et résolutions

des quatre premiers congrès

de l'Internationale communiste 1919-1923

(juin 1934)

Troisième Congrès, juin 1921.

- 11 -

\section{Résolution sur l'Internationale Communiste et le mouvement de la Jeunesse Communiste}

$\underline{\text { Retour à la table des matières }}$

1. Le mouvement de la jeunesse socialiste est né sous la pression de l'exploitation capitaliste de la jeunesse laborieuse et du système illimité du militarisme bourgeois. Il est né comme réaction contre les tentatives d'empoisonnement de la jeunesse laborieuse par les idées bourgeoises nationalistes et contre la négligence et l'oubli dont s'étaient rendus coupables le parti social-démocrate et les syndicats dans la plupart des pays vis-à-vis des exigences économiques, politiques et spirituelles de la jeunesse.

Dans presque tous les pays les organisations de la jeunesse socialiste furent créées sans le concours des partis social-démocrates et des syndicats, qui devenaient toujours de plus en plus opportunistes et réformistes, et dans quelques pays ces organisations se formèrent même contre la volonté de ces partis et des syndicats. Ceux-ci virent un très gros danger dans l'apparition des jeunesses socialistes révolutionnaires indépendantes et essayèrent de réprimer ce mouvement, d’en 
changer le caractère et de lui imposer leur politique, en exerçant sur lui une tutelle bureaucratique, et en essayant de le priver de toute indépendance.

2. En outre, la guerre impérialiste et l'attitude prise dans la plupart des pays par les partis social-démocrates devaient agrandir l'abîme creusé entre les partis social-démocrates et les jeunesses internationales et révolutionnaires et accélérer le conflit. La situation de la jeunesse laborieuse empira pendant la guerre à cause de la mobilisation, de l'exploitation renforcée dans les industries militaires et de la militarisation derrière le front. La meilleure partie de la jeunesse socialiste prit résolument position contre la guerre et le nationalisme, se sépara des partis socialdémocrates et commença une action politique propre (Conférences Internationales de la Jeunesse à Berne, en 1915, à Iéna, en 1916).

Dans leur combat contre la guerre, les meilleurs groupes révolutionnaires des ouvriers adultes soutinrent les jeunesses socialistes qui devinrent par là un point de rassemblement des forces révolutionnaires. Elles prirent ainsi sur elles les fonctions des partis révolutionnaires qui faisaient défaut. Elles devinrent l'avantgarde dans le combat révolutionnaire et prirent la forme d'organisations politiques indépendantes.

3. Avec l'apparition de l'Internationale Communiste et de partis communistes dans différents pays, le rôle des jeunesses révolutionnaires dans tout le mouvement du prolétariat se modifie. De par sa situation économique et grâce à des traits psychologiques particuliers, la jeunesse ouvrière est plus facilement accessible aux idées communistes et fait preuve, lors des combats révolutionnaires, d'un enthousiasme révolutionnaire plus grand que ses aînés les ouvriers. Toutefois ce sont les partis communistes qui prennent sur eux le rôle d'avant-garde qu'avaient joué les jeunes, en ce qui concerne l'action politique indépendante et la direction politique. Si les organisations de la jeunesse communiste continuaient à exister en qualité d'organisations indépendantes au point de vue politique et en jouant un rôle dirigeant, l'on verrait l'existence de deux partis communistes concurrents qui ne se distingueraient entre eux que par l'âge de leurs membres. 
4. Le rôle actuel de la jeunesse consiste en ce qu'elle doit réunir les jeunes ouvriers, les éduquer dans un esprit communiste aux premiers rangs de la bataille communiste. Le temps est passé où la jeunesse pouvait se borner à un travail bon pour de petits groupes de propagande, composés de peu de membres. Il y a aujourd’hui, à part l'agitation et la propagande, menées avec persévérance et avec de nouvelles méthodes, encore un moyen de conquérir les larges masses de jeunes ouvriers : c’est de provoquer et diriger les combats économiques.

Les organisations de la jeunesse doivent élargir et renforcer leur travail d'éducation en se conformant à leur nouvelle mission. Le principe fondamental de l'éducation communiste dans le mouvement de la jeunesse communiste est la participation active à tous les combats révolutionnaires, participation qui doit être étroitement liée à l'école marxiste.

Un autre devoir important des jeunesses à l'époque actuelle, c’est de détruire l'idéologie centriste et social-patriotique parmi la jeunesse ouvrière et de débarrasser celle-ci des tuteurs et des chefs social-démocrates. En même temps, elles doivent tout faire pour activer le processus de rajeunissement résultant du mouvement des masses, en déléguant rapidement dans les partis communistes ses membres les plus âgés.

La grande différence fondamentale qui existe entre les jeunesses communistes et les jeunesses centristes et social-patriotiques devient surtout apparente par la participation active à tous les problèmes de la vie politique et aux combats et actions révolutionnaires, de même que par la collaboration à la construction des partis communistes.

5. Les rapports entre les jeunesses et les partis communistes diffèrent radicalement de ceux qui existent entre les organisations de la jeunesse révolutionnaire et les partis social-démocrates. La plus grande uniformité et la centralisation la plus stricte sont nécessaires dans le combat commun pour la réalisation rapide de la révolution prolétarienne. La direction politique ne peut appartenir au point de vue international qu'à l'Internationale. Il est du devoir des organisations de la jeunesse communiste de se subordonner à cette direction politique (programme, tactique et directives politiques) et de s'incorporer au front révolutionnaire commun. Etant donné les différents degrés de développement révolutionnaire des par- 
tis communistes, il est nécessaire que dans des cas exceptionnels, l'application de ce principe soit subordonnée à une décision spéciale du Comité Exécutif de l'Internationale Communiste et de l'Internationale de la Jeunesse tenant compte des conditions particulières existantes. Les jeunesses communistes, qui ont commencé à organiser leurs rangs selon les règles de la centralisation la plus stricte, devront se soumettre, pour réaliser et diriger la révolution prolétarienne, à la discipline d'airain de l'Internationale Communiste. Les jeunesses doivent s'occuper au sein de leurs organisations de toutes les questions politiques et tactiques, à l'endroit desquelles elles doivent toujours prendre position ; et à l'intérieur des partis communistes de leur pays elles doivent toujours agir non contre ces partis, mais dans le sens des décisions prises par eux. En cas de graves dissensions entre les partis communistes et les jeunesses, celles-ci doivent faire valoir leur droit d'appel au Comité Exécutif de l'Internationale Communiste. L'abandon de leur indépendance politique ne signifie aucunement l'abnégation de leur indépendance organique, qu'il faut conserver pour des raisons d'éducation.

Comme pour la bonne direction de la lutte révolutionnaire, le maximum de centralisation et d'unité sont nécessaires, dans les pays où l'évolution historique a placé la jeunesse dans la dépendance du parti, ces relations doivent être maintenues à titre de règle ; les divergences entre les deux organes sont résolues par le Comité Exécutif de l’Internationale Communiste de la Jeunesse.

6. Une des tâches les plus urgentes et les plus importantes des jeunesses est de se débarrasser de tous les restes de l'idée de son rôle politique dirigeant - survivance de leur période d'absolue autonomie. La presse et tout l'appareil des jeunesses doivent être utilisées pour imprégner les jeunes communistes du sentiment et de la conscience qu'ils sont des soldats et des membres responsables d'un seul parti communiste.

Les organisations de la jeunesse communiste doivent faire d'autant plus attention et donner d'autant plus de temps à ce travail qu'elles commencent, grâce à la conquête de groupes toujours plus nombreux de jeunes ouvriers, à se transformer en mouvement de masses. 
7. La collaboration politique étroite entre les jeunesses et les partis communistes doit trouver son expression dans une liaison organique solide entre les deux organisations. Ce qui est absolument nécessaire, c’est un échange permanent et mutuel de représentants entre les organes dirigeants des jeunesses et des partis à tous les échelons : province, arrondissement, canton et jusqu’aux derniers noyaux, dans les groupes d'usines et dans les syndicats, de même que la participation mutuelle à toutes les conférences et congrès. De cette façon le parti communiste aura la possibilité d'exercer une influence continue sur l'activité de la jeunesse et de la soutenir, tandis que celle-ci pourra également avoir une influence réelle sur l'activité du parti.

8. Les rapports entre l'Internationale Communiste et l'Internationale de la Jeunesse sont encore plus étroits qu'entre l'Internationale et les Partis Communistes. Le rôle de l'Internationale Communiste de la Jeunesse consiste à centraliser et à diriger le mouvement de la jeunesse communiste, à soutenir et encourager moralement et matériellement les différentes unions, à créer de nouvelles organisations de la jeunesse communiste là où elles n’existent pas et à faire la propagande internationale pour le mouvement de la jeunesse communiste et pour son programme. L’Internationale Communiste de la Jeunesse constitue une partie de l'Internationale Communiste et en cette qualité elle est subordonnée aux décisions du Congrès et de l'Exécutif de l'Internationale Communiste. C'est dans ces limites qu'elle exécute son travail et agit en qualité d'intermédiaire et d'interprète de la volonté politique de l'Internationale Communiste dans toutes les sections de cette dernière. C'est par l'échange constant et mutuel et une collaboration étroite continuelle qu'on peut assurer un contrôle constant de la part de l'Internationale Communiste et le travail le plus fécond de l'Internationale Communiste de la Jeunesse sur tous les terrains de son activité (direction du mouvement, agitation, organisation, renforcement et soutien des organisations de la jeunesse communiste). 
Manifestes, thèses et résolutions

des quatre premiers congrès

de l’Internationale communiste 1919-1923

(juin 1934)

Troisième Congrès, juin 1921.

- 12 -

\section{Adresse pour Max Hoelz}

\section{AU PROLÉTARIAT ALLEMAND}

$\underline{\text { Retour à la table des matières }}$

Aux deux mille ans de prison et de peines correctionnelles qu'elle a infligés aux combattants de mars, la bourgeoisie allemande ajoute l'emprisonnement à perpétuité contre :

\section{MAX HOELZ}

L'Internationale Communiste est adversaire de la terreur et des actes de sabotage individuel qui ne servent pas directement aux buts de combat de la guerre civile ; elle condamne la guerre de franc-tireur menée en dehors de la direction politique du prolétariat révolutionnaire. Mais l'Internationale Communiste voit en Max Hoelz l'un des plus courageux rebelles contre la société capitaliste, dont la rage s'exprime par des condamnations de prison et dont l'ordre se manifeste par les excès de la canaille qui sert de base à son régime. Les actes de Max Hoelz ne correspondaient pas au but poursuivi ; la terreur blanche ne saurait être brisée qu'à la suite du soulèvement des masses ouvrières, ce n'est qu'ainsi que le prolétariat pourra conquérir la victoire. Mais ces actes lui étaient dictés par son amour pour le prolétariat, par sa haine contre la bourgeoisie. 
Le Congrès adresse donc ses salutations fraternelles à Max Hoelz. Il le recommande à la protection du prolétariat allemand et exprime son espoir de le voir lutter dans les rangs du Parti Communiste pour la cause de l'affranchissement des ouvriers, le jour où les prolétaires allemands auront brisé les portes de sa prison. 
Manifestes, thèses et résolutions

des quatre premiers congrès

de l’Internationale communiste 1919-1923

(juin 1934)

Troisième Congrès, juin 1921.

- 13 -

\title{
Manifeste du Comité Exécutif de l’Internationale Communiste
}

\author{
VERS UN NOUVEAU TRAVAIL, \\ VERS DE NOUVELLES LUTTES
}

Aux prolétaires, hommes et femmes, de tous les pays!

$\underline{\text { Retour à la table des matières }}$

Le $3^{\mathrm{e}}$ Congrès de l'Internationale Communiste est terminé, la grande revue du prolétariat communiste de tous les pays est finie. Elle a montré qu'au cours de l'année écoulée le communisme est devenu, dans une série de pays où il n'en est qu'à ses débuts, un grand mouvement stimulant les masses et menaçant le pouvoir du capital. L'Internationale Communiste qui, à son Congrès de constitution, ne représentait en dehors de la Russie que de petits groupes de camarades, cette Internationale qui au $2^{\mathrm{e}}$ Congrès de l'année passée cherchait encore sa voie, dispose à présent, non seulement en Russie, mais aussi en Allemagne, en Pologne, en Tchécoslovaquie, en Italie, en France, en Norvège, en Yougoslavie, en Bulgarie, de partis autour des drapeaux desquels des masses de plus en plus grandes se concentrent sans cesse. Le $3^{\mathrm{e}}$ Congrès s'adresse aux communistes de tous les pays pour les inviter à suivre la voie sur laquelle ils se sont engagés et à faire tout ce qui est en leur pouvoir pour réunir dans les rangs de l'Internationale Communiste de nouveaux millions d'ouvriers et d'ouvrières. Car le pouvoir du capital ne sera 
brisé que si l'idée du communisme devient une force stimulant la grande majorité du prolétariat guidé par les Partis de masses communistes qui doivent constituer comme un cercle de fer la classe prolétarienne combattante. « Aux masses », voilà le premier cri de combat lancé par le $3^{\mathrm{e}}$ Congrès aux communistes de tous les pays.

\section{VERS DE NOUVELLES GRANDES LUTTES}

Les masses viennent, affluent vers nous, car le capitalisme mondial leur montre avec une évidence de plus en plus éclatante qu'il ne peut plus prolonger son existence qu'en détruisant de plus en plus tout l'ordre social, qu'en augmentant le chaos, la misère et l'esclavage des masses. En présence de la crise économique mondiale, laquelle jette des millions d'ouvriers à la rue, les criailleries des valets social-démocrates du capital tombent, l'appel que la classe bourgeoise adressait depuis des années aux ouvriers "Travaillez, travaillez sans cesse », ce cri cesse, car le cri « du travail » devient le cri de combat de la classe ouvrière et il ne sera satisfait que sur les ruines du capitalisme, que si le prolétariat s'empare des moyens de production créés par lui. Le monde capitaliste se trouve devant l'abîme de nouveaux dangers de guerre. Les antagonismes américano-japonais, angloaméricain, anglo-français, franco-allemand, polono-allemand, les antagonismes dans le Proche et l'Extrême-Orient poussent le capitalisme aux armements incessants. Ils leur posent la question angoissante : «L'Europe a-t-elle repris le chemin de la guerre mondiale ? » Les capitalistes ne craignent pas le massacre de millions d'individus. Déjà, après la guerre, par leur politique, par le blocus de la Russie, ils ont livré à la mort par la faim des millions d'êtres humains. Ce qu'ils craignent, c'est qu'une nouvelle guerre ne pousse définitivement les masses dans les rangs de l'armée de la révolution mondiale, c'est qu'une nouvelle guerre n'entraîne le soulèvement final du prolétariat mondial. Ils cherchent donc, comme ils l'ont fait avant la guerre, a amener une détente au moyen d'intrigues et de combinaisons diplomatiques. Mais la détente sur un point, c'est la tension sur d'autres. Les négociations entre l'Angleterre et l'Amérique au sujet de la limitation des armements navals des deux Etats créent nécessairement un front contre le Japon. Le rapprochement franco-anglais livre l'Allemagne à la France et la Turquie à 
l'Angleterre. Le résultat des efforts du capital mondial cherchant à mettre un peu d'ordre dans le chaos mondial, ce n'est pas la paix, mais le trouble croissant et l'esclavage de plus en plus strict des peuples vaincus par le capital des triomphateurs. La presse du capital mondial parle maintenant d'accalmie et de détente dans la politique mondiale parce que la bourgeoisie d'Allemagne se soumet aux conditions dictées par les Alliés et parce que pour sauver son pouvoir elle a livré le peuple allemand aux chacals de la Bourse de Paris et de Londres. Mais en même temps, la presse de la Bourse est pleine de nouvelles sur l'aggravation de la ruine économique de l'Allemagne, sur les impôts énormes qui s'abattront comme la grêle, en automne, sur les masses condamnées au chômage, impôts renchérissant de plus en plus tous les articles alimentaires et vestimentaires. L'Internationale Communiste qui, pour sa politique, part de l'étude impartiale et objective de la situation mondiale - car le prolétariat ne saurait remporter la victoire que par l'observation claire et objective du champ de bataille — l'Internationale Communiste dit au prolétariat de tous les pays : le capitalisme s'est montré jusqu'à présent incapable d'assurer l'ordre au monde même dans la mesure d'avant-guerre. Ce qu'il entreprend en ce moment ne peut pas amener une consolidation, un nouvel ordre, mais seulement la prolongation de vos souffrances et de l'agonie du capitalisme. La révolution mondiale avance. Partout les bases du capital mondial sont ébranlées. Le deuxième cri que le Congrès mondial de l'Internationale Communiste lance aux Prolétaires de tous les Pays, c’est celui-ci :

Nous allons au-devant de grandes luttes, armez-vous, en vue de nouveaux combats.

\section{FORMEZ LE FRONT}

La bourgeoisie mondiale est incapable d'assurer aux ouvriers le travail, le pain, le logement et le vêtement ; mais elle montre de grandes capacités dans l'organisation de la guerre contre le prolétariat mondial. Depuis le moment de sa première grande désorientation, depuis qu'elle a réussi à surmonter sa peur des ouvriers revenus de la guerre, depuis qu'elle a réussi à les faire rentrer dans les usines, à écraser leurs premiers soulèvements, à renouer son alliance de guerre avec les social-démocrates et les traîtres socialistes contre le prolétariat et à divi- 
ser ainsi celui-ci, elle a employé toutes ses forces pour organiser des gardesblancs contre le prolétariat et pour désarmer ce dernier. Armée jusqu’aux dents, la bourgeoisie mondiale est prête non seulement à s’opposer par les armes à tout soulèvement du prolétariat, mais encore à provoquer s’il en est besoin des soulèvements prématurés du prolétariat qui se prépare à la lutte ; elle désire ainsi l'écraser avant qu'il ait formé son front commun invincible. L'Internationale Communiste doit opposer sa stratégie à la stratégie de la bourgeoisie mondiale. Contre les caisses du capital mondial qui, au prolétariat organisé, opposent des bandes armées, l'Internationale Communiste dispose d'une arme fidèle : ce sont les masses du prolétariat, le front uni et ferme du prolétariat. Les ruses et la violence de la bourgeoisie n'auront aucun succès si des millions d'ouvriers avancent en rangs serrés au combat. Car alors les chemins de fer sur lesquels la bourgeoisie transporte ses troupes blanches contre le prolétariat s’arrêteront ; la terreur blanche s'emparera alors d'une partie des gardes-blancs eux-mêmes, le prolétariat leur arrachera leurs armes pour lutter contre les autres formations de gardes-blancs. Si l'on réussit à mener sur un front uni le prolétariat à la lutte, le capital, la bourgeoisie mondiale perdront les chances de victoire, la foi en la victoire que seules alors peuvent lui rendre la trahison de la social-démocratie, la division de la classe ouvrière. La victoire sur le capital mondial, ou plutôt la voie vers cette victoire, c'est la conquête des cœurs de la majorité de la classe ouvrière. Le $3^{\circ}$ Congrès mondial de l'Internationale Communiste invite les Partis communistes de tous les pays, les communistes dans les syndicats, à tendre tous leurs efforts, toutes leurs forces, pour arracher les plus grandes masses d'ouvriers à l'influence des Partis socialdémocrates et de la bureaucratie syndicale traître. Ce but ne saurait être obtenu que si les communistes de tous les pays se montrent les combattants d'avant garde de la classe ouvrière pendant cette époque difficile, pendant laquelle chaque jour apporte aux masses ouvrières de nouvelles privations et de nouvelles misères, que s'ils la mènent à la lutte pour un morceau de pain de plus, à la lutte pour le soulagement des charges que le capital impose de plus en plus de manière insupportable aux masses ouvrières. Il faut montrer à la masse ouvrière que seuls les communistes luttent pour l'amélioration de sa situation et que la social-démocratie ainsi que la bureaucratie syndicale réactionnaire sont disposées à laisser le prolétariat devenir la proie de la famine plutôt que de le mener au combat. On ne saurait battre les traîtres au prolétariat, les agents de la bourgeoisie sur le terrain des discussions théoriques, sur la démocratie et la dictature ; on ne les écrasera qu’à 
l'occasion des questions de pain, de salaires, de l'habillement et du logement. Et le premier champ de bataille, le plus important, sur lequel on peut les battre, c'est celui du mouvement syndical ; ils seront vaincus dans la lutte que nous mènerons contre l'Internationale Syndicale Jaune d'Amsterdam et pour l'Internationale Syndicale Rouge. C'est la lutte pour la conquête des positions ennemies dans notre propre camp ; c'est la question de la formation d'un front de combat à opposer au capital mondial. Gardez vos organisations pures de toute tendance centriste, entretenez l'esprit de combat parmi vous.

Ce n’est que dans la lutte pour les intérêts les plus simples, les plus élémentaires des masses ouvrières que nous pourrons former un front uni du prolétariat contre la bourgeoisie. Ce n'est que dans cette lutte que nous pourrons mettre fin aux divisions au sein du prolétariat, divisions qui constituent la base sur laquelle la bourgeoisie peut prolonger son existence. Mais ce front du prolétariat ne deviendra puissant et apte au combat que s'il est maintenu par les Partis Communistes dont l'esprit doit être uni et ferme, et la discipline solide et sévère. C'est pourquoi le $3^{\circ}$ Congrès mondial de l'Internationale Communiste, en même temps qu'il lançait aux communistes de tous les pays le cri de « Aux masses! », «Formez le front uni du prolétariat!» leur recommandait: «Gardez vos rangs purs d'éléments capables de détruire le moral et la discipline de combat des troupes d'attaque du prolétariat mondial, des partis communistes ». Le Congrès de l'Internationale Communiste approuve et confirme l'exclusion du Parti Socialiste d'Italie, exclusion qui doit être maintenue jusqu'au moment où ce Parti rompra avec les réformistes et les chassera de ses rangs. Le Congrès exprime ainsi sa conviction que si l'Internationale Communiste veut mener des millions d'ouvriers au combat, elle ne doit pas tolérer dans ses rangs des réformistes dont le but n'est pas la révolution triomphante du prolétariat, mais la réconciliation avec le capitalisme, et la réforme de ce dernier. Des armées qui tolèrent à leur tête des chefs ayant en vue la réconciliation avec l'ennemi, de telles armées sont vouées à être trahies et vendues à l'ennemi par ces mêmes chefs. L'Internationale Communiste a porté son attention sur le fait que dans toute une série de Partis d'où les réformistes sont cependant exclus, il y a encore des tendances qui n'ont pu surmonter définitivement l'esprit du réformisme ; si ces tendances ne travaillent pas à la réconciliation avec l'ennemi, elles ne s'appliquent cependant pas assez énergiquement dans leur agitation et dans leur propagande à préparer la lutte contre le capi- 
talisme, elles ne travaillent pas assez énergiquement et avec assez de décision à révolutionner les masses. Des Partis qui ne sont pas en mesure, par leur travail révolutionnaire quotidien, de devenir comme le souffle révolutionnaire des masses, qui ne sont pas en mesure de renforcer quotidiennement, avec passion et avec impétuosité, la volonté de lutte des masses, de tels partis laisseront nécessairement échapper des situations favorables pour la lutte, laisseront s’enliser de grandes luttes spontanées du prolétariat, comme ce fut le cas de l'occupation des usines en Italie et lors de la grève de décembre en Tchécoslovaquie. Les Partis Communistes doivent former leur esprit de combat, ils doivent devenir l'étatmajor capable de saisir immédiatement les situations favorables de la lutte et de tirer tous les avantages possibles par une direction courageuse des mouvements spontanés du prolétariat. «Soyez l'avant-garde des masses ouvrières qui se mettent en mouvement, soyez leur cœur et leur cerveau », c'est le cri que le $3^{\circ}$ Congrès Mondial de l'Internationale Communiste lance aux Partis Communistes. Etre l'avant-garde, c'est marcher à la tête des masses, comme leur partie la plus vaillante, la plus prudente, la plus clairvoyante. Ce n’est que si les Partis Communistes deviennent une telle avant-garde qu'ils seront en mesure, non seulement de former le front uni du prolétariat, mais encore, en dirigeant celui-ci, de triompher de l'ennemi.

\section{OPPOSEZ LA STRATÉGIE DU PROLÉTARIAT À LA STRATÉGIE DU CAPITAL, PRÉPAREZ VOS LUTTES!}

L'ennemi est puissant, parce qu'il a derrière lui des siècles d'habitude du pouvoir qui ont créé en lui la conscience de sa force et la volonté de maintenir son pouvoir. L'ennemi est fort parce qu'il a appris pendant des siècles comment diviser les masses prolétariennes, comment les opprimer et les vaincre. L'ennemi sait comment on conduit victorieusement la guerre civile et c'est pour cela que le $3^{\mathrm{e}}$ Congrès de l'Internationale Communiste attire l'attention des Partis Communistes de tous les pays sur le danger que présente la stratégie expérimentée de la classe dominante et possédante et les défauts de la stratégie, en voie de formation à peine, de la classe ouvrière luttant pour le pouvoir. Les événements du mois de mars 
en Allemagne ont montré le grand danger qu'il y aurait à laisser l'ennemi pousser à la lutte, par ses ruses, les premiers rangs de la classe ouvrière, l'avant-garde communiste du prolétariat, avant que les grandes masses se soient mises en mouvement. L’Internationale Communiste a salué avec joie le fait que des centaines de milliers d'ouvriers en Allemagne sont accourus au secours des ouvriers de l'Allemagne Centrale menacés de tous côtés. C’est dans cet esprit de solidarité, c'est dans le soulèvement du prolétariat de tous les pays du monde entier pour la protection d'une partie menacée du prolétariat, que l'Internationale Communiste voit le chemin de la victoire. Elle a salué le fait que le Parti Communiste Unifié d'Allemagne s'est mis à la tête des masses ouvrières qui accouraient pour défendre leurs frères menacés. Mais en même temps, l'Internationale Communiste considère comme un devoir de dire franchement et clairement aux ouvriers de tous les pays : même si l'avant-garde ne peut pas éviter les luttes, même si ces luttes peuvent hâter la mobilisation de toute la classe ouvrière, cette avant-garde ne aurait cependant oublier qu'elle ne doit pas se laisser entraîner toute seule, isolée, dans des luttes décisives, que, contrainte à aller isolée au combat, elle doit éviter le choc armé avec l'ennemi, car ce qui constitue la source de la victoire du prolétariat sur les gardes-blancs armés, c'est sa masse. Si l'avant-garde n'avance pas en masses dominant l'ennemi, elle doit éviter, minorité désarmée, d'entrer en lutte armée avec lui. Les combats de mars ont fourni encore un enseignement sur lequel l'Internationale Communiste attire l'attention des prolétaires de tous les pays : il faut préparer les masses ouvrières aux luttes imminentes, par une agitation révolutionnaire ininterrompue, quotidienne, intense et vaste ; il faut entrer au combat avec des mots d'ordre clairs et compréhensibles pour les grandes masses prolétariennes. A la stratégie de l'ennemi, il faut opposer, au prolétariat, une stratégie avisée et réfléchie. La volonté de combat des rangs d'avant-garde, leur courage et leur fermeté ne suffisent pas. La lutte doit être préparée, organisée, de façon à ce qu'elle apparaisse à celles-ci comme la lutte pour leurs intérêts les plus essentiels et de façon à ce qu'elle les mobilise immédiatement. Plus le capital mondial se sentira en danger, et plus il tentera de rendre impossible la victoire future de l'Internationale Communiste, en isolant ses premiers rangs du reste des grandes masses et en les battant ainsi. A ce plan, à ce danger, il faut opposer une agitation des masses vaste et intense, menée par les Partis Communistes, un travail d'organisation énergique au moyen duquel ces partis assurent leur influence sur les masses, une froide appréciation de la situation du combat, une tactique 
réfléchie tendant à éviter la lutte avec des forces supérieures de l'ennemi et à déclencher l'attaque dans les situations où l'ennemi est divisé et la masse unie.

Le $3^{\mathrm{e}}$ Congrès mondial de l'Internationale Communiste sait que la classe ouvrière n'arrivera à former des partis communistes capables de tomber comme la foudre sur l'ennemi au moment où il est le plus oppressé, et de l'éviter lorsqu'il est dans une situation meilleure, qu'à la suite de l'expérience, qu'elle aura acquise dans la lutte. C'est donc le devoir des prolétaires de tous les pays de s'appliquer à comprendre et à utiliser tous les enseignements, toutes les expériences réunies par la classe ouvrière d'un pays au prix de grands sacrifices.

\section{GARDEZ LA DISCILINE DU COMBAT!}

Les Partis Communistes de tous les pays et la classe ouvrière ne doivent pas se préparer en vue d'une période d'agitation et d'organisation, ils doivent au contraire s'attendre et se préparer aux grandes luttes que le capital imposera bientôt au prolétariat pour l'écraser et pour le charger de tout le poids de sa politique. Dans cette lutte, les Partis Communistes doivent former une discipline du combat sévère et stricte. Les comités centraux de ces partis doivent considérer froidement et avec réflexion tous les enseignements de la lutte, ils doivent observer le champ de bataille, concentrer avec la plus grande réflexion le grand élan des masses. Ils doivent forger leur plan de combat, leur ligne tactique, avec tout l'esprit du Parti et en prenant en considération les critiques des camarades. Mais toutes les organisations du Parti doivent suivre sans hésitation la ligne prescrite par le Parti. Chaque mot, chaque mesure des organisations du Parti doivent être subordonnés à son but. Les fractions parlementaires, la presse du Parti, les organisations doivent suivre sans hésitation l'ordre de la direction du Parti.

La revue mondiale des rangs d'avant-garde communistes est terminée. Elle a montré que le Communisme est une puissance mondiale. Elle a montré que l'Internationale Communiste doit encore former et instruire de grandes armées du prolétariat, elle a montré que de grandes luttes sont imminentes pour ces armées, elle a annoncé la victoire dans ces luttes, elle a montré au prolétariat mondial comment il doit préparer et conquérir cette victoire. Il appartient aux Partis Communistes de tous les pays de faire en sorte que les décisions du Congrès, dictées 
par les expériences du prolétariat mondial, deviennent comme la conscience générale des communistes de tous les pays, afin que les prolétaires communistes, hommes et femmes, puissent agir dans les luttes à venir comme les chefs de milliers de prolétaires non communistes.

Vive l'Internationale Communiste !

Vive la Révolution mondiale !

Au travail pour la préparation et l’organisation de notre victoire !

Le Comité Exécutif de l'Internationale Communiste.

Allemagne : Heckert, Frölich ; France : Souvarine ; Tchécoslovaquie : Bourian, Kreibich ; Italie : Terracini, Gennari ; Russie : Zinoviev, Boukharine, Radek, Lénine, Trotsky; Ukraine : Choumsky; Pologne: Warski ; Bulgarie : Popov; Yougoslavie : Markovicz ; Norvège : Schefflo ; Angleterre : Bell ; Amérique : Baldwin ; Espagne : Merino, Gracia ; Finlande : Sirola ; Hollande : Jansen ; Belgique : Van Overstraeten ; Suède: Tschilbum ; Lettonie : Stoutchka ; Suisse : Arnhold ; Autriche : Koritschoner ; Hongrie : Bela Kun ; Comité Exécutif de l'Internationale des Jeunes : Munzenberg, Lekai.

Moscou, 17 juillet 1921. 
Manifestes, thèses et résolutions

des quatre premiers congrès

de l’Internationale communiste 1919-1923

(juin 1934)

Troisième Congrès, juin 1921.

- 14 -

\section{Thèses pour la propagande parmi les femmes}

\section{PRINCIPES GÉNÉRAUX}

$\underline{\text { Retour à la table des matières }}$

1. Le $3^{\mathrm{e}}$ Congrès de l'Internationale Communiste, conjointement avec la $2^{\mathrm{e}}$ Conférence Internationale des Femmes Communistes, confirme l'opinion du $1^{\mathrm{er}}$ et du $2^{\mathrm{e}}$ Congrès relativement à la nécessité pour tous les partis communistes d'Occident et d'Orient de renforcer le travail parmi le prolétariat féminin, et en particulier l'éducation communiste des grandes masses des ouvrières qu'il faut entraîner dans la lutte pour le pouvoir des soviets ou pour l'organisation de la République Ouvrière Soviétique.

Pour la classe ouvrière du monde entier et par conséquent pour les ouvrières, la question de la dictature du prolétariat devient primordiale.

L'économie capitaliste se trouve dans une impasse. Les forces productives ne peuvent plus se développer dans le cadre du régime capitaliste. L'impuissance de la bourgeoisie à faire renaître l'industrie, la misère grandissante des masses laborieuses, le développement de la spéculation, la décomposition de la production, le chômage, l'instabilité des prix, la cherté de la vie disproportionnée aux salaires, 
provoquent une recrudescence de la lutte de classes dans tous les pays. Dans cette lutte, Il est surtout question de savoir qui doit organiser la production d'une poignée de bourgeois et d'exploiteurs, sur les bases du capitalisme et de la propriété privée, ou de la classe des vrais producteurs, sur la base communiste.

La nouvelle classe montante, la classe des vrais producteurs, doit, conformément aux lois du développement économique, prendre en mains l'appareil de production et créer les nouvelles formes économiques. C'est ainsi seulement qu'on pourra donner leur développement maximum aux forces productrices que l'anarchie de la production capitaliste empêche de donner tout le rendement dont elles sont capables.

Tant que le pouvoir est entre les mains de la classe bourgeoise, le prolétariat est impuissant à rétablir la production. Aucune réforme, aucune mesure, proposées par les gouvernements démocratiques ou socialistes des pays bourgeois ne seront capables de sauver la situation et d'alléger les souffrances insurmontables des ouvriers, car ces souffrances sont un effet naturel de la ruine du système économique capitaliste et persisteront tant que le pouvoir sera entre les mains de la bourgeoisie. Seule la conquête du pouvoir par le prolétariat permettra à la classe ouvrière de s'emparer des moyens de production et de s'assurer ainsi la possibilité de rétablir l'économie dans son propre intérêt.

Pour avancer l'heure de la rencontre décisive du prolétariat avec le monde bourgeois expirant, la classe ouvrière doit se conformer à la tactique ferme et intransigeante préconisée par là troisième Internationale. La réalisation de la dictature du prolétariat doit être à l'ordre du jour. C'est là le but qui doit définir les méthodes d'action et la ligne de conduite du prolétariat des deux sexes.

Partant du point de vue que la lutte pour la dictature du prolétariat est à l'ordre du jour du prolétariat de tous les Etats capitalistes et que la construction du communisme est la tâche actuelle dans les pays où la dictature est déjà entre les mains des ouvriers, le $3^{\mathrm{e}}$ Congrès de l'Internationale Communiste déclare que, aussi bien la conquête du pouvoir par le prolétariat que la réalisation du communisme dans les pays qui ont déjà renversé l'oppression bourgeoise ne sauraient être accomplies sans l'appui actif de la masse du prolétariat et du demi-prolétariat féminin.

D'autre part le Congrès attire une fois de plus l'attention des femmes sur le fait que sans l'appui des Partis Communistes, les initiatives ayant pour but la libé- 
ration de la femme, la reconnaissance de son égalité personnelle complète et son affranchissement véritable ne sont pas réalisables.

2. L'intérêt de la classe ouvrière exige en ce moment avec une force particulière l'entrée des femmes dans les rangs organisés du prolétariat combattant pour le communisme ; il l'exige dans la mesure où la ruine économique mondiale devient de plus en plus intense et intolérable pour toute la population pauvre des villes et des campagnes et dans la mesure où, devant la classe ouvrière des pays bourgeois capitalistes, la révolution sociale s'impose inévitablement, tandis que devant le peuple laborieux de la Russie Soviétique se dresse la tâche de reconstruire l'économie nationale sur de nouvelles bases communistes. Ces deux tâches seront d'autant plus facilement réalisées que les femmes y prendront une part plus active, plus consciente et plus volontaire.

3. Partout où la question de la conquête du pouvoir surgit directement, les partis communistes doivent savoir apprécier le grand danger que présente dans la révolution les masses inertes des ouvrières non entraînées dans le mouvement des ménagères, des employées, des paysannes non affranchies des conceptions bourgeoises, de l'Eglise et des préjugés, et non rattachées par un lien quelconque au grand mouvement de libération qu'est le communisme. Les masses féminines de l'Orient et de l'Occident non entraînées dans ce mouvement constituent inévitablement un appui pour la bourgeoisie, et un objet pour sa propagande contrerévolutionnaire. L'expérience de la révolution hongroise, au cours de laquelle l'inconscience des masses féminines a joué un si triste rôle, doit servir d'avertissement au prolétariat des pays arriérés entrant dans la voie de la révolution sociale.

La pratique de la République Soviétique a montré à l'œuvre combien est essentielle la participation de l'ouvrière et de la paysanne tant à la défense de la République pendant la guerre civile que dans tous les domaines de l'organisation soviétique. On sait l'importance du rôle que les ouvrières et les paysannes ont déjà joué dans la République Soviétique, dans l’organisation de la défense, dans le renforcement de l'arrière, dans la lutte contre la désertion et contre toutes les formes de la contre-révolution, du sabotage. etc...

L'expérience de la République Ouvrière doit être apprise et utilisée dans les autres pays. 
De tout ce que nous venons de dire résulte la tâche immédiate des Partis Communistes : étendre l'influence du Parti et du communisme aux vastes couches de la population féminine de leur pays, au moyen d'un organe spécial fonctionnant à l'intérieur du Parti et de méthodes particulières permettant d'aborder plus facilement les femmes pour les soustraire à l'influence des conceptions bourgeoises et à l'action des partis coalitionnistes, pour en faire de véritables combattantes pour l'affranchissement total de la femme.

4. En imposant aux Partis Communistes d'Occident et d'Orient la tâche immédiate de renforcer le travail du Parti parmi le prolétariat féminin, le $3^{\mathrm{e}}$ Congrès de l'Internationale Communiste montre en même temps aux ouvriers du monde entier que leur affranchissement de l'injustice séculaire, de l'esclavage et de l’inégalité, n’est réalisable que par la victoire du communisme.

Ce que le communisme donnera à la femme, en aucun cas, le mouvement féminin bourgeois ne saurait le lui donner. Aussi longtemps qu'existera la domination du capital et de la propriété privée, l'affranchissement de la femme n’est pas possible.

Le droit électoral ne supprime pas la cause première de l'asservissement de la femme dans la famille et dans la société et ne lui donne pas la solution du problème des rapports entre les deux sexes. L'égalité non formelle, mais réelle de la femme n'est possible que sous un régime où la femme de la classe ouvrière sera la maîtresse de ses instruments de production et de répartition, prenant part à leur administration et portant l'obligation du travail dans les mêmes conditions que tous les membres de la Société travailleuse ; en d'autres termes, cette égalité n'est réalisable qu'après le renversement du système capitaliste et son remplacement par les formes économiques communistes.

Seul, le communisme créera un état de choses dans lequel la fonction naturelle de la femme, la maternité, ne sera plus en conflit avec les obligations sociales et n’empêchera plus son travail productif au profit de la collectivité. Mais le communisme est en même temps le but final de tout le prolétariat. Par conséquent la lutte de l'ouvrière et de l'ouvrier pour ce but commun doit, dans l'intérêt de tous les deux, être menée en commun et inséparablement.

5. Le $3^{\mathrm{e}}$ Congrès de l'Internationale Communiste confirme les principes fondamentaux du marxisme révolutionnaire suivant lesquels il n’y a point de ques- 
tions «spécialement féminines »; tout rapport de l'ouvrière avec le féminisme bourgeois, de même que tout appui apporté par elle à la tactique de demi-mesures et de franche trahison des social-coalitionnistes et des opportunistes ne fait qu'affaiblir les forces du prolétariat et, en retardant la révolution sociale, empêche en même temps la réalisation du communisme, c'est-à-dire l'affranchissement de la femme.

Nous n'atteindrons au communisme que par l'union dans la lutte de tous les exploités et non par l'union des forces féminines des deux classes opposées.

Les masses prolétariennes féminines doivent dans leur propre intérêt soutenir la tactique révolutionnaire du Parti Communiste et prendre la part la plus active et la plus directe aux actions des masses et à la guerre civile sous toutes ses formes et sous tous ses aspects, tant dans le cadre national qu'à l'échelle internationale.

6. La lutte de la femme contre sa double oppression : le capitalisme et la dépendance familiale et ménagère doit prendre, dans la phase prochaine de son développement, un caractère international se transformant en lutte du prolétariat des deux sexes pour la dictature et le régime soviétique sous le drapeau de la $3^{\mathrm{e}}$ Internationale.

7. En dissuadant les ouvrières de tous les pays de toute espèce de collaboration et de coalition avec les féministes bourgeoises, le $3^{\mathrm{e}}$ Congrès de l'Internationale Communiste les prévient en même temps que tout appui fourni par elles à la $2^{\mathrm{e}}$ Internationale ou aux éléments opportunistes qui s'en rapprochent ne peut que faire le plus grand mal à leur mouvement. Les femmes doivent toujours se rappeler que leur esclavage a toutes ses racines dans le régime bourgeois. Pour en finir avec cet esclavage, il faut passer à un ordre social nouveau.

En soutenant les Internationales 2 et $2 \frac{1}{1} 2$ et les groupes analogues, on paralyse le développement de la révolution, on empêche par conséquent la transformation sociale en éloignant l'heure de l'affranchissement de la femme.

Plus les masses féminines s'éloigneront avec décision et sans retour de la $2^{\mathrm{e}}$ Internationale et de l'Internationale $21 / 2$, plus la victoire de la révolution sociale sera assurée. Le devoir des femmes communistes est de condamner tous ceux qui craignent la tactique révolutionnaire de l'Internationale Communiste et de s'appliquer fermement à les faire exclure des rangs serrés de l'Internationale Communiste. 
Les femmes doivent encore se rappeler que la $2^{\mathrm{e}}$ Internationale n'a même pas essayé de créer un organisme destiné à la lutte pour l'affranchissement total de la femme. L'union internationale des femmes socialistes, dans la mesure où elle existe, a été établie en dehors du cadre de la $2^{\mathrm{e}}$ Internationale, sur la propre initiative des ouvrières.

La $3^{\mathrm{e}}$ Internationale a formulé clairement, dès son premier congrès en 1919, son attitude sur la question de la participation des femmes à la lutte pour la dictature du prolétariat. C'est sur son initiative et avec sa participation que fut convoquée la première conférence des femmes communistes et qu'en 1920 fut fondé le secrétariat international pour la propagande parmi les femmes, avec représentation permanente au Comité Exécutif de l'Internationale Communiste. Le devoir des ouvrières conscientes de tous les pays est de rompre avec la $2^{\mathrm{e}}$ Internationale et avec l'Internationale $2 \frac{1}{2}$ et de soutenir fermement la politique révolutionnaire de l'Internationale Communiste.

8. L'appui que donneront à l'Internationale Communiste les ouvrières et les employées doit se manifester tout d'abord par leur entrée dans les rangs des Partis Communistes de leurs pays. Dans les pays et dans les Partis où la lutte entre la $2^{\mathrm{e}}$ et la $3^{\mathrm{e}}$ Internationale n'est pas encore terminée, le devoir des ouvrières est de soutenir de toutes leurs forces le parti ou le groupe qui suit la politique de l'Internationale Communiste et de lutter impitoyablement contre tous les éléments hésitants ou ouvertement traîtres, sans tenir compte d'aucune autorité. Les femmes prolétaires conscientes luttant pour leur affranchissement ne doivent pas rester dans un parti non affilié à l'Internationale Communiste.

Tout adversaire de la $3^{\mathrm{e}}$ Internationale est un ennemi de l'affranchissement de la femme.

Chaque ouvrière consciente d'Occident et d'Orient doit se ranger sous le drapeau révolutionnaire de l'Internationale Communiste. Toute hésitation des femmes du prolétariat à briser avec les groupements opportunistes ou avec les autorités reconnues, retarde les conquêtes du prolétariat sur le champ de bataille de la guerre civile, qui prend le caractère d'une guerre civile mondiale. 


\section{MÉTHODES D’ACTION PARMI LES FEMMES}

Partant des principes ci-dessus indiqués, le $3^{\mathrm{e}}$ Congrès de l'Internationale Communiste établit que le travail parmi le prolétariat féminin doit être mené par les Partis Communistes de tous les pays sur les bases suivantes :

1. Admettre les femmes à titre de membres égaux en droits et en devoirs à tous les autres dans le Parti et dans toutes les organisations prolétariennes (syndicats, coopératives, conseils des anciens des usines, etc...)

2. Se rendre compte de l'importance qu'il y a à faire participer activement les femmes à toutes les branches de la lutte du prolétariat (y compris sa défense militaire), de l'édification des nouvelles bases sociales, de l'organisation de la production et de l'existence selon les principes communistes.

3. Reconnaître la maternité comme une fonction sociale, prendre et appliquer toutes mesures nécessaires à la défense de la femme dans sa qualité de mère.

Tout en se déclarant énergiquement contre toute espèce d’organisation séparée de femmes au sein du Parti, des syndicats ou des autres associations ouvrières, le $3^{\mathrm{e}}$ Congrès de l'Internationale Communiste reconnaît la nécessité pour le Parti Communiste d'employer des méthodes particulières de travail parmi les femmes et estime utile de former dans tous les Partis Communistes des organes spéciaux chargés de ce travail.

En cela le Congrès est guidé par les considérations suivantes :

$1^{\circ}$ l'asservissement familial de la femme non seulement dans les pays bourgeois capitalistes, mais même dans les pays où existe déjà le régime soviétique, dans la phase de transition du capitalisme au communisme. 
$2^{\circ}$ la grande passivité et l'état politique arriéré des masses féminines, défauts expliqués par l'éloignement séculaire de la femme de la vie sociale et par son esclavage dans la famille.

$3^{\circ}$ les fonctions spéciales imposées à la femme par la nature elle-même, c'est-à-dire la maternité et les particularités qui en découlent pour la femme, avec le besoin d'une plus grande protection de ses forces et de sa santé dans l'intérêt de toute la société.

Ces organes pour le travail parmi les femmes doivent être des sections ou des commissions fonctionnant auprès de tous les Comités du Parti, à commencer par le Comité Central et jusqu'aux comités de quartier ou de district. Cette décision est obligatoire pour tous les Partis adhérant à l’Internationale Communiste.

Le $3^{\mathrm{e}}$ Congrès de l'Internationale Communiste indique comme tâches des Partis Communistes à accomplir par l'intermédiaire des sections pour le travail parmi les femmes :

1. Éduquer les grandes masses féminines dans l'esprit du communisme et les attirer dans les rangs du Parti.

2. Combattre les préjugés relatifs aux femmes dans les masses du prolétariat masculin, en renforçant dans l'esprit des ouvriers et des ouvrières l'idée de la solidarité des intérêts des prolétaires des deux sexes.

3. Affermir la volonté de l'ouvrière en l'utilisant dans la guerre civile sous toutes ses formes et aspects, éveiller son activité en la faisant participer aux actions de masses, à la lutte contre l'exploitation capitaliste dans les pays bourgeois (contre la cherté de la vie, la crise du logement et le chômage), à l'organisation de l'économie communiste et de l'existence en général dans les républiques soviétiques.

4. Mettre à l'ordre du jour du Parti et des institutions législatives les questions relatives à l'égalité de la femme et à sa défense comme mère. 
5. Lutter systématiquement contre l'influence de la tradition, des mœurs bourgeoises et de la religion, afin de préparer la voie à des rapports plus sains et plus harmonieux entre les sexes et à l'assainissement moral et physique de l'humanité travailleuse.

Tout le travail des sections féminines devra être fait sous la direction immédiate et sous la responsabilité des comités du Parti.

Parmi les membres de la commission ou de la direction des sections devront figurer aussi, dans la mesure du possible, des camarades communistes hommes.

Toutes les mesures et toutes les tâches qui s'imposent aux commissions et aux sections des ouvrières devront être réalisées par elles, d'une manière indépendante, mais dans les pays des Soviets par l'intermédiaire des organes économiques ou politiques respectifs (sections des Soviets, Commissariats, Commissions, Syndicats, etc...) et dans les pays capitalistes avec l'aide des organes correspondants du prolétariat (syndicats conseils, etc...).

Partout où des Partis Communistes ont une existence légale ou semi-légale, ils doivent former un appareil illégal pour le travail parmi les femmes. Cet appareil doit être subordonné et adapté à l'appareil illégal du parti dans son ensemble. Là, comme dans l'appareil légal, chaque Comité doit comprendre une camarade, chargée de diriger la propagande illégale parmi les femmes.

Dans la période actuelle, les syndicats professionnels et de production doivent être pour les Partis Communistes le terrain fondamental du travail parmi les femmes, tant pour les pays où la lutte pour le renversement du joug capitaliste n'est pas encore terminée que dans les républiques ouvrières soviétiques.

Le travail parmi les femme doit être mené dans l'esprit suivant : unité dans la ligne politique et dans la structure du parti, libre initiative des commissions et des sections dans tout ce qui tend à procurer à la femme sa complète libération et égalité, ce qui ne saurait être pleinement obtenu que par le Parti, en entier. Il ne s'agit pas de créer un parallélisme, mais de compléter les efforts du Parti par l'activité et l’initiative créatrices de la femme. 


\section{LE TRAVAIL POLITIQUE DU PARTI PARMI LES FEMMES DANS LES PAYS DE RÉGIME SOVIÉTIQUE}

Le rôle des sections dans les républiques soviétiques consiste à éduquer les masses féminines dans l'esprit du communisme en les entraînant dans les rangs du Parti Communiste ; il consiste encore à développer l'activité, l'initiative de la femme en l'attirant dans le travail de construction du communisme et en en faisant un ferme défenseur de l’Internationale Communiste.

Les sections doivent par tous les moyens faire participer la femme à toutes les branches de l'organisation soviétique, depuis la défense militaire de la République jusqu’aux plans économiques les plus compliqués.

Dans la République Soviétique, les sections doivent veiller à l’application des décisions du $3^{\mathrm{e}}$ Congrès des Soviets concernant la participation des ouvrières et des paysannes à l'organisation et à la construction de l'économie nationale, ainsi qu'à tous les organes dirigeants et administratif, contrôlant et organisant la production.

Par l'intermédiaire de leurs représentants et par les organes du Parti, les sections doivent collaborer à l'élaboration de nouvelles lois et à la modification de celles qui doivent être transformées en vue de l'affranchissement réel de la femme. Les sections doivent faire preuve d'initiative particulière pour le développement de la législation protégeant le travail de la femme et des mineurs.

Les sections doivent entraîner le plus grand nombre possible d'ouvrières et de paysannes dans les campagnes pour l'élection des Soviets et veiller à ce que parmi les membres de ceux-ci et des Comités Exécutifs soient aussi élues des ouvrières et des paysannes.

Les sections doivent favoriser le succès de toutes les campagnes politiques et économiques menées par le Parti.

C’est encore le rôle des sections de veiller au perfectionnement et à la spécialisation du travail féminin par l'expansion de l'enseignement professionnel, en facilitant aux ouvrières et aux paysannes l'accès des établissements correspondants. 
Les sections veilleront à l'entrée des ouvrières dans les commissions pour la protection du travail fonctionnant dans les entreprises et au renforcement de l'activité des commissions de secours et de protection de la maternité et de l'enfance.

Les sections faciliteront le développement de tout le réseau d’établissements publics comme orphelinats, blanchisseries, ateliers de réparations, institutions d'existence sur les nouvelles bases communistes, allégeront pour les femmes le fardeau de l'époque de transition, amèneront leur indépendance matérielle et feront de l'esclave domestique et familial la libre collaboratrice du créateur des nouvelles formes de vie.

Les sections devront faciliter l'éducation des femmes membres des syndicats dans l'esprit du communisme par l'intermédiaire des organisations pour le travail parmi les femmes, constituées par les fractions communistes des syndicats.

Les sections veilleront à ce que les ouvrières assistent régulièrement aux réunions des déléguées d'usines et de fabriques.

Les sections répartiront systématiquement les déléguées du Parti comme stagiaires dans les différentes branches de travail : soviets, économie nationale, syndicats.

\section{DANS LES PAYS CAPITALISTES}

Les tâches immédiates des commissions pour le travail parmi les femmes sont déterminées par les conditions objectives. D’une part: la ruine de l'économie mondiale, l'aggravation prodigieuse du chômage, ayant pour conséquences particulières la diminution de la demande de main-d'œuvre féminine et l'augmentation de la prostitution, de la cherté de la vie, de la crise du logement, de la menace de nouvelles guerres impérialistes ; d'autre part : les incessantes grèves économiques dans tous les pays, les tentatives renouvelées de soulèvement armé du prolétariat, l'atmosphère de plus en plus étouffante de la guerre civile s’étendant sur le monde entier, tout cela apparaît comme le prologue de l'inévitable révolution sociale mondiale. 
Les commissions féminines doivent mettre en avant les tâches de combat du prolétariat, mener la lutte pour les revendications du Parti Communiste, faire participer la femme à toutes les manifestations révolutionnaires des communistes contre la bourgeoisie et les socialistes coalitionnistes.

Les commissions veilleront, non seulement à ce que les femmes soient admises avec les mêmes droits et les mêmes devoirs que les hommes dans le Parti, dans les syndicats et dans les autres organisations ouvrières de lutte de classes, en combattant toute séparation et toute particularisation de l'ouvrière, mais encore à ce que les ouvrières soient élues à l'égal des ouvriers dans les organes dirigeants des syndicats et des coopératives.

Les commissions aideront les grandes masses du prolétariat féminin et des paysannes à exercer leurs droits électoraux aux élections parlementaires et autres en faveur du Parti Communiste, tout en faisant ressortir le peu de valeur de ces droits tant pour l'affaiblissement de l'exploitation capitaliste que pour l'affranchissement de la femme, et en opposant au parlementarisme le régime soviétique.

Les commissions devront aussi veiller à ce que les ouvrières, les employées et les paysannes prennent une part active et consciente aux élections des soviets révolutionnaires, économiques et politiques de délégués ouvriers. Elles s’efforceront d'éveiller l'activité politique chez les ménagères et de propager l’idée des Soviets particulièrement parmi les paysannes.

Les commissions consacreront la plus grande attention à l'application du principe « à travail égal, salaire égal ».

Les commissions devront entraîner les ouvrières dans cette campagne par des cours gratuits et accessibles à tous et de nature à relever la valeur de la femme.

Les commissions doivent veiller à ce que les femmes communistes collaborent à toutes les institutions législatives, municipales, pour préconiser dans ces organes la politique révolutionnaire de leur parti.

Mais tout en participant aux institutions législatives, municipales et aux autres organes de l'Etat bourgeois, les femmes communistes doivent suivre strictement les principes et la tactique du Parti. Elles doivent se préoccuper non pas d'obtenir des réformes sous le régime capitaliste, mais de tâcher de transformer toutes re- 
vendications des femmes laborieuses en mots d'ordre de nature à éveiller l'activité des masses et à diriger ces revendications sur la route de la lutte révolutionnaire et de la dictature du prolétariat.

Les commissions doivent dans les Parlements et dans les municipalités rester en contact étroit dans les fractions communistes et délibérer en commun sur tous les projets relatifs aux femmes. Les commissions devront expliquer aux femmes le caractère arriéré et non économique du système des ménages isolés, le défaut de l'éducation bourgeoise donnée aux enfants, en groupant les forces des ouvrières sur les questions de l'amélioration réelle de l'existence de la classe ouvrière, questions soulevées par le Parti.

Les commissions devront favoriser l'entraînement dans le Parti Communiste des ouvrières, membres des syndicats, et les fractions communistes de ces derniers devront détacher dans ce but des organisateurs pour le travail parmi les femmes agissant sous la direction du Parti et les sections locales.

Les commissions d'agitation parmi les femmes devront diriger leur propagande de telle sorte qu'elles obtiennent que les femmes prolétaires répandent dans les coopératives l’idée du communisme et, en pénétrant dans la direction de ces coopératives, arrivent à les influencer et à les gagner, étant donné que ces organisations auront une très grande importance comme organes de répartition pendant et après la révolution. Tout le travail des commissions doit tendre vers ce but unique : le développement de l'activité révolutionnaire des masses afin de hâter la révolution sociale.

\section{DANS LES PAYS ÉCONOMIQUEMENT ARRIÉRÉS (L'ORIENT)}

Le Parti Communiste de concert avec les sections doit obtenir dans les pays à faible développement industriel la reconnaissance de l'égalité en droits et en devoirs de la femme dans le Parti, dans les syndicats et dans les autres organisations de la classe ouvrière. 
Les sections et les commissions doivent lutter contre les préjugés, les mœurs et les habitudes religieuses pesant sur la femme et mener la propagande parmi les hommes aussi.

Le Parti Communiste et ses sections ou commissions doivent appliquer les principes de l'égalité des droits de la femme dans l'éducation des enfants, dans les rapports familiaux et dans la vie publique.

Les sections chercheront appui pour leur travail avant tout dans la masse des ouvrières travaillant à domicile (petite industrie), des travailleuses des plantations de riz, de coton et autres, en favorisant la formation partout où elle est possible (et en premier lieu parmi les peuples de l'Orient vivant dans les confins de la Russie Soviétique), d'ateliers corporatifs, de coopératives de petite industrie, et en facilitant ainsi partout l'entrée des ouvrières des plantations dans les syndicats.

Le relèvement du niveau général de culture de la masse est un des meilleurs moyens de lutte contre la routine et les préjugés religieux répandus dans le pays. Les commissions doivent donc favoriser le développement des écoles pour adultes et pour enfants et en rendre l'accès facile aux femmes. Dans les pays bourgeois, les commissions doivent mener une agitation directe contre l'influence bourgeoise dans les écoles.

Partout où il est possible de le faire, les sections et les commissions doivent mener la propagande à domicile, elles doivent organiser des clubs d'ouvrières et $\mathrm{y}$ attirer celle-ci, et en général les éléments féminins les plus arriérés. Les clubs doivent être des foyers de culture et d'instruction et des organisations modèles montrant ce que peut faire la femme pour son propre affranchissement et son indépendance (organisation de crèches, de jardins d'enfants, d'écoles primaires pour adultes, etc...).

Chez les peuples menant une vie nomade il faudra organiser des clubs ambulants.

Les sections doivent, de concert avec les Partis, dans les pays de régime soviétique, contribuer à faciliter la transition de la forme économique capitaliste à la forme de production communiste, en plaçant l'ouvrière devant cette réalité évidente que l'économie domestique et la famille, telles qu'elles étaient jusqu'à présent, ne peuvent que l’asservir tandis que le travail collectif la libérera. 
Parmi les peuples orientaux vivant en Russie Soviétique, les sections doivent veiller à ce que soit appliquée la législation soviétique égalisant la femme dans ses droits par rapport à l'homme et défendant ses intérêts. Dans ce but, les sections doivent faciliter aux femmes l'accès aux fonctions de jurés dans les tribunaux populaires.

Les sections doivent également faire participer la femme aux élections aux Soviets, et veiller à ce que les ouvrières et les paysannes entrent dans les Soviets et les Comités Exécutifs. Le travail parmi le prolétariat féminin de l’Orient doit être mené sur la plate-forme de la lutte de classes. Les sections révéleront l'impuissance des féministes à trouver une solution aux différentes questions de l'affranchissement de la femme ; elles utiliseront les forces intellectuelles féminines (par ex. les institutrices) pour répandre l’instruction dans les pays soviétiques de l'Orient. Tout en évitant les attaques grossières et sans tact aux croyances religieuses et aux traditions nationales, les sections et les commissions travaillant parmi les femmes de l'Orient, devront nettement lutter contre l'influence du nationalisme et de la religion sur les esprits.

Toute l'organisation des ouvrières doit être basée, en Orient tout comme en Occident, non pas sur la défense des intérêts nationaux, mais sur le plan de l'union du prolétariat international des deux sexes dans les tâches communes de classe.

La question du travail parmi les femmes d'Orient, étant de grande importance et en même temps présentant un nouveau problème pour les partis communistes, doit être détaillée par une instruction spéciale sur les méthodes de travail parmi les femmes de l'Orient, appropriées aux conditions des pays orientaux. L’instruction sera adjointe aux thèses.

\section{MÉTHODES D'AGITATION ET DE PROPAGANDE}

Pour accomplir la mission fondamentale des sections, c'est-à-dire l'éducation communiste des grandes masses féminines du prolétariat et le renforcement des cadres des champions du communisme, il est indispensable que tous les Partis 
Communistes d'Orient et d'Occident s'assimilent le principe fondamental du travail parmi les femmes, qui est celui-ci : « Agitation et propagande par le fait ».

Agitation par le fait veut dire avant tout : action pour éveiller l'initiative de l'ouvrière, détruire son manque de confiance en ses propres forces et, en l'entraînant au travail pratique dans le domaine de l'organisation et de la lutte, pour lui apprendre à comprendre par la réalité que toute conquête du Parti Communiste, toute action contre l'exploitation capitaliste, est un progrès soulageant la situation de la femme. « De la pratique à l’action, à la reconnaissance de l'idéal du communisme et de ses principes théoriques », telle est la méthode avec laquelle les Partis Communistes et leurs sections féminines devront aborder les ouvrières.

Pour être réellement des organes d'action et pas seulement de propagande orale, les sections féminines doivent s’appuyer sur les noyaux communistes des entreprises et des ateliers et charger, dans chaque noyau communiste, un organisateur spécial du travail parmi les femmes de l’entreprise ou de l'atelier.

Avec les syndicats, les sections devront entrer en rapports par l'intermédiaire de leurs représentants ou de leurs organisateurs, désignés par la fraction communiste du syndicat et menant leur travail sous la direction des sections.

La propagande de l'idée communiste par le fait consiste, dans la Russie des Soviets, à faire entrer l'ouvrière, la paysanne, la ménagère et l'employée dans toutes les organisations soviétiques, en commençant par l'armée et la milice et en finissant par toutes les institutions visant à l'affranchissement de la femme : alimentation publique, éducation sociale, protection de la maternité, etc... Une tâche particulièrement importante, c'est la restauration économique sous toutes ses formes, à laquelle il faut entraîner l’ouvrière.

La propagande par le fait dans les pays capitalistes tendra avant tout à entraîner l'ouvrière dans les grèves, dans les manifestations et dans l'insurrection sous toutes ses formes, qui trempent et élèvent la volonté et la conscience révolutionnaires, dans toutes les formes du travail politique, dans le travail illégal (particulièrement dans les services de liaison) dans l'organisation des samedis et des dimanches communistes, par lesquels les ouvrières sympathisantes, les employées apprendront à se rendre utiles au Parti, par le travail volontaire. 
Le principe de la participation des femmes à toutes les campagnes politiques, économiques ou morales entreprises par le Parti Communiste sert également le but de la propagande par le fait. Les organes de propagande parmi les femmes auprès des Partis communistes doivent étendre leur activité dans des catégories de plus en plus nombreuses de femmes socialement exploitées et enchaînées dans les pays capitalistes et, parmi les femmes des Etats soviétiques affranchir leur esprit enchaîné par des superstitions et des survivances du vieil ordre social. Ils devront s'attacher à tous les besoins et à toutes les souffrances, à tous les intérêts et à toutes les revendications par lesquelles les femmes se rendront compte que le capitalisme devra être écrasé comme leur ennemi mortel et que les voies doivent être frayées au communisme, leur libérateur.

Les sections doivent mener méthodiquement leur agitation et leur propagande par la parole, en organisant des réunions dans les ateliers et des réunions publiques soit pour les ouvrières et employées de différentes branches d'industrie, soit pour les ménagères et pour les travailleuses de toutes branches, par quartiers, rayons de la ville, etc...

Les sections doivent veiller à ce que les fractions communistes des syndicats, des associations ouvrières, des coopératives élisent des organisateurs et agitateurs spéciaux pour faire le travail communiste dans les masses féminines des syndicats, coopératives, associations. Les sections doivent veiller à ce que dans les Etats Soviétiques, les ouvrières soient élues aux conseils d'industrie et à tous les organes chargés de l'administration, du contrôle et de la direction de la production. Bref, les ouvrières doivent être élues à toutes les organisations qui, dans les pays capitalistes, servent aux masses exploitées et opprimées dans leur lutte pour la conquête de pouvoir politique ou, dans les Etats Soviétiques, servent à la défense de la dictature du prolétariat et à la réalisation du communisme.

Les sections doivent déléguer des femmes communistes éprouvées dans les industries, les plaçant comme ouvrières ou comme employées là où un grand nombre de femmes travaillent, comme cela est pratiqué en Russie Soviétique ; on installe aussi ces camarades dans de grandes circonscriptions et centres prolétariens.

Suivant l'exemple du Parti Communiste de la Russie Soviétique, qui organise des réunions de délégués et des conférences de déléguées sans parti, lesquelles ont 
toujours un succès considérable, les sections féminines des pays capitalistes doivent organiser des réunions publiques d'ouvrières, de travailleuses de toutes sortes, paysannes, ménagères, réunions qui s’occupent des besoins, des revendications des femmes laborieuses et qui doivent élire des comités ad-hoc, approfondir les questions soulevées en contact permanent avec leurs mandataires et les sections féminines du parti. Les sections doivent envoyer leurs orateurs prendre part aux discussions dans les réunions des partis hostiles au communisme.

La propagande et l'agitation au moyen des réunions et d'autres institutions semblables doivent être complétées par une agitation méthodique et prolongée poursuivie dans les foyers. Toute communiste chargée de cette besogne devra visiter tout au plus dix femmes à domicile, mais elle devra le faire régulièrement, au moins une fois par semaine et à chaque action importante des Partis Communistes et des masses prolétariennes.

Les sections doivent créer et répandre une littérature simple, convenable, de brochures et feuilles volantes de nature à exhorter et à grouper les forces féminines.

Les sections doivent veiller à ce que les femmes communistes utilisent de la manière la plus active toutes les institutions et moyens d'instruction du Parti. Afin d’approfondir la conscience et de tremper la volonté des communistes encore retardataires et des femmes laborieuses s'éveillant à l'activité, les sections doivent les inviter aux cours et discussions du Parti. Des cours séparés, des soirées de lecture et de discussion pour les ouvrières seules, peuvent être organisés seulement en cas d'exception.

Afin de développer l'esprit de camaraderie entre ouvrières et ouvriers, il est désirable de ne point créer de cours et d'écoles spéciales pour les femmes communistes ; dans chaque école du Parti, il doit obligatoirement y avoir un cours sur les méthodes du travail parmi les femmes. Les sections ont le droit de déléguer un certain nombre de leurs représentantes aux cours généraux du Parti. 


\section{STRUCTURE DES SECTIONS}

Des commissions pour le travail parmi les femmes seront organisées auprès des comités régionaux et de district et enfin auprès du Comité Central du Parti.

Chaque pays décide lui-même des membres de la section. C'est de même au parti des différents pays qu'est donnée la liberté de fixer selon les circonstances le nombre des membres de la section appointés par le Parti.

La directrice de la section devra être en même temps membre du Comité local du Parti. Au cas où ce cumul ne se rencontrerait pas, elle devra assister à toutes les séances du Comité avec voix délibérative sur les questions concernant la section des femmes, et voix consultative sur toutes les autres questions.

Outre les tâches générales énumérées ci-dessous, incombant aux sections et aux commissions locales, elles seront chargées des fonctions suivantes : maintien de la liaison entre les différentes sections de la région et avec la section centrale, réunions d'information sur l'activité des sections et des commissions de la région, échange d'informations entre les différentes sections de la région et avec la section centrale, réunions d'information sur l'activité des sections et des commissions de la région, échange d'informations entre les différentes sections, fourniture de littérature à la région ou province ; distribution des forces d'agitation, mobilisation des forces du Parti pour le travail parmi les femmes; convocation au moins deux fois par an de conférences régionales des femmes communistes, des représentantes des sections à raison de une à deux par section, enfin organisation de conférence d'ouvrières et de paysannes sans-parti.

Les sections régionales (de province) se composent de cinq à sept membres, les membres du Bureau sont nommés par le Comité correspondant du Parti sur présentation de la directrice de la section ; celle-ci est élue de même que les autres membres du comité de district ou de province à la conférence correspondante du Parti.

Les membres des sections ou des commissions sont élues à la conférence générale de la ville, du district ou de la province, ou encore sont nommées par les sections respectives en contact avec le Comité du Parti. La commission Centrale 
pour le travail parmi les femmes se compose de 2 à 5 membres dont une au moins est payée par le Parti.

Outre toutes les fonctions énumérées plus haut pour les sections régionales, la Commission centrale aura encore les tâches suivantes : instructions à donner aux localités et à leurs militantes ; contrôle du travail des sections, répartition, en contact avec les organes correspondants du Parti, des forces menant le travail parmi les femmes, contrôle par l'intermédiaire de leur représentant ou de leur chargé de pouvoir des conditions et du développement du travail féminin sur la base des transformations juridiques ou économiques nécessaires dans la situation de la femme ; participation des représentants, des chargés de pouvoir, aux commissions spéciales étudiant l'amélioration de l'existence de la classe ouvrière, de la protection du travail, de l'enfance, etc... ; publication d'une « feuille » centrale et rédaction de journaux périodiques pour les ouvrières ; convocation au moins une fois par an des représentantes de toutes les sections provinciales, organisation d'excursions de propagande à travers tout le pays, envoi d'instructeurs du travail parmi les femmes ; entraînement des ouvrières a participer dans toutes les sections à toutes les campagnes politiques et économiques du Parti ; liaison permanente avec le secrétariat international des femmes communistes et célébration annuelle de la journée internationale de l’ouvrière.

Si la directrice de la section des femmes auprès du Comité Central n'est pas membre de ce Comité, elle a le droit d'assister à toutes les séances avec voix délibérative sur les questions concernant la section, avec voix consultative sur toutes les autres. Elle est ou bien nommée par le Comité Central du Parti ou bien élue au congrès général de ce dernier. Les décisions et les arrêts de toutes les commissions doivent être confirmés par le Comité respectif du Parti.

\section{LE TRAVAIL À L'ÉCHELLE INTERNATIONALE}

La direction du travail des Partis Communistes de tous les pays, la réunion des forces ouvrières, la solution des tâches imposées par l'Internationale Communiste et l'entraînement des femmes de tous les pays et de tous les peuples dans la lutte révolutionnaire pour le Pouvoir des Soviets et la dictature de la classe ouvrière à 
l'échelle mondiale, incombent au secrétariat international féminin auprès de l'Internationale Communiste.

Le nombre des membres de la Commission Centrale et le nombre des membres avec voix délibérative sont fixés par le Comité Central du Parti. 
Manifestes, thèses et résolutions

des quatre premiers congrès

de l’Internationale communiste 1919-1923

(juin 1934)

Troisième Congrès, juin 1921.

- 15 -

\section{Résolution concernant les relations internationales des femmes communistes et le secrétariat féminin de l’Internationale Communiste}

\section{(Adoptée dans la séance du 12 juin, après le rapport de la camarade Kollontaï et après l'amendement de la camarade Zetkin.)}

\section{$\underline{\text { Retour à la table des matières }}$}

La $2^{\mathrm{e}}$ Conférence Internationale des Femmes Communistes propose aux partis communistes de tous les pays d'Occident et d'Orient de faire élire par leur Section Centrale Féminine, suivant les directives de la 3e Internationale, des correspondantes internationales. Le rôle de la correspondante de chaque parti communiste est, comme les « directives » l'indiquent, d'entretenir des rapports réguliers avec les correspondantes internationales des autres pays ainsi qu'avec le Secrétariat International Féminin de Moscou qui est l'organe de travail de l'Exécutif de la 3e Internationale. Les Partis Communistes doivent fournir aux correspondantes internationales tous les moyens techniques et toutes les possibilités de communiquer entre elles, et avec le secrétariat de Moscou. Les correspondantes internationales se réunissent une fois tous les six mois pour délibérer et échanger des vues 
avec les représentants du Secrétariat Féminin International. Cependant, en cas de nécessité, ce dernier peut réunir cette conférence en tout temps.

Le Secrétariat International Féminin accomplit, d'accord avec l'Exécutif, et en contact étroit avec les correspondantes internationales des différents pays, les tâches fixées par les « directives ». Ce qu'il doit surtout faire, c’est hâter, dans chaque pays, par le conseil et l'action, le développement du mouvement féminin communiste - encore faible - et donner une direction unique au mouvement féminin de tous les pays d'Occident et d'Orient, provoquer et orienter sous la direction et avec l'appui énergique des communistes, des actions nationales et internationales de nature à intensifier et à étendre sous la poussée des femmes la lutte révolutionnaire du prolétariat. Le Secrétariat Féminin International de Moscou devra s'adjoindre en Occident un organe auxiliaire afin de s'assurer une liaison plus étroite et plus régulière avec les mouvements communistes féminins de tous les pays. Cet organe aura à faire les travaux préparatoires et supplémentaires pour le Secrétariat International, c’est-à-dire qu'il sera purement exécutif, et n’aura pas le droit de décider quoi que ce soit. Il est lié par les décisions et les indications du Secrétariat Général de Moscou et de l’Exécutif de la 3e Internationale. Avec l'organe auxiliaire de l'Europe Occidentale, doit collaborer au moins une représentante du Secrétariat Général.

Pour autant que la constitution et le champ d'activité du Secrétariat ne sont pas fixés par les « directives », ces questions seront réglées par l'Exécutif de la 3e Internationale d'accord avec le Secrétariat Féminin International, de même que la composition, la forme et le fonctionnement de l'organe auxiliaire. 
Manifestes, thèses et résolutions

des quatre premiers congrès

de l’Internationale communiste 1919-1923

(juin 1934)

Troisième Congrès, juin 1921.

- 16 -

\section{Résolution concernant les formes et les méthodes du travail communiste parmi les femmes}

\section{(Adoptée dans la séance du 13 juin, après le rapport de la camarade Kollontaï.)}

\section{$\underline{\text { Retour à la table des matières }}$}

La $2^{\mathrm{e}}$ Conférence Internationale des Femmes Communistes tenue à Moscou déclare :

L’écroulement de l'économie capitaliste et de l'ordre bourgeois reposant sur cette économie, de même que le progrès de la révolution mondiale font de la lutte révolutionnaire pour la conquête du pouvoir politique et pour l'établissement de la dictature une nécessité de plus en plus vitale et impérieuse, pour le prolétariat de tous les pays où ce régime règne encore, un devoir qui ne pourra s'accomplir que lorsque les femmes laborieuses prendront part à cette lutte d'une manière consciente résolue et dévouée.

Dans les pays où le prolétariat a déjà conquis le pouvoir d'Etat et établi sa dictature sous la forme des soviets, comme en Russie et en Ukraine, il ne sera pas à même de maintenir son pouvoir contre la contre-révolution nationale et interna- 
tionale et de commencer l'édification du régime communiste libérateur, aussi longtemps que les masses ouvrières féminines n’auront pas acquis la conscience nette et inébranlable que la défense et l'édification de l'Etat doivent être aussi leur œuvre.

La $2^{\mathrm{e}}$ Conférence Internationale des Femmes Communistes propose par conséquent aux partis de tous les pays conformément aux principes et aux décisions de la $3^{\mathrm{e}}$ Internationale de se mettre à l'œuvre avec la plus grande énergie afin de réveiller les masses féminines, de les rassembler, de les instruire dans l'esprit du communisme, de les entraîner dans les rangs des Partis Communistes, et de renforcer constamment et résolument leur volonté d’action et de lutte.

Pour que ce but soit atteint, tous les partis adhérant à la $3^{\mathrm{e}}$ Internationale doivent former dans tous leurs organes et institutions, à commencer par les plus inférieurs, jusqu’aux plus élevés, des sections féminines présidées par un membre de la direction du parti, dont le but sera le travail d'agitation, d'organisation et d'instruction parmi les masses ouvrières féminines, et qui auront leurs représentants dans toutes les formations administratives et directrices des partis. Ces sections féminines ne forment pas des organisations séparées ; elles ne sont que des organes de travail chargées de mobiliser et instruire les ouvrières en vue de la lutte pour la conquête du pouvoir politique, et aussi en vue de l'édification du communisme. Elles agissent dans tous les domaines et en tout temps sous la direction du parti, mais possèdent aussi la liberté de mouvement nécessaire pour appliquer les méthodes et formes de travail et pour créer les institutions qui sont réclamées par les caractères spéciaux de la femme et sa position particulière toujours subsistante dans la société et dans la famille.

Les organes féminins des partis communistes doivent toujours avoir conscience, dans leur activité, du but de leur double tâche :

1) Entraîner des masses féminines toujours plus nombreuses, plus conscientes et plus fermement décidées dans la lutte de classe révolutionnaire de tous les opprimés et exploités contre le capitalisme et pour le communisme.

2) En faire après la victoire de la révolution prolétarienne, les collaboratrices conscientes et héroïques de l'édification communiste. Les organes fémi- 
nins du parti communiste doivent dans leur activité se rendre compte que les moyens d'agitation et d'instruction ne sont pas les discours et les écrits, mais qu'il faut également apprécier et utiliser comme les moyens les plus importants : la collaboration des femmes communistes organisées dans tous les domaines de l'activité - lutte et édification - des partis communistes ; la participation active des femmes ouvrières à toutes les actions et luttes du prolétariat révolutionnaire, aux grèves, aux insurrections générales, aux démonstrations de rue et révoltes à main armée. 
Manifestes, thèses et résolutions

des quatre premiers congrès

de l'Internationale communiste 1919-1923

(juin 1934)

Troisième Congrès, juin 1921.

- 17 -

\section{Appel des 22 aux membres de la conférence de l'Internationale Communiste}

$\underline{\text { Retour à la table des matières }}$

Chers camarades !

Nous avons appris dans nos journaux que le comité exécutif de l'Internationale communiste discute du «front unique ouvrier »; aussi considérons-nous de notre devoir de communistes de vous informer que dans notre pays le "front unique" est en mauvais état, non seulement au sens large, mais aussi dans son application au sommet de notre parti.

Alors que les forces de la bourgeoisie nous pressent de tous côtés, alors même qu'elles infiltrent notre parti, favorisées en cela par sa composition sociale (40\% d'ouvriers et $60 \%$ de non-prolétaires), notre direction lutte implacablement contre tous ceux, et tout particulièrement les prolétaires, qui ont leurs propres opinions, appliquant toutes sortes de mesures répressives contre l'expression de ces opinions dans le Parti. 
La tentative d'amener les masses prolétariennes plus près du gouvernement est qualifiée d' « anarcho-syndicalisme », et ses partisans sont poursuivis et discrédités.

Dans le mouvement syndical, même tableau : suppression de l'initiative et de la spontanéité ouvrières, lutte recourant à tous les moyens contre l'hétérodoxie. Les forces unifiées de la bureaucratie du Parti et des syndicats, tirant profit de leur position et de leur pouvoir, ignorent nos mandats de congrès visant à bâtir les bases de la démocratie ouvrière. Nos fractions communistes dans les syndicats sont privées du droit de manifester leur volonté dans l'élection de leurs propres chefs, même lors des congrès. La tutelle et la pression de la bureaucratie en sont arrivées à ce point que les membres du Parti sont menacés d'exclusion et d'autres mesures répressives s’ils élisent qui ils veulent au lieu de ceux que les haut placés veulent. De telles méthodes de travail mènent au carriérisme, aux intrigues, et à la servilité, auxquelles les ouvriers répondent en quittant le Parti.

Partisans de l'idée du front unique des travailleurs tel qu’il est interprété dans les 23 thèses, nous faisons appel à vous, avec le souhait sincère d'en finir avec toutes ces anomalies, qui entravent l'unité de ce front, d'abord de tous au sein de notre Parti communiste russe.

La situation dans notre Parti est si difficile qu'elle nous pousse à vous demander de l’aide pour écarter la menace imminente d’une scission en son sein.

Salutations communistes,

Membres du Parti communiste de Russie (bolchevik) :

M. Lobanov, membre du Parti depuis 1904

N. Kouznetsov, membre du Parti depuis 1904

A. Polosatov, membre du Parti depuis 1912

A. Medvedev, membre du Parti depuis 1912

G. Miasnikov, membre du Parti depuis 1906

V. Pliechkov, membre du Parti depuis 1918

G. Chokhanov, membre du Parti depuis 1912

S. Medvedev, membre du Parti depuis 1900

G. Brouno, membre du Parti depuis 1906

A. Pravdine, membre du Parti depuis 1899

I. Ivanov, membre du Parti depuis 1899 
F. Mitine, membre du Parti depuis 1902

P. Borisov, membre du Parti depuis 1913

M. Kopylov, membre du Parti depuis 1912

Jiline, membre du Parti depuis 1915

Tchelychev, membre du Parti depuis 1910

Tolokontsev, membre du Parti depuis 1914

A. Chliapnikov, membre du Parti depuis 1901

M. Borouline, membre du Parti depuis 1917

V. Bekrenev, membre du Parti depuis 1917

A. Pavlov, membre du Parti depuis 1917

A. Tachkine, membre du Parti depuis 1917

Je soutiens [cet appel] : A. Kollontaï, membre du parti depuis 1898 ; et Zoïa Chadourskaïa. 
Manifestes, thèses et résolutions

des quatre premiers congrès de

l'Internationale communiste 1919-1923

(juin 1934)

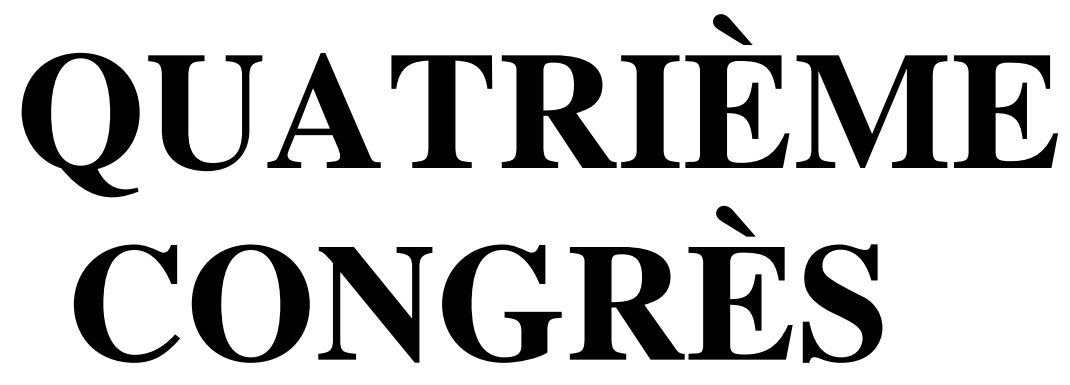

Novembre 1922 


\section{Manifestes, thèses et résolutions des quatre premiers congrès de l’Internationale communiste 1919-1923 \\ (juin 1934) \\ Quatrième Congrès, novembre 1922. \\ - 1 - \\ Résolution sur la tactique de l’I.C.}

\section{I. - Confirmation des résolutions du 3e Congrès}

$\underline{\text { Retour à la table des matières }}$

Le $4^{\mathrm{e}}$ Congrès constate avant tout que les résolutions du $3^{\mathrm{e}}$ Congrès mondial :

1) Sur la crise économique mondiale et les tâches de l’I.C. ;

2) Sur la tactique de l’I.C.,

Ont été complètement confirmées par le cours des événements et le développement du mouvement ouvrier dans l'intervalle entre les $3^{\mathrm{e}}$ et $4^{\mathrm{e}}$ Congrès.

\section{La période de décadence du Capitalisme}

Après avoir analysé la situation économique mondiale, le $3^{\mathrm{e}}$ Congrès put constater avec la plus complète précision que le capitalisme, après avoir accompli sa mission de développement des forces productrices, est tombé dans la contradiction la plus irréductible avec les besoins, non seulement de l'évolution historique actuelle, mais aussi avec les conditions d'existence humaine les plus élémentaires. 
Cette contradiction fondamentale se refléta particulièrement dans la dernière guerre impérialiste et fut encore aggravée par cette guerre qui ébranla, de la manière la plus profonde, le régime de la production et de la circulation. Le capitalisme, qui se survit ainsi à lui-même, est entré dans la phase où l'action destructrice de ses forces déchaînées ruine et paralyse les conquêtes économiques créatrices déjà réalisées par le prolétariat dans les liens de l’esclavage capitaliste.

Le tableau général de la ruine de l'économie capitaliste n'est en rien atténué par les fluctuations inévitables qui sont propres au système capitaliste, dans son déclin comme dans son ascension. Les tentatives faites par les économistes nationaux bourgeois et social-démocrates pour présenter l'amélioration constatée dans la seconde moitié de 1921 aux Etats-Unis et, dans une mesure bien moindre, au Japon et en Angleterre, en partie aussi en France et dans d'autres pays, comme un indice de rétablissement de l'équilibre capitaliste reposent en partie sur la volonté d'altérer les faits et en partie sur le manque de perspicacité des valets du capital. Le $3^{\mathrm{e}}$ Congrès, même avant le commencement de la reprise industrielle actuelle, avait prévu cette reprise dans un avenir plus ou moins rapproché, et il l'avait définie dès lors de la façon la plus précise comme une vague superficielle sur le fond de la destruction croissante de l'économie capitaliste. On peut prévoir nettement dès à présent que si la reprise actuelle de l'industrie n'est pas susceptible, même dans un avenir éloigné, de rétablir l'équilibre capitaliste ou même de guérir les plaies béantes laissées par la guerre, la prochaine crise cyclique, dont l'action coïncidera avec la ligne principale de la destruction capitaliste, ne fera qu'aggraver toutes les manifestations de cette dernière, et par conséquent aussi, dans une mesure extraordinaire, la situation révolutionnaire.

Jusqu'à sa mort, le capitalisme sera en proie à ces fluctuations cycliques. Seules, la prise du pouvoir par le prolétariat et la Révolution mondiale socialiste pourront sauver l'humanité de cette catastrophe permanente provoquée par la persistance du capitalisme moderne.

Ce que le capitalisme traverse aujourd'hui n'est autre que son agonie. L'écroulement du capitalisme est inévitable. 


\section{La situation politique internationale}

La situation politique internationale reflète aussi la ruine progressive du capitalisme.

La question des réparations n'est toujours pas résolue. Tandis que les conférences des Etats de l'Entente se succèdent, la ruine économique de l'Allemagne se poursuit toujours et menace l'existence du capitalisme dans toute l'Europe Centrale. L'aggravation catastrophique de la situation économique de l'Allemagne contraindra l'Entente à renoncer aux réparations, ce qui accélérera la crise économique et politique de la France ou bien déterminera la formation d'un bloc industriel franco-allemand sur le continent ; et ce fait aggravera la situation économique de l'Angleterre et sa position sur le marché mondial ; il opposera politiquement l'Angleterre au Continent.

Dans le Proche-Orient, la politique de l'Entente a subi une faillite complète. Le traité de Sèvres a été déchiré par les baïonnettes turques. La guerre grécoturque et les événements subséquents ont montré avec évidence l'instabilité de l'équilibre politique actuel. Le fantôme d'une nouvelle guerre mondiale impérialiste est apparu clairement. Après avoir, pour des motifs de concurrence avec l'Angleterre, aidé à déterminer l'œuvre commune de l'Entente dans le ProcheOrient, la France impérialiste est de nouveau poussée par ses intérêts capitalistes dans le front commun du capitalisme contre les peuples de l'Orient. Par là, la France capitaliste prouve aux peuples du Proche-Orient qu'ils ne sauraient mener leur lutte de défense contre l'oppression qu'aux côtés de la Russie des Soviets et avec l'appui du prolétariat révolutionnaire du monde entier.

En Extrême-Orient, les Etats victorieux de l'Entente ont essayé de réviser, à Washington, la paix de Versailles, mais ils n'ont fait ainsi que se donner un répit en réduisant pour quelques années une catégorie seulement d'armements, à savoir le grand nombre des navires de guerre. Ils n'ont pas obtenu une solution de la question. La lutte se poursuit toujours entre l'Amérique et le Japon, elle entretient la guerre civile en Chine. La côte du Pacifique reste, après comme avant Washington, un foyer de grands conflits. 
L'exemple des mouvements de libération nationale aux Indes, en Egypte, en Irlande et en Turquie, montre que les pays coloniaux et semi-coloniaux constituent les foyers d'un mouvement révolutionnaire grandissant contre les puissances impérialistes et des réservoirs inépuisables de forces révolutionnaires qui, dans la situation actuelle, se tournent objectivement contre toute l'existence de l'ordre bourgeois mondial.

La paix de Versailles est liquidée par les faits. Mais elle ne fait pas place à un accord général des Etats capitalistes, à une suppression de l'impérialisme ; elle crée au contraire de nouveaux antagonismes, de nouveaux armements. La reconstruction de l'Europe est impossible dans la situation donnée. L’Amérique donnée. L'Amérique capitaliste ne veut faire aucun sacrifice pour la restauration de l'économie capitaliste européenne. L'Amérique capitaliste plane comme un vautour sur l'agonie du capitalisme européen dont elle sera l'héritier. L'Amérique réduira l'Europe capitaliste en esclavage si la classe ouvrière européenne ne s'empare pas du pouvoir politique et ne s'applique pas à réparer les ruines de la guerre mondiale et à commencer la construction d'une République Fédérative des Soviets d'Europe.

Les derniers événements qui se sont déroulés en Autriche sont éminemment caractéristiques de la situation politique de l'Europe. Sur l'ordre de l'impérialisme de l'Entente, salué avec joie par la bourgeoisie autrichienne, la fameuse démocratie - fierté des leaders de l'Internationale de Vienne, pour laquelle ces derniers ont constamment trahi les intérêts du prolétariat et qu'ils avaient confiée à la garde des monarchistes, des social-chrétiens et des nationalistes, qu'elle aidait à se rétablir au pouvoir - a été anéantie d'un trait de plume à Genève et remplacée par la dictature ouverte d'un simple plénipotentiaire de l'Entente. Le Parlement bourgeois même est supprimé en fait et remplacé par un commis des banquiers de l'Entente. Après un court semblant de résistance, les social-démocrates ont capitulé et aidé à l'exécution de ce honteux traité. Ils se sont même déclarés prêts à entrer de nouveau dans la coalition sous une forme à peine masquée, pour empêcher une résistance du prolétariat.

Ces événements en Autriche, ainsi que le dernier coup d'Etat fasciste en Italie, démontrent d'une manière frappante l'instabilité de toute la situation et prouvent surabondamment que la démocratie n’est qu'un simulacre, qu'elle n'est en réalité 
que la dictature masquée de la bourgeoisie, que cette dernière remplace, le moment venu, par la réaction ouverte la plus brutale.

En même temps, la situation politique internationale de la Russie des Soviets, le seul pays où le prolétariat ait vaincu la bourgeoisie et maintenu son pouvoir pendant cinq années contre les assauts de ses ennemis, est renforcée dans une mesure considérable.

À Gênes et à La Haye, les capitalistes de l'Entente ont tenté de contraindre la République des Soviets de Russie à renoncer à la nationalisation de l'industrie et de la charger d'un fardeau de dettes qui la transformerait, en fait, en une colonie de l'Entente. L'Etat prolétarien de la Russie des Soviets fut cependant assez fort pour résister à ces prétentions. Dans le chaos du système capitaliste en cours de dissolution, la Russie des Soviets, de la Bérézina à Vladivostok, de la côte de Mourmansk aux montagnes d'Arménie, est un facteur croissant de puissance en Europe, dans le Proche et l'Extrême-Orient. Malgré les tentatives du monde capitaliste, pour étouffer la Russie au moyen du blocus financier, celle-ci sera en état d'aborder sa restauration économique. Dans ce but, elle utilisera aussi bien ses propres ressources économiques que la concurrence entre capitalistes, qui contraindra ceux-ci à mener des négociations séparées avec la Russie des Soviets. Un sixième du globe est au pouvoir des Soviets. L'existence seule de la République des Soviets de Russie agit sur la société bourgeoise comme un élément de la Révolution mondiale. Plus la Russie Soviétique se relève et se consolide économiquement, et plus ce facteur révolutionnaire prédominant accroîtra son influence dans la politique internationale.

\section{L'offensive du Capital}

Le prolétariat de tous les pays, excepté la Russie, n’ayant pas profité de l'état de faiblesse du capitalisme, déterminé par la guerre, pour lui porter des coups décisifs, la bourgeoisie put, grâce à l'aide des socialistes-réformistes, écraser les ouvriers révolutionnaires prêts au combat, consolider son pouvoir politique et économique et commencer une nouvelle offensive contre le prolétariat. Toutes les tentatives de la bourgeoisie pour remettre en marche la production et la réparation industrielle après l’orage de la guerre mondiale furent faites aux dépens du prolé- 
tariat. L'offensive universelle et systématique organisée par le capital contre toutes les conquêtes de la classe ouvrière entraîna tous les pays dans son tourbillon. Partout le capital réorganisé réduit impitoyablement le salaire réel des ouvriers, prolonge la journée de travail, rogne les modestes droits du prolétariat dans l'industrie, oblige dans les pays à bas cours les ouvriers, réduits à la mendicité, à payer les frais de la misère déterminée dans la vie économique par la dépréciation du change, etc...

L'offensive du capital, qui a pris au cours de ces dernières années des proportions gigantesques, oblige les ouvriers de tous les pays à mener des luttes défensives. Des milliers et des dizaines de milliers d'ouvriers ont accepté le combat, dans les branches les plus importantes de la production. Des groupes toujours nouveaux d'ouvriers entrent dans la lutte, venant des branches les plus déterminantes de la vie économique (cheminots, mineurs, métallurgistes, fonctionnaires de L'Etat et employés municipaux). La plupart de ces grèves n'ont eu jusqu'à présent aucun succès immédiat; mais cette lutte engendre dans des masses nouvelles et de plus en plus considérables d'ouvriers autrefois retardataires une haine infinie contre les capitalistes et le pouvoir d'Etat qui les protège. Cette lutte imposée au prolétariat ruine la politique de communauté de travail avec les entrepreneurs, menée par les social-réformistes et les bureaucrates syndicaux. Cette lutte montre même aux couches les plus arriérées du prolétariat le rapport évident entre l'économie et la politique. Chaque grande grève devient aujourd'hui un grand événement politique. A cette occasion, il est apparu que les partis de la $2^{\mathrm{e}}$ Internationale et les chefs syndicaux d'Amsterdam, non seulement n'apportent aucune aide aux masses ouvrières engagées dans de durs combats défensifs, mais même les abandonnent et les trahissent au profit des entrepreneurs, des patrons et des gouvernements bourgeois.

C'est une des tâches des Partis Communistes de clouer au pilori cette trahison inouïe et continuelle et de l'illustrer dans les luttes quotidiennes des masses ouvrières. C'est le devoir des Partis Communistes de tous les pays d'étendre et d'approfondir les nombreuses grèves économiques qui éclatent partout et, si possible, de les transformer en grèves et en luttes politiques. C'est de même le devoir naturel des Partis Communistes de profiter des luttes défensives pour renforcer la conscience révolutionnaire et la volonté de combat des masses prolétariennes de 
façon que, lorsqu'elles seront assez fortes, elles puissent passer de la défensive à l'offensive.

L'aggravation systématique des antagonismes entre le prolétariat et la bourgeoisie par suite de l'existence de ces luttes est inévitable. La situation reste objectivement révolutionnaire et la moindre occasion peut aujourd'hui devenir le point de départ de grandes luttes révolutionnaires.

\section{Le fascisme international}

La politique offensive de la bourgeoisie contre le prolétariat, telle qu'elle se manifeste de la manière la plus éclatante dans le fascisme international, est dans le plus étroit rapport avec l'offensive du capital sur le terrain économique. Etant donné que la misère accélère l'évolution de l'esprit des masses dans un sens révolutionnaire, processus qui englobe les classes moyennes y compris les fonctionnaires, et ébranle la sécurité de la bourgeoisie qui n’a plus dans la bureaucratie un instrument docile, les méthodes de contraintes légales ne suffisant plus à la bourgeoisie. C'est pourquoi elle s'applique partout à créer des gardes-blanches spécialement destinées à combattre tous les efforts révolutionnaires du prolétariat et qui servent en effet le plus en plus à écraser les tentatives du prolétariat pour améliorer sa situation.

Le trait caractéristique du fascisme italien, du fascisme "classique ", qui a conquis pour un temps tout te pays, consiste en ce que les fascistes non seulement constituent des organisations de combat strictement contre-révolutionnaires et armées jusqu'aux dents, mais encore essaient par une démagogie sociale de se créer une base dans les masses, dans la classe paysanne, dans la petite bourgeoisie et même dans certaines parties du prolétariat, en utilisant adroitement pour leurs buts contre-révolutionnaires les déceptions provoquées par la soi-disant démocratie.

Le danger du fascisme existe maintenant dans beaucoup de pays en Tchécoslovaquie, en Hongrie, dans presque tous les pays balkaniques, en Pologne, en Allemagne (Bavière), en Autriche, en Amérique et même dans des pays comme la 
Norvège. Sous une forme ou sous une autre, le fascisme n'est pas impossible non plus dans des pays comme la France et l’Angleterre.

Une des tâches les plus importantes des Partis Communistes est d'organiser la résistance au fascisme international, de se mettre à la tête de tout le prolétariat dans la lutte contre les bandes fascistes et d'appliquer énergiquement sur ce terrain aussi la tactique du front unique ; les méthodes illégales sont ici absolument indispensables.

Mais la folle équipée fasciste est le dernier atout de la bourgeoisie. La domination ouverte des gardes-blancs est dirigée d’une façon générale contre les bases mêmes de la démocratie bourgeoise. Les plus grandes masses du peuple travailleur se persuadent de plus en plus du fait que la domination de la bourgeoisie n’est possible que par une dictature non déguisée sur le prolétariat.

\section{La possibilité de nouvelles illusions pacifistes}

Ce qui caractérise la situation politique internationale au moment actuel, c'est le fascisme, l'état de siège et la vague montante de la terreur blanche contre le prolétariat. Mais cela n’exclut pas la possibilité que, dans un temps assez rapproché, dans des pays très importants, la réaction bourgeoise ouverte soit remplacée par une ère « démocratique-pacifique ».

En Angleterre (renforcement du Labour Party aux dernières élections), en France (prochaine période inévitable du «bloc des gauches»), cette phase de transition " démocratique-pacifiste » est vraisemblable et elle peut ranimer les espoirs pacifistes dans l’Allemagne bourgeoise et social-démocrate.

Entre la période actuelle de la domination de la réaction bourgeoise ouverte et la victoire complète du prolétariat révolutionnaire sur la bourgeoisie, il y a diverses étapes, et différents épisodes passagers sont possibles. L’Internationale Communiste et ses sections doivent envisager aussi ces éventualités, elles doivent savoir défendre les positions révolutionnaires dans toutes les situations. 


\section{La Situation dans le Mouvement ouvrier}

Pendant que, par suite de l'offensive du capital, la classe ouvrière se voit obligée de prendre une attitude défensive, le rapprochement et finalement la fusion des partis du Centre (Indépendants) avec les socialistes-traîtres déclarés (socialdémocrates), s'accomplissent. A l'époque de l'élan révolutionnaire, même les centristes, sous la pression de l'état d'esprit des masses, se déclarèrent pour la dictature du prolétariat et cherchèrent la voie menant à la $3^{\mathrm{e}}$ Internationale. Pendant la vague descendante de la révolution, qui n'est d'ailleurs que temporaire, ces centristes retombent dans le camp de la social-démocratie d'où au fond ils ne s’étaient jamais dégagés. Alors qu’aux époques de lutte révolutionnaire de masse, ils avaient adopté une attitude sans cesse hésitante et vacillante, ils refusent de participer maintenant aux luttes défensives et retournent au camp de la $2^{\mathrm{e}}$ Internationale, qui a toujours été, consciemment ou non, contre-révolutionnaire. Les partis centristes et l'Internationale $2 \frac{1}{2} 2$ sont en cours de décomposition. La meilleure partie des ouvriers révolutionnaires, qui se trouvait momentanément dans le camp du centrisme, passera avec le temps à l'Internationale Communiste. Par-ci, par-là, ce passage est déjà commencé (Italie). L'écrasante majorité des chefs centristes liés actuellement à Noske, Mussolini, etc... deviendront au contraire des contrerévolutionnaires endurcis.

Objectivement, la fusion des partis de la $2^{\mathrm{e}}$ Internationale et de l'Internationale $2 \frac{1}{2}$ peut être utile au mouvement ouvrier révolutionnaire. La fiction d'un parti révolutionnaire en dehors du camp communiste disparaît ainsi. Dans la classe ouvrière, deux groupes seulement lutteront désormais pour la conquête de la majorité la $2^{\mathrm{e}}$ Internationale, qui représente l'influence de la bourgeoisie au sein du prolétariat, et la 3e Internationale, qui a levé le drapeau de la révolution socialiste et de la dictature du prolétariat. 


\section{La division dans les Syndicats}

La fusion des Internationales 2 et $2 \frac{1}{2} 2$ a indubitablement pour but de préparer une « atmosphère favorable » à une campagne systématique contre les communistes. La scission méthodique des syndicats par les chefs de l'Internationale d'Amsterdam est une partie de cette campagne. Les hommes d'Amsterdam reculent devant toute lutte contre l'offensive du capital et continuent plutôt leur politique de collaboration avec les patrons. Pour n’être pas gênés par les communistes dans cette alliance avec les entrepreneurs, ils cherchent à supprimer complètement et systématiquement l'influence des communistes dans les syndicats. Mais comme les communistes ont cependant, dans beaucoup de pays déjà, conquis la majorité dans les syndicats ou sont en train de la conquérir, les hommes d'Amsterdam ne reculent ni devant les exclusions en masse, ni devant la scission formelle des syndicats. Rien n’affaiblit autant les forces de la résistance prolétarienne contre l'offensive du capital que la division des syndicats. Les chefs réformistes des syndicats le savent bien. Mais comme ils s'aperçoivent que le terrain se dérobe sous eux et que leur faillite est inévitable et proche, ils s'empressent de diviser les syndicats, ces instruments irremplaçables de la lutte de classe prolétarienne, pour que les communistes ne recueillent plus que les débris et les éclats des anciennes organisations syndicales. Depuis août 1914, la classe ouvrière n’a pas vu pire trahison.

\section{La conquête de la Majorité}

Dans ces conditions, l'indication fondamentale du $3^{\mathrm{e}}$ Congrès mondial : «Conquérir une influence communiste dans la majorité de la classe ouvrière et mener au combat la partie décisive de cette classe », subsiste dans toute sa force.

La conception suivant laquelle, dans l'équilibre instable actuel de la société bourgeoise, la plus grave crise peut subitement éclater par suite d'une grande grève, d'un soulèvement colonial, d'une nouvelle guerre, ou même d'une crise par- 
lementaire, garde toute sa force aujourd'hui encore plus qu'à l'époque du $3^{\mathrm{e}}$ Congrès. Mais c’est précisément pour cela que le facteur « subjectif », c'est-à-dire le degré de conscience, de volonté, de combat et d'organisation de la classe ouvrière et de son avant-garde, acquiert une importance énorme.

La majorité de la classe ouvrière d'Amérique et d'Europe doit être gagnée ; c’est la tâche essentielle de l’I.C. à présent comme auparavant.

\section{Dans les pays coloniaux}

Dans les pays coloniaux et semi-coloniaux, l'I.C. a deux tâches : 1) créer un noyau de parti communiste qui défende les intérêts généraux du prolétariat ; 2) appuyer de toutes ses forces le mouvement national révolutionnaire dirigé contre l'impérialisme, devenir l'avant-garde de ce mouvement et mettre en relief et renforcer le mouvement social au sein du mouvement national.

\section{Le gouvernement ouvrier}

Le gouvernement ouvrier (éventuellement le gouvernement paysan) devra partout être employé comme un mot d'ordre de propagande général. Mais, comme mot d'ordre de politique actuelle, le gouvernement ouvrier présente la plus grande importance dans les pays où la situation de la société bourgeoise est particulièrement peu sûre, où le rapport des forces entre les partis ouvriers et la bourgeoisie met la solution de la question du gouvernement ouvrier à l'ordre du jour comme une nécessité politique.

Dans ces pays, le mot d'ordre du «gouvernement ouvrier » est une conséquence inévitable de toute la tactique du front unique.

Les partis de la $2^{\mathrm{e}}$ Internationale cherchent, dans ces pays, à « sauver » la situation en prêchant et en réalisant la coalition des bourgeois et des socialdémocrates. Les plus récentes tentatives faites par certains partis de la 2e Internationale (par exemple en Allemagne), tout en refusant de participer ouvertement à un tel gouvernement de coalition, pour le réaliser en même temps sous une forme 
déguisée, ne sont rien moins qu'une manœuvre tendant à calmer les masses protestant contre de semblables coalitions et qu'une duperie raffinée des masses ouvrières. A la coalition ouverte ou masquée bourgeoise et social-démocrate, les communistes opposent le front unique de tous les ouvriers et la coalition politique et économique de tous les partis ouvriers contre le pouvoir bourgeois pour le renversement définitif de ce dernier. Dans la lutte commune de tous les ouvriers contre la bourgeoisie, tout l'appareil d'Etat devra tomber dans les mains du gouvernement ouvrier et les positions de la classe ouvrière en seront renforcées.

Le programme le plus élémentaire d'un gouvernement ouvrier doit consister à armer le prolétariat, à désarmer les organisations bourgeoises contrerévolutionnaires, à instaurer le contrôle de la production, à faire tomber sur les riches le principal fardeau des impôts et à briser la résistance de la bourgeoisie contre-révolutionnaire.

Un gouvernement de ce genre n'est possible que s'il naît dans la lutte des masses mêmes, s’il s’appuie sur des organes ouvriers aptes au combat et créés par les couches les plus vastes des masses ouvrières opprimées. Un gouvernement ouvrier résultant d'une combinaison parlementaire, peut aussi fournir l'occasion de ranimer le mouvement ouvrier révolutionnaire. Mais il va de soi que la naissance d'un gouvernement véritablement ouvrier et le maintien d'un gouvernement faisant une politique révolutionnaire doivent mener à la lutte la plus acharnée et, éventuellement, à la guerre civile contre la bourgeoisie. La seule tentative du prolétariat de former un gouvernement ouvrier se heurtera dès le début à la résistance la plus violente de la bourgeoisie. Le mot d'ordre du gouvernement ouvrier est donc susceptible de concentrer et de déchaîner des luttes révolutionnaires.

Dans certaines circonstances, les communistes doivent se déclarer disposés à former un gouvernement avec des partis et des organisations ouvrières noncommunistes. Mais ils ne peuvent agir ainsi que si des garanties sont données que ces gouvernements ouvriers mèneront vraiment la lutte contre la bourgeoise dans le sens indiqué plus haut. Dans ce cas, les conditions naturelles de la participation des communistes à un semblable gouvernement seraient les suivantes :

$1^{\circ}$ La participation au gouvernement ouvrier ne pourra avoir lieu qu'avec l'approbation de l'Internationale Communiste ; 
$2^{\circ}$ Les membres communistes du gouvernement ouvrier restent soumis au contrôle le plus strict de leur parti ;

$3^{\circ}$ Les membres communistes du gouvernement ouvrier restent en contact étroit avec les organisations révolutionnaires des masses ;

$4^{\circ}$ Le parti communiste maintient absolument sa physionomie et l'indépendance complète de son agitation.

Malgré ses grands avantages, le mot d’ordre de gouvernement ouvrier a aussi ses dangers, de même que toute la tactique du front unique. Pour parer à ces dangers, les partis communistes ne doivent pas perdre de vue que, si tout gouvernement bourgeois est en même temps un gouvernement capitaliste, il n'est pas vrai que tout gouvernement ouvrier soit un gouvernement vraiment prolétarien, c’està-dire un instrument révolutionnaire de pouvoir du prolétariat.

L’Internationale Communiste doit envisager les éventualités suivantes :

$1^{\circ}$ Un gouvernement ouvrier libéral. Il y a déjà un gouvernement de ce genre en Australie ; il est également possible dans un délai assez rapproché en Angleterre ;

$2^{\circ}$ Un gouvernement ouvrier social-démocrate (Allemagne);

$3^{\circ}$ Un gouvernement des ouvriers et des paysans. Cette éventualité est à prévoir dans les Balkans, en Tchécoslovaquie, etc... ;

$4^{\circ}$ Un gouvernement ouvrier avec la participation des communistes ;

$5^{\circ}$ Un véritable gouvernement ouvrier prolétarien qui, dans sa forme la plus pure, ne peut être incarné que par un Parti Communiste.

Les deux premiers types de gouvernement ouvrier ne sont pas des gouvernements ouvriers révolutionnaires, mais des gouvernements camouflés de coalition entre la bourgeoisie et les leaders ouvriers contre-révolutionnaires. Ces « gouvernements ouvriers » sont tolérés dans les périodes critiques de la bourgeoisie affaiblie pour tromper le prolétariat sur le véritable caractère de classe de l’Etat, ou 
même pour détourner l’attaque révolutionnaire du prolétariat et gagner du temps, avec l'aide des leaders ouvriers corrompus. Les communistes ne devront pas participer à de pareils gouvernements. Au contraire, ils devront démasquer impitoyablement devant les masses le véritable caractère de ces faux «gouvernements ouvriers ». Dans la période de déclin du capitalisme, où la tâche principale consiste à gagner à la révolution la majorité du prolétariat, ces gouvernements, objectivement, peuvent contribuer à précipiter le processus de décomposition du régime bourgeois.

Les communistes sont prêts à marcher aussi avec les ouvriers, socialdémocrates, chrétiens, sans parti, syndicalistes, etc..., qui n’ont pas encore reconnu la nécessité de la dictature du prolétariat. Les communistes sont également disposés, dans certaines conditions et sous certaines garanties, à appuyer un gouvernement ouvrier non communiste. Mais les communistes devront à tout prix expliquer à la classe ouvrière que sa libération ne pourra être assurée que par la dictature du prolétariat.

Les deux autres types de gouvernement ouvrier auxquels peuvent participer les communistes ne sont pas encore la dictature du prolétariat ; ils ne constituent pas encore une forme de transition nécessaire vers la dictature, mais ils peuvent constituer un point de départ pour la conquête de cette dictature. La dictature complète du prolétariat ne peut être réalisée que par un gouvernement ouvrier composé de communistes.

\section{Le mouvement des conseils de fabrique}

Aucun Parti Communiste ne saurait être considéré comme un parti communiste de masses véritable, sérieux et solide, s’il n’a pas de forts noyaux communistes dans les entreprises, les usines, les mines, les chemins de fer, etc... Dans les circonstances actuelles, un mouvement ne saurait être considéré comme systématiquement organisé dans les masses prolétariennes s’il ne réussit pas à créer, pour la classe ouvrière et ses organisations, des comités d'usines comme base de ce mouvement. La lutte contre l'offensive du capital et pour le contrôle de la production est sans espoir si les communistes ne disposent de points d'appui solides dans 
toutes les entreprises et si le prolétariat ne sait créer ses propres organes prolétariens de combat dans les entreprises (comités de fabriques, conseils ouvriers).

Le Congrès estime que c'est une des tâches essentielles de tous les partis communistes de s'ancrer dans les industries bien plus qu'ils ne l'ont fait jusqu'à présent et d'appuyer le mouvement des conseils de fabriques ou de prendre l'initiative de ce mouvement.

\section{L'Internationale Communiste : parti mondial}

L'Internationale Communiste doit de plus en plus être organisée en un Parti Communiste Mondial, chargé de la direction de la lutte dans tous les pays.

\section{La discipline internationale}

Pour appliquer internationalement et dans les divers pays la tactique du front unique, la discipline internationale la plus stricte est plus nécessaire que jamais dans l'Internationale Communiste et dans ses différentes sections.

Le $4^{\mathrm{e}}$ Congrès exige catégoriquement de toutes ses sections et de tous ses membres la plus stricte discipline dans l'application de la tactique, qui ne saurait être fertile que si elle est appliquée dans tous les pays, non seulement en paroles, mais aussi en actes.

L'acceptation des 21 conditions implique l'application de toutes les décisions tactiques des Congrès mondiaux et de l'Exécutif comme organe de l'I.C. dans l'intervalle des Congrès mondiaux.

Le Congrès charge l'Exécutif de déterminer et de surveiller de la manière la plus stricte l'application des décisions tactiques par tous les partis. Seule, la tactique révolutionnaire nettement tracée par l'I.C. assurera la victoire la plus prompte possible de la révolution prolétarienne internationale. 
Le Congrès décide d'ajouter comme supplément à cette résolution le texte des thèses adoptées par l’Exécutif, en décembre 1921, relativement au front unique, ces thèses exposant exactement et en détail la tactique du front unique ${ }^{(\mathbf{1})}$.

1. Ce sont ces thèses qui sont publiées immédiatement après. 
Manifestes, thèses et résolutions des quatre premiers congrès de l’Internationale communiste 1919-1923

(juin 1934)

Quatrième Congrès, novembre 1922. - 2-

\section{Thèses sur l'unité du front prolétarien}

$\underline{\text { Retour à la table des matières }}$

1. Le mouvement international traverse en ce moment une période de transition qui pose devant l'Internationale Communiste et devant ses sections de nouveaux et importants problèmes tactiques.

Cette période est principalement caractérisée par les faits suivants :

La crise économique mondiale s'aggrave. Le chômage s’accroît. Dans presque tous les pays, le Capital international a déclenché contre la classe ouvrière une offensive systématique, dont le but avoué est tout d'abord de réduire les salaires et d'avilir les conditions d'existence des travailleurs. La faillite de la paix de Versailles devient de plus en plus évidente pour les masses laborieuses elles-mêmes. Il est clair que si le prolétariat international n’arrive pas à détruire le régime bourgeois, une ou même plusieurs guerres impérialistes ne sauraient tarder à éclater. C’est ce qu’a démontré avec éloquence la Conférence de Washington.

2. Les illusions réformistes qui, par suite de diverses circonstances, avaient bénéficié d’un regain de faveur dans les grandes masses ouvrières, font place, en 
présence des dures réalités, à un état d'esprit tout différent. Les illusions démocratiques et réformistes qui, après la guerre impérialiste, avaient repris du terrain parmi une catégorie de travailleurs privilégiés, ainsi que parmi les ouvriers les plus arriérés au point de vue politique, se dissipent avant même d'avoir pu s’épanouir. Les résultats des travaux de la Conférence de Washington leur porteront le coup de grâce. Si l'on pouvait, il y a six mois, parler avec un semblant de raison d'une certaine évolution à droite des masses ouvrières d'Europe et d'Amérique, l'on ne saurait nier en ce moment le début d’une nouvelle orientation à gauche.

3. D’autre part, l’offensive capitaliste a suscité dans les masses ouvrières une tendance spontanée à l'unité, que rien ne saurait contenir et qui va de pair avec l'accroissement de la confiance dont les communistes bénéficient auprès du prolétariat.

Maintenant seulement, des milieux ouvriers de plus en plus importants commencent à apprécier la vaillance de l'avant-garde communiste qui engagea la lutte, pour la défense des intérêts prolétariens, à une époque où les grandes masses demeuraient encore indifférentes, voire hostiles, au communisme. Les ouvriers comprennent de plus en plus que les communistes ont réellement défendu, souvent au prix des plus grands sacrifices et dans les circonstances les plus pénibles, les intérêts économiques et politiques des travailleurs. De nouveau, le respect et la confiance vont à l'avant-garde intransigeante que constituent les communistes ; reconnaissant enfin la vanité des espérances réformistes, les travailleurs les plus arriérés se convainquent qu'il n'est, contre la spoliation capitaliste, de salut que dans la lutte.

4. Les Partis Communistes peuvent et doivent recueillir maintenant le fruit des luttes qu'ils ont naguère soutenues dans les circonstances les plus défavorables au milieu de l'indifférence des masses. Mais, portés par une confiance croissante vers les éléments les plus irréductibles, les plus combatifs de leur classe — vers les communistes - les travailleurs témoignent plus que jamais d'un irrésistible désir d'unité. Eveillées désormais à une vie plus active, les couches les moins expérimentées de la classe ouvrière rêvent de la fusion de tous les partis ouvriers, 
sinon de toutes les organisations prolétariennes. Elles espèrent accroître ainsi leur capacité de résistance à la poussée capitaliste. Des ouvriers qui, jusqu’à présent, s’étaient à peu près désintéressés des luttes politiques, veulent vérifier désormais, par leur expérience personnelle, la valeur du programme politique du réformisme. Les ouvriers qui adhèrent aux vieux partis social-démocrates et qui constituent une fraction importante du prolétariat n'admettent plus les campagnes des calomnies des social-démocrates et des centristes contre l'avant-garde communiste ; bien plus, ils commencent à réclamer une entente avec cette dernière. Cependant ils ne sont pas encore complètement émancipés des croyances réformistes, et nombreux sont ceux qui accordent leur appui aux Internationales Socialistes et à celle d'Amsterdam. Sans doute leurs aspirations ne sont-elles pas toujours nettement formulées, mais il est certain qu'elles tendent impérieusement à la création d'un front prolétarien unique, à la formation, par les partis de la $2^{\mathrm{e}}$ Internationale et les syndicats d'Amsterdam alliés aux communistes, d'un bloc puissant contre lequel viendrait se briser l'offensive patronale. En ce sens, ces aspirations représentent le progrès même. La foi au réformisme est à peu près éteinte. Dans la situation actuelle du mouvement ouvrier, toute action sérieuse, même si elle a son point de départ dans des revendications partielles, amènera fatalement les masses à poser les questions fondamentales de la révolution. L'avant-garde communiste ne pourra que gagner à l'expérience des nouvelles couches ouvrières, qui se convaincront par elles-mêmes de l'inanité des illusions réformistes et des effets déplorables de la politique de conciliation.

5. Lorsque commença la protestation organisée et consciente des travailleurs contre la trahison des leaders de la $2^{\mathrm{e}}$ Internationale, ceux-ci disposaient de l'ensemble du mécanisme des organisations ouvrières. Ils invoquèrent l'unité et la discipline ouvrière pour bâillonner impitoyablement les révolutionnaires protestataires et briser toutes les résistances qui les eussent empêchés de mettre au service des impérialistes nationaux la totalité des forces prolétariennes. La gauche révolutionnaire fut ainsi forcée de conquérir, coûte que coûte, sa liberté de propagande, afin de faire connaître aux masses ouvrières la trahison infâme qu'avaient commise - et que continuent de commettre - des partis et des syndicats créés par les masses elles-mêmes. 
6. Après s’être assuré une complète liberté de propagande, les partis communistes s'efforcent aujourd'hui, dans tous les pays, de réaliser une unité aussi complète que possible des masses ouvrières sur le terrain de l'action pratique. Les gens d'Amsterdam et ceux de la $2^{\mathrm{e}}$ Internationale, eux aussi, prônent l'unité, mais tous leurs actes sont la négation de leurs paroles. N'ayant pas réussi à étouffer dans les organisations les protestations, les critiques et les aspirations des révolutionnaires, les réformistes, avides de compromis, cherchent maintenant à sortir de l'impasse où ils se sont engagés, en semant la désorganisation et la division parmi les travailleurs et en sabotant leur lutte. Démasquer en ce moment leur récidive de trahison est un des devoirs les plus importants des partis communistes.

7. La profonde évolution intérieure provoquée dans la classe ouvrière d'Europe et d'Amérique par la nouvelle situation économique du prolétariat, oblige même les dirigeants et les diplomates des Internationales socialistes et de l'Internationale d'Amsterdam à mettre au premier plan le problème de l'unité ouvrière. Alors que, chez les travailleurs récemment arrivés à une vie politique consciente et encore inexpérimentés, le mot d’ordre du Front Unique est l'expression sincère du désir d'opposer à l'offensive patronale toutes les forces de la classe ouvrière, ce mot d'ordre n'est, de la part des leaders réformistes, qu'une nouvelle tentative de duper les ouvriers pour les ramener dans l'ornière de la collaboration de classe. L’imminence d'une nouvelle guerre impérialiste, la course aux armements, les nouveaux traités secrets des puissances impérialistes, non seulement ne détermineront pas les dirigeants de la $2^{\mathrm{e}}$ Internationale, de l'Internationale 2 1/2 et de l'Internationale d'Amsterdam à sonner l'alarme et aider effectivement à l'union internationale de la classe ouvrière, mais ils susciteront infailliblement parmi eux les mêmes dissensions que dans la bourgeoisie internationale. C’est là un fait d'autant plus inévitable que la solidarité des « socialistes » réformistes avec « leurs » bourgeoisies nationales respectives, constitue la pierre angulaire du réformisme.

Telles sont les conditions générales dans lesquelles l'Internationale Communiste et ses sections ont à préciser leur attitude envers le mot d'ordre de l'unité du front ouvrier. 
8. Tout bien pesé, le Comité Exécutif de l'Internationale Communiste estime que le mot d'ordre du $3^{\mathrm{e}}$ Congrès de l'Internationale Communiste : "Aux masses! » ainsi que les intérêts généraux du mouvement communiste, exigent que l'Internationale Communiste et ses sections soutiennent le mot d'ordre de l'unité du front prolétarien et prennent en main l'initiative de sa réalisation. La tactique des partis communistes s'inspirera des conditions particulières à chaque pays.

9. En Allemagne, le Parti Communiste, à la dernière session de son Conseil National, s'est prononcé pour l'unité du front prolétarien et a reconnu possible d'appuyer un "gouvernement ouvrier unitaire » qui serait disposé à combattre sérieusement le pouvoir capitaliste. L'Exécutif de l'Internationale Communiste approuve sans réserve cette décision, persuadé que le Parti Communiste Allemand, tout en sauvegardant son indépendance politique, pourra ainsi pénétrer dans de plus larges couches prolétariennes et y fortifier l'influence communiste. En Allemagne plus que partout ailleurs, les grandes masses comprennent de mieux en mieux que leur avant-garde communiste avait raison de se refuser à déposer les armes dans les moments les plus difficiles et de dénoncer l'inanité absolue des remèdes réformistes à une situation que la révolution prolétarienne seule peut dénouer. En persévérant dans cette voie, le Parti Allemand ne tardera pas à rallier à lui tous les éléments anarchistes et syndicalistes qui sont restés jusqu’à présent en dehors de la lutte des masses.

10. En France, le Parti Communiste englobe la majorité des travailleurs politiquement organisés. Par suite, le problème du front unique y revêt un aspect quelque peu différent de celui qu'il a dans les autres pays. Mais en France également, il faut que toute la responsabilité de la rupture du front ouvrier retombe sur nos adversaires. La fraction révolutionnaire du syndicalisme français combat avec raison la scission dans les syndicats et défend l'unité de la classe ouvrière dans la lutte économique. Mais cette lutte ne s'arrête pas au seuil de l'usine. L'unité n'est pas moins indispensable contre la vague de réaction, contre la politique impérialiste, etc... La politique des réformistes et des centristes, après avoir provoqué la scission dans le Parti, menace à cette heure l'unité du mouvement syndical, ce qui prouve que, de même que Jean Longuet, Jouhaux sert en réalité la cause de la 
bourgeoisie. Le mot d'ordre de l'unité politique et économique du front prolétarien contre la bourgeoisie est le meilleur moyen de faire avorter les manœuvres scissionnistes.

Quelles que soient les trahisons de la C.G.T. réformiste que dirigent Jouhaux, Merrheim et consorts, les communistes, et avec eux tous les éléments révolutionnaires de la classe ouvrière française, se verront forcés de proposer aux réformistes, avant toute grève générale, avant toute manifestation révolutionnaire, avant toute action de masses, de s'associer à cette action, et, sitôt que les réformistes s'y seront refusés, de les démasquer devant la classe ouvrière. La conquête des masses ouvrières apolitiques nous sera ainsi facilitée. Il va de soi que cette méthode n'implique nullement pour le Parti français une restriction de son indépendance et ne saurait l'engager, par exemple, a soutenir le Bloc des gauches en période électorale, ou à faire preuve d'une indulgence exagérée envers les " communistes » indécis qui ne cessent de déplorer la scission d’avec les social-patriotes.

11. En Angleterre, le Labour Party (Parti Ouvrier) réformiste avait refusé d'admettre en son sein le Parti Communiste au même titre que les autres organisations ouvrières. Mais, sous la pression des masses ouvrières dont nous avons indiqué les aspirations, les organisations ouvrières londoniennes viennent de voter l'admission du Parti Communiste dans le Labour Party.

À cet égard, l'Angleterre constitue évidemment une exception. Par suite de conditions particulières, le Labour Party forme en Angleterre une sorte de coalition embrassant toutes les organisations ouvrières du pays. Il est maintenant du devoir des communistes d'exiger par une campagne énergique, leur admission dans le Labour Party. La récente trahison des leaders des trade-unions dans la grève des mineurs, l'offensive capitaliste contre les salaires, etc..., provoquent une effervescence considérable dans le prolétariat anglais. Les communistes doivent s'efforcer à tout prix de pénétrer au plus profond des masses laborieuses sous le mot d'ordre de l'unité du front prolétarien contre la bourgeoisie.

12. En Italie, le jeune Parti Communiste, qui avait eu jusqu'ici une attitude des plus intransigeantes à l'égard du Parti Socialiste réformiste et des dirigeants social-traîtres de la Confédération Générale du Travail — dont la trahison envers la 
révolution prolétarienne est maintenant définitivement consommée - entreprend néanmoins, en présence de l'offensive patronale, une agitation énergique en faveur de l'unité du front prolétarien. L’Exécutif approuve entièrement cette tactique des communistes italiens et insiste sur la nécessité de la développer encore davantage. L'Exécutif est convaincu que le Parti Communiste Italien, s'il fait preuve d'une perspicacité suffisante, deviendra, pour l'Internationale Communiste, un modèle de combativité marxiste et, tout en dénonçant impitoyablement les hésitations et les trahisons des réformistes et des centristes, saura poursuivre une campagne de plus en plus vigoureuse dans les masses ouvrières pour l'unité du front prolétarien contre la bourgeoisie.

Il va de soi que le Parti Italien ne devra rien négliger pour gagner à l'action commune les éléments révolutionnaires de l'anarchisme et du syndicalisme.

13. En Tchécoslovaquie, où le Parti groupe la majorité des travailleurs politiquement organisés, les tâches des communistes sont, sous certains rapports, analogues à celles des communistes français. Tout en affermissant son indépendance et en rompant les derniers liens qui le rattachent aux centristes, le Parti Tchécoslovaque doit savoir populariser le mot d'ordre de l'unité du front prolétarien contre la bourgeoisie et mettre en lumière le rôle véritable des social-démocrates et des centristes, agents du Capital. Les communistes tchécoslovaques ont aussi à intensifier leur action dans les syndicats, restés dans une large mesure au pouvoir des leaders jaunes.

14. En Suède, le résultat des dernières élections parlementaires permet à un Parti Communiste numériquement faible de jouer un rôle important. M. Branting, leader des plus éminents de la 2e Internationale en même temps que président du Conseil des Ministres de la bourgeoisie suédoise, se trouve dans une situation telle que l'attitude de la fraction parlementaire communiste ne peut lui être indifférente pour la constitution d'une majorité parlementaire. L'Exécutif estime que la fraction communiste ne pourra pas refuser d'accorder, sous certaines conditions, son appui au gouvernement menchevique de M. Branting, comme l'ont d'ailleurs fait avec raison les communistes allemands pour certains gouvernements régionaux (Thuringe). Mais il n'en résulte nullement que les communistes 
suédois doivent abandonner quoi que ce soit de leur indépendance ou cesser de dénoncer le caractère véritable du gouvernement menchevique. Au contraire, plus les mencheviks auront de pouvoir, plus ils trahiront la classe ouvrière et plus les communistes devront s'efforcer de les démasquer devant les masses ouvrières.

15. Aux Etats-Unis, l'union de tous les éléments de gauche du mouvement ouvrier syndical et politique commence à se réaliser. Les communistes américains ont ainsi l'occasion de pénétrer dans les grandes masses laborieuses et de devenir le centre de cristallisation de cette union des gauches. Formant des groupes partout où il se trouve des communistes, ils doivent savoir prendre la direction du mouvement de ralliement des éléments révolutionnaires et propager avec énergie l'idée du front unique (par exemple, pour la défense des intérêts des sans-travail). L'accusation principale qu'ils devront porter contre les organisations de M. Gompers sera que ces dernières se refusent obstinément à constituer l'unité du front prolétarien pour la défense des chômeurs. Néanmoins, la tâche essentielle du Parti sera d'attirer à lui les meilleurs éléments des I.W.W.

16. En Suisse, notre parti a déjà remporté certain succès dans la voie que nous avons indiquée. La propagande communiste pour le front unique a obligé la bureaucratie syndicale à convoquer un congrès extraordinaire qui doit se tenir prochainement et où nos amis sauront mettre à nu les mensonges du réformisme et développer, pour l'unité révolutionnaire du prolétariat, la plus grande activité.

17. Dans une série d'autres pays, la question se présente, selon les conditions locales, sous un aspect plus ou moins différent. Mais l'Exécutif est persuadé que les sections sauront appliquer, conformément aux conditions particulières de chaque pays, la ligne de conduite générale qu’il vient de tracer.

18. Le Comité Exécutif stipule, comme condition rigoureusement obligatoire pour tous les Partis Communistes, la liberté, pour toute section passant une convention quelconque avec les partis de la $2^{\mathrm{e}}$ Internationale et de l'Internationale $2 \frac{1}{2}$, de continuer la propagande de nos idées et la critique des adversaires du 
communisme. Tout en se soumettant à la discipline de l'action, les communistes doivent absolument se réserver le droit et la possibilité d'exprimer, non seulement avant et après, mais encore pendant l'action, leur opinion sur la politique de toutes les organisations ouvrières sans exception. En aucun et sous aucun prétexte, cette clause ne saurait souffrir d’infraction. En préconisant l'unité de toutes les organisations ouvrières dans chaque action contre le front capitaliste, les communistes ne peuvent renoncer à la propagande de leurs points de vue qui, seuls, constituent l'expression logique des intérêts de l'ensemble de la classe ouvrière.

19. Le Comité Exécutif de l’Internationale Communiste croit utile de rappeler à tous les partis frères les expériences des bolchéviks russes, dont le parti est le seul qui ait jusqu’à présent réussi à vaincre la bourgeoisie et à s'emparer du pouvoir. Pendant les quinze années qui s’étendent entre la naissance du bolchevisme et sa victoire (1903-1917), celui-ci n’a jamais cessé de combattre le réformisme, ou, ce qui revient au même, le menchevisme. Mais pendant ce même laps de temps, les bolchéviks ont, à plusieurs reprises, passé des accords avec les mencheviks. La première scission formelle eut lieu au printemps de 1905. Mais sous l'influence irrésistible d'un mouvement ouvrier de vaste envergure, les bolchéviks formèrent, la même année, un front commun avec les mencheviks. La seconde scission formelle eut lieu en e janvier 1912. Mais de 1905 à 1912, la scission alterna avec des unions et des accords temporaires (en 1906, 1907 et 1910). Unions et accords ne se produisirent pas seulement à la suite des péripéties de la lutte entre fractions, mais surtout sous la pression des grandes masses ouvrières éveillées à la vie politique et qui voulaient voir par elles-mêmes si les voies du menchevisme s’écartaient véritablement de la révolution. Peu avant la guerre impérialiste, le nouveau mouvement révolutionnaire qui suivit la grève de la Léna engendra dans les masses prolétariennes une puissante aspiration à l'unité, que les dirigeants du menchevisme s’évertuèrent à exploiter à leur profit, comme le font aujourd'hui les leaders des Internationales «socialistes » et ceux de l'Internationale d’Amsterdam. A cette époque, les bolchéviks ne se refusèrent pas au front unique. Loin de là : pour contrebalancer la diplomatie des chefs mencheviks, ils adoptèrent le mot d'ordre de « l'unité par la base », c'est-à-dire de l'unité des masses ouvrières dans l'action révolutionnaire pratique contre la bourgeoisie. L’expérience montra que c’était là la seule vraie tactique. Modifiée selon les 
temps et les lieux, cette tactique gagna au communisme l'immense majorité des meilleurs éléments prolétariens mencheviks.

20. Adoptant le mot d'ordre de l'unité du front prolétarien et admettant des accords entre ses diverses sections et les partis et syndicats de la 2e Internationale et de l'Internationale 2 1/2, l'Internationale Communiste ne saurait évidemment renoncer elle-même à passer des accords analogues sur l'échelle internationale. Dans la question du secours aux affamés de Russie, l’Exécutif a proposé un accord à l'Internationale Syndicale d'Amsterdam. Il a renouvelé ses propositions en vue d'une action commune contre la terreur blanche en Espagne et en Yougoslavie. Il soumet actuellement aux Internationales socialistes et à l'Internationale d'Amsterdam une nouvelle proposition au sujet des travaux de la Conférence de Washington, laquelle ne peut que précipiter l'explosion d'une nouvelle guerre impérialiste. Mais les dirigeants de ces trois organisations internationales ont montré que, dès qu'il s'agit d'en venir aux actes, ils renoncent entièrement à leur mot d'ordre d'unité ouvrière. Par suite, la tâche précise de l'Internationale Communiste et de ses sections sera de dévoiler aux masses l'hypocrisie des dirigeants ouvriers qui préfèrent l'union avec la bourgeoisie à l'unité des travailleurs révolutionnaires et, en restant dans le Bureau International du Travail auprès de la Société des Nations, participent par là même à la Conférence impérialiste de Washington, au lieu de mener une campagne contre elle. Mais le refus opposé à nos propositions ne nous fera pas renoncer à la tactique que nous préconisons, tactique profondément conforme à l'esprit des masses ouvrières et qu'il faut savoir développer méthodiquement, sans relâche.

Si nos propositions d'action commune sont repoussée, il faudra en informer le monde ouvrier afin qu'il sache quels sont les destructeurs réels de l'unité du front prolétarien. Si nos propositions sont acceptées, notre devoir est d'accentuer et d'approfondir les luttes engagées. Dans les deux cas, il importera de faire en sorte que les pourparlers des communistes avec les autres organisations éveillent et attirent l'attention des masses laborieuses. Car il faut absolument intéresser ces dernières à toutes les péripéties du combat pour l'unité du front révolutionnaire de tous les travailleurs. 
21. En fixant ce plan d'action, l'Exécutif tient à attirer l'attention des partis frères sur les périls qui peuvent en résulter. Tous les partis communistes sont loin d'être suffisamment affermis et organisés et d'avoir vaincu définitivement les idéologies centriste et semi-centriste. Des excès peuvent se produire et amener la transformation des partis et groupes communistes en blocs hétérogènes informes. Pour appliquer avec succès la tactique préconisée, il importe que le parti soit fortement organisé et que sa direction se distingue par la clarté parfaite de ses idées.

22. Au sein même de l'Internationale Communiste, dans les groupements que l'on considère à tort ou à raison comme droitiers ou semi-centristes, il existe indubitablement deux courants. Le premier, réellement émancipé de l’idéologie et des méthodes de la $2^{\mathrm{e}}$ Internationale, n'a pourtant pas su se défaire d'un sentiment de respect à l'égard de l'ancien pouvoir organisateur et voudrait, consciemment ou non, rechercher les bases d'une entente idéale avec la $2^{\mathrm{e}}$ Internationale et, partant, avec la société bourgeoise. Le second, qui combat le radicalisme formel et les erreurs d'une prétendue «gauche », voudrait donner à la tactique du jeune parti communiste plus de souplesse et d'aptitude à la manœuvre afin de lui permettre de pénétrer plus facilement les masses ouvrières. L’évolution rapide des partis communistes a parfois poussé ces deux courants à se rejoindre, voire à n'en former qu'un. Une application attentive des méthodes indiquées plus haut, dont le but est de donner à l'agitation communiste un appui dans les actions des masses unifiées, contribuera efficacement à l'affermissement révolutionnaire de nos partis, tant en faisant l'éducation expérimentale des éléments impatients et sectaires qu'en les débarrassant du poids mort du réformisme.

23. Par unité du front prolétarien, il faut entendre l'unité de tous les travailleurs désireux de combattre le capitalisme, y compris par conséquent les ouvriers qui suivent encore les anarchistes et les syndicalistes. Dans divers pays, ces éléments peuvent utilement s’associer aux actions révolutionnaires. Dès ses débuts, l'Internationale Communiste a toujours préconisé une attitude amicale à l'égard de ces éléments ouvriers qui surmontent progressivement leurs préjugés et adhèrent peu à peu au communisme. Les communistes devront dorénavant leur accor- 
der d'autant plus d'attention que le front unique contre le capitalisme est en voie de réalisation.

24. Dans le but de fixer définitivement le travail ultérieur dans les conditions indiquées, l'Exécutif décide de convoquer prochainement une assemblée extraordinaire à laquelle tous les partis affiliés seront représentés par un nombre de délégués double du nombre ordinaire.

25. Le Comité Exécutif consacrera la plus grande attention à toutes les démarches pratiques effectuées dans la voie qu'il vient d'indiquer et demande aux différents partis de l'informer par le menu de toutes leurs tentatives dans ce sens et de tous les résultats obtenus. 
Manifestes, thèses et résolutions

des quatre premiers congrès

de l’Internationale communiste 1919-1923

(juin 1934)

Quatrième Congrès, novembre 1922.

- 3 -

\section{Résolution sur le rapport du Comité Exécutif}

$\underline{\text { Retour à la table des matières }}$

Le $4^{\mathrm{e}}$ Congrès de l'Internationale Communiste approuve complètement le travail politique du Comité Exécutif et déclare qu'au cours des quinze derniers mois, il a bien appliqué les décisions du $3^{\circ}$ Congrès Mondial, en tenant compte de la situation politique.

En particulier, le $4^{\mathrm{e}}$ Congrès approuve complètement la tactique du front unique, telle qu'elle a été formulée par le Comité Exécutif dans ses thèses de décembre 1921 et ultérieurement.

Le $4^{\mathrm{e}}$ Congrès approuve le point de vue adopté par le Comité Exécutif en ce qui concerne la crise du Parti Communiste français, le mouvement ouvrier italien et les Partis Communistes norvégien et tchécoslovaque. Les questions pratiques concernant ces Partis seront traitées par des commissions spéciales dont les décisions seront soumises au vote du Congrès.

À propos des incidents qui se sont déroulés dans un certain nombre de Partis, le $4^{\mathrm{e}}$ Congrès rappelle et confirme à nouveau que le Comité Exécutif constitue l'organe suprême du mouvement communiste dans l'intervalle des Congrès mon- 
diaux, et que les décisions de l'Internationale Communiste sont obligatoires pour tous les partis adhérents. Il en résulte que la violation des décisions de l'Internationale Communiste, sous le prétexte d'un appel au prochain Congrès, constitue une rupture de la discipline. Si l'Internationale Communiste permettait l'introduction de telles pratiques, cela équivaudrait à la négation complète de toute activité régulière de l’Internationale Communiste.

En ce qui concerne les doutes apparus dans le Parti Communiste français touchant l'article 9 des statuts de l'Internationale Communiste, le 4 e Congrès déclare que cet article 9 donne au Comité Exécutif le droit d'exclure de l'Internationale Communiste et, par conséquent, de ses sections nationales, les personnes isolées et les groupes qui, à son avis, expriment des opinions étrangères au Communisme. Il est naturel que le Comité Exécutif soit obligé d'appliquer l'article 9 des statuts, quand un Parti est incapable de se débarrasser des éléments non communistes.

Le $4^{\mathrm{e}}$ Congrès confirme à nouveau les 21 conditions posées par le $2^{\mathrm{e}}$ Congrès et charge le prochain Comité Exécutif de veiller énergiquement à leur application. A l'avenir, le Comité Exécutif doit plus que jamais rester une organisation internationale prolétarienne combattant énergiquement tout opportunisme, et constituée selon les principes du centralisme démocratique.

Les questions de détail pratiques découlant de cet article seront traitées par des commissions spéciales dont les décisions seront soumises au Congrès. 
Manifestes, thèses et résolutions

des quatre premiers congrès

de l’Internationale communiste 1919-1923

(juin 1934)

Quatrième Congrès, novembre 1922.

- 4 -

\section{Résolution sur le programme de l’Internationale Communiste}

$\underline{\text { Retour à la table des matières }}$

1. Tous les projets de programme seront transmis au Comité Exécutif de l'Internationale Communiste ou à une Commission désignée à cet effet, pour être étudiés et élaborés en détail. L'Exécutif est tenu de publier dans le plus bref délai tous les projets de programme qui lui parviennent.

2. Le Congrès confirme que les sections nationales de l'Internationale Communiste qui n'ont pas encore de programme national sont tenues de commencer immédiatement à en élaborer un pour pouvoir le soumettre au Comité Exécutif, trois mois au plus tard avant le $5^{\mathrm{e}}$ Congrès, pour ratification.

3. Dans le programme des sections nationales, la nécessité de la lutte pour les revendications transitoires doit être motivée avec précision et netteté ; les réserves sur les rapports de ces revendications avec les conditions concrètes de temps et de lieu doivent être mentionnées.

4. Les fondements théoriques de toutes les revendications transitoires et partielles doivent absolument être formulées dans le programme général. Le $4^{\mathrm{e}}$ Congrès se prononce tout aussi résolument contre la tentative de représenter 
l'introduction de revendications transitoires dans le programme comme de l'opportunisme, que contre toute tentative d'atténuer ou de remplacer les objectifs révolutionnaires fondamentaux par des revendications partielles.

5. Dans le programme général doivent être nettement énoncés les types historiques fondamentaux entre lesquels se divisent les revendications transitoires des sections nationales, conformément aux différences essentielles de structure économique et politique des divers pays, comme par exemple, l'Angleterre d'une part, l'Inde de l'autre, etc... 


\author{
Manifestes, thèses et résolutions \\ des quatre premiers congrès \\ de l’Internationale communiste 1919-1923 \\ (juin 1934) \\ Quatrième Congrès, novembre 1922. \\ -5 - \\ Résolution sur la Révolution russe
}

\title{
$\underline{\text { Retour à la table des matières }}$
}

Le $4^{\mathrm{e}}$ Congrès mondial de l'Internationale Communiste exprime au peuple travailleur de la Russie des Soviets ses remerciements les plus profonds et son admiration sans bornes pour avoir, non seulement conquis le pouvoir au moyen de la lutte révolutionnaire et établi la dictature du prolétariat, mais pour avoir su défendre victorieusement jusqu'à aujourd'hui contre tous les ennemis de l'intérieur et de l'extérieur les conquêtes de la révolution. Il a ainsi rendu des services immortels à la libération des opprimés et des exploités de tous les pays.

Le $4^{\mathrm{e}}$ Congrès mondial constate avec la plus grande satisfaction que le premier Etat ouvrier du monde, issu de la révolution prolétarienne, a complètement prouvé sa force de vie et de développement au cours des cinq années de son existence, malgré des difficultés et des dangers inouïs. L’Etat soviétique est sorti renforcé des horreurs de la guerre civile. Grâce à l'héroïsme incomparable de l'armée rouge, il a abattu sur tous les fronts la contre-révolution militaire équipée et soutenue par la bourgeoisie mondiale. Il a repoussé toutes les tentatives des Etats capitalistes pour lui imposer, au moyen de ruses diplomatiques et d'une pression économique, l'abandon du contenu prolétarien des buts communistes de la révolution, à savoir la reconnaissance du droit de propriété privée sur les moyens de production 
sociaux et la renonciation à la nationalisation de l'industrie. Inébranlablement, il a défendu contre l'assaut de la bourgeoisie mondiale ce qui constitue la condition fondamentale de la libération prolétarienne, à savoir la propriété collective des moyens de production. En s'opposant à la reconnaissance d'une dette nationale immense, il s'est opposé à ce qu'on rabaisse les ouvriers et les paysans de la République des Soviets au niveau des serfs coloniaux des capitalistes.

Le $4^{\mathrm{e}}$ Congrès mondial constate que l'Etat ouvrier, depuis qu'il n'est plus obligé de défendre son existence les armes à la main, s'efforce avec la plus grande énergie de rétablir et de développer la vie économique de la République et qu'il continue à se fixer comme but l'établissement du communisme. Les étapes et les mesures diverses menant à ce but, la "Nouvelle politique économique », sont le résultat, d'une part, des conditions objectives et subjectives du pays, d'autre part, de la lenteur du développement de la révolution mondiale et de l'état d'isolement de la République des Soviets au milieu d'Etats capitalistes. Malgré les difficultés inouïes qui sont ainsi créées, l'Etat ouvrier peut faire des progrès décisifs dans le domaine de la reconstruction économique. De même que les ouvriers russes ont chèrement payé pour les ouvriers du monde entier les enseignements qui se dégagent de la conquête et de la défense du pouvoir politique et de l'établissement de la dictature prolétarienne, ce sont eux encore qui font les sacrifices les plus pénibles pour résoudre les problèmes de la période de transition du capitalisme au communisme. La Russie des Soviets est et reste le foyer le plus riche d'expériences révolutionnaires pour le prolétariat mondial.

Le $4^{\mathrm{e}}$ Congrès mondial constate avec satisfaction que la politique de la Russie des Soviets a assuré et renforcé la condition la plus importante pour l'instauration et le développement de la société communiste, le régime des Soviets, c'est-à-dire la dictature du prolétariat. Car, seule, cette dictature est capable de surmonter toutes les résistances bourgeoises à l'émancipation totale des travailleurs et d'assurer ainsi la défaite complète du capitalisme et la voie libre vers la réalisation du communisme.

Le $4^{\mathrm{e}}$ Congrès mondial constate la part décisive prise par le Parti Communiste russe, en tant que parti dirigeant du prolétariat soutenu par les paysans, à la conquête et à la défense du pouvoir politique. L'unité idéologique et organique du Parti, sa discipline sévère, ont donné aux masses l'assurance révolutionnaire du but à atteindre et des méthodes à employer, ont élevé ses qualités de décision et de 
dévouement jusqu’à l’héroïsme et créé un lien organique indestructible entre les masses et les chefs.

Le $4^{\mathrm{e}}$ Congrès mondial rappelle aux travailleurs de tous les pays que la révolution prolétarienne ne pourra jamais vaincre à l'intérieur d'un seul pays, mais dans le cadre international, en tant que révolution prolétarienne mondiale. La lutte de la Russie des Soviets pour son existence et pour les conquêtes de la révolution est la lutte pour la libération des travailleurs, des opprimés et exploités du monde entier. Les travailleurs russes ont fait surabondamment leur devoir en tant que champions révolutionnaires du prolétariat mondial. Le prolétariat mondial devra aussi remplir sa tâche. Dans tous les pays, les ouvriers, les déshérités et les opprimés devront manifester moralement, économiquement et politiquement leur complète solidarité avec la Russie des Soviets. Ce n'est pas seulement la solidarité internationale, mais c’est leur intérêt le plus élémentaire qui doit les décider à engager un combat acharné contre la bourgeoisie et l'Etat capitaliste. Dans tous les pays leurs mots d'ordre devront être les suivants :

Ne touchez pas à la Russie des Soviets ! Reconnaissance de la République des Soviets ! Assistance vigoureuse de toute sorte pour la reconstruction économique de la Russie des Soviets !

Tout renforcement de la Russie des Soviets équivaut à un affaiblissement de la bourgeoisie mondiale Le maintien depuis cinq ans du régime des Soviet est le coup le plus dur que le capitalisme mondial ait reçu jusqu’à présent.

Le $4^{\mathrm{e}}$ Congrès mondial demande aux travailleurs de tous les pays capitalistes de s'inspirer de l'exemple de la Russie des Soviets, et de porter au capitalisme le coup mortel, de tendre toutes leurs forces pour réaliser la révolution mondiale. 
Manifestes, thèses et résolutions

des quatre premiers congrès

de l’Internationale communiste 1919-1923

(juin 1934)

Quatrième Congrès, novembre 1922.

- 6 -

Résolution sur

e Traité de Versailles

$\underline{\text { Retour à la table des matières }}$

La guerre mondiale s'est terminée par l'écroulement de trois puissances impérialistes : l'Allemagne, l'Autriche-Hongrie et la Russie. Quatre grands rapaces sont sortis victorieux de la lutte : les Etats-Unis, l’Angleterre, la France et le Japon.

Les traités de paix, dont celui de Versailles constitue le noyau central, sont une tentative de stabiliser la domination mondiale de ces quatre puissances victorieuses : politiquement et économiquement, en réduisant tout le reste du monde en un domaine colonial d'exploitation ; socialement en consolidant la bourgeoisie vis-à-vis du prolétariat de chaque pays et de la Russie prolétarienne révolutionnaire victorieuse, grâce à une alliance de toutes les bourgeoisies. Dans ce but on construisit et on arma une digue de petits Etats vassaux autour de la Russie pour étouffer cette dernière à la première occasion. Les Etats vaincus devaient en outre réparer complètement les dommages matériels subis par les Etats victorieux.

Aujourd'hui, il est clair pour tout le monde qu'aucune des présomptions sur lesquelles étaient bâtis tous ces traités de paix n'était fondée. La tentative de rétablir un nouvel équilibre sur des bases capitalistes a échoué. L’histoire des quatre 
dernières années montre un chancellement continu, une insécurité permanente ; les crises économiques, le chômage et la surproduction, les crises ministérielles, les crises de parti, les crises extérieures n'en finissent plus. Au moyen d'une série infinie de conférences, les puissances impérialistes essayent d'arrêter la ruine du système mondial édifié par ces traités et de dissimuler la banqueroute de Versailles.

Les tentatives pour renverser en Russie la dictature du prolétariat ont échoué. Le prolétariat de tous les pays capitalistes prend de plus en plus résolument position en faveur de la Russie des Soviets. Même les chefs de l'Internationale d'Amsterdam sont obligés de déclarer ouvertement que la chute de la domination prolétarienne en Russie serait une victoire de la réaction mondiale sur tout le prolétariat.

La Turquie, précurseur de l’Orient en marche vers la révolution, a résisté les armes à la main à l'application du traité de paix ; à la Conférence de Lausanne ont lieu les funérailles solennelles d’une partie importante des traités.

La crise économique mondiale persistante a donné la preuve que la conception économique du traité de Versailles n'est pas soutenable. La puissance européenne capitaliste dirigeante, l'Angleterre, qui dépend dans la plus grande mesure du commerce mondial ne peut consolider sa base économique sans la restauration de l'Allemagne et de la Russie.

Les Etats-Unis, la plus forte puissance impérialiste, se sont complètement détournés de l'œuvre de paix et cherchent à fonder leur impérialisme mondial sur leurs propres forces. Ils ont réussi à gagner l'appui de parties importantes de l'Empire mondial anglais, du Canada et de l'Australie.

Les colonies opprimées de l'Angleterre, base de son pouvoir mondial, se rebellent ; tout le monde musulman est en révolte ouverte ou latente.

Toutes les présomptions de l'œuvre de paix ont fait défaut, sauf une : que le prolétariat de tous les pays bourgeois doit payer les charges de la guerre et de la paix de Versailles. 


\section{La France}

En apparence, c'est la France qui, de tous les pays victorieux, s'est le plus accru en puissance. Outre la conquête de l'Alsace-Lorraine, l'occupation de la rive gauche du Rhin, les innombrables milliards de dommages de guerre qu'elle réclame à l'Allemagne, elle est devenue en fait la plus grande puissance militaire du continent européen. Avec ses Etats vassaux, dont les armées sont instruites et dirigées par des généraux français (Pologne, Tchécoslovaquie, Roumanie), avec sa propre grande armée, avec ses sous-marins et sa flotte aérienne, elle domine le continent européen, elle joue le rôle de gardien du traité de Versailles. Mais la base économique de la France, sa petite population diminuant de plus en plus, son énorme dette intérieure et extérieure et sa dépendance économique à l'égard de l'Angleterre et de l'Amérique ne donnent pas un fondement suffisant à sa soif inextinguible d'expansion impérialiste. Sous le rapport de la puissance politique, elle est gênée par la maîtrise de l'Angleterre sur toutes les bases navales importantes, par le monopole du pétrole détenu par l'Angleterre et l'Amérique. Sous le rapport économique, son enrichissement en minerai de fer procuré par le traité de Versailles perd sa valeur du fait que les mines correspondantes de charbon du bassin de la Ruhr sont restées à l'Allemagne. L'espoir de remettre en ordre les finances ébranlées de la France avec l'aide des réparations payées par l'Allemagne est apparue illusoire. Tous les experts financiers sont unanimes à reconnaître que l'Allemagne ne saurait payer les sommes dont la France a besoin pour assainir ses finances. Il ne reste à la bourgeoisie française qu'un moyen : réduire le niveau d'existence du prolétariat français à celui du prolétariat allemand. La famine du travailleur allemand est une image de la misère qui menace pour demain l'ouvrier français. La dépréciation du franc, provoquée consciemment par certains milieux de la grande industrie française, constituera un moyen de rejeter sur les épaules du prolétariat français les charges de la guerre après que l’œuvre de paix de Versailles sera apparue impraticable. 


\section{L'Angleterre}

La guerre mondiale a donné à l'Angleterre l'unification de son empire colonial, du Cap de Bonne-Espérance, à travers l'Egypte et l'Arabie, jusqu'aux Indes. Elle a maintenu en sa possession tous les principaux accès sur la mer. Par des concessions accordées à ses colonies d'émigration, elle a cherché à construire l'Empire mondial anglo-saxon.

Mais malgré toute la souplesse de sa bourgeoisie, malgré son effort pour reconquérir le marché mondial, il est apparu qu'avec la situation mondiale créée par le traité de Versailles l'Angleterre ne peut plus progresser. L'Etat industriel anglais ne peut plus exporter si l'Allemagne et la Russie ne sont pas restaurées éco-

nomiquement. Sous ce rapport, l'antagonisme entre l'Angleterre et la France s'aggrave ; l'Angleterre veut vendre ses marchandises à l'Allemagne, ce que le traité de Versailles rend impossible ; la France veut arracher à l'Allemagne des sommes colossales sous forme de contributions de guerre, ce qui ruine la force d'achat de l'Allemagne. C'est pourquoi l'Angleterre est pour la suppression des réparations, et la France mène dans le Proche-Orient une guerre dissimulée contre l'Angleterre pour la contraindre à céder dans la question des réparations. Tandis que le prolétariat anglais supporte les charges de la guerre sous la forme du chômage de millions d'ouvriers, la bourgeoisie d'Angleterre et de France s'accorde aux dépens de l'Allemagne.

\section{L'Europe Centrale et l'Allemagne}

L'objet le plus important du traité de Versailles, c'est l'Europe Centrale, la nouvelle colonie des brigands impérialistes. Divisée en d'innombrables petits Etats et en une série de régions économiquement non viables, l’Europe Centrale est incapable de vie politique indépendante. Elle est la colonie du capital anglais et français. Selon l'intérêt changeant de ces grandes puissances, ses divers tronçons sont excités les uns contre les autres. La Tchécoslovaquie, sur un domaine économique de 60 millions d'individus, est constamment en proie à la crise éco- 
nomique. L’Autriche a été réduite à l'état de monstre non viable qui ne mène plus, en apparence, une existence politique indépendante que grâce aux rivalités des pays voisins. La Pologne, à laquelle des vastes régions occupées par des populations de langues étrangères ont été attribuées, est un avant-poste de la France, une caricature de l'impérialisme français. Dans tous ces pays, le prolétariat doit payer les frais de la guerre sous forme d'une réduction de son niveau d'existence ou d'un formidable chômage.

Mais l'objet le plus important du traité de Versailles, c'est l'Allemagne désarmée, privée de toute possibilité de défense. Elle est livrée à la merci des puissances impérialistes. La bourgeoisie allemande cherche à lier ses intérêts tantôt à ceux de la bourgeoisie anglaise, tantôt à ceux de la bourgeoisie française. Elle cherche à satisfaire une partie des prétentions de la France au moyen d'une exploitation aggravée du prolétariat allemand et à assurer en même temps sa propre domination sur ce prolétariat avec l'aide étrangère. Mais la plus forte exploitation du prolétariat allemand, la transformation de l'ouvrier allemand en coolie européen, la misère effrayante où il est plongé par suite du traité de Versailles ne donnent pas la possibilité de payer les réparations. L’Allemagne devient donc le ballon de jeu de l’Angleterre et de la France. La bourgeoisie française veut résoudre la question par la force en occupant le bassin de la Ruhr et la rive gauche du Rhin. L’Angleterre s’y oppose. Seule, l'aide de la plus grande puissance économique, les Etats-Unis, eût pu concilier les intérêts contradictoires de l’Angleterre, de la France et de l'Allemagne.

\section{Les États-Unis d'Amérique}

Les Etats-Unis se sont retirés depuis longtemps de l'œuvre de paix de Versailles, en refusant de ratifier le traité. Les Etats-Unis qui sont sortis de la guerre mondiale comme la plus grande puissance économique et politique, et envers qui les puissances impérialistes européennes sont fortement endettées, ne se montrent pas disposés à guérir, au moyen de nouveaux grands crédits à l’Allemagne, la crise financière de la France. Le capital des Etats-Unis se détourne de plus en plus du chaos européen et cherche avec beaucoup de succès à se créer dans l’Amérique Centrale et du Sud et en Extrême-Orient un empire colonial et à assurer à sa clas- 
se régnante l'exploitation du marché intérieur par un système douanier protectionniste. En abandonnant de la sorte l'Europe continentale à son sort, les EtatsUnis, tout en appliquant leur suprématie économique à la construction de navires de guerre, ont contraint les autres puissances impérialistes à accepter l'accord de désarmement de Washington. Ils ont ainsi ruiné une des bases les plus importantes de l'œuvre de Versailles, à savoir : la suprématie maritime de l'Angleterre, et de la sorte il n'y a plus de sens pour l’Angleterre à rester dans le groupement de puissances prévu à Washington.

\section{Le Japon et les colonies}

La plus jeune puissance mondiale impérialiste, le Japon, se tient à l'écart du chaos européen crée par le traité de Versailles. Mais, par le développement des Etats-Unis en puissance mondiale, ses intérêts ont été vivement touchés. A Washington, il a été obligé de dissoudre son alliance avec l'Angleterre, ce qui a ruiné encore une des bases les plus importantes de la division du monde faite à Versailles. En même temps, non seulement les peuples opprimés se révoltent contre la domination de l'Angleterre et du Japon, mais les colonies d'émigration de l'Angleterre cherchent à assurer leurs intérêts au moyen d'un rapprochement avec les Etats-Unis, dans la lutte imminente entre les Etats-Unis et le Japon. Le cadre de l’impérialisme anglais se relâche ainsi de plus en plus.

\section{Vers une nouvelle guerre mondiale}

Les tentatives des grandes puissances impérialistes pour créer une base permanente à leur domination mondiale ont échoué lamentablement devant leurs intérêts contradictoires. La grande œuvre de paix est ruinée. Les grandes puissances arment leurs Etats vassaux en vue d'une nouvelle guerre. Le militarisme est plus fort que jamais. Et quoique la bourgeoisie redoute anxieusement une nouvelle révolution prolétarienne à la suite d'une guerre mondiale, les lois internes de l’ordre social capitaliste poussent irrésistiblement à un nouveau conflit mondial. 


\section{Les objectifs des Partis Communistes}

Les Internationales 2 et 2 1⁄2 s'appliquent à soutenir l'aile radicale de la bourgeoisie, qui représente avant tout les intérêts du capital commercial et bancaire dans sa lutte impuissante pour la suppression des réparations. Comme dans toutes les questions, dans celle-ci aussi, elles marchent avec la bourgeoisie. La tâche des Partis Communistes, et en premier lieu de ceux des pays victorieux, est donc de rendre clair aux masses que l'œuvre de paix de Versailles rejette toutes les charges sur les épaules du prolétariat, aussi bien dans les pays victorieux que dans les pays vaincus, et que les prolétaires de tous les pays sont les véritables victimes. Sur cette base, les Partis Communistes, et avant tout ceux d'Allemagne et de France, doivent mener la lutte commune contre le traité de Versailles.

Le Parti Communiste Français doit lutter de toutes ses forces contre les tendances impérialistes de sa propre bourgeoisie, contre sa tentative à s'enrichir au moyen de l'exploitation aggravée du prolétariat allemand, contre l'occupation du bassin de la Ruhr, contre le morcellement de l'Allemagne, contre l'impérialisme français. Il ne suffit plus aujourd'hui de combattre en France la soi-disant défense de la patrie, il faut lutter pas à pas contre le traité de Versailles.

Le devoir des Partis Communistes de Tchécoslovaquie, de Pologne et des autres pays vassaux de la France, est de lier la lutte contre leur propre bourgeoisie à la lutte contre l'impérialisme français. Il faut, au moyen d'actions communes de masses, rendre clair au prolétariat français et allemand que la tentative de réaliser le traité de Versailles réduit à la plus profonde misère le prolétariat des deux pays et avec lui le prolétariat de toute l’Europe. 
Manifestes, thèses et résolutions

des quatre premiers congrès

de l’Internationale communiste 1919-1923

(juin 1934)

Quatrième Congrès, novembre 1922.

- 7 -

\section{Thèses sur l'action communiste dans le mouvement syndical}

\section{I. - Situation du mouvement syndical}

\section{$\underline{\text { Retour à la table des matières }}$}

1. Au cours de ces deux dernières années, marquées par l'offensive universelle du capital, le mouvement syndical s'est sensiblement affaibli dans tous les pays. Sauf de rares exceptions (Allemagne, Autriche), les syndicats ont perdu un grand nombre de leurs membres. Ce recul s'explique à la fois par les vastes offensives de la bourgeoisie et par l'impuissance des syndicats réformistes, non seulement à résoudre la question sociale, mais même à résister sérieusement à l'attaque capitaliste et à défendre les intérêts les plus élémentaires des masses ouvrières.

2. Devant cette offensive capitaliste d'une part et cette collaboration de classe persistante d'autre part, les masses ouvrières sont de plus en plus désabusées. De là, non seulement leurs tentatives pour créer des groupements nouveaux, mais encore la dispersion d'un grand nombre d'ouvriers conscients qui quittent leurs organisations. Le syndicat a cessé d'être pour beaucoup un foyer d'agitation, parce qu'il n'a pas su et dans bien des cas il n'a pas voulu arrêter l'offensive du capital et maintenir les positions acquises. La stérilité du réformisme s'est manifestée avec évidence dans la pratique. 
3. Le mouvement syndical porte, dans tous les pays, un caractère d'instabilité foncière ; des groupes assez nombreux d'ouvriers ne cessent de s'en détacher, tandis que les réformistes continuent assidûment leur politique de collaboration de classes, sous prétexte "d'utiliser le capital au profit des ouvriers ». En fait, le capital a continué d'utiliser dans ses intérêts les organisations en les rendant complices de l'abaissement du niveau d'existence des masses. La période écoulée a surtout renforcé les liens qui existaient déjà entre les gouvernements et les meneurs réformistes, de même que la subordination des intérêts de la classe ouvrière à ceux de ses dirigeants.

\section{L'offensive d'Amsterdam contre les syndicats révolutionnaires}

4. Au moment même où ils cédaient sur toute la ligne à la pression bourgeoise, les chefs réformistes engageaient leur offensive contre les ouvriers révolutionnaires.

Voyant que leur mauvaise volonté à organiser la résistance contre le capital avait provoqué une fermentation profonde dans les masses ouvrières, et résolus à nettoyer les organisations de la contagion révolutionnaire, ils entreprirent contre le mouvement syndical révolutionnaire une offensive en règle tendant à désagréger et à démoraliser la minorité révolutionnaire par tous les moyens en leur pouvoir, et à faciliter la consolidation de la domination de classe ébranlée de la bourgeoisie.

5. Pour conserver leur autorité, les dirigeants de l'Internationale d'Amsterdam n'hésitent pas à exclure, non seulement des individus et de petits groupes, mais des organisations entières; pour rien au monde les gens d'Amsterdam ne veulent rester en minorité et, en cas de menace des éléments révolutionnaires, partisans de l'Internationale Syndicale Rouge, et de l'Internationale Communiste, ils sont décidés à provoquer la scission, pourvu qu'ils puissent ainsi conserver leur mainmise sur l'appareil administratif et les ressources matérielles.

Ainsi ont fait les chefs de la C.G.T. française ; sur la même voie sont engagés les réformistes de Tchécoslovaquie et les meneurs de la Confédération Nationale 
des Syndicats allemands. Les intérêts de la bourgeoisie exigent la scission du mouvement syndical.

6. En même temps que l'offensive réformiste se déclenchait dans les différents pays, la même offensive se déclenchait dans le monde entier : les Fédérations internationales adhérant à Amsterdam excluaient systématiquement ou refusaient d'admettre les Fédérations nationales révolutionnaires correspondantes. Ainsi les congrès internationaux du sous-sol, du textile, des employés, des cuirs et peaux, des travailleurs sur bois, du bâtiment et des P.T.T. ont refusé d'admettre les syndicats russes et les autres syndicats révolutionnaires parce que ces derniers appartiennent à l’Internationale Syndicale Rouge.

7. Cette campagne des gens d'Amsterdam contre les syndicats révolutionnaires est une expression de la campagne du capital international contre la classe ouvrière. Elle poursuit les mêmes buts : consolider le système capitaliste sur la misère des masses laborieuses. Le réformisme pressent sa fin prochaine ; il veut, à l'aide des exclusions et de la scission des éléments les plus combatifs, affaiblir au maximum la classe ouvrière pour la rendre incapable de mettre la main sur le pouvoir et les moyens de production et d'échange.

\section{Les anarchistes et les communistes}

8. En même temps, une "offensive » toute semblable à celle d'Amsterdam était lancée par l'aile anarchiste du mouvement ouvrier contre l'Internationale Communiste, les Partis Communistes et les noyaux communistes des syndicats. Un certain nombre d'organisations anarcho-syndicalistes se déclarèrent ouvertement hostiles à l'Internationale Communiste et à la Révolution russe, en dépit de leur adhésion solennelle à l'Internationale Communiste en 1920 et de leurs Adresses de sympathie au prolétariat russe et à la Révolution d'Octobre.

Ainsi, les syndicats italiens, les localistes allemands, les anarcho-syndicalistes de France, de Hollande et de Suède.

9. Au nom de l'autonomie syndicale, certaines organisations syndicalistes (Secrétariat Ouvrier National de Hollande, I.W.W., Union syndicale Italienne,

etc...) excluent les partisans de l'Internationale Syndicale Rouge en général et les 
communistes en particulier. Ainsi la devise d'autonomie, après avoir été archi révolutionnaire, est devenue anticommuniste, c’est-à-dire contre-révolutionnaire et coïncide avec celle d'Amsterdam qui fait la même politique sous le drapeau de l’indépendance, bien que ce ne soit un secret pour personne qu'elle dépend entièrement de la bourgeoisie nationale et internationale.

10. L'action des anarchistes contre l'Internationale Communiste, l'Internationale Syndicale Rouge et la Révolution russe a apporté la décomposition et la scission dans leurs propres rangs. Les meilleurs éléments ouvriers sont intervenus contre cette idéologie. L'anarchisme et l'anarcho-syndicalisme se sont scindés en plusieurs groupes et tendances qui mènent une lutte acharnée pour ou contre l’I. S. R., pour ou contre la dictature prolétarienne, pour ou contre la Révolution russe.

\section{Neutralisme et autonomie}

11. L’influence de la bourgeoisie sur le prolétariat se reflète dans la théorie de la neutralité, sur laquelle les syndicats devraient se proposer exclusivement des buts corporatifs, étroitement économiques et non point des visées de classe. Le neutralisme a toujours été une doctrine purement bourgeoise contre laquelle le marxisme révolutionnaire mène une lutte à mort. Les syndicats qui ne se posent aucun but de classe, c'est-à-dire ne visent pas au renversement du système capitaliste, sont, en dépit de leur composition prolétarienne, les meilleurs défenseurs de l’ordre et du régime bourgeois.

12. Cette période du neutralisme a toujours été favorisée par cet argument que les syndicats ouvriers doivent s’intéresser aux seules questions économiques sans se mêler de politique. La bourgeoisie a toujours tendance à séparer la politique de l'économie, comprenant parfaitement que, si elle réussit à insérer la classe ouvrière dans le cadre corporatif, aucun danger sérieux ne menace son hégémonie.

13. Cette même démarcation entre économie et politique est tracée aussi par les éléments anarchistes du mouvement syndical, pour détourner le mouvement ouvrier de la voie politique, sous prétexte que toute politique est dirigée contre les travailleurs. Cette théorie, purement bourgeoise au fond, est présentée aux ou- 
vriers comme celle de l'autonomie syndicale, et l'on comprend cette dernière comme une opposition des syndicats au Parti Communiste et une déclaration de guerre au mouvement ouvrier communiste.

14. Cette lutte contre « la politique et le parti politique de la classe ouvrière », provoque un rétrécissement du mouvement ouvrier et des organisations ouvrières, de même qu'une campagne contre le communisme, conscience concentrée de la classe ouvrière. L'autonomie sous toutes ses formes, qu'elle soit anarchiste ou anarcho-syndicaliste, est une doctrine anticommuniste et la résistance la plus décidée doit lui être opposée ; le mieux qu'il puisse en résulter, c' est une autonomie par rapport au communisme et un antagonisme entre syndicats et partis communistes ; sinon c'est une lutte acharnée des syndicats contre le parti communiste, le communisme et la révolution sociale.

La théorie de l'autonomie, telle qu'elle est exposée par les anarchosyndicalistes français, italiens et espagnols, est en somme le cri de guerre de l'anarchisme contre le communisme. Les communistes doivent mener à l'intérieur des syndicats une campagne décisive contre cette manœuvre de faire passer en contrebande, sous le pavillon de l'autonomie, la camelote anarchiste et pour diviser le mouvement ouvrier en segments hostiles les uns aux autres, pour ralentir ou entraver le triomphe de la classe ouvrière.

\section{Syndicalisme et communisme}

16. Les anarcho-syndicalistes confondent syndicats et syndicalisme en faisant passer leur parti anarcho-syndicaliste pour la seule organisation réellement révolutionnaire et capable de mener à terme l'action de classe du prolétariat. Le syndicalisme, qui constitue un immense progrès sur le trade-unionisme, présente cependant de nombreux défauts et côtés malfaisants, auxquels il faut résister de la façon la plus ferme.

17. Les communistes ne peuvent ni ne doivent au nom de principes abstraits anarcho-syndicalistes abandonner leur droit à organiser des «noyaux » au sein des syndicats, quelle que puisse être l'orientation de ces derniers. Ce droit, personne ne peut le leur enlever. Il va de soi que les communistes militant au sein des 
syndicats sauront coordonner leur action avec ceux d'entre les syndicats qui y ont pris acte de l'expérience de la guerre et de la révolution.

18. Les communistes doivent se charger de l'initiative de créer dans les syndicats un bloc avec les ouvriers révolutionnaires d'autres tendances. Les plus proches du communisme sont les «syndicalistes communistes », qui reconnaissent la nécessité de la dictature prolétarienne et défendent contre les anarchosyndicalistes le principe de l'Etat ouvrier. Mais la coordination des actions suppose une organisation des communistes. Une action isolée et individuelle des communistes ne saurait se coordonner avec qui que ce soit, parce qu'elle ne présenterait aucune force sérieuse.

19. Tout en réalisant de la façon la plus énergique et la plus conséquente leurs principes, tout en combattant les théories anticommunistes d'autonomie et la séparation de la politique et de l'économie, idée anarchiste extrêmement nuisible au progrès révolutionnaire de la classe ouvrière, les communistes doivent, à l'intérieur des syndicats de toutes tendances, s'efforcer de coordonner leur action dans la lutte pratique contre le réformisme et le verbalisme anarcho-syndicaliste avec tous les éléments révolutionnaires qui sont pour le renversement du capitalisme et pour la dictature du prolétariat.

20. Dans les pays où existent des organisations importantes syndicalistesrévolutionnaires (France) et où sous l'influence de toute une série de causes historiques, la méfiance à l'égard des partis politiques persiste dans certaines couches d'ouvriers révolutionnaires, les communistes élaborent sur place, d'accord avec les syndicalistes, conformément aux particularités du pays et du mouvement ouvrier en cause, les formes et méthodes de lutte commune et de collaboration dans toutes les actions défensives et offensives contre le capital.

\section{La lutte pour l'unité syndicale}

21. Le mot d'ordre de l'Internationale Communiste (contre la scission syndicale) doit être appliqué aussi énergiquement que par le passé, malgré les furieuses persécutions auxquelles les réformistes de tous les pays soumettent les communistes. Les réformistes veulent prolonger la scission à l'aide des exclusions. Chassant 
systématiquement les meilleurs éléments des syndicats, ils espèrent faire perdre le sang-froid aux communistes, les faire sortir des syndicats et leur faire abandonner le plan profondément réfléchi de la conquête des syndicats du dedans en se prononçant pour la scission. Mais les réformistes ne pourront pas arriver à ce résultat.

22. La scission du mouvement syndical, surtout dans les conditions actuelles, représente le plus grand danger pour le mouvement ouvrier dans son entier. La scission dans les syndicats ouvriers rejetterait la classe ouvrière à plusieurs années en arrière, car la bourgeoisie pourrait alors reprendre facilement les conquêtes les plus élémentaires des ouvriers. Coûte que coûte, les communistes doivent empêcher la scission syndicale. Par tous les moyens, par toutes les forces de leur organisation, ils doivent mettre obstacle à la criminelle légèreté avec laquelle les réformistes brisent l'unité syndicale.

23. Dans les pays où deux centrales syndicales nationales existent parallèlement (Espagne, France, Tchécoslovaquie, etc...) les communistes doivent lutter systématiquement pour la fusion des organisations parallèles. Etant donné ce but de la fusion des syndicats actuellement scindés, il n'est pas rationnel d'arracher les communistes isolés et les ouvriers révolutionnaires des syndicats réformistes, en les transférant dans les syndicats révolutionnaires. Pas un syndicat réformiste ne doit rester dépourvu du ferment communiste. Un travail actif des communistes dans les deux syndicats est une condition du rétablissement de l'unité détruite.

24. La sauvegarde de l'unité syndicale, ainsi que le rétablissement de l'unité détruite, ne sont possibles que si les communistes mettent en avant un programme pratique pour chaque pays et pour chaque branche d'industrie ; sur le terrain d'un travail pratique, d'une lutte pratique, on peut grouper les éléments dispersés du mouvement ouvrier et créer, dans le cas d'une scission syndicale, les conditions propres à assurer leur unification organique. Chaque communiste doit avoir en vue que la scission syndicale est non seulement une menace pour les conquêtes immédiates de la classe ouvrière, mais encore une menace pour la révolution sociale. Les tentatives des réformistes de scinder les syndicats doivent être étouffées radicalement ; or, cela ne peut être atteint qu'à l'aide d'un travail énergique d'organisation et un travail politique dans les masses ouvrières. 


\section{La lutte contre l'exclusion des communistes}

25. L'exclusion des communistes a pour but de désorganiser le mouvement révolutionnaire en isolant les dirigeants des masses ouvrières ; aussi, les communistes ne peuvent pas se borner aux formes et méthodes de lutte mises en vigueur par eux jusqu'à l'heure actuelle. Le mouvement syndical mondial est arrivé à son moment le plus critique. La volonté scissionniste des réformistes s’est exacerbée, tandis que notre volonté de sauvegarder l'unité syndicale est attestée par des faits nombreux, et les communistes doivent montrer à l'avenir, également pratiquement, la valeur qu'ils attachent à l'unité du mouvement syndical.

26. Plus la ligne scissionniste de nos ennemis devient évidente et plus il faut montrer de vigueur à mettre en avant le problème de l'unité syndicale. Pas une fabrique, pas une usine, pas une réunion ouvrière ne doivent être oubliées, partout doit se faire entendre la protestation contre la tactique d'Amsterdam. Il faut que le problème de la scission syndicale soit posé devant chaque syndiqué et il faut qu’il soit posé, non seulement à un moment où la scission est imminente, mais alors qu'elle est à peine amorcée. La question de l'exclusion des communistes du mouvement syndical doit être mise à l'ordre du jour de tout le mouvement de chaque pays en cause. Les communistes sont assez forts pour ne pas se laisser étrangler sans mot dire. La classe ouvrière doit savoir qui est pour la scission et qui est pour l'unité.

27. L'exclusion des communistes après leur élection à des fonctions syndicales par des organisations locales ne doit pas seulement susciter des protestations contre la violence exercée à l'égard de la volonté des électeurs ; une telle exclusion doit provoquer une résistance organisée bien déterminée. Les membres exclus ne doivent pas demeurer dispersés. La tâche la plus importante des partis communistes consiste à ne pas permettre aux éléments exclus de se désagréger. Ils doivent s'organiser en syndicats d'exclus en mettant au centre de leur travail politique un programme concret et l'exigence de leur réintégration.

28. La lutte contre les exclusions est en fait une lutte pour l'unité du mouvement syndical. Ici, toutes les mesures sont bonnes, toutes les mesures qui aboutissent au rétablissement de l'unité détruite. Les exclus ne doivent pas demeurer 
isolés et coupés de toute opposition, pas plus que des organisations révolutionnaires indépendantes existant dans le pays en cause, en vue de l'organisation commune de la lutte contre les exclusions et pour la coordination de l'action dans la lutte contre le capital.

29. Les mesures pratiques de lutte peuvent et doivent être complétées et modifiées en conformité avec les conditions et particularités locales. Il est important que les partis communistes prennent nettement une position anti-scissionniste de combat et fassent tout ce qui est en leur pouvoir pour tenir en échec la politique des exclusions qui s'est sensiblement renforcée en relation avec le commencement de la fusion des Internationales 2 et $2 \frac{1}{2} 2$. Il n'existe pas de moyens et méthodes universels et définitifs dans la lutte contre les exclusions. Sous ce rapport, les partis communistes ont la possibilité de lutter par les moyens qui sont à leurs yeux les meilleurs pour arriver à ce but : la conquête des syndicats et le rétablissement de l’unité syndicale détruite.

30. Les communistes doivent développer la lutte la plus énergique contre l'exclusion des syndicats révolutionnaires du sein des Fédérations Internationales par industrie. Les partis communistes ne peuvent et ne doivent pas demeurer spectateurs passifs de l'exclusion des syndicats révolutionnaires, pour la seule raison qu'ils sont révolutionnaires. Les comités internationaux de propagande par industrie, créés par l'Internationale Syndicale Rouge, doivent trouver le soutien le plus ardent de la part des partis communistes, de façon à grouper toutes les forces révolutionnaires existantes dans le but de lutter pour les fédérations internationales uniques par industrie. Toute cette lutte doit se faire sous le drapeau de l'admission de tous les syndicats, sans distinction de tendance, sans distinction de courants politiques, dans une organisation internationale unique d'industrie.

\section{Conclusion}

Poursuivant son chemin vers la conquête des syndicats et la lutte contre la politique scissionniste des réformistes, le $4^{\mathrm{e}}$ Congrès de l'Internationale Communiste déclare solennellement que toutes les fois que les gens d'Amsterdam n'auront pas recours aux exclusions, toutes les fois qu'ils donneront aux communistes la possibilité de lutter idéologiquement pour leurs principes au sein des syndicats, 
les communistes lutteront en membres disciplinés dans les rangs de l'organisation unique, marchant toujours en avant dans toutes les collisions et dans tous les conflits avec la bourgeoisie.

Le $4^{\mathrm{e}}$ Congrès de l'Internationale Communiste déclare que tous les partis communistes doivent faire tous leurs efforts pour empêcher la scission dans les syndicats, qu'ils doivent faire tout ce qui dépend d'eux pour reconstituer l'unité syndicale détruite dans certains pays, et obtenir l'adhésion du mouvement syndical de leurs pays respectifs à l’Internationale Syndicale Rouge. 
Manifestes, thèses et résolutions

des quatre premiers congrès

de l’Internationale communiste 1919-1923

(juin 1934)

Quatrième Congrès, novembre 1922.

- 8 -

Thèses générales

sur la question d’Orient

\section{I. - La croissance du mouvement ouvrier en Orient}

\section{$\underline{\text { Retour à la table des matières }}$}

Se fondant sur l'expérience de l'édification soviétique en Orient et sur la croissance des mouvements nationalistes révolutionnaires aux colonies, le $2^{\mathrm{e}}$ Congrès de l'Internationale Communiste a fixé la position principale de l'ensemble de la question nationale et coloniale à une époque de lutte à longue échéance entre l’impérialisme et la dictature prolétarienne.

Depuis, la lutte contre le joug impérialiste dans les pays coloniaux et semicoloniaux s'est considérablement intensifiée sur le terrain de l'aggravation de la crise politique et économique d'après-guerre de l’impérialisme.

Les faits suivants le prouvent : $1^{\circ}$ la faillite du traité de Sèvres, qui avait pour objet le démembrement de la Turquie, et la restauration de l'autonomie nationale et politique de celle-ci ; $2^{\circ}$ une forte recrudescence du mouvement nationaliste révolutionnaire aux Indes, en Mésopotamie, en Egypte, au Maroc, en Chine et en Corée ; $3^{\circ}$ la crise intérieure sans issue où se trouve engagé l'impérialisme japonais, crise qui a provoqué l'accroissement rapide des éléments de la révolution 
bourgeoise démocratique et le passage du prolétariat japonais à une lutte de classe autonome ; $4^{\circ}$ l'éveil du mouvement ouvrier dans tous les pays orientaux et la formation, dans presque tous ces pays, de partis communistes.

Les faits précités sont l'indice d'une modification survenue à la base sociale du mouvement révolutionnaire des colonies; cette modification provoque une intensification de la lutte anti-impérialiste dont, de cette façon, la direction n’appartient plus exclusivement aux éléments féodaux et à la bourgeoisie nationaliste qui sont prêts à des compromis avec l'impérialisme.

La guerre impérialiste de 1914-18 et la longue crise du capitalisme, surtout du capitalisme européen, qui s’ensuivit, ont débilité la tutelle économique des métropoles sur les colonies.

D’un autre côté, les mêmes circonstances qui ont eu pour résultat un rétrécissement de la base économique et de la sphère d'influence politique du capitalisme mondial ont accentué encore davantage les compétitions capitalistes autour des colonies, d'où une rupture d'équilibre dans l'ensemble du système du capitalisme mondial (lutte pour le pétrole, conflit anglo-français en Asie Mineure, rivalité américano-japonaise pour la domination sur l'océan Pacifique, etc...).

C'est précisément cet affaiblissement de l'ascendant capitaliste sur les colonies, en même temps que la rivalité croissante des divers groupes impérialistes, qui a facilité le développement du capitalisme indigène dans les pays coloniaux et semi-coloniaux ; ce capitalisme a déjà débordé et continue à déborder le cadre étroit et gênant de la domination impérialiste des métropoles. Jusqu'à présent, le capital des métropoles persistant à vouloir monopoliser la plus-value de l'exploitation commerciale, industrielle et fiscale des pays arriérés, tâchait d'isoler ces derniers de la circulation économique du reste du monde. La revendication d'une autonomie nationale et économique arborée par le mouvement nationaliste colonial est l'expression du besoin de développement bourgeois éprouvé par ces pays. Le progrès constant des forces productrices indigènes aux colonies se trouve ainsi en contradiction irréductible avec les intérêts du capitalisme mondial, car l'essence même de l'impérialisme comporte l'utilisation de la différence de niveau qui existe dans le développement des forces productrices des divers secteurs de l'économie mondiale, dans le but de s'assurer la totalité de la plusvalue monopolisée. 


\section{Les conditions de la lutte}

Le caractère retardataire des colonies s'accuse dans la diversité des mouvements nationalistes révolutionnaires dirigés contre l’impérialisme et reflète les divers niveaux de transition entre les corrélations féodales et féodalo-patriarcales et le capitalisme. Cette diversité prête un aspect particulier à l'idéologie de ces mouvements.

Dans ces pays, le capitalisme surgit et se développe sur une base féodale ; il prend des formes incomplètes, transitoires et bâtardes qui laissent la prépondérance, avant tout, au capital commercial et usuraire (Orient musulman, Chine). Aussi la démocratie bourgeoise prend-elle, pour se différencier des éléments féodalobureaucratiques et féodalo-agrariens, une voie détournée et embrouillée. Tel est le principal obstacle au succès de la lutte contre le joug impérialiste, car l'impérialisme étranger ne se fait pas faute de transformer dans tous les pays arriérés la couche supérieure féodale (et en partie semi-féodale, semi-bourgeoise) de la société indigène en instrument de sa domination (gouverneurs militaires, ou toukoiuns en Chine, bureaucratie et aristocratie en Perse, fermiers de l'impôt foncier, zémindars et taloukdars aux Indes, planteurs de formation capitaliste en Egypte, etc...).

Ainsi les classes dirigeantes des pays coloniaux et semi-coloniaux n’ont-elles ni la capacité ni le désir de diriger la lutte contre l’impérialisme, à mesure que cette lutte se transforme en un mouvement révolutionnaire de masses. Là seulement où le régime féodalo-patriarcal ne s'est pas suffisamment décomposé pour séparer complètement les hautes couches indigènes des masses du peuple, comme par exemple chez les nomades et semi-nomades, les représentants de ces hautes couches peuvent jouer le rôle de guides actifs dans la lutte contre l'oppression capitaliste (Mésopotamie, Mongolie, Maroc).

Dans les pays musulmans, le mouvement national trouve tout d'abord son idéologie dans les mots d'ordre politico-religieux du panislamisme, ce qui permet aux fonctionnaires et aux diplomates des métropoles de se servir des préjugés et de l'ignorance des multitudes populaires pour combattre ce mouvement (c'est ainsi que les Anglais jouent au panislamisme et au panarabisme, déclarant vouloir 
transporter le Khalifat aux Indes, etc..., et l’impérialisme français spécule sur les « sympathies musulmanes »). Cependant, à mesure que s’élargit et mûrit le mouvement d'émancipation nationale, les mots d'ordre politico-religieux du panislamisme sont évincés par des revendications politiques concrètes. Ce qui le confirme, c’est la lutte commencée dernièrement en Turquie pour enlever au Khalifat son pouvoir temporel.

La tâche fondamentale, commune à tous les mouvements nationauxrévolutionnaires, consiste à réaliser l'unité nationale et l'autonomie politique. La solution réelle et logique de cette tâche dépend de l'importance des masses travailleuses que tel ou tel mouvement national saura entraîner dans son cours, après avoir rompu toutes relations avec les éléments féodaux et réactionnaires et incarné dans son programme les revendications sociales de ces masses.

Se rendant fort bien compte que dans diverses conditions historiques les éléments les plus variés peuvent être les porte-parole de l'autonomie politique, l'Internationale Communiste soutient tout mouvement national-révolutionnaire dirigé contre l'impérialisme. Toutefois, elle ne perd pas de vue en même temps que, seule, une ligne révolutionnaire conséquente, basée sur la participation des grandes masses à la lutte active et la rupture sans réserve avec tous les partisans de la collaboration avec l'impérialisme peut amener les masses opprimées à la victoire. La liaison qui existe entre la bourgeoisie indigène et les éléments féodalo-réactionnaires permet aux impérialistes de tirer largement parti de l'anarchie féodale, de la rivalité qui règne entre les divers clans et tribus, de l'antagonisme entre la ville et les campagnes, de la lutte entre castes et sectes nationaloreligieuses pour désorganiser le mouvement populaire (Chine, Perse, Kurdistan, Mésopotamie).

\section{La question agraire}

Dans la plupart des pays d’Orient (Inde, Perse, Egypte, Syrie, Mésopotamie), la question agraire présente une importance de premier ordre dans la lutte pour l'affranchissement du joug du despotisme métropolitain. En exploitant et en ruinant la majorité paysanne des pays arriérés, l’impérialisme la prive des moyens élémentaires d’existence, cependant que l’industrie peu développée, disséminée 
sur divers points du pays, est incapable d'absorber l'excédent de population rurale qui, en outre, ne peut même pas émigrer. Les paysans pauvres restés sur leur sol se transforment en serfs. Si, dans les pays civilisés, les crises industrielles d’avant-guerre jouaient le rôle de régulateur de la production sociale, ce rôle régulateur est rempli dans les colonies par les famines. L’impérialisme, ayant un intérêt vital à recevoir le plus de bénéfices avec le moins de dépenses, soutient jusqu’à la dernière extrémité dans les pays arriérés les formes féodales et usuraires d'exploitation de la main-d'œuvre. Dans certains pays, comme par exemple aux Indes, il s’attribue le monopole, appartenant à l'Etat féodal indigène, de la jouissance des terres et transforme l'impôt foncier en une redevance qui doit être versée au capital métropolitain et à ses commis, les «zémindaram » et « taloukdar ». Dans d'autres pays, l'impérialisme se saisit de la rente foncière en se servant pour cela de l’organisation indigène de la grosse propriété foncière (Perse, Maroc, Egypte, etc...). Il s'ensuit que la lutte pour la suppression des barrières et des redevances féodales qui restent sur le sol revêt le caractère d'une lutte d'émancipation nationale contre l'impérialisme et la grande propriété foncière féodale. On peut prendre pour exemple le soulèvement des Moplahs contre les propriétaires fonciers et les Anglais, en automne 1921, aux Indes, et le soulèvement des Sikhs, en 1922. Seule, une révolution agraire ayant pour objet l'expropriation de la grosse propriété féodale est capable de soulever les multitudes paysannes et d'acquérir une influence décisive dans la lutte contre l'impérialisme. Les nationalistes bourgeois ont peur des mots d'ordre agraires et les rognent tant qu'ils peuvent (Indes, Perse, Egypte), ce qui prouve l'étroite liaison qui existe entre la bourgeoisie indigène et la grande propriété foncière féodale et féodalo-bourgeoise ; cela prouve aussi qu'idéologiquement et politiquement les nationalistes dépendent de la propriété foncière. Ces hésitations et ces incertitudes doivent être utilisées par les éléments révolutionnaires pour une critique systématique et divulgatrice de la politique hybride des dirigeants bourgeois du mouvement nationaliste. C'est précisément cette politique hybride qui empêche l'organisation et la cohésion des masses travailleuses, comme le prouve la faillite de la tactique de la résistance passive aux Indes (non-coopération).

Le mouvement révolutionnaire dans les pays arriérés d’Orient ne peut être couronné de succès que s’il est basé sur l'action des multitudes paysannes. C'est pourquoi les partis révolutionnaires de tous les pays d’Orient doivent nettement 
déterminer leur programme agraire et exiger la suppression totale du féodalisme et de ses survivances qui trouvent leur expression dans la grande propriété foncière et dans l'exemption de l'impôt foncier. Aux fins d'une participation active des masses paysannes à la lutte pour l'affranchissement national, il est indispensable de proclamer une modification radicale du système de jouissance du sol. De même, il est indispensable de forcer les partis bourgeois nationalistes à adopter la plus grande partie possible de ce programme agraire révolutionnaire.

\section{Le mouvement ouvrier en Orient}

Le jeune mouvement ouvrier oriental est un produit du développement du capitalisme indigène de ces derniers temps. Jusqu'à présent, la classe ouvrière indigène, si même on prend son noyau fondamental, se trouve traverser une époque transitoire, s'acheminant du petit atelier corporatif à la fabrique du grand type capitaliste. Pour autant que les intellectuels bourgeois nationalistes entraînent dans le mouvement révolutionnaire la classe ouvrière pour lutter contre l'impérialisme, leurs représentants assument tout d'abord un rôle directeur dans l'action et l'organisation professionnelle embryonnaire. Au début, l'action de la classe ouvrière ne dépasse pas le cadre des intérêts « communs à toutes les nations » de démocratie bourgeoise (grèves contre la bureaucratie et l'administration impérialiste en Chine et aux Indes). Bien souvent, comme l'a indiqué le $2^{\mathrm{e}}$ Congrès de l'Internationale Communiste, les représentants du nationalisme bourgeois, exploitant l'autorité politique et morale de la Russie des Soviets et s'adaptant à l'instinct de classe des ouvriers, drapent leurs aspirations démocratico-bourgeoises dans du « socialisme » et du « communisme » pour détourner ainsi, parfois sans s'en rendre compte, les premiers organes embryonnaires du prolétariat de leurs devoirs d'organisation de classe (tel le Parti Behill Ardou en Turquie, qui a repeint le panturquisme en rouge, et le « socialisme d'Etat » préconisé par certains représentants du parti Kuomintang).

Malgré cela, le mouvement professionnel et politique de la classe ouvrière des pays arriérés a grandement progressé dans ces dernières années. La formation de partis autonomes de la classe prolétarienne dans presque tous les pays orientaux est un fait symptomatique, bien que la majorité écrasante de ces partis doive faire 
encore un grand travail intérieur pour se libérer de l'esprit de coterie et de beaucoup d'autres défauts. L’Internationale Communiste a, dès le début, apprécié à sa juste valeur l'importance potentielle du mouvement ouvrier en Orient, et cela prouve bien que les prolétaires du monde entier sont unifiés internationalement sous le drapeau du Communisme. Les Internationales 2 et 2 1/2 n’ont, jusqu’à présent, trouvé de partisans dans aucun des pays arriérés, parce qu'elles se bornent à jouer un « rôle auxiliaire » en face de l’impérialisme européen et américain.

\section{$V$. Les objectifs généraux des partis communistes de l'Orient}

Les nationalistes bourgeois apprécient le mouvement ouvrier selon l'importance qu'il peut avoir pour leur victoire. Le prolétariat international apprécie le mouvement ouvrier oriental au point de vue de son avenir révolutionnaire. Sous le régime capitaliste, les pays arriérés ne peuvent pas prendre part aux conquêtes de la science et de la culture contemporaine sans payer un énorme tribut à l'exploitation et à l'oppression barbares du capital métropolitain. L'alliance avec les prolétariats des pays hautement civilisés leur sera avantageuse, non seulement parce qu'elle correspond aux intérêts de leur lutte commune contre l'impérialisme, mais aussi parce que c'est seulement après avoir triomphé que le prolétariat des pays civilisés pourra fournir aux ouvriers de l'Orient un secours désintéressé pour le développement de leurs forces productrices arriérées. L’alliance avec le prolétariat occidental fraie la voie vers une fédération internationale des républiques soviétiques. Le régime soviétique offre aux peuples retardataires le moyen le plus facile pour passer de leurs conditions d'existence élémentaires à la haute culture du Communisme, qui est destinée à supplanter dans l'économie mondiale le régime capitaliste de production et de répartition. Le meilleur témoignage en est l'expérience de l'édification soviétique dans les colonies affranchies de l'ex-Empire Russe. Seule, une forme d'administration soviétique est à même d'assurer le couronnement logique de la révolution agraire paysanne. Les conditions spécifiques de l'économie agricole dans une certaine partie des pays orientaux (irrigation artificielle), entretenues jadis par une organisation originale de collaboration collective sur une base féodale et patriarcale et 
compromises actuellement par la piraterie capitaliste, exigent également une organisation politique capable de servir systématiquement les besoins sociaux. Par suite de conditions climatiques, sociales et historiques particulières, un rôle important appartient généralement en Orient, dans la période transitoire, à la coopération des petits producteurs.

Les tâches objectives de la révolution coloniale dépassent le cadre de la démocratie bourgeoise. En effet, sa victoire décisive est incompatible avec la domination de l'impérialisme mondial. Au début, la bourgeoisie indigène et les intellectuels indigènes assument le rôle de pionniers des mouvements révolutionnaires coloniaux ; mais dès que les masses prolétariennes et paysannes s'incorporent à ces mouvements, les éléments de la grosse bourgeoisie et de la bourgeoisie foncière s’en écartent, laissant le premier pas aux intérêts sociaux des couches inférieures du peuple. Une longue lutte, qui durera toute une époque historique, attend le jeune prolétariat des colonies, lutte contre l'exploitation impérialiste et contre les classes dominantes indigènes qui aspirent à monopoliser tous les bénéfices du développement industriel et intellectuel et veulent que les masses restent comme par le passé dans une situation « préhistorique ».

Cette lutte pour l'influence sur les masses paysannes doit préparer le prolétariat indigène au rôle d'avant-garde politique. Ce n'est qu'après s'être soumis à ce travail préparatoire et après lui avoir soumis les couches sociales adjacentes que le prolétariat indigène se trouvera en mesure de faire face à la démocratie bourgeoise orientale, qui porte un caractère de formalisme encore plus hypocrite que la bourgeoisie d'Occident.

Le refus des communistes des colonies de prendre part à la lutte contre l’oppression impérialiste sous le prétexte de « défense » exclusive des intérêts de classe, est le fait d'un opportunisme du plus mauvais aloi qui ne peut que discréditer la révolution prolétarienne en Orient. Non moins nocive est la tentative de se mettre à l'écart de la lutte pour les intérêts quotidiens et immédiats de la classe ouvrière au nom d'une « unification nationale » ou d'une « paix sociale » avec les démocrates bourgeois. Deux tâches confondues en une seule incombent aux partis communistes coloniaux et semi-coloniaux : d'une part, ils luttent pour une solution radicale des problèmes de la révolution démocratique-bourgeoise ayant pour objet la conquête de l'indépendance politique ; d'autre part, ils organisent les masses ouvrières et paysannes pour leur permettre de lutter pour les intérêts parti- 
culiers de leur classe et utilisent à cet effet toutes les contradictions du régime nationaliste démocratique-bourgeoise. En formulant des revendications sociales, ils stimulent et libèrent l'énergie révolutionnaire qui ne se trouvait point d'issue dans les revendications libérales bourgeoises. La classe ouvrière des colonies et semi-colonies doit savoir fermement que, seules, l'extension et l'intensification de la lutte contre le joug impérialiste des métropoles peuvent lui donner un rôle directeur dans la révolution, et que, seules, l'organisation économique et politique et l'éducation politique de la classe ouvrière et des éléments semi-prolétariens peuvent augmenter l'amplitude révolutionnaire du combat contre l'impérialisme.

Les partis communistes des pays coloniaux et semi-coloniaux d'Orient, qui sont encore dans un état plus ou moins embryonnaire, doivent participer à tout mouvement apte à leur ouvrir un accès aux masses. Mais ils doivent mener une lutte énergique contre les préjugés patriarco-corporatifs et contre l'influence bourgeoise dans les organisations ouvrières pour défendre ces formes embryonnaires d'organisations professionnelles contre les tendances réformistes et les transformer en organes combatifs des masses. Ils doivent s'employer de toutes leurs forces à organiser les nombreux journaliers et journalières ruraux, de même que les apprentis des deux sexes sur le terrain de la défense de leurs intérêts quotidiens.

\section{Le front anti-impérialiste unique}

Dans les pays occidentaux qui traversent une période transitoire caractérisée par une accumulation organisée des forces, a été lancé le mot d'ordre du front prolétarien unique; dans les colonies orientales, il est indispensable, à l'heure présente, de lancer le mot d'ordre du front anti-impérialiste unique. L'opportunité de ce mot d'ordre est conditionnée par la perspective d'une lutte à longue échéance contre l'impérialisme mondial, lutte exigeant la mobilisation de toutes les forces révolutionnaires. Cette lutte est d'autant plus nécessaire que les classes dirigeantes indigènes sont enclines à des compromis avec le capital étranger et que ces compromis portent atteinte aux intérêts primordiaux des masses populaires. De même que le mot d'ordre du front prolétarien unique a contribué et contribue encore en Occident à démasquer la trahison, par les social-démocrates, des inté- 
rêts du prolétariat, de même le mot d'ordre du front anti-impérialiste unique contribuera à démasquer les hésitations et les incertitudes des divers groupes du nationalisme bourgeois. D’autre part, ce mot d'ordre aidera au développement de la volonté révolutionnaire et à la clarification de la conscience de classe des travailleurs en les incitant à lutter au premier rang, non seulement contre l’impérialisme, mais encore contre toute espèce de survivance du féodalisme.

Le mouvement ouvrier des pays coloniaux et semi-coloniaux doit, avant tout, conquérir une position de facteur révolutionnaire autonome dans le front antiimpérialiste commun. Ce n'est que si on lui reconnaît cette importance autonome et s'il conserve sa pleine indépendance politique que des accords temporaires avec la démocratie bourgeoise sont admissibles et même indispensables. Le prolétariat soutient et arbore des revendications partielles, comme par exemple la république démocratique indépendante, l'octroi aux femmes des droits dont elles sont frustrées, etc..., tant que la corrélation des forces qui existe à présent ne lui permet pas de mettre à l'ordre du jour la réalisation de son programme soviétique. En même temps, il essaye de lancer des mots d'ordre susceptibles de contribuer à la fusion politique des masses paysannes et semi-prolétariennes avec le mouvement ouvrier. Le front anti-impérialiste unique est lié indissolublement à l'orientation vers la Russie des Soviets.

Expliquer aux multitudes travailleuses la nécessité de leur alliance avec le prolétariat international et avec les républiques soviétiques, voilà l'un des principaux points de la tactique anti-impérialiste unique. La révolution coloniale ne peut triompher qu'avec la révolution prolétarienne dans les pays occidentaux.

Le danger d'une entente entre le nationalisme bourgeois et une ou plusieurs puissances impérialistes hostiles, aux dépens des masses du peuple, est beaucoup moins grand dans les pays coloniaux que dans les pays semi-coloniaux (Chine, Perse) ou bien dans les pays qui luttent pour l'autonomie politique en exploitant à cet effet les rivalités impérialistes (Turquie).

Reconnaissant que des compromis partiels et provisoires peuvent être admissibles et indispensables quand il s'agit de prendre un répit dans la lutte d'émancipation révolutionnaire menée contre l’impérialisme, la classe ouvrière doit s'opposer avec intransigeance à toute tentative d'un partage de pouvoir entre l'impérialisme et les classes dirigeantes indigènes, que ce partage soit fait ouver- 
tement ou sous une forme déguisée, car il a pour but de conserver leurs privilèges aux dirigeants. La revendication d'une alliance étroite avec la République prolétarienne des Soviets est la bannière du front anti-impérialiste unique. Après l'avoir élaborée, il faut mener une lutte décisive pour la démocratisation maximum du régime politique, afin de priver de tout soutien les éléments socialement et politiquement les plus réactionnaires et afin d'assurer aux travailleurs la liberté d'organisation leur permettant de lutter pour leurs intérêts de classe (revendications de la république démocratique, réforme agraire, réforme des impositions foncières, organisation d'un appareil administratif basé sur le principe d'un large self-government, législation ouvrière, protection du travail, des enfants, protection de la maternité, de l'enfance, etc...). Même sur le territoire de la Turquie indépendante la classe ouvrière ne jouit pas de la liberté de coalition, ce qui peut servir d'indice caractéristique de l'attitude adoptée par les nationalistes bourgeois à l'égard du prolétariat.

\section{VII. - Les tâches du prolétariat des pays du Pacifique}

La nécessité de l'organisation d'un front anti-impérialiste est dictée en outre par la croissance permanente et ininterrompue des rivalités impérialistes. Ces rivalités revêtent actuellement une telle acuité qu'une nouvelle guerre mondiale, dont l'Océan Pacifique sera l'arène, est inévitable, si la révolution internationale ne la prévient.

La conférence de Washington était une tentative faite pour parer à ce danger, mais en réalité elle n’a fait qu'approfondir et qu'exaspérer les contradictions de l'impérialisme. La lutte qui a eu lieu dernièrement entre Hu-Peï-Fu et Djan-SoLin en Chine, est la conséquence directe de l'échec du capitalisme japonais et du capitalisme anglo-américain dans leur tentative d'accorder leurs intérêts à Washington. La nouvelle guerre qui menace le monde entraînera non seulement le Japon, l'Amérique et l'Angleterre, mais aussi les autres puissances capitalistes, telles que la France et la Hollande, et tout laisse prévoir qu'elle sera encore plus dévastatrice que la guerre de 1914-18.

La tâche des partis communistes coloniaux et semi-coloniaux des pays riverains de l'Océan Pacifique consiste à mener une propagande énergique ayant pour 
but d'expliquer aux masses le danger qui les attend et de les appeler à une lutte active pour l'affranchissement national et à insister pour qu'elles s'orientent vers la Russie des Soviets, soutien de tous les opprimés et de tous les exploités.

Les partis communistes des pays impérialistes tels que l'Amérique, le Japon, l'Angleterre, l'Australie et le Canada ont le devoir, vu le danger imminent, de ne pas se borner à une propagande contre la guerre, mais de s'efforcer par tous les moyens d'écarter les facteurs capables de désorganiser le mouvement ouvrier de ces pays et de faciliter l'utilisation par les capitalistes des antagonismes de nationalités et de races.

Ces facteurs sont : la question de l'émigration et celle du bon marché de la main-d'œuvre de couleur.

Le système des contrats reste jusqu'à présent le principal moyen de recrutement des ouvriers de couleur pour les plantations sucrières des pays du sud du Pacifique où les ouvriers sont importés de Chine et des Indes. Ce fait a déterminé les ouvriers des pays impérialistes à exiger la mise en vigueur de lois prohibant l'immigration et l'emploi de la main-d'œuvre de couleur, aussi bien en Amérique qu'en Australie. Ces lois prohibitives accusent l'antagonisme qui existe entre les ouvriers blancs et les ouvriers de couleur, divisent et affaiblissent l'unité du mouvement ouvrier.

Les partis communistes des Etats-Unis, du Canada et d'Australie doivent entreprendre une campagne énergique contre les lois prohibitives et montrer aux masses prolétariennes de ces pays que des lois de ce genre, excitant les inimitiés de races, se retournent en fin de compte contre les travailleurs des pays prohibitionnistes.

D’un autre côté, les capitalistes suspendent les lois prohibitives pour faciliter l'immigration de la main-d'œuvre de couleur, qui travaille à meilleur marché, et pour diminuer ainsi le salaire des ouvriers blancs. Cette intention manifestée par les capitalistes de passer à l'offensive peut être déjouée efficacement si les ouvriers immigrés entrent dans les syndicats où sont organisés les ouvriers blancs. Simultanément, doit être revendiquée une augmentation des salaires de la maind'œuvre de couleur, de façon à les rendre égaux à ceux des ouvriers blancs. Une telle mesure prise par les partis communistes démasquera les intentions capitalis- 
tes et en même temps montrera avec évidence aux ouvriers de couleur que le prolétariat international est étranger aux préjugés de race.

Pour réaliser les mesures ci-dessus indiquées, les représentants du prolétariat révolutionnaire des pays du Pacifique doivent convoquer une conférence des pays du Pacifique qui élaborera la tactique à suivre et trouvera les formes d'organisation pour l'unification effective du prolétariat de toutes les races des pays du Pacifique.

\section{Les tâches coloniales des pays métropolitains}

L’importance primordiale du mouvement révolutionnaire aux colonies pour la révolution prolétarienne internationale exige une intensification de l'action aux colonies des partis communistes des puissances impérialistes.

L’impérialisme français compte, pour la répression des forces de la révolution prolétarienne en France et en Europe, sur les indigènes des colonies qui, dans sa pensée, serviront de réserves à la contre-révolution.

Les impérialismes anglais et américain continuent, comme par le passé, à diviser le mouvement ouvrier en attirant à leurs côtés l'aristocratie ouvrière par la promesse de lui octroyer une partie de la plus-value provenant de l'exploitation coloniale.

Chacun des partis communistes des pays possédant un domaine colonial doit se charger d'organiser systématiquement une aide matérielle et morale au mouvement révolutionnaire ouvrier des colonies. Il faut, à tout prix, combattre opiniâtrement et sans merci les tendances colonisatrices de certaines catégories d’ouvriers européens bien payés, travaillant dans les colonies. Les ouvriers communistes européens des colonies doivent s'efforcer de rallier les prolétaires indigènes en gagnant leur confiance par des revendications économiques concrètes (hausse des salaires indigènes jusqu'au niveau des salaires des ouvriers européens, protection du travail, etc...). La création, aux colonies (Egypte et Algérie), d’organisations communistes européennes isolées n’est qu'une forme déguisée de la tendance colonisatrice et un soutien des intérêts impérialistes. Construire des organisations communistes d'après le principe national, c'est se mettre en contra- 
diction avec les principes de l'internationalisme prolétarien. Tous les partis de l'Internationale Communiste doivent constamment expliquer aux multitudes travailleuses l'importance extrême de la lutte contre la domination impérialiste dans les pays arriérés. Les partis communistes agissant dans les pays métropolitains doivent former auprès de leurs comités directeurs des commissions coloniales permanentes qui travailleront aux fins indiquées ci-dessus. L'Internationale Communiste doit aider les partis communistes de l'Orient, au premier chef, en leur donnant son aide pour l'organisation de la presse, l'édition périodique de journaux rédigés dans les idiomes locaux. Une attention particulière doit être accordée à l'action parmi les organisations ouvrières européennes et parmi les troupes d'occupation coloniales. Les partis communistes des métropoles doivent profiter de toutes les occasions qui se présentent à eux pour divulguer le banditisme de la politique coloniale de leurs gouvernements impérialistes ainsi que de leurs partis bourgeois et réformistes. 


\section{Manifestes, thèses et résolutions \\ des quatre premiers congrès \\ de l’Internationale communiste 1919-1923 \\ (juin 1934) \\ Quatrième Congrès, novembre 1922. \\ - 9 - \\ Programme d'action agraire}

\section{Indications pour l'application des thèses du $2^{e}$ Congrès sur la question agraire}

\section{$\underline{\text { Retour à la table des matières }}$}

Les bases de nos rapports vis-à-vis des masses laborieuses de la campagne ont déjà été fixées dans les thèses agraires du $2^{\mathrm{e}}$ Congrès. Dans la phase actuelle de l'offensive du Capital, la question agraire acquiert une importance primordiale. Le $4^{\mathrm{e}}$ Congrès demande à tous les partis de s'efforcer de gagner les masses laborieuses de la campagne et établit pour ce travail les règles suivantes :

1. La grande masse du prolétariat agricole et des paysans pauvres qui ne possèdent pas assez de terre et sont obligés de travailler une partie de leur temps comme salariés, ou qui sont exploités d'une manière ou d'une autre par les propriétaires fonciers et les capitalistes, ne peut être libérée définitivement de son état actuel de servitude et de guerres inévitables dans le régime capitaliste que par une révolution mondiale, une révolution qui confisquera sans indemnité et mettra à la disposition des ouvriers la terre, avec tous les moyens de production, et qui instaurera à la place de l'Etat des propriétaires fonciers et des capitalistes l'Etat Soviétique des ouvriers et des paysans et préparera ainsi la voie au communisme.

2. Dans la lutte contre l'Etat des capitalistes et des propriétaires fonciers, les petits paysans et les petits fermiers sont les camarades de combat naturels du pro- 
létariat industriel et agricole. Pour relier leur mouvement révolutionnaire à la lutte du prolétariat de la ville et de la campagne, la chute de l'Etat bourgeois est nécessaire, ainsi que la prise du pouvoir politique par le prolétariat industriel, l'expropriation des moyens de production ainsi que de la terre, et la suppression de la domination des agrariens et de la bourgeoisie à la campagne.

3. Afin de gagner à une neutralité bienveillante les paysans moyens et les ouvriers agricoles ainsi que les paysans pauvres à la révolution, les paysans moyens doivent être arrachés à l'influence des paysans riches liés aux grands propriétaires fonciers. Ils doivent comprendre qu'ils doivent lutter avec le parti révolutionnaire du prolétariat, le parti communiste, étant donné que leurs intérêts s’accordent, non avec ceux des gros paysans riches, mais avec ceux du prolétariat. Pour arracher ces paysans à la direction des grands propriétaires fonciers et des paysans riches, il ne suffit pas d'établir un programme ou de faire de la propagande : le Parti Communiste doit prouver par une action continue qu'il est véritablement le parti de tous les opprimés.

4. C'est pourquoi le Parti Communiste doit se mettre à la tête de toutes les luttes que les masses laborieuses de la campagne mènent contre les classes dominantes. Défendant les intérêts quotidiens de ces masses, le Parti Communiste réunit les forces dispersées des travailleurs à la campagne, élève leur volonté combative, soutient leur lutte en la faisant appuyer par le prolétariat industriel, et les mène dans la voie conduisant aux buts de la révolution. Cette lutte menée en commun avec les ouvriers industriels, le fait que les ouvriers industriels luttent sous la direction du Parti Communiste pour les intérêts du prolétariat agricole et des paysans pauvres, convaincront ceux-ci que, premièrement, seul le Parti Communiste les défend réellement, tandis que tous les autres partis, tant agraires que social-démocrates, malgré leurs phrases démagogiques, ne veulent que les tromper, et servent en réalité les intérêts des capitalistes et des propriétaires fonciers, et, deuxièmement, que sous le capitalisme une amélioration véritable de la situation des ouvriers et des paysans pauvres est impossible.

5. Nos revendications concrètes doivent se conformer à l'état de dépendance et d'oppression dans lequel se trouvent les ouvriers, les petits et moyens paysans à l'égard des capitalistes et des grands propriétaires fonciers, comme aussi à leurs intérêts réels. 
Dans les pays coloniaux ayant une population paysanne opprimée, la lutte de libération nationale sera ou bien conduite par toute la population, comme c'est le cas par exemple en Turquie - et dans ce cas la lutte des paysans opprimés contre les grands propriétaires fonciers commence inévitablement après la victoire de la lutte de libération nationale - ou bien les Seigneurs féodaux s'allient avec les impérialistes étrangers, comme c'est le cas par exemple dans l'Inde, et alors la lutte sociale des paysans opprimés concorde avec la lutte de libération nationale.

Dans les territoires où il reste encore de fortes survivances du féodalisme, où la révolution bourgeoise n'a pas été terminée et où des privilèges féodaux sont encore liés à la propriété foncière, ces privilèges doivent disparaître au cours de la lutte pour la possession de la terre, qui est ici d’une importance décisive.

6. Dans tous les pays, où il existe un prolétariat agricole, cette couche sociale constitue le facteur le plus important du mouvement révolutionnaire à la campagne. Le Parti Communiste soutient, organise, approfondit le prolétariat pour l'amélioration de sa situation politique, économique et sociale - contrairement aux social-démocrates qui poignardent dans le dos. Pour hâter la maturité révolutionnaire du prolétariat rural et l'éduquer pour la lutte en vue de la dictature du prolétariat qui, seule, peut le libérer définitivement de l'exploitation dont il souffre, le Parti Communiste soutient le prolétariat agricole dans sa lutte pour :

L'élévation du salaire réel, l'amélioration des conditions de travail, de logement et de culture.

La liberté de réunion, d'association, de grève, de la presse, etc... pour obtenir au moins les mêmes droits que les ouvriers industriels.

Journée de huit heures, assurance contre les accidents, assurance contre la vieillesse, interdiction du travail des enfants, construction d'écoles techniques, etc., et, au moins, extension de la législation sociale dont jouit actuellement le prolétariat.

7. Le Parti Communiste luttera jusqu'au jour où les paysans seront définitivement libérés par la révolution sociale contre toutes les sortes d'exploitation des petits et moyens paysans par le capitalisme, contre l'exploitation par les usuriers, qui jettent les paysans pauvres dans la servitude de l'endettement, enfin contre 
l’exploitation par le capital commercial qui achète à bon marché les légers excédents de production des petits paysans et les revend à des prix élevés au prolétariat des villes.

Le Parti Communiste lutte contre ce capital commercial parasitaire et pour la liaison immédiate des coopératives de consommation du prolétariat industriel contre l'exploitation par le capital industriel, qui utilise son monopole pour élever artificiellement les prix des produits industriels; pour la fourniture aux petits paysans de moyens de production (engrais artificiels, machines, etc...) à bon marché. Les conseils d'entreprises industrielles devront contribuer à cette lutte en établissant le contrôle des prix.

Contre l'exploitation du monopole privé des compagnies de chemins de fer, comme cela existe surtout dans les pays anglo-saxons.

Contre l'exploitation de l'Etat capitaliste, dont le système fiscal surcharge les petits paysans en faveur des grands propriétaires fonciers; le Parti réclame l'exonération d'impôt pour les petits paysans.

8. Mais l'exploitation la plus grave dont souffrent les paysans pauvres dans les pays non coloniaux provient de la propriété privée du sol des grands propriétaires fonciers. Pour pouvoir utiliser pleinement leurs forces de travail et surtout pour pouvoir vivre, les paysans pauvres sont obligés de travailler chez les grands propriétaires fonciers à des salaires de famine ou d'affermer ou d'acheter de la terre à des prix très élevés, par quoi une partie du salaire des petits paysans est accaparée par les grands propriétaires fonciers. L'absence de terres oblige les paysans pauvres à se soumettre à l'esclavage moyenâgeux sous des formes modernes. C'est pourquoi le Parti Communiste lutte pour la confiscation de la terre avec tout l'inventaire au profit de ceux qui la cultivent réellement. Jusqu'à ce que cela soit réalisé par la révolution prolétarienne, le Parti Communiste soutient la lutte des paysans pauvres pour :

a) L'amélioration des conditions d'existence des métayers, par la réduction de la part qui revient aux propriétaires ; 
b) La réduction des fermages pour les petits fermiers, la remise obligatoire d'une indemnité pour toutes les améliorations apportées à la terre par le fermier au cours du contrat de fermage, etc... Les syndicats des travailleurs agricoles, dirigés par les communistes, soutiendront les petits fermiers dans cette lutte et n'accepteront de faire aucun travail dans les champs qui auront été enlevés aux petits fermiers par les propriétaires fonciers à cause de litiges se rapportant au fermage ;

c) La cession des terres, de bétail et de machines à tous les paysans pauvres, à des conditions permettant d'assurer leur gagne-pain ; et non pas des parcelles de terres qui lient leurs propriétaires à la glèbe et les obligent à chercher du travail pour des salaires de famine chez les propriétaires ou paysans voisins, mais des quantité de terres suffisantes pour pouvoir employer toute l'activité des paysans. Dans cette question, il faudra avant tout tenir compte des intérêts des ouvriers agricoles.

9. Les classes dominantes essayent d'étouffer le caractère révolutionnaire du mouvement des paysans au moyen de réformes agraires bourgeoises, de répartitions de terres entre les éléments dirigeants de la classe paysanne. Elles ont réussi à provoquer un fléchissement temporaire du mouvement révolutionnaire à la campagne. Mais toute réforme agraire bourgeoise se heurte aux limites du capitalisme. La terre n’est donnée que contre indemnité et à des personnes qui sont déjà en possession de moyens de production. Une réforme agraire bourgeoise n'a absolument rien à offrir aux éléments prolétariens ou semi-prolétariens. Les conditions extrêmement sévères qui sont imposées aux paysans recevant de la terre lors d'une réforme agraire bourgeoise et qui, par suite, n'ont pas pour résultat d'améliorer véritablement leur situation, mais au contraire de les plonger dans l'esclavage de l'endettement, mènent inévitablement à une recrudescence du mouvement révolutionnaire et à une aggravation de l'antagonisme existant entre les petits et gros paysans, de même qu'entre les ouvriers agricoles qui ne reçoivent pas de terre et perdent des occasions de travail par suite de la division des grandes propriétés.

Seule, une révolution prolétarienne pourra apporter la libération définitive des classes laborieuses de la campagne, révolution qui confisquera sans indemnité 
aucune la terre des grands propriétaires fonciers ainsi que tout l'inventaire, mais laissera intactes les terres cultivées par les paysans, délivrera ceux-ci de toutes charges, fermages, hypothèques, restrictions féodales qui pèsent sur eux, et soutiendra de toutes les façons les couches inférieures de la classe paysanne.

Les paysans qui cultivent la terre décideront eux-mêmes de la façon dont la terre enlevée aux grands propriétaires fonciers devra être exploitée. A ce sujet les thèses du $2^{\mathrm{e}}$ Congrès déclarent ce qui suit :

Pour les pays capitalistes les plus développés, l'Internationale Communiste croit qu'il est bon de maintenir le plus possible les grandes exploitations agraires et de les former sur le modèle des domaines soviétiques en Russie.

Il faudra également soutenir la création de l'exploitation collective (coopératives agraires, communautés agricoles). Le maintien des grandes exploitations agricoles sauvegarde les intérêts des couches révolutionnaires de la population paysanne, des ouvriers agricoles et des petits propriétaires semi-prolétariens qui sont obligés de gagner leur vie en travaillant une partie de leur temps dans les grandes exploitations agricoles. D’autre part, la nationalisation des grandes exploitations agricoles rend la population des villes, au moins en partie dans la question du ravitaillement, indépendante des paysans.

Là où existent encore des survivances du féodalisme, des servitudes, ou le système du métayage, il peut être nécessaire, dans certaines circonstances, de remettre aux paysans une partie de la terre des grandes propriétés.

Dans les pays où les grandes exploitations agricoles ne jouent qu'un rôle relativement petit, et où par contre il existe une grande quantité de petits propriétaires paysans qui veulent conserver la terre, la répartition de la terre des grandes propriétés est le meilleur moyen de gagner les paysans à la révolution, tandis que le maintien des grandes exploitations n'est pas d'une importance primordiale pour le ravitaillement des villes.

Là où se produit une répartition des grandes propriétés entre les paysans, il faudra tenir compte en premier lieu des intérêts du prolétariat agricole. 
Tous les communistes qui travaillent dans l'agriculture ou dans les entreprises industrielles liées à l'agriculture, sont tenus d'entrer dans les organisations des ouvriers agricoles, d'y grouper et de conduire les éléments révolutionnaires, en vue de transformer ces organisations en organes révolutionnaires. Là où il n'existe aucun syndicat, c'est le devoir des communistes de travailler à leur création. Dans les organisations jaunes, fascistes et contre-révolutionnaires, ils doivent mener un travail d'éducation intense en vue de détruire ces organisations contrerévolutionnaires. Dans les grandes entreprises agricoles, ils doivent créer des conseils d'entreprise, en vue de la défense des intérêts ouvriers, du contrôle de la production, et pour empêcher l'introduction du système d'exploitation extensive. Ils doivent appeler le prolétariat industriel au secours du prolétariat agricole en lutte et incorporer celui-ci dans le mouvement des conseils d'entreprises industrielles.

Étant donné l'importance formidable des paysans pauvres pour le mouvement révolutionnaire, c'est le devoir des communistes d'entrer dans les organisations des petits paysans (coopératives de production, de consommation et de crédit) pour les transformer, pour faire disparaître les antagonismes apparents d'intérêt entre les ouvriers agricoles et les paysans pauvres, antagonismes grossis artificiellement par les propriétaires fonciers et les paysans riches, et relier étroitement l'action de ces organisations avec le mouvement du prolétariat rural et industriel.

Seule, la collaboration de toutes les forces révolutionnaires de la ville et de la campagne permettra d'opposer une résistance victorieuse à l'offensive du capitalisme et, passant de la défensive à l'offensive, d'obtenir la victoire finale. 


\author{
Manifestes, thèses et résolutions \\ des quatre premiers congrès \\ de l’Internationale communiste 1919-1923 \\ (juin 1934) \\ Quatrième Congrès, novembre 1922. \\ - 10 - \\ Résolution sur la coopération
}

$\underline{\text { Retour à la table des matières }}$

Durant les dernières années qui précédèrent la guerre mondiale et encore plus durant cette guerre, la Coopération a pris dans presque tous les pays un essor puissant et a entraîné dans ses rangs de larges masses d'ouvriers et de paysans. L'offensive presque universelle engagée par le capital oblige les ouvriers, et surtout les ouvrières, à apprécier encore davantage l'aide que peut leur apporter la coopération de consommation.

Les vieux chefs social-réformistes ont depuis longtemps fort bien compris l'importance de la coopération pour les buts qu'ils poursuivent. Ils se sont installés dans les organisations coopératives et, de là, ils empoisonnent fortement la conscience des masses ouvrières, troublant la conscience et l'activité même des ouvriers ayant l'esprit révolutionnaire. D’autre part, les partis social-démocrates, ayant entre leurs mains la direction du mouvement coopératif, puisent dans certains pays, dans les caisses des coopératives, les ressources matérielles nécessaires au soutien de leur parti. Sous le masque de la neutralité politique, ils soutiennent la bourgeoisie et sa politique impérialiste. 
Maîtres de la direction du mouvement coopératif, les vieux chefs de la coopération ne peuvent ou ne veulent ni comprendre les conditions sociales nouvelles, les buts nouveaux de la coopération, ni élaborer de nouvelles méthodes de travail. Ne voulant pas renoncer à leurs principes coopératifs, consacrés par l'âge, ils détruisent même le travail purement économique et en même temps toute coopération.

Enfin, ils ne font rien pour préparer le prolétariat à la réalisation des tâches immenses qui lui incomberont au moment où il prendra le pouvoir.

Toutes ces, circonstances obligent les communistes à s'appliquer sérieusement à arracher la coopération des mains des social-patriotes, pour la transformer d'un instrument au service des valets de la bourgeoisie en un instrument du prolétariat révolutionnaire.

Le $3^{\mathrm{e}}$ Congrès de l'I.C. avait adopté des thèses concernant l'action des communistes dans la coopération. L'expérience d'une année et demie a justifié ces thèses. Le $4^{\mathrm{e}}$ Congrès les confirme encore une fois et invite avec insistance tous les partis communistes, tous les groupes et organisations, à aborder leur action dans la coopération. De même, il demande aux organes de la presse d'accorder dans leurs colonnes une place suffisante aux questions coopératives.

Pour compléter ces thèses, le $4^{\mathrm{e}}$ Congrès souligne :

1. La nécessité urgente de faire mettre en pratique par tous les partis communistes la résolution engageant tous les membres du Parti à être membres des coopératives et à y défendre la ligne de conduite communiste. Dans chaque organisation coopérative, les coopérateurs communistes doivent former un noyau, soit légal, soit clandestin. Tous les noyaux doivent être groupés en fédérations départementales et nationales avec à leur tête la Section Coopérative du Comité Exécutif de l'Internationale Communiste.

Ces noyaux ont pour but d'établir la liaison avec la masse des ouvriers coopérateurs, de critiquer dans leur milieu non seulement les principes, mais surtout l'action de la vieille coopération et d'organiser toutes les masses mécontentes en vue de créer dans la coopération un front unique de lutte contre le capital et l'Etat capitaliste. Toutes les questions nationales des communistes coopérateurs doivent être soumises à l'I.C. par la section coopérative de cette dernière. Mais les coopérateurs communistes ne doivent pas chercher à isoler les coopérateurs révolution- 
naires ou appartenant à l'opposition, car cette façon de procéder entraînerait non seulement l'effritement de leurs forces, mais aussi l'affaiblissement du contact des coopérateurs révolutionnaires avec les larges masses ouvrières. Les mêmes causes obligent à s’abstenir de faire sortir les sociétés coopératives nationales de l'Alliance Internationale Coopérative. Par contre, les communistes doivent réclamer l'adhésion et l'acceptation par cette Alliance de toutes les coopératives nationales où les communistes ont la majorité, et qui n’y sont pas encore affiliées.

2. Les coopérateurs communistes, de même que les comités centraux des partis communistes, doivent mener une lutte énergique contre cette illusion que la coopération pourrait par ses forces seules aboutir au régime socialiste au moyen d'une incorporation lente dans le capitalisme, sans la prise du pouvoir par le prolétariat. Une seconde illusion serait d'affirmer qu'elle est capable, en usant de ses vieilles méthodes, d’obtenir une amélioration importante dans la situation de la classe ouvrière. Il faut combattre non moins énergiquement le principe de la soidisant neutralité politique, qui cache un soutien ouvert ou masqué de la politique de la bourgeoisie et de ses valets. Cette campagne ne doit pas seulement revêtir la forme de la propagande théorique ; on doit la mener aussi en faisant participer la coopération à la lutte politique et économique menée actuellement par les partis politiques et les syndicats rouges en vue de la défense des intérêts des travailleurs. A cela se rapporte, par exemple, la lutte contre l'augmentation des impôts, surtout contre les impôts indirects à la charge du consommateur, la lutte contre les impôts excessifs on spéciaux sur les coopératives et sur le chiffre d’affaires, la lutte contre la cherté de la vie, la réclamation de cession aux coopératives ouvrières de consommation de la répartition des produits de première nécessité, la lutte contre le militarisme qui provoque l'augmentation des dépenses de l'Etat et, par conséquent, l'augmentation des impôts, la lutte contre la folle politique financière des Etats capitalistes aboutissant à la baisse du change, la lutte contre le traité de Versailles, la lutte contre le fascisme, qui, partout, met en ruines les organisations coopératives, la lutte contre les menaces de guerre, la lutte contre l'intervention armée en Russie, la lutte pour les traités de commerce avec la Russie, etc...

Les coopérateurs communistes doivent tendre à faire participer leur organisation à ces campagnes, à côté des partis communistes et des syndicats rouges, et à réaliser de cette façon le front unique du prolétariat. 
Les communistes coopérateurs doivent réclamer de leurs organisations qu'elles prêtent leur aide aux victimes de la terreur capitaliste, aux lock-outés, etc... Les communistes coopérateurs doivent demander énergiquement dans leurs sociétés l'organisation du travail de propagande et s'employer à ce travail.

3. Parallèlement à cette participation énergique à la lutte politique et économique du prolétariat révolutionnaire, les coopérateurs communistes doivent mener dans leurs organisations une action purement coopérative, afin d'attribuer à cette action le caractère imposé par les nouvelles conditions et les nouvelles tâches du prolétariat : l'union des petites sociétés de consommation ; le renoncement aux vieux principes de la répartition des ristournes, des bénéfices et l'emploi de ces derniers au renforcement de la puissance de la coopération ; la création au moyen de ces bénéfices d'un fonds spécial de secours aux grévistes ; la défense des intérêts des employés des coopératives ; la lutte contre tel crédit des banques qui peut être dangereux pour la coopérative. Lorsqu'il y a une augmentation des actions, les communistes doivent demander que les ouvriers qui n'ont pas le moyen de payer les actions ne soient pas exclus des sociétés et exiger des conditions plus faciles pour eux, etc... Les noyaux de coopérateurs communistes doivent de même lier étroitement leur action à celle des organisations d'ouvrières et des Jeunesses Communistes en vue de mener, grâce aux forces unies des ouvrières et des jeunes, une propagande coopérative conforme aux principes communistes. Il est nécessaire de commencer dans les coopératives une lutte énergique contre la bureaucratie qui, se déguisant sous des devises démocratiques, a changé le principe démocratique en une phrase vide, manœuvre à son gré sans être soumise à aucun contrôle, évite de convoquer des assemblées générales, ne compte pas avec les masses ouvrières organisées dans ces coopératives. Il est indispensable enfin que les noyaux de coopérateurs communistes fassent passer leurs membres sans excepter les femmes dans les comités de direction et les organes de contrôle et qu'ils prennent des mesures pour armer les communistes des connaissances et des aptitudes indispensables à la direction des coopératives. 


\author{
Manifestes, thèses et résolutions \\ des quatre premiers congrès \\ de l’Internationale communiste 1919-1923 \\ (juin 1934) \\ Quatrième Congrès, novembre 1922. \\ - 11 - \\ Thèses sur la question nègre
}

$\underline{\text { Retour à la table des matières }}$

1. Pendant et après la guerre, il s'est développé parmi les peuples coloniaux et semi-coloniaux, un mouvement de révolte contre le pouvoir du capital mondial, mouvement qui fait de grands progrès. La pénétration et la colonisation intense des régions habitées par des races noires pose le dernier grand problème dont dépend le développement futur du capitalisme. Le capitalisme français admet clairement que son impérialisme, après la guerre, ne pourra se maintenir que par la création d'un empire franco-africain, relié par une voie terrienne transsaharienne. Les maniaques financiers de l'Amérique, qui exploitent chez eux 12 millions de nègres, s'appliquent maintenant à pénétrer pacifiquement en Afrique. Les mesures extrêmes prises pour écraser la grève du Rrand montrent assez combien l'Angleterre redoute la menace surgie pour sa position en Afrique. De même que sur le Pacifique le danger d'une autre guerre mondiale est devenu menaçant par suite de la concurrence des puissances impérialistes, de même l'Afrique apparaît comme l'objet de leurs rivalités. Bien plus, la guerre, la révolution russe, les grands mouvements qui ont soulevé les nationalistes d'Asie et les musulmans contre l’impérialisme, ont éveillé la conscience de millions de nègres opprimés 
par les capitalistes, réduits à une situation inférieure depuis des siècles, non seulement en Afrique, mais peut-être même encore davantage en Amérique.

2. L'histoire a dévolu aux nègres d'Amérique un rôle important dans l'affranchissement de toute la race africaine. Il y a 300 ans que les nègres américains ont été arrachés de leur pays natal, l’Afrique, transportés en Amérique où ils ont été l'objet des pires traitements et vendus comme esclaves. Depuis 250 ans, ils ont travaillé sous le fouet des propriétaires américains : ce sont eux qui ont coupé les forêts, construit les routes, planté les cotonniers, posé les traverses de chemins de fer et soutenu l'aristocratie du Sud. Leur récompense a été la misère, l'ignorance, la dégradation. Le nègre n’était pas un esclave docile, il a eu recours à la rébellion, à l’insurrection, aux menées souterraines pour recouvrer sa liberté ; mais ses soulèvements ont été réprimés dans le sang ; par la torture, on l'a forcé à se soumettre ; la presse bourgeoise et la religion se sont associées pour justifier son esclavage. Quand l'esclavage concurrença le salariat et devint un obstacle au développement de l’Amérique capitaliste, il dut disparaître. La guerre de sécession entreprise, non pas pour affranchir les nègres, mais pour maintenir la suprématie industrielle des capitalistes du Nord, mit le nègre dans l'obligation de choisir entre l'esclavage dans le Sud et le salariat dans le Nord. Les muscles, le sang, les larmes du nègre " affranchi » ont aidé à l’établissement du capitalisme américain, et quand, devenue une puissance mondiale, l’Amérique a été entraînée dans la guerre mondiale, le nègre américain a été déclaré l'égal du blanc, pour tuer et se faire tuer pour la démocratie. Quatre cent mille ouvriers de couleur ont été enrôlés dans les troupes américaines, où ils ont formé les régiments de « Jim crow ». A peine sortis de la fournaise de la guerre, les soldats nègres, revenus au foyer, ont été persécutés, lynchés, assassinés, privés de toute liberté et cloués au pilori. Ils ont combattu, mais pour affirmer leur personnalité ils ont dû payer cher. On les a encore plus persécuté qu’avant la guerre pour leur apprendre à « rester à leur place ». La large participation des nègres à l'industrie après la guerre, l'esprit de rébellion qu’ont éveillé en eux les brutalités dont ils sont les victimes, met les nègres d'Amérique, et surtout ceux de l'Amérique du Nord, à l'avant-garde de la lutte de l'Afrique contre l'oppression.

3. C'est avec une grande joie que l'Internationale Communiste voit les ouvriers nègres exploités résister aux attaques des exploiteurs, car l'ennemi de la race nègre est aussi celui des travailleurs blancs. Cet ennemi, c'est le capitalisme, 
l'impérialisme. La lutte internationale de la race nègre est une lutte contre le capitalisme et l'impérialisme. C'est sur la base de cette lutte que le mouvement nègre doit être organisé : en Amérique, comme centre de culture nègre et centre de cristallisation de la protestation des nègres; en Afrique, comme réservoir de maind'œuvre pour le développement du capitalisme ; en Amérique Centrale (CostaRica, Guatemala, Colombie, Nicaragua et les autres républiques «indépendantes » où l'impérialisme américain est prédominant); à Porto-Rico, à Haïti, à Saint-Domingue et dans les autres îles de la mer du Caraïbes, où les mauvais traitements infligés aux nègres par les envahisseurs américains ont soulevé les protestations des nègres protestations des nègres conscients et des ouvriers blancs révolutionnaires. En Afrique du Sud et au Congo, l'industrialisation croissante de la population nègre a provoqué des soulèvements de formes variées; en Afrique Orientale, la pénétration récente du capital mondial pousse la population indigène à résister activement à l’impérialisme.

4. L'Internationale Communiste doit indiquer au peuple nègre qu'il n'est pas seul à souffrir de l'oppression du capitalisme et de l'impérialisme, elle doit lui montrer que les ouvriers et les paysans d'Europe, d'Asie et d'Amérique, sont aussi les victimes de l'impérialisme; que la lutte contre l'impérialisme n'est pas la lutte d'un seul peuple, mais de tous les peuples du monde ; qu'en Chine, en Perse, en Turquie, en Egypte et au Maroc, les peuples coloniaux combattent avec héroïsme contre leurs exploiteurs impérialistes, que ces peuples se soulèvent contre les mêmes maux que ceux qui accablent les nègres (oppression de race, exploitation industrielle intensifiée. mise à l'index) ; que ces peuples réclament les mêmes droits que les nègres : affranchissement et égalité industrielle et sociale.

L'Internationale Communiste, qui représente les ouvriers et les paysans révolutionnaires du monde entier dans leur lutte pour abattre l'impérialisme, l'Internationale Communiste qui n'est pas seulement l'organisation des ouvriers blancs d'Europe et d'Amérique, mais aussi celle des peuples de couleur opprimés du monde entier, considère qu'il est de son devoir d'encourager et d'aider l'organisation internationale du peuple nègre dans sa lutte contre l'ennemi commun.

5. Le problème nègre est devenu une question vitale de la révolution mondiale. La $3^{\mathrm{e}}$ Internationale qui a reconnu le précieux secours que pouvaient apporter à la révolution prolétarienne les populations asiatiques dans les pays semi- 
capitalistes, regarde la coopération de nos camarades noirs opprimés essentielle à la révolution prolétarienne qui détruira la puissance capitaliste. C’est pourquoi le $4^{\mathrm{e}}$ Congrès déclare que tous les communistes doivent spécialement appliquer au problème nègre les « thèses sur la question coloniale ».

6. a) Le $4^{\mathrm{e}}$ Congrès reconnaît la nécessité de soutenir toute forme du mouvement nègre ayant pour but de miner et d'affaiblir le capitalisme ou l'impérialisme, ou d'arrêter sa pénétration.

b) L'Internationale Communiste luttera pour assurer aux nègres l'égalité de race, l'égalité politique et sociale.

c) L'internationale Communiste utilisera tous les moyens à sa disposition pour amener les trade-unions à admettre les travailleurs nègres dans leurs rangs ; là où ces derniers ont le droit nominal d'adhérer aux trade-unions, elle fera une propagande spéciale pour les attirer; si elle n’y réussit pas, elle organisera les nègres dans des syndicats spéciaux et appliquera particulièrement la tactique du front unique pour forcer les syndicats à les admettre dans leur sein.

d) L'Internationale Communiste préparera immédiatement un Congrès ou une conférence générale des nègres à Moscou. 
Manifestes, thèses et résolutions

des quatre premiers congrès

de l’Internationale communiste 1919-1923

(juin 1934)

Quatrième Congrès, novembre 1922.

- 12 -

\section{Résolution sur l’Internationale des Jeunesses Communistes}

$\underline{\text { Retour à la table des matières }}$

1. Le $2^{\mathrm{e}}$ Congrès mondial de l'Internationale des Jeunesses Communistes a décidé, d'accord avec les résolutions du $3^{\mathrm{e}}$ Congrès de l'I.C., de subordonner au point de vue politique les Jeunesses Communistes aux Partis Communistes. Il a décidé également de réorganiser les J.C., qui n’étaient jusque là que des organisations d'avant-garde renfermées en elles-mêmes et uniquement politiques, en grandes organisations de masses de la jeunesse ouvrière qui se donneront pour tâche de représenter les intérêts de la jeunesse ouvrière dans tous les domaines, dans les cadres du travail de la classe ouvrière et sous la direction politique des P.C. Toutefois, comme auparavant, les J.C. doivent rester des organisations politiques, et la participation à la lutte politique doit continuer à être à la base de leur action.

La lutte pour les revendications économiques quotidiennes de la classe ouvrière et contre le militarisme était considérée jusqu'ici comme le moyen direct le plus important d'éveiller et de conquérir les grandes masses de la jeunesse ouvrière. Les nouvelles tâches exigent une réorganisation des formes de travail ainsi que 
de l'activité des organisations. L'accomplissement d'un travail méthodique de formation communiste au sein de l'organisation ainsi qu'un travail parmi les masses des adolescents non affiliés à l'organisation a été reconnu indispensable.

L'application des décisions du $2^{\mathrm{e}}$ Congrès mondial, qui ne pourra être obtenue que par un travail long et persévérant, s'est heurtée à certaines difficultés du fait que la plupart des J.C. avaient pour la première fois à accomplir de pareilles tâches. La crise économique (appauvrissement, chômage) et l'assaut de la réaction ont obligé plusieurs organisations à devenir illégales, ce qui a diminué le nombre de leurs membres. L'esprit révolutionnaire a baissé dans toute la classe ouvrière à la suite de l'affaissement momentané de la vague révolutionnaire. Cette situation a eu sa répercussion sur la jeunesse ouvrière, dont l'esprit s'est modifié pendant cette époque, et qui a manifesté moins d'intérêt pour la politique. En même temps, la bourgeoisie, ainsi que la social-démocratie, redoublaient d'efforts pour influencer et organiser la jeunesse ouvrière.

Depuis leur $2^{\mathrm{e}}$ Congrès, les Jeunesses ont partout appliqué le principe de la subordination aux Partis Communistes ; pourtant les rapports entre ces derniers et les Jeunesses ne s'effectuent pas encore dans le sens de l'application intégrale des résolutions du Congrès International. La raison en est surtout que souvent les partis n'accordent pas dans une mesure suffisante aux Jeunesses l'appui indispensable au développement de leur activité.

Au cours des quinze derniers mois, des mesures pratiques ont été prises dans la plupart des J.C. pour le remaniement des organisations dans le sens des résolutions $d u 2^{e}$ Congrès mondial, de sorte qu'existent déjà les conditions premières pour la transformation des J.C. en organisations de masses. Par la propagande en faveur des revendications économiques de la jeunesse ouvrière, les J.C. ont, en outre, dans toute une série de pays, frayé une voie qu'elles devront suivre pour continuer à influencer les grandes masses et ont déjà entrepris toute une série de campagnes et même de luttes concrètes.

Les J.C., jusqu'à maintenant, ne se sont pas encore entièrement transformées en organisations de masses, tant au point de vue numérique qu'au point de vue de la liaison organique avec les masses, liaison nécessaire pour pouvoir influencer et diriger constamment ces dernières ; aussi ont-elles encore des tâches importantes à accomplir sous ce rapport. 
2. L'offensive du Capital a fortement atteint la jeunesse ouvrière. La baisse des salaires, la prolongation de la journée de travail, le chômage, l'exploitation de la main-d'œuvre, atteignent la jeunesse non seulement au même degré que la classe ouvrière adulte, mais revêtent souvent pour elle des formes encore pires. La jeunesse ouvrière est employée contre la classe ouvrière adulte ; on se sert d'elle pour abaisser les salaires, pour briser les grèves, pour augmenter le chômage des ouvriers adultes. Cette situation dangereuse pour toute la classe ouvrière est maintenue et intensifiée par l'attitude traîtresse de la bureaucratie syndicale réformiste, qui néglige les intérêts de la jeunesse ouvrière, les sacrifie même parfois, et éloigne les masses des ouvriers adolescents de la lutte de la classe ouvrière adulte. Souvent même, cette bureaucratie refuse l'entrée des syndicats aux jeunes. La croissance ininterrompue du militarisme bourgeois augmente également les souffrances des jeunes ouvriers et des paysans, profondément opprimés pendant leur séjour à la caserne qui les prépare au rôle de chair à canon des guerres impérialistes futures. La réaction sévit surtout contre la jeunesse européenne : en certains endroits elle interdit la formation d'organisations de Jeunesses Communistes, même là où il existe des Partis Communistes.

Les deux Internationales des Jeunesses social-démocrates sont restées inactives jusqu'à présent en présence de la misère de la jeunesse ouvrière ; elles ont fait bloc et ont tenté d'étouffer la volonté des jeunes ouvriers de lutter avec les adultes contre la bourgeoisie. La création de ce bloc ne tendait pas seulement à éloigner de la lutte et du front unique les masses opprimées de la jeunesse ouvrière ; elle était spécialement dirigée contre l'internationale Communiste ; elle devait conduire à bref délai à la fusion des Internationales des Jeunesses social-démocrates.

L'Internationale Communiste proclame la nécessité absolue de l'établissement du front unique entre la Jeunesse ouvrière et la classe ouvrière adulte; elle exhorte les Partis Communistes et tous les ouvriers. du monde entier à appuyer énergiquement les revendications de la Jeunesse ouvrière en lutte contre l'offensive du Capital, contre le militarisme bourgeois et contre la réaction. 
Elle salue avec joie la lutte que l'Internationale des Jeunesses Communistes mène pour des revendications vitales, pour l'unité du front de la Jeunesse ouvrière, pour le front unique entre les ouvriers adolescents et adultes, et lui donne son entier appui. Les attaques du Capital qui menacent de plonger la Jeunesse ouvrière dans la misère la plus profonde et d'en faire une victime impuissante du militarisme et de la réaction doivent se briser à la résistance de fer de toute la classe ouvrière.

3. Pour développer son activité et résoudre les problèmes qui surgissent dans la voie de la conquête et de l'éducation des masses, le mouvement des Jeunesses Communistes a besoin d'être compris et soutenu activement par les partis communistes.

Les intérêts et la force politique du mouvement des Jeunesses Communistes doivent être soutenus d'une façon efficace par la collaboration intime du Parti et de la Jeunesse dans tous les domaines et la participation permanente des J.C. à la vie politique des partis. Ce soutien, ce concours sont indispensables aux Partis Communistes dans leur lutte et dans leur œuvre de réalisation des résolutions de l'Internationale Communiste. Ils sont également la base d'un mouvement véritable des J.C. Les partis communistes doivent aider les J.C. au point de vue de l'organisation. Ils doivent désigner un certain nombre de leurs membres, choisis parmi les plus jeunes, pour collaborer à l’œuvre des J.C. et créer des organisations des Jeunesses là où le Parti possède déjà les siennes. Etant donné que les J.C. ont maintenant pour tâche de concentrer leur activité sur les masses de la Jeunesse ouvrière, les P.C. devront surtout intensifier la création et le travail des J.C. (noyaux et fractions) dans les entreprises et les syndicats. Les Partis et la Jeunesse devront avoir une représentation réciproque dans tous leurs organes respectifs (noyaux, groupes locaux, directions régionales, comités centraux, congrès, fractions, etc...).

Les J.C. devront prendre racine dans les masses de la jeunesse ouvrière en intensifiant leur propagande économique, en s'occupant continuellement, d'une manière concrète, de la vie et des questions intéressant les jeunes ouvriers, en représentant continuellement leurs intérêts et en dirigeant la jeunesse dans la lutte commune qu'elle doit soutenir avec la classe ouvrière adulte. C'est pourquoi les P.C. doivent soutenir activement le travail économique des J.C. dans les noyaux et les fractions, dans les ateliers, dans les écoles et surtout dans les syndicats, où il 
est nécessaire de réaliser la collaboration la plus étroite entre membres des J.C. et des P.C. Dans ces organisations, la tâche des membres du Parti est de veiller surtout à ce que les ouvriers adolescents et les apprentis entrent dans les syndicats ouvriers et y jouissent des mêmes droits que les autres membres ; ils doivent insister pour que les cotisations des jeunes soient proportionnées à leurs salaires, et qu'il soit tenu compte de leurs revendications dans la lutte syndicale et lors de la conclusion des contrats collectifs, etc... Les P.C. soutiendront en outre le travail économique syndical des J.C. en appuyant activement toutes les campagnes de ces dernières, en reprenant à leur compte leurs revendications, en en faisant l'objet de leur lutte quotidienne.

Vu la croissance du danger de guerre impérialiste et le renforcement de la réaction, les P.C. devront appuyer le plus possible et diriger pratiquement la lutte antimilitariste des J.C. Les J.C. doivent être les combattants les plus ardents du Parti pour défendre la classe ouvrière contre la réaction.

L'œuvre d'éducation communiste acquiert une grande importance du fait de la réorganisation des J.C. en grandes organisations de masses. En effet, l'éducation et la formation communistes des J.C. deviennent particulièrement nécessaires pour la conquête des masses. L'œuvre d'éducation des J.C. nécessite une organisation spéciale et autonome et doit être réalisée méthodiquement. Le Parti doit soutenir cette œuvre en fournissant abondamment aux J.C. les forces culturelles et les matériaux nécessaires, en aidant à l'organisation de leurs écoles et cours, en réservant aux jeunes des places dans les écoles du Parti, en publiant dans les écoles du Parti des écrits destinés à la jeunesse.

Le Congrès considère comme indispensable que, dans sa presse, le Parti soutienne plus qu'il ne l'a fait jusqu'à présent, la lutte des J.C. ; à cet effet, il fera paraître régulièrement des chroniques et des suppléments spécialement destinés à la jeunesse et, dans tous ses organes, ne perdra jamais de vue les conditions de vie et la lutte des jeunes ouvriers.

Le monde bourgeois qui, dans ses efforts, se heurte à la conscience de la classe ouvrière adulte et à la résistance de la jeunesse ouvrière révolutionnaire, s'efforce surtout d'empoisonner les enfants de la classe ouvrière et de les soustraire à l'influence prolétarienne. Aussi l'organisation et le développement des groupes d'enfants communistes ont-ils une grande importance. Ces groupes seront, au 
point de vue de l'organisation, subordonnés à la jeunesse et dirigés par elle ; le Parti appuiera cette œuvre en fournissant des forces et en participant à la direction des groupes d'enfants. La presse des enfants communistes, dont la création a déjà été entreprise par les J.C. de divers pays, devra être soutenue par le Parti.

Une collaboration particulièrement intime entre les J.C. et les partis est indispensable dans les pays où la réaction oblige le mouvement communiste à devenir illégal.

Montrant l'importance particulière de l'œuvre communiste tendant à la conquête des masses de la jeunesse ouvrière, le $4^{\mathrm{e}}$ Congrès souligne l'importance particulière qu'acquiert actuellement l'Internationale des Jeunesses Communistes, salue en cette dernière le combattant le plus ardent de la cause de l'Internationale Communiste et considère les Jeunesses Communistes comme la réserve de l'avenir. 
Manifestes, thèses et résolutions

des quatre premiers congrès

de l’Internationale communiste 1919-1923

(juin 1934)

Quatrième Congrès, novembre 1922.

- 13 -

Résolution sur l’action féminine

$\underline{\text { Retour à la table des matières }}$

Le $4^{\mathrm{e}}$ Congrès mondial de l'Internationale Communiste approuve l'activité du Secrétariat féminin international de Berlin. Le Secrétariat féminin a fait en sorte que dans tous les pays ayant un mouvement révolutionnaire, les femmes communistes adhèrent aux sections de l'Internationale Communiste, soient éduquées, et attirées par les travaux et les luttes du Parti. En outre, le Secrétariat a répandu l'agitation et la propagande communiste dans les grandes masses féminines, et a mis ces dernières en mouvement pour les intérêts des masses laborieuses.

Le Secrétariat Communiste International des femmes a réussi à relier dans les différents pays le travail des femmes communistes organisées au travail et à la lutte des partis communistes et de l'Internationale Communiste. Il a réussi, d'accord avec les partis communistes des différents pays, à approfondir et à consolider les rapports internationaux entre les femmes communistes organisées dans ces partis. Toute son action s'est déroulée en complet et en constant accord avec le Comité Exécutif, d'après les directives et les décisions du Congrès mondial de l'Internationale des femmes communistes à Moscou. 
Les organismes spéciaux fondés par suite de ces décisions (Secrétariat féminin, sections féminines, etc...), et les méthodes particulières utilisées dans le travail des partis communistes parmi les femmes, se sont montrés non seulement utiles, mais aussi indispensables, pour faire pénétrer dans les couches profondes des travailleuses les mots d'ordre et les idées communistes.

Dans les pays à régime capitaliste, il fallait agir en premier lieu parmi les femmes prolétariennes, les déterminer à se défendre contre l'exploitation des capitalistes, à lutter pour abattre la bourgeoisie et instaurer la dictature du prolétariat. Par contre, dans les Etats soviétiques, il fallait surtout attirer les ouvrières et les paysannes à tous les domaines de la production et de la vie sociale, à l'organisation de l'Etat prolétarien, et les éduquer pour leur permettre de remplir les devoirs qui s'imposent à elles. La signification internationale de la Russie des Soviets, premier Etat ouvrier formé par la révolution mondiale, est d'une grande importance pour l'action communiste parmi les travailleuses dans toutes les sections de l'Internationale Communiste où le prolétariat doit s'emparer du pouvoir politique, condition de la transformation communiste de la société. L’activité du Secrétariat féminin pour l'Orient, qui a effectué sur un terrain nouveau et particulier un travail efficace, montre également que des organismes spéciaux sont indispensables pour le travail communiste parmi les femmes.

Malheureusement, le $4^{\mathrm{e}}$ Congrès de l'Internationale Communiste doit constater que certaines sections n'ont pas rempli ou n'ont rempli que superficiellement leur devoir, qui est de soutenir d'une façon systématique le travail communiste parmi les femmes. Jusqu'à présent, ils n’ont ni appliqué les règles de l'organisation des femmes communistes dans le parti, ni créé les organismes du parti indispensables au travail parmi les femmes et à l'établissement de la liaison avec ces dernières.

Le $4^{\mathrm{e}}$ Congrès exige de ces sections de faire au plus vite ce qu'elles ont négligé. En même temps, il demande à toutes les sections de l'Internationale Communiste d'accorder une attention particulière au travail communiste parmi les femmes. Le front unique prolétarien ne peut être réalisé que si les femmes en font partie. Une liaison solide entre les Partis Communistes et les travailleuses permettra à ces dernières, dans certaines circonstances, d'ouvrir la voie au front unique prolétarien dans les mouvements de masses révolutionnaires. 
L'Internationale Communiste doit rassembler, sans distinction, toutes les forces du prolétariat et des masses laborieuses, leur donner la conscience révolutionnaire nécessaire à la lutte qui anéantira la domination de la bourgeoisie. 
Manifestes, thèses et résolutions

des quatre premiers congrès

de l’Internationale communiste 1919-1923

(juin 1934)

Quatrième Congrès, novembre 1922.

- 14 -

\section{Résolution sur la question de l'éducation}

\section{I. - Le travail d'éducation des partis communistes}

$\underline{\text { Retour à la table des matières }}$

L'organisation d'un travail d'éducation marxiste est une tâche indispensable de tous les partis communistes. Le but de ce travail d'éducation est l'élévation du niveau intellectuel et des capacités de lutte et d'organisation des membres et fonctionnaires des partis. Parallèlement à l'éducation marxiste générale, les fonctionnaires du parti devront recevoir l'éducation qui leur est nécessaire dans leur spécialité.

Le travail d'éducation communiste, qui doit faire partie intégrante de l'activité du parti, doit être soumis à sa direction. Dans les pays où l'éducation des ouvriers est entre les mains d'organisations spéciales en dehors du parti, ce but devra être atteint par un travail systématique des communistes au sein de ces organisations.

Il faudra créer auprès de tous les comités centraux des sections d'éducation, chargées de diriger toute l'activité éducative du parti. Tous les membres du Parti Communiste qui travaillent dans des organisations d'éducation prolétariennes non 
dirigées par le parti (associations d’éducation ouvrière, universités ouvrières, « proletcult », écoles du travail, etc...), devront être soumis au contrôle du parti.

Afin de mener le travail d'éducation communiste, les partis devront, dans la mesure de leurs moyens, créer des écoles centrales et locales du parti, des cours et conférences; ils mettront à la disposition des groupes des professeurs et des conférenciers, organiseront des bibliothèques, etc...

Les partis communistes sont tenus de soutenir matériellement et moralement le travail d'éducation indépendant des Jeunesses Communistes. Ces dernières devront être attirées dans tous les établissements du parti. L’éducation des enfants prolétariens devra être menée en collaboration avec les Jeunesses Communistes. Les directives de ce travail devront être fournies par la section qui sera créée au sein du Comité Exécutif de l’Internationale Communiste.

Cette section d'éducation aura pour tâche d'approfondir les problèmes de l'éducation communiste, de diriger tout le travail d'éducation des divers partis de l'Internationale Communiste et de coordonner le travail dans les établissements d'instruction prolétariens en dehors du parti. Elle rassemblera et fera connaître les expériences internationales, enrichira les méthodes de travail dans les différents pays, rédigera et éditera des directives, des manuels et autre matériel nécessaire au travail d'éducation, et tranchera tous les problèmes spéciaux se rapportant au travail d'éducation dans les différents pays. Elle devra également étudier et préparer les problèmes de la politique scolaire des différents partis et de l'Internationale Communiste.

En vue d'approfondir l'éducation marxiste et la formation communiste pratique des meilleurs camarades appartenant aux diverses sections de l'Internationale Communiste, des cours internationaux seront organisés auprès de l'Académie Socialiste et autres institutions analogues de la Russie Soviétique.

\section{L'agitation}

1. Tous les membres de l'Internationale Communiste sont tenus de faire de l'agitation parmi les ouvriers en dehors du parti. Cette agitation devra être menée partout où il y a des ouvriers, dans les ateliers, dans les syndicats, dans les ré- 
unions populaires, dans les associations ouvrières, sportives, coopératives de locataires, dans les maisons du peuple et les restaurants ouvriers, dans les chemins de fer, dans les villages, etc..., et aussi dans les logements ouvriers.

2. L'agitation devra toujours s'appuyer sur les besoins concrets des ouvriers en vue de diriger ces derniers dans la voie de la lutte de classe révolutionnaire. Il ne faut pas poser des revendications que les ouvriers sont incapables de comprendre, mais les pousser à la lutte pour les revendications communes du prolétariat, contre le régime capitaliste dans tous les domaines.

3. Les communistes devront participer à toutes les luttes des ouvriers contre le régime capitaliste en combattant au premier rang pour les intérêts généraux du prolétariat et en montrant partout l'exemple.

4. Les organes centraux du parti devront fournir à tous les groupes locaux des instructions pratiques sur le travail d'agitation régulier de tous les membres du parti ainsi que sur le travail dans les diverses campagnes (campagnes électorales, campagnes contre la cherté de la vie et les impôts, mouvements des conseils d'usines et des chômeurs) et dans toutes les actions dirigées par le parti.

(Copie de toutes ces instructions devra être envoyée au Comité Exécutif de l'Internationale Communiste).

5. Tous les membres du parti devront réclamer à leur groupe des instructions concrètes sur le moyen de mener l'agitation. C'est surtout aux noyaux communistes, aux "groupes de dix ", à donner de telles instructions et à en contrôler l'application. Là où ces groupes n'existent pas, il faudra nommer des préposés spéciaux à l'agitation.

6. Toutes les organisations du parti devront établir, au cours de l'hiver prochain, à propos de tous les membres du parti :

1) S'ils font de l'agitation parmi les ouvriers en dehors du parti.
a) régulièrement ou
b) occasionnellement seulement ou
c) pas du tout ;

$2^{\circ}$ S'ils accomplissent quelque autre travail pour le parti 

a) régulièrement ou
b) occasionnellement seulement, ou
c) pas du tout.

Les explications nécessaires à propos de ce questionnaire devront être données à toutes les organisations par le Comité Central du parti, après entente préalable avec le Comité Exécutif de l’Internationale Communiste.

Les Comités régionaux et les groupes locaux sont responsables de la réalisation de cette enquête. Les résultats devront en être envoyés par la Centrale du parti au Comité Exécutif de l’Internationale Communiste.

\section{Connaissance des principales résolutions du Parti et de l'Internationale Communiste}

1. Tous les membres de l'Internationale Communiste doivent connaître les décisions importantes, non seulement de leur parti, mais aussi de l'internationale Communiste.

2. Toutes les organisations des divers partis doivent veiller à ce que tous les membres du parti connaissent au moins le programme de leur propre parti et les 21 conditions d'admission à l'Internationale Communiste, ainsi que les décisions de l’Internationale Communiste concernant leur parti. Il sera procédé à la vérification des connaissances des membres du parti.

3. Les fonctionnaires responsables doivent connaître à fond toutes les décisions d'organisation et de tactique importantes des différents congrès mondiaux et être examinés sur ce point. Cet examen est également recommandé (mais non obligatoire) pour les autres membres du parti.

4. Le Comité Directeur de chaque section est tenu de fournir à ses organisations les instructions pour l'application de ces décisions et d'en faire, au printemps prochain, un rapport sur les résultats au Comité Exécutif de l’Internationale Communiste. 


\author{
Manifestes, thèses et résolutions \\ des quatre premiers congrès \\ de l’Internationale communiste 1919-1923 \\ (juin 1934) \\ Quatrième Congrès, novembre 1922. \\ - 15 -

\section{Résolution sur l'assistance prolétarienne à la Russie Soviétique}

$\underline{\text { Retour à la table des matières }}$

1. Les ouvriers de tous les pays, sans distinction d'opinions politiques ou syndicales sont intéressés au maintien et à la consolidation de la Russie soviétique. Outre le sentiment profondément enraciné de solidarité prolétarienne, la conscience de cet intérêt avant tout a déterminé tous les partis et organisations ouvrières à appuyer l'action de secours aux affamés de Russie et a décidé des millions de travailleurs de tous les pays à faire avec enthousiasme les plus grands sacrifices. Grâce à l'appui fourni par l'action du secours prolétarien, action qui est devenue la plus puissante et la plus durable des actions de solidarité internationale depuis l'existence du mouvement ouvrier, la Russie Soviétique a pu traverser les plus sombres jours de la famine et triompher du fléau.

Mais déjà au cours de la campagne d'assistance aux affamés, les grandes organisations ouvrières qui ont pris part à cette œuvre ont reconnu que l'on ne pouvait se borner à fournir un secours alimentaire à la Russie soviétique. La guerre économique des Etats et des groupes impérialistes contre la Russie soviétique continue sans relâche. Le blocus économique subsiste sous forme de refus de cré- 
dit, et chaque fois que des groupes capitalistes entrent en rapports d'affaires avec la Russie soviétique, c’est uniquement dans le but de s'assurer de monstrueux profits et d'exploiter la Russie.

Dans tous les conflits de la Russie soviétique avec les impérialistes, les travailleurs de tous les pays ont le devoir de soutenir la Russie ; de même, dans la guerre économique que mènent contre elle les impérialistes, ils doivent l’appuyer par tous les moyens pratiques et entre autres par des secours économiques.

2. Le meilleur appui pour la Russie soviétique dans la guerre économique est la lutte politique révolutionnaire des ouvriers qui doivent exercer une forte pression sur leurs gouvernements respectifs pour les obliger à reconnaître le gouvernement soviétique et à procéder au rétablissement des rapports commerciaux avec la Russie. Vu l’importance considérable de l'existence de la Russie soviétique pour les travailleurs, le prolétariat mondial doit, concurremment à l'action politique, mobiliser le maximum de ressources économiques pour soutenir la Russie soviétique.

Chaque usine, chaque atelier que la Russie des Soviets remet en marche sans crédit capitaliste, avec le seul appui des ouvriers, constitue un secours très efficace dans la lutte contre la politique impérialiste de brigandage, et tout renforcement de la Russie des Soviets, premier Etat ouvrier du monde, renforce le prolétariat international dans sa lutte contre son ennemi de classe, la bourgeoisie.

Le $4^{\mathrm{e}}$ Congrès de l'Internationale Communiste déclare donc qu'il est du devoir de tous les partis et organisations ouvrières, et en premier lieu des organisations communistes, d’appuyer immédiatement et énergiquement l'action de secours économique développée par les grandes masses pour la restauration économique de la Russie des Soviets.

3. La tâche la plus importante de l'assistance économique prolétarienne consiste à fournir à la Russie des ressources pour l'achat de machines, matières premières, outils, etc... Il faut envisager aussi la participation des groupes, partis, syndicats, coopératives et associations ouvrières à l'emprunt ouvrier en faveur de la Russie soviétique. Toutes les organisations ouvrières et les travailleurs du monde entier peuvent, en participant à l'emprunt, manifester leur solidarité avec la première République ouvrière et paysanne. 
La propagande en faveur de l'emprunt offre l'occasion de développer la meilleure agitation pour la Russie soviétique ; elle doit donc être menée en contact étroit avec les sections des différents pays.

La question de l'appui économique à la Russie soviétique étant une question d'une importance générale pour tout le prolétariat, il est indispensable de créer, pour l'organisation et la direction de cette action, des comités analogues aux comités de secours ouvriers aux affamés de Russie, ou autres associations spéciales, et composés de délégués des différentes organisations ouvrières. Ces comités ou associations qui auront pour tâche d'intéresser et d'attirer les grandes masses ouvrières à l'œuvre de secours économique seront sous le contrôle de l'Internationale Communiste.

4. L'affectation des ressources procurées par les comités et associations sera déterminée en contact étroit avec les institutions économiques étatiques ou les organisations ouvrières russes.

5. Dans la situation économique actuelle, l'immigration en masse d'ouvriers étrangers ne constituerait pas un appui, mais au contraire un obstacle à la restauration économique et ne doit avoir lieu en aucun cas. La Russie se bornera à accepter les ouvriers spécialisés dans des professions absolument nécessaires et qui ne sauraient être remplacés par des ouvriers du pays. Mais, même dans ce cas, l'immigration ne doit avoir lieu qu'avec l'approbation et un accord des syndicats russes.

6. L'assistance économique prolétarienne doit être un effort vers la concentration de la solidarité ouvrière internationale au profit du premier Etat prolétarien du monde, et donner des résultats économiques palpables.

7. Conformément aux principes de la coopération et de l'économie socialistes, l'excédent éventuel des ressources sera exclusivement appliqué à l'extension du domaine d'action de l'assistance économique. 


\author{
Manifestes, thèses et résolutions \\ des quatre premiers congrès \\ de l'Internationale communiste 1919-1923 \\ (juin 1934) \\ Quatrième Congrès, novembre 1922. \\ - 16 - \\ Résolution sur l'aide aux victimes \\ de la répression capitaliste
}

$\underline{\text { Retour à la table des matières }}$

L'offensive du capitalisme dans tous les pays bourgeois a pour résultat d'augmenter le nombre des communistes et des ouvriers sans parti, luttant contre le capitalisme, et qui gémissent dans les cachots.

Le $4^{\mathrm{e}}$ Congrès demande à tous les partis communistes de créer une organisation qui aura pour but d'aider matériellement et moralement tous les prisonniers du capitalisme, et salue l'initiative de l'association des vieux bolchéviks russes qui a commencé la création d'une association Internationale de ces organisations de secours. 


\author{
Manifestes, thèses et résolutions \\ des quatre premiers congrès \\ de l’Internationale communiste 1919-1923 \\ (juin 1934) \\ Quatrième Congrès, novembre 1922. \\ - 17 -

\section{Résolution sur la réorganisation} \\ de l'Exécutif et son activité future
}

\title{
Le Congrès Mondial
}

$\underline{\text { Retour à la table des matières }}$

Comme par le passé, le Congrès Mondial a lieu une fois par an. L’Exécutif Elargi en fixe la date. Toutes les sections adhérentes doivent y envoyer des délégués. Leur nombre est déterminé par l’Exécutif. Les frais sont supportés par les partis. Le nombre des voix dont dispose chaque section est déterminé par chaque congrès, selon l'effectif des partis et la situation politique des pays correspondants. Les mandats impératifs ne sont pas admis et sont cassés d'avance, cette pratique étant contraire à l'esprit d'un parti mondial prolétarien international et centralisé.

\section{L'Exécutif}

L'Exécutif est élu par le Congrès. Il se compose du président, de 24 membres et de 10 suppléants. Au moins 15 membres de l'Exécutif doivent résider en permanence à Moscou. 


\section{L'Exécutif Elargi}

En règle générale, tous les quatre mois se tient une session élargie de l’Exécutif. Cette session est composée comme suit :

1. Les 25 membres de l’Exécutif.

2. Trois autres représentants des partis suivants: Allemagne, France, Russie, Tchécoslovaquie, Italie, Internationale des Jeunes et Internationale Syndicale Rouge.

3. Deux autres représentants d’Angleterre, Pologne, Amérique, Bulgarie et Norvège.

4. En outre, un représentant pour chacune des autres sections qui ont droit au vote.

Le Présidium est obligé de soumettre à une session de l'Exécutif élargi toutes les grandes questions fondamentales admettant un délai. La première session de l’Exécutif Elargi a lieu immédiatement après le Congrès mondial.

\section{Le Présidium}

L’Exécutif Elargi élit, au cours de sa première session, un Présidium dont font partie un représentant des Jeunesses et un de l'Internationale Syndicale Rouge avec voix consultative, et constitue les sections suivantes :

1) Une Section Orientale aux travaux de laquelle l'Exécutif devra accorder une attention particulière pour l'année prochaine. Son chef doit faire partie du Présidium. Dans son travail politique, elle est subordonnée au Présidium ; ce dernier règle les rapports de la section avec la Section d'Organisation.

2) Une Section d'Organisation à laquelle deux membres au moins du Présidium doivent appartenir. Elle est subordonnée au Présidium.

3) Une Section d'Agitation et de Propagande, dirigée par un membre de l’Exécutif. Elle est également directement subordonnée au Présidium. 
4) Une Section de Statistique et d’Information, subordonnée à la Section d'Organisation.

L’Exécutif a le droit d'installer d'autres sections.

\section{La division du travail dans l'Exécutif}

Une précise division du travail doit être faite entre les membres de l'Exécutif ainsi qu'entre ceux du Présidium. Le travail de chaque section est préparé par des rapporteurs responsables désignés par le Présidium, un pour chacun des pays les plus importants. En règle générale, ce rapporteur doit être membre de l’Exécutif ou même si possible du Présidium. Les rapporteurs qui ne font pas partie de l’Exécutif ou du Présidium travaillent sous le contrôle d’un membre du Présidium.

Le Présidium organise un Secrétariat général, dirigé par un secrétaire général ; l'Exécutif fournit deux suppléants. Le Secrétariat n’a pas les fonctions d'un organe politique indépendant ; il n’est qu’un organe d'exécution du Présidium.

L’Exécutif est chargé d'agir dans tous les partis pour qu'une division du travail analogue soit appliquée dans chaque pays, en tenant compte des situations diverses.

Les délégués de l'Exécutif. Dans des cas spéciaux, l’Exécutif envoie dans tel ou tel pays des délégués recrutés parmi les camarades les plus qualifiés des diverses sections. Ces représentants doivent être pourvus par l'Exécutif des plus larges pouvoirs. Des instructions spéciales doivent déterminer les fonctions de ces délégués, leurs droits et leurs obligations ainsi que leurs rapports avec les partis intéressés.

L’Exécutif est chargé de faire avec la plus grande énergie une révision de l'application réelle des 21 conditions et des décisions des Congrès mondiaux. Les délégués seront chargés d’effectuer cette révision avec la plus grande vigilance. Ils devront, au moins une fois par mois, rendre compte des résultats de leurs travaux. 
La Commission de Contrôle Internationale. La Commission de Contrôle Internationale subsiste. Ses fonctions restent les mêmes qui ont été formulées par le $3^{\mathrm{e}}$ Congrès mondial. Le Congrès mondial désigne chaque année deux sections voisines, dont les Comités Directeurs élisent dans leur sein chacun trois membres de la Commission de Contrôle, qui doivent être confirmés par l'Exécutif. Pour cette année, le Congrès mondial charge de ces fonctions les sections allemande et française.

Le Bureau d'Information Technique. Les bureaux d'information technique subsistent. Ils ont pour fonctions de donner des informations techniques et sont subordonnés à l’Exécutif.

«L'internationale Communiste ». L'internationale Communiste est l'organe de l’Exécutif ; sa rédaction est élue par l’Exécutif et lui est subordonnée.

Publications de l'Exécutif. Le Congrès rappelle que tous les organes communistes sont tenus, comme jusqu’à présent, d’imprimer tous les documents de l’Exécutif (appels, lettres, résolutions, etc...) aussitôt que l’Exécutif l'exige.

Les procès-verbaux des Partis Nationaux. Les Comités Directeurs de toutes les sections sont obligés de faire parvenir régulièrement à l'Exécutif les procèsverbaux de toutes leurs séances.

Représentations réciproques. Il est désirable que les sections les plus importantes entretiennent entre voisins une représentation réciproque dans un but d'information mutuelle et de coordination de leurs travaux. Les rapports de ces représentations devront également être mis à la disposition de l’Exécutif.

Congrès Nationaux des Sections. En règle générale, avant le Congrès mondial, les partis doivent tenir des conférences nationales ou des sessions élargies de leur organe exécutif, pour préparer le Congrès mondial et élire leurs délégués. Les Congrès nationaux des sections ont lieu après le Congrès mondial. Les exceptions ne peuvent être admises qu'avec le consentement de l'Exécutif.

De la sorte, les intérêts des différentes sections seront sauvegardés le mieux possible et la possibilité subsistera de faire valoir « de bas en haut» toute l’expérience du mouvement international.

De cette manière, la possibilité est également donnée à l’Internationale Communiste, comme Parti mondial et centralisé, de répartir aux différents partis « de 
haut en bas », par la voie du centralisme démocratique, les directives découlant de l'expérience globale de l'Internationale.

Les Démissions. Le Congrès condamne de la manière la plus catégorique les cas de démission qui se sont produits de la part de camarades de divers Comités Directeurs et de groupes entiers de leurs membres. Le Congrès considère ces démissions comme un acte de désorganisation extrême du mouvement communiste. Tout poste dirigeant dans un parti communiste n'appartient pas au détenteur du mandat, mais à l'Internationale dans son ensemble.

Le Congrès décide : les membres élus d'institutions centrales des diverses sections ne peuvent déposer leurs mandats qu'avec l'assentiment de l'Exécutif. Les démissions acceptées par un Comité Directeur sans l'approbation de l'Exécutif sont nulles et non avenues.

Le Travail illégal. En vertu de la résolution du Congrès indiquant qu'un certain nombre de partis très importants entrent selon toute apparence dans une période d'illégalité, le Présidium est chargé de se vouer dans la plus large mesure à la préparation de ces partis en vue du travail illégal. Immédiatement après la fin du Congrès, le Présidium devra commencer des négociations avec tous les partis en question.

Le Secrétariat International des Femmes. Le Secrétariat International des Femmes subsiste comme par le passé. L’Exécutif nomme la secrétaire des Femmes et, d'accord avec elle, prend toutes les mesures d'organisation nécessaires.

La Représentation de l'Exécutif des Jeunes. Le Congrès charge l'Exécutif d'établir une représentation régulière de l'I.C. à l'Internationale des Jeunes. Le Congrès estime que c'est une des tâches les plus importantes de l'Exécutif de stimuler le travail du mouvement des Jeunes.

Liaison avec l'Internationale Syndicale Rouge. Le Congrès charge l'Exécutif d'élaborer, d'accord avec la direction centrale du Profintern, les formes de la liaison réciproque entre l'I.C. et le Profintern. Le Congrès déclare que dans la période actuelle, les luttes économiques sont plus étroitement liées que jamais aux luttes politiques, qu'elles exigent donc une collaboration particulièrement intime des forces de toutes les organisations révolutionnaires de la classe ouvrière. 
La Révision des Statuts. Le Congrès confirme les statuts adoptés par le $2^{\circ}$ Congrès et charge l'Exécutif de rédiger à nouveau et de compléter ces statuts sur la base des nouvelles décisions. Ce travail devra être fait en temps opportun, être soumis au jugement de tous les partis et être définitivement confirmé par le $5^{\mathrm{e}}$ Congrès mondial. 
Manifestes, thèses et résolutions

des quatre premiers congrès

de l’Internationale communiste 1919-1923

(juin 1934)

Quatrième Congrès, novembre 1922.

- 18 -

\section{Résolution}

sur la question française

\section{La crise du Parti et le rôle des fractions}

$\underline{\text { Retour à la table des matières }}$

Le $4^{\mathrm{e}}$ Congrès de l'Internationale Communiste constate que l'évolution de notre Parti français depuis le socialisme parlementaire jusqu'au communisme révolutionnaire s'opère avec une extrême lenteur qui est loin de s'expliquer par les conditions uniquement objectives, par les traditions, par la psychologie nationale de la classe ouvrière, etc..., mais qui est due, avant tout, à une résistance directe et parfois exceptionnellement opiniâtre des éléments non communistes qui sont encore très forts dans les sommets du Parti et particulièrement dans la fraction du centre qui, depuis Tours, a eu, pour la plus grande part, la direction du Parti.

La cause fondamentale de la crise aiguë que traverse actuellement le Parti se trouve dans la politique d'attente, indécise et hésitante, des éléments dirigeants du centre qui, devant les exigences urgentes de l'organisation du Parti, essaient de gagner du temps, couvrant ainsi une politique de sabotage direct dans les questions syndicale, du front unique, de l'organisation du Parti et autres. Le temps 
ainsi gagné par les éléments dirigeants du centre a été perdu pour le progrès révolutionnaire du prolétariat français.

Le Congrès fait au Comité Exécutif une obligation de suivre de toute son attention la vie intérieure du Parti Communiste français afin de pouvoir, en s'appuyant sur la majorité incontestablement prolétarienne et révolutionnaire, le libérer de l'influence des éléments qui ont engendré la crise et qui ne cessent de l'aggraver.

Le Congrès rejette l'idée même d'une scission, qui n’est en rien suggérée par la situation du Parti. L'écrasante majorité de ses membres est sincèrement et profondément dévouée à la cause communiste. Seul, un manque de clarté subsistant dans la doctrine et la conscience du Parti a permis à ses éléments conservateurs, centristes et semi-centristes, d'apporter un trouble aussi aigu et d'engendrer des fractions. Un effort ferme et constant pour éclaircir l'essence des questions litigieuses devant le Parti groupera, sur le terrain des décisions du présent Congrès, l'écrasante majorité des membres du Parti et, avant tout, sa base prolétarienne. Quant aux éléments qui adhèrent au Parti, mais en même temps sont liés par toute la nature de leur pensée et de leur vie aux mœurs et coutumes de la société bourgeoise et sont incapables de comprendre la véritable politique prolétarienne ou de se soumettre à la discipline révolutionnaire, leur rejet progressif du Parti est la condition indispensable de son assainissement, de sa cohésion et de sa faculté d'action.

L'avant-garde communiste de la classe ouvrière a besoin naturellement d'intellectuels qui apportent à son organisation leurs connaissances théoriques, leurs dons d'agitateurs ou d'écrivains, mais à condition que ces éléments rompent absolument et sans retour avec les mœurs et coutumes du milieu bourgeois, brûlent derrière eux tous les ponts les rattachant au camp dont ils sont sortis, ne demandent pour eux ni exception, ni privilèges et se soumettent à la discipline, à l'égal de simples militants. Les intellectuels, si nombreux en France, qui entrent dans le Parti en amateurs ou en carriéristes, lui causent seulement un immense dommage ; ils le compromettent devant les masses prolétariennes et l'empêchent de conquérir la confiance de la classe ouvrière.

Il faut à tout prix épurer impitoyablement le Parti de pareils éléments et fermer les portes devant eux. Le meilleur moyen pour cela serait d'effectuer une 
révision générale des effectifs du Parti au moyen d’une commission spéciale composée d’ouvriers irréprochables sous le rapport de la morale communiste.

Le Congrès constate que la tentative faite par le Comité Exécutif pour atténuer les manifestations de la crise dans le domaine de l'organisation en constituant les organes dirigeants sur la base paritaire entre les deux principales fractions du centre et de la gauche a été rendue vaine par le centre sous l'influence indubitable de ses éléments les plus conservateurs, qui prennent dans cette fraction une prépondérance inévitable toutes les fois qu'elle s’oppose à la gauche.

Le Congrès estime nécessaire d'expliquer à tous les membres du Parti Communiste français que les efforts du Comité Exécutif tendant à obtenir un accord préalable entre les principales fractions avaient pour but de faciliter les travaux du Congrès de Paris et ne constituaient, en aucun cas, une atteinte aux droits du Congrès comme organe souverain du Paris Communiste français.

Le Congrès estime nécessaire d'établir que, quelles qu’aient pu être les erreurs particulières de la gauche, elle s'est efforcée essentiellement, pendant comme avant le Congrès de Paris, de réaliser la politique de l'Internationale Communiste, et que dans les principaux problèmes du mouvement révolutionnaire, dans la question du front unique et dans la question syndicale, elle a occupé, en face du centre et du groupe Renoult, la position juste.

Le Congrès invite instamment tous les éléments véritablement révolutionnaires et prolétariens, qui sont indubitablement en majorité dans le centre, à mettre fin à l'opposition des éléments conservateurs et à s'unir avec la gauche dans un travail commun. La même remarque se rapporte à la fraction qui par ses effectifs, arrive la troisième et qui mène la campagne la plus vive, et manifestement erronée, contre la politique du front unique.

\section{L'extrême-gauche}

En liquidant le caractère fédéraliste de son organisation, la Fédération de la Seine a repoussé par là même la position manifestement erronée de l'aile soidisant d'extrême-gauche. Cependant cette dernière, en la personne des camarades Heine et Lavergne, a cru pouvoir donner au citoyen Delplanque un mandat impé- 
ratif en vertu duquel le citoyen Delplanque s'engageait à s'abstenir de voter sur toutes les questions et à ne prendre aucun engagement. Cette façon d'agir des représentants déjà nommés de l'extrême-gauche témoigne de leur parfaite incompréhension du sens et de l'essence de l'Internationale Communiste.

Les principes du centralisme démocratique qui sont à. la base de nos organisations excluent radicalement la possibilité de mandats impératifs, qu'il s'agisse de Congrès fédéraux, nationaux ou internationaux. Les Congrès n’ont de sens que dans la mesure où les décisions collectives des organisations - locales, nationales ou internationales - sont élaborées par le libre examen et la décision de tous les délégués. Il est tout à fait évident que les discussions, l'échange des expériences et des arguments de chacun dans un Congrès seraient dépourvus de sens, si les délégués étaient liés d’avance par des mandats impératifs.

La violation des principes fondamentaux de l'organisation de l'Internationale est aggravée dans le cas actuel par le refus de ce groupe de ne prendre aucun engagement à l'égard de l'Internationale, comme si le seul fait d'appartenir à l'Internationale n'imposait pas à tous ses membres des engagements absolus de discipline et de mise en pratique de toutes les décisions adoptées.

Le Congrès invite le Comité Directeur de notre section française à étudier, sur place, tous les éléments de cet incident et à en tirer toutes les conclusions politiques et d'organisation qui en découlent.

\section{La question syndicale}

Les décisions prises par le Congrès dans la question syndicale comportent certaines concessions de forme et d'organisation destinées à faciliter le rapprochement du Parti et des organisations syndicales ou masses syndiquées n'adoptant pas encore le point de vue communiste. Mais ce serait dénaturer complètement le sens de ces décisions que de vouloir les interpréter comme une approbation de la politique d'abstention syndicale qui a été dominante dans le Parti et que prêchent encore aujourd'hui beaucoup de ses membres.

Les tendances représentées dans cette question par Ernest Lafont sont en contradiction complète et inconciliables avec les missions révolutionnaires de la 
classe ouvrière et avec toute la conception du communisme. Le Parti ne peut ni ne veut attenter à l'autonomie des syndicats, mais il doit démasquer et châtier impitoyablement ceux de ses membres qui réclament l'autonomie en vue de leur action désorganisatrice et anarchiste au sein des syndicats. Dans cette question essentielle, l'Internationale souffrira moins que dans n'importe quel autre domaine toute déviation ultérieure de la voie communiste, la seule juste du point de vue de la pratique internationale, comme de celui de la théorie.

\section{Les leçons de la grève du Havre}

La grève du Havre, malgré son caractère local, est un témoignage indubitable de la combativité croissante du prolétariat français. Le gouvernement capitaliste a répondu à la grève par l'assassinat de quatre ouvriers, comme s'il se hâtait de rappeler aux ouvriers français qu'ils ne pourront conquérir le pouvoir et détruire l'esclavage capitaliste qu'au prix de la plus grande lutte, du maximum de dévouement et d'abnégation et de nombreux sacrifices.

Si la réponse du prolétariat français aux assassinats du Havre a été complètement insuffisante, la responsabilité en incombe non seulement à la trahison, devenue depuis longtemps de règle parmi les dissidents et les syndicalistes réformistes, mais aussi à la manière d'agir complètement erronée des organes dirigeants de la C.G.T.U. et du Parti Communiste. Le Congrès estime nécessaire de s'arrêter sur cette question parce qu'elle nous offre un exemple éclatant de la manière radicalement fausse d'aborder les problèmes d'action révolutionnaire.

En divisant d'un façon incorrecte en principe la lutte de classe du prolétariat en deux domaines soi-disant indépendants, l'économique et le politique, le Parti, cette fois encore, ne fit preuve d'aucune initiative indépendante, se bornant à appuyer la C.G.T.U., comme si en réalité l'assassinat de quatre prolétaires par le gouvernement du capital était un acte économique et non un événement politique de première importance. Quant à la C.G.T.U., sous la pression du Syndicat parisien du Bâtiment, elle proclama le lendemain des assassinats du Havre, un dimanche, une grève générale de protestation pour le mardi. Les ouvriers de France n'eurent pas le temps, dans beaucoup d'endroits, d'apprendre non seulement l'appel à la grève générale, mais même le fait de l'assassinat. 
Dans ces conditions, la grève générale était d'avance vouée à l'échec. Il n’y a pas de doute que, cette fois encore, la C.G.T.U. n’ait adapté sa politique aux éléments anarchistes, organiquement étrangers à la compréhension de l'action révolutionnaire et à sa préparation, et qui suppléent à la lutte révolutionnaire par des appels révolutionnaires de leurs coteries, sans se soucier de la réalisation de ces appels. Le Parti, de son côté, capitula en silence devant la démarche évidemment erronée de la C.G.T.U. au lieu d'essayer, sous une forme amicale mais instante, d'obtenir de cette dernière l'ajournement de la manifestation gréviste dans le but de développer une vaste agitation de masse.

La première obligation, tant du Parti que de la C.G.T.U. devant le crime ignoble de la bourgeoisie française, était de mobiliser immédiatement un millier des meilleurs agitateurs du Parti et des syndicats à Paris et en province, pour expliquer aux éléments les plus arriérés de la classe ouvrière le sens des événements du Havre, et pour préparer les masses ouvrières à la protestation et à la défense. Le Parti était tenu, en pareil cas, de lancer à plusieurs millions d'exemplaires un appel à la classe ouvrière et aux paysans, à l'occasion du crime du Havre.

L'organe central du Parti devait quotidiennement poser aux réformistes — socialistes et syndicalistes - la question : quelle est la forme de lutte que vous proposez en réponse aux assassinats du Havre ? De son côté le Parti devait, de concert avec la C.G.T.U., lancer l'idée d'une grève générale, sans en fixer d'avance la date et la durée, en se laissant guider par le développement de l'agitation et du mouvement dans le pays. Il était indispensable de tenter de constituer dans chaque usine, ou dans chaque quartier, ville et région, des Comités provisoires de protestation dans la composition desquels les communistes et syndicalistes révolutionnaires comme initiateurs auraient fait entrer des membres ou des représentants des organisations réformistes.

Seule, une campagne de ce genre, systématique, concentrée, universelle par ses moyens, tendue et infatigable, pouvait, menée pendant toute une semaine et plus, être couronnée par un mouvement puissant et imposant, sous la forme d'une grande grève de protestation, de manifestation dans la rue, etc... Le résultat sûr d'une telle campagne aurait été d'augmenter dans les masses les liaisons, l'autorité et l'influence du Parti et de la C.G.T.U., de les rapprocher mutuellement dans le travail révolutionnaire et de rapprocher d'eux la partie de la classe ouvrière qui suit encore les réformistes. 
La prétendue grève générale du $1^{\mathrm{er}}$ mai 1921, que les éléments révolutionnaires ne surent pas préparer et que les réformistes firent criminellement échouer, constitua un tournant dans la vie intérieure de la France, en affaiblissant le prolétariat et en renforçant la bourgeoisie. La « grève générale » de protestation du mois d'octobre 1922 fut, au fond, une trahison réitérée de la droite et une nouvelle erreur de la gauche. L'Internationale invite, de la manière la plus énergique, les camarades français, dans quelque branche du mouvement prolétarien qu'ils travaillent, à accorder une attention extrême aux problèmes de l'action des masses, à en étudier minutieusement les conditions et les méthodes, à soumettre les erreurs de leurs organisations dans chaque cas concret à une analyse critique attentive, à préparer non moins minutieusement les éventualités mêmes d'action des masses au moyen d'une agitation vaste et tendue, à proportionner les mots d'ordre à la disposition et à l'aptitude des masses à l'action.

Les chefs réformistes s’appuient dans leurs actes de trahison sur les conseils, suggestions et indications de toute l'opinion publique bourgeoise, à laquelle ils sont indissolublement liés. Les syndicalistes révolutionnaires, qui ne peuvent pas ne pas être en minorité dans les organisations syndicales. commettront d'autant moins d'erreurs que le Parti comme tel, consacrera plus d'attention à toutes les questions du mouvement ouvrier, étudiant minutieusement les conditions et le milieu et présentant aux syndicats, par l'intermédiaire de ses membres, telles ou telles propositions, en conformité avec toute la situation.

\section{La franc-maçonnerie, la Ligue des Droits de l'Homme et la presse bourgeoise}

L’incompatibilité de la franc-maçonnerie et du socialisme était considérée comme évidente dans la plupart des partis de la $2^{\mathrm{e}}$ Internationale. Le Parti Socialiste italien a exclu les Francs-Maçons en 1914, et cette mesure a été, sans aucun doute, une des raisons qui ont permis à ce parti de suivre, pendant la guerre, une politique d'opposition, puisque les Francs-Maçons, en qualité d'instruments de l'Entente, agissaient en faveur de l'intervention.

Si le deuxième Congrès de l'Internationale Communiste n’a pas formulé, dans les conditions d’adhésion à l’Internationale, de point spécial sur l’incompatibilité 
du communisme et de la franc-maçonnerie, c'est parce que ce principe a trouvé sa place dans une résolution séparée votée à l'unanimité du Congrès.

Le fait, qui s'est révélé d'une façon inattendue au $4^{\mathrm{e}}$ Congrès de l'Internationale Communiste, de l'appartenance d'un nombre considérable de communistes français aux loges maçonniques est, aux yeux de l'Internationale Communiste, le témoignage le plus manifeste et en même temps le plus pitoyable que notre Parti français a conservé, non seulement l'héritage psychologique de l'époque du réformisme, du parlementarisme et du patriotisme, mais aussi des liaisons tout à fait concrètes, extrêmement compromettantes pour la tête du Parti, avec les institutions secrètes, politiques et carriéristes de la bourgeoisie radicale.

Tandis que l'avant-garde communiste du prolétariat recueille toutes ses forces pour une lutte sans merci contre tous les groupements et organisations de la société bourgeoise au nom de la dictature prolétarienne, de nombreux militants responsables du Parti, députés, journalistes, et jusqu’à des membres du Comité Directeur, conservent une liaison étroite avec les organisations secrètes de l'ennemi.

Un fait particulièrement déplorable est celui que tout le Parti, dans toutes ses tendances, n'a pas soulevé cette question après Tours, malgré sa clarté évidente pour toute l'Internationale et qu'il ait fallu la lutte des fractions à l'intérieur du Parti pour la faire surgir devant l'Internationale dans toute son importance menaçante.

L'Internationale considère comme indispensable de mettre fin, une fois pour toutes, à ces liaisons compromettantes et démoralisatrices de la tête du Parti Communiste avec les organisations politiques de la bourgeoisie. L'honneur du prolétariat de France exige qu'il épure toutes ses organisations de classe des éléments qui veulent appartenir à la fois aux deux camps en lutte.

Le Congrès charge le Comité Directeur du Parti Communiste français de liquider avant le $1^{\mathrm{er}}$ janvier 1923 toutes les liaisons du Parti, en la personne de certains de ses membres et de ses groupes, avec la franc-maçonnerie. Celui qui, avant le $1^{\mathrm{er}}$ janvier, n'aura pas déclaré ouvertement à son organisation et rendu publique par la presse du Parti sa rupture complète avec la franc-maçonnerie est, par là même, automatiquement exclu du Parti Communiste sans droit d’y jamais adhérer à nouveau, à quelque moment que ce soit. La dissimulation par quiconque de son appartenance à la franc-maçonnerie sera considérée comme pénétration dans le 
Parti d'un agent de l'ennemi et flétrira l'individu en cause d'une tâche d’ignominie devant tout le prolétariat.

Considérant que le seul fait d'appartenir à la franc-maçonnerie, qu'on ait poursuivi ou non, ce faisant, un but matériel, carriériste ou tout autre but flétrissant, témoigne d'un développement extrêmement insuffisant de la conscience communiste et de la dignité de classe, le $4^{\mathrm{e}}$ Congrès reconnaît indispensable que les camarades qui ont appartenu jusqu’à présent à la franc-maçonnerie et qui rompront maintenait avec elle soient privés durant deux ans du droit d'occuper des postes importants dans le Parti. Ce n'est que par un travail intense pour la cause de la révolution en qualité de simples militants, que ces camarades peuvent reconquérir la confiance complète et le droit d'occuper dans le Parti des postes importants.

Considérant que la Ligue pour la défense des Droits de l'Homme et du Citoyen est, dans son essence, une organisation du radicalisme bourgeois, qu'elle utilise ses actes isolés contre telle ou telle injustice pour semer les illusions et les préjugés de la démocratie bourgeoise et surtout que, dans les cas les plus décisifs et les plus graves, comme par exemple pendant la guerre, elle prête tout son appui au capital organisé sous forme d'Etat, le 4 e Congrès de l'Internationale Communiste estime absolument incompatible avec le titre de communiste et contraire aux conceptions élémentaires du communisme le fait d'appartenir à la Ligue des Droits de l'Homme et du Citoyen et invite tous les membres du Parti adhérant à cette Ligue à en sortir avant le $1^{\mathrm{er}}$ janvier 1923, en le portant à la connaissance de leur organisation et en le publiant dans la Presse.

Le Congrès invite le Comité Directeur du Parti Communiste français :

$1^{\circ}$ À publier immédiatement son appel à tout le Parti, éclaircissant le sens et la portée de la présente résolution.

$2^{\circ}$ À prendre toutes les mesures découlant de la résolution pour que l'épuration du Parti de la franc-maçonnerie et la rupture de toute relation avec la Ligue des Droits de l'Homme et du Citoyen soit effectuée sans faiblesse et sans omission avant le $1^{\mathrm{er}}$ janvier 1923. Le Congrès exprime son assurance que, dans son travail d'épuration et 
d'assainissement, le Comité Directeur sera soutenu par l'immense majorité des membres du Parti, à quelque fraction qu’ils appartiennent.

Le Comité Directeur doit dresser les listes de tous les camarades qui, à Paris et en province, tout en faisant partie du Parti Communiste et en assumant des postes divers, même de confiance, collaborent en même temps à la presse bourgeoise et inviter ces éléments à faire, avant le $1^{\mathrm{er}}$ janvier 1923, un choix complet et définitif entre les organes bourgeois de corruption des masses populaires et le Parti révolutionnaire de la dictature du prolétariat.

Les fonctionnaires du Parti qui ont violé la prescription établie et réitérée maintes fois dans des décisions visant le Parti français doivent être privés du droit d'occuper des postes de confiance pendant un an.

\section{Les candidats du Parti}

Afin de donner au Parti un caractère vraiment prolétarien et dans le but d'écarter de ses rangs les éléments qui n’y voient qu'une antichambre du Parlement, des conseils municipaux, des conseils généraux, etc..., il est indispensable d'établir comme règle inviolable que les listes des candidats présentées par le Parti aux élections comprendront au moins neuf dixièmes d'ouvriers communistes travaillant encore à l'atelier, à l'usine ou aux champs, et de paysans ; les représentants des professions libérales ne peuvent être admis que dans la limite strictement déterminée d'un dixième au plus du nombre total des sièges éligibles que le Parti occupe ou espère occuper par l'intermédiaire de ses membres; En outre, on fera preuve d'une rigueur particulière dans le choix des candidats appartenant aux professions libérales (vérification minutieuse de leurs antécédents politiques, de leurs relations sociales, de leur fidélité et de leur dévouement à la cause de la classe ouvrière), par des commissions essentiellement prolétariennes.

Sous ce régime seulement, les parlementaires, conseillers municipaux et généraux, et maires communistes, cesseront d'être une caste professionnelle n'ayant dans la plupart des cas que peu de rapports avec la classe ouvrière et deviendront l'un des instruments de la lutte révolutionnaire des masses. 


\section{L'action communiste dans les colonies}

Le $4^{\mathrm{e}}$ Congrès attire encore une fois l'attention sur l'importance exceptionnelle d'une activité juste et systématique du Parti communiste dans les colonies. Le Parti condamne catégoriquement la position de la section communiste de SidiBel-Abbès, qui couvre d'une phraséologie pseudo-marxiste un point de vue purement esclavagiste, soutenant, au fond, la domination impérialiste du capitalisme français sur ses esclaves coloniaux. Le Congrès estime que notre activité dans les colonies doit s’appuyer, non pas sur des éléments aussi pénétrés de préjugés capitalistes et nationalistes, mais sur les meilleurs éléments des indigènes eux-mêmes et, en premier lieu, sur la jeunesse prolétarienne indigène.

Seules, une lutte intransigeante du Parti Communiste dans la métropole contre l'esclavage colonial et une lutte systématique dans les colonies elles-mêmes peuvent affaiblir l'influence des éléments ultra-nationalistes des peuples coloniaux opprimés sur les masses travailleuses, attirer la sympathie de ces dernières à la cause du prolétariat français et ne point donner ainsi au capital français, à l'époque du soulèvement révolutionnaire du prolétariat, la possibilité d'employer les indigènes coloniaux comme la dernière réserve de la contre-révolution.

Le Congrès international invite le Parti français et son Comité Directeur à prêter infiniment plus d'attention, de force et de moyens que jusqu'à ce jour, à la question coloniale et à la propagande dans les colonies et, entre autres, à créer auprès du Comité Directeur un bureau permanent d'action coloniale, en y faisant entrer des représentants des organisations communistes indigènes.

\section{Décisions}

a) Comité Directeur. - Exceptionnellement, étant donné la crise aiguë provoquée par le Congrès de Paris, le Comité Directeur sera constitué sur la base proportionnelle, d'après le vote du Congrès, relative aux organismes centraux.

Les propositions des diverses fractions seront les suivantes : 
Centre : $\quad 10$ titulaires et 3 suppléants.

Gauche : $\quad 9$ titulaires et 2 suppléants.

Tendance Renoult : $\quad 4$ titulaires et 1 suppléant.

Minorité Renaud Jean : 1 titulaire.

Jeunesses : $\quad 2$ représentants avec voix délibérative.

Le bureau politique sera composé sur la même base, les fractions obtenant respectivement : Centre, 3 postes ; Gauche, 3 ; tendance Renoult, 1.

Les membres du Comité Directeur, comme ceux du bureau politique et des organismes centraux importants, seront désignés par les fractions à Moscou, pour éviter toute contestation d'ordre personnel qui risquerait d'aggraver la crise. La liste ainsi élaborée est soumise au $4^{\mathrm{e}}$ Congrès mondial par la délégation qui s'engage à la défendre devant le parti. Le $4^{\mathrm{e}}$ Congrès prend acte de cette déclaration en exprimant sa conviction que cette liste est la seule possibilité de résoudre la crise du Parti.

La liste du nouveau Comité Directeur élaborée par les fractions est la suivante :

CENTRE

Titulaires : $\quad$ Marcel Cachin, Frossard, Garchery, Gourdeaux, Jacob, Laguesse, Lucie Leiciague, Marrane, Paquereaux, Louis Sellier.

Suppléants : $\quad$ Dupillet, Pierpont, Plais.

GAUCHE

Titulaires : $\quad$ Bouchez, Cordier, Demusois, Amédée Dunois, Rosmer, Souvarine, Tommasi, Treint, Vaillant-Couturier.

Suppléants : $\quad$ Marthe Bigot, Salles. 


\section{FRACTION RENOULT}

Titulaires : $\quad$ Bartieret, Dubus, Fromont, Werth.

Suppléants : Lespagnol.

Un Conseil national avec pouvoir de Congrès ratifiera cette liste, au plus tard dans la deuxième quinzaine de janvier.

Jusqu’à ce moment, le Comité Directeur provisoire nommé par le Congrès de Paris reste en fonction.

b) La Presse.

Le Congrès confirme le régime de la presse déjà décidé : 1) Direction des journaux remise au bureau politique ; 2) Editorial non signé apportant chaque jour aux lecteurs l'opinion du Parti ; 3) Interdiction pour les journalistes du Parti de collaborer à la presse bourgeoise.

\section{Directeur de l'Humanité : $\quad$ Marcel Cachin,}

Secrétaire général : Amédée Dunois, tous deux ayant des pouvoirs égaux, c'est-à-dire que tout conflit surgissant entre eux sera porté devant le bureau politique et tranché par lui.

c) Secrétariat de rédaction : un au Centre et un à la Gauche.

La rédaction du Bulletin Communiste sera remise à un camarade de la Gauche.

Les rédacteurs démissionnaires rentreront à la rédaction. 
Pour préparer le Conseil National, la page du Parti sera rétablie avec liberté d'écrire pour chaque tendance.

d) Secrétariat général. - Il sera assuré sur la base paritaire par un camarade du Centre et un de la Gauche, tout conflit étant tranché par le bureau politique.

Titulaires : $\quad$ Frossard et Treint. Suppléant de Frossard : Louis Sellier.

e) Délégués à l'Exécutif. — Le Congrès considère comme absolument nécessaire pour établir des liens tout à fait normaux et cordiaux entre le Comité Exécutif et le Parti Français que les deux tendances les plus importantes soient représentées à Moscou par 6 camarades, les plus qualifiés et autorisés de leurs tendances, c'est-à-dire par les camarades Frossard et Souvarine, au moins pour trois mois, jusqu’à la fin de la crise que traverse actuellement le Parti français.

La représentation du Parti français à Moscou par Frossard et Souvarine donnera la pleine certitude que chaque suggestion de l'Exécutif, faite en accord avec ces deux camarades, aura l’adhésion du Parti tout entier.

f) Appointements des fonctionnaires du Parti. — En ce qui concerne les appointements des fonctionnaires du Parti, rédacteurs, etc..., le Parti créera une commission spéciale composée de camarades ayant toute la confiance morale du Parti pour régler cette question à deux points de vue :

1) Éliminer toute possibilité de cumul des appointements qui provoque une légitime indignation dans la masse ouvrière du Parti ;

2) Pour les camarades dont le travail est absolument nécessaire au Parti, créer une situation qui leur permette de consacrer toutes leurs forces au service du Parti.

g) Commissions. - 
1) Conseil d'administration de l'Humanité : 6 Centre, 5 Gauche, 2 tendance Renoult.

La Commission accepte que la R.P. fonctionne aussi exceptionnellement pour les commissions importantes.

2) Secrétariat syndical : un secrétaire du Centre et un secrétaire de la Gauche — tout conflit entre eux étant examiné par le Bureau Politique.

h) Cas litigieux. - Les cas litigieux qui émaneraient des décisions d'organisation prises à Moscou, dans leur application, devront être réglés par une commission spéciale composée d'un représentant du Centre, un représentant de la Gauche et du délégué de l’Exécutif comme Président.

i) Postes prohibés pour les anciens Francs-Maçons. - Par postes prohibés pour les anciens Francs-Maçons, on entend les postes dont les titulaires ont le mandat de représenter plus ou moins indépendamment, sous leur propre responsabilité, les idées du Parti, devant la masse ouvrière, par la parole et par la plume.

S’il y avait entre les deux fractions, une divergence dans la détermination de ces postes, elle serait soumise à la Commission indiquée plus haut.

En cas de difficultés techniques pour la réintégration des rédacteurs démissionnaires, la commission envisagée précédemment réglera ces difficultés.

Toutes les résolutions ne concernant pas la constitution du Comité Directeur sont applicables immédiatement. 
Manifestes, thèses et résolutions

des quatre premiers congrès

de l’Internationale communiste 1919-1923

(juin 1934)

Quatrième Congrès, novembre 1922.

- 19 -

\section{Programme de travail et d'action du Parti Communiste Français}

\section{$\underline{\text { Retour à la table des matières }}$}

1. La tâche la plus pressante du Parti est d'organiser la résistance du prolétariat à l'offensive du Capital, qui se déploie en France comme dans les autres grands Etat industriels. La défense de la journée de huit heures, la conservation et l'augmentation des salaires acquis, la lutte pour toutes les revendications économiques journalières constituent la meilleure plate-forme pour rassembler le prolétariat dispersé, lui rendre la confiance en sa force et en son avenir. Le Parti doit immédiatement prendre en mains l'initiative des mouvements d'ensemble susceptibles de faire échec à l'offensive du Capital et de rendre à la classe ouvrière la notion de son unité.

2. Le Parti doit mener campagne pour mettre en évidence devant les travailleurs l'interdépendance du maintien de la journée de huit heures et de la sauvegarde des salaires, la répercussion inévitable de l'une de ces revendications sur l'autre. Il doit saisir comme possibilités d'agitation, non seulement les menées du patronat, mais aussi les atteintes portées par l'Etat aux intérêts immédiats des ouvriers, comme par exemple l'impôt sur les salaires, et toutes les questions écono- 
miques intéressant la classe ouvrière, telle que l'augmentation des loyers, les impôts de consommation, les assurances sociales, etc...

Le Parti entreprendra une active campagne de propagande dans la classe ouvrière pour la création de Conseils d'usines englobant l'ensemble des travailleurs de chaque entreprise, qu'ils soient ou ne soient pas déjà organisés économiquement ou politiquement, et destinés notamment à exercer un contrôle ouvrier sur les conditions du travail et de la production.

3. Les mots d'ordre de lutte pour les revendications matérielles pressantes du prolétariat doivent servir de moyens de réalisation du front unique contre la réaction économique et politique. La tactique du front unique ouvrier sera la règle générale des actions de masse. Le Parti doit créer des conditions favorables à la réussite de cette tactique en entreprenant une préparation sérieuse de sa propre organisation et des éléments sympathisants, par tous les moyens de propagande et d'agitation dont il dispose. La presse, les tracts, les brochures, les réunions de toute espèce, tout doit concourir à cette préparation que le Parti étendra à tous les groupements prolétariens comptant des communistes. Le Parti doit faire appel aux organisations ouvrières rivales importantes, politiques et économiques, avec éclat et sans jamais cesser de commenter publiquement ses propositions ou celles des réformistes, les acceptations et les refus des uns ou des autres. Il ne renoncera en aucun cas à son indépendance complète, à son droit de critique des participants à l'action. Il cherchera toujours à prendre et à conserver l'initiative et à influer sur toute autre initiative dans le sens de son programme.

4. Pour se mettre en condition de participer à l'action ouvrière sous toutes ses formes, de contribuer à l'orienter ou de remplir dans certaines circonstances un rôle déterminant, le Parti doit constituer, sans perdre un jour, son organisation de travail syndical. La formation de Commissions syndicales auprès des fédérations et sections (décidée par le Congrès de Paris) et de groupes communistes dans les usines et grandes entreprises capitalistes ou étatiques, fera pénétrer dans les masses ouvrières les ramifications du Parti, grâce auxquelles celui-ci pourra diffuser ses mots d'ordre et accroître l'influence communiste sur le mouvement prolétarien. Les Commissions syndicales, à tous les degrés de la structure du Parti et des syndicats, se tiendront en liaison avec les communistes restés, en accord avec le Parti, dans la C.G.T. réformiste et les guideront dans leur opposition à la politique 
des dirigeants officiels; elles enregistreront les membres du Parti syndiqués, contrôleront leur activité et leur transmettront les directives du Parti.

5. Le travail communiste dans tous les syndicats sans exception consiste en premier lieu dans la lutte pour le rétablissement de l'unité syndicale indispensable à la victoire du prolétariat. Chaque occasion doit être utilisée par les communistes pour montrer les effets néfastes de la division actuelle et préconiser la fusion. Le Parti combattra toute tendance à la dispersion de l'action, au morcellement de l'organisation, au particularisme professionnel ou local, à l'idéologie anarchiste. Il soutiendra la nécessité de la centralisation du mouvement, la formation de vastes organisations par industries, la coordination des grèves pour substituer aux actions localisées et limitées, vouées d'avance à l'insuccès, les actions d'ensemble susceptibles d'entretenir la confiance des travailleurs dans leur force. Dans la C.G.T. Unitaire, les communistes combattront toute tendance contraire au ralliement des syndicats français à l'Internationale Syndicale Rouge. Dans la C.G.T. réformiste, ils dénonceront l'Internationale d'Amsterdam et les pratiques de collaboration de classe des dirigeants. Dans les deux C.G.T., ils préconiseront les démonstrations et actions communes, les grèves en commun, le front unique, l'unité organique, le programme intégral de l’Internationale Syndicale Rouge.

6. Le Parti doit tirer profit de chaque mouvement de masses spontané ou organisé, revêtant une certaine ampleur, pour mettre en lumière le caractère politique de toute lutte de classe, et utiliser les conditions favorables à la propagation de ses mots d'ordre de lutte politique, comme l'amnistie, l'annulation du traité de Versailles, l'évacuation de la rive gauche du Rhin par l'armée d'occupation, etc...

7. La lutte contre le traité de Versailles et ses conséquences doit passer au premier plan des préoccupations du Parti. Il s'agit de rendre active la solidarité des prolétariats de France et d'Allemagne contre la bourgeoisie des deux pays, profiteuse du traité. Pour cela, le devoir urgent du Parti français est de faire connaître aux ouvriers et aux soldats la situation tragique de leurs frères allemands, écrasés sous les difficultés matérielles de la vie, résultant essentiellement des conséquences du traité. L’Etat allemand ne satisfait aux exigences des Alliés qu'en chargeant davantage la classe ouvrière. La bourgeoisie française épargne la bourgeoisie allemande, traite avec elle au détriment des ouvriers, favorise son entreprise de mainmise sur les services publics et lui garantit aide et protection contre le mouvement révolutionnaire. Les deux bourgeoisies se préparent à 
conclure l'alliance du fer français et du charbon allemand, à s'entendre pour l'occupation de la Ruhr qui signifiera la mise en esclavage des mineurs du bassin. Le danger menace non seulement les exploités de la Ruhr, mais encore les travailleurs français, incapables de soutenir la concurrence de la main-d'œuvre allemande, réduite pour les capitalistes français à un bon marché exceptionnel grâce à la dépréciation du mark. Le Parti doit faire comprendre cette situation à la classe ouvrière française et la tenir en garde contre le péril imminent. La presse doit constamment décrire les souffrances du prolétariat allemand, victime du traité de Versailles, et démontrer l'impossibilité de réaliser le traité. Une propagande spéciale doit être faite dans les régions occupées militairement et dans les régions dévastées, pour dénoncer les deux bourgeoisies comme responsables des maux qui affligent ces contrées et développer l'esprit de solidarité des ouvriers des deux pays. Le mot d'ordre communiste doit être : fraternisation des soldats et des ouvriers français et allemands sur la rive gauche du Rhin. Le Parti se tiendra en liaison étroite avec le Parti frère d'Allemagne pour mener à bien cette lutte contre le traité de Versailles et ses conséquences. Le Parti combattra l'impérialisme français, non seulement dans sa politique à l'égard de l'Allemagne, mais dans ses manifestations sur toute la surface du globe, en particulier les traités de paix de Saint-Germain, Neuilly, Trianon et Sèvres.

8. Un travail systématique de pénétration communiste dans l'armée doit être entrepris par le Parti. La propagande antimilitariste doit se différencier nettement du pacifisme bourgeois hypocrite et s'inspirer du principe de l'armement du prolétariat et du désarmement de la bourgeoisie. Dans leur presse, au Parlement, en toute occasion favorable, les communistes soutiendront les revendications des soldats, préconiseront la reconnaissance des droits politiques de ceux-ci, etc... Lors des appels de nouvelles classes, des menaces de guerre, l'agitation antimilitariste révolutionnaire doit être intensifiée. Elle se fera sous la direction d'un organe spécial du Parti, avec participation des Jeunesses Communistes.

9. Le Parti doit prendre en mains la cause des populations coloniales exploitées et opprimées par l'impérialisme français, soutenir leurs revendications nationales constituant des étapes vers leur libération du joug capitaliste étranger, défendre sans réserve leur droit à l'autonomie ou à l'indépendance. Lutter pour leurs libertés politiques et syndicales sans restrictions, contre la conscription des indigènes, pour les revendications des soldats indigènes, telle est la tâche immédiate 
du Parti. Celui-ci doit combattre impitoyablement les tendances réactionnaires existant, même parmi certains éléments ouvriers, et consistant dans la limitation des droits des indigènes. Il créera auprès de son Comité Directeur un organisme spécial consacré au travail communiste dans les colonies.

10. La propagande dans la classe paysanne, tendant à gagner à la Révolution la majorité des ouvriers agricoles, métayers et fermiers, et à acquérir les sympathies des petits propriétaires, doit être accompagnée d'une action pour l'obtention de meilleures conditions de vie et de travail des paysans salariés ou dépendant de gros propriétaires. Une telle action exige que les organisations régionales du Parti établissent et propagent des programmes de revendications immédiates appropriées aux conditions spéciales de chaque région. Le Parti doit favoriser les associations agricoles, coopératives et syndicales qui vont à l'encontre de l'individualisme paysan. Il doit particulièrement s'attacher à la création et au développement des syndicats professionnels parmi les ouvriers agricoles.

11. Le travail communiste parmi les ouvrières est d'un intérêt primordial et exige une organisation spéciale. Une commission centrale auprès du Comité Directeur avec un secrétariat permanent, des commissions locales de plus en plus nombreuses, un organe consacré à la propagande féminine sont nécessaires. Le Parti doit soutenir l'unification des revendications économiques des ouvrières et des ouvriers, l'égalisation des salaires pour un même travail sans distinction de sexe, la participation des femmes exploitées aux campagnes et aux luttes des ouvriers.

12. Il faut consacrer au développement des Jeunesses Communistes des efforts plus méthodiques et plus soutenus que le Parti ne l'a fait dans le passé. Des rapports réciproques doivent être établis entre le Parti et les Jeunesses Communistes à tous les échelons de l'organisation. En principe, la Jeunesse doit être représentée dans toutes les commissions formées auprès du Comité Directeur. Les fédérations, sections, propagandistes du Parti ont l'obligation de donner leur aide aux groupes de Jeunesses existants, d'en créer de nouveaux. Le Comité Directeur est tenu de veiller au développement de la presse des Jeunesses et d'assurer à celles-ci une tribune dans les organes centraux. Le Parti doit faire siennes dans les syndicats les revendications de la jeunesse ouvrière conformes à son programme. 
13. Dans les coopératives, les communistes défendront le principe de l'organisation nationale unique et créeront des groupes communistes reliés à la section coopérative de l'Internationale Communiste par l'intermédiaire d'une commission rattachée au Comité Directeur. Dans chaque fédération, une commission spéciale doit se consacrer au travail communiste dans les coopératives. Les communistes s'efforceront d'utiliser la coopération comme auxiliaire du mouvement ouvrier.

14. Les élus au Parlement, aux municipalités, etc..., doivent mener la lutte la plus énergique liée étroitement aux luttes ouvrières et aux campagnes conduites par le Parti et les organisations syndicales hors du Parlement. Les députés communistes, sous le contrôle et la direction du Comité Central du Parti, les conseillers communistes municipaux, généraux et d'arrondissement, sous le contrôle et la direction des sections et des fédérations, doivent être employés par le Parti comme agents d'agitation et de propagande, conformément aux thèses du $2^{\mathrm{e}}$ Congrès de l’Internationale Communiste.

15. Le Parti, pour s'élever à la hauteur des tâches tracées par son programme et par les Congrès nationaux et internationaux et pour se rendre apte à les réaliser, doit perfectionner et renforcer son organisation, selon l'exemple des grands partis communistes des autres pays et les règles de l'Internationale Communiste. Il lui faut une centralisation sévère, une discipline inflexible, une subordination étroite de chaque membre du Parti, de chaque organisme à l'organisme placé au-dessus. Il est indispensable aussi de développer l'éducation marxiste des militants en multipliant systématiquement les cours doctrinaux dans les sections, en ouvrant des écoles du Parti, ces cours et ces écoles étant mis sous la direction d'une Commission Centrale du Comité Directeur. 
Manifestes, thèses et résolutions

des quatre premiers congrès

de l’Internationale communiste 1919-1923

(juin 1934)

Quatrième Congrès, novembre 1922.

-20 -

\section{Résolution sur la question italienne}

$\underline{\text { Retour à la table des matières }}$

Les $2^{\mathrm{e}}$ et $3^{\mathrm{e}}$ Congrès de l'Internationale Communiste se sont déjà occupés en détail de la question italienne. Le $4^{\mathrm{e}}$ Congrès est donc en mesure de tirer certaines conclusions.

Vers la fin de la guerre impérialiste mondiale, la situation en Italie était objectivement révolutionnaire. La bourgeoisie avait lâché les rênes du pouvoir. L’appareil de l'Etat bourgeois était détraqué, l’inquiétude s'était emparée de la classe dominante. Les masses ouvrières étaient lasses de la guerre et dans diverses régions se trouvaient même en état d'insurrection. Des fractions considérables de la classe paysanne commençaient à se soulever contre les propriétaires fonciers et contre l'Etat et étaient disposées à soutenir la classe ouvrière dans sa lutte révolutionnaire. Les soldats étaient contre la guerre et prêts à fraterniser avec les ouvriers.

Les conditions objectives d'une révolution victorieuse étaient réalisées. Il ne manquait plus que le facteur subjectif ; il manquait un parti ouvrier décidé, prêt au combat, conscient de sa force, révolutionnaire, en un mot: un véritable Parti Communiste. 
D’une façon générale, à la fin de la guerre, une situation analogue existait dans presque tous les pays belligérants. Si la classe ouvrière n’a pas triomphé en 1919-1920 dans les pays les plus importants, cela provient précisément de l'absence d'un parti ouvrier révolutionnaire. C'est ce qui s'est manifesté plus particulièrement en Italie, pays qui était le plus rapproché de la révolution et qui traverse actuellement une période de contre-révolution.

L'occupation des usines par les ouvriers italiens, en automne 1920, a constitué un moment décisif dans le développement de la lutte des classes en Italie. Instinctivement, les ouvriers italiens poussaient à la solution de la crise dans un sens révolutionnaire. Mais l'absence d'un parti ouvrier révolutionnaire décida du sort de la classe ouvrière, consacra sa défaite et prépara le triomphe actuel du fascisme. La classe ouvrière n'a pas su trouver suffisamment de forces, au point culminant de son mouvement, pour s'emparer du pouvoir ; voilà pourquoi la bourgeoisie, en la personne du fascisme, son aile la plus énergique, réussit bientôt à faire mordre la poussière à la classe ouvrière et à établir sa dictature. Nulle part, la preuve de la grandeur du rôle historique d'un Parti Communiste pour la révolution mondiale n’a été fournie d'une façon plus nette que dans ce pays, où précisément, faute d'un tel parti, le cours des événements a pris une tournure favorable à la bourgeoisie.

Non pas qu'il n’y ait pas eu en Italie, pendant ces années décisives, de parti ouvrier : le vieux Parti Socialiste était considérable par le nombre de ses membres et jouissait, extérieurement du moins, d'une grande influence. Mais il abritait dans son sein des éléments réformistes qui le paralysaient à chaque pas. Malgré la première scission qui avait eu lieu en 1912 (exclusion de l'extrême-droite) et en 1914 (exclusion des Francs-Maçons), il restait encore dans le Parti Socialiste Italien, en 1919-1920, un grand nombre de réformistes et de centristes. A tous les moments décisifs, les réformistes et les centristes étaient comme un boulet aux pieds du Parti. Nulle part ils n'étaient autre chose que des agents de la bourgeoisie dans le camp de la classe ouvrière.

Aucun moyen ne fut négligé pour trahir la classe ouvrière au profit de la bourgeoisie. Des trahisons analogues à celles qui furent commises par les réformistes pendant l'occupation des usines en 1920 se rencontrent fréquemment dans l'histoire du réformisme, qui n'est qu'une chaîne ininterrompue de trahisons. Les 
souffrances effroyables de la classe ouvrière italienne sont dues en première ligne aux trahisons des réformistes.

Si la classe ouvrière italienne est obligée en ce moment de reprendre, pour ainsi dire, par le commencement, un chemin terriblement dur à parcourir, c'est parce que les réformistes ont été trop longtemps tolérés dans le Parti Italien.

Au début de 1921 se produisit la rupture de la majorité du Parti Socialiste avec l'Internationale Communiste. A Livourne, le centre préféra se séparer de l'Internationale Communiste et de 58000 communistes italiens, simplement pour ne pas rompre avec 16000 réformistes. Deux partis se constituèrent : d'une part, le jeune Parti Communiste qui, en dépit de tout son courage et de tout son dévouement, était trop faible pour mener la classe ouvrière à la victoire; d'autre part, le vieux Parti Socialiste dans lequel, après Livourne, l'influence corruptrice des réformistes alla grandissante. La classe ouvrière était divisée et sans ressources. Avec l'aide des réformistes, la bourgeoisie consolida ses positions. C'est alors seulement que commença l'offensive du capital dans le domaine tant économique que politique. Il fallut presque deux années entières de trahison ininterrompue de la part des réformistes pour que même les chefs du centre, sous la pression des masses, reconnaissent leurs erreurs et se proclament prêts à en tirer les conséquences.

Ce n'est qu'au Congrès de Rome, en octobre 1922, que les réformistes furent exclus du Parti Socialiste. On en était arrivé au point que les chefs les plus en vue des réformistes pouvaient se vanter ouvertement d'avoir réussi à saboter la révolution en restant dans le Parti Socialiste Italien et en paralysant son action aux heures décisives. Les réformistes ont maintenant quitté les rangs du Parti Socialiste Italien et sont passés ouvertement dans le camp de la bourgeoisie. Ils ont cependant laissé dans les masses un sentiment de faiblesse, d'humiliation et de déception et affaibli considérablement, numériquement et politiquement, le Parti Socialiste.

Cette triste, mais très édifiante leçon des événements d'Italie doit profiter à tous les ouvriers conscients du monde entier.

$1^{\circ}$ Le réformiste : voilà l'ennemi. 
$2^{\circ}$ Les hésitations des centristes constituent un danger mortel pour un parti ouvrier.

$3^{\circ}$ La condition la plus importante de la victoire du prolétariat, c'est l'existence d'un Parti Communiste conscient et homogène.

Tels sont les enseignements de la tragédie italienne.

En considération de la décision par laquelle le Congrès du Parti Socialiste Italien à Rome (octobre 1922) exclut les réformistes du parti et se déclare prêt à adhérer sans réserves à l'Internationale Communiste, le $4^{\mathrm{e}}$ Congrès de l’Internationale Communiste décide :

1. La situation générale en Italie, surtout après la victoire de la réaction fasciste, exige impérieusement la fusion rapide de toutes les forces révolutionnaire du prolétariat. Les ouvriers italiens reprendront courage s'ils voient se produire, après les défaites et les scissions, une nouvelle concentration de toutes les forces révolutionnaires.

2. L’Internationale Communiste adresse au prolétariat italien, si lourdement éprouvé, ses salutations fraternelles. Elle est parfaitement convaincue de la sincérité des éléments prolétariens du Parti Socialiste Italien et décide de recevoir ce parti dans l'Internationale Communiste.

3. Le $4^{\mathrm{e}}$ Congrès mondial considère l'application des 21 conditions comme une chose hors de toute discussion. Il charge donc l'Exécutif de l'I.C., en raison des précédents italiens, de veiller avec un soin particulier à l'application de ces conditions, avec toutes les conséquences qui en résultent.

4. Vu qu'au Congrès du Parti de Rome, le député Vella s’est déclaré contre l'acceptation des 21 conditions, le $4^{\mathrm{e}}$ Congrès estime impossible d'accepter Vella et ses partisans dans l'Internationale Communiste et invite le Comité Directeur du Parti Socialiste Italien à exclure du Parti Vella et ses partisans.

5. Attendu qu'en vertu des statuts de l'Internationale Communiste, il ne saurait y avoir dans un pays plus d'une section de l'I.C., le 4 e Congrès mondial décide la fusion immédiate du Parti Communiste et du Parti Socialiste italien. Le Parti 
unifié portera le nom de "Parti Communiste Unifié d'Italie (section de l’Internationale Communiste)».

6. Pour la réalisation pratique de cette fusion, le $4^{\mathrm{e}}$ Congrès désigne un Comité spécial d'organisation, composé de deux membres de chaque parti, comité qui fonctionnera sous la présidence d'un membre de l'Exécutif.

Sont élus à ce Comité d'organisation :

Pour le Parti communiste, les camarades Bordiga et Tasca.

Pour le Parti Socialiste, Serrati et Maffi.

Pour l'Exécutif, Zinoviev (avec le droit pour l'Exécutif de remplacer, en cas de besoin, Zinoviev par un autre membre de l'Exécutif, de même que les quatre autres membres du Comité).

Ce Comité devra élaborer dès à présent, à Moscou, les conditions détaillées de la fusion en Italie. Il est subordonné dans tout son travail à l’Exécutif.

7. Dans les diverses régions et dans les grandes villes, des comités d'organisation analogues seront également constitués et seront composés de deux membres du Parti Communiste (un de la majorité, un de la minorité), deux camarades du Parti Socialiste (un des maximalistes, un des terzinternazionalistes), le président étant nommé par le représentant de l’Exécutif.

8. Ces comités d'organisation ont pour tâche, non seulement de préparer, au centre et dans la périphérie, la fusion organique, mais aussi de diriger désormais les actions politiques communes des deux partis.

9. En outre, un Comité Syndical sera immédiatement constitué et aura pour tâche de flétrir, à la Confederazione del Lavoro, la trahison des hommes d'Amsterdam et de gagner la majorité de l'organisation à l'Internationale Syndicale Rouge. Ce Comité sera également composé de deux représentants de chaque parti (un de la majorité, un de la minorité du Parti Communiste ; un des maximalistes et un des terzinternazionalistes), sous la présidence d'un camarade désigné par l’Exécutif de l'Internationale Communiste ou par son Présidium.

10. Dans les villes où existent un journal communiste et un journal socialiste, ils devront fusionner au plus tard le $1^{\text {er }}$ janvier 1923. Le $1^{\text {er }}$ janvier 1923 au plus 
tard, un organe central commun devra commencer à paraître. La rédaction de cet organe central sera désignée par l’Exécutif pour l’année prochaine.

11. Le Congrès de la fusion devra avoir lieu au plus tard le 15 février 1923. Si, avant ce Congrès commun, des congrès spéciaux des deux partis sont nécessaires, c’est l’Exécutif qui décidera de la date, du lieu et des conditions de ces congrès.

12. Le Congrès décide de lancer un manifeste sur la question de la fusion, manifeste qui devra être immédiatement publié avec la signature du Présidium et des délégués des deux Partis au $4^{\mathrm{e}}$ Congrès.

13. Le Congrès rappelle à tous les camarades italiens la nécessité de la plus stricte discipline. Tous les camarades, sans exception, sont tenus de faire tout leur possible pour que la fusion s'opère sans gêne et au plus tôt. Toute faute contre la discipline constituerait dans la situation actuelle un crime contre le prolétariat italien et l'Internationale Communiste. 
Manifestes, thèses et résolutions

des quatre premiers congrès

de l’Internationale communiste 1919-1923

(juin 1934)

Quatrième Congrès, novembre 1922.

- 21 -

\section{Résolution sur la question tchécoslovaque}

\section{I. - L'OPPOSITION}

\section{$\underline{\text { Retour à la table des matières }}$}

L'exclusion des camarades Iilek, Bolen, etc..., fut le résultat des violations répétées de la discipline dont ces camarades se sont rendus coupables dans le Parti. Après que leur représentant, le camarade Iilek, de même que celui de la direction du Parti, le camarade Sméral, eurent donné à Moscou leur assentiment à une résolution qui constatait qu'il n'y avait aucune divergence fondamentale dans le Parti Communiste Tchécoslovaque et qui, en même temps, critiquait le manque de pratique dans un certain nombre de questions, il était du devoir de tous les camarades qui reconnaissaient ce manque de pratique de se mettre à l'œuvre afin de le combler.

Au contraire, l'opposition exigea l'existence d'un organe de fraction, Kommunista, se mettant ainsi en contradiction avec la résolution du $3^{\mathrm{e}}$ Congrès interdisant la formation de fractions. Quelques jours avant la réunion de la Commission de la Conférence du Parti, l'opposition accomplit une franche violation de la discipline en lançant, malgré l'avertissement de la Direction, un appel qui soutenait les plus graves accusations contre le Comité Directeur. Par le refus de retirer 
ces accusations, l'opposition a particulièrement irrité la Commission et la Conférence du Parti et provoqué par là son exclusion.

Devant l'Internationale tout entière, l'opposition a lancé une accusation contre la majorité et contre Sméral, en disant qu'ils travaillaient pour une coalition gouvernementale avec les éléments de gauche de la bourgeoisie. Cette accusation est en contradiction avec l'action publique du Parti et doit être reconnue comme étant absolument injustifiée. Dans le programme de l'opposition, tel qu'il a été exprimé par Vajtauer, il y a des réclamations d'un caractère syndicaliste et anarchiste qui ne sont pas des conceptions marxistes.

Le fait que l'opposition se solidarise avec ce programme prouve que dans les questions fondamentales elle ne représente qu'une déviation anarchistesyndicaliste des principes de l'Internationale Communiste.

Cependant, le $4^{\mathrm{e}}$ Congrès, estimant inopportune l'exclusion de l'opposition, réintègre cette dernière avec un blâme et une suspension de toutes fonctions jusqu'au prochain congrès du Parti Communiste tchécoslovaque. La décision du Congrès de ne pas confirmer, pour cause d'inopportunité, l'exclusion de l'opposition ne doit pas être interprétée comme une approbation de la ligne de conduite et du programme de l'opposition. Cette décision est dictée par les considérations suivantes : la Direction du Parti a négligé d'expliquer auparavant à l'opposition que la formation d'un organe de fraction est inadmissible, et c'est pourquoi l'opposition se croyait en droit de lutter pour l'existence d'un tel organe. La Direction du Parti a laissé s'accomplir toute une série d'actes d'indiscipline et a affaibli de la sorte le sentiment de la nécessité de la discipline et de la responsabilité chez l'opposition. Le $4^{\mathrm{e}}$ Congrès laisse les camarades exclus dans le Parti, si l’opposition reconnaît la nécessité de remplir strictement ses obligations, si elle se soumet sans récriminer à la discipline du Parti.

Cette soumission à la discipline oblige l'opposition à renoncer aux affirmations et aux accusations qui sapent l'unité du Parti et qui ont été reconnues sans fondement et fausses par les recherches de la Commission. Elle l'oblige à obéir à tous les ordres du Comité Directeur. Quand un camarade se considère comme lésé dans ses droits, il n’a qu'à s'adresser aux organismes compétents du Parti (Comité Exécutif, Conférence Nationale) et, en dernière instance, aux organes de contrôle 
de l'Internationale Communiste. Jusqu'à la décision de la plus haute instance, chacun doit se soumettre à la décision de l'organisation du Parti.

\section{La presse}

La presse doit être uniquement dirigée par le Comité Directeur du Parti. Il est inadmissible que l'organe central du Parti se permette, non seulement de mener une politique particulière, mais encore de considérer cela comme son droit. Même quand la rédaction pense que la Direction responsable a commis une faute dans un cas concret, il est de son devoir de se soumettre à la décision dont il s'agit. La fonction de rédacteur ne constitue pas une surinstance, mais comme toutes les fonctions du Parti, elle est subordonnée au Comité Directeur. Cela ne veut pas dire que les rédacteurs n'aient pas le droit d'exprimer les nuances de leur pensée dans les articles de polémique signés de leurs noms. Les discussions sur les affaires du Parti doivent être faite dans la presse commune du Parti. Elles ne doivent pas cependant être faites d'une façon qui pourrait mettre en danger la discipline. Le Comité Directeur et toutes les organisations du Parti doivent préparer leurs actions par une discussion à l’intérieur des organisations.

\section{Les défauts du Parti}

Le $4^{\mathrm{e}}$ Congrès confirme les thèses de l'Exécutif élargi de juillet, qui avait indiqué les défauts du Parti Communiste tchécoslovaque et qui déclarait qu'ils provenaient de la transition du Parti du social-démocratisme au communisme. Le fait que ces défauts ont été reconnus aussi bien par le Comité Directeur que par l’opposition leur crée le devoir de travailler ardemment à les corriger. Le Congrès affirme que le Parti avance trop lentement dans la suppression de ces défauts ; ainsi le Parti a insuffisamment songé à la propagation des idées communistes parmi les soldats tchèques, quoique sa légalité et le fait que les soldats tchèques ont le droit de voter le lui permettaient.

Le $4{ }^{\mathrm{e}}$ Congrès exige du Parti Communiste tchécoslovaque de se consacrer plus qu'il ne l'a fait jusqu'ici à la question du chômage. Vu l'extension du chô- 
mage et la situation précaire des chômeurs, le Parti Communiste tchécoslovaque a le devoir de ne pas se contenter de telle ou telle démonstration, mais de mener une agitation systématique et une action démonstrative méthodique parmi les chômeurs de tout le pays. Il a le devoir de lutter de la façon la plus énergique pour les intérêts des chômeurs, tant au Parlement que dans les conseils communaux, d'accorder l'action parlementaire avec l'action des syndicats dans la rue.

L'action parlementaire doit avoir un caractère beaucoup plus démonstratif, elle doit présenter aux masses, sous une forme nette, l'attitude du Parti Communiste devant la politique de la classe dominante et leur donner la volonté de conquérir le pouvoir dans l'Etat.

Vu les grandes luttes économiques qui ont lieu en Tchécoslovaquie et qui peuvent chaque jour se transformer en une lutte politique, le Comité Directeur doit être réorganisé de façon à pouvoir rapidement et résolument prendre position sur chaque question. Les organisations et les membres du Parti doivent, sans hésitation, maintenir la discipline.

Les questions du front unique et du gouvernement ouvrier ont été heureusement résolues par le Parti. La Direction du Parti a, avec raison, repoussé quelques erreurs, comme par exemple la conception du camarade Votava tendant, à propos du gouvernement ouvrier, à la création d'une combinaison purement parlementaire. Le Parti doit savoir qu'un gouvernement ouvrier n’est possible que si l'on réussit, par une large et énergique agitation des masses d'ouvriers socialnationalistes, social-démocrates et indifférents, à convaincre ces derniers de la nécessité d'une rupture avec la bourgeoisie, à séparer de celle-ci une partie des paysans et de la petite bourgeoisie des villes qui souffrent de la cherté de la vie, et à les enrôler dans les rangs du front anticapitaliste ; dans ce but, le Parti doit s’immiscer dans chaque conflit par des démarches décisives pour l'élargissement des conflits, chaque fois que c'est possible, afin d'inculquer aux masses le sentiment que le Parti Communiste tchécoslovaque est un centre d'attraction vers le front unique de tous les éléments anticapitalistes.

Pour que le gouvernement ouvrier puisse se former et se maintenir, le Parti doit concentrer toutes ses forces et réunir en de puissants syndicats les ouvriers exclus des syndicats d'Amsterdam. Il doit, tout au moins, recruter une partie des ouvriers et des paysans pour la défense des intérêts de la classe ouvrière. De cette 
façon on évitera la naissance du fascisme qui prépare la vie à l'oppression de la classe ouvrière par la violence armée de la bourgeoisie.

C'est pourquoi la propagande et la lutte pour le gouvernement ouvrier doivent toujours être liées avec la propagande et la lutte pour les organes de masses du prolétariat (comités de défense, comités de contrôle, conseils d'entreprises). Il est également nécessaire de dérouler devant le yeux des ouvriers le programme du gouvernement ouvrier (report des charges de l'Etat sur les propriétaires, contrôle de la production par les organes ouvriers, armement du prolétariat). Il est nécessaire de montrer aux ouvriers la différence entre la coalition social-démocrate bourgeoise et le gouvernement ouvrier basé sur les organes du prolétariat.

Tous les membres du Parti ont à collaborer à cette œuvre. Ce n'est pas la propagation de fausses accusations et la méfiance contre les chefs du Parti, mais c'est une critique impartiale de leurs défauts, un travail quotidien et positif pour les corriger, qui feront du Parti un véritable Parti Communiste apte à accomplir les tâches que les événements de Tchécoslovaquie poseront devant lui. 
Manifestes, thèses et résolutions

des quatre premiers congrès

de l'Internationale communiste 1919-1923

(juin 1934)

Quatrième Congrès, novembre 1922.

- 22 -

\section{Résolution sur la question norvégienne}

$\underline{\text { Retour à la table des matières }}$

Après avoir pris connaissance du rapport de la Commission, le Congrès décide :

1) Le Comité Central du parti frère de Norvège doit accorder toute son attention à la nécessité d’appliquer avec plus de précision toutes les décisions de l'Internationale, aussi bien celles de ses congrès que celles de ses organes exécutifs. Dans les organes du Parti, ainsi que dans les résolutions et décisions des instances dirigeantes du Parti, il ne doit y avoir aucun doute sur le droit de l'Internationale Communiste à intervenir dans les affaires intérieures des sections nationales.

2) Le Congrès exige que le Parti soit, un an au plus tard après son prochain congrès national, réorganisé sur la base de l'admission individuelle. L’Exécutif devra être informé périodiquement, et au moins une fois tous les deux mois, des mesures pratiques dans ce sens et de leurs résultats.

3) Pour ce qui est du contenu de la presse, le Parti est obligé d’appliquer immédiatement les décisions des précédents Congrès mondiaux et les directives 
contenues dans la lettre de l'Exécutif en date du 23 septembre dernier. Les noms social-démocrates des journaux du Parti doivent être changés dans les trois mois, à compter du jour de la clôture du Congrès de l'Internationale Communiste.

4) Le Congrès confirme la justesse du point de vue de l'Exécutif qui a signalé les fautes parlementaires des représentants du Parti. Le Congrès est d'avis que les parlementaires communistes doivent naturellement être soumis au contrôle et à la critique de sa presse ; mais cette critique doit toujours être basée sur des faits et porter un caractère amical.

5) Le Congrès considère qu'il est permis et nécessaire dans la lutte contre toute la bourgeoisie de profiter des antagonismes entre les différentes couches de la bourgeoisie norvégienne et plus particulièrement des antagonismes entre le grand capital et les agrariens d'un part, et la classe paysanne de l'autre. La lutte pour la conquête des masses paysannes doit constituer une des tâches essentielles du parti prolétarien de Norvège.

6) Le Congrès confirme une fois de plus la nécessité pour la fraction parlementaire, ainsi que pour les organes de la presse du Parti, d'une subordination constante et sans réserve au Comité Central du Parti.

7) Le groupe «Mot Dag », qui est une association fermée, est dissout. L'existence et le maintien d'un groupe d'étudiants communistes ouvert à tous les étudiants communistes est naturellement parfaitement admissible, sous le contrôle entier de la direction centrale. Le périodique Mot Dag devient organe du Parti, à la condition que la composition de sa rédaction soit déterminée par le Comité Central du Parti Ouvrier Norvégien, d'accord avec l'Exécutif de l'Internationale Communiste.

8) Le Congrès donne suite à l'appel interjeté par le camarade $\mathrm{H}$. Olsen, et comme il s'agit là d'un vieux et fidèle camarade du Parti ouvrier et fonctionnaire toujours très actif de ce Parti, le Congrès le réintègre dans tous ses droits de membre du Parti, mais constate en même temps, expressément, l'incorrection de son attitude au Congrès de l'Union des Métaux.

9) Le Congrès décide d'exclure Karl Johannsen des rangs de l'Internationale Communiste et du Parti Ouvrier Norvégien. 
10) Dans le but d'établir une meilleure liaison entre le Parti norvégien et l'Exécutif et de résoudre avec le moins de frottements possibles les conflits, le Congrès charge le futur Exécutif d'envoyer des délégués au prochain Congrès du Parti.

11) Le Congrès charge l’Exécutif de rédiger une lettre éclaircissant la présente résolution.

12) Cette résolution ainsi que la lettre de l'Exécutif devront être publiées dans tous les organes de la presse du parti et portées à la connaissance de toutes les organisations du parti avant les élections des représentants au prochain congrès national. 


\author{
Manifestes, thèses et résolutions \\ des quatre premiers congrès \\ de l'Internationale communiste 1919-1923 \\ (juin 1934) \\ Quatrième Congrès, novembre 1922. \\ - 23 - \\ Résolution sur l’Espagne
}

\title{
$\underline{\text { Retour à la table des matières }}$
}

1. Le Parti Communiste espagnol qui, à la séance de l’Exécutif élargi de février, vota avec la France et l'Italie contre la tactique du front unique, ne tarda pas à reconnaître son erreur et, dès le mois de mai, à l'occasion de la grande grève des aciéries, il expliqua, non par discipline formelle mais avec compréhension, conviction et intelligence, la tactique du front unique. Cette action prouva à la classe ouvrière espagnole que le Parti est prêt à la lutte pour ses revendications quotidiennes et capable d'y entraîner la classe ouvrière en se plaçant à l'avantgarde du combat.

En persévérant dans cette voie, en saisissant toutes les possibilités d'action pour y convier l'ensemble des organisations ouvrières et pour y entraîner et y conduire le prolétariat, le Parti Communiste espagnol gagnera la confiance des masses et remplira sa mission historique en unifiant leur effort révolutionnaire.

2. Le $4^{\mathrm{e}}$ Congrès mondial est heureux de constater que la crise d'indiscipline qui avait miné le Parti au début de l'année s'est heureusement terminée par un renforcement de la discipline intérieure du Parti. Il engage le Parti à persévérer ainsi dans cette voie et il invite la Jeunesse, en particulier, à participer de toutes ses forces à ce renforcement de la discipline intérieure. 
3. La caractéristique du mouvement ouvrier espagnol est actuellement une décomposition de l'idéologie et du mouvement syndicaliste-anarchiste. Ce mouvement qui, il y a quelques années, avait réussi à grouper et à entraîner de larges masses ouvrières, a déçu leurs espoirs et leur volonté révolutionnaire en employant non pas la tactique marxiste et communiste de l'action de masses et de l'organisation centralisée de la lutte, mais la tactique anarchiste de l'action individuelle, du terrorisme et du fédéralisme, c'est-à-dire de l'émiettement de l'action.

Aujourd'hui, les masses ouvrières déçues s'en vont et les chefs qui les ont ainsi égarées glissent rapidement vers le réformisme.

Une des tâches principales du Parti Communiste est de gagner et d'éduquer les masses ouvrières déçues et d'attirer les éléments anarcho-syndicalistes qui se rendent compte de l'erreur de leur doctrine en dénonçant le néo-réformisme des chefs syndicalistes.

Mais dans cet effort pour conquérir la confiance des éléments anarchosyndicalistes, le Parti Communiste doit éviter de faire à leur idéologie, condamnée par l'expérience même du prolétariat espagnol, des concessions de principe et de tactique. Il doit combattre et condamner dans ses rangs les tendances qui voudraient, sur ce point et dans le but de gagner les syndicalistes plus rapidement, entraîner le Parti dons la voie des concessions. Il est préférable que l'assimilation des éléments syndicalistes se fasse plus lentement, mais que ces éléments soient vraiment gagnés à la cause communiste, plutôt que gagnés rapidement au prix d'une déviation du Parti qui préparerait à ce dernier, pour un avenir prochain, des crises nouvelles et pénibles. Le Parti espagnol en particulier mettra en lumière et fera comprendre aux anarcho-syndicalistes la tactique révolutionnaire du parlementarisme, telle que le $2^{\mathrm{e}}$ Congrès mondial l'a définie. Pour le Parti Communiste, l'action électorale est un moyen de propagande et de lutte des masses ouvrières, non un refuge pour les carriéristes réformistes ou petits-bourgeois.

Une application répétée de la tactique du front unique gagnera la confiance des masses encore sous l'influence de l'idéologie anarcho-syndicaliste et leur prouvera que le Parti Communiste est une organisation politique de combat révolutionnaire du prolétariat.

4. Le mouvement syndical espagnol doit attirer plus particulièrement l'attention et l'effort de notre Parti. Le Parti Communiste doit entreprendre une 
propagande intense et méthodique dans toutes les organisations syndicales, pour l'unité du mouvement syndical en Espagne. Pour mener à bien cette action, il doit s'appuyer sur un réseau de noyaux communistes dans tous les syndicats appartenant à la Confédération Nationale et à l'Union Générale et dans tous les syndicats autonomes. Il doit donc repousser et combattre toute idée ou tendance préconisant la sortie des syndicats réformistes. Si des syndicats ou des groupes communistes sont exclus des syndicats réformistes, les communistes doivent éviter de combler les vœux des scissionnistes d'Amsterdam en sortant par solidarité. Au contraire, ils doivent manifester leur solidarité avec les exclus en restant au sein de l'U.G.T. et en y combattant énergiquement pour la réintégration des exclus. Si, malgré des efforts soutenus, des syndicats et des groupes restent exclus, le Parti Communiste doit les engager à adhérer à la C.N.T. Les communistes adhérant à la C.N.T. doivent y constituer leurs noyaux liés à la Commission syndicale du Parti. Ils collaboreront sans doute en toute amitié avec les syndicalistes partisans de l'Internationale Syndicale Rouge et n'appartenant pas au Parti. Mais ils conserveront leur organisation propre, n'abdiqueront pas leur point de vue communiste, et discuteront fraternellement avec les syndicalistes les questions sur lesquelles peuvent exister des désaccords.

Pour mener à bien la lutte pour l'unité syndicale, le Parti Communiste créera un Comité mixte pour l'unité du mouvement syndicale espagnol qui sera à la fois un centre de propagande et un centre de ralliement pour les syndicats autonomes qui adhèrent au principe de l'unité. Le Parti s'attachera à faire comprendre aux masses ouvrières d'Espagne que seules les ambitions et les intérêts de clocher des chefs syndicaux réformistes ou anarcho-réformistes, s'opposent à l'unité syndicale qui est au plus haut point d'un intérêt vital et nécessaire à la classe ouvrière pour son émancipation complète du joug du capitalisme. 
Manifestes, thèses et résolutions

des quatre premiers congrès

de l’Internationale communiste 1919-1923

(juin 1934)

Quatrième Congrès, novembre 1922.

- 24 -

\section{Résolution sur la question yougoslave}

$\underline{\text { Retour à la table des matières }}$

Le Parti Communiste yougoslave a été constitué par les organisations de l'exparti social-démocrate dans les provinces qui forment actuellement la Yougoslavie ; sa création a été le résultat de l'exclusion des éléments de droite et du centre et de l'adhésion à l’Internationale Communiste au Congrès de Boukovar en 1920. L'essor du Parti Communiste a été favorisé par l'effervescence révolutionnaire qui avait envahi alors l'Europe centrale (avance de l'armée rouge sur Varsovie, occupation des usines métallurgiques en Italie, grèves spontanées en Yougoslavie). En un temps très court, le Parti devint une grande organisation exerçant une influence considérable sur les masses ouvrières et paysannes. Les résultats des élections municipales où le Parti conquit de nombreuses municipalités (entre autres celle de Belgrade) de même que ceux des élections parlementaires, où le Parti conquit 59 sièges, en sont une preuve. Cet essor menaçant du Parti Communiste provoqua une panique dans les rangs de l'oligarchie militaire et financière, qui engagea une lutte systématique pour anéantir le mouvement communiste. Après la répression de la grève générale des cheminots (avril 1920), les conseillers municipaux communistes furent chassés de la municipalité d’Agram par cette oligar- 
chie ; la municipalité communiste de Belgrade fut dissoute (août 1920), et le 29 septembre, un décret spécial prononça la dissolution de toutes les organisations communistes et syndicales, ferma tous les organes de la presse communiste et livra les clubs communistes aux social-patriotes. Au mois de juin fut promulguée la loi sur la défense de la sûreté de l'Etat, qui mettait le Parti Communiste hors la loi et le chassait de ses derniers refuges, le parlement et les municipalités.

Outre les causes objectives provenant de la situation générale du Parti, l'anéantissement du Parti Communiste yougoslave doit être en grande partie attribué à sa faiblesse intérieure : son essor extérieur ne correspondait ni au développement, ni à l'homogénéité de l'organisation, ni au niveau de conscience communiste de ses membres. Le Parti n'avait pas encore eu le temps d'accomplir son évolution dans la direction du communisme. A l'heure actuelle, il est évident que l'organe directeur du Parti a commis une série de fautes graves dues à sa compréhension erronée des méthodes de lutte dictées par l'Internationale. Ces fautes ont facilité la tâche du gouvernement contre-révolutionnaire. Pendant que les masses ouvrières, par des grèves spontanées, montraient leur énergie et leur volonté révolutionnaire, le Parti ne fit preuve que d'une très faible initiative. Ainsi en 1920, la police ayant interdit la manifestation du $1^{\mathrm{er}}$ mai à Belgrade, le Comité Central n'essaya même pas de soulever les masses pour protester. Il en fut de même l'année suivante. De même, le Parti ne prit aucune mesure pour défendre les conseillers municipaux d'Agram et de Belgrade, chassés de leurs municipalités. Sa passivité encouragea le gouvernement et lui donna l'audace d'aller jusqu'au bout. Effectivement, à la fin de décembre, ce dernier profita de la grève des mineurs pour procéder à la dissolution du Parti et des syndicats. Et, même à ce moment critique, ce Parti, qui avait obtenu 59 sièges aux élections parlementaires, n'entreprit aucune action de masse !

Si le Parti restait passif devant les coups terribles que lui portait la réaction, c'est qu'il manquait d'une base communiste solide. Les vieilles conceptions social-démocrates pesaient encore sur lui. Quoique le Parti eût adhéré à l'Internationale Communiste (ce qui montrait que les masses étaient disposées à la lutte), ses chefs ne se sentaient pas encore à leur aise dans la nouvelle voie. Ainsi, ils n'osèrent pas publier les 21 conditions adoptées par le $2^{\mathrm{e}}$ Congrès mondial, non plus que les thèses sur le parlementarisme révolutionnaire. Et ainsi le Parti et les masses qui le suivaient ignoraient complètement les exigences que 
l'Internationale Communiste posait aux partis qui désiraient entrer dans son sein. Les chefs du Parti ne prirent également aucune mesure sérieuse pour préparer le Parti et les masses à la lutte dans tous les domaines contre la réaction menaçante. Ils concentrèrent toute leur attention sur les victoires électorales du Parti et se gardèrent d'effrayer les éléments petits-bourgeois en leur montrant ce qu'était un parti communiste et quelles étaient ses méthodes de lutte. Pendant que l'oligarchie militaire et financière de Belgrade se préparait à une lutte décisive, impitoyable et furieuse contre le mouvement révolutionnaire ouvrier, le Comité Central du Parti Communiste yougoslave, consacrait toute son attention et toutes ses forces à des questions secondaires, telles que le parlementarisme, et laissait le Parti inorganisé et exposé à tous les coups. Ce fut là l'erreur fondamentale.

Le Parti yougoslave s'est montré complètement impuissant et incapable de se défendre contre la terreur blanche. Il ne possédait pas d’organisations clandestines lui permettant d'agir dans les nouvelles conditions et de se maintenir en liaison avec les masses. Jusqu’à la dissolution du groupe parlementaire, les députés communistes avaient été le seul lien entre le centre et les provinces. Ce lien fut rompu par la dissolution du groupe parlementaire. L'arrestation des principaux chefs, au centre et dans la province, décapita le mouvement. Par suite, le Parti cessa presque d'exister. Le même sort atteignit les organisations locales qui se virent abandonnées des ouvriers livrés à eux-mêmes. Les social-démocrates, avec l'aide de la police, essayèrent de profiter de la situation, mais sans grand succès.

Sous le régime de la terreur, l’organe central du Parti fixa petit à petit de nouvelles formes d'organisation et de nouvelles méthodes de lutte dictées par les nouvelles conditions. Il resta longtemps passif dans l'attente que la terreur cesserait d'elle-même, sans une intervention active des masses prolétariennes. Il comptait presque exclusivement sur les dissensions intestines éventuelles entre les classes et les partis dirigeants. Ce n'est que lorsque expira l'espoir de l'amnistie attendue pour les communistes condamnés, que le Comité Central commença à se réorganiser, afin de rappeler le Parti à la vie. Ce n’est qu'en juillet 1922 que fut tenue la première séance plénière élargie du Comité Central à Vienne. La conférence de Vienne mérite d’être saluée comme le premier essai de restauration du Parti, malgré les défauts de sa composition et son attitude envers les statuts du Parti. Les conditions dans lesquelles se trouvait alors le pays, les changements survenus dans la composition du Parti à la suite des arrestations de ses membres, 
de la trahison de quelques autres et surtout de sa passivité d'un an et demi, ne permettaient pas d'escompter à cette conférence une représentation véritable du Parti. C’est pourquoi le Comité Exécutif de l'I.C. agit sagement en reconnaissant comme représentation suffisamment autorisée du Parti yougoslave le groupe des délégués de la conférence de Vienne dont il confirma les résolutions, en y introduisant toutefois quelques changements parfaitement justifiés sur la composition du nouveau Comité Central. C’est pourquoi la tentative de quelques camarades yougoslaves de faire échouer la conférence en refusant d'y prendre part doit être, malgré la loyauté des intentions de ces camarades, considérée comme nuisible aux intérêts du Parti et, par suite, condamnable.

Les résolutions de la conférence de Vienne sur la situation générale en Yougoslavie et les tâches prochaines du Parti Communiste, sur le mouvement professionnel, la réorganisation du Parti, et la résolution de la $3^{\circ}$ Conférence de la Fédération Communiste des Balkans, confirmées sans réserve par le Comité Exécutif de l'I.C., ne provoquèrent aucun désaccord essentiel entre les représentants de la majorité et de la minorité de la conférence. Cette unanimité dans les questions essentielles, au moment actuel, est une preuve convaincante qu'il n'y a aucune raison de diviser le Parti yougoslave en fractions sous le nom de majorité et de minorité, et que la scission survenue à la conférence de Vienne entre les groupes dirigeants fut exclusivement provoqués par des raisons personnelles. Au moment de sa renaissance, le Parti yougoslave doit être considéré comme un tout ayant une unité intérieure parfaite.

Cette unité doit être sauvegardée dans l'avenir. En face de la furieuse réaction capitaliste et social-démocrate, rien ne peut être plus nuisible au Parti et au mouvement révolutionnaire yougoslave que le fractionnement. C'est pourquoi il est du devoir du nouveau Comité Central yougoslave de faire tout ce qui dépend de lui pour prendre les mesures nécessaires propres à apaiser les esprits à l'intérieur du Parti, à dissiper les méfiances personnelles, à restaurer la confiance mutuelle des membres du Parti et à rallier tous les militants restés à leur poste et exposés aux rigueurs de la contre-révolution.

À cet effet il est nécessaire, d'un part, de réaliser les décisions de la conférence de Vienne en ce qui concerne l'épuration du Parti de ses éléments indignes ; d'autre part, de confier des travaux importants aux militants de la minorité de la conférence de Vienne. Sous ce rapport, la Fédération Communiste des Balkans 
peut être d'une aide précieuse ; mais pour cela, il est nécessaire d'entrer en liaison avec elle et, à l'exemple des autres partis communistes des Balkans, d'envoyer immédiatement un représentant au Comité Exécutif de la Fédération des Balkans.

L'Internationale Communiste doit aider effectivement au relèvement du Parti yougoslave. Le Comité Exécutif doit, plus qu'il ne l'a fait jusqu’à présent, se tenir en liaison étroite avec le Comité Central du Parti yougoslave. Mais l'avenir du Parti est surtout entre les mains des militants actifs, politiquement et moralement sains. C'est sur eux que compte l'Internationale Communiste et c'est à eux qu'elle s'adresse. Riches de la dure expérience d'un passé récent, bien organisés, unis dans le même idéal, animés d'une foi ardente dans le triomphe de la révolution mondiale, ces militants sauront réunir et grouper derrière eux les éléments prolétariens dispersés et restés sans chef, organiser et fortifier le secteur yougoslave de la Fédération Communiste des Balkans. Le Congrès charge le Comité Exécutif de l’I.C. de prendre toutes les mesures d'organisation nécessitées par les circonstances. 


\author{
Manifestes, thèses et résolutions \\ des quatre premiers congrès \\ de l’Internationale communiste 1919-1923 \\ (juin 1934) \\ Quatrième Congrès, novembre 1922. \\ - 25 - \\ Résolution sur le Parti Danois
}

\title{
$\underline{\text { Retour à la table des matières }}$
}

1. Le Congrès déclare que le Parti Communiste actuel du Danemark qui a été formé par la fusion du «Enhatsparti » communiste et d'une fraction de l'ancien Parti, en accord avec les directives de l'Exécutif de l'Internationale Communiste, et qui a exécuté loyalement toutes les décisions de l'Internationale Communiste, est reconnu comme la seule section de l'Internationale Communiste au Danemark. Seul, son organe central, Arbeiderbladet et les autres journaux reconnus par ce parti sont à considérer comme journaux communistes du parti.

2. Le Congrès demande à toutes les organisations communistes restées en dehors de ce Parti Unifié d'adhérer à ce parti.

Les organisations et les membres de l'ancien parti, qui au cours des trois mois a venir se déclareront prêts à adhérer au Parti Communiste Unifié et à exécuter fidèlement toutes les décisions de ce parti et de son Comité Directeur, ainsi que celles de l'Internationale Communiste, doivent être admis à ce parti sans difficulté. 
Manifestes, thèses et résolutions

des quatre premiers congrès

de l'Internationale communiste 1919-1923

(juin 1934)

Quatrième Congrès, novembre 1922.

- 26 -

Résolution sur l'Irlande

$\underline{\text { Retour à la table des matières }}$

Le $4^{\mathrm{e}}$ Congrès de l'Internationale Communiste proteste énergiquement contre l'exécution de cinq révolutionnaires nationalistes, qui eut lieu les 17 et 25 novembre, sur l'ordre de l'Etat Libre d'Irlande. Il attire l'attention de tous les travailleurs du monde sur cet acte sauvage qui couronne la terreur féroce sévissant en Irlande. Plus de 6000 personnes qui combattaient courageusement contre l'impérialisme britannique ont déjà été incarcérées ; nombre de femmes ont été obligées de faire la grève de la faim en prison, et déjà 1800 procès ont été intentés au cours des cinq mois de lutte contre cette terreur dont les atrocités dépassent celles des «Black and Tans », des fascistes italiens ou des «Trust Thugs » d'Amérique. L’Etat Libre qui, sans hésiter, a employé l'artillerie et les munitions fournies par les Anglais, les fusils et les bombes, et même des aéroplanes avec des mitrailleuses contre la foule, aussi bien que contre les révolutionnaires, a couronné tous ces forfaits par l'exécution brutale de cinq hommes, simplement parce qu'ils avaient des armes en leur possession. Cette exécution est au fond un acte de désespoir, la preuve directe de la faillite de l'Etat Libre qui fait une dernière tentative pour briser la résistance des masses irlandaises combattant contre l'esclavage que veut leur imposer l’Empire Britannique. Les républicains ne peuvent être battus que 
par un gouvernement terroriste impérialiste qui n’hésite pas à employer les moyens les plus brutaux contre le mouvement ouvrier irlandais, dès que ce dernier cherche à arriver au pouvoir ou à améliorer ses conditions d'existence. Il en est indubitablement ainsi en Irlande ; en soutenant ces exécutions, la majorité du Labour Party, dirigée par Johnson, a commis la trahison la plus criminelle qu'elle pouvait perpétrer contre la classe ouvrière, et cela au moment où l'organe capitaliste le plus réactionnaire d’Irlande qui, en 1916, réclamait impérieusement le sang de Connolly, s'élève contre cet acte barbare du gouvernement. L’Internationale Communiste met en garde la classe ouvrière d'Irlande contre ces trahisons de l'idéal de Connolly et de Larkin, et indique aux travailleurs et paysans irlandais que la seule issue au terrorisme de l'Etat Libre et à l'oppression impérialiste est dans la lutte organisée et coordonnée, aussi bien dans le domaine politique et industriel que dans le domaine militaire. La lutte à main armée, si elle n’est pas renforcée et soutenue par l'action politique et économique aboutira inévitablement à la défaite. Pour être victorieuses, les masses doivent être mobilisées contre l'Etat Libre, ce qui n'est possible que sur la base du programme social du Parti Communiste d’Irlande.

L’Internationale Communiste envoie ses salutations fraternelles aux révolutionnaires irlandais luttant pour la libération de leur pays et est persuadée qu'ils s’engageront bientôt dans la seule voie menant à la véritable liberté, la voie du communisme. L’Internationale Communiste soutiendra tous les efforts ayant pour but d'organiser la lutte contre cette erreur et d'aider les ouvriers irlandais et les paysans à obtenir la victoire.

Vive la lutte nationale de l’Irlande pour son indépendance !

Vive la République Ouvrière d’Irlande !

Vive l’Internationale Communiste ! 
Manifestes, thèses et résolutions

des quatre premiers congrès

de l’Internationale communiste 1919-1923

(juin 1934)

Quatrième Congrès, novembre 1922.

- 27 -

\section{Résolution sur le Parti Socialiste d’Égypte}

$\underline{\text { Retour à la table des matières }}$

1. Le rapport des délégués du Parti Socialiste d’Egypte, soumis à la commission, a prouvé que ce parti représente un sérieux mouvement révolutionnaire, conforme au mouvement général de l’Internationale Communiste.

2. La commission considère cependant que l'affiliation du Parti Socialiste d’Egypte doit être ajournée jusqu’à ce qu’il ait :

a) exclu certains éléments indésirables ;

b) convoqué un Congrès où une tentative sera faite pour unir au Parti Socialiste d'Egypte tous les éléments communistes existant dans ce pays en dehors de lui et où les 21 conditions de l'Internationale Communiste seront acceptées ;

c) changé son nom contre celui de Parti Communiste d'Egypte.

3. Le Parti Socialiste d'Egypte est donc invité à convoquer le congrès dans les buts ci-dessus indiqués le plus tôt possible et au plus tard le 15 janvier 1923. 
Le $4^{e}$ Congrès de l'Internationale communiste se tint du 5 novembre au 5 décembre 1922. La séance d'ouverture eut lieu à Pétrograd; les autres séances, à partir du 9 novembre, curent lieu à Moscou. Participaient au Congrès 408 délégués, dont 343 avec voix délibérative, représentant 58 organisations communistes de différents pays. Etaient en outre présents des représentants du Parti socialiste italien, du Parti ouvrier islandais et du Parti populaire révolutionnaire de Mongolie, ainsi que de l'Internationale communiste de la jeunesse, de l'Internationale syndicale, du Secrétariat international des Femmes, du Secours ouvrier international et de l'organisation des noirs américains. Le Congrès adopta les thèses sur le front ouvrier unique élaborées par le P.C.(b)R., ratifia les thèses sur la tactique de l'Internationale communiste, sur les tâches des communistes dans le mouvement syndical, sur la question d'Orient, adopta des résolutions sur la révolution socialiste en Russie, sur l'Internationale communiste de la jeunesse, etc... Le rapport de Lénine "Cinq ans de révolution russe et les perspectives de la révolution mondiale », qu'il fit en alle-mand, fut entendu par le Congrès le 13 novembre au cours de la séance du matin.

Lénine

(5 novembre -5 décembre 1922) 
$\mathrm{Au} 4^{\mathrm{e}}$ Congrès mondial de l'Internationale Communiste, au Soviet des députés des ouvriers et des soldats rouges de Pétrograd

\section{$\underline{\text { Retour à la table des matières }}$}

Je regrette très vivement de ne pouvoir assister à la première séance du Congrès et de devoir me limiter à un message écrit.

Malgré les difficultés gigantesques qui se dressent sur la route des partis communistes, l'Internationale communiste grandit et se renforce. Comme par le passé, la tâche principale consiste à conquérir la majorité des ouvriers. Et cette tâche, en dépit de tout, nous la réaliserons.

L'unification des Internationales 2 et 2 1/2 sera profitable au mouvement révolutionnaire du prolétariat: moins de fictions, moins de duperie, c'est toujours avantageux pour la classe ouvrière.

Aux ouvriers de Pétrograd et à leur nouveau Soviet, qui accueille dans sa ville le $4^{\mathrm{e}}$ Congrès de l'Internationale communiste, j'adresse mes meilleurs vœux et un salut chaleureux.

Sur le front économique également, les ouvriers de Pétrograd doivent être dans les premiers rangs. Nous entendons avec joie parler du début de la renaissance économique de votre ville. A votre invitation de me rendre à Pétrograd, j'espère répondre dans un proche avenir.

Le pouvoir soviétique de Russie fête son cinquième anniversaire. Il est plus solide que jamais. La guerre civile est terminée. Les premiers succès économiques sont là. La Russie des Soviets estime que sa plus grande fierté est d'aider les ouvriers du monde entier dans leur lutte difficile pour le renversement du capitalisme. La victoire sera à nous.

Vive l'Internationale communiste !

\section{Oulianov (Lénine)}

Moscou, le 4 novembre 1922. 


\title{
Manifestes, thèses et résolutions des quatre premiers congrès de l'Internationale communiste 1919-1923 \\ (juin 1934) \\ Quatrième Congrès, novembre 1922. \\ - 29 - \\ Cinq ans de révolution russe et les perspectives de la révolution mondiale.
}

\author{
Rapport présenté au $4^{e}$ congrès de l'Internationale \\ Communiste, le 13 novembre 1922
}

$\underline{\text { Retour à la table des matières }}$

(L’apparition du camarade Lénine est saluée par de vifs applaudissements prolongés et les ovations de toute l'assistance. Toute la salle se lève et chante l'Internationale.)

Camarades,

Je figure dans la liste des orateurs comme rapporteur principal, mais vous comprendrez qu'après ma longue maladie je ne puisse faire un rapport étendu. Je peux simplement donner une introduction aux questions les plus importantes. Mon sujet sera très limité. Le thème « Cinq ans de révolution russe et les perspectives de la révolution mondiale » est, de toute façon, trop vaste et trop grand pour qu'un seul orateur puisse l'épuiser dans un seul discours. C'est pourquoi je ne prends, pour ma part, qu'une petite partie de ce sujet, à savoir la « nouvelle politi- 
que économique ». C’est à dessein que je prends une petite partie seulement afin de vous faire connaître cette question, extrêmement importante aujourd'hui, du moins pour moi, puisque j'y travaille en ce moment.

Je parlerai donc de la manière dont nous avons amorcé la nouvelle politique économique et des résultats que nous avons obtenus à l'aide de cette politique. En me bornant à ce problème, je réussirai peut-être à vous présenter un aperçu général et à vous en donner une idée d'ensemble.

Pour dire comment nous en sommes venus à la nouvelle politique économique, je dois me référer à un article que j’ai écrit en $1918{ }^{4}$. Au début de 1918, dans une courte polémique, j'ai touché précisément la question de l'attitude que nous devions adopter à l'égard du capitalisme d'Etat. J'écrivais à cette date :

« Le capitalisme d'Etat serait un pas en avant par rapport à la situation actuelle (c'est-à-dire de cette époque) de notre République des Soviets. Si, par exemple, d'ici six mois, le capitalisme d'Etat était instauré chez nous, ce serait un immense succès et le plus sûr garant que, dans un an, le socialisme serait définitivement consolidé chez nous et qu’il serait invincible. »

Certes, cela était dit à une époque où nous étions moins intelligents qu'aujourd'hui, mais non pas sots au point de ne pas savoir examiner de pareilles questions.

Ainsi, en 1918, j'étais d'avis que, par rapport à la situation économique de la République des Soviets à l'époque, le capitalisme d'Etat était un pas en avant. Cela paraît très étrange et peut-être même absurde ; car déjà à ce moment notre République était une république socialiste; nous adoptions alors chaque jour, avec la plus grande précipitation, - précipitation excessive sans doute, - de nouvelles mesures économiques de toute sorte que l'on ne saurait qualifier autrement que de mesures socialistes. Néanmoins, je pensais que, compte tenu de la situation économique qui était à l'époque celle de la République des Soviets, le capitalisme d'Etat était un pas en avant. Et pour expliquer cette pensée, j'ai énuméré simplement les éléments du régime économique de la Russie. Voici quels

4 Lénine fait allusion à son article : Sur l'infantilisme «de gauche » et les idées petitesbourgeoises. (Euvres, Paris-Moscou, tome 27, pp. 337-370.) 
étaient, selon moi, ces éléments : « $1^{\circ}$ la forme patriarcale, c’est-à-dire la forme la plus primitive de l'agriculture; $2^{\circ}$ la petite production marchande (ici se classe également la majorité des paysans qui vendent du blé) ; $3^{\circ}$ le capitalisme privé ; $4^{\circ}$ le capitalisme d'Etat et $5^{\circ}$ le socialisme. » Tous ces éléments économiques existaient dans la Russie de ce temps. Je m’étais assigné pour tâche d’élucider leurs rapports, et je me demandais s'il ne convenait pas de considérer l'un des éléments non socialistes, en l'espèce le capitalisme d’Etat, comme supérieur au socialisme. Je le répète : cela paraît fort étrange à tous de voir que dans une République qui se proclame socialiste, un élément non socialiste soit considéré comme supérieur, comme placé au-dessus du socialisme. Mais la chose devient compréhensible, si vous vous rappelez que nous ne considérions nullement le régime économique de la Russie comme un système homogène et hautement évolué ; nous nous rendions entièrement compte qu'en Russie l'agriculture patriarcale, c'est-à-dire la forme la plus primitive de l'agriculture, existait à côté de la forme socialiste. Quel rôle pouvait donc jouer le capitalisme d'Etat dans ces conditions?

Je me demandais ensuite : lequel de ces éléments prédomine ? Il est clair que dans un milieu petit-bourgeois, c'est l'élément petit-bourgeois qui domine. Je me rendais compte alors que ce dernier prédominait ; il était impossible de penser autrement. La question que je me posais - au cours d'une polémique qui n’a rien à voir avec la question que nous sommes en train d'examiner, — était celle-ci : quelle est notre attitude à l'égard du capitalisme d'Etat ? Et je me suis fait cette réponse : le capitalisme d'Etat, sans être une forme socialiste, serait pour nous et pour la Russie une forme plus favorable que celle d'aujourd'hui. Qu'est-ce à dire ? C'est que, tout en ayant déjà accompli la révolution sociale, nous n’avons surestimé ni les germes ni les principes de l’économie socialiste. Au contraire, déjà à ce moment nous avions conscience, jusqu’à un certain point, de cette vérité : oui, en effet, mieux eût valu passer d'abord par le capitalisme d'Etat pour, ensuite, arriver au socialisme.

Il me faut tout spécialement insister sur ce point, car j'estime que c'est seulement en partant de là qu'on peut, d'abord, montrer ce qu'est la politique économique actuelle; en second lieu, on peut en tirer des conclusions pratiques très importantes aussi pour l'Internationale communiste. Je ne peux pas dire que nous avions déjà un plan de retraite tout prêt. Non, nous ne l'avions pas. Ces quelques 
lignes écrites à l'occasion d’une polémique n’étaient pas le moins du monde, à ce moment, un plan de retraite. On n'y trouve pas un mot sur un point essentiel, savoir sur la liberté du commerce, qui est d'une importance fondamentale pour le capitalisme d’Etat. Cependant l'idée générale, encore imprécise, de la retraite, y était déjà indiquée. Je pense que nous devons porter là-dessus notre attention non seulement du point de vue d'un pays qui, par son régime économique, était et est encore très arriéré, mais aussi sous l'angle de l'Internationale communiste et des pays avancés de l'Europe occidentale. Ainsi, à l'heure actuelle, nous nous occupons du programme. J'estime, pour ma part, que nous ferions bien mieux, pour le moment, de ne discuter tous les programmes qu'à titre préliminaire, pour ainsi dire en première lecture, et de les faire reproduire tels quels, sans adopter une décision définitive tout de suite, cette année-ci. Pourquoi ? Tout d’abord, selon moi, parce que nous ne les avons guère étudiés à fond, c'est évident. Et puis aussi parce que nous n'avons presque pas réfléchi du tout sur la question d'une retraite éventuelle et des moyens de l'effectuer. Or, c'est là un problème auquel — étant donné les changements radicaux qui s’opèrent dans le monde entier, tels que le renversement du capitalisme et la construction du socialisme avec les immenses difficultés qu'elle comporte - il nous faut absolument porter notre attention. Il ne suffit pas de savoir ce que nous avons à faire quand nous passons directement à l'offensive et que nous remportons la victoire. En période révolutionnaire, cela n’est pas si difficile, ni si important ; du moins, ce n’est pas le plus décisif. Pendant la révolution, il y a toujours des moments où l'adversaire perd la tête, et si nous l'attaquons à un de ces moments, nous pouvons facilement le battre. Mais cela ne veut rien dire encore ; si notre adversaire est suffisamment maître de lui, il peut ramasser ses forces à temps, etc... Dès lors, il peut aisément provoquer une attaque, et puis nous rejeter en arrière pour de longues années. Voilà pourquoi je pense que l'idée que nous devons nous ménager la possibilité d'une retraite a une très grande importance, et non seulement du point de vue théorique. Sur le plan pratique également, tous les partis qui s’apprêtent dans un proche avenir à passer à l'offensive déclarée contre le capitalisme, doivent dès maintenant songer aussi à se ménager une retraite. Je pense que si nous mettons à profit cet enseignement, ainsi que tous les autres fournis par l'expérience de notre révolution, loin de nous porter préjudice, cela nous sera très vraisemblablement utile en maintes occasions. 
Après avoir souligné que dès 1918 nous envisagions le capitalisme d'Etat comme une ligne de retraite éventuelle, j'en viens aux résultats de notre nouvelle politique économique. Je répète : à ce moment-là, c'était encore une idée très vague ; mais en 1921, après avoir franchi cette étape très importante qu'était la guerre civile, et franchi victorieusement, nous nous sommes heurtés à une grande - je pense, la plus grande - crise politique intérieure de la Russie des Soviets, crise qui a amené le mécontentement d'une partie notable des paysans, et aussi des ouvriers. C'était, dans l'histoire de la Russie des Soviets, la première et, je l'espère, la dernière fois que l'on a vu de grandes masses paysannes se tourner contre nous, instinctivement et non consciemment. Qu'est-ce qui avait provoqué cette situation particulière et, bien entendu, fort désagréable pour nous ? C'est que, dans notre offensive économique, nous avions trop pris les devants, sans nous être assuré une base suffisante : les masses ont senti ce que nous ne savions pas encore formuler pertinemment à l'époque, mais que bientôt, quelques semaines plus tard, à notre tour, nous avons reconnu, savoir : qu'il était au-dessus de nos forces de passer tout de suite aux formes purement socialistes, à la répartition purement socialiste ; et que si nous nous montrions incapables d'opérer la retraite de façon à nous borner à des tâches plus faciles, nous étions menacés de mort. La crise a commencé, je crois, en février 1921. Déjà au printemps de cette même année, nous avons décidé à l'unanimité — je n’ai pas observé de désaccords sensibles entre nous à ce sujet — de passer à la nouvelle politique économique. Aujourd'hui, à la fin de 1922, au bout d'un an et demi, nous pouvons déjà faire quelques comparaisons. Que s'est-il donc passé ? Comment avons-nous vécu cette période de plus de dix-huit mois ? Quel en est le résultat ? Cette retraite nous a-telle profité, nous a-t-elle réellement sauvés, ou bien le résultat est-il encore incertain ? Telle est la question principale que je me pose. J'estime qu'elle est d'une importance primordiale aussi pour tous les partis communistes. Car, si la réponse était négative, nous serions tous condamnés à périr. J 'estime que nous pouvons tous répondre, la conscience tranquille, par l'affirmative, notamment en ce sens que les dix-huit mois écoulés prouvent, positivement et absolument, que nous avons triomphé de cette épreuve.

J'essaierai maintenant d'en faire la démonstration. Il me faut pour cela énumérer en bref tous les éléments constitutifs de notre économie. 
Je m’arrêterai tout d'abord à notre système financier et au fameux rouble russe. Je pense que l'on peut dire du rouble russe qu'il est fameux, ne serait-ce que parce que le nombre de ces roubles dépasse actuellement le quadrillion. (Rires.) C'est déjà quelque chose. C'est un chiffre astronomique. (Rires.) Je suis certain que tous ici ne savent pas même ce qu'il signifie. Mais nous ne tenons pas ces chiffres pour très importants, du point de vue de la science économique : des zéros, on peut toujours les biffer. (Rires.) Dès à présent nous enregistrons quelques succès en cet art qui, considéré sous l'angle de la science économique, est de même sans aucune importance. Et j'ai la certitude que, par la suite, nous ferons des progrès encore plus grands dans cet art. Ce qui importe réellement, c’est la stabilisation du rouble. Ce problème nous préoccupe, il préoccupe nos meilleurs cadres, et nous lui attribuons une portée décisive. Si nous arrivons à stabiliser le rouble d'abord pour une longue période, et puis pour toujours, nous aurons gain de cause. Alors tous ces chiffres astronomiques — tous ces trillions et quadrillions - ne seront plus rien. Nous pourrons dès lors assigner à notre économie une base solide et la développer sur cette base. Je crois pouvoir vous citer à ce sujet des faits assez marquants et décisifs. En 1921, la période de stabilité du cours du rouble-papier avait duré moins de trois mois. En cette année 1922, qui du reste n’est pas encore terminée, elle a duré plus de cinq mois. Je pense que cela seul suffit. Bien entendu, ce serait insuffisant si vous exigiez de nous la preuve scientifique que, dans l'avenir, nous résoudrons entièrement ce problème. Mais d'une façon générale il est impossible, à mon avis, d'en faire la preuve pleine et entière. Les chiffres cités montrent que, depuis l'an dernier, depuis que nous avons inauguré notre nouvelle politique économique, jusqu’à ce jour, nous avons déjà appris à marcher de l'avant. S'il en est ainsi, je suis sûr que nous saurons à l'avenir également progresser dans cette voie, à moins que nous ne commettions quelque grosse sottise. Mais ce qui importe le plus, ce qu'il nous faut surtout, c'est le commerce, ce sont les échanges. Et puisque nous nous en sommes tirés pendant deux ans, bien que nous fussions en état de guerre (car, vous le savez, nous avons repris Vladivostok il y a quelques semaines seulement), bien que nous ne puissions aborder notre activité économique d'une façon vraiment méthodique qu'aujourd'hui, puisque malgré tout nous avons fait en sorte que la période de stabilité du rouble-papier est passée de trois à cinq mois, je crois pouvoir affirmer que nous avons des raisons d'être satisfaits. C'est que nous sommes seuls. Nous n'avons reçu ni ne recevons le moindre emprunt. Aucun de ces puissants Etats capitalistes, qui organisent 
leur économie «brillamment » au point d'ignorer jusqu'à présent où ils vont, ne nous est venu en aide. Par le traité de Versailles ils ont créé un système de finances dans lequel eux-mêmes ne peuvent se retrouver. Si ces grands Etats capitalistes mènent ainsi leurs affaires, j'estime que nous, pays arriéré et inculte, nous pouvons être contents d'avoir compris l'essentiel : les conditions de la stabilisation du rouble. Ce qui le prouve, ce n'est pas une analyse théorique quelconque, c'est la pratique ; et celle-ci, selon moi, importe plus que toutes les discussions théoriques du monde. Or, la pratique montre qu'ici nous avons obtenu des résultats décisifs. Savoir : nous commençons à orienter l'économie vers la stabilisation du rouble, ce qui a une portée majeure pour le commerce, pour l'échange libre de marchandises, pour les paysans et la grande masse des petits producteurs.

J'en viens maintenant à l'examen de nos objectifs sociaux. L'essentiel, bien entendu, c'est la paysannerie. En 1921, le mécontentement d'une partie considérable des paysans était un fait flagrant. Puis ce fut la famine. Epreuve la plus pénible pour les paysans. Rien de plus naturel que toute la presse de l'étranger se fût mise à clamer : "Vous voyez, voilà bien les résultats de l'économie socialiste. » Rien de plus naturel, bien entendu, qu'ils eussent passé sous silence que la famine était en réalité la conséquence monstrueuse de la guerre civile. Tous les grands propriétaires fonciers et les capitalistes, qui avaient entrepris leur offensive contre nous en 1918, essayèrent de faire croire que la famine était le résultat de l'économie socialiste. La famine a été en effet un grand malheur, un malheur si grave qu'il menaçait d'anéantir toute notre œuvre d'organisation, toute notre œuvre révolutionnaire.

Eh bien, je demande maintenant : après cette calamité inouie, inattendue, où en sont les choses aujourd'hui, depuis que nous avons institué la nouvelle politique économique, depuis que nous avons accordé aux paysans la liberté du commerce? La réponse est claire, elle est évidente pour tous : en une année, la paysannerie n'a pas seulement eu raison de la famine ; elle a acquitté l'impôt en nature dans des proportions telles que nous avons déjà reçu des centaines de millions de pouds, et cela presque sans la moindre mesure de contrainte. Les soulèvements paysans qui, avant 1921, étaient pour ainsi dire un fait général en Russie, ont presque complètement cessé. La paysannerie est satisfaite de sa situation actuelle. Nous pouvons le dire sans hésiter. Nous estimons que ces preuves importent plus que toutes les démonstrations à coups de statistique. Que la paysannerie 
soit chez nous un facteur décisif, personne n'en doute. Elle est aujourd'hui dans une situation telle que nous n'avons pas à craindre de sa part un mouvement d’hostilité contre nous. Nous le disons en pleine conscience, sans exagération. C’est là un fait acquis. La paysannerie peut être mécontente de l'activité de notre pouvoir dans tel ou tel domaine, elle peut se plaindre. Certes, cela est possible et inévitable, puisque notre appareil d'Etat et notre économie nationale sont encore trop défectueux pour le prévenir. En tout cas, ce qui est certain, c’est qu'un mécontentement sérieux de l'ensemble de la paysannerie contre nous est absolument exclu. Ce résultat a été acquis en l'espace d'un an. J'estime que c'est déjà beaucoup.

J’en viens à l'industrie légère. Nous devons précisément faire le départ entre l'industrie lourde et l'industrie légère, puisque leur situation est différente. Pour ce qui est de l'industrie légère, je puis dire sans hésiter : on assiste ici à un essor général. Je n’entrerai point dans les détails. Et je ne me propose pas de produire des statistiques. Mais cette impression d'ensemble est fondée sur des faits, et je puis garantir qu'elle ne renferme rien de faux ou d'inexact. Nous pouvons constater un essor général de l’industrie légère et, partant, une amélioration notable de la condition des ouvriers de Pétrograd et de Moscou. Dans les autres régions, cela s’observe dans une mesure moindre parce que là prédomine l'industrie lourde. Il ne faut donc pas généraliser ce fait. Toujours est-il, je le répète, que l’industrie légère est incontestablement en progrès et l'adoucissement du sort des ouvriers de Pétrograd et de Moscou est indéniable. Au printemps de 1921, il y avait du mécontentement parmi les ouvriers de ces deux villes. Aujourd'hui, ce n'est plus le cas. Nous qui suivons au jour le jour la situation et l'état d'esprit des ouvriers, nous ne nous trompons pas en cette matière.

La troisième question concerne l'industrie lourde. Je dois dire qu'ici la situation reste encore difficile. Un certain changement s’y est produit en 1921-1922. Nous pouvons donc espérer, très prochainement, un tournant. A cet effet, nous avons déjà réuni, en partie, les moyens nécessaires. Pour améliorer l'état de l'industrie lourde dans un pays capitaliste, il aurait fallu emprunter des centaines de millions, sans lesquels le redressement eût été impossible. L’histoire économique des pays capitalistes montre que, dans les pays arriérés, seuls les emprunts à long terme de centaines de millions de dollars ou de roubles-or pourraient aider au relèvement de l’industrie lourde. Nous n’avons pas bénéficié d’emprunts de ce 
genre, et nous n'avons rien reçu jusqu'à ce jour. Tout ce qu’on écrit maintenant au sujet des concessions, etc..., c'est à peu près lettre morte. Ces temps derniers, nous avons beaucoup écrit à ce sujet et surtout à propos de la concession d’Urquhart. Cependant notre politique de concessions me paraît très bonne. Cela n'empêche que nous n'avons pas encore de concession rentable. Je vous prie de ne pas l'oublier. De la sorte, l'état de l'industrie lourde est réellement une question très grave pour notre pays arriéré, car nous ne pouvions espérer d'emprunts dans les pays riches. Néanmoins, nous observons déjà une amélioration notable, et puis nous voyons que notre activité commerciale nous a déjà rapporté un certain capital. Fort modeste, il est vrai, pour le moment : un peu plus de vingt millions de roubles-or. En tout cas, c'est un commencement : notre commerce nous procure des ressources que nous pouvons utiliser pour relever l'industrie lourde. De toute façon, à l'heure actuelle, notre industrie lourde se trouve encore dans une situation fort difficile. Mais j'estime que nous sommes déjà en mesure d’économiser quelque peu. Nous le ferons à l'avenir également. Bien que, souvent, cela se fasse aux dépens de la population, nous devons quand même économiser dès maintenant. Nous travaillons en ce moment à réduire notre budget d'Etat, à comprimer notre appareil d'Etat. Tout à l'heure, je dirai encore quelques mots de notre appareil d'Etat. Nous devons, en tout cas, le comprimer, nous devons économiser autant que faire se peut. Nous économisons sur tout, même sur les écoles, cela parce que nous comprenons que, si nous ne sauvons pas l'industrie lourde, si nous ne la relevons pas, nous ne pourrons construire aucune industrie, et à défaut de celle-ci, c’en sera fait de nous, en général, comme pays indépendant. Cela, nous le savons bien.

Le salut pour la Russie n'est pas seulement dans une bonne récolte, — cela ne suffit pas encore, - et pas seulement dans le bon état de l'industrie légère qui fournit aux paysans les objets de consommation, - cela non plus ne suffit pas encore, - il nous faut également une industrie lourde. Or, pour la mettre en bon état, il faudra bien des années de travail.

L'industrie lourde a besoin de subventions de l'Etat. Si nous ne les trouvons pas, c'en est fait de nous comme Etat civilisé, je ne dis môme pas socialiste. Donc, à cet égard nous avons fait un pas résolu en avant. Nous nous sommes procuré les ressources nécessaires pour mettre debout l'industrie lourde. La somme que nous nous sommes procurée jusqu’à présent dépasse à peine, il est vrai, vingt 
millions de roubles-or. En tout cas, cette somme existe, et son unique destination est de relever notre industrie lourde.

Je pense que, dans l'ensemble, je vous ai exposé brièvement comme je l'avais promis, les éléments essentiels de notre économie nationale. Et je pense qu’on peut conclure de tout cela que la nouvelle politique économique a donné, dès maintenant, un bon résultat. Nous avons, dès aujourd'hui, la preuve que nous sommes en mesure, en tant qu'Etat, de faire du commerce, de garder de solides positions dans l'agriculture et l'industrie et de marcher de l'avant. Notre activité pratique l’a démontré. Je pense que cela nous suffit pour le moment. Nous aurons encore beaucoup à apprendre, et nous avons compris qu'il nous était encore nécessaire d'apprendre. Nous sommes au pouvoir depuis cinq ans, et cinq années durant nous avons été en état de guerre. Donc nous avons remporté un succès.

Cela se comprend : c'est que les paysans étaient pour nous. Il serait difficile d'être pour nous plus qu'ils ne l'ont été. Ils comprenaient que, derrière les gardes blancs, se tenaient les grands propriétaires fonciers qu'ils haïssent plus que tout au monde. Aussi étaient-ils pour nous avec le plus grand enthousiasme, le plus grand dévouement. Il n’a pas été difficile de décider la paysannerie à nous défendre contre les gardes blancs. Les paysans qui, naguère, exécraient la guerre, faisaient tout pour la guerre contre les gardes blancs, pour la guerre civile contre les grands propriétaires fonciers. Néanmoins, ce n’était pas encore tout. Car, au fond, il ne s’agissait là que d'une chose : le pouvoir resterait-il aux grands propriétaires fonciers ou aux paysans ? Pour nous ce n'était pas assez. Les paysans comprennent que nous avons pris le pouvoir pour les ouvriers et que notre but est de créer le régime socialiste à l'aide de ce pouvoir. Aussi, le plus important pour nous, c'était la préparation de l'économie socialiste. Nous ne pouvions la préparer directement. Nous avons été obligés de le faire par voies détournées. Le capitalisme d’Etat, tel que nous l'avons établi chez nous, est un capitalisme d'Etat particulier. Il ne répond pas à la notion ordinaire de capitalisme d'Etat. Nous détenons tous les leviers de commande ; nous détenons la terre ; elle appartient à l'Etat. Cela est très important, encore que nos adversaires présentent les choses de façon à faire croire que cela ne signifie rien. C'est faux. Le fait que la terre appartient à l'Etat est de la plus haute importance et a également une grande valeur pratique du point de vue économique. Nous avons obtenu cela, et je dois dire que toute notre activité ultérieure doit se développer uniquement dans ce cadre. Nous avons déjà obtenu 
ce résultat que nos paysans sont satisfaits, que notre industrie revit, de même que notre commerce. J'ai déjà dit que notre capitalisme d'Etat se distinguait du capitalisme d'Etat pris à la lettre, en ceci que notre Etat prolétarien détient non seulement la terre, mais aussi tous les éléments les plus importants de l'industrie. Avant tout nous avons donné à bail une certaine partie de la petite et moyenne industrie ; mais tout le reste demeure entre nos mains. Pour ce qui est du commerce, je tiens encore à souligner que nous nous efforçons de fonder des sociétés mixtes, que nous en fondons déjà ; ce sont des sociétés où une part du capital appartient aux capitalistes privés, aux surplus étrangers, et l'autre part, à nous. D’abord, nous apprenons ainsi à faire du commerce, — nous en avons besoin, et, ensuite, nous avons toujours la possibilité, si nous le jugeons nécessaire, de liquider une telle société, de sorte que nous ne courons, pour ainsi dire, aucun risque. En revanche, nous nous instruisons auprès du capitaliste privé, nous tâchons de savoir comment nous pouvons progresser et quelles fautes nous commettons. Je crois pouvoir me borner à ce que je viens de dire.

Je voudrais encore toucher quelques points secondaires. Il est certain que nous avons commis et que nous commettrons encore des sottises en quantité énorme. Personne n'est mieux placé que moi pour le voir et en juger. (Rires.) Pourquoi donc commettons-nous des sottises ? Cela se conçoit : premièrement, nous sommes un pays arriéré ; deuxièmement, l'instruction, dans notre pays, est minime ; troisièmement, nous ne sommes pas aidés ; aucun Etat civilisé ne nous aide. Au contraire, ils œuvrent tous contre nous. Quatrièmement, la faute en est à notre appareil d'Etat. Nous avons hérité de l'ancien appareil d'Etat, et c'est là notre malheur. L'appareil d'Etat fonctionne bien souvent contre nous. Voici comment les choses se sont passées. En 1917, lorsque nous avons pris le pouvoir, l'appareil d'Etat nous a sabotés. Nous avons été très effrayés à ce moment, et nous avons demandé : «Revenez s'il vous plaît. » Ils sont revenus, et ce fut notre malheur. Nous avons maintenant d'énormes masses d'employés, mais nous n'avons pas d'éléments suffisamment instruits pour diriger efficacement ce personnel. En fait, il arrive très souvent qu'ici, au sommet, où nous avons le pouvoir d'Etat, l'appareil fonctionne tant bien que mal, tandis que là-bas, à la base, ce sont eux qui commandent de leur propre chef, et ils le font de telle sorte que, bien souvent, ils agissent contre nos dispositions. Au sommet nous avons, je ne sais combien au juste, mais de toute façon, je le crois, quelques milliers seulement, ou, tout au 
plus, quelques dizaines de milliers des nôtres. Or, à la base, il y a des centaines de milliers d'anciens fonctionnaires, légués par le tsar et la société bourgeoise, et qui travaillent en partie consciemment, en partie inconsciemment, contre nous. On ne saurait y remédier dans un court laps de temps, cela est certain. Nous devons travailler durant de longues années pour perfectionner l'appareil, le modifier et y faire participer des forces nouvelles. Nous le faisons à un rythme assez rapide, trop rapide peut-être. Des écoles soviétiques, des facultés ouvrières ont été fondées ; des centaines de milliers de jeunes gens étudient. Ils étudient, peut-être trop vite, mais en tout cas, le travail a commencé, et je pense qu’il portera ses fruits. Si nous ne travaillons pas trop à la hâte, nous aurons dans quelques années une masse de jeunes gens capables de refondre radicalement notre appareil.

J'ai dit que nous avions commis une énorme quantité de sottises, mais, làdessus, je dois dire aussi quelques mots de nos adversaires. Si nos adversaires nous reprennent et indiquent que, voyez-vous, Lénine lui-même reconnaît que les bolcheviks ont fait une énorme quantité de sottises, je réponds à cela : oui, mais nos sottises, vous savez, sont quand même d'une tout autre espèce que les vôtres. Nous avons seulement commencé notre apprentissage, mais nous apprenons d'une façon assez systématique pour être certains d’obtenir de bons résultats. Et si nos adversaires, c'est-à-dire les capitalistes et les paladins de la $2^{\mathrm{e}}$ Internationale, soulignent les sottises faites par nous, je me permettrai, pour la comparaison, de citer ici, en les paraphrasant un peu, les paroles d'un célèbre écrivain russe : quand les bolcheviks font des sottises, ils disent : «Deux fois deux font cinq. » Mais quand ce sont leurs adversaires, c’est-à-dire les capitalistes et les paladins de la $2^{\mathrm{e}}$ Internationale, qui font des sottises, ils semblent dire : « Deux fois deux font une bougie. » Cela n’est pas difficile à démontrer. Prenez, par exemple, le traité conclu avec Koltchak par l'Amérique, l’Angleterre, la France, le Japon. Y a-t-il au monde, je vous le demande, des Etats plus éclairés et plus puissants ? Or, qu'est-il arrivé ? Ils ont promis leur aide à Koltchak, sans avoir calculé, ni réfléchi, ni observé. Ce fut un fiasco difficile même à concevoir, selon moi, du point de vue de la raison humaine.

Et cet autre exemple, encore plus rapproché de nous et plus important : la paix de Versailles. Qu'est-ce que les « grandes » puissances, « couvertes de gloire » ont fait là, je vous le demande ? Comment peuvent-elles maintenant trouver une issue à ce chaos et à ce non-sens ? Je pense ne pas exagérer en répétant que nos 
sottises ne sont rien en comparaison de celles que commettent, ensemble, les Etats capitalistes, le monde capitaliste et la $2^{\mathrm{e}}$ Internationale. C'est pourquoi j'estime que les perspectives de révolution mondiale - thème que je dois toucher brièvement - sont favorables. Et je présume qu'à certaines conditions, elles deviendront encore meilleures. C'est de ces conditions que je voudrais dire quelques mots.

En 1921, au $3^{\mathrm{e}}$ Congrès, nous avons voté une résolution sur la structure organique des Partis communistes, ainsi que sur les méthodes et le contenu de leur travail. Texte excellent, mais essentiellement russe, ou presque, c'est-à-dire que tout y est tiré des conditions de vie russes. C'est là son bon mais aussi son mauvais côté. Son mauvais côté, parce que je suis persuadé que presque aucun étranger ne peut la lire ; avant de dire cela j'ai relu cette résolution : premièrement, elle est trop longue : 50 paragraphes ou plus. Les étrangers, d'ordinaire, ne peuvent aller jusqu'au bout de pareils textes. Deuxièmement, même s'ils la lisaient, pas un de ces étrangers ne la comprendrait, précisément parce qu'elle est trop russe. Non parce qu'elle a été écrite en russe, — on l'a fort bien traduite dans toutes les langues, - mais parce qu'elle est entièrement imprégnée de l'esprit russe. Et, troisièmement, si même quelque étranger, par exception, la comprenait, il ne pourrait l'appliquer. C'est là son troisième défaut. Je me suis entretenu avec quelques délégués venus ici, et j'espère, au cours du Congrès, sans y prendre part personnellement, - à mon grand regret, cela m'est impossible, — du moins causer de façon détaillée avec un grand nombre de délégués de différents pays. J'ai eu l'impression qu'avec cette résolution, nous avons commis une faute grave, nous coupant nous-mêmes le chemin vers de nouveaux progrès. Comme je l'ai dit, le texte est fort bien rédigé, et je souscris à tous ses 50 paragraphes ou plus. Mais nous n’avons pas compris comment il fallait présenter aux étrangers notre expérience russe. Tout ce qui est dit dans la résolution est resté lettre morte. Or, à moins de comprendre cela, nous ne pourrons aller de l'avant. J'estime que le plus important pour nous tous, tant pour les Russes que pour les camarades étrangers, c'est que, après cinq ans de révolution russe, nous devons nous instruire. C'est maintenant seulement que nous pouvons le faire. Je ne sais combien de temps nous aurons cette possibilité. Je ne sais combien de temps les puissances capitalistes nous laisseront étudier tranquillement. Mais chaque instant libre, à l'abri des 
batailles, de la guerre, nous devons l'utiliser pour étudier, et cela par le commencement.

Tout le Parti et toutes les couches de la population de la Russie le prouvent par leur soif de savoir. Cette aspiration montre que la tâche la plus importante pour nous, aujourd'hui, est de nous instruire, encore et toujours. Mais les camarades étrangers, eux aussi, doivent apprendre, non pas dans le même sens que nous, c'est-à-dire à lire, à écrire et à comprendre ce que nous avons lu, — ce dont nous avons encore besoin. On discute pour savoir si cela se rapporte à la culture prolétarienne ou bourgeoise. Je laisse cette question en suspens. Une chose, en tout cas, est certaine : il nous faut, avant tout, apprendre à lire, à écrire et à comprendre ce que nous avons lu. Les étrangers, eux, n'en ont pas besoin. Il leur faut quelque chose de plus élevé : notamment, et avant tout, comprendre aussi ce que nous avons écrit sur la structure organique des Partis communistes, et que les camarades étrangers ont signé sans lire ni comprendre. Telle doit être leur première tâche. Il faut appliquer cette résolution. On ne peut le faire en une nuit, c'est absolument impossible. Cette résolution est trop russe : elle traduit l'expérience de la Russie. Aussi est-elle tout à fait incompréhensible pour les étrangers ; ils ne peuvent se contenter de l'accrocher dans un coin, comme une icône, et de l'adorer. On n’arrivera à rien de cette façon. Ils doivent assimiler une bonne tranche d'expérience russe. Comment cela se passera, je l'ignore. Peut-être que les fascistes d'Italie, par exemple, nous rendront un signalé service en montrant aux Italiens qu'ils ne sont pas encore suffisamment éclairés et que leur pays n’est pas encore garanti des Cent-Noirs 5 ? Cela sera, peut-être, très utile. Nous autres, Russes, devons aussi rechercher les moyens d'expliquer aux étrangers les principes de cette résolution. Sinon, ils seront absolument incapables de la mettre en œuvre. Je suis persuadé que nous devons dire, à cet égard, non seulement aux Russes, mais aussi aux camarades étrangers, que le plus important, dans la période qui vient, c’est l'étude. Nous, nous étudions dans le sens général du terme. Ils doivent, eux, étudier dans un sens particulier, pour comprendre réellement l'organisation, la structure, la méthode et le contenu de l'action révolutionnaire. Si cela se fait, je suis persuadé qu’alors les perspectives de la révolution mondiale

5 Les Cent-Noirs, bandes monarchistes, formées par la police tsariste pour la lutte contre le mouvement révolutionnaire. Elles assassinaient les révolutionnaires, attaquaient les intellectuels progressistes, organisaient des pogromes. 
seront non seulement bonnes, mais excellentes. (Vifs applaudissements prolongés. Les acclamations : «Vive notre camarade Lénine !» provoquent de nouvelles ovations enthousiastes.) 